
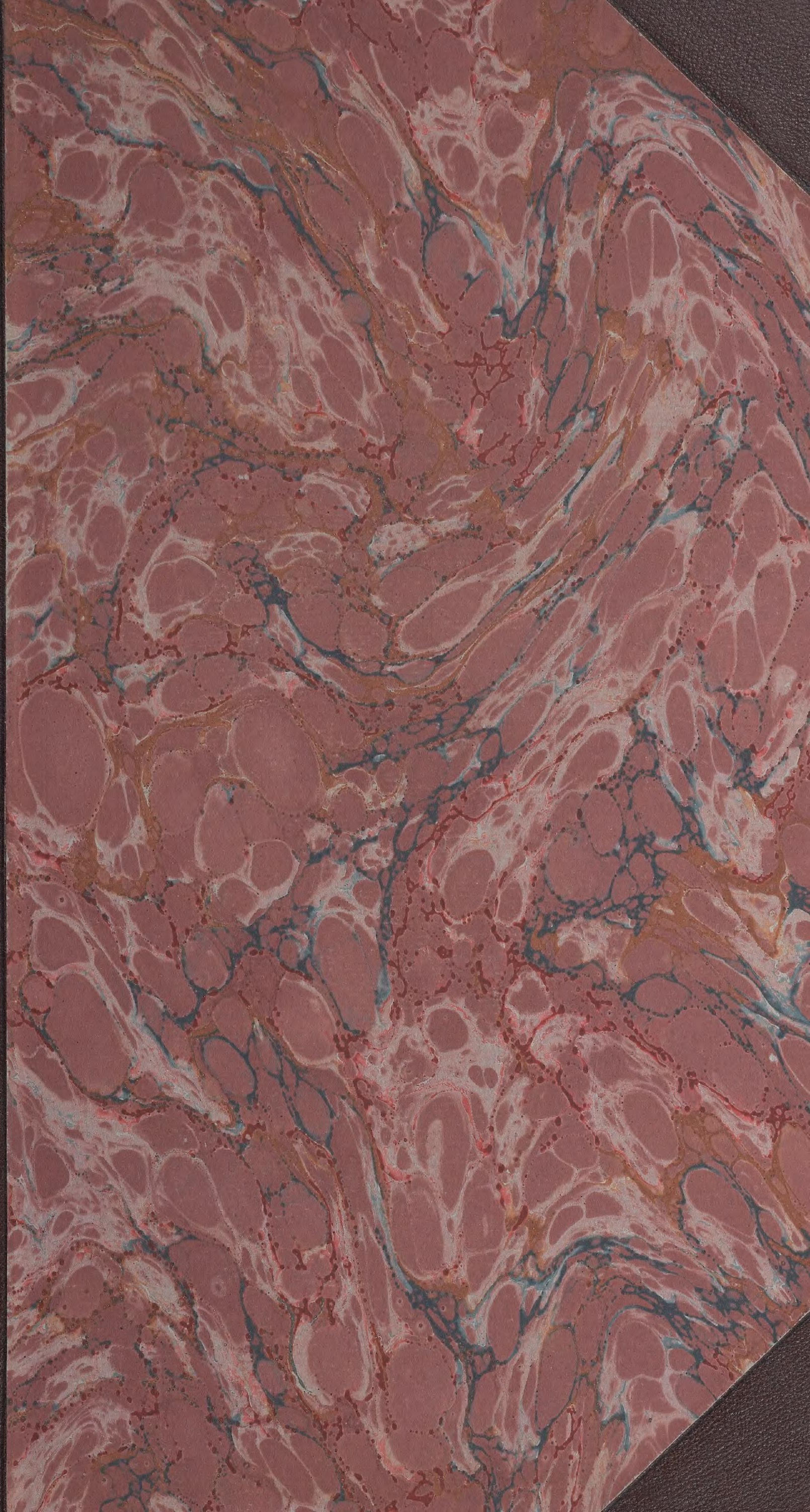




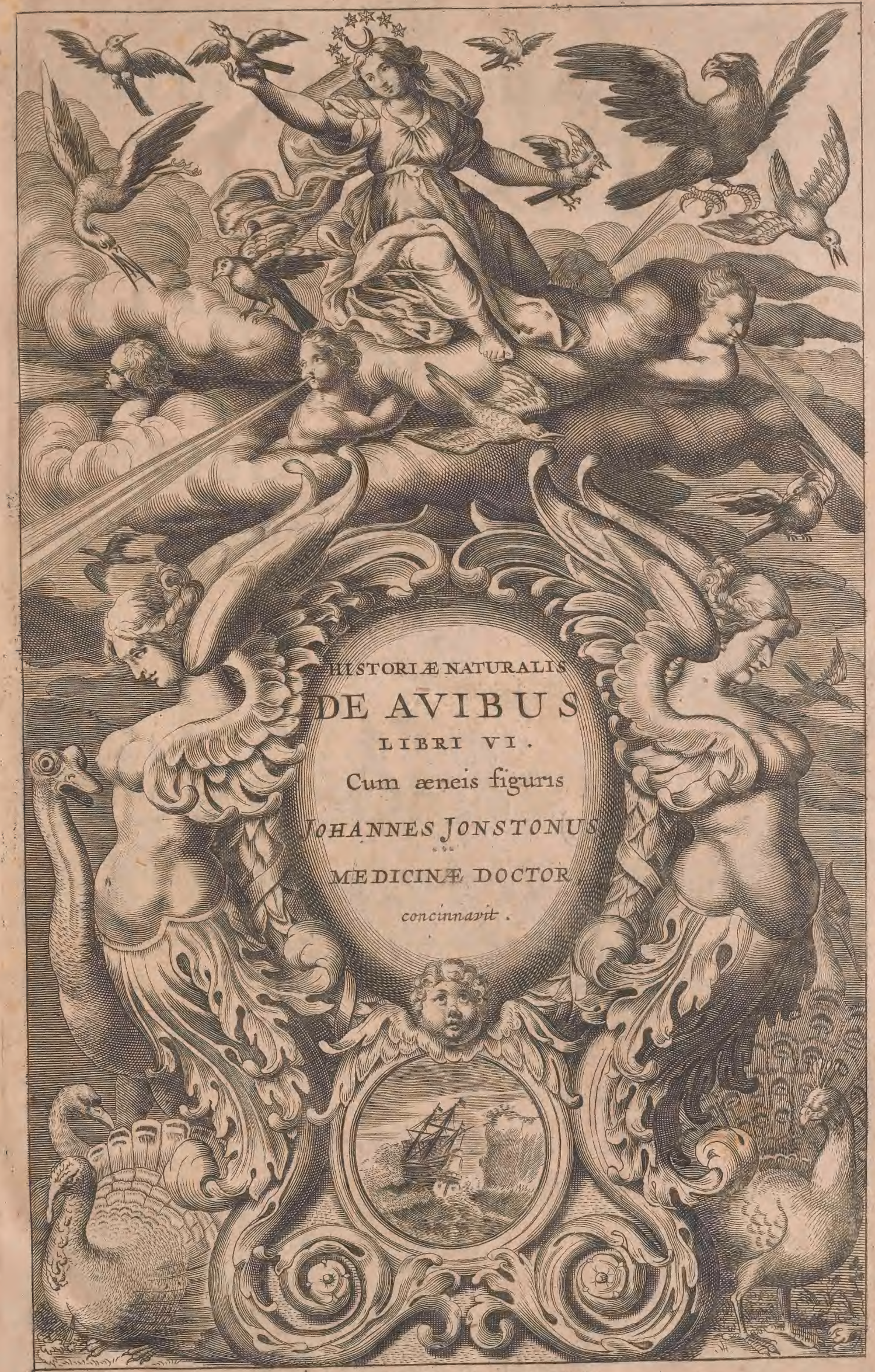

AMS TELOD A M I

Apud IOANME IM I COBI FIL. SCHIPPER. MDCIVII. 

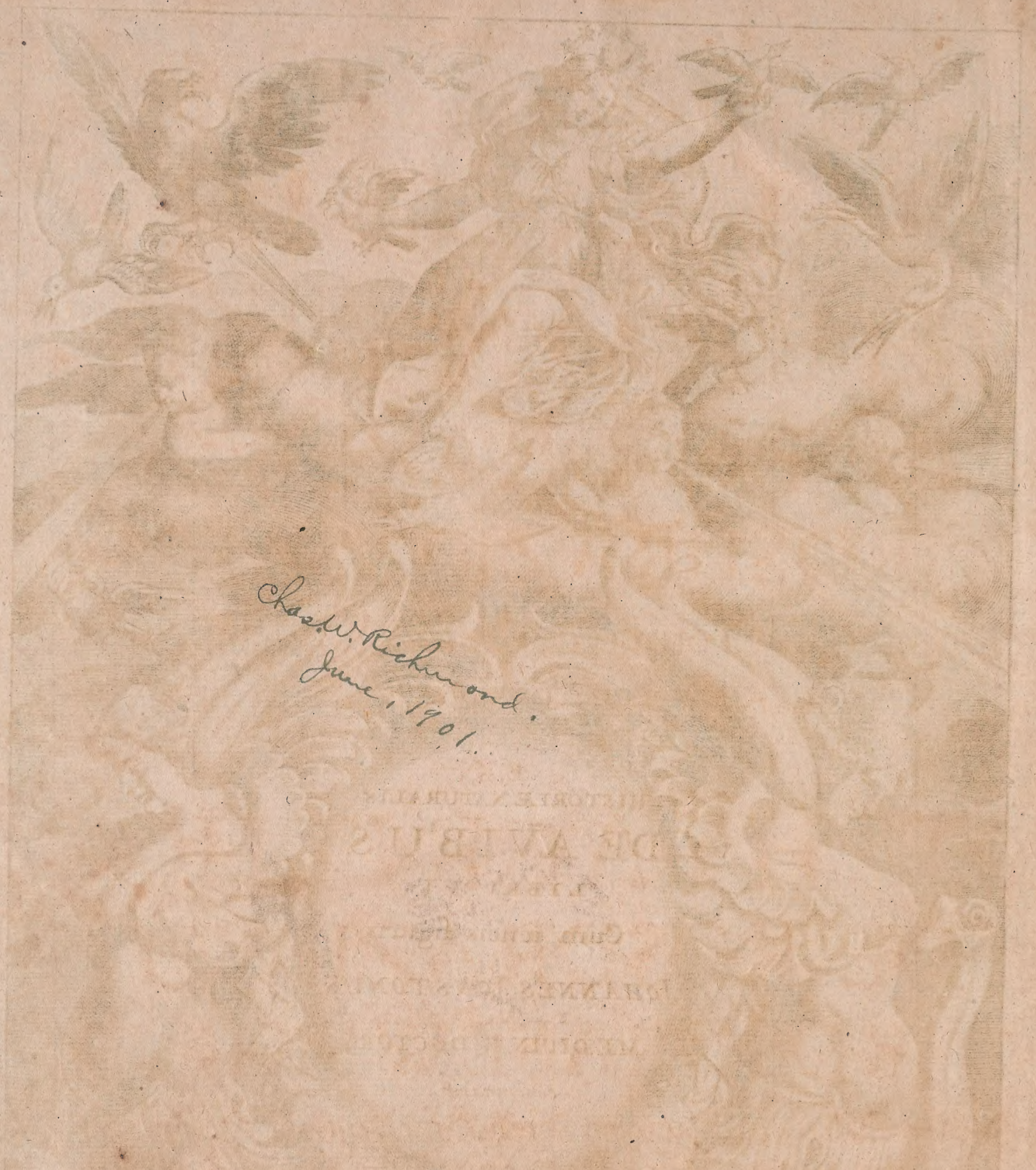
ILLUSTRISSIMIS HEROIBUS:
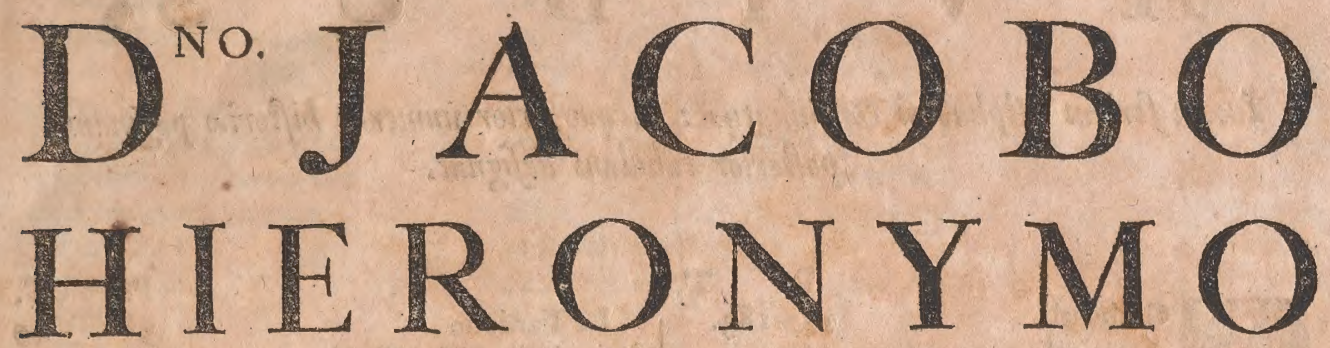

\section{DE ROSDRAZEWO ROSDRAZEWSKI,}

Domino in Crotofzyn, Caftellano Califienfi, Capitaneo Conienfi, \&c.

U T E T

\section{D ${ }^{\text {No. }}$ HYACINTHO \\ DE ROSDRAZEWO \\ ROSDRASEWSKI,}

Nowomiafto, in Exercitu Sereniffimi Polonix \& Suecix Regis, Equitatus gravis armaturæ Chiliarchr, \&c.

DOMINIS SVIS GRATIOSISSTMIS,

Hanc Hiftorix Naturalis de Avibus Partem, obfervantix monumentum, exhibiti fibi favoris memor, offert $\&$ dedicat

JOA N NES JONSTONUS

Medicine Doctoris. 


\section{I $\quad$ N $\quad$ D $\quad E \quad X$ \\ I N}

HISTORIAM NATURALEM

D E

\section{A $\quad \mathrm{I} B \mathrm{U}$,}

Iuxta Seriem Alphabeti concinnatus : in quo prior numeras biftoria paginam, pofterior tabulam defignat.

Acacaloti
Acanthis
Afterias
Fringillarius
Palumbarius
Sacer Egyptius Bellonio
Accipiter major
minor

Achalalactli

Acitli feu aquatilis lepus $\quad$ i $\quad$ is

Acolchis Indiarum $\quad 157$

Acolin

Acototloquichitl

Eifalonus accipitris fpecies

Afalo falconum fpecies

Ajaja

Ajuru fpecies

Alauda

- criftata

criftata fenex

non criftata

maxima feu Calandra pratorum

Alaudæ congener

Albulus aquaticus

Alcedo vocalis

Alchata feu Filacotona

Aluco

Amalozque

Ampelides

Ampelides Aldrovandi feu Garrulus Bohemicus Gefneri

Anas

- campeftris Bellonii

Carina

Domeftica

Indica.

Lybica

Anas fera feu fylveftris

Bofcas major

Caudacuta

Circia, Rernell dicta

Fiftularis

Fufca major.

Glacius

Herle

Mufcaria

Nigra

Penelope

Platyrinchos major

Plyrinchos minor

Puffinus

Querquedula criftata
P. $T$.

127.183 .

127.

68.

18.

IO.

Io.

Io.

I2. 9

28.

58.
157.

127.

127.

IO.

I39.

140.

69.

70.

70.

$7 x$

$7 \mathrm{I}$.

107.

64. $\quad 32$

32. I9

I 28.

IgI.

28.

$95 \cdot 158.49$

43.

99.

96.

96.

96.

96.146 .49

97. 49

98.

97.

98.

97.

97.

98.

97.

98.

$9^{8 .}$

97.

98.

96.

97.

49

49
La Tardone

Anas marina Nect Enole

Anas fera sebebogel

Anas fera Epiegclende

Andira Aca

8 Anhima

Anbinga

Ani

I Anfer Baffanus

- Domefticus

Magellanicus

Sylveftris

Anthus

Apos

Aquili in genere

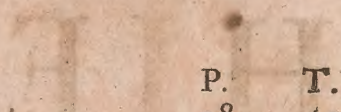

8. $T$

0

I3

in Ipecie

Aquila alba feu Cygnæa

anataria feu Morphons

anopxa

Bellonii

Gefneri

Haliætus

Heteropos Gefneri

Melanærus feu Valeria Alius

Morphnos Bellonii

Morphno congener

Percnopteros

alius

Pygargus

alius peregrinus

Aracari alius

Araracanga

Ardea

49 minor

49 Cinerea major

alba

alia feu congener

Egretta Gallorum

Garletta Italorum

Garzetta bianca dicta

Squajotta Italorum

49
49

Nigra

$$
\text { Congener }
$$

Ardea afteria feu ftellaris major

altera minor

Congener

Criftata

49 Ardeola

Arquata

49 Afio

Afio feu Otus Deteru

\section{9}

49

146.

144.

147. 61

148.60

I32.

94. 47

92. 48

326. $\quad 56$

93.48

88. 45

84.

I.

3.

6.

$4 . \quad 2$

6.

3.

5

$x$

6.

3. 3

3. 3

4. 4

4. 5

4. 4

$4 . \quad 5$

148

$14 \mathrm{I} 59$

IO2. 50

50

103. 50

103.50

103.50

103. 51

103.

104.

IO 4 .

104.

104.

$5^{\mathrm{I}}$

5 I

$5 \mathrm{I}$

$5 \mathrm{r}$

105.

105.

$143.6 \mathrm{r}$

I08. 5 I

82. $4 x$

3. 18 Afio
4.3 


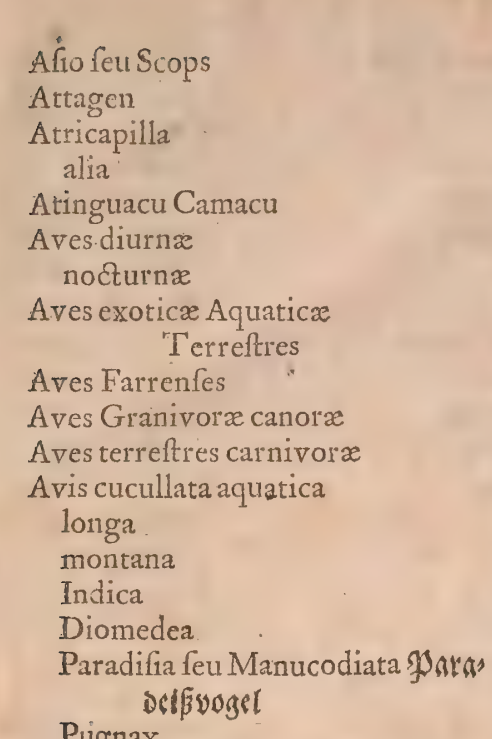

$\begin{array}{lrrr}N & D & E & X \\ P . & T . \mid\end{array}$

$X$.

32. I8 Ciconix

P. T.

4x. 26 nigra 99.50

90. 45 Cinclus II2. 53

45 alius Gallinago minima Bellonii $\quad 53$

47. 60 Cinclus Gallinago minima Bellonii
I.

29. Circus 152.

126.150. Citrinella Sitenile 7 r. 36.38

I17. Cocoi arderfpecies $\quad$ I43. $6 I$

I29. Coccotrauftes $\quad 76 . \quad 37$

68. Indica $\quad 77.37$

I. 53. Columbadomeftica $\quad \sigma_{2}, 3_{2}$

I60. variicoloris $\quad 32$

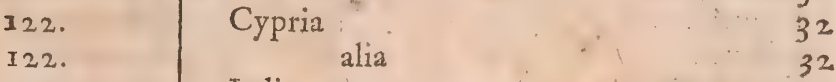

$\begin{array}{rll}\text { 1x3. } & \text { Indica } & 32 \\ \text { 9x. } & 46 & \text { Hirfutis pedibus major }\end{array}$

Livia

52 Columba

Scythica Nitternåditifter 20ler. 6.5

Stellata feu Stella Eternoogel.

Avium natura in genere

Avofetta feu Spinzago d'acqua

Avofettæ fpecies

Aura

Aurivittes carduelis fpecies

Ayayam

B Arge Gallorum
Boarina

B.

Bernicla

Boudree Bellonii

Branta feu Bernicla

Brenthus

Bubo

Bubo §ิergh

Bubo פactitenle

Bubo Ran/ dictus

Buteones

$\mathbb{C}_{\text {Calcamas }}^{\text {Abure }}$

43. 26

Columbus

Collurio

Colymbus major

90. 48

major:Bellonii

maximus

$64 . \quad 32$

9: $3^{2}$

63.146 .32

62. 32

I2. : 43

89. $\quad 48$

89. $\quad 48$

$2 \mathrm{I}$.

68. 43

minor
Coracia

I50.

Cornix

frugivora

\begin{tabular}{rl|l} 
ro6. & & $\begin{array}{l}\text { cinerea } \\
\text { 8. }\end{array}$ \\
corulea
\end{tabular}

Corvus

94.

Aquaticus

\begin{tabular}{rr|l} 
I2. & 7.I I & Aquaticus \\
94. & 48 & Sylvaticus
\end{tabular}

90. Cotta Anglorum

29. $x 8$ Coturnix

29. I 8 Cozquauxtli

29. I8 Crex

8 Cuculus.

II. 7.11

alter.

Cuntur:

Curicaca

I 45.

Curucui

Cygnus $\begin{array}{cc}\text { Calidris Bellonii chevalier, rubra } & \text { 108. } \\ \text { nigra } & 109 .\end{array}$

Canarias Bucfervogel/ Eantriopgel

Cannevarola

Capricalca

Caprimulgus

alius

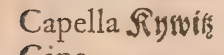

Capo

Caracara

Caracura

Carduelis Diffelfind

ciliis albis

mas

Cariama

Caripira

Catarrhacta

Caryocatactes 9?upbictich

Cenotzqui

Ceoan

Cepphus

88. 45

94. 48

34. 20

D A aje

90.

89.

89. 48

26. 16

24. 16

25. $\quad 37$

25. $\quad 17$

25. 17

23. 16

95. - 47

95. 47

98.

$7 \cdot .557 \cdot 27.28$

$12 \mathrm{x}$.

I08.

I4. IO

14. 10

I24.

I30. 57

144.60

90. 48

I22. 56

49 .

olus marinus Parifienfum 98

Diomedea avis 9I. 46

\begin{tabular}{rr|lrr} 
59. & 30 & EMbriza & & \\
144. & $6 \mathbf{1}$ & alba & 68 & 35 \\
15 & & 68 & 35
\end{tabular}

I50. pratenfismas $68 . \quad 35$

68. 36.37 $\quad$ foemina $\quad 68 . \quad 35$

36 Emeu Clufii 2 II9. 56

138. i9 Nieremb.

I50. $\quad$ Erythra gallinulæ aquaticæ fpecies. 35

94. $\begin{array}{r}47 \\ 27.40\end{array}$

123. ${ }^{27.40}$ F. F Alcinellus feu Falcata . $\quad$ \$05. 5 I

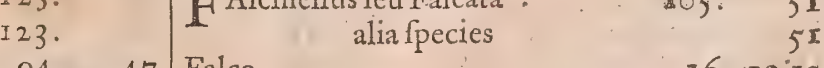

94. 47 Falco $\quad$ 16. 12:13

Cercio 13 . 53 Albus 5 I8. I2

Certhia

8०. 42

II3. 26.53

Characirios

70. 33.38

Chicuatli

Alius

Arborarius feu Dendrofalco

123.

Chloris ङ̈ruenfince

7r. 36.37

SBaumfalcé

Cyanopus

Gentilis

Gibbofus

I09.1Ix.3I

Italicus

$19 . .10$

19.
18.

18.
*39. Lana




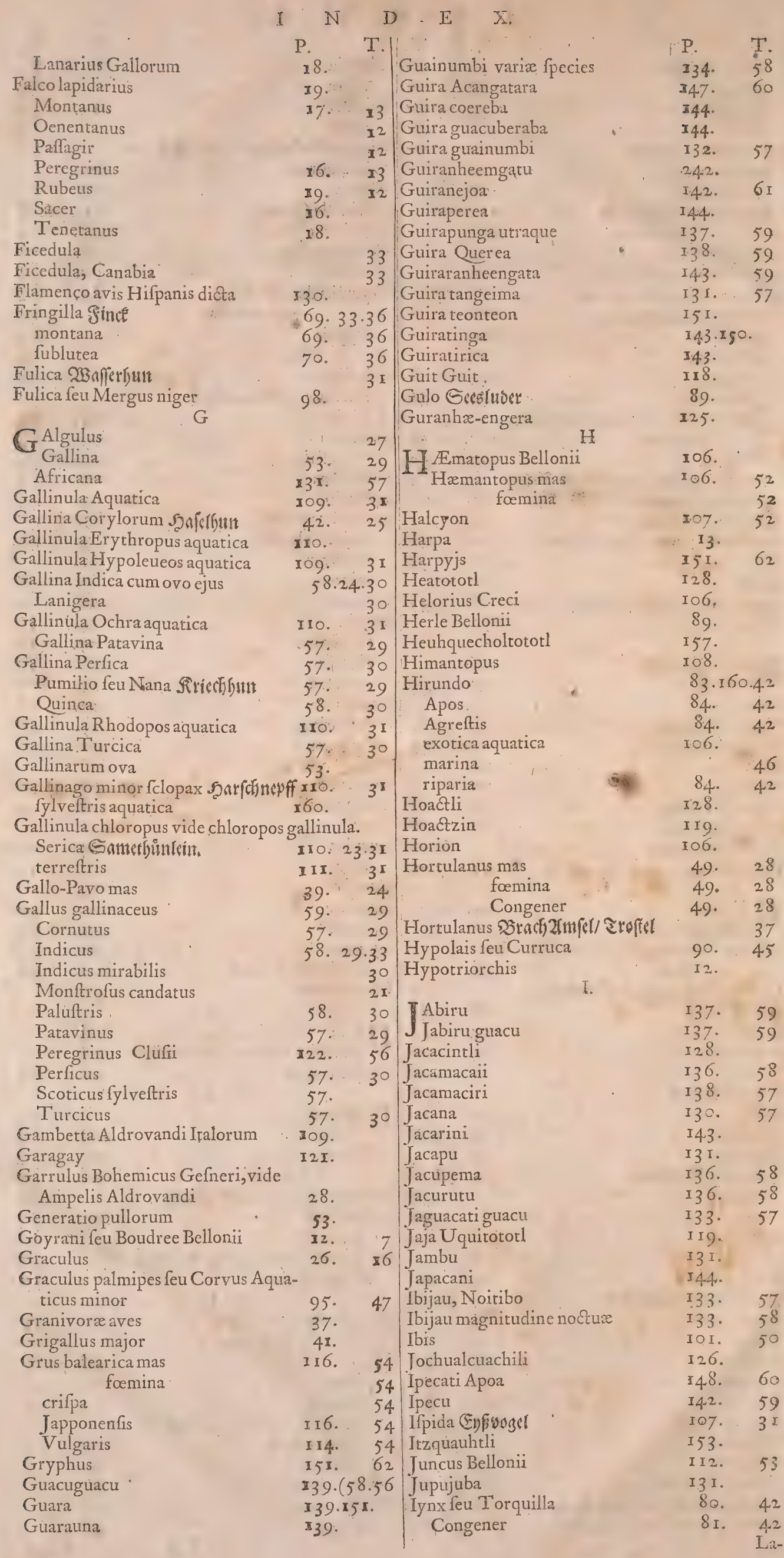





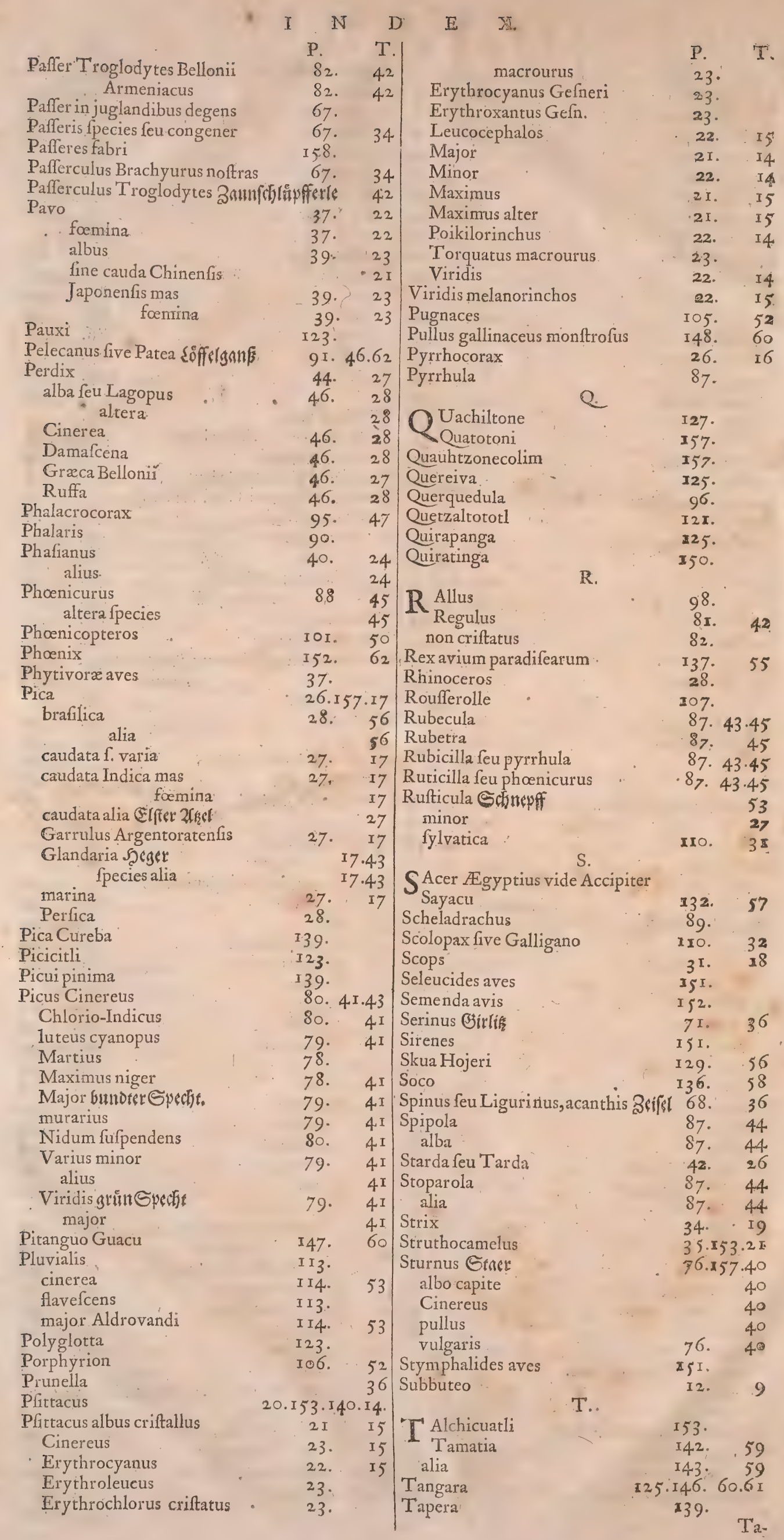




\begin{tabular}{|c|c|c|c|}
\hline $\begin{array}{l}\text { Tacoletl } \\
\text { Tarda }\end{array}$ & $\begin{array}{l}153 \\
42\end{array}$ & Tzinitzian & 122. \\
\hline Teitei & 144 . & JAnellus feu capella §yuin & II 3. \\
\hline Tempatlahoac & 159. & Vefpertilio & 34. \\
\hline Tentzontototl & 119. & lectans & 35. \\
\hline Tijeguacu & I44. 60 & $\begin{array}{l}\text { pullus } \\
\text { Vinago }\end{array}$ & \\
\hline $\begin{array}{l}\text { 1 ijeguacu Paroara } \\
\text { Tijepiranga }\end{array}$ & $\begin{array}{ll}146 . & 00 \\
\text { I3I. } & 57\end{array}$ & Ulula & 32.18 .19 \\
\hline Tinnunculus mas & I I. 8 & Ulula Sirchence & \\
\hline foemina & II. 8 & alia & \\
\hline Canchris 93 antuth ălyet & $\therefore 10$ & Upupa & $85 \cdot 27 \cdot 42$ \\
\hline Tlacoquauthli & I53: & Uria & 90 \\
\hline Tlauquechul & 126 & Urogallus major & 40. \\
\hline Tominejo Nieremb; & I24, 56 & minor & $4 \mathrm{t}$ \\
\hline Torquilla & 80 & $\begin{array}{l}\text { alius } \\
\text { anbiting }\end{array}$ & $4 r$ \\
\hline Totanus & 108. & Urubitinga & 346. \\
\hline Totoqueftal & 122 & Urubu & $I_{42}$ \\
\hline Triorches feu buteo & I I & Urutaurana & I39. \\
\hline Tritonus & Irg. & Vulpanfer & $93 \cdot 94$. \\
\hline Trochilus & $81.90 \cdot 48$ & Vulturum differentiæ & 7.6 \\
\hline Trynga & IIr. $\quad 53$ & Vultur alpinus vel aureus & 7. \\
\hline alia & III. $\quad 53$ & Boeticus & 7. \\
\hline Tucana & 125. & aquaticus & 30. \\
\hline Tucan & $\therefore \quad \therefore 5$ & Cinereus & 7 \\
\hline Tuidara & I39. & Leporariuś & \\
\hline Tuputa & II & 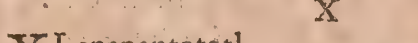 & \\
\hline Turdus & $71 . \times 8.37$ & X Lepapantototl & $\div 28$ \\
\hline vifcivorus & 73. $\quad 39$ & Xochitenacatl & $126.1 \times 9.156 .56$ \\
\hline Turdus leucocephalos & 73 & altera & II9. \\
\hline Illas & 73 & Xochitototl. & $I_{2} \mathbf{I}$. \\
\hline $\begin{array}{l}\text { Simpliciter dictus } \\
\text { Trichas. }\end{array}$ & $\begin{array}{l}73 \cdot 39 \\
73\end{array}$ & Xomotl & $x_{27}$ \\
\hline Turtur & 64.32 .33 & Y Andeu & $153^{\circ}$ \\
\hline Indicus & & Yutu & 158. \\
\hline
\end{tabular}

\section{$I N D E X$ :}

2uibus paginis Tabule aviun font Jubjungenda:

Tabula I

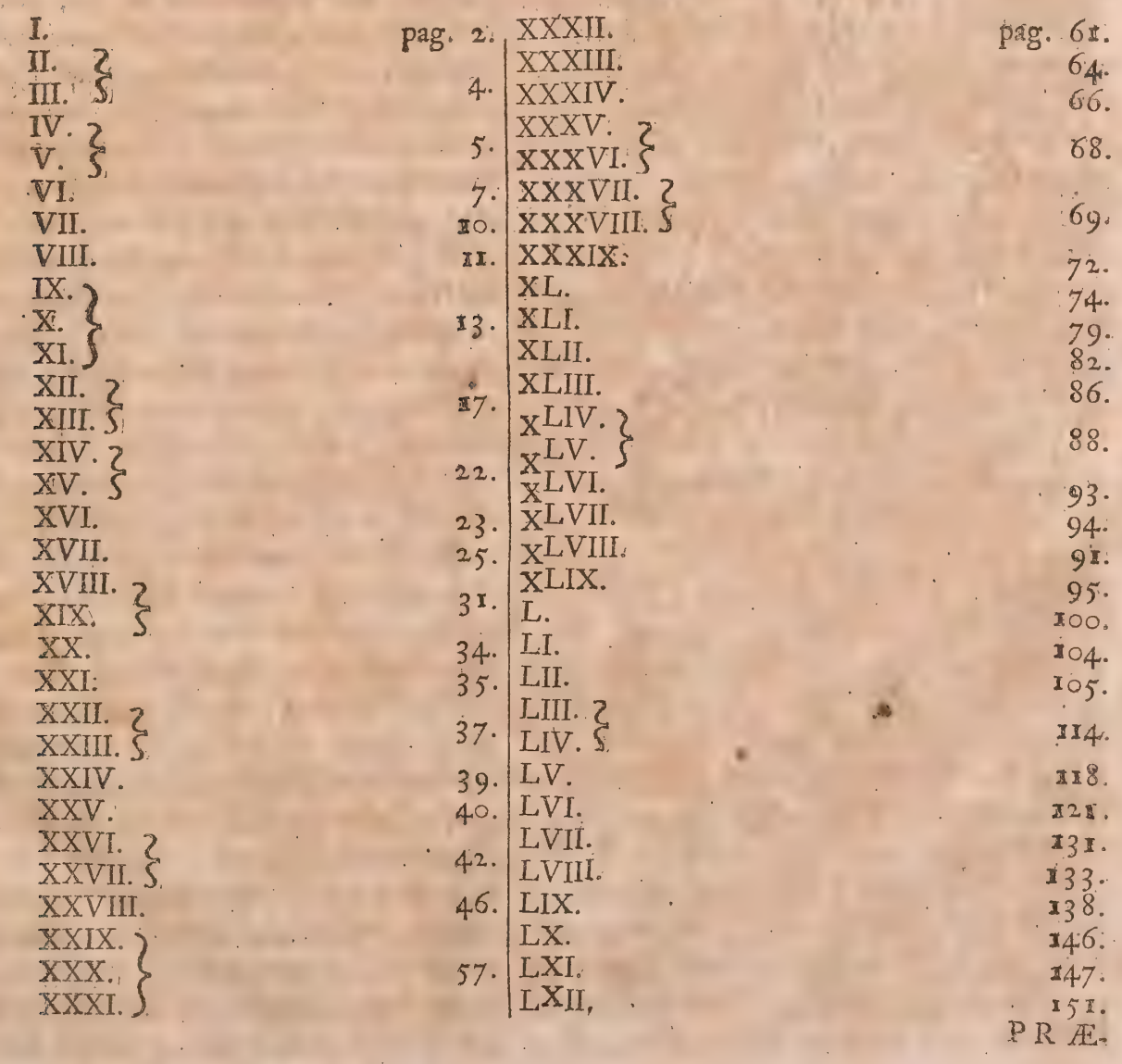




\section{$\begin{array}{lllllllll}P & R & \mathbb{E} & \mathrm{F} & \mathrm{A} & \mathrm{T} & \mathrm{I} & \mathrm{O}\end{array}$}

I N

\section{HISTOR I A M N T URALEM}

D. E
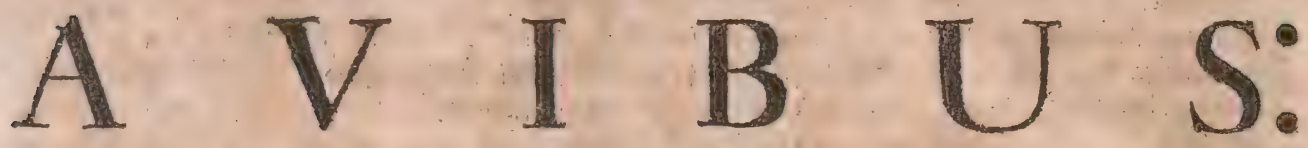

\section{In qua de Operis ratione, \& de Avium natura in genere, agitur.}

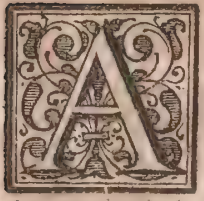

Quaticosgreges, aëreus Avium feu volucrum grex infequitur, Beñevole Lector. Inditum iis id nomen, non tam quod pervia difcurrant, iifdemque delectentur, ut Ifidoro $\&$ Perotto placet: vel ab adventu, quod inde venient, unde quis non fufpicetur, ut Fefto: quàm velà volando, quod Ebreis 7 'y diciScaliger in tur, ut Martinius in Lexico deducit, vel ab 1. r.p. 45 . ătev, audiendo, quod Scaligero patri vi-

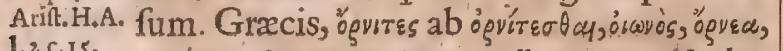

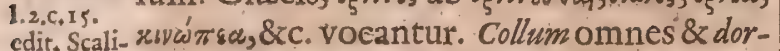
geri. $\quad$ fum \& eas qux terram fpectant, quxque pectoris vicem gerunt, partes, cum cærteris animantibus communes habent : peculiares præ cæteris, alas, pennas, quibus caulis, plumas \& roftrum, quod in fenecta durefcit. Neque labia ipfis funt, neque dentes, neque manus pedefve anteriores, neque auricula, neque nares, fed meatus horum fenfuum, ad odoratum in roftro; ad audiendum in capite. Oculos fimiliter atque alix animantes, duos fine palpebris habent.Connivient inferiore gena graviores:nictant $a b$ angulo obeunte membrana omnes. Ariftoteles,

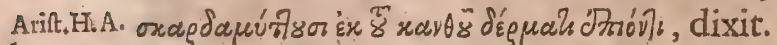
1.3.C.II+ Femur fimile coxæ, longum, ad medium ufque fubeuntem atque affixum ventrem : quod cum avulfum eft,coxam putes: At ipfa coxa, qux inter hoc \& tibiam eft, alia quxdam pars effe videatur.Maxima uncunguibus, \& pectsss, aliis robuftius. Pro cauda clunis eft, iis quibus aut crura longa, aut pedes continuata planicie dati, brevis, longus a-

Arift 1. c. liis. Alas in priora curvant. Omnium aniPlin. H.N. malium bipedes funt ut homo: quamvis re1. $\& 47_{*} .45$. trorfum curvant crura, quadrupedum moPlin. $\mathrm{H}_{+} \mathrm{N}$. do, uncos habentium longi, \& que ad aquas verfantur. Carent tamen iis Cypfeli, \& quoddam Manucodiatorum genus. Omnes funt $\pi \lambda^{2} \omega^{\prime} v 0$ x ob, fed \& omnes quodammodo $\pi 0 \lambda v \sigma \chi \omega \delta$. Plurimis namque digi-

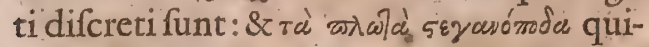
dem, dearticulatos tamen atque diftinctos

Plin.H. N. habent digitos. Plinius eos alias habere di1.11.6.47\% xit, palmipedes effe alias, alias inter utrumque divifis digitis, adjecta latitudine.Qux volatu fublimes feruntur, omnibus quaterni digiti, tresin anteriore parte, unus ponè pro calcaneo plurimis. Paucx binas ante, totidem poft habent: Quibufdam etiam calcaria funt, Uncungues autem \& calca * rigeræ, nullx. Plinius, nifallor, radios dixit. Ille funt volucres; hr humiles. Data nonnullis \& furrectis pennis crifta. Soli gallo peculiaris, qux nec caro eft, nec à natura carnis aliena. Interiora fi attendamus, $\operatorname{Lin}$ Arit. H. $_{1.213}$ gram fortitæ omnes funt, fed diverfam:aliæ edit. Scal. longam, latam alix, qux præter cxtera animalia, literas fono exprimunt : alix ante ex cornu acutifimo, retro ex carne compofitam, ut in hiftoria occurret. Lingula quæ Albert $M$. gurgulioni impofita eft, nulli : apertione $\&{ }_{2 . t t_{*}, x_{0}, 6.6}^{\text {deAnimal. }}$ contractione ita meatum temperant, ut prohibeant, ne quid gravioris in pulmonem demittatur. Vif cert \& inter fe \& ab aliis Arift.H.A. animalibus differunt. Præjacet in quibuf- ${ }^{1.22 . c .22 .}$ dam ventriculo ingluvies, feu cavum am- ger.

plumque corium, in quod receptus cibus per initia coquitur; à gula anguftius, dein laxius, \& rurfum, quo ad ventriculum demittitur,arctius. Ventriculus plurimis carnofus \& compactus : pelle interiore robufta, etiam cum à carnofo ablata eft. Ingluvie deftituta, gulam capacem latam, aut totam qua ventriculo jungitur obtinuere, ut monedula, corvi, coturnices: qux tali carent, longam habent, \&liquidius pre cæteris excernunt,utPorphyrio.Complurimis inteftinum tenue, \& fi explicetur fimplex. Appendices explicatre funt, fed paucæ, neque fuperne ut pifcibus, fed in ima parte ad inteftini extrema. Fel non eodem loco habent, qua Arit.H.A.

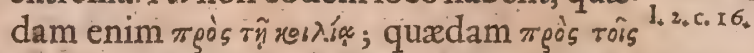
Ėvéśpors, ut columba, hirundo, \&x. Tefticulos Arit. H.A.

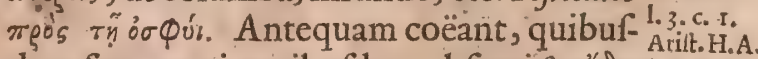
dam funt parvi, quibufdam obfcuri \& $\alpha^{\prime} \delta y-1.6$. c. 9 . $\lambda_{0,1} ;$ tempore coitus majores fiunt. Genitura Arift. H.A. alba eft. Vefica carent, quod larga humoris copia ad pennarum ortum \& incrementum requiretur, ut Aphrodifreo vifum. Pennige- Aphrodif. ri hujus exercitus locus funt, Aër, aqua, terra. probl.p. Illum fulcant, unde Aves cœli dicuntur; in hac gradiuntur; in ifta quxedam natant. Sunt tamen qux in quibufdam locis non inveniuntur, de quibusita Plinius: Hac quso- Plin. H.N. que mira nature differentia: alia aliis locis negat, 1. 10.c.29. tanquam genera frugum fruticumve, fic \& ani malivins non nafci tranflatitivim; invect a emori, mirum. 2uideft illud unines generis faluti adverfum, queve ifta natur a invidia? aut qui tertarum dicati avibustermini? Rhodus aquilam non habet: Ir ampadana Italia juxta Alpes Larium la- 


\section{E A V I B U S.}

cum appellat, amicnum arbufto, agro, adquem Ciconise non permieant: ficutinec oct avum circa lapidem ab eo, immenfa aliogivi finitimo In ubriwn tractuexarnina graculorum monedularumve. Picus Niartius in agroT Tar entino negatur effe, doc. Arit. H. A. Sed nec eadem lemper omnibus regio. Fa-

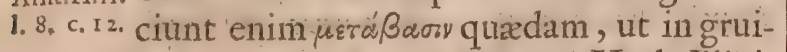
Plin, H.N. bus, Ciconiis \& aliis dicemus. Unde Plini$1,10, c_{0}{ }^{8+}$ us: Temporim magna differentia avibus. Perennes, ut columbe, fermeftes it birundines: trimefres ut turdio turtwres, oj que cum fatum eduxere abeunt, ut galgali, upup. Scilicet migrant quxedam, alio non procul à locis in quibus morabantur fecedunt, \& feipfas abArift. H.A. dunt, \& quidem nullo dif́crimine, tam घu-

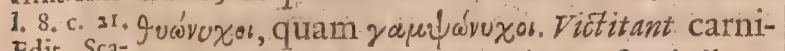
Edit. Sca- bus, infectis, herbis, granis, \& feminibus, Plin. H.N. pifcibus \& ranis. Sola Emmo prunas etiam 1.10, ${ }_{2} 46$ devorat, ut in ejus defcriptione dicetur. Bibunt fuctu ex his quibus colla longa, intermittentes, \&z capite refupinato velut infundentes fibi : Porphyrio folus morfu.

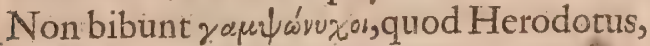
Arif.H.A. ut Ariftoteles fribit, ignoravit. De Genera1. $8+$ c. 18, tione notandum, duobus modis fieri coiI. 1.. c.52, tum; foemina humi confidente ut in galliPlin. H.N. nis: aut ftante, ut in gruibus. Quxdam o1.10, c.53. mni tempore coeunt, ut gallinæ, \& pariunt, præterquam duobus menfibus hyemis brü-

Arilt:H.A. malibus: plerumque tamen vere \& ineunte 1.5.c. 8. xfate : quo tempore etiam pleræque pariArif.H.A. unt, \& quidem femel. ofoimes prater exce1. 6. . . I. ptas, inquit Plinius, non temere fatus faciunt 1. $10, c, 3_{1}$. ante equinodtium vernim, aut poft autumnale: ante folfitium autem dubios, poft folftitium vitales. Ova ferunt omnes, vefpertilione excepto, qui animal.Infocunda funt qux adunPlin.H.N. cos habent ungues. Tribuit hoc avium ge1. I $, c, 52$. neri natura, ut foccundiores effent fugaces earum quam fortes. Ovorum alia funt candida, ut columbis \& perdicibus : alia pallida, ut aquaticis : alia punctis diftincta, ut meleagridi : alia rubri coloris, at Phafianis. Plin. H,N. Intus omne bicolor. Exeunt rotundiffima 1. ro, c. 53 , fui parte dum pariuntur, molli putamine, $59,60_{*}$ fed protinus durefcente, quibufcunque emergunt portionibus. Tempus à coitu, partus excubationis, \& numerus variant, ut apud Plinium videre eft. Aliquando foemiPlin. H.N. na tantum incubat, aliquando mas. In co1. Io. c.4I. lumbarum genere, interdiu mas, noctu foe-

1.6. c. I. mina:inter palumbes poft meridiem in matutinum fomina, cætero mas. A coitu inhorrefcunt \& fe excutiunt, fre etiam aliqua feftucaluftrant:quod ix edito ovo faciPlin. H.N. unt. Sunt etiam quxdam his bella amici1. 10, c. 73, tirque, unde \& 2 affectus. Diflident olores $\& x$ aquilix: corvus \& chlorio, noctu invicem ova exquirentes. Simili modo corvus \& milvus, illo præripiente huic cibos. Rurfus cum terreftribus, muftela \& cornix : $\mathbb{E g i -}$ thus avis minima cum afimo; \&c. De Motw Plin, $H, N_{*}$ th a liquis certus \& uni u modi \& in fuo cuique genere inceffus eft:aves folx yario motu fe runtur, \& in terra \& in aëre. Ambulant aliquæ, ut cornices: faliunt aliquas ut pafferes, merulæ:currunt, ut perdices rufticula:ante fe pedes jaciunt, ut ciconix, grues : expandunt alas pendentefque raro intervallo quaciunt (ut milvi) aliæ crebriusfed \& primás duntaxat pennas alix \& tota latera pandunt : (ut corvi) quxdam majore ex parte compreflis volant $u t$ pici) percufloque femel aliqux \& gemino ictu aëre feruntur: (cardueles) vel ut inclufum eum prementes ejaculantur, fefe in fublime, in rectum in pronum. (birundines) Impingi putes aliquas, (perdices)aut rurfus ab alto cadere has, (alaude) illas falire, (coturnices) Anates folæ, quxque funt ejufdem generis in fublime protinusfe tollunt, atque è veftigio coelum petunt, ut hoc etiam ex aqua.Itaque in foveas, quibus feras venamur, delapfæ folæ evadunt. Vultur \& fere graviores, nifi ex procurfu, aut altiore cumulo immiffx non evolant, cauda reguncur. Alize circumfpectant, aliz fiectunc colla. Siné voce non volant multæ: aut è contrario femper in volatu filent. Subrectæ, pronæ, obliquæ, in latera, in ora, quædam \& refupinæ feruntur: ut fi pariter cernuntur plura genera, non in eadem natura inftare videantur. De cæte- $\mathrm{Plin}, \mathrm{H}_{4} \mathrm{~N}$, ro, porrectis ad caudam cruribus volant, $1.11, c, 47$, quibus longi pedes: quibus breves, contractis ad medium. 'Uncos ungues habentes altivolæ ferefunt, exceptis nocturnis. De Plin. H.N. voce hoc dicere fufficiat, loquaciores qux ${ }^{I_{*} I I_{0} c_{0} \xi I_{*}}$ minores, \& circa coitus maxime. Alisin pugna vocem, ut coturnicibus, aliis ante pugnam, ut perdicibis:aliis cum vicere, ut gallinaceis. Iifdem fua maribus : aliis eadem, ut fominis, ut lufciniarum generi. Quxdam toto anno canunt, quædam cer- Plin.H.N. tis temporibus. Palumbibus omnibus fimi-1.10. c.35. lis \& idem trino conficitur verfu, præterquam in claufula gemitu. Eft qux boum mugitusimitetur, in Arelatenfi agro taurus appellata, alioquin parva. Eft quæ equo- $\mathrm{Plin}_{6} \mathrm{H}_{4} \mathrm{~N}_{\text {。 }}$ rum quoque hinnitus anthus nomine, her- 1. 10. $c_{4} 42$, bx pabulo adventu eorum pulfa imitatur, ad hunc modum fe ulcifcens. Varium \& vi- Plin. $H_{4} N$. te inter eas fpacium.Mares pafferes negan- $1,10, c_{*} 35$. tur anno diutius vivere. Columbæ \& turtures octenis durant. Cornicibus \& cervis, nefcio quot tribuuntur luftra: Morbis infeftari nullum dubium, \& habenturapud au-

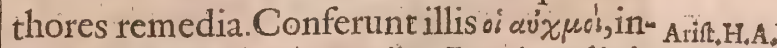

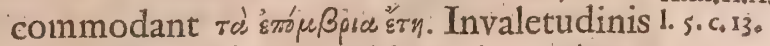
indicium in pennis. тареiनी

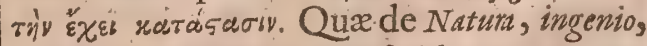
cicuratione, docilitate, \& affectibus occurrunt, abunde in Hiftoria explicabuntur. Divina. tionis iifdem aliquid ineffe, compertum eft. Grues ex mari in mediterraneo volantes, fi A1. H. A: filent, ferenitatem pollicentur, fi clamant, $l_{*} 7 * c_{*} 7$ \% 
PR I F A T I I N HIST OR. N A T U R.

atrocem turbinem. Idem fonans in crepu- caccifat : Vefpertilio ftridet:Pica picatur : fculo matutino Ardea, prenunciat; quæ\& Cuculus cuculat. Bubo bubulat : Noctua pluviam fi ad mare recte tendet, prædicit. cucubat. Ulula'ululat:Buteo bubit. ReguSereno canens noctua; yolubilifono croci- lus zinzilutat, Parus tinninat. Reliqua, ne tans corvus, crepufculo vocales cornix \& nimis prolixus fim, non attingo. Ego eas graculus; monedulx modofusfum, modo in hoc Opere, in Terreftres \& Aquaticas dideorfum verfus volantes, \&c. tempeftatem ftinxi. Illas iterum in Carnivoras, fub quiinnuunt, \&c. Vfum homini prebent, in cibo, bus funt Aquilx, vultures, Accipitres, FalMedicina, venatione, re veftiaria \& pluma- cones, Pfittaci, Corvi, Cornices, Noctur, ria, oblectatione \& aliis. Caro earum levior Vefperrilio, \&c. In fect tvoras non canoras \& \& fanior, purgatifimaque in fuo genere eft, canoras: Granivoras, fub quibus pulveratri. ut Alberçus dixit.Differentic Avium funt infinitx, ex multifque fontibus petuntur.Partes fi refpicias, alix habent roftrum rectum, aliæ, fuperius, inferius, aut utrinque incurArirt.H.A. yum, Pedes, quxdam longos, breves quxEdit. Sca- dam. Aliæ funt digitatæaliæ palmipedes, lig. alix inter utrumque divifis digitis,nonnullæapodes:Caput aliis criftatatum, fine crifta AII. H. A. aliis,funt \& cornutx, ut àpud Alianum vi$1_{9} 17 c_{0} c_{0}$ 10. dere eft. Collum alix longum, ut grues; alix breves obtinuere. De Lingua fuperius attigimus. Ale plerifque proportione: fola Dodo tam exiguas habet, ut fe à terra tollere non poffit. Omnes plumis veftiuntur, recens natas fi excipias, \& Dodonem, quæ laHerbert. na quafi tegitur. Candate quoque funt fere in Itinerar, omnes Cacato infulæ Mauritix avis cauda P. 347. Faret, \&c. Ratione Magnitudinis, funt, parvæ, - mediocres, magnx,apum quantitate, \& bo-

FI. H. A. bus majores, ut Flianus fabulatur. Ratione 1. 17. c. 14. Loci, funt terreftres, marinæ, lacuftres, paluftres, domefticx \& villaticx, fylveftres, campeftres. Alix arboribus infident, vel illis fe affigunt, alix cavernis delectantur. Quantum ad 2ualitates, funtalbæ, nigræ, verficolores, $8 x$ quidem tales plereque. Mutant quxdam colorem, vocemque tempore anni ac repente fiunt alix, ut ofcimes \&rgrues: non mutant alix. Ratione Cibi funt cánivoræ, ut rapaces, infectivoræ, granivoræ, \&c. Deglutiunt\&lapillos \& ferrum quxdam. Ratione Generationis omnes fere, ut dictum, ovum ponunt, fola vefpertilio aniPlin. H.N mal. Infocund $x$ funt uncungues : foecun1, $10, c, 53$. diores alix. Columbx decies anno pariunt: hirundines, turtures, merulæ bis. Nihil de congreffus, partụs, incubationis, exclufionis, differentiis dicam. Motus diverfitatem fuperius jam attigimus. Sed \& de vocis varictate actum.Philomela modulatur:A quila clangit: Accipiter pipat: corvus crocitat, crocit, corniculat. Perdix cacabat: Anfer, gratitat, glacitat: Cygnus drenfat: Turtur \& Columba gemunt: Palumbes plaufitat: Ciconia gloterat. Gallus cucurrit: Gallina gracillat, glocit:glocitat. Pavo pupillat: Grus gruit. Vultur pulpat, Grxculus frigulat: Milvius lipit, lugit. Anas tetrinit:hirundo trinfat.Paffer pipit: Sturnus pifitat.'Turdus trutilat : Acredula mittat. Coturnix gryliffat: Galgulus glocitat. Merula ftridet vel modulatur: Upupa popiffat. Meleagris veratricefque \& lotrices fimul, \&c, \& Baccivoras. Aquatice in Palmipedes \& Fißipedes qux etjam fua fortiuntur genera, difpefcuntur, prout in fyllabo librorum \& Capitum prxfixo apparet. Et tantum de Avium natura in genere præmittere placuit. Quod reliquum eft, fcire te Benevole Lector yelim, exhiberi hic Tibiquafi in tabella, quicquid de Avibus veteres \& recentiores habent. Addidi enim omniá illa quxà Gefnero \& Aldrovando omiffa funt. Ideo \& totum quîntum librum Marcgravii de Avibus Brafilienfibus Appendicis loco adjeci, paucis quibufdam omifis, qux alibi abunde explicata funț.De Ufu fi quæ defiderabuntur, in Additamentis, Deo bene volente, proftabunt, in quibus una quxque Exoticarum fux Claffi reftituetur, Quapropter, fi aliqua nunc bis occurrerit, veniam dabis. Similes aliquando appareant fpecies, qux tamen vel icone, vel quibufdam in defcriptione pofitis differunt. Quia vero duplici Ariftotelis Hiftorix Animalium editione ufus fum, vulgari nempe $\&$ Scaligeranz; ideo illam abfque addito, hanc cum nomine Commentatoris citare foleo. Indicem tibi dabo, poftquam totum de Animalibus opus paratum fuerit, illumque totius operis ad fipecies, partes, \& affectionesreducti, prout Plinius Hiftoriæ fux libro undecimo, capite trigefimofeptimo \& aliis pluribus in locis fecit, Compendium, fed Alphabetico ordine difpofitum : fi tituli marginales omifli funt, ne mirere. Primus hic in hac Hiftoria labor, \& jam fere per triennium apud 'Typographum delituit : nec tum mihi iftos addere animus, prout $\&$ in hiftoria de Pifcibus vidifti. Fruere interim his, Benevole Lector, cum Deo; \& authori juventutis literariæ ftudio. fiffimo, profperam valetudinem \& ad plures curas vitam apprecare, ut Tuo bono, opus Hiftorix Naturalis, de Homine in. primis, quod parat, aliaque huc fpectantia, feliciter abfolvere poffit. Vale. Lefna ex Mufroo Io. Febr, A. C. M. D. C. L. 
Fol. I

\section{HISTORIE NATURAIIS}

D E

\section{A V I B U

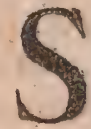

L I B E R $I M U S$.

\section{De Avibus Terreftribus Carnivoris.}

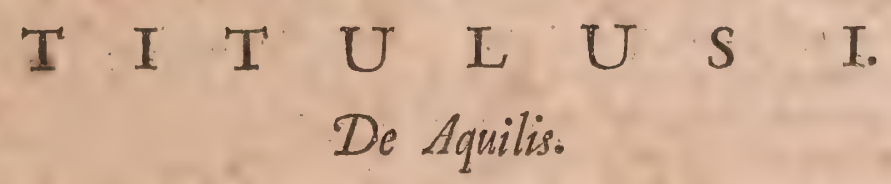

\author{
C A P U T I. \\ De Aquila in genere.
}

Wonsen.

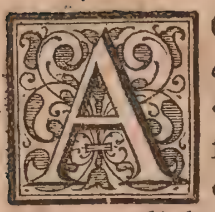

Quit A Gracis feu $\pi$ apd $\pi \partial$ ä $\sigma \sigma \sigma \omega$, concitus feror, feu

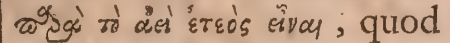
femper augurium ejus veridicum effe foleat, disris; $\mathrm{Cy}-$ priorum dialecto ár roe \& i 1' $\beta_{w v}(\sigma$, , Macedo-

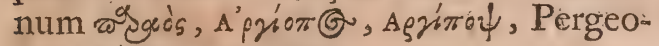
$\operatorname{rum} A^{\prime \prime}, \beta \varepsilon \pi \delta s$ vocatur.

Deforiptio. Totam avis molem fi fpectes. Corpus ipfi denfum, frgura erecta. o Ja folida \& nihil ferè medullæ habentia. Magnitudo determinari non poteft. Viginti cubitales in Athen. Ptolomxi pompa delati fuere. Inter MifeDipnof.1.5 nam \& Drefdam tres in nido, pulli, totidem patulas quercus ingenti fpacio complexo, inventi; quorum maximis alæ per transverfum extenf $x$ feptem ulnas, ungues viri grandis digitos æquabant, crura leoninis majora erant. Partes, fi in rationem veniant, anterior Capitis pars paulatim arctatur \& in rofrrum definit; quod durum, aduncum, ad fenectutem crefcit, fed tractu temporis fit inutile. Oculi funt, parvi, charopi, concavi, profundi, nec nimium oblongi,nec exactè rotundi. Dentes nulli. Cerebrum adeò calidum, ut in pulverem redactum, maniam, exhibitum, inducat. Ale rect $\&$ extenf $x$; in fummitate recurv $x$; nervofx, paucæque carnis, magnitudinis Honseris tantæ ut eas Homerus, januis thalami Iliade ult. compararit. Penne in iis funt duræ \& aliarum, Anferum inprimis \& Columbarum permixtæe pennis eafdem abfumunt. Dum pulli excluduntur, inedià albefcunt. Pes dexter finiftro major, colore uterque difformis. Vngues adunci \& recurvi, quos in inceflu, intrò femper vertit; nifi folem aut prædam intueatur, perpetuò infpicit, \& hebetatos, roftro, aut ad Lapides atterendo, acuit, quique cum pullos nutriunt, in- vertuntur. Alous propter cibi humiditatem mollior. Fel xrugineum, impensè Galen dè acre \& mordax. Sanguis craffus \& fibrofus. Compor. Stercus tantæ acrimonix, ut nulli in Medi- Medic. f. $_{\text {. }}$ cina ufui effe poffit. Quantum ad Sedes \& loca, nec in infulis, facult. parvis inprimis, (cum Rhodi in culmine tocus. domus Tiberii confédiffet, portenti loco Sueton. in fuit) nec in locis propè Mrootidem palu= $S$ trabon. dem, nec in extrema Scythia, \& Sarmatia, Geogri.l. $o b$ aeeris fortè inclementiam reperiuntur. In Caucafo, Tauro, regno Peruano, Germania, Polonia, Britannia, Dania, \&c. in quibus prædx copia, eas invenias; \&

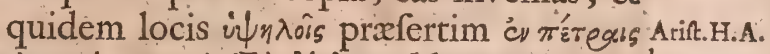

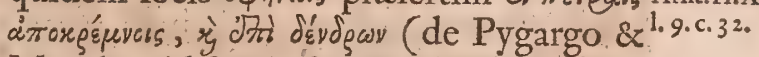
Morphno id fumendum non eft ) feu we's

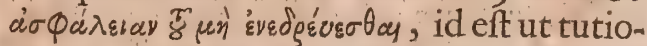

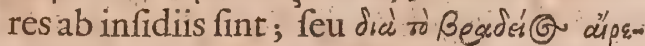

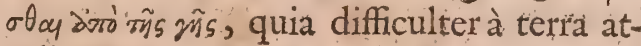
tolluntur.

Nutrimentum ipfis Carnes funt, Colum-Nutrimentbarum, Anferum, Cygnorum, Gallinarum, Ovium, Cervorum, hinnulorum ; ob fui à morbo tutelam, leporum, teftudinum terreftrium, pifcium, etiam \& cancrorum : ferpentum imprimis, feu propter odium, feu propter eam quam ex humido \& frigido cibo capiunt, voluptatem. Sed nec à fui generis avibus iratæ \& famelicæ abftinent. Cadavera tamen non tangunt, Percnopterum fi excipias. A meridie venari quadam incipiunt, ab orto fole quædam. In prædam confpectam, \& injurix patentem (lepus in planis, teftudo poft coitum fupina invaditur) velocilfime \& tormenti inftar (hinc ${ }^{3} \xi u \lambda a \beta \tilde{s}$ s) fe demittunt, pofteriore pedis digito feriunt, \& occifam in nidos deferunt. Falluntur tamen interdum, quod in Falcone Scâlig. Exerc. 237. Scaliger obfervavit : fed \&à Polypo apricante in profundum detractas, Elianus anno- Flian. $H$ tavit. Potus iifdèn nullus, fortè quòd ad A.l.7.c.1 to eum fanguis animalium fufficiat. Vife ta- 
men aquam bibiffe, medicinx gratia; \& occurrunt. Callitrichum herbam in niw ultimo in fenio, roftro præ ficcitate incur- dum fuum contra noxia animalia ingerere vato, vitam aliquandiu bibendo fuftinere coguntur.

Sexus. De Sexs Aquilarum dubitari non debet. Datur genus, quod propter tres teftiGeneratio. culos, Triorchis appellatur. Coeunt verò frequenter; \& foemina ter decies in die compreffa, fi mas revocet, denuò accurrit. Unde Agyptiis \& Venus dicitur, \& foli dicatur. Commifcentur aliquando cum accipitre, fed ovis incubare non dignantur: fed \& marem cum lupa aliquando coire, fcriptores Africani referunt. Ovis majoribus XXX. minoribus XX. diebus incubant, \& ad exclufionis promotionem lapidem aëtitem, qui xftum ovorum $\mathrm{ab}$ incubatione contractum, utpote frigidiffimus, temperat; \& peculiari qua pollet vi partum accelerat, in nido deponunt. Duos plerumque excludant pullos, quandoque tres, Exclufos folem adverfos intueri cogunt, \& invitos eidem obvertunt. Si fortè oculos vi fplendoris inflexerint, aut nictatione obnubant, tanquam adulterinos abdicant ; fi immotis eum afpexerint, genuinos agnofcunt. Volatum affectantes, Sinefius in altum fublatos, dimittunt, fibi relictos, in Dione. aut fortè dilappos fufcipiunt, grandiufculos, longiffimè tanquam rapinæ æmuloš,

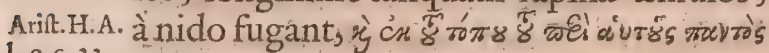

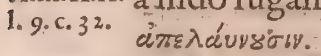

Volktus. Quantum ad volatum, à meridie ad vefperam moventur; manè, quiefcunt, donec hominum conventu fora impleantur. Tam fublimes rectâ viã feruntưr, \& deorfum tanta mole corporis labuntur, velificatas alas modico caudx gubernaculo advertentes, ut cæteras omnes aves fuperent,

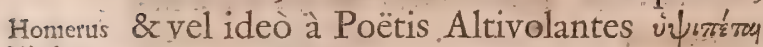
rliade o. dicantur Tempore incubatus, \& nutricaCyniag.. r. tionis pernicitas illa imminuitur, fed moLucret.1.5. tus tonicus perpetuo peculiaris manet.

Yox.

Vocem ipfis clangere feu $\chi \lambda \alpha_{\alpha}^{\prime} \mathrm{Gev}_{\mathrm{V}}$ quidam,

Yliade $\mu$ ut Homerus, \& Author Philomelx, tribuint, qui reboatus quidam eft propter ftrepitum gravem, avicularum motum obtundens : nonnulli penè mutas aut vix vocales, quod de tertio genere Ariftoteles affirmat, tradunt. Pullos mutos effe conftat, quod illis lingua humore quopiam tenellis impediatur. Sed de hoc inferius dicetur.

Senfusex- De fenfibiss externis non eft quòd multa Plutar. de dicam, tam exacti eft vifus, ut fola conHomer. tra rotantis jubaris lucem immotam teneAug. 1. 2. at aciem; fola fublime ita volans, ut à no-
de morib. Manicli. bis tanta luce difficile cernatur, latentem fub frutice lepufculum, fub fluctibus nantem pifciculum, videre comperta fit.

Animam ipfi olere certifimum eft, propter quam contacta $a b$ ea corpora facillimè

Jagenism. putrefcunt. De ingenio ac docilitate pauca affirmant. Subveniffe Arifomeni in Cea- Paufan. $t_{0}$ dam demiffo; gratiam virgini Seftenfi, \& ${ }^{4 .}$ Plin. H. . . puero pro educatione, ruftico pro lato l.ro.c. s. contra ferpentem auxilio, retuliffe; infan- A.lian. $\mathrm{H}$. tem recens natum ab exitio fervaffe, apud c. 37 .

Authores invenies. Indi pullos educatos Alian. H. ad leporum, vulpium venatum, defcripto $\mathrm{A}$ c. $\mathrm{l}$ I. $\mathrm{ab}$ Aeliano modo, inftituebant. Tales \& Aflian. H. Cublai Tartarorum Imperator habuit. Alut. in Sed \& Pythagoras aquilam ita manfuefe- Numa. ciffe, ut certis vocibus fifteret \& devocaret, Superodantem, dicitur.

Inimicitzas gerunt cum Cygnis, (pugnæ Amtipaapud Statium defcriptionem vide) Tro- Arif.H.A. chilo, Gruibus qux ideo montem Taurum l. g. c. I. tranfmiffurx, lapillis vocem cohibent, $\&$ Stat. Thenoctu transvolant. Ardeolis, Ciconia, Hierofalcone, vulturibus, Dracone \& Serpentibus.

Vita quamvis falaci diuturna eft. In fe- $V$ isto nectute vifus hebetudine, \& roftri aduncitate tentatur; cum vero fe illa gravari fentit in fublime fertur, inde, oculorum caligine folis calore difperfa, fervida, in aquas frigidiffimas fe dat præcipitem, qui- $\mathrm{Rhodig}$. bus tertio immerfa, nidum petit, \& inter Antiq.1. 7 pullos capturie aptos quafi febre correpta; cum fudore quodam plumas exuit. Oppetit ergò mortem non tam fenio vel ægritudine, quàm fame, in tantum fuperiore accrefcente roftro, ut aduncitas aperir non queat.

\section{A P U T I I.}

De Aquila in Specie.

\section{A R $\quad$ T I C U I U \& I. De Chryjaêto.}

C $\checkmark$ Hryfaëtos Aquilæ genus à fulvo Co- Nomet. lore ita dictum eft. Ariftoles $\chi \nu^{\prime}$ riov, Albertus Herodium, Elianus Aquilam Alian. $\mathrm{H}$. ftellarem, Pindarus Jovis alitem, Hefiodus Pindarus $_{\text {Pind }}$ IEgiopen, \&c. vocat. Iythio. De externa ejus conftitutione veteres hoc Ode 4. duntaxat, produnt, quùd maxima fit omnium inter cæteras aquilas eademq́ue ruffa feu fulva aut fubrutila (qui color interdum cum xtate mutatur) \& oculis Charopos. Qux Aldrovando à Ferdinando Medicæo miffa erat, pendebar libras duodecim, coloris, in minutioribus totius corporisplumis, ex fufco caftanei albis fparfim intercurrentibus maculis, paucis dorfo, pluribus ventre, radicibus albis; in alis \& cauda fufci, eò magis quò majorès pennæ, in cruribus ad pedes ufque ferruginei : Longitudo ei ab extremo roftro ad ultimam calldam, quinque dodrantum, à roftro ad extremos ungues, quatuor Spithamarum, \& 
ultra. Latitudo expanfis alis Spithamarum octo. Roftro quod palmam fuperabat aduncitas infra inferiorem mandibulam ad pollicem unum propendebat, latitudo plusquam duorum digitorum, medii præfertim,erat. Color,in acie nigrior, alibi. Corneus ad cæruleum dilutum tendens, fufco maculatus. Oculos habebat Charopos, quos palpebrx in uno quoque binæ, fupernè, \& infernè integebant, inter nictandum tunica quadam craffa, ab infra furfum exporrecta, mufculo confpicuo, cujus initium haud procul ab eruptione nervi optici à cerebro erat, quamq́ue palpebrx fuperioris loco à naturâ datam, \& ad angulum internum inprimis collocatam, quod cutis capitis ob duritiem in palpebras abire nequeat, creditur inftructa; $\mathrm{ab}$ angulo majori ad minorem, obducebantur. Humor aqueus in iis copiofus, Cryftallinus, Seffilis, utroque latere compreffus, \& $x$ folidus. Lingua erat humanx fimilis, lata, extremo teres, verfus radicem duobus utrinque ceu hamatis utrique appendicibus corneis armata. Siniftri pedis pofticus unguis fex digitos in circumferentia longus erat, dextri quatuor, fingulos digitos, quatuor femicirculares tabellæ, extremos propè ungues, integebant; maximo interiori excepto, quem tres duntaxat veftiebant. De ingluvie, Oefophago, ventriculo, confulat Aldrovandum qui volet.Mufculos collum Oldrev. Althol. moventes anticos \& pofticos habebat duo1. 2. c. 2. decim, feu fex paria, laterales tres. In tho-

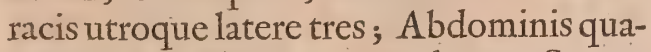
tuor paria; Alas moventes decem, Scapu$1 \mathfrak{x}$ quatuor; Úlnam moventes, fex; eam partem qui carpo in homine refpondet totidem, crura quinque, Tibiam octo; Tibiam \& digitos, plurimus.

Cibus ipfi carnes leporum, gruum, AnfeNutrimen- rum, Hinnulorum, Cervorum, quos ex declivi precipites agit; \& Taurorum, quos magno \& aufu \& aftu aggreditur : aliquanda fame premente fructus, \& fruges, ut hac Arift. H. in parte deceptus videatur Ariftoteles,
A.1.8.c.8. qui fruges etiamfi in os ingeras refpuere afferit, comedit.

Generatio. Ova ad fummum tria ponit, fi juvenis eft \& vegeta, ut plurimum duo, quorum alterum fxpiffime putre deprehendi teftimonio acupum, per octennium nidum explorantium, Albertus affirmat, qux de ovorum vel $\mathrm{ab}$ alterius generis Aquila Chryfaëto, vel à Chryfaëto alteri Aquilæx fuppofitione fcribuntur, dubia nimis funt. Si duo excludit', alterum pullorum ejicit, feu nutricatus difficultate, feu quia minus generofus apparet. Prædam nifi fame coaata fola minime abfumit. Impertitur avibus regià magnificentiâ portio, qux ea fpe fectantur, adulatorum aulicorum ingenia exprimentes.

\section{A R T I C U I U S. II.}

\section{De Faliato \& Melancto.}

$\mathrm{H}$ Alixtus, Halixëtos Phavorino, A- Nomen of quila quila marina Latinis, Nifus, fed non Ovid.1. 8. recentiorum, Ovidio dicitur, German. Metamor. Niecralder.

Qui à Bellonio exhibetur, magnitudine Bellonius eft Milvi. Caro ei cinerea ad nigrum ver- ${ }_{20} c_{-} 8$. gens, fibrofa. Alarum ad pedes duos Römanos, \& digitos undecim extenditur longitudo. Caput album \& fufcis lineis diftinctum, roftrum aquilinum, Oculi in medio nigri, in ambitu aurei. Lingua ferè humana, appendice ad radicem utrinque inftricta. Eolore per fumma Afturis, perima albo, Guttur maculis ruffis notatum. Perius purè candidum. Venter gutturi colore refpondens. Crura craffa \& fquamofa. Cauda ad commoditatem volatus lata, $P \boldsymbol{P}$. des fiffi, hamaci, cærulei. Digiti quatuor per fuperna ad dimidiam longitudinem fquammofi, ad reliquam incifi, per inferna afperi $\&$ aculeati, tam validi, ut flexos vix ulla vi diftendas.

Species Aquilarum marinarum plures effe Differenvidentur, exquibus, tum illa eft Bellonii ${ }^{\text {tia. }}$ quam teftas in cruribus \& ungues omnino rotundos habere fcribit : tum illa Alberti M. \& Anglorum, qux pede eft uno anferino \& natante, altero fiffo \& præd $x$ dicato; adipem in cauda gerit, quo guttatim in aqua dimiffo, pifces attoniti, prædx fiunt opportuni.

Habitat circa mare, littora \& oras. Locuss.

Cibus ei interdum columbx, interdum A. A. 9. c. aves marinx; quas univerfas nunquam in- 32 . vadit,fingulas cum emergentes obfervavit ${ }^{\text {Nutrimen- }}$ aggreditur, \& immerfas vel ftrangulat in Aelian. $\mathrm{H}$. humore, vel per fumma corripit, fed pifci- ${ }_{45}$. 1 . 3. c. bus prxcipuè victitat, quos in fublimi inprimis natantes, in altum mare fe præcipi- Oppian.

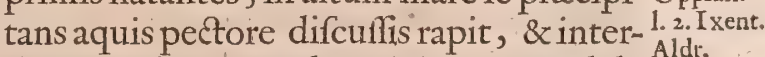
dum pondere victa demergitur. Quod de ${ }^{\text {Aldr. }}$ adipe fuperius dictum, quia \& teftimonio fide dignorum nititur, \& pari, in ardea pede in aquam demiffo, pifces alliciente; exemplo comprobatur, fidem videtur mereri; \& viribus narcoticis, quales, feu in torpedine, feu in opio, feu in fpiritu vini fentimus, adfcribendum eft. Vixit quidam \& quidem quietus ad feptimum fine cibo. De ipfius Ortu mira Plinius, qux quia Plin. H.N. mendo non carent, diligentius expendi 1. 10. с.3. debent.

Fel ipfius ad oculorum fuffufiones \& $Y$ fuss nubeculas cum melle mixtum prodefle Plin. H. fcribit Plinius.

6.

ME L A N E T o $s$, Aquila Valeria Her- Nomen.

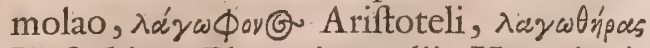
Hefychio \& Phavorino, aliis Hyperionis avis dicitur.

A 2 Mi- 
Defcriptio. Minor eft reliquis nigra, roftro adunco extremitate nigro cxteris corneo fubcrnuleo. Initium ejus fupra narium foramina, membrana quxdam transverfm obveftit. Verex ac cervix obfeuro ferrugineo tinguntur, Ocali pupilla ef nigra, iris charopa, \& ex luteo ruffefcens. Doriam ternis exiguis notulis albicantibus afpergitur. Ale ad uitimam ferè caudan exporriguntur. Crara tota propemodum plumis operiuntur ; quod nudatum eft, id luteum, vix ad digiti unius fpacium ad pedes pacet. Locur. Degit in fylvis \& montibus. Tidticat lepor:Aritu. H.A. bus quos, fenfin in terram delap?a, in pla. 1.9.c. 32. na digreflos opprimit. Pugnat tamen $8 x$ Pugra. cum cervis animofe. Multum pulverem volatu collectum, infidens cornibus excutic in oculos, pennis ora verberans, donec precipitet in rupem; fed \& curn Dircone, Ova hic confectatur Aquilcaviditate malefica: at illa ob hoc rapit, ubicunque vifum. Ille multiplici nexu alas li-

Plin.H.N. gat, ita fe implicans, ut fimul decidant.So

1. ro.c. 3. la Aquilarum foetus fuos alit, eft liberatis, fola fine clangore \& mumuratione.

\section{A.R T I C U l, U \& $\mathbb{H} I$.}

\section{De Pygargo E M Mrphizo.}

Noman. D) rgargus, Gazæ Albicills, Hinnularia 1 aliis Melanxto \& Morphn najore?t at minor Percnoptero.

Defrriptio. Qui ab Aldrovando exhibecur, majufculi Galli erat magnitudine, vertice ac collo dillutè caftaneo ex cinereo. Ocati, pupilla nigerrima, iride lutea, Rofiro adunco, \& paulo quam cateris Aquilis, proportione habita, longiore. Dorjum alarumque pars fuperior, ferrugineis obfcurè plumulis ac fubnigris integuncur, uti venter ac femora. Cauda ab Uropygio ad finem ufque tota albicat: dux tamen pennæ minores, majoribus incumbentes extremo nigra funt. Tibre totx fere nudx, impenfe lutex, tabellis fuper intectr. Vngues acexrimi.

Eocus. Colit oppida \& campos, plana \& lucos; fylvas \& montes nonnunquam. Romæ rarò vifam ex Symmachi epiftolis colligitur. Adoritur cervos, ut Melanætus, cum hinnulis; à dextro latere infilit, in oculos involat, \& tamdiu alis percutit, donec precipites agat. Aëtitem in nidum infert, à quo $\&$ is nomen obtinuit. Sed in alendo foetu reliquis eft difficilior.

Tiffcren- Duplex illius genus Bellonius recenfet. Vnsm, corpore colore inter album \& cinereum ambiguo, extremis alarum nigris, fupina parte tota candicans, quod Ardeam volacu refert; caput verfus terram deprimens \& perdicibus cuniculis, gallinaceis, \& aliis minutis volucribus, victitat, \& ut plurimum Oriente \& Occiden-
NATUR A L I S

te fole confpicitur. Altrom Milvo regaix adeo fimi?e, we unifinic \& minor effet, 82 ventre intonfus riobfente, (pennas circa Wropygium cun fipetioibus candidifimas obtinet) urvas ab altero non dignofcerecur. Trugues babet atros, crafos, \& in forricent criatos. Infeetaru alaudas per campos, \& cuma fúbbuteone de preda tam. acritor certar, tat uterque alis \& pecibus conferis in wixm delapfus, frpifime aucupibus in prodam cedat.

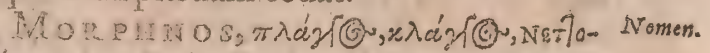
Wóvos, Ex seopuòs Cracis; Nevia, clanga, Mlarga autilancus, Anataria feu Avicida Plin.H.N. L, atinis, dicitur.

Veteres cama magnitudine Melanatum Defriptio. fuperarcio \& ningro ac fis $\mathrm{b}$ ob feuro colore, Arift.H.A. qui tan en iaris quibe dum intorizguawe ofe fcitume Hominus rlas ejus tanEima pater, munte valve of cul cujus duru viri dvice, ecine. Rete cencioribus Aldrovandiss xulian fo vidife cui omnia vecenin competercirt, fatetur. TurneItis zund Gefnern, nomen hoc Balw bufrdo Anglontu, qui ef Buteone major, nievo in capite albo colore fufco proxino; quitue ae rrpas dofit, in terra inter armalt eta finger aquas nidificat, volatu Locss, non admodren yoü, pifces \& cuniculos dilaniat, adfribit. Esllonius avem falconem fectulo mingem, odibus carileis, digitis oblorigi, Unguibus patulis, Gallis Gerfaledician, \&x terrefti venatuiadhibitan, pro Monhno, fed dubius, oberudit. Salcus convalles $8 \times$ lacussincolit. Aquaticis avibus ut fulicis \& anatibus plarumque, fape \&r pifcibus virivat. Spectanda di- pugato micatio eft,inquit Plinius, ave ad perfugia plin.H.N. littorum tendente, maxime fi condenfa ${ }^{1}$ 1. r.e.3. $_{\text {. }}$ harundo fit: Aquila inde ictu abigente alæ, \&rcum appetit, in lacus cadente, umbranique fuam nanti fub aqua, à littore 0 . ftendente ; rurfus ave in diverfa, \& ubi minime fe credat expectari, è mergente. $\mathrm{Na}$ foitur ex Oflifragis fi Ariftoteli credimus.

Morphno CONGENER Aldrovandus Ginerustio. appellat aquilam fibi miffam, cujus magnitudo galli gallinacei erat. Color totius ferrugineus, roftrum deorfum recta propemodum tendens, membranula lutea capiti conjunctum. Extremæ alx verfus ventrem maculis ovalibus infignitæ, remiges extremo apice albicantes. Crura hirfuta, \& albis notis è bærico afperfa digiti fuperne fquammis, inferne tabellis feu annulis inteetx.

\section{$A$ R T I C U L U S IV.

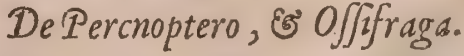

D Ercnopteros, qui \& Cypaëtos, vel Nomen. Hypaêtos, Ægyprias, \& Oripelar gus dicitur. 
Befcriptios Brovitor à veteribus, diverfin à Ncotericis defcribitux: Ariftoteli eft capice albicante, corjore, quan catera cictx majore, fed brevioribus alis, longiore cau-: da, vulturis referens. Aldrovandus bi- nos ejusdem icones exhibet. Rrior Chryfaëto non multo minor, habet Corpus coloris caftanei ad nigrum vergentis, ro= ftrum mediotenus rectum, extremo in un: cum infignem curvatum, principio juxta frontem album, cxtera nigrum. Caput fubalbidum ad futcum vergens. Oculos iride fubalbida, pupilla nigra. Collum dimidia fere parte eaque fuperiore propemodum calvum, \&x paucifimis iifque exilibus plumulis conficum, candicans, ad cujus finem, medio prope collo inftar pilorum quoruncian hirfutorum ac crifporum, pluk muix veluti fetæe oblongx fupra cæteras, plumas extabant In tergo veluci cucullus quidam, ad medium ufque protenfus in actitum finem, velut triang:lum quendam definebar. Alter ignavus, colore pennarum totius fere cortori erat fufco ad caftaneum obfcurum vergente, quem in ultitho collo nonnihil albicantium ordo continuus, angulum acutum in dorfum exeuntem conftituens qui veluti cuculli humeris inducti bafis erat, diftinguebat. $C_{a-}$ pise ad occiput ufque; calvo, ita ut pennæ poft verbum furrectx, cuculli fpeciem exhiberet. Bellonius avem Gallis bufard diAtam, buteone majorem, coloris nigri, alis brevibus ignavam Cypaërum vult effe. Gefnerus aliam ciconix forma \& coloribus fimilem. Frigoris impatientem, corporis intenfe calidi, carnivoram, fed pifces refpuentem, quæ quatuor horas uno loco fedebat, \& folem aliquando fplendentem intuebatur, fi non Gypaëtum, ex altero faltem parente natum, credit.

Locus. Incolit lucos \& plana, ut plurimum, montes, quandoque, in Syria \& Agypto maxime invenitur.

Nutrimen- Cióus foli inter aquilas, cadavera. Gra${ }_{\text {Arit. H.A. vis enim, \&zad rapinam iners, à corvo cx- }}$ Arif. I. $_{3} 2_{2}$. terifque id genus alitibus verberatus, fugatur, capitur. Muribus quoque circa Gazaram $\mathbb{E g y p t i}$ urbem victitat. Pullos ftatim parere, $\mathbb{E}$ Llianus auditione fe recepiffe fcribit. Avicenna fel ejus deftillatum cum oleo violaceo ad aurium dolorem \& tinnitum; fimum ad abortum commendat.

Nomen. OssifRA G A Oflifragus, Grxeis

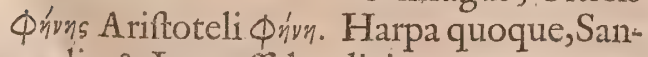
qualis, \& Immuffulus dicitur.

Defrriptio. Ariftoteles de ea. Ollifragx magnituArif. H.A. do major eft quam Aquila (Chryfaëto nempe excepto) Color ex cinere albicans. Parum oculis valet. Nubecula enim eos habet oblæfos. Quæ ab Aldrovindo exhibetur, quatuor dodrantes \& medium erat longa, novem, alis extenfis. Spitha- mas, lata, libras undecim penderis. Plumis totitis corporis, fub-albo, fufco, \& ferrugineo colore variabant. Cutem proximè vefientes, molliculx \& candidifimx eraut, remiges ex toto ad caftaneum tendebant: Coput \& collum anguftis \& oblongis pennis rigebat. Roftrum ei duos digitos latum, pal. mum longuin, fubnigrum, è Corneo fuf: cum, $a b$ initio membrana quadam ultra navium foramina protenfa, marginibus fuis literam s. exprimente teetum, ita aduncum, ut uncus folus pollicen laturi adæquarct. Lingua humanæ fimillima, lato apice, hamatis utrinque duris $8 x$ corneis appendicibus, membranula tenui ad infe: riorem mandibulam connexa. Mandibula inferior canalis inftar excavata; palatum medio rimam quandam exhibebat per quam pituita à capice deftillabat. De mento plumula tenues villorum inftar; ad barbrefpeciem quod oflifragx Plinius tribuit Plin. propendent. Crura fúcis plumulis aliquan- 1. 10, C.23. tulum fulvefcentibus fere tota obtegebantur. Vngues nigerrimi, pra arorre fplendebant, ix femicirculum ad amufim reprofentabant: Subftantia ipforum incus alba \& oflea, foris fufco cortice intecta erat. Duodecim caude pennæ albo \& niigro maculabantur, intus albre, extus fuffer. Et hxc externarum partium ratio eft. Interna fi attendantur, Uvea, qure homini in pupilla perforatur, tenuifimam quandam membranulam pupillx prætenfam habebat unde, ut Philofophus notavit, minus vifu pollet. Pars, quæ iriclis ambitu clauditur, ne prorfus vifio prepediretur, fub tiliffima, ¿zyoGa, \& pellucida erat, $A b d 0=$ men pinguedine copiofa redundabat. Lien illi rotundx figuræ, ventriculi corpus membranofum, fundo fuperiori orificio latius, ingluvie carens, quod de fua offifraga Plinius, cujus vicem Oefophagus, fimul atque jugulum trantiie, paulatim ad ventriculum ufque dilatatus, gerere videbatur. Vefice fellis nullum cum epate confortium hoc fub ventriculo multo immerfum erat adipi. Vterus craffo corpore, pyri forma, $\mathrm{fe}$ mine plenus. Vropygium medii pugni craflitudine, \& adipofum confpiciebatur \& c Ad hujus genus Bellonii illa, qux corpulentia colore 8 f́pecie milvi eft, duabus maculis nigris ad alarum latera notata, capite accipitris frellaris, cruribus \& pedibus vulturinis, \&c. non pertinet: fed illa qux in comitatu Tyrolenfi, colore accipitrum in dorfo, in ventre albicante; orgyix, diftentis alis latitudine, rupicapras ex alto ad. montes prixcipitar, frufta offium etiam majufcula deglutit; referri huc poteft : ut \& illa, quam Gefnerus, plumis albis, capite undo \& flavo, Saxis injecta ofla confringentem, amici verbis defcribit.

Cibus ipfi Rupicapræ, Hinnuli, canes 

${ }_{\substack{\text { Num } \\ \text { Num }}}$ - Venatici, Anguillæ, cujus frufta in diffe- Latinis etiam Vulturius, à tardo forfan cto ventriculo inventa, tam acuti fotoris erant, ut fpectatores in animi ferè deliquium conjicerentur.

Generatio. Probèfatificat', ut pullos fuos \& Aquilæ, quos ifta nido volandi facultatem adepAritt H. tos, \& edaciufculos, ejicit, nutrit, \& abrep-

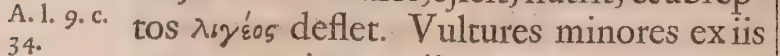
progenerari, \& ex iis magnos qui omninò Plin. H.N. non generent, fcribit Plinius.

1. 10.c. 3. Pugnat cum vipera; \& fauciata, herba thia. foncho fimili, fibimedetur.

Lucret. 1.5.
Vox.

Ufis.

Plin. H.N.

Vfum fi fpectes, fel ejus cum melle po-

1. 30. . . 7. tum leucen curat : ftercus aridum tritum concoctionem promovet. Venter potus calculos pellit. Inteftini extremum ad alligatum, colicam fiftit: Os ad coxam fufpenfum, varices fanat.

\section{$A R T I C U L U S$ V}

De Anopaa, Aquila alba, Aquila beteropode Es Scythica Ave.

A Nopæx fit in Homero Odyff. $x$. mentio, qux quibufdam eft å $\phi$ av̀s

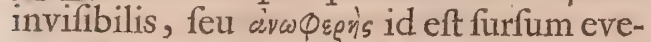
cta. Alii $\pi$ cavóm asa fcribunt, \& hirundinem intelligunt.

$A$ QVila A z в a feu Cygnea, magnitudine eft Chryfaëti, candoris nivei, in rupibus circa Rhenum invenitur. Leporum, cuniculorum, procellorum \& pifcium venatu vivit, \& volatu tarda eft.

HE T E R O P o $s$ Gefneri, finiftrum crus cxruleum, dextrum fufcum albicans habet, de cætereo, pectus, collum, \& venter fufca funt, punctis nigricantibus maculofa. Capztis \& cervicis pennær rigent. Oculi fubrubent, dorfinitium circa alarum fummitates in gibbum attollitur.

DESCYTHICA ave ita Ariftoteles. In Scythia genus avium Otides. Hæc duos pullos parit. Ovis non incubat, fed in pelle leporis aut vulpis impofitos pullos relinquit. Obfervat in fumma arbore an adfit qui pullos furripiat. Quod fi quis afcendat, pugnat \& verberat alis, ut Aquilæ. Olaus M. oculatus teftis, utriufque hiftoriam confirmat, quam Albert.M. falfi infimulat.

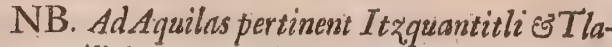
coquantili Indorum, vide infra MantifJam. $N^{\circ}$. I.

\section{T I T U L U S I I.} De Vulturibus.

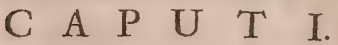

De Vulturibus in genere. volatu, \& per periphrafin, Avis Titii, torva, avida, magna, Palatina, caucafea, dicitur: Lycophron eas olores rapaces, Her- Lyco-

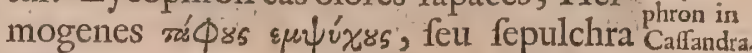
animata vocat.

Toto corpore Aquilam ferè imitatur, $D e f c r i p$ illamque, fefquialtera proportione, fi Bel- ${ }^{\text {ti }}$ lonio credendum, excedit; nec tamen, quod in rapacium genere folemne, marem fomina magnitudine fuperat. Roftrum ipfi obuncum, oculi truculenti; quatuor, apud Philen, narium fpiracula, unde тz-

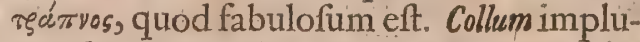
me, feu potius capitis plumæ ita breves, fi cum Aquilis conferantur, ut implumes videantur. Guttur longitudine \& capacitate, quod propendens ante ventrem ingluvies oftendit, infigne, fub quo fpacium palmi latitudine, non tam plumis quam pilis, ruffis, vitulinis fimillimis, inftar leniffimi cujufdam velleris, omni fcapo calami deftitutis, veftitur. Alarum incumbens corporipars, leni tota vellere, quod foli inter rapaces peculiare integitur. Crura tota ad pedes plumofa, contra gelu \& frigus munimentum. Vngues adunci.

Sedes in altiflimorum montium jugis, tocus. ponere, Ariftoteles, Plinius, \& Homerus Arit. H. funt authores. Poëtæ Caucafeas vocant. A.lin. H. ..5 A recentioribus in Creta, Zazyntho, N.1. 10. Apennino, monte Gallix Aureo, vifi funt. c. 7 . Aftate in aprica, frigoris vitandi caufá Hliade 2. demigrant, \& in Arabiæ defertis \& Egy * pti inter Cairum \& mare rubrum planis, numerofos Bellonius vidit, quod iter illud Camelorum cadaveribus plenum, paftum ipfis fuppeditet. Agricola in fylvis Agricola degere afferit. Juvenali nidulantur etiam ${ }_{\text {ran. }}^{\text {de fubter- }}$ in arboribus. In Creta \& alibi in præcipi- Juvenal. tiis, montium mari imminentibus. Prop- Satyr. 14. terea Herodotus Briffonis Rhetoris pater ait, effe vultures in terra altera nobis igno- Arit. $\mathrm{H}$. ta, eo argumento, tum quòd nemo vul- A. 1.6. c.5. turis nidum confpexerit; tum quòd magno numero repente apparent fequentes exercitus.

Victitant morticinis \& quidem folis, illi, Nutrimenqui cum Aquilis, Offifragis, \& Accipitri- ${ }^{t w m}$ bus nullam cognationem habent,fui generis volucres mortuas, fi Herodoto Pontico credimus, ne attingentes quidem. Vivis etiam tum volucribus (ruunt enim in anferes) tum quadrupedibus, illi, qui Spurii funt. In Creta \& Helvetia agnos, hoe- Bellon. 1. dos, lepores, cervorum hinnulos; In Chile do Avibus Americæ provincia pecudes, infeftant. ‥ 23.

Datur quoddam genus quod Torgos $\sigma^{2}$ Hrema- deAromat. torrbophum dicitur.

Venantur à meridie ufque ad noctem, $a b$ ortu folis ad illud tempus quiefcunt.

De eorum Sexu, Coitu, Partu, \& Incubatu Grneratio. non conveniunt Authores. Fœminasdun- 
feliani H. taxat inter eos reperiri, Alianus, Orus, ne Siferis Cretici vehementer oblectatur. A.l. 2.c.46. Philes, Tzetzes \& $r$ alii authores funt, vel fi
L. I. Hietogl. Aufter non fpiret, ad Eurum ventum oris Phile de hiatu fe pandunt. Spiritus venti influens,
propriet. propriet. intra quinćue dies, quibus nec cibum néc Animal. intra quinque dies, quibus nec cibum nec
Tzezzes potum capiunt,ipfos implet. Tertio à con439. ch. ceptu anno, non ova fed pullos parere,

Geoponicorum fcriptor, Philes, \& Simocattus produnt, intra centum \& viginti Arift. H.A. dies ova deponere, Orus \& Tzetzes. Ari1.6. c. 5. ftoteles \& Plinius nidificare fcribunt. Niplin. H. N. phus nidum in Italia vidit. Ille bina com1.10.c.6. plurimum ova ponere reliquit : hic ex Umbricio Arufpice tria. De tempore partus nihil determinant, hoc interim à Divo Hieronymo proditur, vulturem cùm cœperit ova edere, quippiain ex Indico tractu adferre, nucis inftar, intus habens, quod moveatur,fonumq́ue fubinde reddat. His veritas fubfribere videtur; attamen cum Aquil $x$, offifrag $\&$ \& vultures, ut ex Ariftotele, \& Plinio palam eft, promifcuo coitu inter fe utantur : facilè ex diverfarum fpecierum avibus, tertia fterilis, ut ex equa \& Afino Mula, generari poteft, quæ ob fimilitudinem cum vulturibus, quam Aquilis majorem, inter illos potius collocetur. Edu-

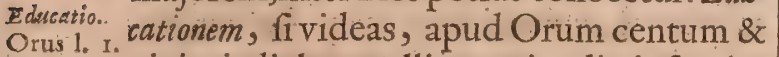
Orus 1. I. viginti diebus pullis nutriendis infumit, alimento deficiente femoribus fuis roftro vellicatis fanguinem ciet, ipfifque fugendum præbet. Apud Albertum verò unguibus eos vulnerat, \& de fuperfluo fibi cibo pafcit.

Intas. Extendit retatem ad centefimum annum. Ambrof. 1. Euè- Quantum ad facultates s' actiones animales, mer.1. 5. Oriente fole in occafum, occidente in orc. 20 :
Ifidor. O. tum prof́picit, ut apud Orum extat. Non rigin. Ii 12. ultra maria tantum, fed per quingenta c. 7. etiam millia pafluum cadavera odoratur: Thoni. A- feu quood inftrumenti fit exquifiti \& ficci; quinde A- feu quòd copiofa ab integris quandoq́ue Comment. exercitibus exhalatio fit, feu quòd eadem 9\% conglobata, ventis eoáem deferatur.

Volatus. Moventur tardè propter corporis molem, $\&$ volant turmatim.

Ingenism. Ingenium exinde colligas, quòd Regionés frigus evitaturi mutent. Ægypto rion minus, quàm Ciconix advenx, quòd ad idem cadaver, à quio fatiati, frpius recefferunt, identidem redeant, expeditos ad bellum exercitus prefentione quadam confequantur : ac ut aliqui addunt, biduò triduove, imò feptenis diebus antè ea loca Nicander circumvolent, in quibus cadavera futuin Theriac ra funt, quod domi cadavera à venenoAntipa- fo ferpente percuffa fugiant, \& hepatis thia.
Ariftot, in morbo laborantes magnarum aviuim jeci-

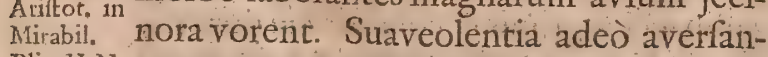
Plin.H.N. tur, ut ne armenta quidem mortua, un-

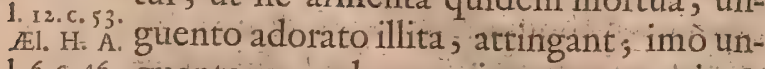
1.6.c. 46 . guentorum odore perimantur; perit \& Plin. H.N. . . mali Punici grano vultur : fed femine Si-

Inter ejus morbos funt, Hepatis obftrua Marbs, ctio, \& pediculi, infectum venenofrm, pediculo par, vel eiqui in inguine nafeitur, perfimile.

Vflum in medicina partes ejus, nothrium $r$ fus. obtinent. Medicamentum ex integroab Aëtio paratur, ad abfcéflus, condylomatas Aët, 1. 13'

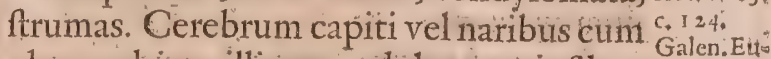
oleo cedrino illitum, dolorem ejufdem poritt. Iit 9 : fedat. Cor pulli adalligatum adverfum ${ }^{\mathrm{c} .9 \mathrm{~g} \text { : }}$ comitialem morbum prodicatur. Serenus jecur ad jecoris dolores commendat: Fel. Opftalmicis benè ex Sammonico admiff cetur. Penna pedibus fubjecta parturientes adjuvat; fed nifi tempeftive auferatur in uteri proçidentiam conjicit. Si dentes ea fcalpentur, acidum anhelitum reddit. Nidore pennarum, fi utantur, ferpentes fugantur. Pellis ventriculo appofita con-Lennn de coctionem egregiè juvat. Nervi ex cruri- occul. Nabus \& fummis pedibus collecti, \& ad talos Tralliani xgri alligati, podagram curante. Externa l. r. fi attendaś, ex oflibus vulturis tibias Scý- Pollux Othæ Anthropophagi, Malenchleni, Ari- nom. 1. 4: mafpi conficiebant. E cruribus candelabra quidan, quod ipfa, innatâ vi venenum explorare \& attrahere crederent. -

\section{A P U T I I: De vulturum Differentits.}

V Ulturum duo duntaxat genera Ari- Aric. 1. 8: Atoteles agnofcit; at Neoterici plura c. 3 . effe obfervant.

Primum eft Albicantius, \& parvirn, quod in montibus Rheni, Danubii, Helvetio Albert.1.7. rum circa Clavonam, apparet, in Scythia; de Anima\& fubjectis Septentrioni regionibus frequens eft.

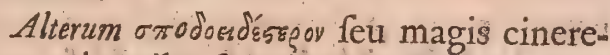
um, cujus pilos feu plumulas albas capillaceas \& capillamentorum inftar fubtiles, adeò candidas effé Bellonius fcribit, ut pellem fubdititiam \& elaboratam, muftelæalpinæ albx, feu etiam vulpis albæeffe, quispiam exiftimare poffet.

Tertium Bxticum, quod Aquilâ paulò minùs habet pennas colli, dorfi, ventris, totiufque adeò corporis, caftaneo colore tinctas; dorfi \& laterum exiguas; \& fquammarum inftar latiufculas, qux dorfum, ventriculum, ventrem, \& uropigii radicem veftiunt, ruffas plumas verticis breviculas ac curtass, fi Aquillis comparetur. Colli an guftas ac longiufculas, quales gallis gallinaceis, \& fturnis propendent. Crura brevia, plumis undiquaque ad fiperiorum ufque digitorum partem contecta.

2 iartum Nigrum, quod eft cauda brevis; alarum \& caudæ pennis ejufdem cum Boetico coloris. Albertus minus hoc, fed viribus preftantius feribit. 
2uintum Leporarium, roftro obunco, brum puniceis literis fcriptum, in quo cul- praparat: nigro, foedis oculis, corpore firmo \& ma- tus Deorum forma continebatur, Thebas Euangel. gno, alis latis, cauda longa \& directâ, colore in rutilo nigricante, quod ex vulture \& Aquila compofitum videtur, \& illud quod Homero Albertus melanocon vocari fcribit. Huic enim peculiare leporibus infidiari: $\&$ folus inter cxteros velox \& ad docendum aptus eft.

Sextum Aureum Gefneri, quod ita defcribit. Longus eft à roftro ad extremam caudam fex dodrantes \& paulò amplius, ad extremos ungues quinque dodrantes aut paulò minus, longitudo fuperioris roAtri quantum illud aperitur, feptem ferè digiti transverfi. Cauda longitudo circiter tres dodrantes. Tota pars fupina, id eft collum inferius, pectus, \& venter \& pedes quoque ruffo colore funt, dilutiore quidem caudam verfus, rubentiore verfus caput. Digiti pedum fufco vel corneo colore funt. Alarum penna longifima quatuor dodrantes æquat. Subnigricant feu fufco funt omnes alarum pennæ uno ferè colore: parvula tamen fupremæ in alis nigriores funt, ut per medium alix fubruffis maculis, aliæ fubalbidæ circa imum diAtinguuntur, eo nigriores autem funt, quo propiores dorfo, ubi præ nigredine fplendent. Pennx per medium dorfum nigræ funt, fplendentque in earum medio cauliculi albi, præfertim quæ circa medium dorfum funt, \& dimidia colli parte, reliqua enim colli pars, pennas ex albido ruffas habet. Caudx pennis idem color eft qui alarum, nempe fufcus. Hifce addit Albertüs quoddam collo craffo, alifque ad dorfum valdè retortis \& magno pectore, quod frequenter in ripis maris degit, \& quod venatur, eò defert.

\section{T I T U L U S III. De Accipitribus.}

\section{A P U T $\mathrm{I}$.}

\section{De Accipitribus in genere.}

porphyr: 1 jus tanta apud veteres veneratio, ut 1. 4. de ab. \& præfagiendi poft exactam hanc vitam vi ftinent. pollere, crediderint : \& legem qua capitis porphyr. damnatur, qui eum etiam imprudens ocPlutar. de cidiffet, tulerint : tanta apud Egyptios, Ifide \& $\mathrm{O}-$ ut ipfum Soli acceptum putarent, picto
firide. firicle. Iib. Ofirim proponerent. Tentyrita \& Philaso.de Ani- rum incolix fanctiflimè colerent, interfemal.c. 24. ctum fepulchri honore afficerent, \& in ur37. Gcogr. bem Butim afportarent; feu quod ipfius in Euterp. fubftantiam ex fanguine \& fpiritu conftaPorph. l.c. re dicerent; feu quòd regionem à veneDiod. Sic. natis animalibus eos repurgare cernerent; Euf.l. 2. de feu quòd Accipiter prifcis temporibus liad facerdotes, detuliffe crederetur.

Dicitur Gracis communiter "हea. $\mathrm{Ma}$ Diod.1.e. cedonibus raegios, apud Lybias $\beta \alpha \_\beta a s$, Norncr. Hefychio, repryòv, Tyrrhenis äegros; aliis $\mu^{\prime}$ śguivis. Latinis Accipiter, feu à rapacitate, feu quòd ter fit acceptus. Unde \& facer ales vocatur.

Avem ipfam fi fpectes, corporis ipfi moles Defcriptio. incerta. Nonnunquam vix Aquilis cedit, in Ægypto minores quàm in Græcia, in Arit. 1.9 . regionibus Aquiloni obverfis \& rupibus, $\mathrm{C}_{1} 2 \mathrm{H}_{\text {. }}$ quia fanguine \& f piritu abundant, majores. Major mare foemina, quòd in illo humidum ab immodico abfumatur calore ; in hac, fanguis cum moderato calore copiofior, multum argumento materix fuppeditet. Color ipfis ut plurimum ex albido fulvo \& nigro diverfus, maculifque diftinctus alibi, albi \& leucophxi reperiuntur, \& qui in frutice fpinofo aut acere habitant, ad ruffum aut nigrum declinant: qui in fago, ad gilvum feu pallidum. Caro eft afperior, quàm cuculi, copiofioribus plu- Athen. $\mathrm{K}$. mis integitur, quàm graviores aves, quòd A.1. s.c.9. fuperflua materia ad pennas amandetur, eorumque generationi ferviat. Rofrum habet aduncum extremo plærumque corneum. Oculos fplendidos, unde Soli facri, \& perpetuò mobiles, quorum color cum xtate mutatur. Cerebrum copiofum, linguam latam, principio obtufam, nec bifidam, nec acutam. Pequrs acuriflimum, modicâ carne munitưm. Alas rapacium acutiores. Anhelitum foetidum, cor magnum, cufpide obtufa. Lienem adeò exiguum, ut fenfum propè modum effugiat. Fel nonnunquam ærugineum, jecori \& inteftino adjunctum.

Si loca fpectes, frequentifimi funt, in zocsso Anglia, Suecia, Pruffia, Livonia, Rufia, quod iftx avibus tardioris volatus, \& multæ carnis abundent $:$ minus frequentes in . Syria, Perfia, Africa, Græcia, \& Cretâ. Nidulantur in præruptis \& altis rupibus, in Alpibus inprimis, fed vel inter vepreta, vel Homerus in arboribus, acere imprimis, fago, quercu, Ody氏. : abiete, pinu. Qui Maffilix agros incolunt, Plin. H.N. 'humi foetificant, nec alibi nafcuntur. '1. I o.c.8.

Potu omni, Tinnunculo excepto, abfti-Nutrimernent, fi Ariftoteli \& Suidæe credimus : bi- ${ }^{\text {tum. }}$ Arit. 1, 8. bere Plutarchus, etiam poftquam hominis Hitt. c. 38 . defuncti corpus tetigerit, fi affluentis co- ${ }_{\text {in vocc } i \pi}$. pix aqua invitetur, Gyllius, prodidere; Plut.de quandiu viventium fanguis fedandx fiti Iride \& $\mathrm{O}$ fufficit, non bibere : fi exanguibus vefci co- Gyllius in gatur, potare, credibile. Cibus ipfis aves, Aliats. gallinacei inprimis \& columbacei generis, Turdi, Fringillæ, Coturnices, Corvi,Picx, Cornices, nobilioribus cancri \& caro leporina vehementer fapiunt : vilioribus etiam mures, ranx, \& talpx; manfuetis 
quoque fruges \& pànis. $N e c$ à cordibus, Aritot. 9. quod cum Ariftotele, Plinius \& $\mathbb{E}$ Elianus Hittic. 1t. non credidere, tefte Alberto \& Aldrovan1. 10. c. 8. do abftinent, quin cerebro è cranio divulAldrovan- fo \& abfumpto, reliquum corpus involant. dus 1.23.de Nulli ad reliquias prædæ fuæ revertuntux, Albert.1.c. dutm fylveftres funt; nec unquam cadaveri infidere vifi: fed omnes interdum tam avidi, ut ftercora præ fame deglutiant. Venctur autem Accipiter, non tantum TurtuColumella res; Gallinas albas maxime propter̂ can1. 9. de re doris infigne, Anates, Cornices, Sturnos, rut. Picas \&c. fed \& proprium genus, quod praterquam Aquilx \& Olori, ut quibusdam placet, nulli aliarum avium cum eo commune eft. Cuculus ab eodem abfuArir.H.A. mitur, fi quando una apparuere. fola om1.6.c. 7. nium avis à fuo genere in terempta. Le-
Plin.H.N. 1. x. H. . N. porem poftquam cœepit, finiftrum pedem terræ infigit, dextro prædam retiner, \& quam primum poteft oculos ejus cruit. Venaturus folus volitat; prxda confpecta humilis prope terram fertur, \& omni conamine inftar fi primo nifu fruftratur, perfequi definit, \& fibi indignatur.

veneratio. Focunditate negata, quod humorem Arift. 3. de ad crura, ungues, pennas, \& genitalia logener. A- ca fimul nequeat transmittere natura; ;alasimal. c. I. catatem ipfi adfcripfit antiquitas. Certe, \& Ariit. 2. de cum Aquilis coëunt, \& A Ateria cum Accigener. A- pitre congreditur. Quoddam genus,cum nimal, c. 5. pin venerem ruit, minimarum etiam avium Flian.1. 2. morfibus patet : aliud, more hominum de Animal. amataria levitate flagrantium, fominas ๔. 43. femper fectatur; abfentes clangore profequitur. $\mathbb{E g} g$ ptii foeminam una die requifitam, quantumlibet fecefferit, à marito vocatam, obfequi tradunt, \& inde foeminas morigeras titulo Accipitris honeftant: Tria ut plurimum quatuor aut quinque Albert.lib. quandoque ova pariunt, \& vicenis diebus 10. c. 8. incubant.

Atats. Etas hujus avis in multos fe protendit Alian.lib. annos. Agryptii ad feptingentos perveni10. de A- re, fed falfo afferuerunt. Multis etiam in-

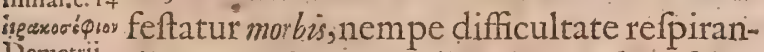
Demetrii
ed, Rigal- di, \& tum fontum elidit ; aliquando ofcitaed. Rigal- tur, \& vomit : tineolis, \& tum ipfi venter \& collum glabefcunt : cholera, in qua liquorem viridem evomit. Spongia, qua affectus,præter confuetudinem bibit, multum feflitat, nec ex manu, nec ex pertica difcedit. Febri, tum puftulas filigini fimiles in ore habet. Tineis; tum caudam, frequenter motitat. Suppreffione alvi, tum crebro anulum perticx admovet, \& excrementa nigra reddit. Intemperie frigida, \& tum excrementa crocea aut cruenta reddit, alas autem remiffas \& laxas, capitis plumas horrentes habet. Pituita ficca, \&rtum liquorem per nares non emittit. Gravedine, \& tuin ipfi liquor per nares, fpuma per oculos elabitur. Tremore,
\& tum pinnas ut ftruthiocamelus habct, \& volare nequit. Plura apud citatum $\mathrm{Au}$ thorem vide. Vox Accipitribus alia alio Vox: tempore, \& generi. Apud Grecos verbo 'púżav per olımapopoeiam conficto, apud LatinosPipandi exprimitur.Gallinæ fi eam audierint, dum interim incubant, ova vitiantur. Vifus tam acer, ut nullo negotio Vifuss.

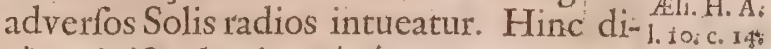

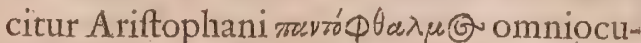
lus. Cum Apolline, qui eft fol, magnam convenientiam habere credebatur; \& ejusdem imagine folem denotari Agyptiis Plut.lib.dic folitum.

Volatu funt velociffimi, \& adeo cele firide.

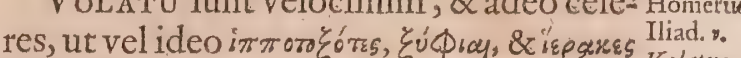

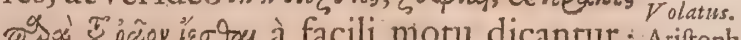
foli a cicantur; Ariftoph. foli qui velociffimus facri fint; \& fummam in Avib. cum igne cognationem habere credantur. Ao, c. c. 24, lib; Ita fane fe aliquando efferunt, ut humanum vifum effugiant ; nihilominus prædam inde vifam, jaculo citius demiffi, affequuntur. Peculiare illis \& cum fola Nootua commune, in aëre fefe refupinare, caudam deorfum, \& $x$ alas expandere, his vice foli uti.

I NGENIU M ex parte attigimus, foli- Yngeninm? tariam femper, preterquam tempore coitus volare ; juftre magnitudinis cum vulpibus etiam, Aquilis, \& vulturibus certare; in Thracix parte fupra Amphipolim cum Aeli. H. A. hominibus focitate quadam aucupatum 1.2. c. 42 . fuiffe; in toto avium genere docillimam Plin. 1. Io. effe; avem fibi forte fub noctem oblatam totam noctem fub pedibus tenere, ex oriente fole manumittere, obviam non perfequi, tandem, fucco Hieracii herbæoculos tingere, fic claritatem priftinam recuperare, addi poteft. De cxrero, mortuum lugére, \& in oculos ejus terram ingerere, Elian. lib. noctux à reliquis avibus infeftatæ auxiliari. Io. c. 17. Turturem deprehenfam' dimittere; unde 4. de abrtiEgyptii, ne quando imprudentes avem nentia. ab Accipitre dimiffam guftent, toto eorum genero in cibo abftinent, à Tinnun- Plin. 1. ro. culo, crocodilo, \& vite nigra fibi metuere; c. 37. cum falvia, mentha, abiete \& falice fym-Ifide \& $O$. pathiam habere; Authores quidam pro- fride. diderunt.

VJum fi fpectes, pulli fuaves funt valde, Vifuss. adultorum caro dulcis \& levis. Totus afius \& in cibum fumptus, morbum facrum ; in rofaceo elixus, oculorum vitia, pulvis in quo fe volutavit, lino rutilo ægri collo alligatus, quartanam, adeps oculis inunctus caliginem, oculià collo fufpenfi tertianam; depellere, fed fruftra creduntur. Stercus in vino dulci tritum, conceptum Hippociate juvare; fumum vero ex eo, fpolio ferpen- de morbis tis; opoponace, myrrha, galbano, caftoreo, yillaniv. fulfure citrino, \& felle vaccino excitatum, in Breviag \& per fiftulam in uterum exceptum, foetum educere, credibile eft. 


\section{A P U T II.}

De Accipitribus in jpecie.

A R T I C U I U S I.

De Afteria, Accipitre Palumbario, E़

$$
\text { Frimgillario. }
$$

Arit.lib. S T E R T.A.s, qui \& Aftur aliis, cor-

Hitt. c. ${ }^{6}$. Palumbario comparatur, punctis \& notis quibusdam ftellas referentibus répergitur, hinc ipfi nomen. Capitis pars anterior extenfa paulatim eft in roftrum. Oculi varii \& pellucidi : collum longius Aquilino. Femora longiona quam falconum, crura horum refpectu brevia, \& craffa. Pedes magni. Cauda ob longitudinem dependet. Eft ex eorum genere, qui, quod emifli præterito pugno revocentur, Pugillarés manfuefactariis dicuntur. Differentias fortiuntur Aftures varias. A natura. Alii aut rupes mari adjacentes incolunt, ant flumina $\&$ aquas dulces fectantur, qui humilem prope terram volatum .exercent, \& clandeftino aftu prodam adoriuntur. A lii diffitis à mari locis delectantur, \& \& ex excelfis arboribus prædam defpiciunt, \& infeftant. A Sexu, in quo foemina colore ad Aquilam accedit, nifi quod maculis denfioribus \& rufis afpergatur. A magnitudine, qux Aftures ita commendat, ut in Syria aves qux pradx ac aucupio ferviunt, ad pondus emantur. A loco, funt namque Armeni, qui oculos habent virides : \& fi cum dorfo nigricantes, optimi cenfentur; crura candida, pedes magnos. Per $/$ is, corpus grande,plumis bene veftitum;oculi concavi, fupercilia pendentia. Grecis capuir grande; \& raræ in collo plumx. Afrieanis dorfum nigrum, oculi, in juventute nigri æetatis progreffu ruffëfcunt. Sardis penna nigræ, crura brevia, femora longa, pedes pallidi. Illyricis, five Sclavis,ftatura mediocris, pennx rubre, majori ex parte prunarum candentium adinftar; pëdes magni,femo$\mathrm{raab}$ interna parte plana, volx manus inftar xqualia. Alpinis corpus magnum, oblongum, pedes ferecandidi, fuifficiens ad leporum venationem robur. Germanis oculi iris \& fuprema capiti contigua roftri pars, cruta, tibix \&spedes, crocea: Pennæ caudx nigris \& canis iifque latis \& obliquis maculis afperguntur; colli fuperioris \&x capitis ruffefount, \& punctulis, nigris interftinguuntur Carcani Aftocellus, eft forte Tardici \& Bellonii Semi Aftur:

Adctpiter Palumbarios, quiGri-

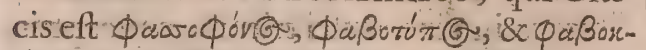
ro(G), feu columbicida, quis fit, certo dici Atirt 1. 8. noin poteft. Ariftoteles meram nomenclaHilt, c. 3. turam fuppeditat, \& fimpliciter Accipitrem nominat. Ephefits à Nifpho citatus, Falconem gentilem vulgo dictum ex eo fa- cit. Alberto cum Afure idem effe videtur, Turnero cum Fringillario idem. Ariftoteli eft Chalcidis avis magnitudine, \& Carni-1. 3. de abvolus:Porphyrio omnium celerrime volat, ftin. $a b$ at

A C CIPITER FRINGILLARIUS nimal.

Gracis veteribus $\Sigma \pi \xi_{\text {has }}^{\prime}$ recentioribus $\xi_{\mathrm{au}}$ rzes, corrupto forte ab Oxyptero vocabtzlo; Latinis Nifus, quod ei Alberti ni fallor primum revo impofitum eft, fed non Ovidij, cui Nifus idem cum Haliæto, aliquibus Sparverius, ab Italorum Sparviero dicitur. Mas qui Mufcetus vocatur, \& frmina minor eft, quique $a b$ Aldrovando exhibetur,roftrum habet breve, unco acu tifimo prxdituin coloris cornei fubcærulei. Oculi pupillam ochræ colore pallido, lutea iris excipit, quiod reliquum eft intentu flavet. Caput, collum, pertus, venter, crura albicant, \& variis maculis diftinguuntur. Dorfum $\&$ alas muculix multæ albæ refpergunt. Caisda nigris \& fufcis maculis tranfverfim ornata, celiqui fere corporis longitudinem æquat. Pedes \& tibix crocei funt coloris. Femine, vertex, collum, dorfum, alæc coloris funt obfcure fufci. In Syncipite, \& alarum medio, qua dorfo incumbunt, alba macula confpicitur. Pars totius corporis prona, eft candida, \& transverfis lineis luteis interfecatur. Dogit tempote hy. berno in fylvis cæduis, earumque gracilibus. Non ante occidentem folem ad feden fuam revertitur. Plærumque adverfo vento volat. In legibus Salicis de eo legituri, quod qui furatus fuerit, centum \& viginti denarios perfolvere deprehenfus teneatur.Dividiantur ab Aetate, in Nidarios, Ramularios qui necdum plumarum depofuerunt exuvium \& mutatos. A loco natali in $I l$ liricos, qui ut plurimtim lumbos, ac dorfum nigra abtinent, \& vitam brevem agunt. Orientales quibus cauda duodenis pennis inftruitur, Africanos quibus oculi nigri, pedus nigris \& transverfis maculis varium, alælongx. Tridentinos, qui funt proceri, volaces, frepe captàs, alaudas in terram deorfum dejiciunt; mox furfum arripiunt. Vincentznos, qui aut in montibus Vincentinis nafcuntur \& omnes ftatura funt exigua; aut in Mucrofticanis Spiranoli dicti, capite magno, reliquis minores, \& ad aucùpia inepti : \& I Irotos, quil corpore medio cres maculis ferragineis ad rubrum inclinantibus, refperguntur. A colore Albos namque in Septentrionalibus onis reperiri, Olaus Magnus author eft,

$$
\text { A R T I U L U S II. }
$$

De Circo Afalone ES Tininculo.

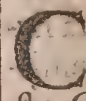

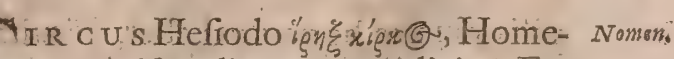
jo \& Arrftotelix ror (6) fimpliciter, $\mathrm{Fe}$ fto Circanea vel Circenda, forte, quod, cum infidiatur, circuitum in acre faciat, dicitur.
$\mathrm{Si}$ 
Defriptio. Si defcriptionem Bellonii fequimur, dus \& Tinnunculum forminam alteram; haud multo milvo minor eft: Capitis vertex \& guttur inferius ex ruffo albicant, plumulæ qux auditus foramina tegunt nigræ funt. Roftrum capiti continuum plumbeum eft, extremum atrum, collum breve. Crura gracilia, lutea; falsò altero claudicare, Plinius prodidit.

socus. Gallix eft inquilina, \& ibidem in Arvenix planis nidalatur.

Nutrimen- Cuniculos, vulpes, columbos, Turtures, plin. 1. ro. Mures infeftat. Bibit cum in maritimis verH. N. c. s. fatur. Amaraginem, lactucam fylveftrem, Arift. 1. 9. vel crocum nido imponere creditur.

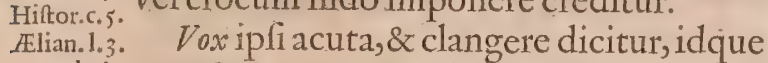
c.45. deA- tum facit, cum prædæ propiquus, de ea Honer. in apprehendenda eft follicitus. Volat in gyBatracho- rum, \& quidem velocifime, hinc Homo-

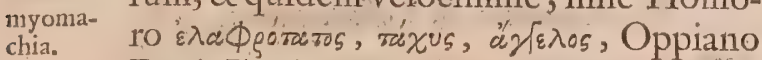
Vox. Equis Iberis velocifimis celerior.

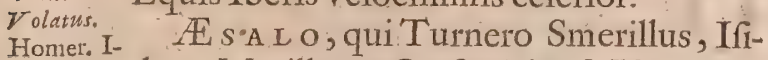
Honer. I- doro Merillus, Crefcentienfi Ifmerlus, Euftat. in Alberto Mirle, inter rapaces minimus eft, meri lo- \& tum coporis fpecie, tum pennarum cocum. lore, Falcones refert.

Odyffr. v. Perdices \& columbas venatur. Alaudas
Nomen. Nutrimen- tam avide ut ad clibanum ufque ardentrim. 10. c. 13. dat, fi peritia, \& ufus accedat, quatuor Plin. 1. ro. merilli, cygnum etiam dejiciunt. Solus c. 8. Hilt. omni tempore apparet, quod tamen Bum c. 3. teoni Ariftuteles adfcribit.

Inimicitia. Inimicitias cum vulpe \& corvo gerit; 1 ilius Aritit. 1. 9. catulos interficit :s hujus ova confringit:

Plin.1. 10. Corvi vulpibus auxiliantur.

Tinnungu us Gazx aliquando Triftunculus, ut Italis Triftarellus , \& Canibellus \& Gavinellưs: Graci rézæż‘s,

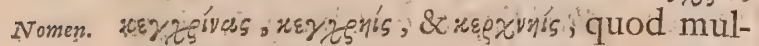
tis milii inftar punctis infignis fit, dicitur.

Defcriptio. - Mas, prout ab Aldrovando defcribi1.5. Orni- tur, habebat, caput in fummo vertice nonn-
thol. c. 6 . thol.c. 6 . hil compreffum, coloris cum univerfa cervice ad dorfi initium ferme cinerei.Rofrum ftatim deorfum molli declivitate tendens, unco infigni ac longiufculo, cujus pars capiti contigua fulvefcit, media colore eft cinereo, ad latera appendix erat, hemicycli forma. Alas \& dorfum ferrugineis pennis natis atris diftinctis; gulam, pectus', ventrem flavis maculis nigris perfperfis veftitum. Alas oblongas, \& quinque digitorum fpacio Altra Uropygium extenfas. Caudam maxima fui parte cineream, rejiqui corporis longitudinem æquantem.

- Fomince, quix major erat, roftrum brevius cum roftro magis recurvo, cinereum. Dor/f. \&alarum pars fuperior ferruginea ad ruffum accedens. Pennæ extremæ dorfi cinerei coloris, \& notis transverfim fufcis obliquis utrinque in angulum medio fcapo coëuntibus maculatx. Habet Aldrovancujus defcriptionem apud eundem vide:

Nidulatur in altis xdificiis, muris, turri- Lotus. bus \& cavis quercubus, monedularum mare, non fuper fronde, fed in latibulis.

Fominas Mas femper fectatur, de ab- Generatio. fentibus dolet: Illx fupra quaterna ova de Animal. edunt,minii modo rubentia. Pullos tam diu c. 43 . alit, donec proprio volatu vivere poffint. Atitt.lib 3 .

Viftitat papilionibus, Locuftis, verpis, c. $\mathrm{c}$. muribus. Inventus aliquando in nido ejus ${ }^{N u \text { trimen }}$ \& ferpens:fed \& ipfe in picarum nido cum pullis inventus eft. Bibat annon dubium. Ariftoteles raro \& folum inter incungues 1. 3. de ge-

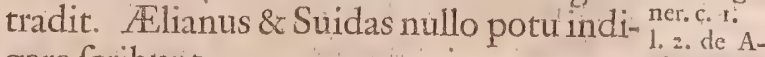
gere fcribunt.

Cum columbis fingularem colit amici- 43 . tiam, cum Accipitribus aliis, etfi fui generis capitalem hoftilitatem exercet. Ideo, Plinius. Avis, qux Tinnunculus vocatur, 1, ro. Hit. cum columbis habenda eft. Defendit e- Nat.ci 37 . nim illas terretque Accipitres naturali potentia in tantum, ut vifum ejus vocemque fugiant. Hac de caufa prxcipuus columbis anor eorum, feruntque fi in quatuor angulis defodiantur in ollis novis oblitis, non mutare fedem columbas. Fú mus ejus albugines oculorum extenuat.

$$
\text { A R I I U L U S III. }
$$

De Bubeone, Subbuteone, aliis Accipitrum apud Ariftotelem generibus, \& Jacro Agyptio.

12 UTEONES, quil \& à numero tefti- Nombn. 1. un Triorchis, Marcello, Millo dici- Plin 1.10 . tur, qux ternam difcriptionem Aldiovandus exhibet.

Prima fub nomine Buteonis ex monti- Defariptio. bus Vineolanis allati ponitur. Corpus ereeti duarum Spithamarum erat. Caput habebat compreffum, figura trigona. Rofirum nigrum membrana circa nares lutea veftitum. Iridem circa pupillam in oculis nigerrimam. Collum breve \& plumofum. Dorjum ad'caudam coloris ferruginei. Altera ex Gefnero fub Bushardi ut Sabaudis dicitur, maris cognomento, eaque duplex Magnitudine prior magnam Gallinam referebat. Caput pennis fufcis integebatur : Collum brevifimum erat. Pennx nonnihil ruffi coloris prx fe ferebant ; in ventre \& pectore albicantes nigrisque plarxque maculis per medium infignes vifebantur. Tefles deerant. Alteri, circulus in oculis flaviffimus iridem nigram ambibat, colore nonnihil a fuperiore variabat. Venter , latera \& crura fuperius plumis albis veftiebantur, quas latiufculi circuli obfcure ruffi per tranfverfum diftinguebant. Teftes bini albi \& pufilli ad fpinam dorfi inter utrumque renem confede- 
rant, in quorum medio particula tefte mi- lonius Smerillum effe exiftimat. Rabetarinor \& flava, tefticulo proportione refpon- us vel idem eft cum Levi, quia de utroque dens, vifebatur. Tertia eft Bellonii fub no- Ariftoteles. Abunde vivunt, \& humivomine Guyrani feu Boudree. Huic roftrum la funt, vel Milvi fpecies. Qui: $S_{\text {A CER }}$ eft curtum, acie nigrum, \& hamatum, E E G P T I U Bellonio dicitur, corporis narium regio \& rictus flavefcunt. Venter candidis plumis, quarum apicem macula nigra, juxta fcapi medii ductum infignis, veftitur. Rectrices alarum plumx, crenas inftar ferræ exhibent nigras, ubi albere incipiunt. Caudx color varietate Attaginis fimilis. Crura antica \& poftica annulis imbricata. Quarta eft illius in quo diffecto tres teftes inventi, \& qui hactenus defcriptis in omnibus fere conformis erat.

Nuirimem Victus ipfiex herbis felarea, afperula feu tamm: alyfo \& Matrifylva; exanimalibus, mures, Bellon. 1. Avib. ran $x$, rubet: $x$, lacert $x$, limaces, ferpentes, c. 10. fcolopendre, erucx. Erepta illi aliquando c. Arit. 9. a ardea \& anguilla; inventa in diffect Simonid a- ventriculo \& talpa. Volatus eft tardi, tam pudẢthen. defés etiam, ut telo petitus vix ad tertium ictum cedere dicatur, ideo nullo negocio capitur.

Vfuss. V/usipfius tum incito, tum in Medicina.

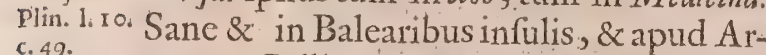
c. 49. vernos Gallix populos in honore menfarum eft. Carnem quippe habet teneram, Bapt. Por- hyeme prefertim, \& dulcem. Tefticuli ex

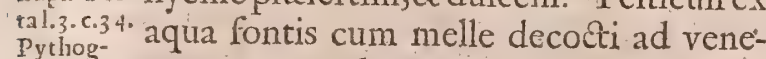
nom. rem commendantur?

Defriptio. SUBBUTEO feu Hypotriorchis, quod noArif. H.A. men Ariftoteles illis qui in Accipitrum genere latiores funt adfcribit, prout ab Aldrovando defcribitur, verticem habet ex cinereo \& caftaneo ad nigrum vergentem; ejusdemque coloris macula, una à capite per tempora ad gulæ latera defcendit; altera $a b$ initio rictus fub oculis utrimque per-gulam in longum protenditur.Palpebrefunt fublutex. Plumx menti \& gulx totx albre, \& color ille continuus, ad cervicis \& verticis per tempora initium, quod minori oculorum cantho ex oppofito eft, perducitur.Pectoris totius plumæ,nec non \& ventris medio macula fufca oblonga notatx in oris albicant, In pedumplanta, tubercula veluti calli ubique eminent. In nemoribus celfis \& denfis degit, \& homines quos Perdicum vel Coturnicum venationi operam dare confpexit, ipfi infequi folemne eft, ut aviculas Canum metu fubvolantes arripiat. Sed hxc de iftis fufficiAritot.1. . unt : quid vero Ariftoteles per Pernem, Hit....36. Percum, Rubetarium, \& Levem, intelligat, difquiritur. Pernos apud Hefychium \& Phavorinum genusvenatorii eft accipitris, ultra ignoratur. Percus, feu Percuus idem cum Fringillario propter alarum nigritiem, effe videtur. Ariftoteles per Fringillarium, Nifum fominam; per Percuum marem vulgo Mafchettum dictum, forte intellexit. Levis quis fit ignoratur. Belmagnitudine Corvum refert, capite Mil vum, colore ad Falconem facrum accedit. In Agypto eft frequentior, quàm ulla alia Avis qux rapto vivit:Rara in Syria confpicitur; fed \& in Caramania aliquando. Serpentibus potifimum vefcitur. Unde ei olim apud incolas tanta reverentia, ut Herdot. in illius vel per imprudentiam occifor, mor- Euterpe. te multaretur; ipfa mortua honorifice fepeliretur.

\section{A R T I C U L U S IV.}

\section{De Lanariis \&ै Collurionibus.}

E Lanariorum ignobili genere, $\mathrm{Bu}=$ teonibus rectius annumerando hic res eft, de nobili inter Falcones agemus. Nomen: Nomen ipfi feu à laniandis avibus: feu quod plumas lanarum inftar molles habeat. Aliquando Lanius Molliceps Falco albus, degener, \& buteo albus dicitur.

Aldrovandus duplicem iconem exhibet. Aldrovan Prior, accipitri palumbario magnitudine dusl. s. c. par, vertice erat lato ; capite \& collo craffis ; ${ }^{1 \mathrm{r}}$. omnibus uti \& ventre, tota parte prona, femoribus uropygio, \& cauda inferna: Inter oculi canthum majorem \& roftrum, maculam habeat nigram, alas oblongas; longe ultra uropygium protenfas, tibias luteas, \& pro reliqui corporis proportione valde graciles, easdem à poplite ad ungues paulo plus palmo longas, \& culmo triticeo vix craffiores: Unguiculos uncos, fed tenues. Alteri lingua erat lutea \& nigra. Caput \& dorfun cum levicophro fufcum, pectus totum leucophæum, ad anum ufque maculis in longum ferrugineis diftinctum. Alarum remigia ex fex ordinibus ratione coloris conftare videbantur. Uropigium totum candicabat.Pedes habebat luteos, femora plumis ad poplitesufque veftita. Tibias erectas \& inftar ftipitum. Ungues longos \& admodum recurvos.

Victum ex muribus in agris quærit; fed Albert. I. \& avium pullos, in nido, vel cum per ter- 23 .de Aniram volandi impotentes, reptant, rapit.

COLLURIONEs de minore funt $\mathrm{La}$ nariorum genere; illique vel Majores, vel Minores. Exmajoribus, qui IEliano Meru- Differes. læ venaticx, Fomina eft turdi mediocri tia. magnitudine, è longinquo contemplanti tota cinerea. Capite ad reliqui corporis proportionem triplo majore. Rofrum habet parte fuperiore valde inflexum : inferiore furfum modice curvatum. Linguam in extremo multifidam, \& in fibras acutas, \& quafi capillamenta quxdam definentem. Otulos totos nigros. Caudam picx fimilem; 
Jens; que explicata, corniculatx crefcentisve lunx imaginem exhibet. In Mare gula, pectus, venter,femora, cauda prona dilutius quam in fxmina albicant. Vertex $\&$ dorfum obfcurius fufcefcunt, plumuli harum partium adeo funt tenellæ, ut pili potius glabriac leves effe videantur. Erat $\&$ silter totus albus, roftro, tibiis \& unguibus exceptis. Interdiu femper fere arbori fummx aut dumeto infident:in Helvetia inter frutices fpinofos, \& confidentes caudam erigunt.

Nutrimer- Vitus ipfis Papiliones, fcarabxi, vermes, juli, erucx hirfutx, locuftx, grilli; quos, preda uberior fi contingat, defectum penuria providi in aculeis \& fpinis arborum. fingunt : inter aves Turdi, Fringillx, Picx fylveftres. Offa comminuta devorant, \& famelici, tantos carnis bolos in gulam ingerunt, quantos rictus capere poteft.

Generatio. Nidos ex mufco, lana, fundos eorundem Bellon.l.2. ex erica, componunt. Senos pullos exclude Avib.c. dunt, parentibus roftro,cruribus, pedibusque exceptis, quia plumularum radices ad virorem nomnihil vergunt, omnino diffimiles.

Vox. Voce, canum à longè au ditum latratum, autNoctux aliam appellantis ululatum referunt, \& vocem Houin, quam frepius iterant, exprimunt. Uniformis ea hyeme \& autumno; vere \& xeftate varias A vium modulationes imitati, eas ad fe capiendas alliciunt. Capti in caveam inclufi, muti \& elingues permanent. Hyberno tempore facile capiuntur. Nam avem cavex inclufam invadunt, decipula decidente, intercipiuntur.

lib.s.c. 14. Collarionum minorum quinque genera obfervaCollurio-
nesminonesmino- befcentia:duo cinerea. Avicula funt Alat-
yes. dis paulo majores, duos palmos \& pollicem cireiter longx. Omnes utraque roftri quod recurvim eft, modice tamen parte, ternos pilos inftar barbx prominentis habent. Utrorumque pulli, antequam frequentibus integantir plumis, virefcere nonnihil apparent. Tanta eis (expertus Bellon.1.2. Bellonius) fimilitudo, ut difficillime digde Avibus nofci poflint. Cibus ipfis forices, mures, la-
c.25.
certæ, talpæ. Inter edendum, uni tibix infiftentes, cibum pede altero furfum retracto prehendunt. Humilius volant, \& pradx inhiantes aliquandiu fefe in aëre librando fufpendunt. In carduis frepiflime quiefount. Octonam aliquando, fenam nonnunquam prolem excludunt. Rubore verticis qui infignes, in Italia inter delicatos cibos.

\section{$A$ R T I C U L U S V.}

\section{De Milvo \&s Harpa.}

Nomen: Ilvus, quod vocabulum \& pifcem, ${ }_{6.26 .9}^{\text {Plin. 1. 9. }} 1$ \& f fellam in Septentrionali parte

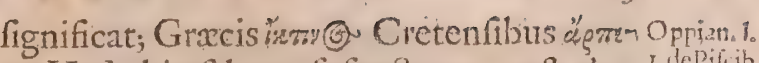
ros, Hefychio fi locus fufpectus non eft, ara- r, depifib.

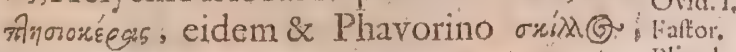

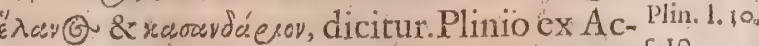
cipitrum eft generibus: Ariftoteli inter carnivcras, fed vix rapacium nomine dignus.

Tria ipforum func genera. Vnum, bixtw (G) Differen

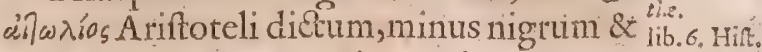
robuftum. Alterum majus, colore prope-Anim. c. $\sigma_{2}$ modum ruffo, infirmius. Milei regalis nomine gaudet, quod à binis falconibus facris in ipfum cmiffis, intra nubes etiam fe condens, fumma cum Principum voluntate in terram dejiciatur. Cui \& Milvus paluftris accenferi debet. Tertium, albidius Et Boufaté \& rapacius, Anglix, \& Septentrionalibus Sabatido. regionibus, in quibus nigredo $\&$ albedo in matinus candorem vertitur, frequeńs.

Defcriptione operofa opus non eft. Ric-Defcriptios Itum habet rectum, nulla marginum appendice à fræno feu lateribus extremis ad unci ufque initium. Inteftino \& hepati fel ad-Athen.1.8. junctum habere Athenæus tradit. ... c. 8 .

Loca temperata Milvo funt familiaria, Loctss. nifi quod in Lybia, circa fontes Nili peren- Herodoto nare dicatur. Ideo \& infula S. Dominici, vicinoque mari multi; quibus bifurcata cauda, vifi funt : \& in Anglia, nullo non anni tempore apparent, \& quod fpurcitiem in plateis \& ad flumen Thamefin legant, lege ab omni noxa immunes funt.Ideo hyeme adventante vel calidiores regiones \&tolii citius, quam Regales petunt, ibidemque hybernant; (fane ultimo Aprilis tot circaPontumEuxinumBellonius vi- lib; s.c. $2 s$. dit,ut, fi quindecim dierum fpacio tot prxtervolaifent, hominum fuperaturos fuiffe numerum credcret) vel in nidis ad bres ve tempus plumarum fuarum vellere corpus à frigore tuentur : vel in quercubus aliisve arboribus carie exefis, coprus fovent. Ideo denique reftu accedente, $\mathrm{ca}$ lidas regiones deferunt, \& in Europam, tardius tamen Atolii, quam Regales revertuntur; \& xftu in eadem urgente; fupra nubes, quò radiorum folarium rẹflexio pertingere non poteft, ideo nec æiftus ita urget, elevantur, ibique aliquantisper hrerent.

Viclitant carne animalium, pullorum in- Nutrimonprimis gallinaceorum \& anferinorum tam Arif. H.A vivorum, quam mortuorum, \& fructibus. 1. 8.c. 3 . In Feypto in palmas devolaffe, \& dasty- Bellon l.: los comediffe vifi funt. Fruges refpuere c. 28. Ariftoteles credidit. Bibunt raro, quia lib. cap. ficco cibo rariflime utuntur ; \& fi quando; ex folis pluvialibus aquis, fi Tzetzi credimus; à quibus tamen dum pluit, abftinent.Quod ad feneftras domum in Kgyp- Bellon lib. to advolant, \& in infula S. Dominici pro- 2. de Avib: pe ad homines accedunt, in eorumque c. 28. confpectu corpus à pulicibus expurgant, manfietudinis eft indicium : quod pueris cibum 
fes exenterantibus, pileos deambulantbus in urbe, nidulationis inprimis tempore, eripiunt, rapacitatem arguit : quod in Plin 1. 10. Elide nihil ex funerum ferculis efculenti;
io ro. nihil Olympix ex ara carnium Jovi facrificatarum, auferre dicuntur, vel falfum eft, Ovid. 1. 2. vel timiditatis, quia turba prafens, arguMetamor- mentum præbet. Creduntur primo anno
plof. præ audacia nihil mortuum guftare; fecundo præ metu nihil vivum edere; tertio fame interire.

Generatio. Pariunt bina, magna ex parte, interdum Arif. H.A. tamen terna, totidemque excludunt pullos, poft vicenorum dierum incubatum : fed qui $\mathbb{E}$ tolius vocatur (male Plinius $\mathbb{E}$ golium vertit) quaternos.

Vox. tive.

Vocem fi fpectes, lippire vel jugere dici-

Vifus. Vifus ipfi fatis acutus. Unde Ariftopha-

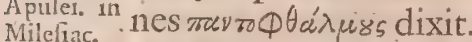

In avibus. Volatu \& præftant, \& in eo aliquid pecu-

Volatis. liare habent. Illud, tum quia intra nubila férecondunt, \& indefeffo labore maxima Iurenal. aëris fpacia emetiuntur:tum quia tanta ve-

Sutyra 4. locitate fe precipitant, ut frepe projecta in altum pulmonum bubulorum feginina, unguibus antequam in humum delabeBellon.1.2. rentur, arripuiffe, vifi fint. Hoc, tum de Avibus quia ducunt per aëra gyros, unde Circa-

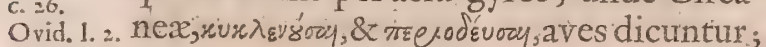
de. Anore: tum, quia inmotis alis diutiffime in aëre, motus tonici beneficio hrrent: Scilicet, elata ea ex parte paulifperala; unde fubit aura, motum aëris in reliquum etiam corpus excipiunt, \&rita fuftinentur. Sufficitur lata in alarum vicem cauda, quam, prout res poftulat, dilatant, conftringunt, deprimunt, attollunt. Videatur, inquit Pli-

Plin.H.N. nius', artem gubernandi navium docuiffe caudee 1. 1o. c. 10. flexibus, in calo monfirante notura, quid opus efSetin profundo.

Amicitid. Amicitiam colunt cum Harpa \& Cuculo.

Arift.lib.9. Inimicitias cum vulpe, corvo, gallinis \& co-

Hitt. c. Is
Alianus s. lumbis exercent. A folftitiis afficiuntur po-

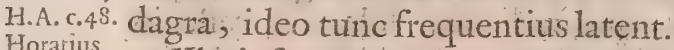

in Epod. VJus ipforumapud pauperiores nonnul-

Plin.H.N. lis in locis in cibo. In Medicina cinis cremati

lib.ro.c.1. bibitur, contra Epilepfiam; tefticuli ex aqua fontis, contra impotentiam; fimus, contra articulorum dolores, quod \& vermes, qui ex co XL diebus in fimo macerato, nafcuntur, faciunt, commendatur. De H A R A inter Arifotelem, Plinium \& Oppianum non convenit.Gefnerus vulturem aureun Harpam Oppiani, quod fub mento plumas harbx inftar habeat, 1ib.5.c.16. effe credidit Aldrovandus Milvum paluftrem opinatur.

A R T I C U I U $s$ VII

De Cuculo.

$\mathrm{C}$ culus, quo nomine mons in agroBo- Nomen. onienfi, pifcis marinus, herba, invo- Athen. 1.\% lucrum papyraceum, \& alia veniunt, Gr $x$ - Fernel.1. 6 . cis rórru $\xi$, nomen à voce fortitus eft. Acci- ${ }_{\text {c. } 20 .}$ pitri apponitur,quod eum tanta fimilitudine referat, ut Arifotelis wtate hoc ipfo creditus fit prognatus, \& apud Gallos Falco Bellon.1. . cuculiparens communi proverbio dicatur. ce Avibus Plinii is videtur error. Nam Ariftoteles, dum Cuculú ab Accipitre interimi fcribir, Aritoteles quod nulla avis in fuo genere folet facere, $c_{0}$. . accipitrinigeneris eundem non effe docet.

Duo funt ipforum genera, Majus nempe Differen\& Minus, qux fola inter fe magnitudine foriptio. differunt. Nec eft quod curiofe defcriban- Arit.1. c. tur. Neque aduncis funt inquit Ariftoteles unguibus, ut Accipitres, neque capite accipitribus fimiles. Sed ea utraque parte columbos potius quam accipitres imitantur:nec alio quam colore reprafentant $A c-$ cipitres, nifi quod ifti maculis feu lineis diftinguantur, cuculi velut punctis. Cave tamen, illud quod de pedibus, extra aduncitatis defectum intelligas. Nec enim iis terni ante \& retro unus ut columbis; fed bini antici \& totidem poftici,utPicis, \& nocturnis avibus, quod Antiquitati ignotum. Sed \&id, quod de punctis dicitur, ftricte fümendum eft. Nam quos Aldrovandus defcribit, prona parte tota tam cinerei funt, quam albi, lineis feu maculis tranfverfim ductis oblongiufculis, fufcis, \& interruptis interdum, interdum magis continuis difineti. Crura corporis magnitudini in is non congruunt. Nam \& femora brevia, \& tenuiafunt, \& tibie vix pollicem latum longæ: Juvenem totum nigricantem maculis fubruffis per alas refperfum, Aldrov.notavit, foramina narium in roftro multum eminebant. Oris pars interior flavi coloris erät. Loca, fi attendamus, ubique fere gentium Locuso reperitur, novim orbem, \& Athiopiam, fi Alvarezius fidem meretur, fi exceperis. ZEftate pro natura avis, in cujus nido parit, in arboribus, petris, \&zfluminum ripis degit : hyeme in terræ, lapidum, \& arborum cava fe abdit, in iifque per totam hyemem latet Auditam ejus latentis yocem fabulantur, cum truncus fornaci calefaciendx immitteretur.

Cibus ipfi erucx, mufcx, fruges; fed \& car- Nutrimen nes; fi verum eft, grandiufculos nutricis tums.

pullos, imo ipfam devorare, quod quibus- Arit.H.A: dam creditum, quanquam exinde carnivo- 1 . 9 . c. $29 \%$ rus effe negetur, quod nonnunquam Acci- Arift. 1. . . . . . . pitri in cibum cedat. Hyeme dum latitat Plin.H. N. \& implumis eft, vel congeftis \& ibidem re- ${ }^{\text {1. 1 o.c. } 9 \text {. }}$ Author de pertis vivere, vel hirundinum \& urforum Natura. modo vitam fuftentare, credendus eft. 
Gencratio. Qyantum ad Generationem, quia naturx Arith.lib.3. eft frigidx, majori ex parte fingula parit Idem 1. 6. ova, raro bina. Genus quoddam in petris Hittor.An. nidificat; (fic Ariftotelis verba fumenda Hitt. Ani- funt) reliqua in palumbi, alaudix, luteomal.1.6.6.1 $l x$, fed curruc $x$ inprimis nido ovis jam f $x$ Arit. Ani- to, ova fua deponunt : fert, quod ob memal.c. 29. tuin \& ignaviam non fore tutam generi Allian. 1.3. fur ftirpem opinentur; feu quod propter c. $3{ }^{\circ}$ frigidam corporis coftitutionem, ex ovis 1. 10. c. 9. pullos excludere non poffint.

Arittlib.3. De ingratitudine in nutricem, non conde gen.c.s. veniunt Authores. Alii, negant, dum, vel deAnimal, avis eum duntaxat in cujus nidum fua c. $30 .{ }^{\text {rngeniws. }}$. importat, ova comedere, propria fubjiceArritlib.6. re : vel deprehenfa poftquam adoleverint Hitt. c.7. fraude, à nutrice relinqui; vel ad volatum. Ifidor.l. 12
Orig.c. f. firmos, fibi confcios ad parentem evolare; Oppian.in vel nutricem, feu vifo cuculi; cujus ovim T. Flian. I.c. citius excluditur, pullo, tanquam eo conINiplus tentam à fuis incubandis defiftere; feu exapud Al- clufos, fpecie cuculi elegantiore captam (arripit hic cibos avidus, '\& pinguefcit) Arif.lib.g. tanquam fpurios occidere, \& in cibum cuH.A.c. 29. culi pullo dare, fcribunt. Alii affirmant dum, vel pullos nutricis ab iis vel conculPlin.H. N. cari, vel cibo fraudari, vel ipfa infpectante I. 10.c.9. abfumi; \& jam volandi potentes, ipfam nutricem corripere credunt. Utut fit, hoc certum eft, educare currucam fubditum cuculum adulterato foetam nido.

Volatus. Volatus ipfis brevis, interruptus, humilis, \& ut hoftem effugiant, inftabilis. Ideo Milvorum fcapulis, quo tempore adveniunt, fufcipi putantur, ne per longa aëris fpacia defatigati deficiant. Solent autem ineunte vere apparere; cujus adventantis primi poft amphisbænam funt nuncii. Canicula Plin.1. c. ortu occultantur, poft rarifimè cernuntur. Alian. 1.3. Hyeme deplumes in cavernis torpent:

c. $30 . \quad V 0 x$ ipfortum propria $\mathrm{Cucu}$. hanc minus Atit. 1. g. explanant, cum fe abdituri funt. Ad ultiA.H.c.49. mum alibi Julium, ad S. Johannis, apud nos, feftum, perfectam edit, fi ultra, uve vix maturefcent.

Anipa- Inimicas tum omnes fere aviculas præcithia. pue cum ova pariunt, habent, feu quod illorum fint fraudis confcix; feu quod Accipitri perquam funt fimiles: tum cicadas Ifiodor. 1. ex ejus faliva ortas, qure eos frequenti ag12. orig.c. mine invadunt, \& poftquam fub alas ir4. repfere, morfibus lancinant. Ideo fub ortum canicula, quo raucis

Sole fub ardenti re fonant arbufla cicadis.

sympatix. cantilenam fuam abrumpit. De ejusdem cum Milvo amicitia fuperius dictum eft,

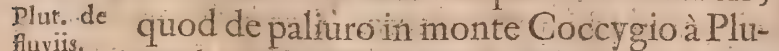
fluvis. tarcho refertur, omne animal; folo cucule excepto quod infederit, tanquam vifco retinente harere, non minus fabulofum eft, ac quod de cicadis ex ipfius faliva natis dicitur. hyeme deplumefcit, peninás mutat, \&zf mul colore immutatuit. Exivio depofito; corpus ejus fcabrefcit.

Ufus ejus, \& in Medicina, quia cineres $v$ fus. ufti ad dolorem ventriculi valent; \& in ci- plin, 1,1, , bo, quia ejus pullo, qui jam volare poteft, nulla avium fuavitate carnis comparari poteft, obtinuit.

\section{T I T U L U S I V}

\section{De Falconibus:}

\section{A $P$ U T I}

\section{De Falconibus ingenere.}

$\mathrm{F}$ Alconis ut avem fignificat, vocabu Nomom lum adeo generale eft, ur eo omne rapacium genus Authores incluferint; \& $A \rightarrow$ Albert. 1. quila, cum Theodotione \& Symmacho, ${ }^{23}$.de Anis omnes quarum in venatu volatico ufus eft, Falcones nominarint: Recentiores illis avibusà falcato unguium hamo nomen indidere, quæ Thufcis Campanis vernacula Capys dicebantur, \& à nobis jani defcri bentur; nec tamen tam frricte, ut non quxdam Accipitribus communia intercurfura fint.

Ad tres ipfos claffes Migratores nempe, Different Campeftres, \& Riparios Bellonius redigit; ad ${ }^{\text {ti.e. }}$ sobiles, ignobiles, \& Hybridas feu medii generis, quod promifcuo generoforum \& ignat vorum coitu generentur, Albertus. Sub 1,23. de illis Falconem facrum, Hiorofalcum, Fal- ninal. conem montanum, peregrinum, gibbofum, album, rubeum, cynopodam arboravum, \& lapidarium; fub iffis. Buteones, Lanarios., Tinnunculos, fed perperan, comprehendit.Sub his, Germanos \& Tunctanos quidam enumerant, fed \& hiomnes, xtate, colore, \& corporis forma variant. Hinc Hornotinorum, qui eodem anno nati funt: Nidulariorum, quiftatim à nido domi adoleverunt, nec ita ut ramularij pennas producunt. Ramalium, qui circa nidum ramulatim obvolitant; Mutatorum, qui vel deplumes funt, vel plumam veterem. cum nova jam commutarunt; nomina.

Quantum ad defcriptionem exactam, In Defcrips capite, dorfo, fuperiore colli, exteriore alarum \& caudę parte cinereus fit \& fubniger; in aliis paffim partibus varius, \& virgulis quandoque interruptus: fed primo anno fecundus color ruffus eft, remiffx rubedinis, albefcit deinceps paulatim, eo magis, qua pennas mutarit fxpius. Caput habet craftum, nec oblongum, nec frictum; fuperiore parte à rotunditate deficiens. Collum \& roftrum brevia, maculas in maxil lis nigras, circa oculos albas; oculos croce os ad rubedinem accedentes, pectus cuni offe pectoris acato \& duro. Pedes patulos" croceos, \& ad albedinem, declinantes: 
Crura brevia. Coxas longas, \& pennatis \&cc. Morantur in tota feptentrionali plaga, \& quidem optimi. Bofnia albos profert, fed \& Orientis regiones haud malos. Degunt vel in altifimis montium verticibus vel fylvarum arboribus excelfis.

Fox.

Volatus.

$V_{0 x}$ ab acuto in graviorem flectitur.

Mira quadam volandi ratione, in principio, medio, \& fine venationis utitur. Ad prædam pergens celeri volatu in fublime adfcendit, \& rurfus compofitis ad pectus, quibus inturus eft unguibus, tanto impetu in avem obliquato volatu defcendit, ut ftrepitum quafi concitati venti fuo defcenfu exciret, in defcenfu avem percutiens, adeo longum vulnus infligit, ut à capite ad caudam ufque difciffa, aut toto capite truncata, nonnunquam in humum decidat.

pugnat. Cum Ardea ipfi periculofum certaParicusl. men. Hxc enim ubi infra pofitam fe vide homin. det, roftro fuo prælongo ac acuto, quod praft. prius abfconderat, furfum elato, irruentem ita excipit, ut co femet Falco frpifime medium pectus induat, \& ambo interdum illifis interraneis humo afligantur.

Morbi. Cum multis frepe morbis conflictantur, Febri: Apoplexia, Apoftematibus capitis, vertigine, oculorum fuffufione, afthmate, Antipa- vermibus, podagra, pediculis, \&c. Anti-
thia. pathiam cum illis gerit, tum Alauda, qure in hominis manus, quam falconis ungues mavult incidere : tum Drepanis avicula lacuftris, qux auditis falconis tintinnabulis, tantoperè confternatur, ut malit lapidibus ab homine obrui, quàm volatu fe in aèra attollere.

\section{A P U T II.}

De Falconibus in pecie.

\section{A R T I C u L u s I. \\ De Falcone peregrino, Jacro छั Gyrfalcone.}

$\mathrm{F}$ Alcontm fpecies fuperius expofuimus. PER E G I N o qui primum ob audaciam \& generofitatemlocum fortitur, nomen ex eo eft inditum, vel quod femper de regione in aliam migret, vel quod nidus ejus nullibi gentium inventus, fuerit.

Differen- Quatuor ipforum à colore genera pofuit ti.e. Carcanus, duo ab codem Belifarius. Vnum quod pennis æreum colorem præ fe fert, \& in fingulis pennarum capitibusad coronix modum albedine figillatim diftinct $x$ peninx; quafi figuram oftendunt. Si excellere debet, Caput neceffe eft aliquantum in fornicem, vertice leniter elevato ac rotundo, curvatum, cinereo colore habeat: fimul atque volandi potens evafit, in roftri parre fuperius plumulas quasdam, qux veluti barbulæ fpeciem gerant; oftentet. Gula lineis in longum ductis nigris maculetur. Supercilia \& maxill admixto modico rubore albicent. Dorfum livefcat. Alre fint longx in ultimam caudam recumbentes. Cauda longa, craflis pennis conftans, in acumen paulatim definens, femora longa, tibir breves, pedes colore inter flavum \& plumbeum ambigente tincti, digiti graciles. Ungues magni,nigri \& acuti \&c. Natales, Sardinix, Agypto, Cypro, Cretx \& Rhodo debet. Si qui in Italia vel alibi capiuntur, vi ventorum eo depulfos fuiffe creditum eft. In Alpibus etiam nidulari, fide veteri cujusdam Falconarii, Albertus M. refert. Alterum, Nigrius, quod multis à priore notis variat, femora lineis transverfim diftincta, crura item colore croceo fed diluto maculata, gerit. Qui ex hoc genere ab Aldrovando defcribitur,verticem Aldror.1.\% capitis habebat planum ac compreffum, ${ }^{\text {c. I. }}$ Roftrum membrana lutea intenfi coloris, nares ambiente, capiti conjunctum. Caput, cervicem, dorfum; alas fufca, per fingulas fere pennas maculis atris transverfim per alarum maiores refperfx confpiciebantur. Gula ex albo nonnihil flavefcebat, parte fui infima, maculis veluti guttis nigris transverfis diftincta. Pectus, venter, \& femora alba, lineis latiufculis nigris transverfis variegata. Videtur hoc genus idem cum illo effe, quod alii Nigrum abfolute, alii Carbonarium \& Falconarium appellant.

Creditur primo in montanis prope Ba- Locas. bylonem vifum, poft in Salamine apparuiffe. Nunc in alpibus \& Pyrenxis reperitur: in Germania adhuc rarum eft.

Utrumque rarius in volando alas movet, volatus: fic à montano diftinguitur : \&à fublimi in pronum velociffime defcendit.

Adeo mites funt, ut quandoque irafci Ingeniams. nequeant; ad hominumque nutus magnitudine quadam animi potius, quam inedia venantur. Cretenfes capiunt etiam Grues, Anates, Mergos, Tardas, Phafianos:Ardeas, inprimis fi cibiabftinentia inducantur. Si Aquilam viderint nunquam inpofterum aucupantur.

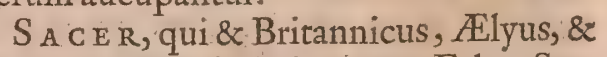
Aëriphilus apud Avicennam Falco Sacchari, vel Gracorum imitatione quafi Hierax Accipiter,per excellentiam dicitur,vel à corporis magnitudine viriumque præftantia, ita appellatur. Sane à Bellonio Ac- Bellon. de cipitrum adjicitur numero. Tria ipforum Avib. 1. apud Tardivum genera; Vnum; quod lepo- ${ }^{\text {c. } 14 .}$ res \& hinnulos; alterum, quod capreas parvas capit, tertium peregrinum exprimit, de quo fuperius.

In defcriptione Albertus \& Fridericus Defcriptia: Imperator diffident, fi Carcanum fequi- 
nur, corporis ipfi ftatura plcrumque oblongiufcula. Capite vertice plano canum. Roftrum cærulèum; Nares exigux, peetoris, dorfi, \& alarum fuperiorum macu$l x$ fufcæ, femora interiora alba. Crura pedefque tota fere coloris cxrulei. Cauda maculis circularibus phafeolorium aut renum figuram exprimentibus varia, \&rc. Excellit, cui color rubicundus, ruffus aut incanus, lingua craffa, pes amplius, digiti craffi, \& colore cæruleo diluti.

Inveniuntur apud Tartaros; \& Mofcovi-

exploratores comperit, in arboribus'non ita proceris nidulantur. Cum verfus meridiem victus quxrendi gratia proficifcuntur, $-\mathrm{ab}$ aucupibus adventus gnaris, Egei maris infulis intercipiuntur, \& Venetias etiam è Creta afferuntur. Nutrimen- De viftu fcriptores inter fe non confen-
sum. dicit. Tardivus cibos etiam craffiores facile concoquere fcribit. Albertus delicate, eos cibandos, cibo femper recente, cerebellis, fanis carnibus, reliquit. Volaciffmi funt, nifi è nidis abducantur, \& nubes etiam transcendunt. Capiznt Anferes fylveftres, Grues, Ardeas, Lepores, Capreolos. His infident, \& cerebrum capite perforato excutiunt. In eorum confpectu ne Aquilæ quidem volare audent:

Defcriptio. Gyrfalco feu Gyrfalcus (male à quibufAldrovan- dam Horodius dicitur) qui id ab Aldrodus 1.7. vando defcribitur, verticem habebat complanatum colore cinereo. Roftrum breve cæruleum, unco modico, deorfum incurvato, fubcæeruleo, inftructum. Dorfum, alæ, venter, cauda alba erant. Verum tergi, alarumque plumæ pene fingulx nigra macula notatx, quæ cordis quodammodo figuram emulabantur. Alæe erant admodum longx. Remiges prope extremum apicem nota majori ac longiori nigra ornabantur, quæ tamen albo claudebantur margine. Gula, pectus, \&venter pura tingebantur albedine. Caudo erat breviufcula notis nigris tranfverfim variegata. Pedum digit oblongi, validi, late expanfi, tabellarum continua ferie per totum intecti.

Differen. Genera ipforum à colore petuntur. Alii tia. funt, flavi, rubei, \& cinerei.Albos etiam in Mofcovia reperies. Qui in pectore albicant, magis etiam albi funt, \& $\times$ primo anno dorfum partim albicat, partim fubruffum, vel fubrubeum eft. Ubi vero mutati funt, color ille fubruffus in nigredinem permutatur.

2ocus. Locum ipfis natalem Norvegiam \& Hiberniam Belifarius ponit:at certum in TarPaulus taria quoque \& Mofcovia in veniri.

Vanet. I.r. Vefountuŕ inprimis Columbis, \& id genus Mifchov. aliis : \& poftquam femel de aliqua ave guc. I 4 . Afia- ftarint : illa deinceps relicta, novam fem- per prædam perfequuntur. Aggrediuntur Nutrinesto \& Aquilas. Accipitres, Nifi, Falcones, iis ${ }^{\text {tum. }}$ advolantibuis, prixdam ulterius non profequuntur, fed pavidx perfiftunt. Siquin que Grues libero aëris campo unus emittatur, non prius perfequi definit, quam fingulas in terram dejecerit.

Duo habent peculiaria. Unum, quod Ingenithro. cum fimul aliquot vehuntur, certo quodam fenii ordine cibum capere foleant. Alterum, quod preter ceterarum rapacium morem, nunquam fefe aqua abliant, fed fola arena uitantur. Frigore etiam tantopere gaudent, ut perpetuo, aut fuper glacie, aut lapide, marmoreve algido ftare geftiant.

A R T I C U I U S II.

De Falcone Montano, Gentili, Tunetano.

H Alco Mon t A N US, quod fit magis Defriptio. reliquis indomitus per excellentiam ita dicitur. Caput habet vertice faftigiatum \& nigrum, coronula quadam einerea cinctum, cui in fronté nón longe à roftro plumulæ quxdam exiles, \& capillares eminent. Guttur ad fternum ufque nonnihil candefcit, maculis confjerfum majufculis, pectus reliquum verfus inferiora, notis quibufdam, quandoque ferrugineis, nonnuriquàm rubeis nigricantibus aliquando infignitur, quibufdam guttur \& pectus nigris plumis veftiuntur, Dorfum ac lumbi. majori ex parte plumis fufcis, minutis obteguntur. Aliqui èoruin poft medium dorfuim, lineas quasdam albicantes, aut rubefcentes, qux deorfum vergunt, habent. Crura \& pedes plerumque crocei, vel'ex flavo paleari flavefcentes, \& fquammis denfiffimis integuntur. Mutatos facilius eft cognofcere:\& optimus eft hornotinus fufcus.

Non Anates folum, fed \& Anates \& Ar- Nutrimers: deas capit, \& parfequitur. Vifus aliquundo tum.

\& Aquilam, quæ fibi præedam præripuerat, \& feipfum interemiffe.

Ponit \& alterum ejus genus Aldrovandus, Differere quod Lieucopibceium nuncupat. Corpus ejus to- tia. tum cinerei eft ad cæruleum vergentis coloris, pro diverfa partium ad lu cem obverfione dilutioris obfcuriorifve. Roftrum craffum, breve, nigrum, robuftum, pollicaris crafitudinis, tam validum, ut vix ulli alteri fortius. Pectus valde teres ac grande. Diverfum primo ab aliis Aldrovandus putabat: fed cum cum defcriptione Montani apud Albertum conferret, \& vero Montano, quialiquoties plumas vetercs cum novis commutavit, mediam partem. dorfi cæruleam affingi, \& quo frequentius fenectutem exuit, eo tergum magis cærulefcere, gulam cum pectore, abolitis, quæ diftinguebant cum æate maculis, C albe- 
albefcere, obfervaret, alterim Montani effe genas conclufit.

Difcriptio. GENTILIS per excellentiam propter 0. Diffe- generofitatem ita dicitur. Friderico Im-
rentise. peratori alii funt Gentiles Peregrini, alii /mmpliciter ita dicti. Illi Falconibus facris funt minores, \& quo plus cum Gyrfalconibus participant, eo elegantioris effe formx exiftimantur. Vertex capitis debet effe plănus, occiput latum. 'Roftrum craflum, \& recurvum. Collum breve, prope caput fubtile, prope fpatulas craffius. Habere debent pealus foris prominens, \& carnofurm, cavitatem inter peetus \& collum magnam \& profundam. Coxas plumis complurimis opertas, \& fub genibus etiam dependentes. Crura craffa ac brevia, pedes amplos, digitos expanfos \& macilentos. Cum adhuc hornotini funt. Alii funt abfolute fufci: alii rubris, nonnulli pallidis maculis ceu guttulis perornantur. Alii ruffi funt, aut fimpliciter, aut ad nigredinem vergentes. Alii fulvi, vel abfolute, vel cum quadam rubedine: Maculæà collo ad pectoris furculam parvæfunt, inde vero progreffiad anum ufque majores evadunt. Fulvis ad rubeum vergentibus, color eft exæquo permixtus. Laudabiliores in fuprema capitis parte ceu corona quadam in circuitu perornantur'; prope nares durities roftri virefcit. Maxillis fub oculorum parte fubrubex funt. Dorfum fufco eft colore, ac rubedinem inclinante, marginibus rubefcentibus \& majufculis fine guttis tamen exornatum. Penne alarum maiores fufcæ cum marginibus. Cauda ejufdem cum dorfi pennis coloris, modo quod margines in ea in plurimis fint pallidiores, feu quod à corde fit remotior; feu propter aliam caufam. Simpliciter didti trium eidem funt generum, ficut \& peregrini, de quorum datis notis quo plures obtinent, eo magis probantur. Aldrovandus eofdem cum Carcani GERMANIs facit, qui Peregrino forma, capite, roftro \& pedibus funt fimillimi. Corona albicans caput ipfis prope collum cingit, femora interna plumis albis veftiuntur.Mutatis caput, collum, \& humerifufca funt, dorfum cyanea tingitur. Mares feu Tertiarii à maribus Peregrinorum nulla poffunt ratione difcerni. In volando crebriore fpifioreq alarum motu utuntur. Rapiunt omne avium genus, Aquaticum præfertim, quod fi è nido exemptus adhuc pullus ad hoc inftituatur. Grues etiam capere audet. In eo folum Peregrino cedunt, quod non fola animi magnitudine, fed etiam cibi aviditate prædam invadere dicantur.

De Tunetano inter Carcanum \& BelBeilon 1.2. lonium non conftat. Tlle corporis effe exi-

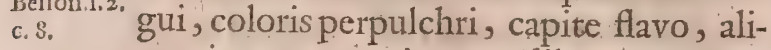
as nigro, peregrinos pedibus præfertim * ita exprimere, ut mulci fallantur, fcribit.

Hic magnum effe, ad Lanarii fimilitudinem, plumis \& pedibus accedere, diutius \& conftantius volare, capite craffo \& tereti effe, ftrenue fublimem aëra fcandere, reliquit.

$$
\text { A R T I c U. L u } s \text { III. }
$$

\section{De Falcone Gibbo 0 , Albo, EG Gallorum} Lanario.

H. Alco G I в в о s u s, quod ei ob brevi- Defriptio? t tatem colli, caput ante juga alarum dum eas fupra dorfi latera componit, vix appareat, ita ut gibbum geftare videatur, ita dictus eft. Corpus habet exiguum, planum collo fere continuum. Caput reliqui corporis proportione magnum. Rofirum perbreve \& rotundum, oculos flammeos. Alas prælongas, \& valde exertas; in facie guttas. Crura proportione cæterorum membrorum longiufcula \& fquammofa. Pedes in articulis digitorum, pracipue ad interiorem plantæ pedem nodofos. Nidulatur in montibus inacceffis. Tam alte volat, ut hominis vifum effugiat. In aticupio non $\mathrm{fta}$ tim inter defcendendum percutit, fed potius cum à defcenfu rurfum afcendere incipit, tunc pofteriore ungula ante pectus difpofita ferit, \& quandoque tam fortiter, ut unguem fibi amputet, pectus $1 x$ dat, imo feipfum aliquando occidat.

Eft \& aliud Falconis Gibbofi genus, Falco az quod femper alas tanquam ad volandum lius. extendit,animofius quam robuftius. ALBo nomen color impofuit. Albertus eum in dorfo \& alis fubalbum effe, alibi guttas valde albas aliis guttis fubpallidis interpofitas habere; \& regionem frigidam, \& humidam in caufa effe, fcribit. Addit,Falcone Peregrino majorem, \& ad fimilitudinem Lanarii albi, qui per campos muribus infidiatur, accedere. Mittit eum feptentrio, \& ex illo inprimis Norvegia, Suecia, Eftonia. Non tam eft in volando velox ut Niger : diutius tamen in Avium perfecutione perdurat. Non debet ad venandum emitti, antequam pennas mutaverit. Ad eum refert Aldrovandus quendam Sparverium, cujus defcriptionem Roma ac- Aldrovan: ceperar, qui corpore toto colaris lactei, ma- dus 1. 7.c. culis flavis perfperfi, roftrum habebatalbum magis quam cæruleum, alas candidiffimas ac fine maculis, in cauda pennas duodecim candidas \& flavis maculis confperfas: quarum confpectum, pennarum præcipua \& aliarum quafi tegumentum; tota candida, eripiebat, eafdem quafi in vaginam recondens. Pendebat mortua tredecim uncias, pondus in ejufmodi ave haud leve. LANARIUS (generofum intellige) Gallorum dicitur, quod Reiaccipitrarix authorum teftimonio, Gallix peculiaris \& proprius. 
Defritio Rofrum \& crura cum pedibus habet carulea, plumas anteriores albo \& nigró varias, maculis non transverfis, fed plumas in longum difinguentibus. Pluma dorfi, alarum \& caulæe, partem externam fi fpeetes, non admodum funt variegatx. Extenfarum interiora notis rotundis, inftar exiguorum nummulorum per fuperfciem diffeminatis; confpectuntur. Sic à Tardivo \&Bellonio defcribitur Xqua Gallix eft perpetuus, fémperque tam hieme; quam xfate ibidem confpicitur.

Ingenium. Ingenii funt tractabilis, \& ad omne au cupii genus idonei. Picas, Coturnices, Perdices, Cornices, Phafianos; imo Anates \& Grues, fi infticutio accedat, capiunt, \& focietate maxime gaudent. Quoniam alis diutilime in athere fupra prædam fufpenfi hiærent, tantopere Anates fatigant, ut \& canum opera, \& fuftibus plurima occidantur:

zealicifal- Carcanus Italicorum meminit. Habent cones. ifticaput totum planum.Roftrum falconis, peregrini \& montani roftio minus \& cæru- leum. Pectus flavum raris \& ferrugineis maculis diftinctum. Extremas alas veluti ocellis rotundis albifque pictas. Mutatis, caput univerfum ad humeros ufque, flavo colore ad rubeum vergente, \& lineis tenuibus diftindto, tingitur. Pes, qui ante cæruleus fuerat, in luteum abit. Nafcuntur in montibus Vincentinis \& Alpibus, qux Germaniam ab Italia dividunt.Solent alarum æquilibrio, in aërefefe diu admodum \& frequenter fufpendere, fic metu incuffo, ne Perdices, Coturnices, aut Phafiani diffugiant, faciunt, rarenter occifas in terram pracipitant. Vifus aliquando qui \& Accipitrem exanimaret.

\section{A R T I C U L U S IV}

\section{De Falcone Lapidario. Arborario Eु Rubeo.}

Aidrovan- TAlco Lapidarius recte Lethofaleus dus 1 . 7. c. 1 dicitur.Eft medix interPeregrinum \& 13.

Gibbofum magnitudinis. In præruptis petris, \& Alpium rupibus nidificat. Regitur \& nutritur fimili modo quo Peregrinus.

Arborarius, quem Gefnerus defcripfit, roftro erat caruleo, oculis nigricantibus, peEtore albidis \& nigricantibus maculis variegato; pennis alarum nigrioribus; dor fo nigro, cujus pennarum margines infimos, macula excandido ruffe difinguebant: An idem fit cum Accipitre Fringillario dubitatur. $\mathrm{Ni}$ dum in arboribusexftruit. Rarus ipfius in aucupio ufus; jucundum in conflictu cum monedula fpectaculum exhibet. Adeoquoque placidus eft, ut per fylvas \& agros emiflus ad dominum redeat. In diffecti ventriculo plumas \& Cantharides reperit Gefnerus.
R U B.E US à guttarum feu notularum quibus difinguitur, rubro colore distus ent: Peregrino minor eft, nec citius rubere apparet, quana alas exerat. Calordcbilis Albert. 1. in fuperficiem corporis effufus, \& fumo- 10.c. 9 . fum humidum, quod ad generationem ${ }_{23}$.c. c. 22. pennarum excernitur, adurens, rubedinis caufa effe putatur. Invenitur in locis planis \& paluftribus. Plucenireos in Mofcovia dariperhibent.

Volatus eftagilis, fed non diu perfeveran- Volatux. tis. Nam penna rubea, quia mollior; non diu volandi impetum fuftinet.

Facile cicurari, Albertus innuit, diffi- Ingenism. culter regi Tardivus. Poft fecundam aut tertiam penuarum mutationem melior; quod remittentibus per xtatem humoribus calidis, non parum temperamentum juvetur:Vite eft minus quam reliqui longæ. Adifum dus ex Indizs orientalibus allatos Aldrovandus reducit, qui parte anteriore Aldrovan. tota \& alis internis adeo rubebant, ut qui dus l. 7 . c. pronos infpexiffet, nihil prater colorem rubeum vidiffet. Majorem putat fuiffe fœminam; minorem, marem. Mares enim ob hoc ipfum Tertiarii dicuntur, quod tertia parte foeminis fint minores. Mentum in fomina, macula oblonga cinerea, qux inferne definebat, diftinguebatur. Pectus quoque ejufdem coloris notulis anteriorifterno raris refpergebatur. In mare color rubeus, faturatior \& evidentior erat. Mentum nulla macula infigniebatur. Pennæ remiges interiores notis fufcis trans:verfim frequentibus; fatoque intervallo diftinctis, albebant.

\section{A R T I C U L U. S V.}

\section{De Falcone Cyanopode, ES illis, qui pre mifcuo coitugignuntur.}

H Alco $\mathrm{C}$ y.A N OP.Us ad quod referri Aldrovandebeat genus, cum quatuorFalconum dus 1.7.c. genera pedibus cæruleis infruhta inveniantur, difficile eft dicere. Ad Lanarium tamen potius, quam aliam fpeciem pertinere videtur. Eft Falconi Peregrino \& magnitudine æqualis, \& figura fimilis: fed in hoc differt, quod dorfum ejus, \& exterior alarum pars minus nigredinis, \& pectus plis albedinis habeat ; alx fint breviores, cauda longior aliquantum; pedes hyacinthini.

Vocom acutiorem, quia humidior, Pe- Vox. regrino habet. Raroaves Pica, vel cornice majores invadit Plærumque fe præcipitaturus, propter thetum loco manet, $\&$ fufpenditur. Audacior evadit; fiaucupis accedat prafentia. Qui in Helvetia reperitur, diverfus eft ab ifto.

Nidifacalin excelfisjuxtaaquas,autprofun- 'tocus." das valles, petris. Nidis exemptus manfue-Aldr. 1. $\%$ 
fit. Capit Perdices, Columbas, Cornices, Anates, Phafianos, \& Tetraones.

Aldror. 1. Falcones Prom IS CU o có I T U ge7.c. 16. niti, à Peregrinis plærumque proveniunt. Hi enim à parentibus fatim expelluntur, $\&$ cum fue fpeciei conjuges non inveniant, ad fpeciem alteram quam fibi fimillimam invenerint, libidinis tempore convertun'tur. Carcanus exaltero parente Peregrino, altero Montano procreatos, Falcones traverfos vocat: Albertus quatuor eorum genera ponit Cxterum, fi cum Falcone pedis cærulei Peregrinus commifceatur, fere fimilis Peregrino generatur avis, $\mathrm{fi}$ cum Lanario nigro, ignobilis Falco niger. fi cum Lanario albo, fimilis Falconi albo; fi cum Lanario rubeo; fimilis colore \& figura Falconi rubeo. Patriffant autem plorimque, \& ignobilitatem matris, inftitutio poft unum vel alterum annum compenfat.

\section{T I T U L U $S$ V. De Pfittacis.}

$$
\begin{aligned}
& \text { C A P U T I. } \\
& \text { De Pfittacis ingenere. }
\end{aligned}
$$

Nomen. D Apacibus Pfittaci fubnectuntur, tum I quod roftrum \& ungues aduncas habeant; tum quod cicures, carnem etiam ipfam devorent. Nomen fortiti funt, feu

Steph. de à Pfittace' urbe juxta Tigrim celebri, feu

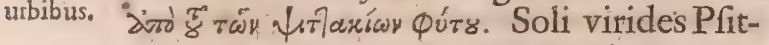
taci veteribus cogniti, Pfittaci fructus, in intimo quoque cortice \& tota nuclei carne, infolenter admodum eundem imbibit.

Defcriptio. Magnitudinem fi fpectes, in regione cui nomen dedere, brachium cum dimidio

Scalig. longitudine explent. Vifus Scaligero qui Exerc $23^{6}$. clathratz feneftræ fere impleverat fpacium. in quadam novi orbis regione Phafanos fuperant. in infula Banda, columbam noftratem vix excedunt. Alibi, Gallinis, Turdis, hirundinibus, imo Pafferibus xquantur. Color quoque illis varius. Scalig. In nova Hifpania, Ethiopia \& ultima InExerc. 59، dia, quosdam totos albos invenies. Circa
fect. I. Tarnaffaram feptuplici colore fuperbos; in Ternate Moluccarum una, Brafilia , \& A Athiopia rubros : in quibusdam Ethiopix fylvis nigros; in Malabar; praflinos; fcutelatos; purpureos; cinereos \& crruleos alibi.Bellonius magnos quosdam totos canere, mediocres ex rubro variegari, pufillos nonnullos prolixa cauda, totos virides effe ait. Circa Javam, alii funt rubri roftro luteo; alii verficolores, candidi quidam.Ee quis omnes diverfitates enumeret,cum fupra centenosmagnitudine \& colore difcreApul.1.2. pantes, curiofi obfervaverint. Antiquis fo-
Eloridor. lus in intimis plumulis \& extimis pinnulis; viror, notus erat. Vnde Avis viridis dice- Stat,12: batur. Com munia fere omnibus funt: Ca- Sylv. put pregrande, ingenii fignum, roftrum, quod qua collo committitur, in folis inferne fúb faucibus apertum eft, adeo durum, ut ferreis clathris vix parcant. Statius cornu vocet: aduncum idem, ut eO, tanquam Plin:H. N. hamato \& femicirculari forma conftructo, 1, 18: c. 43. fe.cum devolant, excipiat, illi innitantur, liviorefque fe ita pedum infirmitati faciant.Mandibula fuperioris, quod ipfis cum folo Crocodilo, \& Thrmatopode fi Oppiano credimus commune, motus. Lingua quæ cucurbitæ feminis figuram reprefentat cxteris avibus latior. Unde Aritt. 1.s,

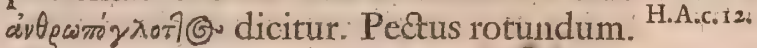
Pedum fpecies, quia ante \& poné binos habet, rara ; illos in regno $\mathbb{E}$ thiopia interioris prope mare arenofum, fi excipias, quorum quidam fex in pede digitos habent, quidam tres.Crura breviufcula,infirma, \& plærumque fufca. Ungues adunci, quibus efcam elevant, \& ad os extrorfum convertunt. Capitis Anatomiam apud Aldrovandum vide.

Locum ipforum natalem folam Indiam Locuso effe, veteres credidere. Tempore Alexan- ${ }_{c a p}$ Plin. $11.0^{\circ}$ dri $M$ : in Taprobana primum inventi, Paufanias Neronis, in Gaugada $\mathbb{E}$ thiopiæ infula viff inCorinth: funt; Diodori Siculi, in ultimis etiam Sy-c.29. riæ nafcebantur. Avorum temporibus, terræc cuidam fupra Caput bonæ fpei, nomen ob copiam indidere. In regno Calecut tanta ipforum eft ubertas, ut Oryzam fæpiffime depafcantur; tanta in Occidentali India, ut Pfittacorum regioni inde nomen creverit. Nec Nigritæ in regno Senegx illis carent.

Vifus ipfis feris adhuc, frumenta, legu-Nutrimen:mina, femen Carthami feu Cruci, quo ${ }^{t u m}$ pinguefcunt, cum homo purgetur; fructus omnigeni, cum molli tum duro cortice intecti. Nux etiam myriftica, ad quam in Infula Banda fxpifime advolant: Cicuribus, quicquid porrigetur, caro, panis, faccharum inprimis.Bibunt aquam, fed vinum multo libentius, cujus potu non folum lafcivi, \& folito loquaciores redduntur,fed \& humano inebriantur more, \& intra bibendum, pedibus fufpenfi caudam in altum, \& caput deorfum ad aquam extendunt. Nidos fi Cadamufto credimus ex furculis ad tenellos procerarum arborum ramos penfilibus, pili modo rotundos, per quam exiguo foramine, conftruunt, ut ferpentum infidiisviam pracludant. Maximi, gallinaceis haud minora ova ponunt, mediocres columbaceis paria, frecunditatis indicium, ingens illorum in natalibus.locis copia; caltitatis, quod bini femper, mas \& foemina agere videantur.

Volatus ipfis in natali folo expeditior. In Volasws. noftris oris propter colli frigidioris in cle- 
thentiam mint co valent, impotentiam, keptandifacilitas, qua furfum, deorfum, \& in maximam altitudinem fcandune, $o b$ congruam roftri \& pedum conformationẹm, compenfat. Illius unco, dum pedes promovere nituntur, appenfos fefe fuftinent; dum provolant, ne pedes ob corporis deorfum labentis pondus debiles offendant, fefe obvio adminiculo apprehenfo, codem velut anchora \& prafidio excipiunt.

Vox: Vocem articulatam nullam naturaliter habent, quidam etiam fere muti funt; nec quicquam unica illa voce Perroquet excepta, qux in ipforum nomen abiit, ingeminant.

Amicitia. Anticitiam fingularem colunt, cum lupo, Oppian. 1: cum quo fimul pafcuntur; homine, unde 2. Cyne- in America relictis fylvis interdiu prope

domicilia agunt, \& Turture, quod OviEleg. 2. 6. dius notavit.

Ingenium. Ingenio prope ad hominem accedunt. Accipiunt namque verba \& pronunciant articulate omnia; facilius, fr intra alterum xtatis annum docueris :fegniores, ferreo in caput verberantur radio. non fentiunt aliRhodig. 1. ter, propter duritiem, ictus. Sic Afcánii 3. Antiq. c. Cardinalis continuatis perpetio verbis 32. fymbolum Apoftolicum pronunciabat. Henrici VIII. Anglix Regis in Thamefin delapfus auxilium implorabat, viginti libras promittens; extractus, quatuor dèmarios hofpitatori fuo dari juffit. Meditari eosdem Cardanus addit; Pherecides mafculos, eos obfervare, \& deferre, qui venena propinare moliuntur, \& in domos important, refert. Quosdam circa Javam intelligere, \& ad interrogata refpondere, quidam nạrrant. Non facile crediderim. At Albert. ib. pueros interdum imberbes amare; blande scalig. Ex. attrectatos libidine, ita ut ofcula figant, ${ }_{236 .}$. Ex. tangi; quosdam pueros ita odio profequi, 236. ut in eorum capita de fublimi loco non aliter impetum faciane, atque Falco in AnaManafes tem ; fi inter fugentes agant; lamentari,
in Anna- tem in Anna- quod Conftantinus Manaffes in hiftoria Bafilii Imperatoris teftatur. Saltantes capitis geftu, depreflis agitatisque alis imitari, Scalig. 1.c. dubitandum non eft. Fominas nunquam De leg. aut rarenter humanas reddere voces, $T$ :glo. I. p. i raquellus reliquit. Virides macrouros, quibus collum torque rubro cingitur, annulo illo primum apparente, nil præterea difcere quidam affirmant. Scaliger acceptas ê via publicitus voces reddidiffe fcribit. In infulis vero $S$. Michaëlis \& Divite fimplicitatis tantx effe, ut ad crocitantem Pfittacum innumera, ex arbore in cujus ramis auceps latet, multitudo convolet, facileque lib. io. de- fe capi patiatur,apud Martyrem legimus. cad. 3. re- V V fus Pfittacorum apud Occidentales Inan. Oce- dos in cibo, apud Orientales olim, Ælia$r$ fus.

no tefte, facri habebantür. Heliogabalüs capita ipforum in convivio exhibuit, lis tlia, H.A. demque lecnes, pantheras, \& alia anima- ${ }_{\text {Lampi. }}^{1}$ 13. c. 18. lia pavic. Oblcetamenti loco apud Roma- Heliogab. nos olim fuere. Nam cum Gallinis rufticis \& Merulis in publicis ornatibus poneban- Varro 1 . 3. tur. Viros Pfittacos manu geftare M. Ca- de re rult. to conqueritur. Articulatam ipforum vocem in tantum eosdem miratos effe, Suidas author eft ut eosTindi mercem fecerint: Unde caveis eburneis, argenteis, vel ex alia pretiofa materia factis includebantur. Indis pennx ipforum in magno ufu. Exhis imagines varias, papiliones, flores, herbas, pileos \& perizomata conficiunt; veftes, àulia \& tapetes contexunt; enfes \& clypeos exornant, aliaque utenfilia miro ar tificio conficiunt. Sed de plumario opere alibi.

\section{De Pfittacis vide quoque infra Mantif $\int a m$ N. 4.}

\section{A P U T I I.}

\section{De Tfittacis in Jpecie.}
A
$R$ i I C u t i u s I.

De Pfittaco maximo Cyanocroceo, Maximo Tfittaco altero, Tfittaco albo criftato, Eु P fittaco viridi aldruin cofta $\int$ uperna rubente.

\section{P} Sittacus maximus Cyanocroceus in aula Defcriptio. Ducis Manture ab Aldrovando vi- ${ }_{21}$. Ornithis: fus eft. Magnitudine bene faginatum ca- c. 2. ponem exxquabat, $a b$ extremo roftro ad caudam extremam bicubitalis. Vertex capitis erat planus \& viridis, roftrum aduncum, in hemicyclum compofitum, extrinfecus in perfectam dimidii annuli rotunditatem formatum, palmum longttm, totum nigrum; fuperius longitudine duobus digitis, inferius excedebat. Oculos habebat albos \& nigros, quos ternæ lineæ nigrra à roftro ad colli initium ductx, figuram litere S. jacentis reprefentantes, in longum fuccingebant. Gistent veluti torques nigra ambiebat. Pectus, venter, femora, Uropygium, cauda inferior, crocea erant. Cervix fuperna, dorfum, alæ, caudx pars fuperior, colore cæruleo veftiebantur. Quiapud Comitem S. Floræerat, femel fingulo die inftante vefpera bibebat, notis \& familiaribus adblandiebatur. Æffivo tempore aquis fe immergebat, aut pluviæe donec totus maderetexponebat, à madore frigore correptus, ad folem fe vel focum ficcabat, ex podagra mortuus eft.

Maximus Pfittacus alter apud eundem Aldrov. 1. Principem fuit. Corpus ei non ita ut fuperio- ${ }^{c} \cdot 3$. ri craffum. Capitis vertex compreftus, palmo longior. Roftrum quam fuperiori brevius, nec longo adeo hamo incurvum, tres propemodum digitos longum, \& totidem, 
NA T UR A L IS

qua capiti committitur latum; mandibula fuperiote alba, inferiore nigra. Oculorum regio \& tempora albefcentia. Dorfum, alx incipientes, gula, pectus, venter, femora, cauda tota fuperne', punicea. Remigum tegetes fécundo in alis ordine lutei, puniceis marginibus, cxruleo velut ocello prope apicem ornatie, \&rc. Pfittacus albus criftatus magnitudine erat columbo domeftico par. Corpus ciniverfum candido plumarum Agmine veftiebatur. Capitis verticem habebat plumis' grandiufculis, fefqui palmum altis, retrorfum nonnihil incurvis, acuto apice denuo antrorfum reflexis, candidis, denis, velut crifta perornatum. Roftrum cinereum, ad nigrum vergens, qua capiti committitur naribus patulis pervium, ac harum medio tuberculo, quodam tereti clivofum. Oculos iride lutea, pupilla nigra. Linguam latam, rubicundam. Caudam in altum plumis dodrantalibus frequentibus, candidis, furrectam. Crura cum pedibus Aldrovan- fublutea. Pfittaco viridi alarum cofta fuperna rudus c:5. bente pullaftri anniculi erat corpulentia, capitis vertexluteus. Roftrum fuperius extremo nigrum, poft fubcxruleum, reliqua rubicundum; inferius vero allbum. Oculi iride croceo aut potius rubente, cincti pupilla nigra, corpus totum viride, parte quidem prona virore flavefcente ac diluto, alis vero \& dorfo faturiore, \& qui in maxima \& extrema penna remige ad cæruleum nonnihil tendat. Cofta fuperna alarum in tantum rubet; uti \& cauda eaque breviufcula, parte inferiore ad latera, rubra in longum macula infignitur; fuperne vero flavefcit.

\section{A. $R$ T I C U L U S II.t}

DeIfittaco poikilorincho, viridi melanorinchio, Leucocepbalo \&5 Erytbrocyano.

Aldrovandusl.i i.c. Sittacus poikillorinclos magnitudine erat - gallinæ minoris. Corpore plaroque virefcens, dorfo obfcurius, peetore \& ventre, interlucente luteo, radicibus ubique cinereis, dilutius. Roftrum fuperius in parte-fuperiore habebat ex viridi cæruleum; ad latera, colore ochre, in cujus extremitate macula transverfalis candida percurrebac, inferius circumcirca coloris plumbei in medio lutefcentis. Vertex plumulis aureis ornabatur. Remiges parte exteriore, tentrem verfus, initio virides, paulatim in colorem fubcxruleum, feu amethyftinum, purpureumve potius terminabantur, nigra cxtera. Secund $x$ in ordine longiffim $x$ totx lutex erant. Qux mediis ferme alis confpiciebantur, ad principium latere exteriore, quod ventrem refpicit, primum viridi, dehinc miniaceo obfcuro, inde viridi, poftremum apice ipfo partim violaceo, partim nigro vicinim variabant.Couda duodenis inftructa pennis, quarum que è latere funt, utrinq; quaterna, qua enafcuntur, initio fui primum virides erant latere exteriori, lutee interiori, inde rubeo, coccineove colore, textio ordine denuo viridi poftremoluteovariegatę.Reliqueq quatuor medir to tr virides, at fine fui nonnihil lutei habebant Pedes plumbei quaterni digiti bini ante, retro totidem, ut in PicisMartis, interiores quidem exterioribus multo bre viores, Vngues ut rapacibus adunci. Tibice brevifim $x$, nempe inter poplites \& talos, digitum longæ fed craffufula. P P fttacovi ridi melanorincho collum, dorfum cum alis virore pleno tinguntur. Cofta alx, qua corpori adnectitur, extrema, coccineo rubet, penna in extremis alis, qua ventrem fpectant, eft nigra. Uropygium inferius coccineum. Roftrum totum nigrum. $\mathrm{Ca}$ put \& pectus lutea. Pfittacus Lucocepholus ita ab Atdrovando defcribitur, \&c. Dodrantem $\&$ digitum unum longus eft. Rofrum duos digitos craffum, album : \& pars capitis roftro continua item alba. Oculi pupilla nigra, iris ferruginea. Vertex \& frons, qux albent, maculis nigris variegatæ funt. Occiput, collum, dorfum, alæ, uropygium fupernum obfcuro ac pleno virore tinguntur. Gula \& alatum cofta fuprema rubore cinnabarino. Peitus ac femora virent denuo. Pars ventris inter femora \& pectus interjecta fufco fubrubido, aut eo colore, quem pictorum vulgus terræ umbrx vocat, infignitur. Alarum latera pennas quasdam, quxe remiges tegunt, easque extremas cæruleas habeat, albo tamen nonnihil admixto. Venter poftremus uropygio proximus lutefcit. Cauda medio rubra, ad latera rubro \&luteo, inde cæruleo variegata eft. Pennæ pene omnes extremo apice nonnihil nigrefcunt, cxtera virides funt. Tibix \& pedes cinerei. Poffet \& hic idem ob multiplicem colorum varietatem Pfittacus $\pi$ osx nos, id eft verficolor appellari. Eft enin coloribus non paucioribus quam feptem diftinctus, quorum tamen præcipuus eft viridis. Pfettaco Vrytbrocy ano, caput, pectus carulea funt. Vertex fummus macula lutea infignitur. Roftrum haud ita ut prioribus grande, nigrefcit. Oculorum regio albicat. Pupilla nigra, Iris fufca. Ventris latera fub fummis alis lutea funt. Venter viridis. Femora è viridi albicant. Vropygium luteum eft. Summum dor fum dilute cæruleum eft. Alarum tegetes viridi, luteo, rofeo promifcue conteguntur. Sic remiges \& cauda. totx rofeo perfufa funt. Dorfi extrema pars feu lumborum regio flavefcit. Caudx denique pennæ pauculę, exque virides obtegunt. Crura \& pedes cinereo imbuintur, cxtera rofeo. Hic forteille eft, quem in Tarnafari urbe Indix pulcherrimum ac fe- 
D E A V

ptemplici colore diftinctum reperiri Ludovicus Patricius fcriptum reliquit.

A.R T I C U L U S III

DePfittaco Cinereo, Erytbroleuco, Torquato macrouro, Minore macrouro toto viridi, Erytrochloromacrouro, Erytrochlorocriftato, Ë aliis E Ge/neropo/itis.

Aldrovan- DSittacus Cinereus ex Mina adfertur, \& à dusl.ri.c. 13. 14. 15. eft. Corpus enim totum cinereo obfcuro, x6. feu potius æqualiter fubcæruleo tingitur, remiges paulo faturiore vifuntur. Oculos macula candida cingit. Carda vix ultra extremas alas protenditur, \& tota cinnabarino colore tincta eft.

Pfittaco Erytbroleuco magnitudo eft caponis grandiufculi, corpus candidum, poftrematergi pars, uropygium, cauda tota,alarum remiges miniacei coloris. Roftrum unco quam in aliis longiore.

Torquatus macrourus folus antiquis cognitus fuit. Caput \& corpus omne habet viride. Roftrum miniaceum. A roftro inferiori fub mento \&c. Minor macrourus totus viridis in Hifpaniola reperitur, nec totus turdo major eft. Roftrum habet fuperna parte rubrum, inferna è rubro ingricans. Iridem oculi rubicundam \& croceam. Corpus herbaceo virore amonum. Pedes \& tibias rubicunda.

Erytrocbloro macrouro ex Japonia allato, corpus quatuor coloribus, quorum potiores viridis \& ruber infignitum erat. Verticem habebat planum ; roftrum rubeum, exiguum, \& inferius etiam aduncum. Retio \& ante oculos maculam cæruleam. Caudam corpore toto longiorem.

Erytbrocblorocriffato alæ, cauda ac crifta, quæ fex pennis, tribus majoribus; totidem minoribus conftabat, funt rubri coloris, corpus reliquumviridis.

His adde Pfittacum Erytbrocyanum, nec non Erytbroxantum Gefneri; quorum ille, parte fupina rubet, alis fuperius in flavo viridibus, cætero cæruleis; cauda partim rubra, partim cxrulea, bic, illi per omnia fimillimus, in hoc tantim difcrepat, quod per medium alarum plurimum flavioris coloris habeat, nonnihil etiam in cauda.

Huc etiam Aldrovandus Avem illam, quæ in Hifpania capta, magnitudine erat fringillx; roftro nigro, adunco; capite, collo viridi, vertice ut in Garrulo Bohemico crifta infignito ; alis cæruleis, extremo nigricantibus; uropygio ferrugineo; femoribus albis; pedibus nigris; digitis quaternis, binis ante, retro totidem; refert.
$I B \cup S$.

T I T U L U S VI.

De Corvinogenere, Es aliis nonmilis Avibus, quibus roftrum durum ac robu= ftume ejt.

\section{A P P U T $\quad$ T}

De Corvo.

COrvus, Græcis, feu à colore nigro feu Défriptito. à capitis magnitudine ró $^{\prime} \boldsymbol{c o s}_{\xi}$. L. Floro Satyra avis, feu propter falacitatem. Vi- In Hittor rile enim membrum veteres Graci óín ap-Val: Corpellabant; feu à Satyrá palude, qux \& ${ }^{\text {vinit }}$ Rhodig. Pomptina, viginti quatuor olim urbium Antiq.lcet. capace loco, dicitur. Locus ipfi poft Pfit-1. 29. c. $25^{\circ}$ tacos vel eam ob caufam datur, quod \& ad rapacium naturam accedat, \&rolim apud veteres in tanto precio fuerit, ut per illum Ariftoph: jurarent. Magnitudine Cornicem fuper-in Avibus. at, \& adeo eft ater, ut præ nimia nigredine cxrulæus quodammodo appareat, nec ab aquis mutetur. Rofrum habet aterrimum, Scalig. ad nonnihil aduncum utrisque marginibus liz.de caur: incidens; Oculos lucidos; Lingusam in apice latam, ad radicem rotundam, nigram. Vifi tamen in Septentrionalibus regionibus, Anglia, Neapoli apud Alphonfum Olats Sicilix Regem, Leftorum Indix extra Magno lib. Gangem regione, quin \& tempore Arifto- Arittoteles telis, albi; feu quod ob afpectum nivium l.5. de gein nivofis locis tales nafcantur, feu quod frigus id efficiat, feu quod alimento id attribuendum fit. Interiora ejus fi attendas; gulam patentiorem prope ventriculum pro ingluvie habet. Fel renibus, \& parte tantum Arif.H.A. altera inteftino jungitur. Excrementa alba 1. 2.c. ult. effe apud Horatium legimus. Cuidam Ariftu.N. vero apud Livones \&Botnios generi, quod 1. 2.c. 15.

marinum dicitur, roftrum dentium fere inftarferratum, fed forte falfo; adfcribitur.

Quantum ad Locum, in Afia non nafci Locus. Theophraftus prodidit. Locis defolatis, plin. H.N. 1. c. 29. humidis, excultis, turribus, celfis æedificiis, Efa. c. 34 . $^{\circ}$ morari, nec ea, dummodo cibus fuppetat, Theon. in deferere; in agris uberrimis gregatim ferri, \& ejus frequenti fuo numero bonitatem, quam innata fagacitate cognof cunt prodere, compertum. Binos per fterilem \& in- 지.1.2 de fructuofum campum, nec non aretiora lo- Anim. c. ca volare, quod non fatis cibi pluribus, un- Arif. H.A de in Cranone Theffalix oppido nun-1.9.c.3\% quam plures diobus reperiri, à quibusdam notatum. In Gallix oppido, quod Corvatúm|dicitur, annos plus, quam centum egiffe, Albertus nefcio, qua fide refert.

Vilititat corvus frumento, pomis, ficubus, Nutrimen'cerafis, qux cum pediculis deglutit, \& $\mathrm{t}_{\text {Athen. }}$ lib. dum binis è paftu, horis pulpam rejicit, ${ }^{13}$. offa evomere folet;nec non vermibus, hinc Ornithol aratoris veftigia rodit; pifcibus, unde apud 1. I2.c... Anglos lege fub gravi muleta cautum, ne Bellon.1.6. 
quis vim corvis inferat, cadaveribus, qux fi non attingit, infecta effe conjiciuntur. Plin.H.N. Quin nec à vivis animalculis abftinet: 1.10.c.47. Alaudam \& pafferem devoraffe vifus eft pullos vero alimonia deftitutos, parentem Alianus ipfum invadere, \& devorare ZElianus au1.3. de A- thoref. In Bothnia non tantum lepores nis. c. 43. \& cuniculos interimunt; fed agnorum etjam \& arietum ftragem edunt. Conftitutum è publico premium, qui eos occidiffent Potus eft vehementer appetens. Tradedum putavere memorix quidam, vifum corvum per fitim lapides congerentem in fitulam monumenti, in qua pluvix aqua durabat, fed qux attingi non poffet, ita defcendere paveutem, expreffiffe tali congerie, quantum potaturo fufficeret. IEfti-

Atll.1.r. de vo tamen tempore fexagenis diebus, dum
Animal. Animal. ficus maturefcunt, non bibit, feu quod,nifi Hyginus fallit, guttur pertufum, dum ficus maturefcunt, habeat; feu quod eó tem- pore relaxatione alvife laborare fciat.

Generatio. Generationem quod attinet. Ore coire Plin. 1. ro. vulgus prodidit, inde fellatorum ipfis nocul2. men, fed falfo. Nam \& vulvas habent, \&

* Arif. 1.3. Ova juxta feptum, nec cogitare quomodo de gen. A- femen perventriculum, qui femper quod nim.c.6. injectum eft concoquit, perveniat, abfurdum eft, \& vifi duo Avicennæ, qui aliorum congrediebantur more. Roftrorum fit inter eos ante coitum conjunctio, feu ut alii, Oppian. cantu prius quodam velut hymenæo de1.r. de Au- mulcentur foeminæ ; tum mares admit-
cupio. tunt, hinc exorta fabella. Ponit bina, frepe quaterna aut quina ova, poft viginti dierum incubatum pulli excluduntur. Exclufi, for-

Gieg. M. te quod color ipfis fit albicantior, negli1.30.c.8. guntur à parentibus, \& ad feptimum diem, 1. quo atrocem induunt, feu coelefti rore, ut Cafliodorus credit, feu à mufcis pretervolantibus aluntur. Agniti recipiuntur in curam, donec firmiores evaferint, mox pulfi, qux funt ad vivendum neceffaria inquirunt. Circa Cranonem tamen fingula perpetuo paria degere, \& genitores foboli plin.H.N. loco cederePlinius afferit. AEtatem eis lon1. 7 cap. 48.
Plin. H.N. grvam Hefiodus tribuit, fabulofe fi geved $v$ 1.8.cap.48. pro centum fumas annis; verifimiliter fi pro uno, intra quem \& omnia, qua terra profert perficiuntur, \& ipfe homo in utero: Sic longæ vitas intra C V I I I. annos confiftet. Vox eidem minime fonora quamvis, InAulula- cantarePlautus dixit, quia crocitat, rauceria. dine \&x.ftridore aures offendens; hanc feu Lucret.1.4. propter diverfos effectus, feu imbrium \& de Natura ventorum inftantem incurfum, ita mutat, Virg. Ge- ut Fulgentius fexaginta quatuor diverfas org.t.r. habere dixerit. Odoratu cum vulturefere certat, involatu tardior \& gravior eft, ideo non Plut. in mirum aliquando populi clamore diffono

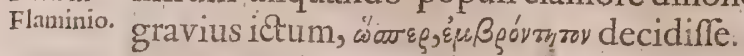

Ingenium. Mores \&ingenium admirationem merentur. Ad trigefimum \& quadragefimum

una viventes, conjugii jura fervant, uno defuncto alter per vitx reliquum viduus permanet. Nummos quidam Erfordix fu-Albert. rabatur, \& 2 fub lapide abfondebat. Alter ${ }^{1}$ Animal. Auguftum ex Actiaca victoria reducem, Macrob. verbis, Ave Cxfar, victor, Imperator falu- ${ }^{I_{2} .2}$ tavit, viginti millibus feu $D$ : aureis folatis emptus. Quidam fub. Tiberio Princi- Plin.A. N. pe fingulis matutinis in roftra evolans, in 1.10.6.43. forum verfus, Tiberium, deinde Germanicum \& Drufum Cæfares nominatim, mox transeuntes P. R. falutabat. Occifi funus innumeris elatum eft exequiis, interfectus, qui occiderat. Taceo illum futoris, Crefarem falutare edoctum, in quo opera \& impenfa periiffet, nifi operam \& impen-Macrob. fa periiffe, eloqui potuiffet. Nec non illum, 1.c. qui Cunradum coquum in fame implora- Scalig. bat, adeo expreffe ut ab homine voca- Exerc.237. tus crederetur. Difficilimum elementum, optime exprimunt. Venatici (primum Ludovicus Gallorum Rex inftituit) per- Scaliger. dices \& corvos feros venantur. Phafianos aliquando.

Amicitiam naturalem colit, cum lauro, Amicitia. quem depafto Chamæleonte comedit cum afaro \& aro ; quibus. remediis in qui- Ruell.1. busdam morbis utitur ; cum falicè Ameri- ${ }^{\text {I. }}$ de Nat. na, qua tanquam amuleto nidum munit; cum Coracio, qua vim toxici deguftati Arint. de frangit; cum Oenuta qua fe ad ebrietatem ${ }^{\text {Mirabilib. }}$ exhilarat.

Inimicitzas autem gerit, cum Milvo \& Ynimicitia. Percnoptero, propter cibum, cum AEfa- Cicerol.r. lone, propter ovorum fractionem, Cha- Deorum.: maleonte, Circo, Turture ; \& aliis. Cum Arit.H.A. Erucx femine, quo interit.

Tllian.1.6.

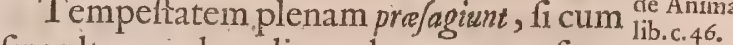

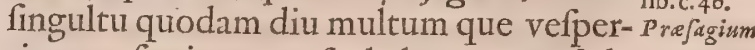
tino præfertim crepufculo latrant; \& fi de Plin.H.N. arbore pendent alas fepenumero moti-1. r8.c.39\% tant. Serenitatem, fi contra folum hiantes Ael.1. 17. mane per arborum ramos plumas \& alas lib.c.7. expandunt, fi privatim primo crocitantes, Virg. Ge, mox turmatim congreffi liberius vociferantur, aut fi fub nocturnum crepufculum gregatim verfantur, \& dum feparantur fumme crociendo ad nidos advolant. $\quad V$ Jus.

Vfus ejus in Medicina aliquis eft. Pulli menfe Martio combufti contra Epilepfiam propinati funt: Ova ad denigrandos pilos adhibebantur; à Villanovano ad Epilepfiam commendantur. Cor portatum vigilias inferre quidam.afferunt. Pes à collo pueri tufientis fufpenfus eum, fi Pfello credimus, fanat.

\section{A $\quad$ P $\quad$ U $\quad$ T II.}

\section{De Cornice in genere.}

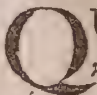
Uæ⿱ Latinis Cornix , Græecis vulgo Defriptis. roé́vy, hæc iisdem hodie useẃvua vel x'exru. Polyrnæniis Cretæ populis róp $\beta$ a, 
tudine vincit graculos. Roftrum, crura, ec totum corpus habet undiquaque nigerrima, (falfus Strabo, dum peculiare efie Hifpaniæ, ut nigre ibi fint cornices fcribit) illud tamen, durifimum alias \& acutinimum, prope caput albicat, fuperiori parte barbulas quafdam veluti fetas circa palpebras haber, inferiore nigra, eaque minima veluti granula. Albam, capite nigricante, cæteris alarum apicibus in rubedinem vergentibus, Rhodiginus vidit:

Verfantar circa urbes, domos, maris ripas, fluminum littora \& fterquilinia. In Britannia ingens ipfarum copia, quoniam in pabulo humido ejus foli vermes abundant.

Vigitant frugibus, nucibus, olivarum baccis, vermibus, pifcibus, \&x carnibus, \& vere $\pi \dot{\alpha} \mu \varphi \varphi_{c}$ yor dicuntur.

Generationem earum quod fpectat, Nidulantur in fummis arborum frondibus. Non temere nec impudenter inter femifcentur; \& candem cum corvis in conjugio fidem fervant: hinc folitarix cornicis occurfus, malum in nuptialibus aufpiciis omen : eliminare cornicem virgo jubebatur. Ova pariunt poft folfitium gemina, natura ita Aphrodir. difpenfante, ut qux diu vivunt pauca 1.2. Irobl. 64. $\mathrm{P}$ ut afliduo, in incubitu plumas exuant. Pulrig.l.1 2. los à cauda de ovo exire, feu pedibus pric.7. Generat. fimilius eft. Non prius pafci quani plumis 1.4.c.6. veftiri incipiant, vulgo creditur. Volandi Arif.H.A. potentes diu profequuntur, \& avolantes 1.6. c. s. fubinde comitantur, ideo jufta naturx taIfidor: 1. c. lione \&r decreto, quantum tempus impen* dere in fatibus educandis, tantum \& ipfe fenio confectx, à pullis fuis aluntur.

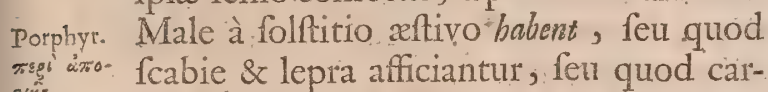

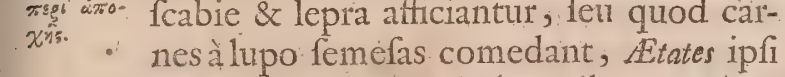
Plin. lib.7. humanas ter tres authores tribuunt. Arac. 48. tro éved́dgeg: ropávn dicitur, forte quiod diu vivat ro $v^{\prime} m e$ n namque Theon ex-

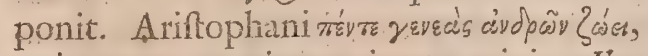
quinque generationes virorum vivit. Vox

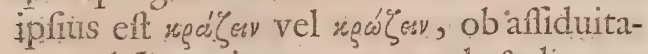
tem obftreperi cantus, garrula \& loquax

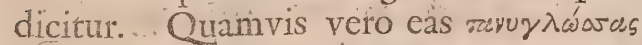

Odyf. : Homerus vocet, id eft lingua longa \& exPlin. í. ro. tenfa, tamen tempore Plinii allata, è Batic. 43. casplura contexta verba exprimens, \&x alia atque alia crebro addifcens.

Volatus. Volat celeriter. Graditur lente inftante pluvia; celeriter dum pullos pafcit.

Afeetus. Amicitias colit, cum Ciconiis quibus maria tranfvolantibus Ducem fe prabet, \& Arift.H.A. cum Ardeola, cum qua contra vulpem

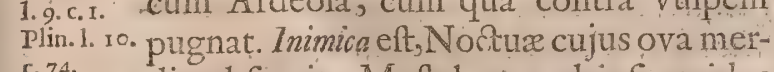
c. 74.
Ftian de die abfumit; Muftelx, quod ipfius nidos Anim. 1. 3. frepe diripiat; \& cum Tympano ave, quam cap. 9. folertiam multa oftendunt. Si nucem perfringere nequit, in altum fublatam ad taxa \& tegulas precipitat. Verbenacam fupi- plin: 1 .

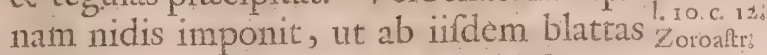
aliasque beftiolas abigat. Apud Marrem in Geop. Egyptiorum Regem educata,literas, quocunque, juberet, detulit. Mortur fepul- Filia.H.A: chrum adlacum Mytidis prope Crocodilo- 1.6.6.7. rum urbem eredum eft.

QuantumadVfum cerebrum coctum 8 V Vusto in cibo fumptum inveteratis capitis doloribus remedio effe Plinius teftatur. Car- Plin.H.Mi nem in morbis chronicis utiliter fumi, ni- ${ }^{1.20 . c_{6} 6 \%}$ dum corpori illitum vitx dies prolongare, olim vane creditum eft.

\section{A P U T III De Cornice in Secie.}

A R T I C U L. U N I C U $s$ :
De Comice Frugivora; Cinerea, (6) Ceruleo.

Ornicis tres funt fpecies. Frugivora Dsfcriptiof nempe, Cinerea \& Cerulei. Frugivoram

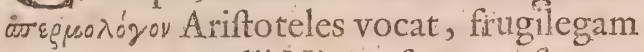
\& granivoram alii.Nigra eft tota, roftro ex-1 cepto, quod albicat.Magnitudine eft inter Corvum \& Cornicem media.

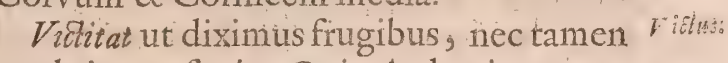
lumbricos refpuit. Quia Ardea in earum. nidis nidulari folet, ideo circa villas nobilium, qui Ardearum aucupio delectantur, in fummis arboribus impune nidos faciunt. Anglix funt maxime infeftr. Ideo olim fancitum eft, ut funditus extinguerentur; precium occifori daretur.

Cinerea Turnero Marina dicitur. Minor: eft Spermologo. Dorfum totum, collum. fuperius, alarum latera, nates \& totum ventrem cinerea habet. Eftivo tempore altos montes incolit, in quibus fobolipropagandx incumbere, ex eo colligi poteft, qeod nullibi in planis nidulari reperiatur. Sub autumni finem ad plana defcendit, ibique totam poft hyemen prope oppida \& pagos degit. Fit id ob ru pium afperitates, \& nives continuas; vel $\mathrm{ob}$ intolerabilem frigoris fevitiam. Viitus ipfus idem qui nigra. Quadrupedum, hominum fufpenforum cadavera \& pifces affectat: nec à lacticinis abftinet. Gefnerus in diffecto ventre, quafdam quifquilias, \& cortices granorum, nec non fübftantiam quandam albam, pinguem, ex iifdem forte granis concretam \& lapillos invenit. Nunquam in Helvetia nidulari di citur. In inferiore Germaniam cibum à plebecula admittitur.

Ceruleam cornicibus, quamvis vix fciri poteft, an ex earum fitnumero, Gefnerus, Kentmannus \& Aldrovandus annumerarunt. Crivleo paffim colore, in capite, alis, Aldrovis is
D 
cauda, circa Uropygium \& tota parte fupina, nitet, alibi finceriore, alibi viridi admixto. Dorfi \& colli proni color fufcus eft:majoresalarum pennx nigræ. Crura fufca, \& pro corporis proportione parva habet. Reperitur transAlbim in falcu Luchoviano, \& fylvis finitimis. Verfatur in locis non frequentatis. A projectis, præter catera, cadaveribus victitat, \& nidum ut upupa ex oleto conftruit.

\section{A $P$ P,$T$ IV.}

De Graculisingenere, Ẽ in pecie.

Varro 1. 4. Paculus feu quod gregatim volet, de Lingua 7 qux etymologia Quintiliano improQuintilia. batur, feu quod jacta fegetum femina plu1. I. Inftit. rimum gerat, feu quod ex olivetis cubitum Orat. fefe recipiens binas baccas pedibus, ore vero tertiam ferat, dicitur.

Vichus. Victitai preter fegetes, carnibus glandiPlin.H.N. bus, \& locuftis. Unde à Lemni intulæ in-

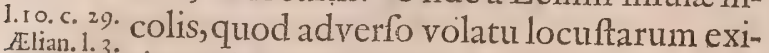
de Aninal, tio occurrat, colitur.

c. 12 .

Ad coitum verno tempore excitatur.

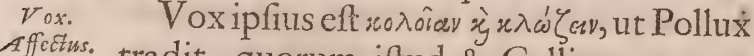
Alian.1.9. tradit, quorum iftud \& Gallinaceo quoc. I. dam generi tribuitur. Amicitiam cum Gavia gerit, hofpitalitatem cum Accipitre: Hoc Homerus fub Hectoris \& $Æ$ nex Grxcis infenfifimorum exemplo prodidit. Avem congregem effe, vel vulgaris paræmia, femper graculus affidet graculo oftendit. Mas inortem potius fubit, quam

zx.lian. 1.9. conjugem derelinquat, altero mortuo, alter dolorem perpetua viduitate teftatur. Loquaciffimi funt, coitus inprimis, \& quo pullos enutriunt, tempore. In vini potu mira ipfis lafcivia. Manibus retenti, ocu-

Nicolaus los impetere maxime folent, feu quod Leonicus. effigiem fuam in illis cernentes, velut ad cognita defideria tendant, feu quod à rebus fulgentibus \& mobilibus quales oculi, facillime alliciantur. Cicures voces proBrujer.1. nunciare difcunt adeo, ut è caveis emiffi 15. c. 78 .
de re ciba- fponte fua eas repetant. Matutino, vero ria. fuboriente fole tempore, citius eas capiunt, \& memoriæ tenacius mandant. SueAriftoph. tum id \& veteribus. Paxillos enim in pain vefpis. rietibus domi fuæ, quibus infifterent facieDalech. in bant.Epileptico morbo obnoxii, velut exPlin.l. 3.c. tincti ex arborum, tectorumque culmini22. bus decidunt. Annuum faftidium lauri purgant folio.

$V$ fus. Vfus ipforum apud plurimos in cibis.

Generatio. Quantumad generâ, tria Ariftoteles po1.9.c. 24. fuit, quartum palmipes, tria \& Gefnerus, Tullam nempe Becuam, \& Taham. Nos Coraciam, Pyrrbocoracem, \& Lupum feu Monedilam ponimus.

ÇOR ACra magnitudinem haber cornicis, illa inprimis, qux nigra \& pamphaga. Roftrum quatuor fere digitos longum,
N A T U R A L S

quodammodo arcuatum, coloris punicei, feu inter aurantium, rubrum \& fubflavum medii Pedes ejusdem coloris, unguibus exceptis, qui fimul cum toto corpore funt nigerrimi. Incolit præruptos montes, \&r raro ad plana defcendit. Cicur fimila ex lacte, carne, pane, \& tritico vefcitur.

PYRRHOCORA X Cornice eft minor, Monedulæ xqualis, luteis cruribus \& ro- Plin.H.N. ftro, quod parvum Turnerus, in extremi- 1. xo.c.48. tate nonnihil aduncum Bellonius dixit, cætera nigerrimus. Tam frequens eft in AIpibus ut peculiarem Alpium. Plinius fcribat, fed "\& in Anglia, Creta, Cycladibus monte Jura \& alibi reperitur. Apud Bellon.1.s. Rhætos hyeme duntaxat cernitur. Agros frumento confertos depafcitur. Altum vociferat, \& vocem Merularum acutam, ac ad fiftulæ fonum nonnihil accedentem imitatur. Ex ejus volatu alto frigus augeri, humili minui quidam colligunt.Pulli in cibum pauperioribus menfis cedunt.

Monedula, Ariftoteli $\lambda$ íc(a) omnibus nota avis eft. Caput, pedes, totumque corpus \& roftrum nigra funt. Nigredo de cinereo aliquid participat; rof irum circa narium foramina albicantibus punctulis infignitur, prope ventriculum gulam pro Arif.H.A. ingluvie patentiorem habet. Loca plana 1.9.c.24. amant, fed \& in altiffimis turribus fxpe tam numerofe nidificant, ut in una centum interdum nidi confpiciantur. Quia frumentialiorumque granorum, ubi fatiata fuerit reliquias terra recondit, \& fpicas fub fequenti anno ex iis colligit, ideo frumentum ferendirationemohominibus oftendif- Plin.H.N. fe creditur. Auri \& argenti furacitas in ea li: I4.c. F7. $_{\text {Ovid.1. }}$ mira.Unde Monedula à moneta dicta cre- Metamor. ditur. Gaudet in capite fricari, quafi pruriret, ideo carnem 'ejus pruritum inducere Albertus credidit.

Eft \& aliud Monedulx genus, quod collum habet albo torque circumdatum, forte illud quod Hefychius \& Phavorinus ระ. Qávioy feu coronatum dixere, forte \& illud, quod inHelvetia circa'Tugium albo circulo collum ambiente diftinctum, cętera alteri fimillimum, reperiri, Gefnerus prodidit.

\section{$\begin{array}{lllllll}C & A & P & U & T & V\end{array}$}

\section{De Picis ingenere.}

Dİca, qux Atticis «'ñ communiter x'arc, Laconibus жêara, Hefychio \&

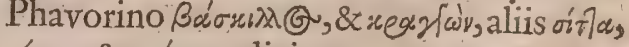

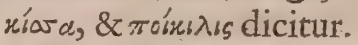

Genus ipfarum unicum duntaxat agno- Genus: viffe Ariftoteles videtur. Alii in urbanas \& fylueftres dividunt.In nulla non regione obviafunt. Glandaria in Batavia rara.

Viçum fi attendas, eft pamphaga. Suum vians: alveos quandoque cibi caufa petit, \& quosvis acrodryos fructus. Vifa pafferem de- 
Cardan. 7 vorafe, fed \& una, à cancro, quem è flu$c_{3} 3$ s.deva- vio abreptum in arborem vicinap porta-
riet. rer. verat, collo fub forcipibus comprefio, mifere interempta legitur. In libidinem valde funt proclives.

Generatio. Ovacirciter novem parere; multos fed imperfectos imo cócos pullos excludere Arif. H:A. Ariftoteles prodidit. In nidis conftruen1. 9.c.13. dis fingulari utuntur artificio. Nam eum in locis fpinofis figunt, terra intus oblinunt, foris in circuitu, infra \& fupra fpinis diligentifime muniunt, foramen unum (duo quibusdam placent) idque arctifimum pro introitu relinquunt. Ova verò interdum alio transferunt. Binos frequenter exftruere; ut qui pullis infidiantur dubios reddant, prodidere nonnulli.

Volatus ipfis raro altus, quem etiam alarum brevitate impeditæ parum protrahunt. Saliunt, \& caudam more Motallicæ

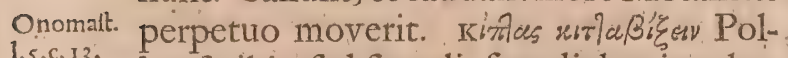
1.5.c. 13. lux fcribit; fed fingulis fere diebus imo horis, vocem mutare, \& unius cujufque anipaufanias mantis imitari, certum. Puerili vagitum in Arcadic. expreffiffe quandam, alteram hoedi primum veluti à matre feparati querulam vocem ediffe, mox vituli inftar mugiiffe, ovis more balaffe, tandem adinftar paftoris, cum poft pafcua oves ad potum deducit, fibilafie, fide digni authores prodidere.

Plut.lib.de Aliquid illi apud Plutarchum ne fubfuerit folert: ani- metuo, qux alioquin loquacifima, audi-
malium. tis Romæ buccinatoribus obftupuit, paucospoft dies quafi expergefacta, omnem eam buccinatorum hormoniam fumma cum admiratione expreffit.

Affectus. Infeftantiuab Alucone \& ulula. EpilepArit. H.A. tico eas corripi morbo quidam prodidere. Mlin.H.N. Variæ quotannis cum rapx feruntur. cal1., o.c. 29 . vefcere, proptium. In Augufio id fieri Gefnerus prodidit.

$V$ fuis.. V Vus ipfarum \& in cibis \& in Medicina aliquis. Glandarix Bononix in foro venduntur, fed duræ carnis funt; A thenæus tamen Corhyin Thracum Regem appofuifie teftatur. Quidam feu vino albo ad confumtionem coctas, fet in olla toftas, \& in pollinem redactas, feu diftillatas, oculorum hebetudini, rubori, \& dolori prodeffe, prodidere. Nonnulli vivam in partes diffectam, laborantibus articulis imponunt.

\section{A $\mathrm{P}: \mathrm{U}$ T $\mathrm{TI}$. De Ticis in Specie.}

A R T I C U L U s $I$.

De Pica varia Sen Caudata, Caudata Indi$c a$, Glandaria, Garrulo Argentoraterifi, Pica Marina, E Terfica. A Ariftoteles unicum duntaxat genus
Plinius id duplex, fumpta a pedibus differentia,facit, nec de vario reticet. Nos\& has, 8x qux fequentur, huc pertinere credimus. Varice feu Caudatx caput dorfum, col lum, pectus, alir femora, cauda, pedes corumque; digiti atque ungues aterrima, extremum alarum albicans, dorfum \& cauda \& maxima nigredine viridefcendentia, tota ventris fuperficies candida.

Caudata Indica quam Aldrovandus čxhibet, ex Japoniaallata erat. Rofram, tibix \& pedes rubefcebant. Capuc totum \& col: lum, quod torquis albus ambit, erant cxrulea, dorfum \& fcapulæ ferruginea. A fuperiore roftri parte inter utrumque oculum macula tres fere digitos longa, \& pollicem lata punctulis feu potius lineolis nigris transverfalibus confperfa ad dorfum ufque protendebatur. Alarum pennæ ve ftitrices caftanex, fed lineis nigris crafluf culis per longitudinem pofitis refpargebantur, reliqux virides erant. Pectus \& ventẹr ad anum úfue candefcebant.\&c:

Glandaria, Ariftoteli radaxiórearns feu Molliceps, recentioribus Gracis xaeaxd $\xi a$, aliis Picata Granata dicitur. Differt à varia, tum magnitudine, tum maxime colore. Haber ad alarum latera tranfverfales notas cxruleas, quales in nullo ferme volucrum genere confpicias; tam amplum oris hiatum, ut glandes integras deglitiat. Nares plumis albis \& nigris operiuntur. Roftrum aliquantulum recurvatur, lingua bifida eft. Color corporis varius eft. Nam cervix ex rufo \& cæefio mixta eft. Uropygium candicat, dorfum pallefcit. Cauda longiufcula eft, \& duodecim pennis nigris conftat.

GARRULUS Argentoratenfis à garritu, \& loco in quo maxime degere folet, nomen fortitus eft, veteribus vel ignotus, vel faltem non defcriptus. Caput ipfi craffum colore ex cæruleo \& viridi mixto, maculis per longitudinem albis, quæ per totum pectus ventremque deorfum feruntur. Roftrum mari duos digitos longum, craffiufculum, aliquantulum recurvum. Ocula magni, nigri, Dorrum à fecunda, vel tertia vertebra ad Uropygium ufque caftaneum. Alarum color varius. Cauda fuperna parte virefcit, inferria partim violaceo, partim cæruleo permifcetur. Frmina toto coelo à mari diverfa eft. Caput, collum, pectus, venter ex caftaneo ad Leucophæum vergunt. Roftrum eft craffius. Alo prope fcapulas cxrulex, mox ex coeruleo virides, remiges nigræ. Caudalatiufcula, ex viridi \& cærruleo ad fufcum inclinans.

Pica marina, qui \& Gaza dicitur, tota, caput, cervicem, pedes, \& alarum par tem fi excipias, fulviridis apparet $R$ O frum habet robuftum, paulo quam in $\mathrm{Pi}$ cis longius. Capitisverticem coloris caftanei 
diluti, inferiorem ejus partem ad tempora luteam. Digitos longos, pedes infigniter aduncos, fecundiordinis alarum pennas ex caftaneo dilutas.

PICA PERS IC A, tota fere fubfufca eft, roftrum habet breviufculum \&albicans. Oculos albos. Alarum fecundi ordinis pennas, cum Uropygio, \& prioribus in caudaluteas, pedes fubcreruleos, tabellis nigris infignes.

NB. De Picaruin generibus quibusdam exioiicis vide Mantiffam. Num. 5.

A $R$ T I I C U L

De Garrulo Bobemico, Gejneri, feu Ampelide Aldrovandi.

Defcriptio. Vem, quxe Garrulus Bohemicus GefAldrovan. 1 nero dicitur, Ampelidem, à potiori dus lib.rz. victu, Aldrovandus appellat.Magnitudine Ornit.c. 18 Merulas exæquat. Caput habet quodammodo compreffum, coloris ferruginei, more alaudx criftat $x$ apice retro vergente, coloris verfus roftrum fubcaftanei diluti, retro fubcinerei ad fufcum vergentis, terræ Umbrix haud difimilis, infignitum. Collum breviufculum, antica \& poftica parte nigrum, ad latera ruffum, prope roftrum candidum. Pectus caftaneum dilutum ad rofeum vergens. Dorfum fubcaftaneum, prope Uropygium leucophrum. Ventrem totum fubcinereum. Exteriores alarum pennas nigras maculis fpectatu jucundiffimis infgnitas: Nam primæ numero feptem folidæ \& quodammodo cartilaginex albæ funt, appendices cinnabaris inftar rubefcunt, has aliæ maculis luteis perornatæ, literam L.figura exprimentes fubfequuntur,ficque difpofitæ funt, ut in quibusdam feptem, in aliśs fex, in quibufdam quinque tantum appareant. Ultimx maculas albas habent. Cauda maris decem, fæmellæ duodecim pennis conftat. Inieriora fi fpectes, ex Anatome habeto. Inteffina in diffecta duos dodranteslonga fuiffe, abfque revolutionibus \& anfractibus, ideo celerius fæces excernebat.Ventriculum in medio epatis velut reconditum, exiguum, carnofum \& duro callo obductum ; tunicam in eo fubftantix diverfix, uvex quoad colorem non diffimilem, duriffimam \& quafi cartilagineam; Iecur in duas partes xque divifum, pro fua magnitudine maximum. Lienem exiguum, linguæ humanæ figura, oblongiufculum: Pericardium duplicatum, \& veluti pinguedini merfum:Pulmones qui in omni fére avium genere ad medias ufque coftas protenduntuir, colli \& dorfi vertebris \& coftarum duntaxat fuperiorum principiis adhærentes;afperam arteriam in principio laxiorem \& ovalem, mox anguftiorem, tandem latiorem iterum: Linguam duram \& offeam, \& in

extremo, ubi velut alas quafdam habere \& fagittam præ fe ferre videtur, bifidam, \& quafi in duas aciculas divifam. Os byoides, quod reliquis animantibus pro implanta* tione lingux datum eft, $a b$ offe occipitis ad latera foraminis, per quod fpinalis medulla à capite ad dorfum tranfmittitur,originem fuam deducere, \& ubi ad radicem lingux conjungitur, acutifimum angulum efformare videbatur. Ejus medio afperæ arterix caput infertum erat. Couli intus adeo magni, ut cerebri ipfius magnitudinem fuperare viderentur. Cerebrum fphæricam referebat figuram; \& fuperiores ipfius ventriculi ad mediam regionem capitis collocabantur.

Locum fi attendas, Bohemix quidem pe- Locus. culiaris eft, fed migratoria eadem. In Italiam delatx, in Placentino \& Mutinenfi agro, ubi XL. fimul capiebantur, morabantur ; in Ferrarienfi, nullæ vifebantur, forte quod terræ motum ibi futurum præfenfiffent. Anno I 552. inter Moguntiam \& Bingam, in tanta copia apparuere,ut, qua tranfvolarent, ex earum umbra, veluti nox induceretur.

ViCtus ipfis uvæ, liguftri, juniperi, Cy- Viaus. norrhode baccæ, pinex nuclei, uvæ paffe, poma, amygdala. Baccas hederæ, carnem, \& frumentum nonnifi famelicx attingunt. Volant pernicifime \& gregatim.

Vox earum erat ziziri, unde forte zinzi- $V$ ox: vellæ quibufdam dicuntur. Facile cicurantur.

Cibum fibi invicem offerunt, mas fominx, fomina mari. Caro faporis eft in cibo gratiflimi.Nec ergo vere effe Pica videtur, quamvis jam, quia de genere non conftat, inter eas repofita fit; quia linguam latam non habet, nec insendiaria Plinii, quia nec in incendiis nafcitur, nec carbones apportare vifa eft, nec avis Hercynia Plinii, quia ei noctu lucere non competit, utut in Voitlandiæ fylvis, quædam Turdi minoris magnitudine, colore partim cæruleo, partim aureo, quam croceo, talis effe dicatur; Nec avis Novis Plinii, quia columbo minor eft. Nec denique Merops Ariftotelis, qui nec apibus infidiatur, nec vermibus yefcitur.

\section{A R T I C U L U S III.}

\section{De Pica Brafilica \&5 Rbinocerote ave.}

D Ica Brafilica, aliis à roftri magnitudine Ramphaftos, Hipporynchos, \& Burynchos, aliisBarbara \& Piperivora dicicur. Magnitudo ipfi inter Picam \& Merulam media. Caput pro corpore majufculum \& crafliufculum \& atrum. Roftrum duos palmas longum, unum latum, ferratum, \& velut è fquammulisquibufdam compactum, fubstan- 


\section{E A V I B U}

fubftantiâ ad inftar membranx tenuifi- cauda de ovo exire, feu quod, fi reliquamx, oflex, fplendid $x$, levifim $x$, cav $x$, atque aëris intus capaciffimx, unde Naribus carere crediderim. Oculi in medio capite, illique majufculi. Collum, dorfum, atque alæe nigrx. Pectus aureo colore cum quadam rubedine prope initium micans. Venter \& foemora cinnabarino colore veftita. Cauda nigra, \& in extremitate infigniter rubefcens.

Victitat pipere, quod avidinime devoratum, inconcoctum \& crudum adhuc ejicit. Incolx, vim ea ratione piperis domitam credentes, recenti illud prxferunt.

RHINOCER os à cornu, quod in fronte geftat, ita dicitur. Occifa in ipfo volatu tum effe dicitur, cum Turcas Chriftiani ad Naupactum fuperarent. Caput erat duorum propemodum dodrantum, cirrhis nigris, altis, deorfum fpectantibus ornatum. Roftrum quatuor fere dodrantes longum, inftar arcus cujufpiam recurvum.. Inferior pars tota exluteo albicabat ; fupina verfus caput colore miniaceo, reliquum ex luteo, albefcat. Cornu è fronte enafcebatur, \& fupinæ roftri parti adhærebat, prope frontem palmum unum latum, in fine recurvum, colore fupera \& infera parte miniaceo, media luteo, \&c. Fit talium Avium apud veteres mentio. Nam \& Hefychius Rhinocerotem avem in Ethiopia reperirifcribit; \& Tragopanda Plinii, Aquila major, capite phæniceo, cornibus in temporibus infignitur, \& Tragopa Golini in capite arietinis cornibus armatur ; \& Pomponius Mela ejufmodi aves Tragopremanes appellat. Et Cardanus avis memiSalig. Ex- nit Aquila majoris, ex luteo \& rubro fplen-

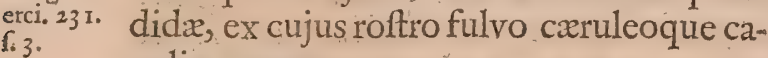
puli parentur.

\section{A P : U T VII. De Loxia.}

Defcriptio. T OxIa feu corvi roftra, Trogon Plinii Roberto Conftantino effe, videtur; ignota fine dubio Ariftoteli. Magnitudine parum maximum vincit. Roftrum habet contra omnium avium morem ab utraque parte recurvum, craffum, \& admodum robuftum. Unde ipfi nomen eft. Colorem fingulis annis hyeme inprimis, mutat, ita ut nunc ad viridem, flavum, nuinc ad rubrum \& cinereum vergat. Rubere primum folét pectore, collo, \& ventre, deinde flavefcere. In vertice, cervice, \& circa oculos cxruleus apparet ; in cauda \& extremis alis nigricans, crura rubicunda.

Iocus. Plurima Germanix loca incolit, in Italia rarius videtur.

Viaws. Victitat feminibus cannabis, nucleis abietum, \&, ut quidam produnt, cadaveribus. Voracifima autem eft.

eneratio. Nidificat in abietibus, \& verifimile eft à rum more prodiret, exitus à roftri curvitate impediretur; feu quod, củm media hyeme nafcatur, fubinde $a b$ ambientis inclementia, calor animalis fuffocaretur. Hyemali tempore antat,$\&$ quidem fuaviter, in $x f t a-$ te abftinet. Caveis inclufa Pfittacorum more furfum atque deorfum reptitat. A potu pocillum roftro fi poteft abjicic imaginem forte fuam in aqua confpicata.

\section{T I T U L U $S$ VII.} De Noctuis:

\section{$C$ A P U T I} De B̈uboné.

A Bfoluta Avium diurnarum Carnivo- Aldrov 1:8 rarum hiftoria, ad Nocturnas defle- $\cos$. ctendum eft. Hæ vero ob cæfios oculos y $\lambda$ aurérroy, dicuntur, \& magnitudine inter fe differunt. Oculos magnos amplos \& cæfios habent. Non folum in tenebricofis montium \& rupium cavernis, fed \& in cavis arboribus, defertis ædificiis, domorum, templorum, \& turrium tectis latent. Inter duo denique crepufcula, (de noete parum Arit:H.A? aut nihil vident; de die excedéns fenfibile ${ }^{\text {1.g.c.j.j } 4_{0}}$ fenfum lædit) lacertas, fcarabxos, apes, vefpas, mures, hirundines, interdum lepufculos, \& cuniculos rapiunt. Numerantur autem inter rapaces nocturnas. $B u b o, A / 30$ five Otus, Scops, Aluco, Vlula, Noctua, Strix, Caprimulgus.

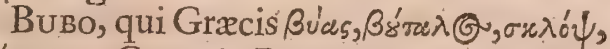
B'́øQ; ; Goropio Becano, cum Ariftotelis Cyminde, Chalcide, Hubride, \& Ptyn* ge, idem : Ariftoteli forte $A$ fcalaphos, $O$ mnium nocturnarum eft maximus, nec $A$ - Aritt. H:A quila minor. Corpus ipfi breve, \& propter ${ }^{1.8 . c_{3} .3}$. caudæ brevitatem veluti decurtatum. Cor- Geogr.1.1. poris tegmen plumeum ferrugineo feu obfcuro quodam xris colore eft. Maculis nigris fparfim \& incerto ordine refpergitur. Caput habet, adeo grande, ut ob ejus magnitudinem pullus à cauda primum in lucem prodire credatur ; frontem orbi- Plin.H. N: culatam feu teretem, plumis velut auri- lino. c. 16 bus eminentibus in regionibus prout in Oto, infignitam. Cavernas ad auditum patulas, hocce pennarum ornamento ob magnitudinem tectas. Oculos maximos; \& qui igneo fplendore, ingenti magnitudine, \& truci obtutu, terrorem afpectantibus incutiunt. Roftrum aduncum; Collum pro fua magnitudine perbreve; Ungues Aquilinis majores; crura brevia. Cujus Gefnerus iconem exhibet, magnitudine Gefrerus Anferen vincebat. Alas habebat ad tres in Ornititio dodrantes longas. Caput magnitudine \& forma felinum. Pennæ fupra utramque aurem nigricante, \& tres digitos fubrigebantur. Cujus Aldrovandus, in multis ab illo

D 3 differe 
Aldrovan- differebat. Nam huic quidem etiam ad ex-/ tilis. Cor ejus, fi impofitum manmæ mu- Plin.H.N.

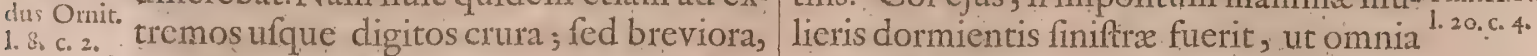
graciliora, nec ita fupra genu torofa. Color ei erat per totum corpus ex cinereo ferrugineus, in portore potifimum, ubi etian fubnigris macúlis per longum dutis, promifcue refperfus erat. Dorfum $8 x$ alæ è ferrugineo magis fucceffebant. Et cum ille Gefneri in fingulis totius corporis plumis magis variegatus, \& tenuibus quibusdam lineolis, transverfin ductis Accipitrum \& Anatum inftar, minatim diftinctus fuerit : \& univerfo corpore magis vero dorfo \& capite, maculas quasdam incerti ductus, lituris nigris, craflis, \& quodammodo figuratis geflerit: hic in alarum pennis majoribus, \& cauda, lineis fubnigris, transverfis, largiufculis, diftinguebatur, quæ ita efformatæ in cauda prefertim fuere, ut fingula latiores fuperne \& inferne inftar fim briarum triplici ordine difpofitx, aliis fubtilioribus, clauderentur.

Locuss. Locum fispectes deferca incolit, nec tanPlin. H.N. tum defolata, fed dira etiam \& inacceffa. Inter fepulchra etiam diu noctuque verfatur; aliquando propter mures, \& juxta horrea reperitur. Coetum aliarum avium Ovidius in fugit. Hinc folicana \& devia vocitatur. Epitt. Nidulatur in altiflimis rupibus, ne foetum injuriis exponat, \& ut fecurius ad prædam evagetur. Ovum ejus Plinii tempore vix Plin.H.N. vifum eft, noftris non adeo rarum.

1. 29. c.4. Cibus ipfi carnes avicularum, cuniculoAritt:H:A. rum, \& leporum. Tantum pred $x$; dum pul-

1. 8. c. 3. los educat congerit, ut \& venatoribus fatis lucriadferat. Templa noctu frequentare, ut fe oleo ex lampadibus ingurgitet, vix credi poteft. Noctu autem victum quirit, \& fubluftri crepero gaudet in vefpere. Plin.H. N. Unde Nocticanicana, \& $x$ noctis monftrum 1.10.c.i2. vocatur. Si diuturno tempore prodeat, ab aliis avibus feu vifu infolens, convellitur. Roboris eft magni. Vifus \& feroces canes abegiffe, \& cum Aquila depugnaffée. Si fe viribus imparem fentit, in dorfum fupinus procumbit, unguesque ac roftrum fic adverfum erigit, ut hoftium nullus accedere audeat.

volatus. Quantum ad volatum vix movet natas. Metamor. per inertia brachia pennas, nunquam voPlin. 1. 10. lat quo libuit,fed transverfus. Hebetes ipc. 12. fi interdiu oculi, minus tum quam Noctua

Plin. 1. c. videt. Non cantu aliquo, féd gemiru vocalis eft, \& bubulare, quod Gracis eft $\beta u^{\prime}-$ ¿esv, dicitur.

V fus. . V Jus ejus eft, tum in Aucupio. Nam \& aviculæa dum eam interdiu circumvolant, \& percutiunt, facillime retibus capiuntur; \& Bellon.1. 2. Gailli ejusdem opera, Milvos venantur: de Avibus tum in cibo. A quibiusdam enim editur:
cap. 28 . tum in Medicina. Cerebrum vulnera cum adipe anferino glutinat; cum aphonitro fcabiem fedat. Sanguis afthmaticis eft un fecreta pronunciet; fi axillæ, ut canes obmutefcant, efficere; fed falfo tradunt. Creditur Agripp $x$ Rom $x$ captivo; primo Tofeph.1.s. regnum cum libertate, poft mortem por- ${ }^{\text {Antiq. c. } 8 .}$ tendiffe, Chingis Canum ab hoftibus victum, quafi fervaffe, ideo à Tartaris honorari, ferenitatem denique fi totam noctem cecinerit, portendere.

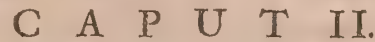 De. Afrone fen Oto.}

Sio feu Otus forte $a b$ auribus, qui Défcriptio. Alexandro Myndio apud Athenxum Lagotia, quod aures leporinas habeat; aliis apud Ariftotelem Nyaticorax; quia Buboni peromnia, magnitudinem fi excipias (mugnitudine columbx effe fcripfit Athenæuis, quod de maximis intelligen-Athen. lib. dum, eft fimilis ternos quoque digitos habet anticos, pofticum unum (male noctuæ fimilem Plinius dicit, male \& Gaza Plin.H.N.

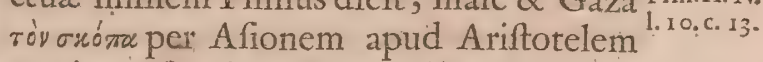
vertit ; \& Oppianus; cum A thenæo Otum Oppianus cum Otide confundit) Bubonem fequi- in Cyneg: tur. Aldrovandus binos defcribit. Priori Aldrovancaput erat auribus velut cornibus plumeis dus Ornit. infignitum, cinereobxtico diluto \& nigro ad fupercilia ufque \& nares propemodum colore varium. Facies tota anterior, è cinereo candicabat, minutifimis plumulis veluti pilis tota obfita. Corpus totum è cinereo feu leucophro ad ferrugineum dilutum vergebar, maculis ubique fufcis confperfum,tam majufculis, quam punctorum inftar minutifimis. Per ventrem notæ fufcx in longum recta ducebantur, \& in acumen definebant \&c.

Alterum femipalmum in longitudine minus, Fulvum Aldrovandus appellat. Toto propemodum anteriori corpore maculas fufcas; in longum protenfas; \& fingulis plumis albicantibus decus fatas, ut crucis aut lilii Francici referrent figuram, habebat. Crura \& pedes ad ungues ufque hirfuti, uti totum corpus, flavefcebant. Caudo infra alartim longitudinem, uno fere digito erat. Defcribit \& Bellonius tertium, au-Bellon.1.8. ribus patulis, cruribus ad ungues pilofis, $\mathrm{fa}_{2}-\mathrm{cap} \mathrm{z}$. cie Aluconi fimili, ventre maculis nigris variegato. Cauda alarum longitudinem $x-$ quante, ulula multo majorem, qui vel fuperiori eft finilis vel Ariftoteli incognitus \&x Arvernis in Gallia montibus peculiaris fpecies,dicendus. Cranii Anatomen vide in Aldrovando. Auris \& oculi hifce verbis idem exequitur. Avi huic fupra aures cutis in longum producitur complicata, rugofa, fponte concidens, \& meatum eo loco occludens, inftar membranarum, qux tamen in amplifimum, fi voles, ambitum 


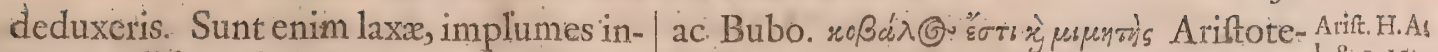

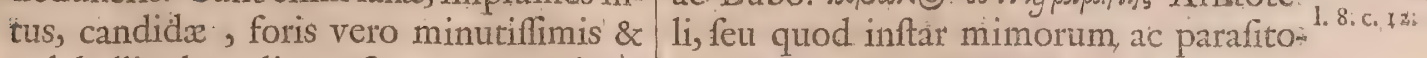
pulchellis plumulis confitæ, \& qux orbem rum collum contorquendo nunc in hanc, venuftum in marginum ambitu conftiti- nunc in illam partem ridiculos \& mimicos unt. Non alteri rei magis appofitx, hafce geftus edat, feu quod imitattione gaudeat: cutaneas valvas, quam branchiis pifcium Quicquid facientem aucupem cernit, compararim. His apertis, auditus fora- idem quoque agit. Stant illi èregione, \& Athen. 1 g g; men amplum ac patulum in medio apparet, multis anfractibus inftar humani tortuofuim. Oculus inventus fuit fubftantia quadam cartilaginea, velut capfula circumclufus, non tamen undique. Nam infra in parte oculi pofteriori haudquaquam membrana hæc fubfternebatur, fed circumquaque ad latera, à qua circulus fupra totum oculum exporrigebatur, ante quidem hâc membrana anguftaerat, intra vero \& qua magis ad pofteriora vergebat, dilatata: Oculus ipfe ante orbicularis erat retro feffilis, \& compreffus, longe quam vel in medio latior. Refecta cornea uveam $\mathrm{ab}$ illa intus plurimo nigrore tinctam \& veluti atramento perfufam, quippe quæ etiam humores fubjectos digitis contrectata tingeret, obfervavi. Huic in orbem alia tenuiffima pellicula inftar annuli circumponebatur, crocea, feu aurea per totam fubftantiam, ita uvex connata, ut nullo modo integra ab ea fecerni poffet. Hujufmodi fane nullam, quod equidem fciam, in aliis animantibus repeririputo. Duæ igitur hæ membranæ coloribus diverfis tinct $x$, \& per corneam transparentes, horrendum illum nocturnarum avium oblutum faciunt; concurrentibus fimul è nigro $\&$ croceo exadverfo radiis \& velut flammæ è filice excuf$f \mathfrak{x}$ micantibus. Humor cryftallinus minime durus aut folidus erat, qualem in Aquilis \& aliis obfervavimus, fed tener \& molliculus, utpote qui facillime vel fua fponte diffolutus refecta cornea fimul cum aqueo humore efflueret.

zocus. Locum fi attendas, montes plerumque inhabitat, locaque edita. In montibus A.rvernix copiofi inveniuntur, \& in Italia in monte Plumbicio pafim funt obvii. In Cilicix campis de die inter Ambrofix plantas abditum Bellonius invenit, cum tamen eo loci,ne ad quartum quidem milliare, arborem ullam nafcentem videre liceat. Nidulatur in arborum cavernis, \& Arit.H.A. foraminibus Ariftoteli \& Plinio migratorius 1.8.c.ing. eft. Nam cum Eingulaca, matrice, \& Cyn1.ro.c.23. chramo, Coturnicibus hinc proficifcentibus ducem effe fcribunt.

Volatus o Levi facilique volatu fertur. Vocem edit Vox: . ei fimilem, qua homo frigore affectus reclamare folet hu, hu. Repetit eam folis occafu inftante, aliquanto intervallo interpofito, fonoram, tanquam fi fiftula tenui ederetur. Cum à quopiam laceffitur, fibilum aut crepitum emittit, qualem felis folet. In pugna eadem ratione fe defendit vifcofo quodan Pharmaco oculos inungurt, illud poft in pelvibus relinquunt $\&$ abeunt. Accedit Otus \& oculos fibi conglutinat, ficque cápitur. Ariftoteles eum Arit.H:A in altero aucupe intentum, $a b$ altero cir ${ }^{1}, 8, c_{0}, z$. cumveniri reliquit. Magi recenti Afionis felle glaucomata curari dicunt.

\section{N.B: Efl ङ genus exoticum Otid de quo vide} in Mantifsa. Num. 2.

$$
\begin{aligned}
& \text { C A } P \text { U T III. } \\
& \text { DeScope. }
\end{aligned}
$$

Cops, Alexandro Myndio abfqués a- - Attenn. i. $\checkmark$ pud Latinos nondum invenit nomen, quamvis Bellonius Ululam ex ipfo faciat. Bellon.la: Gracis velà voce inepta, vel quod '́v o:

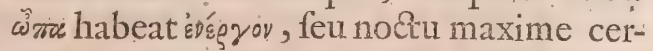
nat, vel quod varietate gefticulationum, Euntat. in quibus naturaliter utuntur homines, $\sigma \% \omega-$ Odyfi. 5 : \#óvrses, id eft, qui alios deludere folent, referat, fic dicitur. Habet ferecum omnibus nocturnis aliquid commune. $\mathrm{Cum} \mathrm{Bu}$ bonibus \& Otis, quod auritus fit. Cum Ululis \& Alucone, quod pedes utrinque in æquum digitorum numerum difpertitos habeat. Cum Noctuis, quod pedum compofitione, figura; colore denique \& magnitudine, his quam aliis propior fit: $A b$ Athenæo \&r Eliano ita depingitur, ut minor Noctua effe, in colore plumbeo albicantia puncta habere, \& ab utrisque temporibus duas pinnas fubrigere, dicatur.

Duplex apud veteres ipforum genus. Alii Generditio. funt vocales, qui omnibus temporibus pa- Athen.lig:

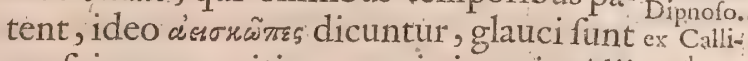
ac efui propter vitium carnis inepti. Alii macho. muti qui autumno interdum apparent, nec plus uno vel altero die commorantur, $\mathrm{Sco}_{\mathrm{C}}$ pes abfolute dicuntur, \& ab Aëifcopibus craflitie differunt, turturi \& palumbo fimiles. Tot \& apud Neotericos differentix. Vna Italix frequens, quam iffi Chiuvina vocant. Altera huic apud Germanos fimilis, paulo albidior, cauda \& auriculis longioribus. Illa prout ab Aldrovando defcribitur, noctua eft minor, palumbo par, omnium fere nocturnarum minima, illam fi excipias, quæ Alaudam non fuperat ; \& rara eft. Caput ei teres plumulis coloris ubique plumbei veftitum. Aurium plumulæuna tantum pinnula conftabant, quæ in mortuo vix appareat. Totius corporis fuperficie tenus color cinereus eft, hinc inde nonnihil admixto, plumbeo, macu 
maculis albicantibus diftinctus. Majores alarum \& caudx pennas, maculx albx, transverfim ornant; minores reliquas omnes etiam liner in longum nigra fecat. Circa collum of alarum initium ruffo decore promifcue relpergitur. Pedes habet exiguos fufcos, ad plumbi calorem abfcurum accedentes, fquanimofos, depiles, in digitos binos anticos, \& totidem poiticos difpartitos, unguibus fufcis inftructos.

Generatio. De Generatione ipfius nihil exploratum Arit.H.A. effe fcribit Ariftoteles, nifi quod Favoniis 1.9.c.28. flibibus apparcant. Plinius amplius na1.10.c.49. fci negat, forte quod ipforum fatyricos motus, cum infident, plxrisque memoratos concipere mente non poffit.

Fox. De Voce fuperius diftum eft. Quod ei Athen.1.9. ex Athenæo potius quam Eliano dे Gyllio.

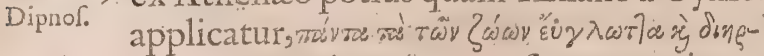

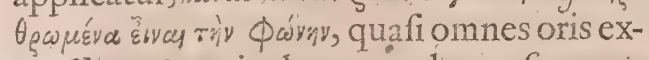
preflione \&x articulata voce longe fuperet; ad aves, quarum lingua latiufcula pertinet. Ridiculos fipe'exercent geftus. Cum enim colla retro agilia habeant, caput modo adducendo, modo protendendo, vertice nutando, humeros, jactando, \& faltitando, hiftriones imitantur. Unde Scops faltationis apud antiquos genus, quod $\& x$

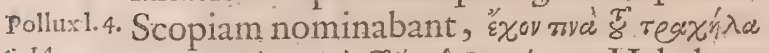

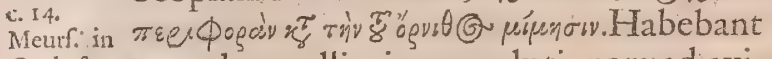
Orcheftra. quandam colli circumvolutionem ad aviFlli. H. A. um imitajionem. Perire mali Punici gra1.6.c. 46. um, Gyllius in Eliano addit.

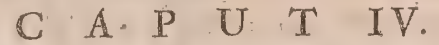 De Alucone Eु Ulula.}

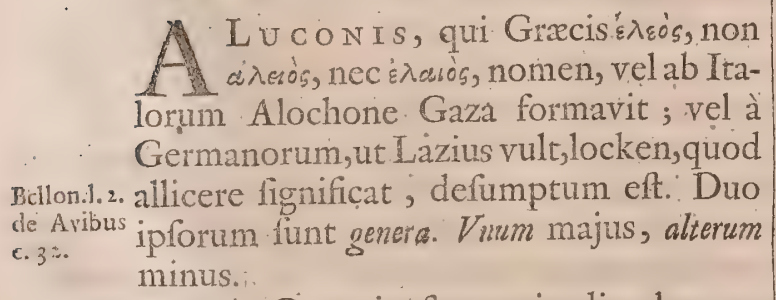
c. $3 \div$ minus

Aldrov.1.8 .. Majus Caponis eft magnitudine,hoc pecap. 5. A culiare habet, ut palpebram à fummo ocu1.8.c.3. lo ad imum adducens, conniveat. Auriculis caret; fed eortum loco coronam quandam è plumis confrudtam, qux faciem .tam, pinnulis fupra oculos fuperciliorum altorum modo, elevatis, \& utrinque per tempora nec non fub mentum defcendendo in orbem coëuntibus, flammei muliebris forma, habet. Roftrum ipfialbum. Oculi cavitatem profundam, à plumulis undique furrectis conftitutam, magni, \& toti atri immerguntur. Dorfum coloris eft plumbei, notulis albidis variegatam. Crura plumis candidis conteguntur, pedes duntaxat pilis. Incolit tam laco campeftria, quam faxa prexrupta, rimas turrium, \&z cavernas quercuan. Muribus \& aviculis \& interhas picis vitititat. Quod forte animalculum copit, Arir.H.A. deglutit, integrum. Tam ampla enim ei 1. 8. c. 3* gula, ut bolos ovo majores integros transmittat: neque quicquam cibi fim mit antequam offa, pilos, \& plumas rejecerit. Transverfim, Ardearum more inter volan dum fertur.

Minus fimili cum majore maculorum diverfitate variegatur , domefticam columbam magnitudine non excedit. V'ertex capitis, collum, dorfum, alæa ad pennas remiges ufque plumis veftuntur ab initio prope radicem cinereis obfcura; reliqua ferruginies dilutis. Anterior capitis pars, plumulis candidis informam flammei cinCta videtur, quas circulus luteus undiquaque ambiens olaudit. Oculi nigerrimi verfus interiorem canthum plumeis luteis obfidentur.

Tibie \& pedes villis horrentes nonnihil rubent, binis ante \& totidem retro digitis inftructi. Vnguibus armatur longis, validis, acutiflimis, \& aterrimis.

Vocem noctu edit adeo terribilem, ut Vox. pueris \& fominis terrorem incutiat. $R_{a}$ rior multo confpectu eft, quam major. Vlula flammeata Gefneri eadem cum Alucone.

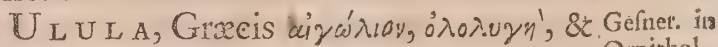

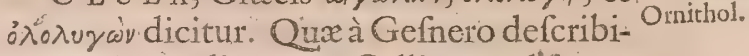
tur, magnitudine erar Gallinæ, velfupra, colore ruffa, vel nigro refperfa. Roltrum breve $8 x$ aduncum albicabat. Oculos habebat magnos nigros, pupillam obfcure ruffam, pinnulas inter oculos \& roftrum multas, denfas, cinerei fere coloris, margines palpebrarum rubicundi, membrana nictanti fuperne abducebantur. Collum erat multum retro agile. Crura albicantia pundtis confperfa lividis, hirfuta ad pedes ufque. Pedum digiti bini ante, totidem retro. Quam Aldrovandus difcribit, \& inter ulu- Aldrov 1.8 las, quod vocem non flebilem ejulando, capit $\sigma_{c}$ fed Gallinaceorum haud abfimilem roftro frendendo, ediderit, reponere metuit. Caput, dorfum, alas, caudam colore cinereo, maculis albicantibus ac nigris diftinctam habebat, fub ventre albicabat, \& nigris maculis variegabatur. Capite erat valde magno, tereti, enormiter crafío, admodum plumofo. Oculis ex toto nigricantibus, \& plumulis albis undiquaque in orbem cinctis, in quorum ambitu, ad palpebrarum oras lippientium, inftar rubefcens circulus conficiebatur, fuperiori tantum palpebra inter nictandum ocuilus contegebatur. Roftrum erat fubvirefcens; \&c.

Colit \& campeftria \& faxa, 860 cu (G) eft, Locus \& feu gemeni cibi. Fruges in humilioribus colli- Cibus. gic. In excelfis rapinas agit, 8 carnes in ci- 1 . 9 . c. ${ }_{17}$ bum parat. Picas venatur: fed \& colorem Arif.H.A. (fubeft mendum, nec nota cuiquam avis) Idem. $\mathrm{H}$.

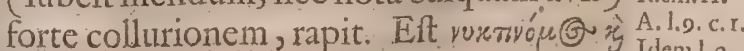
ijuseas c.17. 


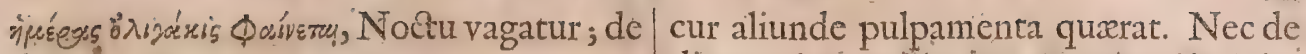
die raro apparet.

Generatio $\quad$ Parit quaternos, fi bene Plinius AriftoPin. H.N. telem intellexit. Nam ne de Ætolio MilAitit.H.A. vo res fit verendum eft. Vox ejus eft ulula1. 6. c. 6. re, feu moefta \& flebili voce plangere, idApul. 1.2, 2, que vefpertino tempoíe.

Ilin. 1. 29. Fel ejus predicatur ad albugines, fuffu$V \int_{\text {fus. }}$. N. fiones, \& caligines. Adeps ad claritäten.

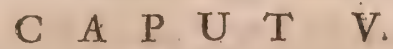

\section{De Nocitua in pecie fic dictd.}

Geniratio TOctua Latinis quod noctu canat \&

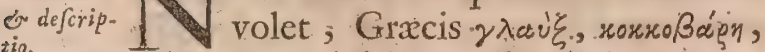
Hefychius reim, \& $\tau$ rot dicitur. Duplicis ipfarum in Lex. generis mentionem faciunt Authores, $M a-$ joris nempe \& Minoris. Utrique collum brevè, gulx pars inferior paulo latior. 2 đro $\phi \cup \alpha$ Arir:H.A. $\delta_{\varepsilon}$ feu appendices infra ubi inteftinum defi-

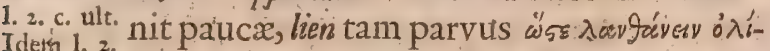

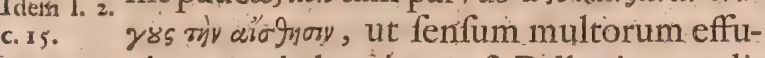
Albert. 1. giat. Cauda brevís, \& fi Bellonium audiBellonius mus, pedes pilofi. Capitis vertex ex plumu1. 23 . de A-larum ibidem pofitu, vèluti introrfum exvib. c. 32. cavatus. Quxab Aldrovando defcribitur, Aldroran- Orni- erat columbæ magnitudine, capite majufthol. 1. s. culo fuperne depreffo. Ocislis magnis \& c. 7. glaucis. Roftro longiufculo, dilute flavo, carpore toto plumis partim bætico, partim albo diftinctus. Cruribus plumofis, \& ad pedes ufque hirfutis, coloris è cinereo bxtici. Pedum digitis fubfufcis, cinereis, implumibus. Quam Germani faxatilem nominant, tota parte prona fufci, modico ruffo permixti, \& albicantibus maculis diftincti eft coloris. Crura \& digitos peduin habet hirfuta, plumis albidis. In extincta roftrim fuperius riubebat, cum prius in viva rubere non videretur. Inter oculos \& roftrum pennula quxdam ceu pili aut barbulærigent. Locum fi attendans, in Creta nafci negat
Plin.H.N. Plinius, illatam mori tradit, nec in Alpinis 1. ro.c. 29. Helvetix regionibus inveniri fcribit. E Gallia Cifalpina, Longobardia, \& GermaApótól. nia ad Rhenum eò advehuntur. In Attica Cent. 6. plurimx. Unde Noctuas Athenas. SaxaProv. 4r. tiles montana \& faxofa incolunt. Ideo ad frigus arcendum plumas cruribus \& digitis natura induit:

$V$ ictiss. Cibus ipfis vefpr, apes, lacertæ, mures, Arift. H.A. quarum cicuratæ, in domibus etiam venaCrefent. tionem exercent, femel faturatx trium

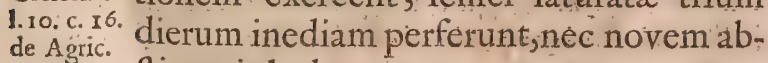
de Agric. Atinentia læduntur.

Generatio. Quantum ad Generationem, quod de Bu-
Plin l. 10. P.N.c.17. bone, id \& de hac Plinius dicit, folam inter uncungues, \& carnivorás non coecos parere pullos, Euftathius \& Varinus falfo tradunt; nec verius, cum formicas à fuis pullis abigere cupiunt, vefpertilionis cor in nido tanquam amuletum habere, Oppianus reliquit. Si enim ipfa lepus eft, die omnino crecutire verum; nect própter in fitam vim.igneam tenebras penetrare, ac luna filente videre, quod Euftathius, \& Varinus fcribunt. Die exorto quafi fplendore vifus èjus hebetatur, \& quafi quibus- Aitbro i.s. dam errat in tenebris. Sicca nimis \& te ${ }^{2}$ Hexan. nuis humoris fubftantia facili negotio diffipatur. Noctu, quia aẹre, qui vilionis incdium eft, nion illuminato,objectx colorum fpecies non exprimuntur, fi propius accefferis, haud loco fefe movebit. Maderata Bellon.t. lux quia Noctux conveniens, ideo Yygéuses de Avibus

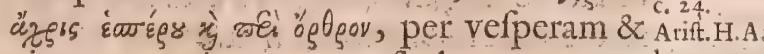
circa matutinum crepufculum venatur. 1.9., c.34. Sonum edit duplicem, unum tou, tou, alterum vocant cucabare. Ariftophani $\varkappa$ :

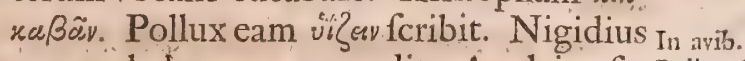
novem habere voces prodit. Apulejus fe- Pollux Orum \& intortum ejus cantum vocat. nom. 1 .

Eft etiam faliatrix, \& corpus \& cervicem Plin lo to. frequenter in orbem contorquendo, nunc ${ }_{\mathrm{A}}^{\mathrm{C}_{1}}{ }_{\mathrm{pul}}$. torvo \& fixo obtutu hominem afpicit, nunc 1.3 . Milecapite huc illuc acto fcurras \& hiftriones fior: imitatur. Luce vagantem aviculx reliqux Crefcent. fturnatim admirantium fpecie primo cir- Agricult. 1 . cumvolitant, mox impetunt. Ab his cir- plin. 1. 1. $0 \%$ cumdata, refupina pedibus repugnat, col- H.N. c.s7\% lectaque in arctum, roftro \& unguibus tota tegitur.

Inimicitins gerere dicitur cum cornice, Inimicitia. feu quod fibi ova meridie abfumat, feu Aritt.H.A. propter aliam caufam. Lucretius fane cor- Lucretius nices metu Noctuarum in Athenarum l. de Natumœnibus unquam volaffe negat: cum or chilo, ejus ova itidem exedente; cum Pi- Aritt. 1. g: co Garrulo, \& ovibus. Contactu frondium H. A.c. x. platani torporem contrahere, fic à ciconiis à nido fubmoveri, fabulatur Elianus. A uxiliatur ei contra aviculas collegio quo- Plin.1. ro. dam naturæ paffer, bellumque partitur. H.N.C. 170 Vfus captx tum in aucupiis, prout in Oto $V$ fus. dictum eft: quod genus aucupii hodie, à pipatu avium circumvolantium noctuam Pipatam vocant. unde Pipare quod decipere, tum incibis, apud tenuioris fortunæ homines; tum in Medicina. Nam cibus aqua in qua Noctua lavit perfufus; Gallinarum pituitam pellit. Sangtis inter pfilothra numeratur, jecur parotidas fanat. Anginis cerebro fuccurritur. Ebriofis ova per triduum in vino data, trdium ejus adducunt.

Prafagia fi refpicias, fi nemore deferto Prasag frequentior in urbibus apparuerit, fterili tatem ; fi vefpertino crepufculo de fuis luftris citius pro confuetudine egreffa, plurimum concubaverit, pluvias ; fi pluvia durante, ceffaverit, ferenitatem, Aratus in polliceri creditur.

NB. De Norture genere exotico vide Manphanome. nis. tifsam. Num, 2. 


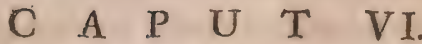

\section{De Strige \& Caprimulgo.}

Defriptio. STrtx quxnam fit avium, non conftare 1.r 1.H. N. $S$ arbitratur Plinius. Ovidius eam brevi c.39 compendio defcripfit, dum feribit

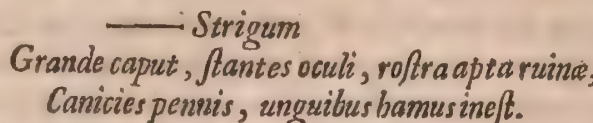

Ubera eas infantium labris immulgere, fanguinem in cunis noctu exugere, imo \& dilaniato unguibus corpore mortem affer-

Ovid 6. re,credidit fuperftitiofa Antiquitas. Ifido-

Ifiodor. I. rus vero propriis pullis lacteum humorem 12. inftillare, eofque ultra modum amare proOrigin.c. didit.

Vox. Vox ipfarum proprie ftridor eft Latinis. Omen femper trifte habebatur.

1. 8. Ornithol.c.8.

Aldrovandus huc nocturnam quandam avem refert, qux habebat caput magnum, rotundum, anteriore parte plumulis exiguis, in orbem velut flammeum pofitis exornatum. Oculos grandes cum iride dilutè flavo ac pallente, pupillas maximas, \& vehementer atras. Roftrum corneum, fufcum. Pennas univerfi corporis ferrugineas, maculis fufcis in remigibus tranfverfim diAtinctas. Caudam palmo fere alis longiorem. Crusa ad digitorum ungues ufque inftar pedis leporini pilofa. Digitos pedum binos ante, totidem retro. Magnitudine erat Afionis.Dicebatur caprarum ubera exugere.

Defcriptio: CAPRIMULGUS etfí fpecie à reliquis multum differat; nocturnis tamen, ratione vifus, accenfetur. Græcis A'ryoy' $\lambda$ ys

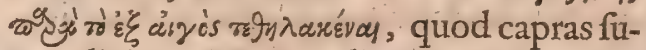
Arit.H.A. gat, dicitur. Magnitudine eft paulo major 1. .. c. 30. quam Merula, minor quam cuculus, feu ut

H.N. c. 40. Plinius, grandioris Merulæ afpectu. Cujus iconem Aldrovandus exhibet, erat cuculo ita fimilis, ut nifi inufitata pedum,crurumque exilitas $\&$ brevitas cum diverfa conftructione obftitiffet, is idem effe crederetur. Caput habebat vertice longo \& compreffo. Oculos grandes, iridem \& pupillam nigerrimas. Roftrum vix pafferino majus, modicum aduncum, plumulis tanquam pilis quibufdam fuperne ad nares $\&$ inferne fub mento, ornatum, \&xc. Quam Gefnerus exhibet, roftrum habebat aduncum, \& tibias plumis obveftitas.

Lockss. Degit in montibus circa mare inprimis Aritt.l.c. in Creta, propter viciniam ftabulorum quibus capræ includuntur. Intrant namque ifti fures nocturni paftorum ftabula, caprarumque uberibus advolant, propter fuctum lactis, qua injuria uber emoritur; capræ, quas ita mulfere, cocitate percutiuntur. Adeo terribilem clamorem habent, ut etiam audientibus pavorem incu-

Arift.l.c. tiant. Duo aut tria cum plurima ova pariunt. De vifu ita Ariftoteles: ह่ร s'

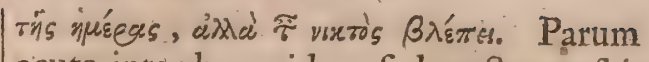
acute interdum videt, fed noctu perficaxeft.

\section{T I T U L U S V III.}

\section{De Carnivoris medice naturc.}

\section{C $\quad \begin{array}{lllll}A & P & U & T & I\end{array}$}

De Vefpertilione.

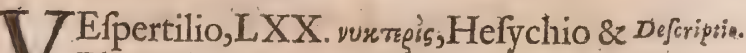
Phavorino $\phi a ́ \lambda x \eta$, Phili vvrrá̀ $\omega \psi$ \& $\phi i \lambda \varepsilon^{\prime}$ шाє९), Victorino Avis forex, Vallæ femimus, Platoni in ænigmate, Avis non

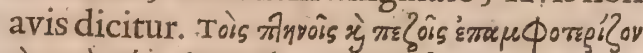

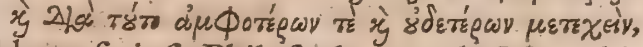
bene fcripfit Philofophus, male Macrobi-1.4. de parus, quatuor pedibus ingredi, \& inter qua tib. Anim. drupedes referendum, ut inferius patebit. Macrob. Color nonnullis fulvus, aliis niger, fubal- Saturnal.c. bus, cinereus. Magnitudo diverfa. Majo- Strab.1. is res in urbe Affyrix Borfippa, quam alibi, in Livius novo orbe columbas adxquant, in Brafilia Gomara monedulas, circa Vrabam turtures, in O- Hitt. c. 6r, rientali India, fi Pompilio Azalio credendum,tanti,ut illas tranfeuntes,alarum verbere profternant, multos etiam occidant. Caput quibusdam murinum eft, caninum aliis. Roftrum à cæteris avibus diverfum. $\mathrm{Na}$ res vituli inftar.Dentes XXXIV, in mandibula inferiore octodecim,fedecim in fuperiore Bellonius obfervavit, viginti quatuor in fingulis mandibulis duodenos, eosque ferratos, teretes \& longiufculos Aldrovan-1.9 0 mi dus utrinque in fuperiore mandibula fe- thol.c.r. nos, in inferiore feptenos quorum anteriores cæteris longiores; omnes valde albi, Clufius: Maxillas intus \& foris pilus oblongus, niger, obveftit. Auriculas interdum binas, quaternas interdum habet: fimilitudo eis Afininarum, \& fuperiores quadruplo funt inferioribus majores. Mamille foli volucrum datæ funt, lacte fola nutrit ubera admovens. Alas, qux pellitx, exangues Plir.H.N. quidam dixere. $A b$ armis incipiunt, \& 1. 10.c.65. per latera per axillas continuo ductu ad crura ufque feruntur, easque circumambiunt. Quatuor hreflexus, plicas feu articulationes habent, quibus alas inter volandum dilatant, \& contrahunt, mediis fuperiorum, (cubitos Albertus nominat) quique in plures alios deorfum flexas divaricantur, digituli finguli, unguículis hæmatis inftructi, quibus parietibus fe affigunt, annectuntur. In fupremis alis rudimenta, quxdam brachiorsm nervofa apparent, qux in uncum definunt. Pedes illi bini, in quinos digitos diffecti \& unguiculis acutis inftructi, finguli in medio, ac fi palmam efformarent, ampli. Innituntur inferiori alarum membranæ; atque ex ventre ad caudx, fi qux eft, latera, exporriguntur. Cauda quippe aliis nulla, ut recte Ariftoteles, A- 
de partib. fricanis murium inftar oblonga, \& quatuor Animal. I. digitos extra membranas alarum promiBellonil. i. niens. Aldrovandino mediis atque infimis de avib. c. alarum membranis fub ventre involvebatur, \& ad extremam earundem exporrigebatur apicem. Penis mari fat magnus; exertusque, qualis fimiarum eft, genitalis foeminx meatus pone podicem apparere folet. Quid fibi Plinius, verbis, Coxendix huic avi una traditur, velut, cum duo crura habeat, intelligivix poteft.

Locus. Locum fi fpectes, loca obfcura, cavernas, \& meatus fubrerraneos amant. Ideo \& in labyrintho Cretx inter Cnoffum \& CortiStrabo. nam, Borfippam, urbem adde, plurimi, \& Geog.1.16 in Appennini prope Puteolos, fpeluncis multa millia, \& in monafterio quodam Mifnix tanta, ut excrementorum acervis multi carri onerari poflint. Delectantur Plin. H.N. in viđa culicibus \& mufcis, fed \& lardum, 1. 10. c.61. candelas, \& alia pinguia arrodunt. Succidiam fxpe ita exedunt, ut in excavata fcrobe Atabulentur. Invadunt \& nudam corporis partem culicum more, \& fanguinem exugunt, in Dariene ita infeftatos Hifpa-

1. 6. dec. 3. nos, tabe contracta obiiffe, Martyr author eft. Gallinas, canes \& catos morfu aculeo in criftam infixo interemiffe addit. Solus Plin.1. cit. volucrum, animal tantum parit, $\& x$ foetus lacte uberibus admotus nutrit. Recens nati mufculis funt fimiles, glabri, infantis humani inftar; fed omnibus partibus abfo: luti, matris uberibus, cum primum enixa eft adeo tenaciter adhrent, ut ne à mortua quidem fponte decidant. Nullis fecundinis obtectos quidam putavere produci, 1. 2. de A- refellit Bellonius, qui plures vigenis fe in vib.c. 2. Pfeudolabyrintho Cretx prægnantes fecuifle tradit, has etiam mater devorat, dum proli nuper natx ob teneritudinem metuens, primo vel fecundo die ad paftum evolare prohibetur. Cum duo tantum ei natura ubera dederit, plures geminis uno partu non edit; quia vero magna eorundem Gemma interdum copia ingruit, haud male quidam Cofino- è putri etiam materia oriri, opinati funt.

$\checkmark$ oldsus. Volant mane \& vefperi potifimum; foeminæ fxpe geminos implexæ infantes; volatu ob timorem indirecto feu tortuofo,atque haud longe à terra femper. Volitatione feffi, hamis digitulorum, quorum in meHomer. diisalis rudimenta habent, parietibus faxis, Odyff. $\mu$. arboribus, aut cavernarum fornicibus fefe Odyf. a. appendunt, \& continuata ferie, ac veluti Alex. A- catena quadam inter fe cohrent. Melius phrob.1.r. de nocte vident; quia fpiritus ipforum vifo Ingeniwm rius tenuiffimus \& dilucidiflimus, per no stem modice incraffefcens, idoneus ad confpectum redditur, de die extenuatus, expandiur \&zevanefcit, ideo face vél gla dio volantibus objecto, decidunt.

$V_{0 x} \quad V_{0 c e}$ exili gannitum potius \& latratum canum imitantur, quam murium fibillum.

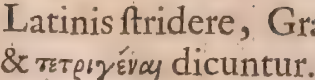

Homer.

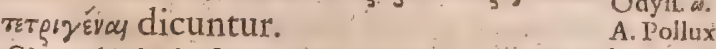

Singularis ipfis cum columbis amicitio, 1. 5. C.13: detinentur iftæ, fi caput vefpertilionis in Afretus. peris fummo columbarii faltigio fufpendatur. Inimicitias vero gerunt cum Ciconia, As l, r, de quia à folo illius contactu hujus ova fterilefcunt, ni platani foliis in nidum pofitis fibi caverit: Cum platano, qui præ foribus fufpenfus ne involent, prohibet; cum he dera, cujus fuffitu \& odore perimuntur; cum formicis, ad quarum nidos fi alas fufpenderis, nulla ipfarum egreditur; cum locuftis, qux locum ubi vefpertilio fufpen- Democrir. fus non transvolant.

Vfus vefpertilionum eff tum in cibis; nam $V$ fus. à Borfippenis condiebantur, ab incolis in 1 , I 6 . fularum Catigan \& S. Johannis eduntur, Scalig. Ex. ferventi aquæ immerfi \& excoriati edun- ${ }^{2}{ }^{23} 6$. tur, inOriente gallinas fapore vincunt; tum berg. Nain Medicamentis, toti præparati, bene fcir- turæ Exot rho, \& podagræ adhibentur. Sanguinem 93.940. trichiafi conducere, Archigenes \& Se- Galen. in renus credunt, Galenus \& Julius Alexan- Galen.1:4: drinus negant. Cor \& lingua hydropho- de Combiam inducit. Caput dextro alligatum pof.medic.s. brachio vigilantis fomnum impedit. $\mathrm{Ma}$ gicx revera vanitatis eft quod tradunt, fi ter circumlatus domui vefpertilio vivus per feneftram inverfo capite infigatur, amuletum effe, præfertimque ovilibus circumlatum toties, \& pedibus fufpenfum in fuperliminari.

\section{A P U T II.}

\section{De Strutbocamelo.}

Truthocamelus spogis Philoftrato \& Defctipsos.

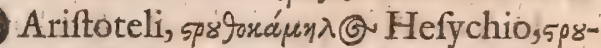

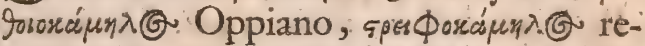
centioribus Græcis dicitur,melius Chæñocamelum, quia $\chi$ ĩva five anferem potius, quam sesfor five pafferem, nificum Scaligero, gallinam reddere malis, dixiffent. Plautus eum Pafferem marinum appellavit, Phavorinus Lybicam avem,Diodorus Siculus Cervinam dixit. Ariftophanis $\lambda u=$ Bıxòv ó ģveov; Horatii Afra avis, gallinx potius funt, quas prægrandes Africa terra tulit.Maximus eft omnium avium. Diodorus Diodor. Camelo parem effe. Plinius equitis equo Biblioth ${ }_{3}$. c. 12. infidentis magnitudinem excedere ; \& Ve- Plin. H.N: rum eft, fi collum quantum poteft erigat. ${ }^{1, \text { Io.c. I: }}$ Rofrum habet exiguum fed acutum. Caput in quo fere nullum cerebrum, parvum, exiguis pilis, in formina pallide lutefcentibus, in mare flavefcentibus, collo ad rubrum colorem vergente. Palpebras utrinque folus omnium alitum ut homo, pilos in fuperiore palpebra. Collum longiffimum. Dorfum, cujus penn in mare nigerrim $x$, in fomina fufc $x$, lanæ quandam fubltantiam fua mollicie efficiunt, tam latum, ut puerum la- 
Oppian. Ctentem infidentem ferre poflit. Alarum

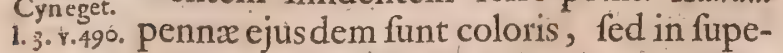
riori parte candidiffimæ. Gordianus miniatos habuit. In interioribus alarum cubitis

Albert. 1 . foricula fecundum quosdam, quibus fetit, numalib. habet; offeos in extremis alis, fecundum alios, mucrones, quibus ceu calcaribus ad curfum velociorem fe incitat. Aldrovan dus obfervare eos non potuit. Caude pen$n x$ in mare fubalbidæ, in foemina fubfufc $x$ funt. Coxis pragrandes, quod in angurtum fenfim juxta femur finiantúr; femur humanum potius imitantur. Pedes Camelorum

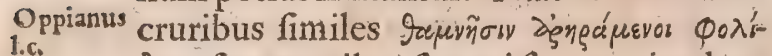
$\delta \varepsilon a r$, frequentibus firmati fquammis ad geminos, ufque duros poplites integuntur. Pedes more boum bifidi, in binas ungulas dividuntur. Cur bifulcum potius quam folipedem aut digitatum natura fecerit, ignorare me fatteor.

Tocis $\quad$ Reperiuntur, in Africa, Lybia, Ethio1. 4. Hift. pia, Arabia, \& Syria. Amant deferta \& feplant.c. 4 re aquofa, \& tanta eorum aliquando conPlin.H.N. ro. s. I. ficitur copia, ut velut equitum quandam Xenoph. I. aciem eminus efforment.

S. Exp. Diod. Si- ex Strabone colligi poteft. ferrum, lapicul. 1. 3. c. des, offa, \& quicquid obtigerit, fine dẹle$\checkmark$ iens. ctu devorare certum fere eft : fed an eaStrabo. dem concoquet, dubitatur, fi fit, quod 1.6.Geogr. Langius credidit, fpecificx potius proprieEpit. I2. tati,quam intenfiffimo calore tribuendum Aphrodir, id erit. Nam leo ftruthocamelo calidior, in procem. ferrum concoquere non poteft. InterroVorfius in gatus, qui circumducebat, àBrentio, degluemend. ad tire quidem ferri particulas fed iterum, 1.3.deIdol. vel integras, vel fummum perpufillo imminutas, refpondit.

Generasio. In Venerem proclivis eft, \& Cameti Plin.1. 20. Bactriani inftar, averfus coit. Complura A. 52. . ponit ova, octuaginta nempe, \& quidem 1.9. c. Is. menfe Julio; illaque lapidea quafi crufta munita; \& XV, plus minus libras penden - Tlian. de tia. In arena condita, \& neglecta, folis ${ }_{{ }_{14}}$ cc. $_{13}$. calore foventur: folo vifu ex iis pullos ex cludi quidam credidere, quod intueri ea avem viderent, nec propter gravitatem iis incubare poffe fcirent. Non excluduntur fimul. Pars intra ova formatur, pars in lucem prodit, pars fovetur.

De ejus voce nil memoratu dignum oc $r$ ax. currit. Non elevaturà terra propter cor= poris molem ; feftinantiffime tamen interdum incedit, ingruente in alas vento, \& tanquam vela eas extendente. Naturaliter eum calvere Plinius dixit; equum odiffe PliniH.N. alii tradunt. Collum fruticeoccultat, feu ${ }^{1, t} i, t, 37$.

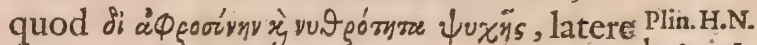
fe ita exiftimet; feu quod eam corporis partem, quam fe inferiorem habere novit, contra perfequentium injurias muniat.

V/um fi fpectes, ova propter amplitudi- V rus. nem pro quibusdam habentur vafis. Garamantes potoria \& capitum tegmenta ex iis conficiunt. Pennæ conos bellicos \& galeas adornant, quas apud Turcas folis Janitzaris gerere conceffum. Lapis in ventriculo repertus, \& collo furpenfus, concoquendi vim promovet. Sebum efficacioris ad omnia quam adeps anferinus ufus : ideo cum auctio regia per Catonem Uticenfem fieret, LXXX. feftertiis væniit; \& apud Eginetam emplaftrum diacinnabarios ingreditur. Carnes Arabibus, $\mathbb{E}$ thiopibus, Numidis \& aliis in ufu, hinc Struthophagorum nomen. Heliogabalus Lanprid. fexcentorum capita una coena, ad edenda in Helioeorum cerebella appofuir. Firmus. Seleu- gabalo. cius,qui Hippopotami adipe delibutos inter Crocodilos impune natabat, totum uno die comediffe dicitur. Sceletum apud l.24, c 25: Pareum vide.

NB. Eft $G^{3}$ alia Strutbocamelorum fpersies.

Vide Mantilfam N. 3 . . 


\section{HISTORIENATURALIS}

D E

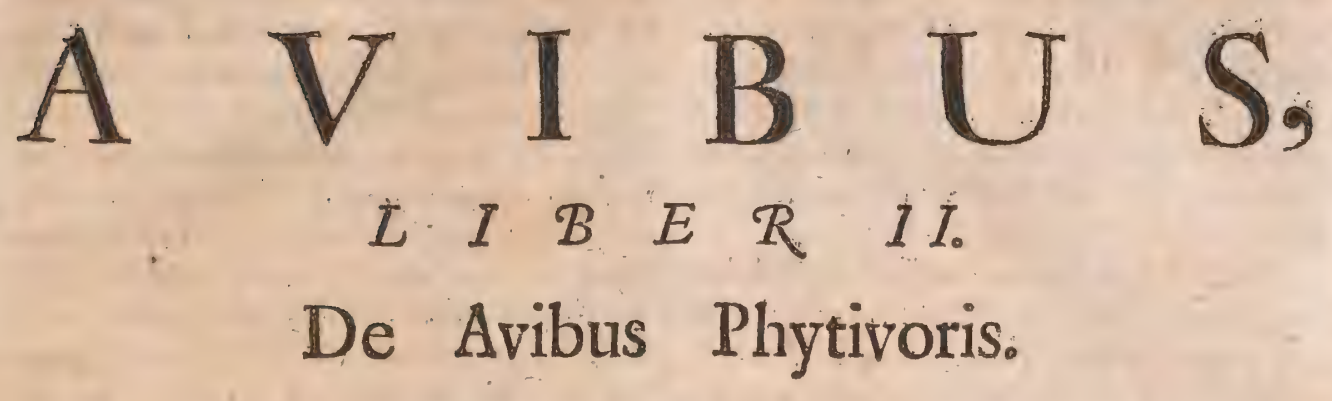

$\begin{array}{lllllllll}\mathrm{T} & \mathrm{I} & \mathbf{T} & \mathrm{U} & \mathbf{L} & \mathrm{U} & \mathrm{S} & \mathbf{I} .\end{array}$

De eAvibus Graniboris, $\mathcal{X}$ Con Canoris.

C A P U T I.

De Pulveratricibus Sylveftribus.

A R T I C U L u s I.

De Pavone.

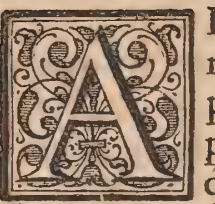

Bfoluta Avium Carnivorarum hiftoria ad Phytivoras pergendum eft, inter quas pulveratrices tam fylveftres, quam domefticx primo occurrunt. Inter illas primus $P$ avo, propter Iucian. de exquifitum pennarum ver, \& gemmantes domo. colores, quos adverfo maxime fole, quia Plin.H.N. fic fulgentius radiant, expandit; JunoVarro 1.3 nium inceffum, ingenium, de quo in fede re ruft. quentibus fingulare, \& magnum apud veOppian. 1. teres xftimium occurrit. Athenis ftatuto Lucret.1.2. precio fingulis noviluniis per annos $\mathrm{XXX}$ de Natura fpectabatur, multi Lacedæmone \& ex rerum. Theffalia fpectatum confluebant. Alexan. Animal. 1. vifis iis apud Indos, graviffimas in eum qui 5.c. $2 \mathrm{r}$. occideret pœenas conftituit. Tiberius ob Sueton. in fubtractum è viridario unum, capite mulTiber. $\quad$ tavit. In Lybia fi quis tantummodo ladiffet, non impune ferebat, fi Euftathio credimus. Quod fi precium fpectes, mille drachmis marem \& fœeminam venditos In Orat. fuiffe Antiphon fcripfit : \& tempore VarcontraEra- ronis ova earum denariis væniebant quiVarrol.3. nis, ipfi facile quinquagenis, grex centede re ruf. narius facile quadraginta millia feftertia a. 6. reddebat, ut quidam Albatius ajebat, fi in fingulos ternos exegiffet pullos, perfici fesuidas. xagena potuiffe. Dicitur \& Medica, PerAriftoph. fica, Junonis; \& picta avis.

in Avibus. Diverfitas illorum à colorum inprimis, \& Sylvo loci diverfitate fumitur. Noftrates fatis Athen funt noti. In Terra Firma quidem ventre E. 19. 2 \& pectore nigris, cætera flavi; alii pectoEenera. re \& ventre flavi, cæetera nigri confpiciunter. In Curiana regione funt fylveftres, qui per nemora vagantur, \& adeo viles Martỳ. funt, ut unica funt, ut unica duntaxat ven- $\mathrm{dec}$, $\mathrm{reb}$. $\mathrm{O} c \mathrm{c}$ dantur acu, alibi in paluftribus inveniun- cani 1.8 . tur. Quod fi \& Sexum attendamus, fœmina mare multo minor eft, neque in cauda oculos illos gerit, Japonenfem fi excipias, qux quatuor in Uropygio obtinet.

Placet maris \& foeminx defcriptionem ex-Defcriptios hibere. Mas iôitur capite, collo, \& pectoris initio intenfe crrulei, feu fapphirini coloris eft. Caput pro corporis proportione habet exiguum, \& quodammodo ferpentinum, maculis duabus oblongis candidis, quarum una oculos fuperequitat, altera brevior at longe craffior fubjacet, orna tum. Apicem in vertice è nudis quodammodo fcapis tenerrimis, viridefcentibus, in fummitate ejufdem coloris liliorum flores ferentibus confpicuum. Rofrum candicat \& infigniter hiat. Collum eft longiusculum tenue \& exile. Dorfum ex albo cinereum, maculis atris transverfalibus confperfum. Cauda in duas quafi dividitur. Non longioribus qux ex dorfo prope po* dicem oriuntur pennis, in rotam extenfis, minores quædam eæque fufcæ non rigent, fed ut in reliquis avibus extenfe confpiciuntur, datas ut longiores fuftinerent

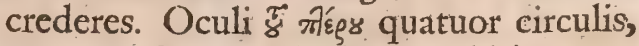
aureo, caftaneo, viridi \& fapphirino conftant, \& varios ad folem obverfie colores jaciunt. In fremina pauca colorum confpicitur varietas. Alæ totæ, dorfum, venter, coxæ⿱ ac pedes coloris funt fufciad cinereum vergentis. Capitis vertex \& apex Plin.H.N ejufdem coloris, in vertice tamen aliquot 1.ro. c. 29 . maculæ exigur, veluti pundta virefcentia Varro de interferuntur, \&c. c. 6 .

Quantum ad Loum in Afia fuiffe inve- Diod. Sictitios Theophraftus author eft, transma- ${ }_{53}$. rinos Varro Babylonia multos pulchrio- Rhodig: re quam alibi varietate aluit. Media gu-1. x. c. זø 3 lofis 

aluntur. Amant edita loca, pafcuntur tamen cum Gallinis, \& Gallinarium fub vefperam fimul repetunt.

Generaiio. Summaipfis Coëundi cupiditas. MafcuColumella lus quinque foeminas defiderat, \& n ni adfit rufticac. 1 alia, incubantem invadit, ac ova frangit. de re ruft. Agnof citur irruiffe libido, quoties circa fe c.28: amictum caudx gemmantis incurvat, \& Columel. fingularum pennarum capita occulta,locis \&. Pallad. fuis exerit, cum ftridore procurrens. Accenditur eadem, fi leviter toftam fabam tepidamque jejunis quinto quoque die exhibeas. Coëunt ab Idibus Februarii ad Martium, vere præfertim, locis fere apricis, cum Favonii fpirare cœeperunt. Partus à

Alian.1.5 trimatu obvenit, cum varii colöres func. 32 . duntur, brevi coitu agitur tempore. Ter la $1.5 . c_{0} 32$. is aniro à foeminis, quæ non incubant editur : at qux fovent ova totum tempus foecunditatis aut excludendis, aut etiam educandis pullis confumunt, ita ut vere H. A.1. S. femel in anno parere Ariftoteles dixerit. c. Ir. De numeroovorum non confențiunt autho- res. Ariftoteles octona in primiparis numerat, duodecim aut paulo pauciora in aliis, nec ifta continuatis, fed binis ternisve interpofitis diebus ponuntur. Alii primoanno unum \& alterum, fequenti quaterna quinave, cæteris duodena edere volunt,nec hic numerus transfenditur. Quxe Columell. ter pariunt, earum primus partus, quin1. c. qué ovorum eft, quatuor fecundus, trium aut duorum tertius. In Temiftana viginti imo triginta aliquando enituntur. Conci-

F.lian.1.5. piunt tamen \& fine coitu, \& ova Zephyria

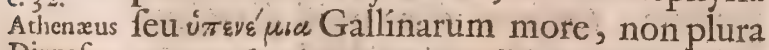
Dipnof. tamen duobus ponunt. Ut commodius excludantur Gallinis, fed non Rhodiis fupponi poffunt, recentiora; luna nonaria exiften-

Columel- te, hoc eft, novem à primo Lunæ increla. mento diebus. Commodius inquam. Nam \& mas feu libidine turgens, feu incubandiflagrans defiderio, illa interdum frangere folet; ideo à foemina celantur; \& quia fœElian de mina non continue duorum dierum inter5.c.32. vallo incubat, refrigerata, infoecunda evadunt.

Aritas. Et.A. Etas ipfis viginti annorum tribuitur.InArif.H.A. dicus centum memoratur vixiffe. Volatu paAclian, de rum valent; feu quodUropygium flenti inIr.c.33. eptum obtineant, feu quod longitudine II. C. 33. caudæ \& corporis gravicate premantur.

Vox.

Vocem fiattendas, Philomelæ author eas pupillare dixit, Varro à voce fua dictos tradit.

\section{A T U R A L I S}

Si Ingenuim, inceflum furum ita compo- Ingeniuģ. nit, ne maculetur, pullus adhuc, fi made: fcit (fide Alberti refero) moritur. Lauda- Plin.H.N. tus gemmantes expandit colores, adverfo l. ז0. c. 20: maxime fole, quia fic fulgentius radiant, fimul umbræ quofdam repercuffus cæereris, qui in opaco clarius micant, conchata quærit cauda, omnesque in acervum contrahit pennarum, quos fpectari gaudet, oculos. Si tacitus fpectes recondit fuas Ovid.l.2t opes. Refrigerationis indigus, paffis pen- de arte a nis, \& in anteriorem reflexis, corpus fuum operit ingruente à tergo vento, alas pandit, \& fuaves auras excipit. Lini radicem elian.1. naturale fafcini amuletum, fub altera ala- r.H.A.c. rum retrorfum geftat. Qui eos venenum ${ }^{\text {"I. }}$ detegere, defollum eruere referunc, fidem fuam exfolvant.

Duplici inprimis morbo afficiuntur. Do- Morbi. loribus nempe dentientium infantum fimilibus cum crifta produci incipit, \& pennarum defluvio; de qua Plinius. Idem cau- Plin. H.N. da annuis vicibus amiffa cum foliis arbo- ${ }^{\text {.1 }}$ 0. c. 20 rum, donec renafcatur iterum cum flore, pudibundus ac mœerens, quærit latebram.

De Vi prefagiendi hoc dixiffe fufficiat, Prefagiam cum plus folito clamitant, noctu inprimis. pluviam imminere. Vocis enim illius ob-Mizald. in ftreperæcongeminatio, vegetum \& acu Ephem. tum intus cum calore vocalem Spiritum, text.t.s.43 per arteriam vaporofo aëre imbutum, erumpere teftatur. Quod vero extra tem. pus cantillantem, Paracelfus mortem alicu. jus ea in domo præfagire tradit, fabula eft.

Vfum \& $\mathrm{x}$ in Medicina \& in ribis aliquem $r$ foss. præftat: Nam jus pavonis pingue pleuritidem fanat, linguarum ufus ab epilepfia præfervat. Ova ufta \& in aceto trita impe. tigines emendant, fumus è pennis exceptus rubefcentes oculos, propter fignatu- PortaPhyram curat. Fimus podagra fervorem mi togn. 1. 3. tigat. Caro propter ficcitatem \& frigidita - 29. tem, dura \& concoctu difficilis audit. Etiam. mortui poft annum nec olet; nec putre Auguft. de fcit, vifa poft quadriennium cariem foe-Civit. Dei niculi odore; faporis amari \& falfi con-Aldrov. 2 . traxiffe. Primus eos Aufidius Lurco cir Ornithol. ca noviflimum bellum piraticum fagina- Ilin. H.N. . re inftituit, \& ex eo quæftu, reditus feu 1. I0.c. zo. feftertium feu minorum fexaginta millia slian.1.5. habuit.Hortenfrus Orator, primus editiali de Animal. cœena cibi caufa occidit, \& ideo in jus vo- Sueton. in catus eft. Cerebella Vitellius in famofa illa Vitellio. patina, quæ Minervæ clypeus, cum aliis Athen,1.13 prodigiofis cibis appofuit: Qux vel de virgine à Pavone in Leucadia adamata, stlian.1.1x velde Pavone Indico, Jovi confecrato, de Animal. quem facrilegi fuffurari non potuerunt, di- ${ }^{2} 33$ cuntur; inter hiftorica recenferi debent. 
A R T I C U L U S II.

De Pavone albo, Pavonibus Iafonenfibus EG Gallopavone.

$\mathrm{P}$ Avones Al br Septentrioni peculiares effe credebantur : \& in calidioribus regionibus eosdem nafci, fucceffu temporis Cadam. cornpertum eft. Vidic Aloyfius CadamuNavigat. ftus in Maderis; Johannes Laurentius AIn fabrica nanias in parva infula, plures, Scaliger in
Anan. Mundi to. Gallia binos; Gaudentius Merula Medio3.cit.Al- lani plures; Aldrovandus unum Bononiæ Aldrov. natum. Cum ex Norvegia Coloniam adOrnith.l. veherentur, numero per feminium aucto, I3.c. $\dot{2}$. cum penitus in frigidiora loca commea rent, \& matres in ipfo. vere ovis incubantes nivofa loca perpetuo ob oculos haberent, vulgatioris facti funt. Tales \& in calidioribus rëgionibus nafcentur, fi caveas in quibus incubant \& excludunt ova, ex parte albis velaminibus obtendas.

Defriptio. PAVONUM JAPONENSIUM Maris \& fæmellæ defcriptionem Marchioni Facchineto, qui eam à Julio IX. Pontifice accepit, Aldrovandus debet. Mas nullam cum noftrate præterquam in cauda \& $x$ pedibus fimilitudinem gerebat. Roftrum erat, ut in noftrate cineritium, fed longius $\&$ fubtilius. Vertex capitis, qui planus erat, \& collum fuperius virefcebant, \& maculis cæruleis ceu punctis, qux pariter in medio exiguas lineas albas deorfum defcendentes habebant, refpergebantur. Apex in capite quatuor ferme digitos longus partim viridis, partim cæruleus, figura filiginis fpi$\mathfrak{x}$ non omnino diffimilis. Oculorum pupilla nigra, iris lutea, hanc ruber circulus ambiebat. Pectus \& dorfum velut ex fquamis, fed colore variantibus conftabant. Pectoris enim fquamæ, fi ita vocare licet, ex cæruleo, viridi \& aureo : dorfi ex cæruleo \& viridi tantum tingebantur. Alarim principium ejusdem cum dorfo erat coloris, fed fquamæill $x$ virides haud ita apparebant, cærulex vero majores erant \& lucidiores. Pennarum fecundi ordinis primæ ejufdém erant cum fuperioribus colores; reliqux in medio virides, ubi lineis nigris tranfverfalibus notantur : poft fublutex fimiliter nigris lineis notatæ; in extremitatibus denique nigrx. Venter, coxx, 3 denique pedes colore leucophro \& maculis nigris infigniuntur, quarum quæ in ventre funt, lineas albas habent. Cauda pennis, quam in noftrate rarioribus colore, magis fufco ad caftaneum vergente, calamo candidiffmo. Oculi caudæe multo quam in noftrate majores, primum aurei, dein cærulei, poftremo virides; ut in noftrate. Femina mari quidem minor eft, fed capite toto, collo, dorfo, pectore $\&$ alis fimillima. Illud vero in hac admirandum eft, fupra uropygium, nempe ad dorfi finem, quid veluti cau dam habere,eämque oculatam, ut in mari : fed oculi, licet quam in illo fint minores, funt tamen pro pennarum portione $\mathrm{ma}$ gni.Habebat itidem caudam viridem pennis in ambitu cæruleis, \& calamis albis. Póftremo in co etiam â mare differebat , quod ventrem haberet prorfus nigrum. G A L L ò P A y o, aliis Gallus Indicus, Peregrinus, \& Calecutenfis dicitur, \& idem efle cum Meleagride, cujus fynonima funt, Gallina Africana, Numidica, Afra Varro 1. 5. avis, Numidica guttata, \& alba Lybica, vi- ce. 2 . detur; fi vera eft illa defcriptio, quam ex Plin. H.N. Clyto Milefio Athenæus adfert. Verba Athen.l.14 ejus funt. Circa templum virginis, Minervie Dipnof. nempe in Levo (fic legendum non Olero.In- Cafaufula eft maris Icarii Sporadum una) Melea- then. 1. It.

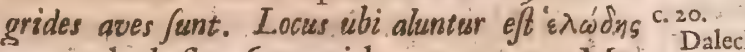
non paludofus, (ut quidam vertunt, Me- ad 1. eund: leagrides enim Ariftoteles ab avibus palu- $\begin{array}{cl}21.1 .5 . c_{0} \\ 27 . \text { de Ami }\end{array}$

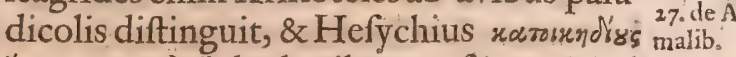
ópyes vocat) fed arboribus confitus. Animál illud non ita prolem amat; Ej junzores puillos adeo negligit, ut facerdotibus illos curare nece]/um fit. Avis magnitudo ist gallina generofae eft, capite ampliore, quam pro modo reliqui corporis, glabro, ac superipfo crifta carnofa, dura, rotunda, que clavi modo Juper caput extuberat, colbre ligneo. (Sic le-

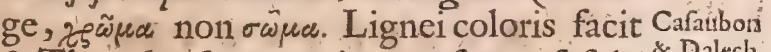
\& Theophraftus mentionem; forte eft fub- " * Dalechart? flavus.) Ad malas jacet inftar barbe longa caro, ad.1.. . incipiens ex ore, ribentior quam in gallinis: at eam ${ }_{\mathrm{Pl} \text { aut. }}^{\text {Hit }}$ que roftro Gallinarum infidet, \& quam barbam c. 3 . nonnulli vocant minime babet, tanquam ea parte $\int 26$ mutila: roffrum acutius \& grandius quam gallines. Cervix nigra, crasfior \& bretior quam Galline. Corpus totum varium. Nigrefcit enim totim, crebris masulis albis notatum ac compunctum, lenticula majoribus, que rbomborum figura par vis nigrisque circulis ambiuntur, E pennarum illam variotatem efficiunt, quia niger color afpergitar candido, छै vicifJim candidus nigro. Alarum pennxlinearum ductibus candidis ferratisque diftinguentur, in Spiras protractis, intervallo pari diremptis. Nullum calcar in cruribus, que gallenaceis fimilia funt. Maribus adeo fremine fimiles, ut vix Meleagridum fexus difcernatur. Similitudinem in colore \& mole corporis intellige. Eo enim veluti clavo ligneo carent. Quem. Aldrovandus ex Gyllio defcribit ex novo orbe allatus erat, eadem qua Pavo proceritate. Collum ei fimul cum capite à plumis omnino nudum, tantum purpurafcente pelle obducebatur, \& tam erat craffum, ut pellem qux antea laxa \& vacua, cum vocem emittebat, fpectabatur, fic inflaret, ut ald brachii craffitudinem accederet. Cun quis ad Gallinam accederet, totis inhorrefcebat plumis, \& gradu fuperbo exterrere accedentes conábatur.

Quantum ad Locim Boeotii foli indige- Locks, nx Meleagrides effe videntur. IEtolix peculiares, Menodotus fanius facit; \& in- 
Vicus. de in alias partes translatas credit. DiodoAthen. 1. rus ultimam Syrix partem, Strabo ArabiDiodor. 1. am ipfis tribuit. Certum, noftras calidio3. Biblioth. ribus locis delectari, una cum Gallinis paStrab.1. r6. fci, \& longius à domo per agros divagari. Geogr. Quod autem Scylax Cariandenfis lacui Scylax Ca- Cephifio, in Africa, Mnafeas lacui ibidem
riandenfis in Periplo Cratum amnem de fe promenti,eas vendiorbis. plin.1. r6. cat; vel error eft, vel Gallinis, quibusdam H.N.c.44. Africanis, quæ paludes amant, rutilam gaColumel- leam \& criftam in capite gerunt, quæque rè rufft.c. .2. noviflimx peregrinarum avium in menfas Plin. H. N. propter ingratum virus (quod noftri Meleagridibus non competit) receptæ funt, nomen Meleagridum propter fimilitudinem indidere.

Generatio. Coërst aliquando cum Pavonibus, \& exBapt. Por- cluduntur pulcheirimi pulli, nitidiffimis Nat. $c_{1}$ 14. pennis fulgentes. Incubant verno tempore diebus tricenis.

Vox. Ad Vocem earum extendit Pollux verbum rasxa'ces. CrocitationiGallinacè $\mathrm{Pa}$ voninæque non diflimilem edit, cum fragore per collum longe lateque vagantem, \& inftar liquoris in dolium infufi opftrepentem. De ufu ipforum in cibis non eft Paufan in quod dicamus. Olim Ifidi Tithonex à Booticis. pauperioribus immolabatur.

$$
A \text { R T I C U L U S III. }
$$

\section{De Pbafiano, Urogallo Jeu' Tetraone; ma' jore EE minore.}

P Hajionus, Galeno Gallius Sylveftris, Statio Phafidis ales, Scythica volucris Juvenali, Itis quibusdam dicitur. Magnitudo non omnibus eadem. In regionibus Ergimul \& Cerguth qux Magno Chamo fubfunt, maximos reperiri Paulus Venetus fcribit, cum tantæe prolixitatis cauda, ut decem \& octo palmos excedant. Is quem Aldrovandus defcribit libras tres duodecim unciarum pendebat. Rofrum coloris erat cornei, pollicis transverfilongitudine, in extremo recurvum, fuperius inferiore longius. Membrana carnofa, qua capiti conjungitur tuberofa, fub qua nares occultantur, inftructum. Caput in vertice colore cinereo fere micabat; ad latera fupra coccineam maculam, \& prope roftrum viridi, \& admodum vel in fole, vel in umbra varia. Ab utraque capitis parte è regione aurium pennæ, quas Plinius cornicula vocat, elevabantur, fub his caruncula feu mufculus qui cornicula illa movent, apparebant. Aures erant admodum latx, profun$\mathrm{d} x, \&$ rotund $x$. Colli penn $x$ infra prope pectus, \& pestoris etiam prope collum tribus coloribus variabant, fufco nempe prope radices, dein aureo \& viridi; fed viridis nifi complicatis fimul pennis non confpicitur,fi unicam à corpore ablatam examines, niger jam apparet, fed \& aureus, fi pennas inverrtas fplendorem amittit. Tergoris pennæ erant totæ ferruginex ad ruffum vergentes, \& velut in exigua flamenta definebant. Cauda, qux organi pneumatici figuram obtinet, duos dodrantes,cum duobus palmis explebat. \&c. Fœmina mare per omnia deformior eft, Coturnicis fere colore.

Locus iplis Phafis amnis, unde nomen Locus. fortiuntur Athenæus ex Media accerfiri Dipnof. folitas quafi meliores, tradit; in Indix hor

tis cum Pavonibus enutritas $Æ$ lianus. In Alianus1. Curiana regione tam numerofi capiun- ${ }^{3}$.de Anitur ut finguli duabus aciculis venditi fue-Martyr. 1 . rint.

In Scandinavia äliquando absque cibo $v$ ictus.

fub nive latent. Fridericus Saxoniæ Dux ducentos emiffos capi vetuit. Victitant granis, feminibus \& baccis. Avena inprimis delectantur.

Coëunt menfe Martio \& Aprili. Unus Generatio. mas duabus foemellis fufficit. Viginti fere ${ }_{\text {rufti } ;}^{\text {Pall } c_{i} z q_{a}}$ ovis, illisque rubris pariendi ordo concluditur. Semel in anno foetificant, \& trigefimo die maturos pullos emittunt. Optime Gallinis incubanda cömmittuntur, ut una matrix quindecim ova operiat. Quomodo vero ex Phafiano mare \& Gallinis Gal= linaceis fimul coeuntibus Phafiani procreari poflint, docet apud Aldrovandum, Aidrov. 1. Löngolius. Interëunt pediculis nifi fe pul- 13 . Ornith. verent. Pennas dum nimis pinguefcunt, $\mathrm{fi}^{\mathrm{c} .5}{ }^{\mathrm{s}}$ quibusdam credendum, amittunt. Capite in terram immiffo, totos fe latere exiftimant; \& dum propriam imaginem admirantur prius fe capi finunt, quami aufugere poflit.

Quantum ad $u$ / $u m$ medicum non pingues $V$ jus. bene purulentis in cibis exhibentur. Vi- Trullian. $1_{0}$ num in quo unus extinctus eft bibitum, torfiones, fi Marcello Empirico credimus, tollit. Adeps, tetanicis, marricis fuffocationi, \& renum affectibus prodeft. In cibis Galen. de vehementer laudantur, nec vel Perdicibus ren. affect. vel gallinis domefticis, fi pulli èdantur,ce- ${ }^{c}{ }^{\circ}$

dunt. Olim inter fummas delicias nume- Philoftr: 1. rabantur, à quibus Ptolomæus abftinebat: S. de vita at quibus Heliogabalus Leones \& alia Apollin. bruta pafcebat.
in Heliog. UR OGALL U S major, qui veterum Defcriptis. Tetrao Ariftotelis Tetrix, ut Gefnero; Agricolæx, Jovio \& Aldrovando placet, à quibusdam cum Otide feu Starda,vel Tarda; à nonnullis cum Ortygometra confunditur; ex Gallinaceorum eft genere. Quem Aldrovandus defcribic, habet collum dodrantale, palmis nigricantibus, cinereo diluto colore fparfim notatis. Caput nigrum, roftrum breve, gibberum,latum. Supercilia \& pelliculam circa oculos rubra. Pectus \& ventrem coloris nigri. Alarum pennas longifimos palmorum quinque nigricantes, 
aut potius fufcas, minores fub alis albiffimas. Poplites \& femora plumis albis, crura ad digitos ufque furcis veftita. Ex albis in cauda maculis xtas conjicitur, quo majoresfunt, eò pauciorés illas habere feruntur. Reperiuntur qui libras quatuordecim Germanicas : imo \& viginti tres Italicas pendunt.

Generatio. De coitu ipforum mira tradic Encelius. Ore coire, Gallum fperma ex ore tempore coitus evomere; Gallinas poftquam id deglutiverunt, concipere; mox comprimi. Reliquias rore vel pluvia fuperveniente, putrefacta materia, in ferpentes mutari, non fuperveniente, in gemmam translucidam \& candidiffimam abire, fit penes authorem fides.

Y fus.

Saporis funt gratifimi: Caligula fibi eos immolari voluit:

UR O G A L L U M minorem Stumpfius, Phafianum montanum appellat. A Gefnero confpeatus multo majora fupercilia \& pellicula rubente, quandoque cærulea, quam Urogallus habebat, Roftrum longitudine transverfi digiti, plumas in vertice nigras. Collum plumis Indicis, \&c. In Septentrione, fi Olao fides, fub nive duobus aut tribus menfibus latitant. Capiuntur laqueo, ita ut collo adftricto fuffocentur.

$$
\text { A R T I C U L U'S IV. }
$$

\section{De Grigallis \&5 Attagine.}

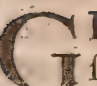

Rigallus vel major, vel minor eft. Illam Iub nomine Tetracis Nemefianus Poeta defcribit, dum ait.

\section{Et Tetracem Rome, quem nunc vocitare Taracem Coperunt, Aviumefit multoftultiffima.}

Aldrovandus duplicem tradit defcriptionem. Prima eft illius quia à Medico Cracovienfi miffus fuit. Erat magnitudine anferina, roftro nigro adunco, gibbofo. Capite plano, à roftro ad narium foramina ufque cinereo, nigris maculis confperfo. Reliquum, collum item, pectus, venter, \& coxæ coloris erant ruffi, modo nigris, modo albis maculis afperfi. Cauda ruffa, fed magis quam reliquo corporead caftaneum accedens, maculis nigris maximis confpergebatur. Digit is nudis, cinereis, quatuor erat inftructa. Oculorum cilia coccineus color ambiebat. Tota avis fi roftrum more rapacium \& ungues aduncos habuiffet, \& parvo fuiffet corpore, vel Lithofalcus, vel AccipiterFringillarius videri potuiffet. Altora ex Gefnero defumpta eft,cujus GrigalIus erat toto corpore Perdicis fere, prefertim rufticx infiar colorato, \& punctis maculisque nigricantibus diftincto, ima colli pars prona intercedentibus lineis excreruleo virentibus rubebat, in ventre plurialdrovan- mum albedinis confpiciebatur.Propter midusl Or- rificam colorum varietatem, Attagenem aithol. 1. Alpinum vocare poffes. Minor perdice eft major, fed eidem perfimilis. Creditur à be tulx colore Germanis Birckhun dictus. Sur premum à betula corticem fi detrahas qui albo fubeft, in nigroque-ruffefcit, precipuum hujus alitis colorem imitatur. Denfa \& opaca loca ut bombardarum minas fugiat petit, ideo frepe in betuleto latêt, \& inde in fata \& fænilia callidifime excurrit.

A t т $\Lambda$ GEN, Perdix Afclepica qui- Defriptio. bufdam inter pulveratricis ab Arifotele Atir. H.A. ponitur; quod inter paluftres ab Arifo- $A$ riftopl. phane \& ejus fcholiafte; vel error eft, vel in Avfbus ideo fatum, quod interdum ex montibus ad loca vicina defcendat ibidemque Bellonius moretur; vel illa, nifi Turnetus fallic, in- 1.5 . telligenda eft, qux ad ripas fluminis moratur. Gallinagini ita fimilis eft, ut nifi paulo major effet, \& pectoris color magis ad cinereum vergeret, altera $a b$ altera difficulter diftingui poffet; roftrum habet longum, fed capta triticum non fecus ac columbi comedit. Quantum ad veterum defripizonem, Alexander Myndius, perdice paulo majorem, totum circa dorfum ratá $\phi$ es rov, id eft verficoloribus maculis pictum, figulin $x$ teftx colore, fed magis ruffum, corpore gravi, alis brevibus facit. Quantum ad Recentiorum, Gefnerus Attagenem Corylorum Gallinam effe putat.Bellonius fuum Anati campeftri, quem Bellonits coturnicibus bene maculatis comparat, fimilem effe fcribit. Julius Alexandrinus Jul. Alex: genus quoddam longiore collo \& cruri- l.r. ra.falub. bus, plumis non iifdem macularum notis diftinctis, ex Hifpania allatum fe vidiffe referc. Florentix obfervatus roftro nigro Aldrovat: fed in extremo rubefeente, oculi pupilla nigra, iride cinerea, maculis per ventrem albis, dorfo ferrugineo, nigris maculis infignito, pedibus ferrugineis. Aldrovandus avem ex Sicilix montibus allatam pro Attagene ponit, qux magnitudine \& toto habitu ad Phafianum accedit. Roftrum habet breve, nigrum, \& in acuto recurvum. Colorem totius varium. Caput inprimis afpectus pulcherrimi, criftam in medio vertice erectam, fubluteam, nigris \& albis maculis variegatam. Pupillam oculorum nigram, iridem luteam, fupercilia ex pellicula coccineo colore rubente. Sub roftro \& gulæ principio ceu barba ex tenuifimis plumis dependet. Collum eft longiufculum, \& ad corporis habitum aflimilatum, tenue, \& exile, cinereum, maculis albis nigris confperfum. Pedum digiti anteriores longi, pofterior brevis, finguli adunco hamo armati.

Loci fi ratio habeatur, nulli funt in Cam- Locss. pania, quod ibi aconitum, quo purgan- Ambr.Lee tur, non proveniat.In Creta nonnifi in $\mathrm{Cy}-{ }_{343}$. doniatarum regione. In Cypro etiam do- Plin. $\mathrm{H}_{1} \mathrm{~N}_{\mathrm{N}}$ mi aluntur.In Rhodo \& Jonia laudatifimi ${ }^{1.8}$. habentur, fed \& in Hifpania Pyrenxis, Ar- 
vernienfibus Gallix \& Alpibus reperiuntur.

ritus. Victitant granis \& frugibus. Loquintur Athen.1.9. nomen furum qua poffunt voce, \& decanPlin.H.N. tant. Vocales capti, obmutefcunt, fi Pli1. ro.c. 48. nio \& Eliano credimus : in fuas fedes di-

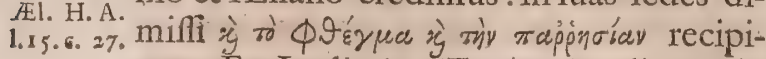
unt. Ex Lydia in Egyptum aliquando deportati, \& in fylvam dimifi, coturnicis primo vocem emifere, poft rès rois raxiôs ráeara explanatifime protuliffe finguntur.

Afeettrs. Amant cervos \& dorfis illorum infiliunt. Alian , de Cum Gallinaceis vero inimicitias exercent Animalib. C. 45. Caro in Cibo eft laudatiffima, feu fanguinis optimi generationem feu excrementi paucitatem, feu concoitionem alimenti attendas. Candida eft, tenera, \& fibris prorfus carens. Conceditur purulentis à Tralliano ; Nephriticis à Galeno. Cerebrum genituram augere Avicenna reliquit.

\section{A R T I C U L U S V.}

\section{De Gallina Corylorum.}

Defrriptio. Allina Corylorum Alberto Bonafa I \& Orix, Longolio falsò Otis, Bellonio Gallina ruftica M. Varronis, aliis Perdix montana \& Sylvatica dicitur. Caput ipfi \& roftrum ex defcriptione Bellonii $\&$ Gefneri, eft inftar Perdicis, rubet in fuperciliis. Dor $/ 2$ pennæx fuperiores Afcolopacis fimiles: fub ventre è regione ventriculi albefcunt, nigro maculatæ, in utroque latere fub alis. Remiges alarum ad inftar Aluconis maculantur. Cauda grifea, in extremitate alba, deinde nigra ad pollicis magnitudinem; macula, qua fuperiores pennæ quæ cæeteras tegunt, carent, tincta, cxtera colli Tetraonis colore. Tibire plumis ad digitos ufque teguntur, qux villos leporinos fere referunt. Digiti pedum corticofi, fquammofi, glauci, multis lineis articulati. Aldrovandus fufcx maculæ meminit, è qua ejusdem coloris tenues quxdam pennæ ceu villi dependentes, tanquam barbam efficiunt.

tockss.

Reperiuntur in Hercynia fylva; fed \& circa radices Alpium, ubi Coryli \& rubi abuhdant. Iis enim infident, rapacium volucrum infidias magis timentes quam hominum aftum.

Vicius. Vefcuntur granis, fed inprimis julis feu nucamentis, qux piper longum referunt.

Generatio. Pullos educatos extra locum educationis ipforum abducunt : illi vero bini, mas \& fomina aliorfum fe conferunt:

$v$ voss. Cibum fuppeditant laudatiflimum, \& caro earum quatuor diverfis coloribus fecundum Gefnerum tingitur, fecundum

Gernerus. Albertum foris eft nigra, intus alba. Mulieres quxdam pennis certo tempore decerptis, adverfus uteri fuffocationem, utuntur. Stumpfius Epilepticis falubres tradit.
Hippiatri tres quatuorve earuindem ventriculos una cum cibo in eis contento, equis afthmaticis devorandos, dari præecipiunt.

\section{A R T I C.U L U S VI.}

\section{De Otide five Tarda.}

Q1 Tum \& Otidem ex veteribus Ari- H.N.lir. ftoteles, Athenæus, Plinius \& Oppia- c. 22. nus confudêre; Starnam \& Stardam feu Tardam ex recentioribus Conciliatoribus rapacem Albertus facit, \& Biftardam vocat. Tetraoni congenerem non effe, quod. ex Plinio Bellonius opinatur, vel peculia ris pedum conftitutio, trydactilos enim eft, evincit.

Quantum ad Formam fidipes eft Athe- Defriptio. næo, tribus infiftens digitis, magnitudine ${ }_{\mathrm{D} \text { ipn. I. g. }}^{\text {Athen }}$ Gallinacei majoris, capite oblongo, oculis amplis, roftro acuto, lingua offea, gracili collo. Bellonio \& Gefnero, craftior eft \& Bellon.1.2. validior, gravis , tredecim cum dimidio de Aribus libras interdum pendit. Caput habet in- ${ }^{c}$. Io concinnum, cinerei cum collo, \& ad ventriculum ufque procedentis coloris. Raftrum robuftum valde, linguam ferratam, utrinque acutam, \& in extrema duram. Meatus auditorius adeo patulus, ut extremitas digiti immitti poffit. Si introfpicias duo apparent fub plumis anfractus, unus roftrum verfus, alter recta ad cerebrum vergens. Peitus craffum ac rotundum, cum ventre \& cruribus quatenus plumis veftiuntur ad media ufque femora albicans. Dorfum caftaneis ac fubnigris maculis refperfum. Alarum pennas majores candidas, circa finem nigras. Pennarum radices rubras. Caudam pennis ruffis, cum teniis quibusdam \& maculis nigris fuperiore interioreque parte albis ornatam. Tibias pollicem craffas, medium pedem longas, fquammofas. Pedes admodum craffos, fub quibus talus magnus inftar mufeuli confpicitur. Digitos pedis utriufque contra reliquarum avium morem ternos tantum. Interiorespartes fi fpectes, ventriculum habet ma- Gefner. in gnum, in quo interdum calculi albi Ornith inveniuntur, in extrema gula ante ftomachum parten capaciorem ex multis rotundis carunculis compactum. Inteftinis diductis \& extenfis id quodà fundo ventriculi ad alvum rectà procedit, dodrantum eft feptem cum dimidio : appendices vero duxab alvo retrocedunt ; quarum altera tenuior eft tres dodrantes longa; altera amplior, duos cum dimidio, tres vero ifti meatus juxta alvum in unam capacita- Locus: $_{\text {Aldrova }}$ tem conveniunt. AldrovanQuantum ad Locum in Italia non vifun- thol.1. 13. tur, nifi forte turbine advectx. Hifpanix- Caufant in $_{2}$ peculiares effe credit Plinius', fed falfo. Phocic. in Nam \& in Græcia circa Cephiffum Boco- Plin. H. Na 
D E : A V

Hector tix nafcuntur, \& in Britannia magno funt

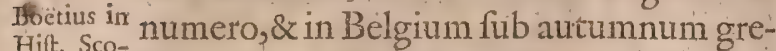
tica. ' gatim advolant, ibidemque in agris pro cul ab urbibus diflitis morantur, nihil de Polonia dicam. Falfum itaque cum coturniPlin.H.N. cibus quod à Plinio traditur, qux ab eo 1. 1o. c. 23. tempore Italiam deferunt, avolare. Arboribus nunquam infident, nec aquas nifi eas, quas poft pluvias in camporum foveis relinquintur, fitis fedand $x$ caufa, frequentant.

Vicuss. Vefoitur frugibus fed \&x herbis, ut auricuLongol. Il muris ; \& rapis ventrem implet.

$D$
viabus. Generatio. batum abfolvit, \& parit cum matura feArirt. H.A. ges eft.

Volatus. Volatu eff propter corporis pondus adXenoph. 1 modum brevi \& tardo, \& capitur manu, $f$ Iivosiofsws quis celerius inftet.

Affectus. Amicitiam cum Equo colit, huic approAtilian.I. z. piriquare \& fimum dejicere gaudet, ita cac. 28 . pitur. Inimicitiam vero cum vulpe \& cane Plut. de pitercet. A vulpe inverfa in terram abjenimal. Eta, caudamque ut collum avis extenden-

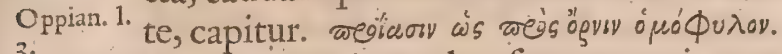

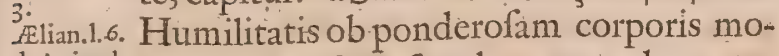
deAnimal. lem fibiconfcia, fimul ac canes latrantes

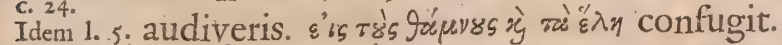
c. 24: Vfum \& in Cibus \& in Medizina prebent. $V f_{i s s}$.
Athen. in In Cibis caro Xenophonti apud Athenæum Dipnof. fuavis, à Demetrio Conftantinopolitano Demetio Accipitribus tanquam fuaviflima prafcricipitrum bitur. Julio Alexandrino quamvis nigra \& cura: durior, valenter tamen alit ;i vel exquifiAlex Sabba $_{1}$ r. tam in ventriculo concoctionem adepta c. 5. fuerit, vel captæ \& jugulatæ durities dometur.

Plinius in In Medicina. Nam adeps apud Phryges H. N. \& Lycaones mammis puerperio vexatis applicabatur. Fini ufum Avicenna contra impetigines predicat. Ova eodem tefte capillos nigro colore tingunt. Pifcatores reprefentatis ex ipfarum pennis mufcis, pifcibus infidiantur.

\section{A R T I C U U U V VII.}

\section{De Anate Campeftri \& Ave Stella dicta.}

A Nas Campeftris propter confimilem digitorum numerum Otidi fuccedit Bellonio Anas Campeitris, Canne Petiere Gallorum : \& Tetrax', \& Gallix peculiaris effe creditur; à rufticis Gallis Oliva dicitur.Ex ejufdem defcriptione, eft Phafiani corpulentia, Capiie, fi craflitiem demas, Coturnicem, roftro quod nigrum pullum gallinaceum refert. Dorfum tribus aut quatuor coloribus, nempe flavo tendente ad rubrum, fubcinereo, \& rubro intermixto wariegatur. Quatuor pennx alarum in fuc periori parte in extremitatibus fuis nigrefcunt. Pectus alba torquis juxta ingluviem circumdat. Radices omnium plumarum
I $\cdot B \cdot U \cdot S$.

rubre funt \& fanguincx. Tres duntaxat in pedibus digiti. Omnia intus in avibus granivoris communia.

Vefoitur granis abfque difcrimine oinni- $V$ aftit:

bus, nec non formicis, fcarabxis \& muf cis. Quamvis color colli \& capitìs femper idem non fit, \& in hoc maris à foemina differentia confiftat; dorfum tamè $\&$ alx nunquam colorem immutant.

Stella tribus quoque digitis incedit. Totum corpus, fi ventrem \& caudam \& alas majores excipias ex albo, luteo, \& nigro ita variegatum eft; ut qui color fuperet difficile fit judicare. Roltrum eft longiusculum, in extremitate parum recurvum, nigricans. Venter \& coxæ candicant. Cauda maculis nigris plurimis, quarum binx tranfverfales infigni funt magnitudine, confperguntur.

\section{$A$ R $\mathrm{T}$ I C u $\mathrm{x}$ u $\mathrm{s}$ VIII.}

\section{De Oedicnemo Bellonii, बேं ejus congenere Aldrovinidi.}

A Vis, quam Bellonius Oedicnemum Decriptio. à tibiarum infra genu propter os Bellon. lis $_{\text {s. }}$. quod valde craffum eft, qua nota vel fola de Avibus agnofci poteft, fingularem craffitiem, vocat; magnitudinem habet Elori, roftrum longiufculum, in extremo nigrum \& flavum qua capiti jungitur. Alis intus albis, extra nigris Otidem, dorfo Attagenem refert. Coloris enim eft fumofi,maculis nigris per longitudinem ductis variegati. Digitos habet in pedibus ternos, tibias ut fupra.Tarde parit; \& ineptæad volandum, fub finem menfis Octobris repertæ funt. Huic refpondet illa quam fub CHAR ADRII Ariftotelici nomine Gefnerus defcripfit. Gallinæ parvæ aut columbx ei mágnitudo. $R 0$ - Gefneruts frum longiufculum, anterius nigricans, pofterius flavefcens, extremis partibus inferiore \& fuperiore leviter decuffatis. Perne in collo, capite, \& pectore maculof $x$, pofteriore colli parte ad fufcum tendente; in dorfo \& alis fufc $x$, maculis quibusdan ruffis infignite. Crura oblonga, coloris fublutei. Digiti terni, brevibus interiore parte membranis juncti. Vngues breviffimi \& mutili. Degit in pratis paluftribus : \& aliquando in lacu Tugurinenfi glacie adftricto manibus fe capi permifit.

Victitat muribus quos", de noçte vena- Victuss tur.

Vocem tanquam fiftulæe edit. Domi inclu- $v$ ox. fa fubinde ambulat, aliquando in orbem ad multum tempus, circa columellam aut aliud quidpiam ; aliquando recto tramite; \& fi quid impedimento fuerit, tranfilit potius, quam à via recta deflectat. Oculos etiamfi digitos admoveas, non claudit.

Addit Aldrovandus aliam Oedicnemo 
congenerem. Crafitie corporis \& pedum conftitutione Otidem refert. 'Roftrum habet fuperius \& inferius æquè longım, rutilum, rictu amplifimo, naribus valde, ut in Anfere patulis. Caput, cervicem, dorfum, caudam, \& alas, ex flavo \& caftaneo elegantifime diluta \& maculata. Ventrem totum, \& femora, intus candida. Gulam \& pectus albicantia, intercurrentibus maxime in pectore, maculis. Tibias fi digitos pedum compares longiflimós.

\section{$A \mathbb{R}$ i I C U L u s IX}

\section{De Perdicibus in genere:}

$\mathrm{P}$

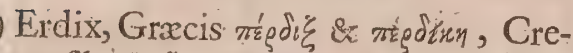

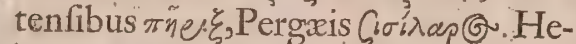
fychio rasrá, $b a$ dicitur. Quo nomine noftra $æ$ tate hæc avis indicetur, non fatis eft compertum. Perdicem rufum, veterum minorem vulgarem Perdicem effi placet Athen. 1.9. Turnero ; fed roftrum illius cinnabarinum InDialogo non admittit. Quidam apud Longolium
de Avibus, Bellon.1.5. Otidem cum Perdicibus confundit. Belde Avibus lonius ex eo quod Ariftotelis Perdicem c. 13: cum aliis ayibus modo magnitudo par fit, coire fcribit, Coturno Grxcorum, qui cum Gallinis rem habuiffe vifus eft, id nominis imponit. Aldrovandus cui Coturnus, \& Coturnix, magnitudinem qux pro diverfitate terrarum variat, (funt in Allobrogibus Scaliger Perdices mediocri pulfo non minores, Exerc.236. fi excipias, exdem; Coturnicem, Perdi1. 3. cem ruffam effe fentit, \& Perdices minoAthenxus res ab Athenxo appellåtas, eafdem cum Dipn. 1. 9. Avibus novis Plinii effe, \& Starnas tanquam externas vocari contendit; Rufticulam autem Plinii, quam Dalechampius \& Sueffanus Perdicem minorem effe credit, Gallinagini quam Afcolopa feu Scolopacem Ariftoteles vocat, ex defcriptionum collatione accenfet.

Genera. Genera ipfarum funt plurima. Strabo Inlib. 17. dicos vulture \& Anfere majores tradit. De Alian.l. I7 Graca feu majore ruffa áliquid diximus. deAnimal. Ælianus Syroperdicen vocat avem, perdice minorem \& nigram, roftro ruffo, manfuefcere nefciam, quxque circa Antiochiam Pifidix lapidem exeft, \& conficit. Athenxus Idem Perdices Cyrrhæos vocat, qui neque H. A.1.4.c. ad certamina valent; neque pulchre cantaAthen 1.g. re fciunt, \& allio vefcuntur. In Chio infuDipporof la funt rubre, Gallinx magnitudine. In
Nicoli de Nicol de AEypto cinerex, alibialbr. Apud Tro2. Trin. O-glodytas Gallinacei magnitudine, roftro Scal. Ex. \& cruribus feu fufcis feu luteis. In regno 236. 13. Barnagafii, qurdam Caponum magnitudine,pedibus \& roftro luteis, minores Gallinis, alias pedibus \& roftro purpureis, nonnullas roftro \& pedibus cinereis. In Hifpaniola diverficolores, fuaviffimi faporis. In continente, fi Oviedo credendum, Hifpanicarum Gallinarum magnitudine, duplici pulpajalia alteri fubftrata, exque tantx molis, ut unam ne infignis quidem helluo abfumere queat. Colore funt in pectore, alis \& collo cinereo. Ova ponint ovorum noftratium Gallinarum magnitudine, colore lapidem cæruleum æmulante.

Quantum ad internamconfitutionem bina Plin. H.N.

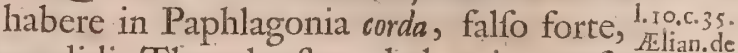
prodidit Theophraftus, hybernis menfi- Animal. bus nullos habere, $t e f e s$ eadem fide alii. In- 1.16.c.15. gluviem ventriculo in ipfis præjacere ap- Arift.H.A. pendices non fuperne ut pifcibus, fed in- Arit. H.A. ferne ad extrema inteftini haberi, cum Arit. H.A. coëunt turgidos valde teftes obtinere; ve- 1.3.c. r. riflime Ariftoteles prodidit.

Loca fi quæras, In Hibernia \& Lemniorum infulis nullæ fint, fi Botero \& Liberali credimus, nec minores in Creta, ruffre in Belgio rarx. A duabus in Anapheu infulam immiffis, tanta vis procreata, ut incolx de loco deferendo cogitarent. Apud Tarnaffaros, Ethiopas, Samios, Cretenfes, \&c. eximia ipfarum foecunditas. In infula Caprea adeo pinguiefcunt, ut adipem eximant incolx, \& in futura convivia fervent.Qux in Bocotia,fines in Atticam non transvolant, fi A thenæo fides, \& fi forte aliquo migraverint, voce $a b$ indigenis di- Athenreus gnofcuntur.

Vefcuntur limacibus, unde ibi nulli, ubi: $V^{i}$ itus. Perdices, in Sciatho infula cochleis, allio, Arit. 1. ....... quod de Cirrhæis Elianus prodidit; Sa- Athen.lig. bulo, granis \& aliis. Pamphagam effe fu-c.4. fpiceris.

\section{El. H. A.} 1.4. C. 13:

Libidinis funt profufffimæ, unde falaci- $\begin{gathered}\text { Scalig. in } \\ \text { Arift. de }\end{gathered}$ tatis venerex Symbolum. Sane Mares non plantis. tantum vifis foeminis, fed \& voce illarum Generatio.: audita, femen emittunt, ex animi forte Dipnæus. impreffione. Nam \& fi fpeculum contra eos pofuerimus ad imaginem fuam accurrentes idem faciunt. Tidem, fi Alexandro Myndio credendum, hiantes coëunt, \& toto coitus tempore lingua exerta volant. Nata jam ova, ne circa pullitiei educa- Elian:1.2: tionem occupatis fominis, earum focieta- de Anim. te fruftentur, frangunt, in aucupantes in- ${ }^{c .5}$. terdum Veneris impatientia ruunt, \& ca- Arif.H.A. pitibus ipforum infident. fi foeminarum plin. copia non detur, vociferantur \& pugnant 1.10.6.33. inter fe. Victum ajunt Venerem pati, \& quidem tamdiu donec ipfe alterius victor slian. de evaferit, quin in proprios pullos idem fce- Animal. lus committunt, eofdemque fimul ferme $e^{1 \text { 10. c. } 47}$ ac exclufi funt; fubagitant, nec Gallinaceo parcunt generi, ex quorum cum Perdici- . bus congreflit, tertium quid progigni Ari- Arit.1.2. ftoteles reliquit. Nec remifior $F_{c k}$ ellla fa- de Gener. lacitas. Si contra mares fteterint, aura ab Plin.H.N. his flante prxgnantes fiunt. Hiantes per 1.ro.c.33. tempus exerta lingua æftuant, concipiuntque fupervolantium afflatt, frpe voce tantum audita mafculi. Adeoque vincit etjam libido foetus charitatem, ut illa furtim Dipn. 1. g. 
\& in occulto incubans, ctrm fenfit foemi- dunt, pugnant. acuitur pugnacitas, fi trinam aucupis accedentem ad marem, recanat, revocetque \& ultro fe prabeat libidi$\mathrm{ni}$; quod tamen Plutarchus inficiatur. $\mathrm{Ni}$ dum cæterarum avium more non exftruunt, fed partui vicinx aream feu receptaculum è feftucis fubfternunt, idemque fpina

plin. 1.c. \& frutice; tum ut contraferas abunde val4elian. 1.3. lentur; tum ne ova à tore decidente vel imc. 16. co. bribus $\&$ fic infoecunde evadant, afficiantur, muniunt, nec in quo loco peperere incubant. Septem vero diebus nidum contexunt, feptem in pariendo confumunt, fep1. 17. de tenos pullos enutriunt, fi Eliano crediAnim.cirs mus: Ova bis quotannis ponere Albertus dicit; decem, frpius quindecim \& fedecim, illaque feu alba, feu ovis colutimbæ fiAritt:H.N. milia, alii addidene. An utraque Perdix in1.9. c. 8. I.lian. 1. cubet, ab aucupibus inquirendum eft. ExcluPo.de Ani-fronem quod fpectat, pullos ntoræ impatienmal.c.35. tes, occupatis fpatiis fpontc erumpere pertufisque ovis, ubi primum caput exeruerint, pedefque protulerint, reliquo corpore adhuc adhærefcente, procurrere, fibique cibum dustu matrum inquirere, flian.1.4. ajunt. Sane more Gallinarum, plumis obde Anin.c. veftiti, in agros ubi mefis ftetit, deduVarix.h- cuntur, quod mater fuo volatu is cibum fto. c. 3. fubminiftrare nequeat.Vitam ad quindecim Dipnof.1. 9 vel fedecim annos extendunt, quod ad viPlin.H.N. 'gefimum quintum pervenire, apud A Arifo1.ro.c. 33 . telem legimus, mendum eft. Olfactus ip1. 9. c.7. fis exquifitus.

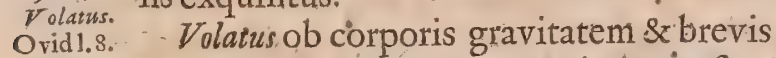
Metamor \& humilis; velox tamen \& impetuofus, hyberno tempore gregatim, verno, cum proli ftudent, binæ tantum volant.In Bootia fui cum volant non effe juris, fed in ipfo aëre, quas tranfire non audent, metas habere, inde ultra notatos jam terminos nufquam exire, nec in Atticum folum tranfPolyhirt. meare, Solinus fabulatur. Vocem non ean-

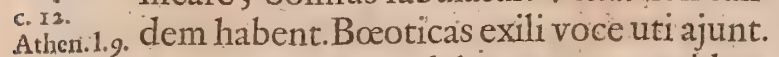
AtheniscircaCorydalum pagum oppidum verfus caccabant, ultra vero $\left.\pi 70 \beta^{\prime}\right\} 8 \sigma$.

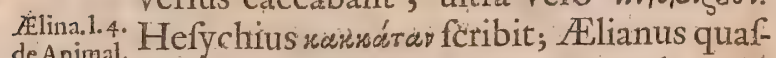
de Animal.
C. 13. Ex ipfarum cantu certiflimum jam appropinquantis diei fignum, fed falfo afferit 1.5.deAvib. Bincllonius.
c. I4. Bellonts

Prugna. De Pugnasitate earunt quxdam produnLampid. in tur. Alexander Severus Perdicum \& $\mathrm{Ca}$ Lutigna- tulorum certamine fefé oblectabat. Cynus in hitt prii eafden ad ejufmodi certamina enutriunt: A pud Gefnerum è Sedunis allata, felem mordebat. Pugnant \& inter fe cum gregatim per nemora pafcentibus, foemina ceu futuri certaminis fpectatrix fefe offert, \& nifi victori copiam fui faciens.

Vichus. Victus nunquam in confpectum prodit. de Animal. Pulli cum primum ad coitum educuntur, c. . $\quad$ fua cute armati, quam vel ad arbores affricando; vel luto oblinendo afperam redchomannes \& polytrichum in cibo offe Lieralis in rantur, fi Liberali credimus. cong. mir.

Sed \& fingulari pollere Perdices ingenio Ingenitim. certum eft. Si ad nidum coperit accedere Plin. H.N. auceps, pracurrit ad pedes foeta, prxgra- Arift. $H$. $A$.

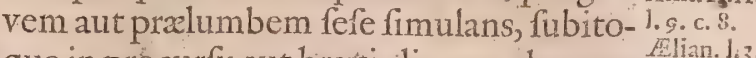
que in procurfu aut brevi aliquo volatu ca- de Anim. dit, fragita aut ala aut pedibus, procurrit c. 16 . iterum jam jam prehenfurum effugiens, Spemque fruftrans, donec in diverfum abducat à nidis. Eadem pavore libera, \& materna vocans cura, in fulco refupint, gleba fe terrx pedibus apprehenfa, operit. Difcunt \& pulli aftum, \& quamprimum ho- Plutdefominem adeffe fibillo fignificarit mater, fu- mal. pini fe collocant, \& corpus quifquiliis tegunt. Nec deponit has venator fraudes. Ante retia propofitus, cantum ad pugnani laceffentem orditur. Sylveftribus ingruentibus pedem refert, ipfi in laqueos incidunt. Nolo fermoni humano enunciando aptos dicere, quod aliqui ex fcriptoribus Statius I. z. innuere, \& latiufcula earundem lingua fua- Sylv.

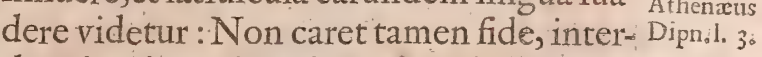
dum ita cicurari poffe, ut, cum Gallinarum domefticarum cohorte promifcue habitent, quod apud Aloyfium Mundellam fa- Aldrovan-

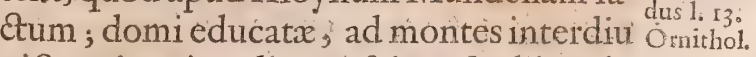
victum inquirendi ergo fub cuftodibus di- c. 16 . mittantur,fibilo revocatæ fub vefperam redeant, quod Nicolaus à Nicolais in Chio Nicol. 1. infula communiter fieri prodit; \& ab ho- Navig. Omine de loco in locum ad quatuor millia, rientalicis ita ut ille terra iter faciat, iftx per aërem volent, quiefcente quiefcant, ducantur; quod in Ponto vifum, Odoricus de Foro Julii tradit. Ova deperdita per alterius ma- Cafiodot: tris damna, ut adoptione alienæ fobolis var. $1_{6} 2_{2}$ fux orbitatis incommoda reparent, refard cire; Natos in campos eductos, ut fuerint materna voce commoti, ovorum genitri cempetere; ubi fenfere medicamentum $1 x$ - कtrus 1. is

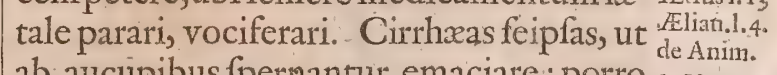
ab aucupibus fpernantur emaciare : porro c. rin. ad vocem fonoram conciliandam uti; vul- Arit. 1.2 . neri ori anum, manfum imponere; lau 1.39 . ri foliis annum faftidium purgare; arun- Atlian.1.5. dinis lecta, \& feu comefta, feu in nicium ${ }_{\text {c. } 46 \text {. }}^{\text {Anim }}$ impofita coma, oculorum fafcinazionem Plinius in vertere, adductorum Authorum fide re- H.N. fertur:

Vfus Cirrhæ̧arum in cibo,nullus alliis enim c. 35. vefcuntur : noftrates laudem apud omnes, c. I 1. Martialem fi excipias, muruerunt, qui pul- $V$ jus. los veteribus, alas reliquis partibus preferunt. Fuere \& exta \&x ova in ufu. Helio- Lampr. in gabalus Palatinis ingentes dapes is re- Heliogab. fertas exhibuit. Sed nec Midicina il- Cardanum in lis deftituitur. Caro Elephantiacis, lue Aphotif. venerea affectis, fluxu alvi laboranti-1.3. Hediabus prodeft. Medulla \&c cerebrum cum ta. bus prodeft. Medulla \& cerebrum cum Plin.H.N vino, ictericis; ventriculus ex vino 1l1- 1 , з थ. c.6. 
Idem 1.16. nigro iliacis; jecur aridum comitiali morGalen. 1. bolaborantibus, fanguis fuffufioni oculorodefim- rum; fel in hebetudine vifus, \& albugiDifcorid. nibus cum melle commintum; pennæ 1. 2. c. 72 . combuftxad uteri ftrangtilatum; ova ad. ${ }_{\text {1). } 14 .}{ }^{\circ}$ lactis copiam, facere creduntur.

A R T I C u L u s X.

\section{De Perdicibus in pecie.:}

\section{P U N C T.U M I. \\ DèTerdice Graca Bellonii, Perdice ruffa. Cinerea \& Damafcena.}

Bellon.1.5

DERDix Gr E A craffa quoque \& dicitur. Noftratibus duplo craffior eft ; rofro pedibusque rubris, maculis ad anteriorem ventriculi partem eifdem quibus ro- $^{\circ}$ Atra refperfa, médiocris Gallinx magnirudine. Frequens eft in rupibus Colmenfibus, infulis Cycladibus \& Cretæ maritimis. Vox noftrarum voce major, coịtus inprimis \& partus tempore. Nidificant fub dio menfe Majo. Ova edunt fub aliquo magno lapide octodecim, quandoque fedecim, ovis Gallinæ fimilia, minora, alba, mac ulis fubrubris exiguis refperfa, ufui peridonea, fed quorum vitellus non congelatur.

PERDIX R UFF A five major, coIumbam exprimit, roftrum habet Cocci colore, pedes minus rubent. Color cinereus per dorfum, pectus \& caput decurrit. Oculorum palpebræ in marginibus rubent; $a b$ iis linea nigra retro per collum tendit, inde reflexa per pectoris partem fupremam fxpe circulum facit : quod intra eam eftalbicat.

PERdix Cinerea, feu minor, Græcis ignota, ex defcriptione- Gefneri, coloris eft varii, nec defcriptu facilis. Ro' frum fubfufcum. Caput è ruffo fufcum; fynciput, partes circa oculos, proram capitis fimpliciter ruffa : collum \& pectus cinerea, exiguis maculis nigris quafi per verfus, crifpos \& undantes, interftincta : Dorfum, caudam \& alas varios colores præ fe ferendo, crura ex fufco albicantia. Gregatim volat, vere vero bimatim.

Perdix qux fub $\mathrm{D}$ A M A S CEN RE nomine Aldrovando transmiflą eft, brevitate \& craflitie corporis ad Perdices accedit, minor tamen eft, roftrum habet prolixius; A. H. A. pedes quodammodo luteos. Nec tamen 1. 16. c. 7. Eliani Syroperdix eft, etfi magnitudo refpondeat. Nec enim eft nigra, neque roftrum habet ruffum, inmo illa manfuefcit, cum hac femper in feritate perfeveret.

\section{P. U N T U M II.}

De Perdice alba, feu de Lagopode.

D Erdix alba, Lagopus à pedibus leporinis \& villofis; Ariftoteli, qui nullum Arit.H.A. animal præter unim leporem pedes villo-1.3. c. I2. fos habere fcribit, incognita; Hefychio \& Phavorino $\lambda \alpha$ ywituys. Horatio Lagois, nifi Horat. 1.2. fortè pifcem Romæ rarum \& ideo carum, fermon. quod interpretes volunt, intelligat; aliis AldrovanPerdix petrofa dicitur. dus $1 . I_{3}$

Duorum autem funt Generum. ， Ornith. c. Prius eft columbarum magnitudine, Genera. tanti candoris, ut à vënatoribus hoc folo, 1 1. 10. c.48. quod nives fuperat, vifu deprehendatur, Scalig. Expedes tamen \& roftrum nigricant, fuperci- ercit, 59. lia in mare inprimis rubent : collum ma-dus l.c. culis quibufdam nigricantibus perfpergitur, \& radiçespennarum nigrefcunt.

Alterum nomine eodem à coturnicibus magnitudins tantum differens croceo tinctu; quod Aldrovandus Perdicem Bellonii Damafcenam, feu. Syroperdicem effe credit. Dorfi \& colli colore Gallinaginem æmulatur. Alæ qux corpori junguntur, albas, fufcas \& fulvas pennas habent; decem remiges cinere $x$ funt; pars interior \& venter albent, \& torquem in pectore rubro, fulvo, flavioque coloribus conftantem habent.

Defcribit \& Gefnerusaliud, quod per Gefnet.' in xłtatem fulvefcere, \& ne per hyemem qui- Ornith. dem albefcere dicitur.

Reperizintur Lagopodes in Alpibus, \& Locus. Pyrenæis montibus inque fummis jugis Plin. i.c. imminentibus ei valli cui nomen Arbuft, Scal.1.c. qua fauces aperiunt, iter: Ita vero frigore, nive, \& glacie delectantur, ut ubi locis in ferioribus liquantur nives, altiora \& foli averfa profequantur loca, in quibus nix perennat.

Vocem edebat, quam Gefnerus defcribit, $V_{0 x}$. cervinæ non diffimilem.

Naturam fi fpectes, non extra terram, in Ingeniwis. qua nafcuntur, iis vefcifacile; quando nec Plin. $\mathrm{l}_{\text {a }} \mathrm{c}$. vivæ manfuefcunt, \& corpus occifarum ftatim marefcat. Latent quidem homine confpecto; eoque diffimulato fefe moru prodere cavent, tanta iis fallendi fimilitudine nivis fiducia ; fed tantx etiam fimplicitatis funt, ut à venatoribus difpofitam stumpf. lapidum feriem transire non audeant, fed apud Aldr. fecundum illam, quafi fecus murum infuperabilem decurrentes in decipulas incidant.

VJus earum \& in cibis eft. Præcipua fa- V fus. pore effe Plinius dicit. Saluberrimas tefte Scaligero Norici credunt guftu; fubama-Scaliger. ras Gefnerus reliquit. Exerc. 59.

NB. Perdices Indicas vide in MantifJa. N.8. 


\section{A R i t c u t u s X I}

\section{De Coturnice Latinorum:}

Generdi:

Coturnix Græcis antiquis ógtu dernis ó Quisquila, Gafio Quaquila dicitur. 'Unum duntaxat ipfarum obfervatum genus. Vifa tamen \& Alba,fi Ariftoteli credimus; Arift. 1. de \& in campis Ruflicis \& Podolicis virenticolorib. bus pedibus, quarum ufusfpafmum indu1. r. de Po- cat, inveniuntur. Notæ quas fuis veteres lonia. tribuunt, \& in noftris reperiuntur. Parvæ Plin.H.N. funt, pedes fiffos, \& pinnas duras habent. 1.10.c. 23. Theophrafto forte Perdices nanx dicunAritoto in tur. Mas \& Fomina diftinguuntur, quod Phyfiogn. Fœminx totus color quodammodo teftaceus fuperius ad cervicem, dorfum, caudam \&alas, ad mentum \& pectus fubluteus; ad ventrem fere albus. A roftro ejus fupra oculos \& aures linea infignis longitudinis alba, circulares aliquot maćulas habens excurrit. Cauda pro proporrione major eft. In Mare roftrum magis nigricat. Supra illud capilli quidam extant. Collum lineolis albis intercurrentibus ruffefcit. Pedes minus lutefcunt; digiti vero éorum ita conftituti funt, ut medius primo \& tertio longe major fit, pofterior quem pro calce habet, longe exiguis. In internis partibus fingulare quid obtinent. Arit.H.A. OfJa ipfis dura \& folida. Ingluvies \& gula 1.c. . prope ventriculum ampla \& lata. Cor tev́Athen. 1.9. Borov, feu muricis modo in tres cufpides divifum. lecur \& fellis conceptaculum inteftinis agglutinata. Fellis ad inteftina labentis canalem vix afpectabilem. Teftes jecorifubditos.

Quantum ad Locum Averrhoës in AnGal. 1. de dalufia, tefte Galeoto Martio reperiri nepromiftua gat, in mediterraneis Galliæ tractibus funt doctina. rarx. In Delo, unde nomen Ortygix forAofenh. tita eft; ad finum Arabicum, in fuperiore Antiq.1.r3 Æthyopia, Terra fan@ta, Madera, Capreis c. J. magna ipfarum copia, ad Trnarion, qux Procop. 1. nunc Cerempolis, tanta, ut hodie Porto de r3. de bel- Qualeis nominetur. In agrum Neopolilico" tanum tanto numero ex A frica propelluntur,ut glomeratim fxpe in æedes maritimas incidant, \& fine ulla difficultate capiantur. Migratorias effe aves, omnes, Albertum fi excipias, concedunt. Adyeniendi habent tempora xftate depulfa. Cum maria tranant, impetus differunt, \& metu fpacii longioris vires fuas nuitriunt tarditate: Ubiterram perfentifcunt, coëunt catervatim, deinde globata vehementius

Polyhift. properant, quæ feftinatio (funt verba Soc.r8. lini \& Plinii) plerumque exitium portat Plin.H.N. navigantibus Accidit enim plerumque noetibus, ut vela incidant, \& praponderatis finibus alveós invertant. Auftro nunquam exeunt, nam metuunt vim flatus tu- midioris. Plutimum fe Aquilonibus cre dunt, ut corpora pinguiufcula atque eò tarda facilius provehat, ficcior \& vehementior fpiritus. Ortygometra dicitur quæ gregem ductitat. Eandem térrx proximantem fpeculatus Accipiter rapit, ac propterea opera eft univerfis, ut follicitent ducem generis externi, per quem fruftrentur prima difcrimina. Quod de tem pore dixit erratum eft, nifi de terris tepidioribus xftate apud eos depulfa intelligantur : quod de continuo volatu cum malis \&r velis infediffe obfervarit Bello- Bellonit.5: nius, in Delum frepiffime delatas alii; in de Avibus Ponticis infulis inquiefcendi cáufa paucos dies morari Varro; falfum, quod de navi- Varro 1.3. gantium exitio vix credibile, nec tantam de re rut fimul abire multitudinem verifimile, cum nonnullo corporis pondere \& vento apto deftitutx, in locis apricis \& tepidioribus remaneant. Auftro nunquam exire falfum. Cum \& Bellonius à Septentrione in Bellon.1. meridiem tendentes, cum è Rhodo Ale- de Avibus xandriam Agypti navigaret, obfervarit; \& Ariftoteles Auftro tanquam humido \& gravi molefte volare prodiderit. Sec nec de Ducibus inter authores convenit. Ariftoteles hæc loča adeuntes, fine Ducibus per-Arift H:A.

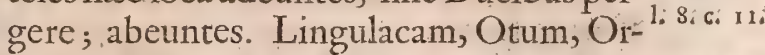
tygometram, \& Cynchramum Duces habere; $a b$ hac noctu etiam revocari, fcribit. Plinius id ad ventum transfert, \& de Plin, H:N Ducibusita. Glottidem feu Lingulacam ${ }^{1 . c}$ initio blandita peregrinatione avide profectam, pœnitentia in volatu cum labore fcilicet fubit. Reverti incomitatam piget, \& fequi, nec unquam plus uno die pergit. In proximo hofpitio deferit. Verum invenitur alia anno intercedente relicta : fimili modo in fingulos dies. Cynchramus perfeverantior feftinat etiam pervenire ad expetitas terras.

Victitant granis milii, tritici, \& aliarum $V$ ictus. frugum. In Capreis infulis Acinis herbarum; apud Holandos Bryoniz, fecun- Junius in dum Portam malo Punicos femine can- Novendal. nabis, lolio, \& tritico faginantur, fed \& Hellebori femen perinde ipfis cibus, ac Lucret.14s. fturno cicuta, qux hominibus venena effe de natura creduntur; (ideo Plinius veneni femen Aritt. 1. de dixit) recuperandx fanitatis caufa, cum plantis. Epilepfia tentantur, quod Aquæ placet, Galeni ad feu peculiari quadam naturæ fue praroga- Aplirodif. tiva, concoetio enim non vi duntaxat ca- problem. loris, fed tota ventriculifubftantia perfici- Ambr. 1.3 . tur; feu, quod, cum pertenues habeant Hexami.c. ad corda penetrantes meatus, antea devo- $1.10, c, 23$. ratam cicutam concoquant, quám indé le $\& 7^{2}$. thale gelu ad precordia pervenerit, ut $\mathrm{Di}^{-}$Solin. $\mathrm{Po}$ vus Bafilius cenfet. Aquam fimul ac bibe-re, turbant, feu quod tali delectentur, feu quod fingularem cum Camelis \&Elephantìs, quibus idem folenne, amicitia gerant. 
NA T UR A L I S

Generatio. Solacitas ipfis qux Perdicibus, frpius Atirt. H.A. coïtum repetunt, \& humi nidulantur.
1. g.c. \&:

Athen.1.9. Sunt qui quotannis quater prolem edere velint; bis in his quas petunt, bis in his ad quas revertuntur regionibus. Utut fit, quo loco pariunt non incubant, ne quis locum longioris temporis mora percipiat. Sedecim ova cornicis fimilia, fi, Bartholomro Anglico credendum, excludunt; ex his pulli fominæx, rurfus ad decem menfe Augufto pariunt. Unde non mirum tantam Coturnicum copiam, \& menfe Majo incubanti infidiantem, fpem centum \& amplius perdere.

Volatis. Volatus funt modici, Auftro prifertim flante, cujus humiditas corporis gravitatem auget, fed defectum curfu compenfavit natura, hinc Comeftori Currelii dicuntur.

Vox.

Vocem imari Ariftoteles ademit, exilem Albertus credit, foemin $x$ craffam. Menfis Aprilis initio canere incipiunt; num fubito cum ad nos venerint, dubium. Vox nemini nota non eft, \& ideo apud Athenæum Pratinæ placuit, ut doó $\phi$ wvov dixerit. Sapientes olim pro gnomone utebantur, quod verum cantu fuo horofcopi emerfum fignare crediderint; cum in eo certum numerum fervet.

paghas. Pugnacitas quæ avibus duræ pennæ comAint. in munis, in iftis adianthi ufu accenditur, Diofcor. in \& occafionem, ut Ariftophanes Carcini 1.4. c.131. Poëtxe filios, ofrúras ouroysvês dixerit, \&

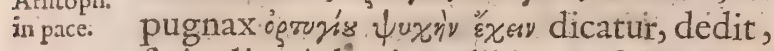
fatis olim Athenis \& alibi nota fuit: ubiad certamen tanquam ad gladiatores ludos effuffifime conveniebatur, \& Solon pugnantibus fpectandis tempus impendere jubebat. Necignota Neapolitanis hodie, aliquoties viotrix, duodecim frepe aureis venditur. Auguftus quoque tanti fecit; ut Erotem Egypti Præfectum, quod victricem per contumeliam ediffe, morte infami Quintil. 1. multaverit, \& Areopagitæ puerum, quod 5. Intiti. Coturnicibus quas comprehenderc poffet, oculos erueret, damnaverint Antipatbia Flian.1. de ipfis cum Pelicano, fed \& cum Luna \& So${ }_{49}$ Animal. $c_{+}$le exorientibus, fi Oro credimus. His vifis terram fodicant, pupillafque identidem confcribillant.

A1orbi. Epilep/ia eas laborare, experientia comPlin. H.N. probavit, fed folas præter hominem quod 1.xo. c. 22. Plinius prodit, falfum; cum Hippocrates, ré morbo capras \& oves, Scaliger canes, Rhodigifacto. nus feles \& arietem, Abfyrtus Equos, BroArit: Con drus A ccipitres \& Graculos, eodem morriftot in bo vexari fcribant. Qux de Ingenio ipfaRhad: 1.6. rum Oppianus \& Plinius, nempe adverfo. Aniq.leat. flatu pondufculis lapidum appenfis aut c. 7. gutture arena repleto ftabilitas volare, \& Oppian. in cum mare transvolant, fingulas ternos ore Ixeuticis, lapillos ferre, fingulos per intervalla dimit1. 10. с. 29. tere, fic utrum mare tranarintobfervare;

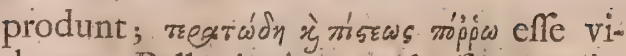
dentur. Bellonius in naves lapfas aperuit, \& milium duntaxat reperit, lapidum non obliturus, fi aliquos inveniffet.

$V$ fus Coturnicum olim in cibis apud quof- $V$ fass.

dam nullus, quod veratro vefcantur, \& Plin. H.N. comitiali morbo laborent. Galenus quof: t. to.c. 23. dam, qui ediffent, in Doride, Bootia, Galen. I.6. \& Theffalia mufculorum diftentionibus comm. 5 . correptos obfervarit. Nos nihil tale fentis . mus, ut nec ex capris vel avibus quicquam, ex modico efu aftarum inprimis optimun pollicetur fanguinem Aldrovandus, ex immodico, pinguiorum inprimis, putredinalem febrim minatur. V/um in Medicina fi requiras, cerebrum ex unguento myrteo Galen: de tritum, \& ftanneo vafe repofitum, Epile- Eupotift. ptico paroxyfmo medetur,fi faciem co illeveris. Adeps cum pauco lielleboro membro pudendi inunctus, venerem auget, cum melle, myrrha, \& chalcanto albo oculorun vitia corrigit. Cum Zingibere tritus, Equorum oculos incolumes fervat: Caro inveterata porcorum \& pifcium efcre immifcetur.

\section{NB. Coturnicis genus exoticum vide in Mantiffa. N.7.}

\section{A R T I C U L U'S XII.}

\section{De Ortygometra.}

D E Ortygometra quam Plinius \& Ga- Plin. I. ro. za Matricem, Villanovanus Ethigometram, Scaliger Coturnicomatrem, \& Scaliger in verius vocat; vix, quid certi dicendum Comkı. ad fit, habemus. De forma nihil fere ab An- 1.8. tiquis traditum eft. Ariftotelem fi excipi-c. I5. H.A. as, qui paluftribus avibus facie fimilem ef- Aritt.H.A. fe reliquit. Sed nec ex Recentioribus quic- 1: S. co I zo quam certi colliges. Scaliger non abfimi-Scalig. 10. lem gallinagini, magnitudine parem, co- co citato. lore tamen dilutiore, facie tota coturnicis, effe, \& ab aucupibus matrem Qualearum, ab aliis Rafcle dici, fcripfit. Bellonius duplicem ponit. Vram quam Rafcle Belloni.1. quoque nuncupat. Alteram quam in geni- de Avibus ftis degere affirmat, magnitudine Ortygo- ${ }^{\text {c. } 19 .}$ metræ nigræ, quam falfo Rallum nominat, colore precipue ruffo, in alárum coftis fubrubente, in femoribus caftaneo, maculis albis interftincto; capite perdici cinerere fimili. Aldrovandus, qui aquaticarum hane ferefpeciem effe putat, ut crura habeant oblonga, digitum qui pro calce eft perbrevem, corpus gracile, plumas plærunque varias, ventrem albicantem, caudam brevem, roftruin longiufculum, modice flexum, avem, quam à Cardinali Paleotto acceperat; quixeque roftrum coturnice majus, caput, collum, dorfum, \& majorem alaxum partem teftacei coloris, alas qua ventrem contingebant ruffefcentes; crura pe- 
desque pro corporis portione longos; co- ribus Hortulanis fimilia, color duntaxat lore inter croceum \& viridem medio, ob- in omnibus pallidior. tinebat, pro Ortygometra pofuit.

\section{A R T I C U L U S VIII.}

\section{De Cynchramo.}

Arift. H.A.

C Ynchramus Hefychio Cynchramas, Ariftoteli Cychramus,aliis Cenchramus quoque dicitur.Quxnam fit avis inter graviores non convenit, etfi fere certum eft, nec linariam miliariam effe; ut Rucllio placet, \& in fequentibus patebit, nec ex cenchritis avibus milio quidem pinguefcentibus fed aquaticis, \&ex Anferum genere : nec Cenchrin,à varietate punctorum milii inftar dictum, ex Accipitrum faGefner. in milia. Gefnerus Helvetiis stractuogel diOrnithol. dtam, fere effe putat, quæ cruribus eft proceris, roftro oblongo, eodemque modice inflexo, qure autumno avolat, \& tem-

- pore verno cum coturnicibus redic, \& paBellon.1.4. Iuftribus delactatur.Bellonio eft Gallorum de Avibus le Prujer aut Preyer, qux alauda criftata Defcriptio. eft major. Roftrum habet breve, craffum, tuberculo confpicuum, ad inftar offis $\mathrm{du}$ rum, inferius cum fuperiore conjunctum, foveam in medio efformans, ventrem pallidum \& nigris quibufdam maculis diftinetum. Crura pedefque inter rubrum \& cafta neum media, pofticum digitum longum. Verfatur in pratis, hordeo \& milio delectatur, nidos in agris avena \& milio confitis exftruit, \& fex pullos excludit.

Vox ipfi Tirtertirteriiz.

Vox.

Cum volat crura contra aliarum avium morem pendere finit. Aldrovan- Aldrovandus Hortulanum omnino effe
dus Orni- credit, avem alaudre magnitudine, at pau thol: 1.13. lo minorem, cuiroftrum, crura tota, pedumc. 24. que digiti rubefcunt. Caput, collum \& pectus in mare intercurrentibus punctis croceis, fla$v i$, in foemina partim flavi, partim viridis funt coloris, alarum pennæ inter coftales in utroque fexu, flavo \& nigro colore tinguntur, mas fub oculis ad latera maculam habet rotundam, intenfe luteam, qux in fomina non eft.

Reperitur in agro Bononienfi \& Florentino, ex milii efu vehementer pinguefcit, \& magno numero depilata, \& fcatulis affervata,Romam tranfmittitur, ibidemque caro pretio venditur, funt vero \& alia Hortulanorum genera, Flavus nempe colore propemodum paleari, alarum coftis \& remigum pennarum extremitatibus albis. Albus cygno ipfo fere candidior, $\Xi 3$ Hortulanocongener. Caput ipfi ex cinereo ad flavum vergit, collum cinereum nigrismaculis punctatim diftinguitur. Venter, crura, pedefque crocea funt. Cauda tota fufca ad latera latefcens. Albicilla cujus cauda alba, cetera vulga-

\section{A P U T . II.}

De Avibus fulveratricibus domejticis.

$$
\begin{gathered}
\text { A r } \mathrm{x} \text { I c u L u s. I. } \\
\text { De Gallo Gallinaceo: }
\end{gathered}
$$

Allus Gallinaceus, Grecis cevus à $\lambda \varepsilon \varepsilon$ -

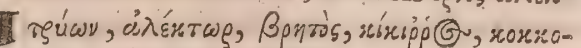

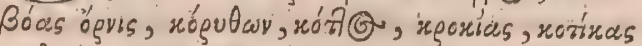

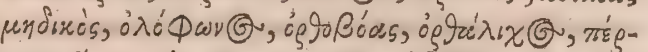

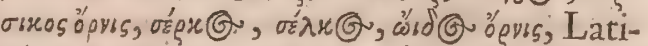
nis cohortalis avis, lucis, criftati oris, \&c.

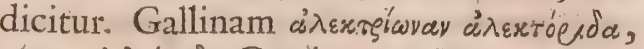

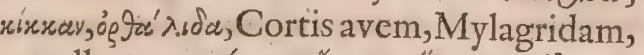

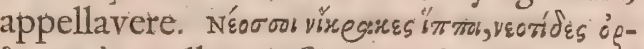
Pacia ò, pullorum funt nomina.

Differentiz ipfarum funt variæ, quæà locis, Genera: voce, integumento, partu \& incabatione fumuntur. Hadrianarum Gallinarum Ariftoteles Arift.H.A: mentionem facit, quæ pennæ verficolo- ${ }^{1 .}$ G. . . I. ris, quotidie pariunt, fed pullos interimunt; quas Athenienfes alere ftudebant, Athenxus quxque vel funt exdem cum nanis, \& pis. Dipn. 1.7 . milionibus feu Plinii, quibus certa foecun- plin. 1. re: ditas rara, \& incubatio ovis noxia, feu c.53.\&56. Columellæ, quæ etfi vetuftæ propter in columelfoecunditatem improbantur, pluribus ta- lade re rumen locis focundx reperiuntur, \& ova tical. plurima edunt, vel cum Longolii Parturientibus feu Leyhennen, quas verficolores, \& fortro longiufculo facit. Pümilas enim, qux paffim extant, \& claudicando potius, quam incedendo per terram reptant, nemo iftis accenfuerit. Sunt \& $T_{a}$ nagræx, Lydæ, Rhodiæ, Chalcidicx, Medicx, \& Alexandrinæ. Ex Tanagrais Galli inprimis probabantur, alii $\mu \alpha \chi^{s} \mu 06$ feu pugnaces dicti; alii Cofliphi \& Merulæe dicti, qui Lydas magnitudine æquabant, paufanias, Corvis colore fimiles, paleariam \& criftam in Bootiinftar anemones, nec non candida \& exi- cis. gua in roftro fupremo \& caudx extremitate figna, habebant. Cum omnes à præ- Varro de liis commendentur ; \& amplitudine pa- Re ruftica. res lint, facile ejusdem generis efie fufpiceris, forte \& cum Longobardicis, qui la. pedibus ufque fublatis incedunt, plumis ex auro fulvis teguntur, eofdem. Patavinas Hermolaus, \& Longolius dixere; fed quia cauda deftituuntur, quod veteres in fuis non reticuiffent, vix eft credibile. Sunt \& in regno Senegx, Gallinæ Pharaonis dict $x$ : in regino Tarnaffari noftris triplo majores. In Jamaica infula $\mathrm{Pa}$ - Petrus vonibus nec magnitudine, nec fapore ce-Martyr in dunt.

Reperitur \& prope Theffalonicum ge Aliand de rus quoddam Gallinaceorum perpetuo Anim.L is mutum nunquam familiari his alitibus cantu vocale. Nonnullx quoque funt $\mathrm{Lani-}$ gere: ut in quadam Orientis urbe, \& nivei 
coloris in regno Mangi pilis more felis ni- fupernum \& internum per quod fub fepto

grisviftiuntur:De reliquisfuislocis agemus. transverfo inchoatum, ad formam perfe-

Forme. Quantum ad Formam, Gallum gallinaceum Alucone fcilicet majore minorem prodiArit.H.A. dit Ariftoteles. Sóli fidipedum altilium 1. 9. c. 8. colores diverfifunt, \& nitorem hune fi attenLaërt, in das, majori fpeciofitate quam Crofus veSolone, fin H.N. Aiuntur. Spectatifimum infigne ipfis, cor1.ro. c. 17. poreum ferratum, nec carnem id effe, nec Arit.H.A. cartilaginem, nec callum jure dixeri1. 2.c. 8. mus, verum peculiare. Criftam Latini $\phi_{0 .-}$

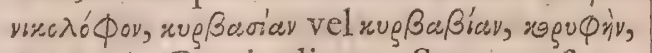
$\&$ doiфion Graci, dixere. Semper eft exerta \& rubens dum integra fanitate fruiIn itinere tur,\& mirum de ea Herberfeinius: Cum Mofcoriti- cuidam in Mofcovia frigore jam fere eneco.

cto, abfciffa fuiffet, fibireftitutum, erecto ftatim collo cantaffe. Plicabilem Gallinæ obtinuere, \& per medium caput deorfum dependentem. Oculos omnes habent fplendidos, falacitatis indicium. Palex (Ariftoteles rásxasay ob purpureum floridumque colorem vocat) ex rutilo albicantes, fub mento \& collo, velut incanæ barbæ dependeant. Rofrum robuftum, in fuperiori parte aduncum, coloris plærumque cornei vifitur. Caroqux roftrum undique cingit, nonnullis mentum, Columellæ gena eft. Iuba (fic longiores cxteris plumas Columella dixit) collum $\& x$ cervicem undique ambiunt. Vel pectus vel pars ventris pofte-

A pic, 1. 6. rior Navis, à qua pullum aperiri jubet Apic. ult. cius, vocatur. Cauda, quam or "reav Hefychius vocat, maribus major, quam fœminæ, binæ longiffim $x$ incurvi arcus imaginem propter teneritudinem præ fe ferentes, in foeminis funt; quæcapis faginandis fub cauda evelluntur, pinguefactorias Germani

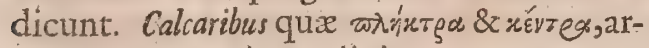
mantur mares ; inque iis in magnam quandoque molem excrefcunt, fed \& gallinæ cum mares vicerint, cucuriunt, crifta etiam caudaque érigitur, ita ut difficile fit, an fint fominæ, cognofcere, nonnunquam calcaria parva, errorene naturx an opere ignoro, Plin.H. N. iis enafcuntur. Plinius Gallinas probat im1. ro, $c_{*}, 6$ paribus digitis, aliquando \& fuper quatuor transverfo uno, Columella quinque, ita tamen ne cruribus emineant transverfa calcaria,fed hrec ad Oeconomiam fpectant.

Galen.l. In Internarumpartium ifta eft ratio. OJ a habent de ufu par- confiftentiam laxam, cavam \& levem. In-

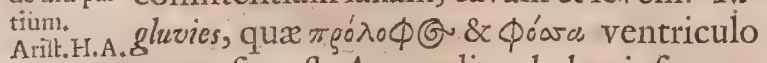
1. 3 , c ult, prepofita eft. Appendices habet infra, qua definunt inteftina, ut vere ultra ventricu-

Plin.H.N. lum effe Plinius fcripferit. Pellicula intra 1. Ii.c. 37. ventriculum ftercorideftinata, Echinus, ab afpredine dicitur, Diofcordes roı $\lambda$ ían vocavit. Teftes gallinaceis funt fub jecore, foeminæ fupra caudam. Uterus ex defcriptione M. Antonii Ulmi duplex habet foramen. Infernum per quod ovum $\mathrm{ab}$ externa refpiciens jam perfectum egreditur: Cam fufcipiendam ingreditur. Totus in parte finiftra ad finam fitus eft, dextram abdominis \& centrum, inteftina obtinent. Exitum ipfi in fuperna ad fpinam definente parte dedit natura, quia animalia fupergreffu coëuntia, inftrumenta in proximo habere oportebat, in inferiore podicis ad ventrem pofitus, quia infra illius eft ofcium. Uterque tam proxime cute, quod preputium dixeris, \& mufculo, fphæric figuræ, ut extenfioni magis accomodi effent, obtéguntur, ut arctiflime conniventia,fenfim ipfum aliquando fallere poffent. Uteri fubftantia membranea \& craffa eft, figura concava, trium digitorum longitudine, qua ad exitum pertinet latior. Porrigitur ab infimo abdomine, juxta ipforum inteftinorum exitum, ad locum conceptionis ovorum fub fepto transverfo, eftque cum extenditur longitudine dodrantali, cujus longitudinis ratione, membranam obtinuit à fpina dorfi proportionalem omnino ac perfimilem inteftinorum mefenterio, quam \& venæ frequentes percurrunt, cum ad nutritionem ipfius uteri; tum ad ovi intrinfecus contenti, dum pertranfit à loco fub fepto transverfo, ad ipfius uteri exitum, alitionem.Membrana autem (verba funt UImi.) fpinæ colligans, eadem prorfus exiftit ipfi menfenterio inteftinorum, quin imo eadem eft \& fubftantia, \& origine:quapropter confenfum habetuterus cum ipfis inteftinis.Figura uteri inæqualis, alibi angufta, oblonga, alibi lata, brevis, juxta hanc varietatem, varia quoque fortiri nomina debet.Nam uteri latitudo infimo abdomini proxima, \& in qua ovum jam abfolutum continetur, eftque ipfemet uterus, reliquum vero corpus anguftum, oblongum, rotundum, quod ad feptum transverfum extenditur, vel uteri ftomachus, vel uterus productus extenfufve, vel uteriguls, nuncuparipoffet. Eft autem membranea \& tenuis, admodum diverfa àreliquo utero protenfo, \&à fubftantia ipfius uteri, qui ad exitum jacet. Nam finis hic membraneus fubtilis \& pellucidus exiftit, ac exanguis. Intefinum quoque uteri, ratione figurx \& quantitatis,cumcum longitudine rotunditatem cavernofam habeat, merito diceretur. Cui accedit membranæoccafio hanc uteri extenfionem, vel productionem fpinæ colligantis, quod Mefenterium uterinum appellamus. Intermedia pars uteri, qux eft illius portio ab utero propriè dicto, finem interjacens,craffam obtinet fubftantiam,albam, lacti fimilem, \& in femetipfam confidentem, cujus mefereon multiplices venas habet. Hujus fubftantia cocta ovi albuminis guftu faporem exhibet.

DeVictu non eft quod multa dicamus. Viäns. 
Präcepta faginandi ad Oeconomiam pertinent. Uvis \& ficubus impenfe, fed infeliciter vefcuntur. Steriles enim evadunt, Mathioli \& pituitofi, fi vel femen cannabis appofuein Diofcor. ris; numeroforum ovorum partu gaude1. 3. c. 148 bunt, fi vel hordeum femicoîum, vel Nafturtii femen cum furfure \& vino fubactum, exhibueris, majora deponent, ad faginandum tum triticum cum aqua coctum, potu interdicto, tum Cytifus vehementer laudantur.

Generatio. Quantum ad Generationem;, \& qureiadhxrent. Sexus in hac ave manifeftis fignis diftinxit, \& mas erecta crifta, juba, à cervice per.collum dependente, cauda majore, \& infigniad praliandum calcari fuperbit. Salacitatis vero funt inexhauftix. Nam etfipeculiare ipfis coeundi tempus, vernum effe, unde majores forte tum teftes, Ariftoteles innuere videatur, \& ad unum Oppian,in ovum foecundandum multoties cum eaIxeuticis. dem gallina gallus coeat, quin \& quidam Aritt. 1. 9. effominati à primo ortu nafcuntur, ut nec
c. 49 . Theophr. cucuriant, neque fominas ineant, \& Theoapud A- phraftus agreftes cortalibus ad venerem procliviores dicat: certum tamen fimul, fingulis diebus quinquagefies \& amplius uxores fuas Gallum inire, fi eas mori contingat, morore animi interdum contabefcere, fi illæ defint, ne à mafculino quiElian.1.4: dem genere fibi temperare, unde lege viPlut. in 1. vicomburio damnabatur, alias non fui genum bruta neris volucres, Phafianos nempe \& Perratione
tantur. Athen.1.9. confpectum \& vocem emittere. Quin Dipnor. nunquam qui in $æ$ deHerculis pafcebantur c. $46 . \quad$ ad Gallinas, qua in Hebes, interfluente utramque ædem rivo perenni, tranfvolabant nifi cum libidinis vexabantur ftimulis. Non rque tamen falaces omnes, lacertofi, rubenti,erectaque crifta, roftro, brevi, pleno, acuto, oculis ravis aut nigris, palea rubra, collo vario, foeminibus pilofis, unguibus longis, cauda magna, frequentibus pinnis, profufifimi in Venerem effe creduntur. Coitus tempus rhari, ftatim ac à cubili furgit, foeminx, progreflo jam die, Arit.H.A. fuperveniente illo, confidet ifta humi. à 1.5.c.2. coitu inhorrefcit, frepe feftuca aliqua fe luftrat, \&r vapore per libidinem cxcitato membra extendente, fefe excutit. De partu $\mathfrak{B}$ ovis ne hoc caput nimia mole legentes perturbet, in fequentibus feparatim dicemus. Animales attiones quod fpectat, quia Gallinæ unico oculo fuirfum elevato, rapaces aves obfervant, Vifu, quia aridiffimum quodque modo id ore recipere queant, ilScaliger lico dijudicant; guftu pollere videntur.

Exer. $266 . \quad V 0 x$ Gallinæ nutabilis, Circa partum
$V_{0 \%}$

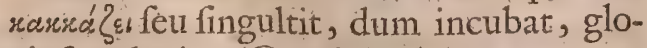
cit feu glocitat. Cum iniri debet, mancam \& exilem vocem format; in genere gracillare \& pipare dicitur. Cantus, pro malo

omine accipitur ; \& inter obftétricum numeratur obfervata. Galli propeTheffaloni cam nullam habent, apud nos graviorem. fed vere $\alpha$ đ $\pi \omega \delta$ ov, qui nec choro, nec fidibus concardat, ád $\delta$ \& \& cucurrire folent. Vigiles hos nocturnos excitandis in opera mortalibus, rumpendoque fomno natura ge- Plin.tide nuit. Norunt fydera, \& ternas difinguunt horas interdum cantu, cum fole eunt cubitum, quartaque caftrenfi vigilia ad curas, laboremque revocant, neclolis ortum incautis obrepere, diemque venientem nunciant cantu, ipfum vero cantum plaufi laterum, hinc inpéco фovos , \& lucis prenucius dicitur, \& veteres gnomonibus horariis deftituti, noctis deliquium \& diei acceffum commetirifolebant. Matutinum cantum, quidam alimenti defiderio, (avide animal calidiffimum nutritur :) alii falacitati (initurus cucurrire incipit)nonnulli aure nutationibus, qure ex folis contingunt motibus, multi cum \& fatur, \& à coitu canat; occultre cum fole a micitix vendicant. Qui profunda nocte validius, mane remiffius cantare putant cantum vento ferri,ventum noctu magis quam fub crepufculum fpirare, fic gallum longius audire, opinantur. Muti evadunt, fi vel circulum è farmentis Plin.H.N. callo addideris, vel caput \& frontem oleơ 1. 29.0 . c. 4. inunxeris, fi Plinio \& Alberto credendum.

Singularum is inefre Fafum tum inde colligi poteft, quod imperitant uto gene- Plin. $H: N$ o $\mathrm{ri}$, \& regnum in quacunque domo funt $\mathrm{c}^{1, c_{0} c_{0} \mathrm{I}_{0}}$ exercent: tum quod nullam ineundi fui abfque atrociflimo certamine copiam faci- Athen:lig.' ant, tum quod xdes ingreffuri, fefe, ne fcilicet crifta ufpiam offendatur, inclinent.

Pugnacicas nulli eft ignota. Ejus fpecta- Frian. de culum., quo Miltiades Grrecos in Perfas 1.4.c. $3 \%$. feliciflimo fucceffu animavit, Socrates Iphicrati Duci animos adjecit, Themiftocles exercitum contra perfas ducens inftituit, Pergameni quotannis celebravere. Eo Tarnaffari Indix populi, Ambivariti, apud quos per octo dies fum-Becan. in mo partium ftudio in curia* quotannis Goittodacommittuntur, Galli, Angli,hocce tempore delectantur. Accendi, \& allio, unde Rhodig.

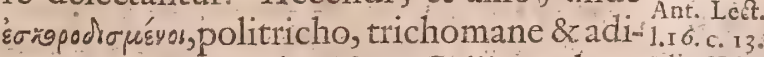
antho, forte quod criftam Galli quodam- Plin. H.N. modo xmuletur, dicuntur, apud veteres porta is ftimulis ferreis æneifque, quos plectra vo- Phitogin. cant, armabantur, ut fe facilius tutarentur in pugna.Nec hre caret fingulari artificio. Videre eft ibi intenta projectius capita, in Auguti. i. flatas comas, vehementes ictus, cautifimas de ordine evitationes, \& in omni motu animalium Ruticis. rationis expertium nihil non decorum. $\mathrm{Si}$ ex certamine victoriam reportavit, tum Plu. Hi. oculorum eminentia, tum cervice erecta ${ }^{\text {l.t.o.c.zo. }}$ fimul, \& cantus contentione infolenter ef- Anim. 1.4 , fertur, \& triumphantis fimilis eft, vere $c_{0} 29$.

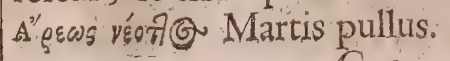

G 2 Vidons


Victus idcirco non canit, quod ex illa mala pugna fpiritus, fracti vocem fupprimunt. Cujus offenfionis verecundia confufus, in primam quamque latebram fefe occultat. Ad Sympathiam \& Antipathiam, Afectus. qux fequuntur, pertinent. Quod de GalColumell. linis circa præfepia decidit, immiftam padeR. R. bulo necem bobus affert. Porphyrionem tanto amore Gallum profequutum, tut hoc A. 1. H. A. occifo; ille inedia perire voluerit, Alia1.5. c. 28. nus oculatus teftis eft. Apes deficiente cibo gallinarum carnibus; \& uvis paffis refocillantur. Leo Gallum,\& maximè album, Ambrof. ut Ambrofio placet, metuit, quem excanHexam.1,6 tu à longe, ex crifta propius agnof cit, feu
Al. H. A. A. 1.8. c. 28. ob occultam quandam caufam, nam à leonibus \& Pantheris homines non attingi, qui jure Galli peruncti fuerine, maxime fi Plin. H.N. ei allium admifceatur, Plinius vere an fal1.29. c. 4. fo prodit: feu quod fint

de Natura Gallorum in corpore quedam rerum.

Semina, qua cum fint oculis immiffa Leonum, Pupillasinterfodiunt, Eंc.

Bafilifcum, cum cucurrientem audit adeò Rllian. de tremere dicunt, ut emoriatur. Sic in Cy$\mathrm{A}_{43, \mathrm{C}_{i} 3 \mathrm{I}_{*}}$ renenfium arenis $\mathrm{ab}$ itinerantibus abigitur. Vulpes una nocte quadraginta interdum \& amplius aufert. Voce muftellæ Gallinæ fero exanimantur. Superventu vero eorum, qui ferpentis vel canis rabidi morfu læfi fuere, incubitus vitiantur. Eo tamen die quo peperere, fer ferpentibus non læduntur, \& caro earum tum à ferpentibus morfis remedio eft. Florem vitis fi comederint maturefcentium 'uvarum efu abftinent. Ex Sambuco magis canoram buccinam. fieri paftor credic, fri ibi cædatur, ubi Gallorum cantum frutex ille non exaudiat, feu quod in locis fylveftribus, in quibus Gallorum cantus non auditur, ficciora \& folidiora ligna nafcantur, ex talibus tibia magis fonora tornetur, feu \& ob aliam caufam. Nam ob ftreperam Galli yocem, ftridore fuo fungofam fambuci materiam convellere, vix verifimile fuerit. Denique

Diofcor. taxi baccis quidem impunè vefcuntur, fed $\mathrm{i}_{4,4}, c_{7}, 75$ fpartifemine, \& hominis qui helleborum bibit excremento, ut Avicenna teftatur, Arit, in intereunt : ficum incubant tonuerit, ova H. N. inius in pereunt, \& femiformes pilli interimunColumel. tur. Auro liquefcenti fi Gallinarum memColumel. tur. mifceantur, confumunt id in fe, ita Plin.H.N. hoc venenum auri eft, falfo fcripfit Plinius, 1.29.C.5. Scaliger. Exer. 8s. Morbi. Plin, $\mathrm{H}_{0} \mathrm{~N}$ 1.20.c. 6 . Columell de re ruft.

\& ab experientia confutatur.

Morbi Gallis peculiáres, Phtiriafis \& Pituita. Hac inter meflis \& vindemiæ tempurs, \& cum ficus ac uva immatura ad fatietatem permiffa eft, laborant. Aqua in qua origanum maduit, præfervantur, reftituiuntur fanitati, fi vel urina roftrum ablueris, membrana qua tum lingua obducitur leviter unguibus avulfa; vel fcillam in aqua maceratam cum farina exhibueris.
Aphtiriafi maxime dum incubant infeftantur, fi arena littorali vel faponariorum è lixivio relicto cinere cura mulierum fefe pulverent, liberantut. Solenr \& cum abortu canflictari, qui ovi candido affato, cum uvis paffis toftis rquo ponderejritis \& ante alium cibum exhibitis,præcavetur. Pulli facile Podagra tentantur, fi ftercus pedibus eorum adhæreat: quanquam an Galli quibus calor multus, cibi abftinentia non minor, ea laborent, dubitetur. Capis Scalig.Ex。 fane quibus pufillus calor \& edacitas mul- $277, f_{0} \approx$. ta fämiliaris eft.

Qux de Ingenio dici poterant fuperius Ingeninm. funt attacta, fingulari familiam amore profequi, \& fimul ac aliquid efcæ nactus eft, Gallinas \& pullos ad vefcendum invitare, eafdem contra Milvos defendere, parientibus foeminis condolere, \& mœrorem exi- porphyr. . $_{\text {. }}$ li teftari voce, Luna exoriente lætari, \& $3 . \pi \sec ^{2} \alpha^{2}-$

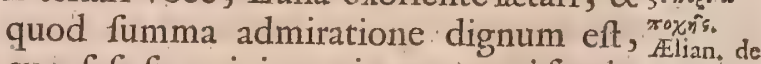
cum fefe fanguinis copia aggravari fentit, Animal.

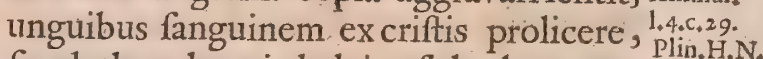
fic plethora levari, helxine fe herba purga- $1,8, c_{2}, 2 \%$. re, adjeciffe fufficiat.

Nec omittendum, Gallos fi tempore presagi- $^{\text {pes }}$

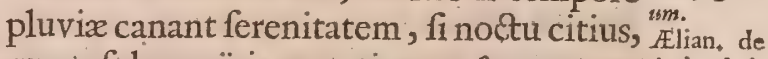
quam folent,aëris mutationem \& ventum, Animal. ${ }_{*}$. fi paulo poft folis occafium vel à vefpertino $7 \cdot c_{0} 7 *$ crepufculo, infolentes in raucifonum cucurritum non fine alarum motu prorumpant, tempeftatem prédicere. Scilicet, Aufter vocalia inftrumenta replete, ea farcina dum fe per motum exonerare volunt, ad cantum infolito modo ftimulantur. Sed \& Gallinæ, fi vel mane exire recufant, vel pediculos quærant, \& paludes more Ana- Aldro.Ortum alis verberent, vel pectora roftro pur- nith. $1_{\text {i }}$ I $_{4}$ gent, vel in arena ultra folitum fefe concutiant, vel in principio pluvix locum opertum quxrant, imminentes imbres maximos præfagire, creditum eft: 'Tempeftive ferendum effe monent, fi pennas, cum deplumantur, ur ante hyemem folent, à capite amittere coperint; ferotinè, fi à pofterioribus.

V/us harum avium in cibis frequens $8 z \mathrm{ab} \quad V$ fus. omnibus laudatur, faginatarú inprimis. Ideo hoc primum antiquis conarum interdi- Plin.H.N. tis exceptum invenio jam lege C. Fannii, 1:10,6.50. annis undecim arite tertium bellum Punicum,ne quid volucrum poneretur, præter unam Gallinam, qux non effet altilis, quod. deinde caput translatum, per omnes leges ambulavit. Inventumque diverticulum eft in fraudem earum, Gallinaceos quoque pafcendi lacte madidis cibis, multo ita gratiores appobantur. Nec tamen in hoc mangonio quicquam totum placet. Pertinax Imperator lumbos amicis mitte- Capitolin. bat,\&dorfo laganis funt fimiles. Meffalinus invita eCotta criftas cum palmis pedum \& Anfe-Athen. ribus torrere; atque patinis condere reperit 1.14 . 
Cerebrum affum cum pauco fale \& pipere $\mid$ ferè veterum \& recentiorum eft fententia: editur. Jecinora inter omnia edulia Car- Priori concipiuntur modo, quando mare danus celebrat. Ventriculus fi concoqua- abfente, defiderio ipfus projiciunt intrà Galen.1. तe tur, uberrime nutrit. Inteftina quæ \& $\mathrm{Gi-}$ mali \& leria vocabantur, cum aliis quibufdam fircci. rebus incocta edebantur. Teftes apud Bononienfes Calend. Augufti comedere folemne eft. Uropygium inter militares ciGalen.l.3. boş à Gallis computatur. Erant Galeni ment. tempore, qui \& fanguinem Gallinarum Alpin. 1. 3. edebant. A pud \#gyptios nigrx arte certa de Medic. faginatæ in familiari funt ufü. Jus formina c.16. in balneis potant, fic pingues evadunt. Apparatum pullorum, Conchiliatorum, Parthicorum, Oxyzoniorum, laferatorum, cum cucurbitis exiliatorum, Varrianorum, Frontonianorum, tractogalatorum, farfilium, leucozoniorum, \& his fimilium, in Apicio vide, ex quo multa AldrovanHippocr. 1. dus defumfit. Olim tamen qui morbo fa-
de norbo de norbo cro laborabant, Galli carnibus abftine-
facro. Cxfar 1.5. bant. Britannis olim nefas Gallinam gude bello ftare, hodic in Socotora infula eandem contingere, religio eft.

De Vfi in Medicina quis unquam dubitaverit. Inde olim fuperftitiofe AEfculapio immolabantur, nec quifquam fere eft morbus cuidepellendo non adhibeantur. Reperti qui ex forbili ovo ter quaterve excreverunt, fi Brafavelo fides. Febrientibus albumen ovorum in aqua concuffum Hippocr. exhibuit Hippocrates. Teftes in hectica 1.3. de commendantur. Cerebrum Gallinarum Trallian. in tremore \& narium fluxu. Melancholi1.12. 5. 5. cis Gallina nigra per medium diffecta bene fupra caput imponitur. Sunt qui Gallinx pennam in aceto intinctam ad fomni profunditatem conferre tradunt. Jus Galli veteris Afthmaticis prodeft. Stercus album Galliad occultas anginas commendatur, \& certò vomitum educit, nec male in colica exhibetur, \& cum oleo \& nitro mixtum clavos pedum fanat. Membrana ventriculo fubdita cornu fimilis trita, ftomachicis feliciter exhibetur: Jecur affatum Ilæo refiftit. Marcellus denique Empiricus prodidit, officulum extremum ex ala Gallinacea cochleari terebratum, nodifque feptem litio ligatum, atque ita brachio vel cruri ejus partis, qux inguina habet fufpenfum, iis mirabile remedium exhibere. Pro Colophone notandum eft, quod Cxlius Aurelianus reliquit, quendam à Gallo pugnante leviter lafum, in rabiein cecidiffe.

\section{A D A R T I C U L u M I}

A P P E N D I X I.

De Gallinarim ovis.

Wupliciter Gallinam ova concipere, Per fe nempe, \& excongreffu, conifans

fefe femen gallinx; fic, tanquam maris Arittot. $\mathrm{H}$. initum paffx effent, prægnantes fiunt. $E x-A$ : 1. 10:

citat ingentem in partibus genitalibus pruritum, feminantis materix abundantia; quam mutua inter fe libidinis imaginatio auget, fed \& fi tempore certo fuaviter attrectentur, idem motis attrectatione Arint.H.A. humoribus faciunt, ut haud falfo, etiam ${ }^{1.6 . c_{0} .}$. pulvere Plinius dixerit. Accedit vento: rum Auftrinorum Autumno \& vere auxilium. Hiš flantibus, aves multiparæ loca ani per qux concipiunt, obvertunt, iis ad libidinem concitantur. Continuus caudx ut motus, femen quod copiofum, nec menftruorum difceflio ulla, ad matricem attrahit. Hinc à vento concipi aliquando Varro R?

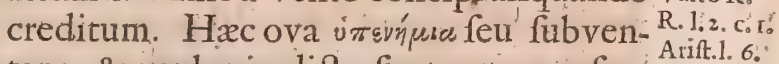
tanea \& zephyria dicta funt, ut cynofura $\mathrm{H}$. A. $c_{0}^{\circ} z^{\prime}$ \& urina illa, quæ æitate $\mathrm{ab}$ humore con- Scalig. in tento inutili generantur. Neque tamen 1 1. 10. Ari- Hift. omnino inania credas. Omnes enim par-animali: tes habent, minora yóvreors, liquidiora, mi= c. 6 . nusfuavia, \& infoecunda perfe, à fuperveniente Gallo foccundantur. Nec obeft. vel ex luteo in album mutatio, ut Ariftoteles credidit, vel utriufque à membrana ambitus. Exalbumine enim pullus generatur ; ova pifcium jam exclufa, poft à mare injecto femine foecundantur, \& ovum in matrice fubventaneum, præter teftam $\&$ pellem completum, à femine Galli foecundari Albertus M. teftatur. Quanto tempore naturefcant, incertum : tardius propter caloris in femine penuriam, verifimile. Reliquias eorum qux è femine generata funt effe falfum. Nam in gallinarum \& Anferum genere, à novellis fine coitu edita, compertum eft.

De Ovis que ex congreffiu fic habe. Poft- Aritti quam foemina de fuperiore loco qux præ- Aldrov. $_{2}$ cincturx feu fepto transverfo fubeft geni- Ornir. turam excepit, formantur ex ea à facultate 1.14.c. Is formatrice ibidem ova, qux fpinx pedunculis adhærent, exiguum tum primo quiddam ut candidum videtur, \& venulis diftinctum, rubrum dein \& fanguineun, luteum, \& flavum totum tandem. Mox de fpina in inteftini uterini principium decidua \& ad primos uteri loculos tranfmiffa continuato congreffu eo citius, quo ifte frequentior, augefcunt, \& albugo à croceo fecernitur. Tum in fecundos loculos detrufa, juftam molem acquirunt, \& luteum allbumine involvitur: Deveniunt tandem in terciam cellulam, in qua teftx natura duritiem largitur, eam tamen, ut mollia adhuc exeant, nec nutritio, qux per èdem fit, impediatur. Sic vitello \& albugini conftantia, (gallatura feu fperma Galli, fi Alberto \& Aldrovando credimus, per toG 3 tum 
tum albunien, ufque ad virellum pertingit, | minus, plicis rugifque infigne in Aldrovdinhuic verfus partem ovi acutiorem infigi- di Mufro refervabatur. Cxterum ponatve tur. Decimo à coitu die perfecta, tribus \& Gallus ova inter doctos quæritur. Nontunicis, quarum una vitellum ambit, altera nulli decrépitum \& ad coitum ineptum, tanquam pia materalbumencomplectitur, feptimo, nono, aut ad fummum decimotertia inter quam \& illam humor crudus nafcitur, \& dum formatur foetus excernitur, teft x adhærens, duræ meningis locum implet; intus inftructa, mollia,ne dolorem pariant, latiore parte,ut molliụs deponantur, \& quia acutior adhæret, ideo poftrema exit, egrediuntur, ac refrigerata, evaporato humore qui exiguus, relictaque portione terrea, juftam duritiem, fed acuta parte, qua pullus exit, \& ubi grandinem generationi inutilem, qui non cernitur nifi fracto putamine, \& injesta parte lutei infra, Ariftoteles ponit, exactiorem, fervata fua figura, acquirunt. Poni confecta brumà incipiunt. Circa Calendas Januarii etiam locis tepidioribus ac focundifimis. Optima foetura ante xquinoctium vernum editur, poft folftitium nata, magnitudinem non implent, tantoque minus, quanColuniel- to ferius provenere. Parituras fe fingultu lade R.R. produnt; eodem, peperiffe teftantur, facilius, fi feftucam ore apprehenfam dorfo Oppianus impofuerint, fi Oppiano credendum, liin Ixeuti- bentius, fi jam prius ovum in nido confpe-
cis. xerint fine dolore, vel exinde quod tefta membrana mollis fuerit, egreffo demum induretur, colligas.

Numerus pro ætaris ratione variat, qux multa pariunt, bis in die ponunt, fed hyperinæ evadunt, \& cito commoriuntur. Sunt qui quasdam noctu tenera, \& nifiad magnam diei partem, dura, eniti credunt, tenera edituras, dura, fi aliquot horis antelucanislumen viderint, ut fub ortum folis ponere cogantur, \& falisfupponatur paululum. Monftrofa interdum circa ea accidere certum. Vidit Aldrovandus cujus putamen punctis \& lineis fanguineis confperfum. Uterum læfum vix dixerim. Sanguinem quo uteri interdum turgent ven transfudaffe verifimile eft. Vidit \& Albertus totum fphrricum, duabus teftis inclufum, abfque ullo vitello, cum albumine aquofo tenui, \& altero intra interiorem teftam. Dantur \& fine tefta tam hypenemia, quam vera : forte quod illa aquofa fint, \& exiguo, fi humidus Gallinis cibus apponatur, calore dotentur: his propter intum, vel ex multitudine compreffionem tale quid accidat, fi Nicandri opinioniftandum eft. Nec inter rara trilecitha, id elt triplicis vitelli habentur; illaque plarumque in medio teft $x$ cavitatem habere Elluchafis prodidit. Vidit \& Gefnerus aliquando cujus putamen, $a b$ altera parte extrema, in anguftum velut collum inftar cucurbitze fe colligebat. Unum fphæricum ad columbarum vix accedens : alterum anferino haud quarto $x$ tatis anno, pro virium vel imbecillitate vel robore ponere ajunt. Ortuin. id putrefacto intus femini debet; vel ex humorum colluvio conflatur. Editur fub caniculx exortum, quod tunc maxime als ambientis calore expultrix languida in alite decrepita juvetur. Vifum in Imperati Mufro oblongum, ab Aldrovando rotundum, colore modo luteo, buxeo, flavefcente,lurido, fed \& quoddam ruptum, vitello omnino carere dixiffes. Quin \& Lemnius Zirizxæx duos annofos Gallos non tantum ovis incubaffe, fed \& xgre fuftibus ab illo opere abigi potuiffe, reliquit. Confracta tandem ova, \& ftrangulatus à civibus Gallus,quod,ne Bafilifcus excluderetur,metuerent. Et hrc eft quorundam opinio. Ovo fimile aliquid ex conglobata intus putri concretione, in ultimo fenio, cum non amplius coit, concipere, verifimilius eft : At ovum cum non magis tefta excludere poteft, quam vir fotum, cum parere non didicerit. Bafilifcum ex eo produci inprimis fi rubeta incubaverir, nugæ, tefta carere, \& adeo duræ pellis effe, ut fortifimis ictibus refiftat, fabulofum.

$$
\text { A P P E N D I XX II. }
$$

\section{De Generatione Pullorum.}

\section{A} BfolutaOvorum hiftoria, de generatione pullorum aliquid nobis dicendum eft. Horum vero principium veteres Arit. 1. ?? Græci, \& inter eos Alcmæon Crotoniates, de Gener. \& Hippocrates Cous in vitellum; nutri- ${ }_{\text {Hippoc }}$. de mentum in albumen conjecere. Recentio Natura ribus contrarium fentire placuit. Ex aibo pueri. liquore ovi corporatur animalibus vitellus

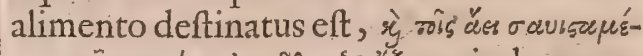

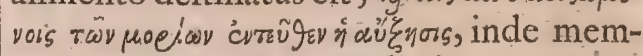
bris fubinde conftituendis incrementum adminiftratur. Et certe pullo jam conftituto fape vitelli pars extat, \& cum albumen тvę́rievov, ignitum, quod incubatione fit \&

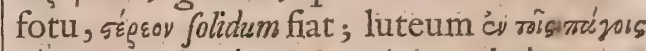
का coit, calore bumefcit. Excluduntur incubatu, vel ávrópars in terra. Nam in Egypțo \& defodiuntur in fimo terra obruto, \& turmatim fornacibus Cairinis exclufi prodeunt. Sy- Arift.H.A: racufis, potatorem quendam ovis fub fto- $1.6 . c_{3} 3^{\circ}$ rea humo ftratis tamdiu potare nunquam opera intermiffa folitum fuiffe dum excluderentur, proditum eft. Liviam ovum in finu exclufffe, apud Plinium legitur; \& vas in quo abfque Gallinx opera excluderentur, à Porta defcripfit. Oblonga \& acuta excludunt fominam, obtufa rotundaque 
$\mathrm{ab}$ ea parte qux acution efle folet marem. ferum, ac id genus aliarum ovis locun miIncerto id argumento ab Ariftotele proditum, contrarium apud Columellam legimus. Dies ter feptem exclufioni adfcriplit Philofophus, minuuntur, fi tepidus aër accefferit, $\eta$ tí $\psi$ is greprótus zis Concoctio calor quidam eft, féd \& depravantur aliquan-

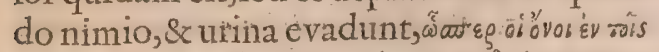

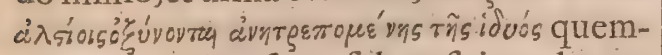
admodum vina fǽce fubverfa in calore acefcunt. Formationem, \& quomodo alimentum pullus factus affumat, diligentiffime expofuit Ariftoteles; hunc Aldrovandusfecutus, fequentia nobis reliquit, qux ipfius verbis proponemus. Secundo incuit $\mathrm{ab}$ incubatu die, luteum obfervavi deferri ad cacumen, aliquo pacto alteratum, \& in medio quafi fubalbidum : cujus rei inprimis Arifoteles non meminit: In aliqua vero parte albuminis, qux pariter crat alterata, femen Galli apparebat, quod tres illas videbatur obtinere qualitates, quales jam ante diximus. Tertia die ablato putamine in parte ovi obtufa; vidialbumen, \& reliquam fubftantix ovi partem in fuperiori putamine feparatam. Recefferat autem albumen aliquantulum à putamine, quemadmodum fieri videmus in ovis omnibus, quæ minus recentia funt. Hinc Plinius ova fchifta appellat tota lutea, qux triduo incubatu tolluntur. Vocat autem $\int c h i f t a$, tefteHermolao, quia dividantur, \& difcedebat vitellus à candido. Videbam item manifefte admodum membrânas illas tres quas ovis ineffe ex Alberto dixi, \& ex Ariftotele etiam colligitur : neque verim eit, quod fecunda earum fit recenter genita. Si enim illud ita effet, minime in ovis nondum incubatis confpiceretur.Ineft autem \& his, ut etiam vidi,fed albior in incubatis caloris caufa. Eadem die vitellus videbatur verfus ovi partem acutàm : atque hoc eft, quod dicebat Philofophus. Effertur per id tempus luteus humor ad cacumen, ubi eft ovi principium, nam ibi eft major calor, \& vis fpermatis. Apparebat etiam in albumine exiguum velut punctum faliens, eftque illud quod Philofophus cor ftatuit. Ex eo vero evidenter admodum videbam enafci ven $x$ trunculum, \& ab hoc duos alios ramulos proficifci, qui meatus illi fuerint fanguiferi, quos ad utramque, tunicam ambientem vitellum, \& albumen protendi ille dixerat. Sum autem omnino ejus fententix, ut ejufmodi viás credam effe venofas, ac pulfatiles, fanguinemque in iis contineri puriorem, principalium membrorum generationi, jecoris nempe, \& pulmonis, fimiliumque idoneum : adeo ut recte dixerit Philofophus, tertiadie figna apparere, an ova foecunda fint futura : licet ejufmodi obfervatio in majorum avium, utpote Cycnorum, Annime habeat. In ejufmodi enim, utidem Philofophus teftis eft, paulo tardius ea fi gna apparent. 2uarta die bina videbancur puncta, \& quodlibet corum fefe movebat! qux haud dubio cor, \& jecur fuerint, qux vifcera in ovis triduo incubatis idem dixit. Apparebantitem duo alia puncta nigticantia, nempe oculi: \& jam luteum manifefte ad acutam ovi partem, ubi major calor eft, \& fpermatis vis fefe receperat. Trahitur autem à fpermate illud pro carnis generatione, ut in omnibus animantibus fit, qux fibi fimile generant. Quinta die non amplius punctum illud, quod cor effe diximus; extra videbatur moveri, fed obtegi, ac cooperiri, \& duo illi meatus venofi evidentiores confpiciebantur, alter vero inajor al tero: nec verum eft, quod Albertus fcripfit; apparere in tunica illas qux albumen inclum dit: nifi forte id de tertia tunica, feu fecundaria dixerit, cui evidenter venx infunt, nam alioqui in illa nullius venxe veftigium inerat. Harum venarum infita vi reliqua albuminis portio quafi in palearum colorem immutatur. Videbantur etiam ramuliad locum tendere, in quo caput formatur, eo fcilicet puriorem materiam, à qua caput, ac in eo cerebrum fiat, una ctim virtute formatrice deferentur: Erat auteni capitis fabrica valde rudis adhuc ac informis: oculi vero confpectiores, atque ervi quafi magnitudine. Sequenti dein die ablato fuperiori partis obtufx putamine, ejectifque duabus prioribus tunicis, tertia evidenter cernebatur venulis referta: de hac locutum fuiffe Philofophum arbitror cum inquit: Membrana etiam fibris diftincta fanguineis : atque hrc meo judicio fecundina' dici poteft: Dein inter hanc, \& quartam membranam, qux foetum involvebat, humor erat aquofus: quem autumo ferofam albuminis partem effè, qux poft natum fotum fupereft, tanquam ad generationem inepta.Eam vero membranam innuere videtur Ariftoteles à meatibus illis venarum ortum ducere, quatenus feilicet vi fibrarum à venofo illo meatu ortarum in palearum, vel fanguineum colorem immus tatur. Cernebatur deindè totus foetus moveri, \&xoculi jam majores erant, quam in præterita die : at partes inferiores, thorax nempe, venter, \& pedes, erant valde imperfectx, nec difcerni adhuc poterant, \& roftrum erat muccofum : ut recte dixerie Ariftoteles : pars inferior corporis nullo membro à fuperiori diftingui inter initia cernitur. Caput denique tota inferiori corporis parte majus erat. Septima die aperta quarta tunica fotum confpeximus parvum adhuc, acindiftinctum cum oculis tamen magnis, triplicique in illis huniore, cryftallino nempe,vitreo \& aqueo A perto capite jand 
jam cerebrum aperte cernebatur, minus vero reliqux partes. Unde dicebat Philofophus. Paulo poft (intelligit meo judicio diem quintam ufque ad nonam inclufive) \& corpus jam pulli difcernitur, exiguum admodum primum, \& candidum, confpicuum capite, \& maxime oculis inflatis, quibus ita permanet diu, uti nos confpeximus: \& fero, inquit, decrefcunt oculi, \& fe ad ratam proportionem contrahunt; quod quidem verifimum eft: fiquidem in quarta decima, aut quinta decima die aliquantum refident diminuti propter caloris digeftionem. Octava rurfus die oculi majores adhuc videbantur, utpote ciceris fere magnitudine. Totum corpus tunc fefe velociter movebat, \& jam crura, \& alx diftinctè cerni incipiebant. Roftrum tamen interim muccofum adhuc erat. Sed forte quifpiam quxrat, cur prius fuperiores, quam inferiores partes in ejufmodi formatione appareant : cui refponfum velim, virtutem, feu facultatem formatricem in fuperioribus magis quam in inferioribus vigere, quod fpiritales fint, \& per confequens plus caloris obtineant. Cæterum ifthæc omnia, qux hac die videbam, fequenti manifeftiora apparebant. Decima die non amplius caput toto corpore majus erat, magnnum tamen, ut in infantibus etiam videmus: magnitudinis autem caufa eft humidifima cerebri conftitutio. Quod vero Ariftoteles dicit oculos fabis majores effe, id profecto minime verum eft, fi de vulgaribus noftris fabis locutus fuerit, cum alioqui ervi,vel ciceris albi, magnitudinem non excederent : atque hinc etiam non abfurde quifpiam colligat fabas antiquorum fuiffe rotundas, quales araci funt, quem ideo fabam veterum quidam exiftimant. Neque etiam verum eft : quod tradit, tunc fcilicet oculos pupillis adhuc carere. Etenim hre non tantum hac die apparebant, fed duabus etiam præcedentibus, una cum omnibus partibus ac humoribus. Quod vero ait, detracta cute nihil folidi videri, fed humorem tantum candidum, rigidum, \& refulgentem adlucem, nec quicquam aliud, id de cryftallino humore mihi dixiffe videtur, qui tamen haud folus apparebat, fed vitreus quoque \& albugineus, unde non parum hallucinatus videri poteft Philofophus, uti etiam Albertus, qui eo tempore nil duri, \& glandulofi in iis reperiri exiftimat, cum cryftallinus humor folidus fit, ac quam maxime confpicuus. $E_{a-}$ dem item die vidi omnia vifcera,nempe cor, jecur, pulmonem. Cor autem, \& jecur erant albicantis coloris : \& cordis motus non folum apparebat; antequam fotum aperirem, fed jam fecto etiam thorace moveri videbatur. Erat autem pullus involutus quartæ illi membranæ plurimis venis refertx, ne in humore jaceret. Cernebam etiam vafa umbilicalia prope anum ad umbilicum deferri,ibique inferi,ut cibum per illum petat foetus. Vide denique, quod Ariftoteles non advertit, in dorfo prope uropygium pennarum principia nigricantia menti humani cuti non abfimilia, cui pili abrafi fint. Die fubfequenti hæc omnia erant manifeftiora, \& in fuperioris roftelli extremitate erat quid albidi : cartilagineum, \& fubduriufculum, quod rurfus die decimatertia magis erat confpicuum. Erat autem rotundum milii grano haud abfiniile. Sagaciffima rerum parens natura id ibi fabricaffe videtur, ut impediat, ne roftello fuo vel venulas, vel membranulas, vel alias quafcunque tenerrimas particulas pertundat. Ajunt mulierculx, pullos jam natos cibum capere non poffe nifi prius id auferatur. Decimequarta die pullus jam totus plumefcebat. Decimaquinta in digitis ungues albicantes apparebant. Die vero docimafexta ovum aperire placuit in oppofita parte, ubi nativa tunica,fed unica tantummodo apparebat, eaque alba. Alteram enim quam in altera parte femper videram, hic obfervare minime datum eft. Itaque dubitabam an ea tantum pro albuminis tutela nata fit, cum fcilicet ovum non fit recens, vel ad pulli defenfionem in ovo incubato. Nam indies illa magis magifque decidere videtur, \& foetum fequi, qui fui gravitate deorfum decidit. Ariftoteles etiam unicam tantum effe ejufmodi tunicam his verbis innuere videtur: Sunt, finquit, quandoque locata ova hoc ordine, prima poftremaque ad teftam ovi membrana pofita eft, non teftripfius nativa, fed altera illi fubjecta : liquor in ea candidus eft, quafi diceret, omnes partes in ovo locate funt hoc ordine : nempe prima, poftremaque ad teftam ovi membrana pofita eft. Intelligit meo judicio per primam, \& poftremam membranam, eas membranas recens in incubato ovo genitas, eas videlicet, quas aliquotics appellavi tertiam fecundinam, \& quartam, quam involventem foetum dixi. Nam cum dicit teftre nativam non effe, oftendit nec.primam, nec fecundam effe, quxab altera ovi parte reperitur. Videtur igitur excludere hanc nativam five primam, vel fecundam, \& intelligere tertiam, quam fecưndinam frepe vocavi. Cum vero dicir, fed altera illi fubjecta, intelligit eandem fecundinam, nempe teftr fubjectam, quod vel ex hoc maxime liquet, quod candidum in ea liquorem ineffe dicat.Is enim, ut fupra oftendi, inter tertiam \& quartam continetur. Hinc manifefto errore Sueffanus convincitur, qui ex Ephefio pęr primam interpretatur eam, qux tefte adh $x$ ret, per poftremam vero, quxalbumini. 
Quæ omnia à nobis obfervata.quotidie in | li \& Gallinæ Indicx, Guineénfeš, Capl. fequentibus diebus evidentiora, utpote in Gallina $\mathrm{P} \mathrm{u}$ M I L I o feu Nana, quam Al perfectifimo pullo apparebant Die vero vigefima pullus putamine à parente Gallina ablato hora vigefima fecunda fua fporite exivit: Poft exclufionem reperiri in putamine tunicas duas albas nativas una cum duobus aliis in incubatu genitis fecundina nempe, \& qux foetum iplum involverat, in qua excrementum adhuc inerat fubalbidum. Evidenter adhuc apparebant in pullo tria illa vafa umbilicalia, dux fcilicet arteriæ; \& vená una , \& orificium umbilici valde érat contractum. Vena vero jecori per alium rarum, qui recta ad illud tendebat, inferi videbatur. Mirum autem erat, quod extra id nihil lutei appareret, cum tamen in cavitate abdominis, ubi inteftina funt, prope anum pullus per umbilicum totum fere id abforbuerat, fimul cum quinta tunica, qux id involverat. Tanta autem ibi lutei inerat copia, ut vix duplo plus fic in ovo nondum incubato. Ariftoteles etiam fcripfit, decima ab ortu die, fi alvus abfcindatur, aliquid adhuc lutei in ea confpici. Sed confideratione inprimis dignum eft, quomodo ejufmodi membrana, quam una cum vitello à pullo abfumi diximus, poft ejiciatur. Videtur autem dicendum, quod per eandem viam, umbilicum videlicet, regredi debeat, vel per anum, quod potius credo. Tunicx huic duo vafa implantantur, quorum unum arteriam effe, \& à corde proficifci, pulfus indicat : alterum vena eft, deferturque ad inteftina, lutei videlicet vehiculum : Hepar erat coloris admodum lutei, forte quod ex luteo per venas attracto nutriatur. Hactenus Aldrovandus. Auxit naturæ dotes ingenium. Fœminas habebis fi luna plena nata, eadem fuppofueris. Eo colore nafcentur, quo tinctà ova fuerint, pulcherrimi excludentur, fi cum $\mathrm{Pa}$ lumbi mare Gallina creverit, \& ne de monftrofis laboremu's, à Johanne Baptifta Porta abfque caufa provifum eft. Solent in partu numerofo quod conceptus cohrreant frepe monftra nafci; nec vel geminas vel quadrupedes pullos, nulla fectis membrane vitellis, vidiffe, rarum eft.

$$
\text { A R T I C U L U } s \text { II. }
$$

De Gallis Gallinaceis \& Gallinis in pecie.

P U.N C T U M I.

\section{De Gallinis Patavinis, Pumilione, E aliis} quibufdam monftrofis.

$\mathrm{H}$ A.tenus de Gallis \& Gallinaceis; in fpecie occurrunt nobis Gallinæ, $\mathrm{Pu}-$ milio, Patavinx, Gallinæ Turcicx, Perfi$\mathfrak{C x}_{2}$ Galli Scotici fylveftres, Paluftres, Gal- drovandus defcribit, erat fere tota nigra. Majores alarum pennæ in extremitatibus candicabant. Maculis in collo mediam lunam remulantibus ornabantur. Oculas macula fublutefcentis coloris rotunda ambiebat. Caput erat cirratum. Palc \& crifta intenfius rubebant. Ungues impenfe can ${ }^{2}$ dicabant.

Ex P A T a vin is Gallina tota ex nigro virefcebat. Criftam gerebat exiguant coloris vix rubri. Pellicula quam picpe auriam foramina obtinent, albebat. Más quinque duntaxat coloribus ornabatur,nigro, albo, viridi, rubeo \& liuteo. Corpore erat ater, caput cirrhatum, cirrhi radices erant albx, roftro \& pedibus luteis. Vifa aliquando Gallina tota candida, criftata; vifa \& alia in lapideam fubftantiam inter parietes converfa, caudiculis fuis abfque pennis hiftricis inftar horrida. Dantur \& pedibus pennatis feu hirfutis quarum defcriptionem apud Aldrovandum vide: AldrovanCriftam Gallus habebat duplicem nion ad- dus 1. I4. modum magnam. Vifialiquando \& mon Ornit. c.s: ftrofi. Tacebo gallinam quæ tres pedeś, tertium prope anum enafcentem habebat, pullum, qui totidem inftructus, tertium velut ex Vropygio enatum oftentabat. Nihil vel de eo dicam, cui pes à podice natus, quinque digitis inftructus, vifebatur, vel cui feu quatuor, priores imperfecti \& pallidi; perfecti \&lutei pofteriores, feu quinque erant, vel de eo pullo cui quatuor alæ erant : non tantum contrarium alarum pennæ fitum; fed \& cervicis plumulas caput verfus cirri inftar erectas Tagliaferus Medicus obferyavit in quodam. At qui in aula Hetrurix Ducis vifebatur Gallus, habebant caput \& paleàs ex plumis'militum, conos quibus galeas exornant æmulantibus duos in fronte pènnarum calamos velut duo cornua furrectos; totidem ab utraque roftri prope nares parte, qui in extremitate plumas tenuifimas fetarum inftar edebant, unum in cervice, qui è principio fere ejufmodi fetis ornabatur. Pennæ veluti fquammas toto corpore $æ$ mulabantur. Prope Vropygium qua cauda exit tuberculum rotundum \& fubalbidum vifebatur. Cauda carnofa, pilis nuda, in extremitate floccum album habern's propende bat. Tibix velut ocreis induebantur.

$$
\text { PUNCTUM II }
$$

De Gallinis Turcicis, Perficis, Gallo $S_{60}$ tico Sylueftri \& Taluftribus. dus defcribit corpore erat candicante. Alis \& alvo nigris. Cauda furtim viridi, 
partim nigra. Tibiis \& pedibus fub cæru- De collo fuperiori \& Uropygium pennæ cæ⿱ leis. Toto corpore, modo argenteis, mo- rulex albis calamis ornat $x$ dependent. $A l$ do aureis lineis variegato. Gallina tota erat terum fimpliciter Indicum idem nominat. alba, maculis ubique nigris confperfa, pe- Coloris toto corpore erat aterrimi. Roftro dibus fubcæruleis. Vifa \& alia cum pedi- fuperiore adunco, utroque caput verfus bus cæruleis ex albo \& nigro maculata.Poft luteo, cætera atro. Ubi foramina narium carneam criftam, aliam ex pennis albis A-aliis, ibi rotundum quid \& luteum cerafi laudx inftar habebat, ut in icone expref- magnitudine confpiciebatur. Grift $x$ loco fum eft.

PERsicus criftam veluti caudam obtinebat, pedes cinereos,ipfe totus niger erat. Gallinæ totæ coloris ferruginei vifuntur.

Gallus S COT ICVS fylveftris Phafiano carne ac magnitudine eft fimilimus, fed nigra pluma, rubentibus admodum Boeth. in palpebris. Mas collo, pectore, alis, coxifque

punctis rubicundis afperfus eft; fominam leucophæam, maculæ nigrx variant, fupercilia \& barbulæ in utroque fexu maculis nigris afperguntur. Similis eft huic ille, quem Turnerus Morhenam vocat. Mas enim totus fplendefcentis eft nigredinis, eam caudx partem, qux podicem tegit, quxque alba eft fi exceperis. Caput ruber fed corneus cirrhus tegit, \& circa genas duo velutilobi rubri \& carnei. Fœmina tota maculis diftincta eft, \& à Perdice nifi major effet, \& ruffa, magis ægre dignofcitur. Degunt in defertis, \& erica confitis locis. Granis, \& fummis erucx germinibus, vefcuntur.

Gallo P ALVSTR 1 corpus eft fubruffum aut fufflavum, punctis nigricantibus undique diftinguitur. An idem fit cum illo qui frumento abftinet, \& enafcentibus minutifque Cytifi foliis vefcitur, ut Boëthius prodidit, dubito.

\section{P U N C T U M III.}

De Gallinaceis \& Gallinis Indicis.

\section{G} Allum I ND I cu M duplicem nobis Aldrovandus exhibet. Primus eft auritus, tridactylos, nulli volucrum generi pulchritudine inferior. Roftrum illi in fuperiore parte aduncum, totum rubrum. Caput, peitus, \& venter integer colore rofeo diluto, qui in pectore maculis fubrofeis dilutioribus exiguis, in ventre longe majoribus, quas alba linea tranfcurrit, infigniuntur. Criftes habebat duas, carneam unam, qux prope roftrum eft, inter quam \& roftrum fuperius, macula oblonga cærulea eft : alteram pennis luteis prope primam criftam parvis, mox majoribus quæ furfum primo afcendunt, mox defcendunt deorfum, conftantem. Oculi eundem fere qui in homine eft præfe ferebant fitum, oblongum fcilicet, in cujus medio illi pofiti: Aures habebat erectas afininis non abfimiles. Alas admodum diverfi coloris. Caudam duplicem. Priorem exiguam, quinque pennis ruberrimis conftantem. Aliam novem longifimis, diverfum colorem obtinentibus. cirros gerebat.Cauda \& calcaribus carebat.

Tibix pedefque tabellis albicantibus prexditi erant. Gallinas I ND IC A S, tres idem exhibet. Primam colore corporis fufo. Capite cirrhato, roftro in medio tuberofo, albicante, nigris maculis infignito. Coxis ex ferrugineo lutefcentibus. Cauda nulla. Uropygio, fimix inftar, nudo. Alteram corpore à roftro ad caudx extremitatem exiguo, ad cæruleum vergente, roftro recurvo \& rubicundo. Cauda longa, ut in Pica extenfa, candida, \& lineis nigris confperfa, quæque in fronte tuberculum magnum, figura ficus; coloris fere cærulei gerebat. Tertiam colore fufco, in collo \& alis ad cinereum vergente, roftro rubicundo, fed non adunco, tuberculum fimile in fronte gerentem. Numidica dicebatur.

\section{P U N C T U M IV. De Gallinis Guineis.}

Allinæ Guinex à regione ita dictx, Bellonius (1) Perdices Terre novx quoque di- 1.5. de Acuntur. Corpulentia vix noftrates Gallinas fuperant, iifdemque quoad mores \& vocem fere fimiles funt. Peculiare ipfis acervum quendam pilorum fupra caput obtinere, fed qui in anteriori parte reflectuntur,à prima vertebra aut offe colli procedendo per pofteriorem capitis partem. Gallum Mauritanum ita Gefnerus ex Cajo defcripfit. Pulcherrima inquit avis eft, magnitudine corporis figura, roftro \& pede Phafiano fimilis, vertice corneo in apicem corneum à pofteriori parte præcipitem, in anteriorileniter acclivem elevato, armatus. Eum natura videtur inferiori capitis parti tribus veluti laciniis fe promittentibus committere atque deligare : inter oculum \& aurem utrinque una omnibus ejufdem cum vertice coloris : ita ut infideat capiti eo modo quo Ducalis pileus Duci Veneto, fi quodjam adverfum eft averfum fieret.Rugofus is eft inferius per circuitum: qua fe attollit in directum in fummo collo ad occipitium, nafcuntur erecti quidam atque nigri pili in contrarium yerfi. Oculi toti nigri, xque \& in orbem palpebres \& cilia. Si maculam in fumma \& pofteriori parte fuperciliiutriufque demas. Imum caput per longitudinem utrinque çaro quxdam callofa colore fanguineo occupat, qux ne propendeat veluti palea, ut replicaretur, natura voluit, \& averfo ductu in duos procef- 
proceflus acutos à capite liberos finiret. Ex infar fonum ederet. Brevi quidam pinguéhac carne attollunt fe utrinque carunculx, fcerefcribunt, fi cerevifiam aqux locø apquibus nares in ambitu veftiuntur, \& caput pofueris.

in anteriori parte à cetero roftro pallido V/us in cibo multus eft. Optimum enim feparatur. Harum ad roftrum margines funt nutrimentum \& perfectum generant inferiores, replicantur leviter fub utraque hare. Quod inter verticem \& carnem eft à dextra \& finiftra parte, fquammofa duplici incifura notata : in pofteriori nulla fed laves, \& veluti punctis quibufdam fui coloris refperfx. Color illi in faucibus exquifite eft purpureus : in cætero corpore per fumma contuenti, qualis confurgit, fi album \& nigrum pollinem, utcunque tenuiter tritum, colorifufco rarius afpergas, nec tamen commifcens. Tali colori maculæ ovalesaut rotund per totum corpusineffe vifuntur, per fumma majores per ima minores comprehenfx intervallislinearum, ut apparet in plumarum compofitione naturali, qua fe mutuo interfecant obliquo hinc inde ductu per fumma tantum corporis, non item perima. Id non ex toto corpore folum deprehendes, fed ex fingulis avulfis pennis. Superiores enim obliquis lineis $\mathrm{fe}$ interfecantibus, aut fi mavis, orbiculis quibufdam ex albo \& nigro, ut dixi polline confectis, \& per extremitatem conjunctis; ut in favis aut retibus, maculas ovales aut rotundas, in fpaciis fufcis comprehendunt, inferiores non item. Utraque tam fimili lege pofit $x$ funt. Nam in aliis plumis ordine ita juncta funt, ut fere triangulos acutos faciant; in aliis ut ovalem figuram reprafentent, \&c. Voxillis divifus fibilus non fonorior, nec voce Coturnicis major: Similem Gallinis communibus fribit Bellonius. Foecund $x$ funt, \& nutriendis pullis fedulix.

\section{A R T I C U L u s III.}

\section{De Capo.} Colunsel- mittendo fufficit, inflicto, teficuli per po1.R.R.18. feriora evelluntur.Morinterdum continc. 2 .

git, fi erratum fuerit : \& Gallum à caftratione ita intumuife Aldrovandus obfervavit, ut pellis digitis pulfata, tympani bellici

fanguinem, ut omnium avium laudes quantum ad obfonia pertinent, una caro Gallinacea,cujus patina ftomachum juvat, pectus lenit, vocem fonoram facit, corpus obefat, Platina comprehendat. Maxime circa fex, feptem, vel octo menfum ætatem probantur. In Medicina jus caponum ad virium reftaurationem commendatur. Quidam offa crurum medicamentis ad alba mulierum menftua, immifcent. 'Alii Fi-' fulæ indolenti pelliculam ventriculi interiorem, in fole torrefactam, sx in pulverem redactam infpergunc. Græciafferunt, fabx femina caporum fanguine macerata,ab adverfantibus herbis immunia fore ; \& fi pridie quam feruntur aqux fimpliciinfufa fuerint, citius nafcituras; fin nitrata diffcilimam coctionem non habituras.

\section{A P U T III.}

\section{De Avibus, qua fe pulverant fimul G lavant.}

\section{$A \quad R \quad T$ I C U L U U S I}

\section{De Columbis.}

A Ves, quas LatiniColumbas, feu quod Vare 1. 3 A in culminibus villarum degere fo-de rerutt: leant; feu quod bibentes roftrum aqua diutius immergant, ut Hermolao videtur; ( frequenter colant, ut Alberto M. placet,

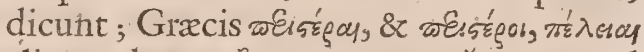

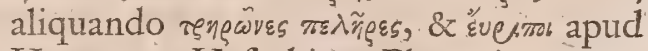
Homerum, Hefychium, Phavorinum \& alios dicuntur. Defcriptionem non eft, quod apponamus. Proprium omnibus utraque connivere pálpebra. Ariftoteles pedibus Arit. 1.' \& unguibus cucullum repræfentare dixit. de patrib. Internas fi fpectes partes Ingluviem parvam Arim.c. I 3 . \& fere rotundam ultra ventriculum, id eft 1 . 3 .c.ult. geminos finus habent; unum in quo merguntur recentia, ut guttur : alterum in quem ex eo dimittunt concoctione maturata. Ventriculus ipfis ferventior. Lien tam Arif. $1_{+}$; exiguus, ut vifum fugiat. Defelle inter eru- de partib. ditos non conftat. Sunt qui habere negant, Galeno ridiculi, funt qui affirmant, feu in Galenus do Uropygio vel dorfo, quod vefimile non atrabile. eft: feu non eo loco, quo cætera animantia, fed\& inter eas aliis ventri, aliis inteftino jungitur. Cyfiti carere dum affirmat Galenus, ne decipiatur metuo.

Quantum ad Locum, ubique fere confpi- Losus: cluntur. Ingens olim earum in Affyria circa Eufebius Afcalonem, quia facr $x$, \& lege edi vetitx; prxp. Euin Cypro, Papho, Cythera, Sicilia, Cnido, 5. quia Veneri dicatx, copia. Tanta apud Athenæis 
Poeonas \& Illyrios, ut incolas militari con- / columbarum quandoque in uno perifteTextor in tra eas ordine exire, Textor nefcio cujus roptrophio colebantur, cum vel decem Cornu co- fide, prodiderit. Nil de portu, \& navali, paria paucis annis in talem numerum expolyhit. Thisbxorum, Infula Columbaria Solini, crefcere queant. Incubatio maris \& foemic. 9. quæ in Tyrrheno mari fita eft ; Lucaiis infulis, in quibus columbis quandoque onerantur naves, regno Pegu, Feffa, \& aliis dicam. Amant vere propter innatum pavorem eminentia loca : naturaliter tamen fpecus \& latebras quxrunt. qux de nidula-

Horat. 1. r. trone in arboribus dicuntur, Palumbis pooda. z. tius competunt. Sexum difficulter, nifi interiora fcrutentur, difcernas. Voxtamen exigua fæmellam, gravior marem prodit.

Generatio. Coituri mutuo fe exofculantur, \& fenior quidem primum congreffum ab ofculo exordicur, fequentem fine ofculo celebrat, Arif.H.A. at junior quoties libet coire, ofculatur. ob1. c. 2.
Aldrovan- fervatum tamen fine of culo marem addus Orni- mitti, fi foemellæ ereptus poft triduum eithol.1. 1. dem reftituatur. Si mares defunt, ruunt in c. x. mutuos amplexus foeminx, ita fingulis diebus ad octiduum \& ultra hypenemium ponitur. Ovum quinto à coitu die perficiPlin.H.N. tur : per oblivionem factum, quod Plinius 1. 10. intra decem maturefcere fcripfit, \& fœmiAthenæus na frepe ipfa qua peperit, poftridic aliquan1.9. do, marem repetit, ut forte ad partumalterius ovi alacrior accedat. Vexata, vel fponte paulo morofior, ovum per triftiPlin.H.N. tiam retinet. Bina fere ponuntur, ita na1.10. c. 52. tura moderante, ut aliis crebrior fit foetus, Ariftot. de aliis numerofior. Sed \& quia volaces, conAnim. Ge- fumitur volatu materia, \& $x$ in alas pennafc. r. que abit. Ex priori marem, forminam ex Arift.H.A. pofteriore edi veteribus creditum, vifæ ta1. 6. c. 4. pon binas foeminas aliquando, binos ali-

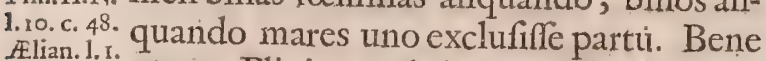
var. Hit. autem Plinius erebriorem iifdem foetum c. r. innuit, \& falfo d'zovov appellavit Varinus. 1. $6 . c_{0}$. . Singulis namque feu tricenis, feu quadraVarro. I. . . genis diebus concipiunt, pariunt, incude re ruft: bant, \& pullos enutriunt. Continuatur Idem 1. 5. toto anno focunditas, fi locum apricum; Plin.1. 1o. unde $\not$ Egyptix duodecies pariunt; \& cic. 53. bum, quem facile acquifitum eximio corporis $\&$ ventriculi calore nullo negotio conficiunt; (hxe foecunditatis caufa Ariftoteli) habuerint, fi horum aliquid deVarro. 1.3. eft, à bruma ad xquinoctium hybernum de re rult. otiantur. Sic duodecim ex eis imo tredePlin.H.N. cim \& quatuordecim, haberi poffunt pa1.10.c. 58. ria. FEftate enim binis interdum menfibus terna edunt, fepe inter pullos ova inveniuntur, \& alii provolant, alii erumVarro. 1. 3. punt, hi rurfus fimul ac creverunt, \& robur de te rutt. habent, cum matribus pariunt, \& quanArit.H.A. quam Ariftoteles intra annum cos coire, 1.6.c.4. femeftres incipere Venerem agnofcere fcribat: Plinio tamen quinquemeftres foetificare fcribenti, Albertus \& experientia fubfribunt. Non eft ergo mirum quod M. Varronis temporibus, quinque millia nx perficitur opera, hxc noctu, ille inter- Athen.i.g. diu incubat, de tempore inter feriptores ${ }^{{ }_{0} I}{ }^{6}$. non conftat. Plinius, reftate octavo decimo die excludere putat, vicefimo aliàs. A pud Plin.H.A. Ariftotelem, quod ovum prius editum fue- ${ }^{1}$. 10. c. c. 5 . 3 . rit, intra vicefimum diem \& abfolvitur \& $1.6 . c_{0}$ c $_{0}$. excutitur à pullo. Pertundunt ovum prididie quam excludatur pullus. Alberto denique completur feptem in utero diebus, fovetur per quatuordecim, poftea fiffo Aritt 1. 4 ovo, pullus exit. Experientia ab Ariftote- de Generile militat, qui etiam coecos \& imperfectos, ${ }^{\text {bus. c. } 6 .}$ quod, quia pauciparx funt, copia alimenti cum prole parere foleant, pari affirmat. Poffunt ab ortu verficolores haberi; fi mi- Oppian. I. fcentibus jam of cula maritis,

\section{Sargula flammeolis oculis rubrofque tapetes Et veftes oftroperfuf as objicit auceps.}

Vitam culumbarum oftonis annis Pli- Atas. nius definivit ; quos etiam allętricibus, Plin. H.N. excocatis Ariftoteles tribuit. Albertus ${ }_{\text {Arit. H.A. }}^{\text {I. IO. }}$ domefticis viginti annos adfcribit. Athe- Ar. 9. c. . . . næus ad triginta producit, fuit, quæ vigin- Athen. I.g. ti duos annos vixit, \& femper, excepto ultimo generavit.

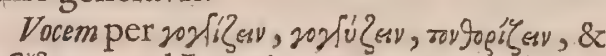
тоनंरु $\mathrm{kv}$, quod Latini gemere, murmurare, Vox. \& meditari dicunt, expreffere Graci.

Volatum quod attinet, nullæ domeftica-Volatiss. rum neque longius domo, neque diutius abvolant, fed \& alte per aëra volitaffe, in Paphlagonia Bellonius obfervavit, ut con- Bellon.1.6. fpectum effugerent, feu iis cum aëre tanta de Avibus intercedit familiaritas, ut fecurius in eodem degant: feu alia caufa. Celeritatem multiteftantur authores, hujus opera uno Virgil. 1.5. eodemque die victoria Taurofthenis ex Eneid. Olympia Æginum parenti ipfius nuncia- riar. 1.90 ta eft. Sueta intecta fides, ut Hircius \& Brutus in Mutinenfi obfidione; Leyden- Flin. 1. ro. fes in fua; Romani in Circum vel Thea- ${ }^{\text {C. }} 37$. trum euntes, quæ vellent domum nunciaturi; Ægyptii, Cyprii, \& Cretenfes Bellon.1.6. nautæ ad terram appropinquantes; Benen- de Avibus fes Cattix urbis incolæ eis ufi tanquam ta- Botter. bellionibus fuerint; effecit. Fruftra val- Relationilum \& vigil obfidio per collum eunte nun- ${ }^{\text {bus. }}$ cio. Duplicatur celeritas, dum fe à rapacibus infectari fentiunt. Sed \& ftrepitum Virgil. IEin volatu quandoque edunt, qua oftenta- ${ }^{\text {neid. }}$ 1. 5 . tione, ut vinctx præbentur Accipitri implicatis ftrepitu pennis, qui. non nifi ipfis Plin.H.N. alarum numeris eliditur. Speculatus Oc- ${ }^{\text {I. Io. C. } 36 .}$ cultus fronde latro, \& gaudentem in ipfa Ingenium. $\begin{array}{ll}\text { gloria rapit. } & \text { Athenxus } \\ & \text { Dipn. 1. } 9\end{array}$ Ad Ingenium \& Mores Columbarum per- Plin.H.N. tinet, quod cum bibunt, collum non refu- 1 . 1. c. c. 34 . pinant, fed quia breve 2 amplum, multa- 1 . g. g. c. 7 . rumque 
itumque aquarum capax hábent, large jumentorum more bibunt, quod -ubimollia frangunt

Nubila, jam longum coloque domoque gregate, Sijurxit pentlas, diverfoque bofpita traetus

Venit avis, cuncteprimum mirantur \&ु borrent, Mox propiusq; volant, focium jamg; in aere ipfo Paulatimfecere funtm, plaufuque fecundo

Circumeunt bilares, É ad alt a cubilia ducunt;

quod corpus primo humectant, dein pulArif.H.A. vere fefe confpergunt, fic à pulicibus \& 1. ..c.49. omni forde mundantur, quod mane foeminas vagantes in nidum compellunt, \& incubare cogunt. Sxpe ex hac caufa caftigatio pigrius intrante foemina ad pullos, Plin.H.N. quod conjugii fidem non violant, com mu1. 1o.c.34. nemque fervant domum. Nifi coelebs aut vidua nidum non reliquit, \& imperiofos mares fubinde etiam iniquos ferunt: quippe fufpicio eft adulterii quamvis natura non fit. Tunc plenum querela guttur, $f_{x}$ vique roftri cibus, mox in fatisfactione exofculatio, \& circa veneris preces pedum orbibus adulatio. Appetunt tamen maribus defunctis, cujufcunque coloris, non nigrę tantum, quod proditum quibusdam, Aldrov. novas nuptias; \& fi domini juffu conjugia Ornithol. permutent, priftino domicilio reddita, 1.15.c. I. prioribus fpretis, novifimis adhærefcunt, quin \& nonnullas ex maritatis cum aliis coire Ariftoteles dixit: \& ut nigra apud Egyptios mulier perpetuo vidua, quod pulla femper incederet fignificabatur : fic ingrati apud eosdem columba, quod mafculus validior factus, partem roftro inceffit, \& à matre abigere conatur. Huc etiam Arif.H.A. pertinet, quod mas adultos pullos, cum ex 1.9.c.7 nido tempus prodeunti eft, fubigit, quod Ezechicl. eis pavore perculfis (funt autem timidific. $7 . \quad$ mæ) medix natium partes tremunt, quod, Tzeket
Chilia, I2, dum etiam fub menfis cum Gallinis con433. $\quad$ verfantur, hominum cenfuetudine fe delectarioftendunt, qnod denique Aquilam fublimipetam $\mathrm{ab}$ humipeta difcernere noEl. H. A. runt, \& fi hic invadit, in fublime feruntur, 1. 3. c. 45 . fi ille, deorfum verfus ruunt. NectacenAritt. H.A. dum, recens natis pullis vel terram falfu-
1. 9. c. 36. dum Arit.H.A. ginofam, quam in locis lotio confpergi 1.9. c. 24. fuetis quærunt; vel falis ipfius grana, feu ut
A.l. H. A. 1. 3. c. 4s. livorem abigant, ne fafcinantium noceant Gomefius imprecationes; feu, ut ad recipiendos ci1. r. de Sa- bos præparentur'; feu, quod verifimilliA Apn. 1. . mum, ut eis tam foecunditatem quam cibi Dipn. 1. 9. appetentiam ingerant; infpuere, corporis mundiciei impenfius ftudentes, nidos à 2El. H. A. fimo repurgare. Helxine, herba ad evacua1. I.c.35. tionem uti, laurinos ramulos tenues primum pro amuleto colligere, deinde ad pullorum cuftodiam nidis imponere. Colores fuos varietatemque difpofitam noffe. Memoria, ideo temporis, quando foemiRhodig. 1. $\mathrm{n} x$ in cucubitu fuccedendum eft, nun20.c. xo. quam mas oblivifcitur, pollere. Ita denique cicurati, ut \& literas ferant, \& cibum ex auribus, quibus præftigiis nebulo ille Sara cenus Muhamedes ufus eft, capiant.

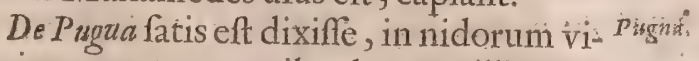
cinia mares pro uxoribus has pro illis pugnare. Antequam coiverint, mares adhuc cœlibes, fuas aliis fubtrahere conantur. Vidit \& Avicenna duas pro formina pugnantes; hæc victori adhæfit; quem, pugna repetita, deferuit victum.

Amicitia eis intercedit cum homine, Al Amicitiés liciuntur in columbaria \& manent, fi vel humano fanguine cum pifis integris in $\mathrm{va}$ fe figulino circumacto illinantur, \& pifa Gefueris deglutiant; vel cranium hominis fenis in de colurtiis fufpendatur; vel lorum quo homo ftran- Albertis gulatus eft, deponatur; vel lac mulieris de Avibuss puellam à bimatu lactantis, occultetur. Palladius Cum capite captæ, quod excruciatum, cum multo fale, \& cumino Romano coctum, ac ibidem depofitum, eos retinet. Cum tinnunculo \& vefpertilionibus utfuis locis expofitum eft, denique cum vite agrefti, perifterione, faliva, carlina, femine viticis, \& aliis. Detinentur vel peregrinas adducunt, fi aliquid horum vel in columbario fparferis, vel fufpenderis in nido.

Inimicitias autem exercent cum circo, Inimicitidos ad cujus vocem perhorrefcunt, quod vociferans invadat; Milvo, Aquilis, marinis Hont. i. Finprimis; Bubone, qui ova exforbet. No- pod.od.16. ctua, corvino genere, vulpibus, catis, Allian.1.3. Muftellis, helleboro albo, \& dentibus c. 45 . humanis, quibus virus quoddam ineft, Serapio. $I_{3} 4$ quod \& fœetus implumes necat, taceo de do c. II. 4 aliis.

Plin. $\mathrm{H}_{0} \mathrm{~N}_{\mathrm{z}}$

Affectus ipforum funt, Pulices \& pediculi, ${ }^{1.11 . c .}$ Morbi. quibus nifi mundentur, macilentæe eva- Crefcent duint; varioli circa oculos, qui menfe $\mathrm{Au}-$ 1. $_{\text {Herodot. }}$. $90_{\circ}$ gufto inprimis infeftant; \& vitiligo ac le- 1. I. pra ob quam à Perfis pulfas apud Herodotum legimus.

De Vfu columbarum in Medicina multa pro- V fust dita funt. Ventriculo quia funt ferventiore, lapillos comefos conficiunt, Margaritas eis exhibitæ poliri Cardanus prodidit. Cardantis Peftiferis haud corripi morbis, qui carne de varietat: affidue in cibo ufi fuere, ex $\mathbb{E}$ gyptiorum accepimus arcanis. Odor etiam fylveftrium in aërem refolucus, ab Epilepfia \& $\mathrm{Pa}$ ralyfi, fi Villanovano \& Abenzoari credimus, præfervat. Cerebella coecitatem inducendi proprietatem habere, metuo ne falfo, dicuntur, medicamentis venerem promoventibus recte præfcribi, certum. Sanguis cruorem membranis cerebri ema- Diofcotí nantem cohibet, \& oculis fuffufis eximie des. prodeft: Lufciofis bene illinitur. In ma- Galen. dé fculis efficaciori Hierocles eundem medi- dic. c. 3 . camento ad ftranguriam Equi admifcet. Adepsad dyfuriam commendatur.Pennæ primum enatx \& cum urtica uftx podagræ dolores leniunt, ut Marcellus author

$\mathrm{H}_{3}$ 
eft. Ovis recte condyloma fovetur; fed defidere ante ager in aqua debet, in qua verbena deconta eft. Fimus tanti eft fervoris, Galen.1.9. ut ignem fxpe concipiat, \& in ea Mylia de Tempo- qux eft Afrix pars, domus hac' ratione conflagrarit. Cum hordeacea farina velaceto mixtus, ftrumas difcutit; arefactus, \& cum nafturtii femine tritus, inveteratos coxendicis, cervicis, \& lumborum dolores exGefnerus tirpat, ut fcriptum Fernelius reliquic. Probis.

lud propinetur colatum; vel in eodem feptem diebus infufus, \&aqux rofacex inftar deftillatus exhibeatur. Excutit fotum, fi cum Caftoreo, opoponace, myrrha, vel felle vaccino fuffitus excipiatur. Emplaftrum cum aceto forti, recte fuper ani ficus pofueris. Imbecillius tamen domefticarum ftercus, validius earum qua in montibus vagantur. De reliquis confule Aldrovandum.

Laudatus so in cibis Columbarumu us. ComHippocr. mendantur in epatico morbo ab Hippoterm. affe- crate, in virum, poft diuturnum morbum ctibus. imbecillitate à Rhafe; \& Peguaniita iis delectantur, ut advenis, interdum vendere nolint. Sylveftres', quas elixabis, domefticis, quxafix, magis valent. Pulli propter molliorem fuccum veteribus, vernales xftivis \& autumnalibus (vefcuntur tamen \& hæ melioribus granis) præferuntur. Et videbis ex iis, apud fcriptores Meflos, Cruftas, Miranfe Catalonicum ludebat, quod \& Rui dicitur, \&alia cibarii genera. Pullos tamen, caput \& oculos lædere, lepram nimio ufu gignere, Simeon Sethi; Cynanchen inducere Rhafis, meminere. Varro. de Quod vero Varronis tempore, fingulorum R. Ruft. I. paria ducentis nummis, \& fi eximia effent; fingulis millibus feftertiorum vendeban-

Columel- tur, quod Columellæ diebus funt inventi,

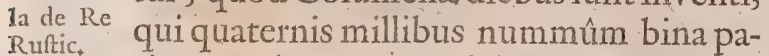
Plin. H.N. ria mercabantur : quod denique Plinius L.

1. 10.c. 37. Axium Equitem Romanum ante bellum civile Pompejanum denariis quadringentis fingula paria venditalle fcribit, luxurix potius \& deliciis quam ufui adfcribendum eft.

\section{A R R T I C U L L U S II.}

\section{De Columbis Domefticis.}

Genera. Varro 1. 3. de re ruft. c. 7 .

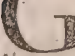
Enera columbarum tria Vario pofuit.Vium agrefte, feu faxatile, quod in turribus \& culminibus villæ habetur, quod falfo Perottus $7 \varepsilon \lambda \varepsilon i c$ das effe credidit, quidam male cum illo faxatili, quod in agro Bononienfi capitur, prorfus ferum, faxatilibus Varronis majus, coloris lividi, Gal. 1. so. roftro rubicundo, conferunt; quodque Gade Compl. leno vópas \& Bórwas, dicitur. Alterumcledicanen. mentius, quod cibo domeftico contentum, intra limina januæ folet pafci, Karobrístov feu
Domefticum Galeno. Tertiun ex his firpibus Mifcellum fructus caufa. Ariftotelifexfunt fpecies, nempe, Columba, Oenas, Gazæ vinago, Pbabs, Pbafa, Pelejas, \& Turtur. Aldrovandovero ex magnitudinis ordine, Phaffa primum, Pbabs fecundum, $O e^{-}$ nas tertium, Columba quartum, Livia feu Pelias fextum, Turtur poftremum locum occupat. Palumbum Pyrallidem, Columbam, \& Turturem, nihil inter fe fimilitudinis habere falfo à Callimacho dictum, in fe- Elianus

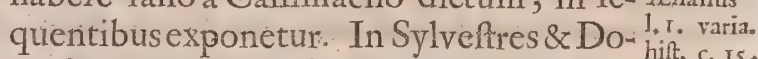
mefticas commodifime diftinguuntur. Et Domefticæ quidem, fi Differentias attendas coloris, magnitudinis partium, \& coitus ratione variant. Fuere in infula Capitis viridis \& Madera fylveftres adeo mites, ut domefticarum more fe capi manibus paterentur. In Therapne maximas nafciaic Perottus,Spoleti perexiguas. Tantum duodecim paffuum millia efficiunt defcrimen.

Habentur in Norvegia totæalbæ, quas \& alibi vulgatiflimas confpicias. In Græcia eo Athenxus. primum tempore vife funt, quo Perficus Dipn. 1.9. exercitus circa Athon montem interiit. In Eryce Sicilix ingens numerus unum ru- Elianus. brum tanquam Ducem fequitur. In Per-1.4. de Afia denique Columbi fi qui funt, oblon- Scaliger. go \& anferino illi funt collo. Genera tam exerc, 23 r, indigenarum quam Exoticarum plurima apud nos funt, quæ an veteribus cognita fuerint, jure dubitari poteft, etiamfi Romanos Columbarum amore infaniiffe Pli- Plin. H.N. nius prodiderit. Sunt Gutturofe vulgaribus 1. 10. c. 17. domefticis duplo fere majores, pedibus hirfutis, qux inter volandum, \& dum murmurant, fauces in ingentem tumorem inducunt, Plinii Campanas dixeris. Alix Cyprice, feu ut Gefnerus nominat, Rufticx, Anglicæ, Monachicx, feu Ferrarienfes, ex quibus quxdam Cucullate, criftam gerunt, \& pedes vel pennis ornatos vel nudos habent: quxdam crifta carentes, roftro funt admodum exiguo, pedibus nudis. Alix Turcice \& Perfice colore toto pullo feu betico, præter oculos, qui miniacei, pedes qui pallide rubent, \& roftrum, quod lutefcit. Alix Indice roftro Anatis, nihil prater pedes, \& magnitudinem cum columbis commune gerentes, quarum illa quam Aldrovandus Vienna acceperat, roftroalbicabat, circa nares rubefcebat, poftremo ferpentum inftar fubcxruleis \& nigris maculis, qux per totum ferme verticem producebantur, variegatam erat. Sub oculis macula longa alba totum caput tanquam. torquis ambiebat, Alix, qua, quod in honorem foemellæ, vel fux vel aliarum poft longa murmura à terra fefe elevent, \& ul tra illas volando alas quatiant, Belgis OverMagers dicuntur. Alix Gyratrices, qux dum in orbem fupra foemellas maxime obvolitant, tam fortiter alas quatiunt $t_{2}$ ut duorum 
D E A V

afferum fimul colliforum fonitum fuperent. Unde remiges earum pennx femper ferinæ fractx confpiciuntur. Alix Galeaté, quarum caput, cauda, remiges, femper alius coloris funt, quam reliquum corpus. Taceo hic monftrofas, quarum una in Germania prope pagum Rikenhoven capta, prixter quatuor pedes, duplicem alvum habebat ; altera duplici quoque alvo Bononix nata eft; tertia bicorpor quodammodo erat, ex uno nimirum corpore, alterum par pedum remittens, cum reliqui duo alteri corpori perfecte ineffent.

A R T I C U L U S III. De Columbis Sylveftribus.

$P$ U N C T U M I. De Palumbis.

S Ylveftres columbx qux fint, præteritoex Ariftotele articulo recenfuimus. Primus ex illis Palumbus, qui vel Major, vel Minor. Hic Phabe Philofopho dictus, à nemine hactenus defcriptus eft. An ille fit, qui in Marchia Anconitana Palumbo vocatur, incertum.

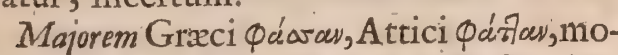
derni $\varphi^{d}$ xece, Niphus Torquatum, Servius, Titum vel Titium; fed per hos forte vultures intellexit Perfius ut Aldrovandus opinatur; Villanovanus Cadonem vocant. An Generis diverfitatem admittat, nondum liquet: Hifpani in quadam novi orbis infula grandiores noftris. Guftu \& fapore meliores Perdicibus qui aromaticum fpirabant, odorem, \& quarum diffecta ingluvies floribus plena deprehenfa, invenere.

Defcriptio. Corporis craffitie ad Gallinas propemodum accedunt, magnitudine haud multo minores. Color eft cinereus, caput ex rubro \& creruleo mixtum, alæ in lateribus maculis albis infigniuntur, torquis coloris eft à capitis, dorfique colore diverfi. IngluviArif. H.A. em ventriculo præpofitam habent. Ideo

1. z. c.ult. benePlinius, Aves quædam finum unum habent, quo merguntur recentia, ut guttur alterum, in quem ex eo demittunt, $\mathrm{Co}^{-}$ ctione maturata, urPalumbes. Teftes, cum Venerem exercent, infigni magnitudine augentur; hybernis menfibus, ne ullos quidem habere arbitrantur nonnulli.

zocks. Locum fifpectes, nullibi noti non funt. Apud Delphinates, \& Vefates Aquitanos, magnus eorum proventus. Raro hnmi infdere vifx arboribus vel editioribus locis A rir.H. delectantur. Ariftoteles dum. campeftres A.t. r.c. r. vocat, per loca campeftria, illa quæ arboribus confita funt, intelligere videtur. MiPlin.H.N. grare prodidit Plinius, nec abnuit expe-

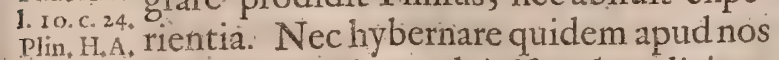
1. $8, c_{0}, 2$, fefe pati, falfo apud Ariftotelem dicitur. Nam fi tepidiora de fuerint loca, in angu-
I B U S.

ftis montium jugis fefe recondunt. Ideo verno tempore deplumes conficiciuntur. Phattasfemper confpici, quod apud Ariftotelem extat, error eft. De Phabis id in telligendum Athenæus innuit.

Cibus eis inprimis Fabx. Unde Faburia Nutrimentnum apud Ferrarienfes nomen, Gallia ${ }_{\text {Scaligi in }}^{\text {tumi }}$ glandibus frepius; cum ilicis cocciferre tuni Arift de fuberis; ilicum viridium, nec non frago- Animalib rum repletum inventum in Gallia ftomachum, Bellonius affirmat. Hinc Glandiferarum appellatio. Alica vehementer faginantur.

Coëunt \& fotificant trimeftres, unde tan- Generaito. ta ipfarum copia. In Venerem accenfe, 1.6. c. . . $4^{\circ}$ mutuo féfe ante initium exofculantur.An- Oppian ide te veris ingreffum, intenfo adhuc frigore ${ }^{\text {venat. }}$ nidificare, \& plumas fibi, ut pulli calidius recumbantevellere, ex infipectione, an authoritate. Alciat. prodidit. Nido locus Maninatr. arbores, juniperi inprimis, fi Theocrito 1. T.de Cals credimus. Bis quotannis parere ex Plinio Eidyll. $\varepsilon_{0}$ habemus; femel ex Ariftotele. Terna plu- Plin. H.N. rimum pariant ova. Sed quamvis tot pe-Arift.H.A.

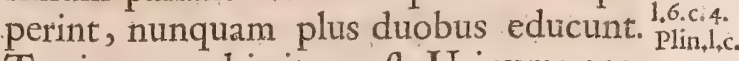
Tertium quod irritum eft, Urinum vocatur. Palumbes incubat fomina poft meridiana, in matutinum cæetero mas. Incubatus Arif. ${ }_{1}$.A citius quam à columbis perficitur. Decem ${ }_{1,6} c_{*} c_{4} \psi_{*}$ \& quatuor diebus uterum ferunt.'Totidem iterum foetus, fed cocus \& imperfectus Arift 1. 4i involucris evadit, atque perficitur. Vivere de Gener. palumbes ad XX X. annum, aliquos ad Plin. 1. ro. $\mathrm{XL}$. habemus authores, uno tantum in- $\mathrm{H}_{\mathrm{i}} \mathrm{N}_{\mathrm{o}} \mathrm{c}_{3} 35$. commodo unguium eodem \& argumento, fenectx, qui citra perniciem reciduntur. Marem prius mori credunt, cum in avibus Arif.H.A, cæteris fominæ prius abeant. Salacitas for $1,9 . c_{,}, 7_{0}$ te in caufa. Nam \& in pafferum quifalaciffimi genere idem contingit.

Quantum ad Vocem gemere Philomela Vox. authore, minurire Spartiano dicitur. Cantus omnibus fimilis, inquit Plinius, atque Plin. H.N. idem trino conficitur verfu ; præterquam ${ }^{1, x_{3} \cdot c_{3} 354}$ in claufula gemitu. Hyeme mutis, verevocalibus. Audiunt tamen, fi ex afperrima hyeme placidum \& ferenum tempus fuccefferit, fi aurito tefti Nipho credimus. Genere ordinarie vere incipiente, \& nifi Plin. $\mathrm{H}_{6} \mathrm{~N}_{\text {o }}$ confecto folftitio incipiunt. Sic hujus tem- $1.18, c_{i} 28$. pus indubitatis notis fignavit natura. Et vox rufticis prefentis veris fignum habetur.

De corporis affectibus nil occurrit, un-Morb: guium in fenectute incrementum, de quo fupra, fi exceperis.

Sed nec de Ingenio \& Moribus multum. Ingenitum: Amifo corporali confortio folitariæ ince- Oridor in dunt, nec carnalem ultra copulam requirunt. Adulterio corruptæ; corruptorem, if Porphyr. affequi poffunt, interimunt. Ingenii funt 1 . de Abtti= fimplicis, ideo in eorum nidis deponit ova ${ }^{\text {nentias }}$ cuculus; \& Plautus hominem ignavum, 
Palumbem vocat. Vulnere denique acAllian. H. cepto origanum imponunt, \& ad fanitaA.l.5.c.c.46. tem redéunt.

$V \int_{\text {uss. }} \quad$ Invenere \& in sibis \& in Medicina Ufum. In Carani nuptiis appofitas Athenæus ; in Dipn.1,4. Nafidieni convivio fine clune ceu lautioHippocr, res Horatius meminic. Garnes in fluxu 1.2, de menfium pituitofo Hippocrates : in tymmierb ${ }_{\text {ieru- }}$ panite Trallianus; in Elephantiafi Aretæus, in colic̀ affectu Aëtius; in peftilentia Alexànder Benedictus; in dyfenteria \& colica Plinius prefcripfere. M. Cato Cenforinusægrotis exhiberi voluit. Paulus tertium inter aves locum eidem aflignavit. Venerem propter glandium efum extinguere creditum quibusdam Oculi,quia Portal. $r$.
Phytog. c. confoffi renafcuntur, ad vulnera oculorum Phytog. c. \& cicatrices commendantur.Jumentorum Plinius in verminatio finitur, ter circumlato verenH.N. dis Palumbo, palumbus emiffus moritur, jumentumque liberatur confeftim. Sanguis vulnera purgat. Fimus urinam procovat, \& calculo in faba fumptus refintit. Lapilli in ventriculis inventi, potioni con tra cosdem infperguntur.

\section{PUNCTUM II.}

\section{De Oenade feu Vinagine, Alchata Jeu Filacoa Arabum 'E ColumbaLivia.}

$\mathrm{O}$

Enas Tzetzi o'vyı', non tam $2 \dot{0} \pi \dot{\tau} \tilde{\tau}$ ivãy à fibris carnis, qux dura, \& nifi tergus detraxeris efui inepta eft ; quam, vel à colore uvarum nigrarum maturarum, quas ócvwròv Græci vocant ; vel à vindemix tempore, quo \& confpicitur \& capitur; unde Lycophronióovóregoms $\phi a \psi$ dicitur. Gaza vinaginem, Jofephus Scaliger Vinitorculum, alii viniferam, Julius Scaliger Rupicolam, vocavit. Major eft columba. Roftrum habet, fi Oenas eft quam Aldrovandus exhiber, cinnaberinum, longum, in extremoacutum. Caput totum ventrem \& alarum pennis cinerea. Remiges notabilis magnitudinis \& nigricantes. Cervicem, intercurrentibus plumis nigris viridem. Caudam verfus Vropygium cineream cxtero nigram. Pedes rubros.

$A L C H A T A$ quam cum Filacotona eandem Aldrovandus facit, alx funt oblongæ, pennæ \& plum $x$ coloris coturnicum, cutis extrema dura, in Syria pedes nigri \& breves. Ad eam proxime accedit illa, qux nomine Angeli Monspeffulanis venit, quamque Perdici perfimilem, roftro \& pedibus nigris, plumis ex fufco colore in nigrum vergentibus, \& luteis ruffum, effe Rondeletius ad Gefnerum fribit.

COLVMBA LIVIA Alberto Cavernalis; Græcis $\pi \dot{\varepsilon} \lambda \leftrightarrow \alpha s$, ex defcriptione Gefneri, eft columba domeftica minor. Roftrum ipfi albicat, \& circa nates parum

purpurei habet. Collum pronum ad latera haber pro diverfo ad lucem pofita varie fplendens, in fe partim fubviride, partim purpureum. Supinum ex cinereo tale. Plumas ubique cinereas, alarum pennas quatuor longiores cinereas, medias, partim cinereas, partim ad extrema nigricantes, ultimas dorfum verfus fubruffas. Pedes rubros.

Vefitur glandibus' \& granis. Nidificat in arborum cavis \& templorum muris. Migrat, \& in cibo, palumbo tantum tenerior, prefertur. In India, prodente $\mathbb{Z}$ Eliano, virides pennas habent, Pfittaco fimillima: Cruribus \& roftro Græcam refert Per dicem.

\section{P U N C T U M III.}

\section{De Turture.}

卫 Urtur in Columbaceo genereultimo Diferentia loco ponitur. Tria aut quatuor earum in Hifpaniola obfervata genera. Vifie in locis frigidioribus, \& nivofis candid $x$ \& in Aquitania duas ejufmodi fe vidiffe teftatur Scaliger. Turcarum vero Imperator, Scalig. Expar rari \& Peculiaris generis Henrico Gal- ${ }^{\text {erc. } 19 .}$ liarum Regi tranfmifit. Ex.Alexandria diverfi à noftratibus adferuntur coloris. $\mathrm{Ob}$ fervatum \& noftro ævo quoddam genus, cujus foemella candicat naturaliter; mas coloris eft cinereiad fubruffum vergentis, habetque torquem nigrum.

In Defcriptione non eft quod immoremur. Defcriptio. Falfo Orus Apollo foli inter omnes volucres dentes \& mammas tribuit. falfo Ovi- Ovid. in dius nigrum dixit. Collum torquis ambit Epittol. longe aterrimus, viridibus maculis confperfus, ante vix confpicuus. Ale funt verficolores. Dorfo \& pectori vicinx elegantiflimo colore ruffefcunt, nigris, quarum extrema viridia, intercurrentibus. Hinc virides cum ruffis marginibus fequintur. Remiges funt atræ; fi albi aliquid occurrit, in extremitate illud eft. Fœmina nifi inte- Arif.H.A. riorum afpectu difficulter cognofcitur. Ex l.9.c.7.

Indicis foemina, pedibus exceptis, qui rubri, \& roftro quod nigricans, tota eft candida. Mari caput, collum, pectus, alx ad remiges, dorfum ad Uropygium dilute ruffefcit, nec ulla macula refpergitur. Iris in oculis miniaceo colore refplendet. Torquis tenuis \& nigra circum quoque collum ambit. Venter prope anum lutefcit. Pedes rubei tabellis albicantibus ornantur.

Nullibi fere non vifuntur, rarius alicubi Locuss, vel frequentius. In $\mathbb{E}$ thiopia tanto numero pet aëra volare traduntur, ut nebulas effundant, \& folis radios impediant. Apud Tartaros quia in cibis prohibiti, abundant. Sed \& Peru numerofe eas alit. Morantur fere fempervel in montium jugis vel ulmi aut aliarum arborum cacumini- 
bus Hyeme vel latent, vel tepidiora loca petunt. Unde Trimiftres, quod totidem Varro de menfibus nobifcum agant, Plinio. Cum de $R_{e}$ ruft ad Italiam veniunt, in Pontiis infulis, pri$1,3, c+5$. ma volatura requiefcendi caufa paucos dies morantur. Redeunt ad nos adventantis veris nuncix, cum jam prolem fecerunt.

$V e f c u n t u r$ frugibus, glandibus \& olivis. Nutrimen- Milio vehementer delectantur, Efitate Arit.H.A. fua fponte dummodo fit facultas cibi; hye1. 8. c. 3. la de R.R. \& fi novella funt xtate, in tantum, ut pinTheoph: guedine fuffocati intereant, tanquam ni1. 5, c. 20. mio infartu elifis faucibus.

De Generatione eadem fere qux in Palumbis occurrunt. Bis anno pariunt \& trimeftres fœetificant. Mas \& formina vicifim incubant. Nidus inter denfos arborum ramos ex duris \& nodofis lignis conftruitur. Indicx quotiefcunque ova rumperentur, nova pariebant; forte non facturæ, fi illa exclufifent. Proprium omnibus crepitus ventris ; \& cum vocem edunt, noviffima pars alvi vehementer citatur. OAtonis annis vivere, reliquit Ariftote-
Barthol: 1. les; quindecim iifdem cubare Bartholo3.de propr. les; quindecim

34. Gemere Latinis dicuntur; Græcis rqú $a v$, Vox.

quibufdam śves. Tum volatu, tum pedibus plurimum valent.

Amicitiam colunt cum Piictaco, Merula, Scaliger in Pavonibus.

Theophr. Inimicitiam cum corvo, \& chloreo exerInimicitia. cent. Helleboro, quo columbre intereunt, 1.6. H. A. propter peculiare temperamentum impune vefcuntur; malo punico trito perimuntur.

Ad Ingenium pertinet, quod fi mori alteIrgenium. Autuan. rutrum contingat, à fecundis nuptiis abftiLib.2. Part nere, foli volare, nec ramis frondentibus Anbr. 6, infidere,nec limpidam aquam bibere,nido Hexam. 4. fuo contra lupi incurfus, fquillæ folia, quæ ifti fugere confueverunt, fuperjacere, \& gladiolum, feu tanquam fafcinationis amuletum comedere, feu nido imponere; qua fide non addo, prodatur.

V/wm quod fpectat, Egyptii iis, quod Accipitris facri fibi alitis ungues aliquando evaderent, abftinebant. Martialis, cújus $x$ vo capita Turturibus amputabantur; Porphyr. Jus ar
1. 4. de Ab- cluneslaudac. Vulgus pinguiores commenftinent, 1.7. dat. In Medicina idem quod Palumbes præEpigr.

ftant; Fimus albugines cxtenuat. Facilitatur partus, fi tribus juniperi feptem lauribaccis, cum cinnamonidrachma \& corticis caffix drachma una \& femis farta affata \& pinguedine Gallinx ad ignem inun$c_{t a}$, vefperi bis in hebdomade fumatur. Non tangi venereis, qui in corio lupi cor Turturis delatum guftavit, falfo à Mizaldo proditum e
$\Lambda$ R T I C U L U S IV.

DeTaferibus ingenere.

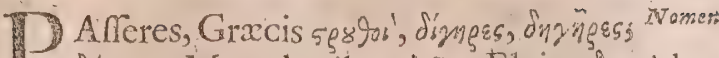

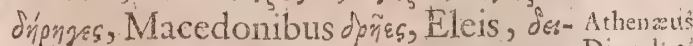

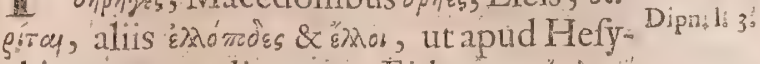
chium extat; dicuntur. Eidem opägobor pafferculus eft.

Ariftoteles vix alios prater domelticos Differets novit : ideo omnia qua de illis fcripfit, hifce conveniunt. Athenæo ex Alexandro Myndio, alii funt fylveftres, quorum foemi nx corpore funt debiliores, roftri coloré magis teftacco, facie id eft anteriore parte; nec nigra, nec valde alba; Hollandorum.

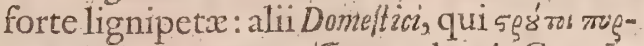

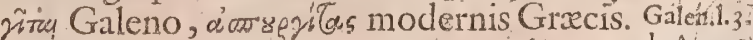
Alberto func quidam in vertice rubei, in de Ament: cavis arboribus nidulantes. Vifuntur \&s alibi, \& femper, fi Pfeudo-Ariftoteli credi- Preudo-A mus, tempeftatem nunciant confpecti. rift. in fecr. Sunt in infula S. Thomx virides, canori. Scaliger in Meminit Avicenna-cujufdam, qui quinde- Exerc.236. cim diebus continuis in principio veris Avicenia fuavifime cantillet, poft colorem immu- 1.8 , de Atet, mutefcat, \& fefe abfcondat. Ef in India Pafer Nocturius, qui noctu volat, interdiu quiefcit. Hirundinibus eft alis \& $\mathrm{vo-}$ latu fimilis, ex cineréo niger, nifi quod in. mediis alis albam habeat fafciam. Nocuam odio ingente profequitur. Forte A riftotelis Colaris, quem ab elula capi affir- Arit. H.A. mat, vel Actuarii Paffer fylveftris magnus, in fummis fruticum furculis defidens, colore \& magnitudine Alaudx, voce garrula, hyeme latens, quique à Noctua capicur. Sunt ibidem \& Turdo minores, velociflimi volatu, qui aquas fequuntur, \& natant. Sunt \& alii de quibus inferius dicetur.

Defriptionem non eft, quod quis à nobis $D e f c r i p t i t$ s poftulet. Pennæ quoties acriora urgent frigora abeunt in albas. Non eft ipfis gula, necingluvies, fed ventriculus longior. Ad Arin.H.A. imum inteftinum pauce appendices vi 1. 2.c. ult funtur. Fel aliis ventri, aliis inteftinis jungitur. Nullibi non ínveniuntur. In Media Diodortis tanta aliquando eorum copias ut incolæ, Sicul. 1.4. quia femina terris concredita abfumebant, alio commigrare coacti fuerint. Delphis in Hollandia, fxpe una die in uno cerevifiariorum granario aliquot centurix capiuntur. Migratorios effe vel fefe occultare, Hieronimus innuere videtur. Athenxus mares hyeme latere, foeminas permanere, ex eo quod color in ipfis mutetur; collegit. Aldrovandus inter migratorias vel latentes ponicredit; quod, mares vere, calore tam interno quam externo accrefcente, quando iterum calor accrefcits conjuges fuas ad fobolis propagationem adhortari incipiant.

Victitant oranis jat in terram fernini Nutrimst 
bus milio, mufcis, formicis, grillis, fcarabxis, vefpis, apibus delectatur \& hordeo, cujus corticem celeriter à grano feparant. Sed nec grana fambuci rejiciunt. Et hyofciami femina abfque ullo detrimento, feu proptervenarum exilitatem feu caufam de Coturnice redditam, devorant.

Generstio. Generationem quod attinet, falacifimi ef Scalig. E- fe comperiuntur. Vidit unum Scaliger in xercit. 269. cavum quoddam plus decies ad foemellam quam iniret, ex adverfo muro, pufillis inAldrovan- terpofitis momentis advolaffe. Vidit Aldus Orni- drovandus alterum, qui longe minori
thol. 1.15. thol. 1.15. quam horéfpacio, vigefies foeminam inic. 10. vit, pluries initurus, nifi ifta locum mutaffet. Nidulantur vel fub tegulis tectorum, vel in foraminibus parietum, \& ut pulli mollius cubent in fono \& plumis. Occupant \& hirundinum aliquando nidos. Unde apud $\mathbb{E g y p t u m ~ o b ~ l i m u m , ~ q u e m ~ i n v e h i t ~}$ Nilus, cum hirundinibus artem parietum è luto conftruendorum inveniffe, credunAritt. 1. 4. tur. Pariunt cœecos \& imperfectos pullos: de Gener. bis terve quotannis, octo ad fummum, quac. 4. tuor ad minimum, ut plurimum feptem.

Etas. Etas pafferum diverfimode definitur Mares negantur anno diutius vivere, argumento, quia nulla veris initio appareat nigritudo in roftro, quæ ab æftate incipit. Plin.H.N. Fominas longiufculum fpacium, ait, Pli1. 10. c. $3^{\text {S. }}$ nius. Albertus id à tempore coitus comScaliger in putat. Scaliger nullum excedere bima-
Arittot. de Arittot. de
plantis. tum verifimile effe credit. Ex illis, inquit, plantis. parum captatur, minimum capitur; foecundiflimi funt, frequentia non magna. Aldrovandus eam ad quadriennium extendit, quod columbxetiam falaciffimx, decimumfextum imo plures attingant. Cognofcitur ætas ex roftto, cinereum hoc, $\&$ circa fauces croceum juvenibus, nigrum ac durum provectis. Vox eorum apud Grxcos eft spstísv, quod itridere vertitur. Apud Homerum reí' $\leftrightarrow v$ apud authorem Philomeli pipære. Rhadivus cantillare dixit. Cum gradiuntur, faliunt.

Ingenium. Ingenium fi attendas, ita funt timidi ut 1.7. c. I9. fre à fomno excitentur, ad domorum faftigia conculrrunt, ut à fufpectis cafibus reddantur alieni, qui multis periculis proIden Var. bantur obnoxii. Vifus qui ab Accipitre Hitt. 1. ${ }^{23}$. impetus in Xenocratis finum confugit. Acoita.l.r. Taprobanenfes in alto mari emiffos, terHit. Ind. ram petituri, fequuntur. Evadunt interdum ita domeftici, ut ad puerorum manus vocati advolent. Ad Noctuam confugere, dum aucupis artes effugere conantur, quod Orus Apollo prodidit,falfum. Quid iis nocturnis avibus?

Inimicitia. Gerunt \& Inimicitias cum Vulture, MuBartholus
Angl.t.12. ftela \& aliis. Calamodyles, qui ex Paffec. $33^{\circ}$ rum genere effe videtur, folio cedri perit. 1.6. H. A. Peftem à milio atque panico, Sturnorum, 1. 6. c. 46. Pafferumve agmina,fcio abigi herba,cujus

TA T U R A L I S

nomen eft ignotum, in quatuor angulis fegetis defoffa : mirum dictu, út omnino nulla avis intret, inquit Plinius : Eodem referente mulci ad remedia ejufdem fegetis ru- Plin.H.N. betam noctu arvo circumferri jubent, 1.18. c.17. priufquam farriatur, defodique in medio inclufam vafe fictili : ita nec Pafferem, nec vermem nocere; fed eruendam priufquam metatur, alas amarum fieri.

Vfus Pafferum in cibis rarus. Galenus tamen eos alibi cum columbis, Perdicibus, \& Phafianis inter cibos attenuantes numerat. Alibi autumno maxime laudabilem carnem habere teftatur; \& Suidas in deliciis habitas prodit. At Platina ob nimiam platina 1.5 caliditatem male alere, difficulter concoqui, \& libidinem excitare ponit. Invenere $8 x$ in Remediis locum. Caro venerem exci- Plin.H.N. tat; \& rite Epilepticis, Tympaniticis, re- 1.3 c.c. 15. num calculo, vel articulorum vitio labo- Galen.1.6. rantibus præfcribitur. Idem de cerebellis tuendac.2. \& ovis prodidere fcriptores. Adeps $\mathrm{Ni}$ colai ad tophos Emplaftro inferitur. Fimus, faciem purgat; qur facultas ex maribus agnofcitur, quod guttatim albis, \&r porta 1. 5. nigris punctulis diftinguantur. Idem cum Phytogn. vino potus virgam erigit. Cum fputo ho- ${ }^{\text {c. }} 6$. minis illitus, varices extirpat, cum adipe porcino inunctus alopeciam fanat. Stomachum exfolutum \& naufeabundum in- Archiger. fperfus corrigit. Cum oleo calefacto pro- apud Gaximæ auriculæ infufus, dolorem dentium fen. lib. 8. pellit. Cinis denique pullorum utiliter ad 4. eundem infricatur.

Plin. H.N. 1.30. c. 3 .

\section{De Pafjeribus in Specie.}

\section{$\begin{array}{llllllll}P & U & N & C & T & U & M & I\end{array}$}

De Pafere Albo, Flavo, Maculato, $A l$ bicilla; \&ु Montano.

D Affer Albus totus eft candidus, roftrum, pedefque, qux partes flavx funt, fi excipias. Oculorum etiam nigram pupillam lutea iris ambit.

Flavus ad Aldrovandum delatus, totus erat flavus, preter oculos, qui nigri. Supra per dorfum, caput, alas, \& caudam ad caftaneum vergebat colorem. Quali etiam. femora, tibix, \& pedes tegebantur.

Maculatus qui dicitur, albo, nigro, \& fubflavo conftabat colore. Caput totum, ac collum alba, intercurrentibus maculis fubluteis. Roftrum erat flavefcens in fuperiori parte, in inferiore omnino flavum. Alx tribus prædictis coloribus ornantur. Oculorum iris candida. Cauda tota pene flava erat.

Albicille roftrum \& cauda ex cinereo candicat. Caput \& omnes infe fores partes ex alba lutefcunt. Dorfum maculx coloris ferruginei amplx, lineolis admodum. candi- 
D E A V V

candidis, exiguis decoratx, percurrunt. Pennæ alarum caftanex funt, circumcirca lutex, tibix pedefque fufcx.

Aldrovan- Montamus eft omnium Pafferum noftradus Orni- tium pulcherrimus. Vertex capitis eft co-
thol.1., c. 15. loris fere punicei, vel potius caftanei.Mentum, ut vulgaribus atrum ; inter quod \& verticem color albus eft, qui defcendens totum ventrem occupat. Ad oculorum latera maculæ funt binæ, una altera major, utraque nigra. Dórfum atque alæ partim flavx, partim nigrx. Alx, qua ventrem contingunt,modo ferruginex, modo atræx, modo albx. Cauda tota ex luteo fufcefcit. In foemina funt omnia pallidiora, \& mentum eam maculam non habet.

\section{P U N C T U M II.}

DePafsere Sylveftri, Torquato, Pufillo in juglandibus degente, ftulto Bononienfium, E Illyrico.

Aldrovandus Ornithol. 1. I s: c. 16.

Iden1 1ib. Tor quatum Bellonius ab albo torque ocuc. I8. los fub fupercilio ambiente vocat. Macu1. 7. de A- la ei lutea eft. Dorfum \& alæ cinerea. Havibus c. 2o. bitat in fylvis, in cavis arborum nidulatur, vocem edit magnam, \& aliter fe \& pullos, quam is, qui in urbe degit, alit.

Paffer in juglandibus degens omnium eft minimus. Roftro admodum brevi, nigro, craffo; pedibus, cruribus, capite, alis, Pafferi murali fimilis.

Idem c,20. Paffer fultus Bononienfum, eft avicula habitu Pafferibus fimilis, fed colore diverfiflima. Totus namqueflavefcit, maculis ubique ferrugineis, aut potius ruffis, oblongis, fed per dorfum multo longioribus \& craffioribus, ubique deorfum defcendentibus - confperfus. Roftrum ipfi eft ruffum, craffum, curtum. Oculi majufculi, quorum pupillamilutea iris ambit. Cauda \& alæ ad nigrum vergunt;" extremitates tamen pennarum minorum in alis candidx funt, pedes toti ex luteo ruffefcunt.

Idem c.2. Illyricus noftratibus majori eft, colore fere fimilis. Pronus enim plane candicat. Supinus pallide ruffefcit, nullo intercurrente alio colore. Oculi \& roftrum, quod candi-
I. B U S

cat, pro corporis proportione funt magni. Cauda bifurcata, pedes lutei, lineis transverfalibus coloris pene carnei ornati.

His adde Pafferculum Brachyurum noffratem; cui cauda admodum bievis. Totum corpus flavefcit. Pectus \& venter magis albicant, Roftrum intenfius luteum eft.

Sed \& avicula Pafferibus congener huc refe- Identic in: ratur, cui roftrum, ut in domefticis, candicat, totum corpus maculis fubruffis, oblongis, deorfum defcendentibus tingitur: Venter ac femora albefcunt. Tibix, pedefque fubflavi funt.

\section{P U N C T U M III.}

\section{De Taferibus Indicis.}

$\mathrm{P}$ Afferes Indici funt varii, fed precipua Aldrovatiipforum genera funt quatuor. $V_{\text {uns }}$ of $\mathrm{d}$ dus Orinie macrour us, \& bic duplex. Alius roftro miniaceo ma- $c_{1.22} .15^{\circ}$ gnitudine domefticis, caudam fi excipias, par, roftro brevi,craflo, \& prædicti coloris. Capite plano prope cervicem elevato, intercurrente fubviridi ad caruleum vergente colore, fubnigrum. Gutture, collo inferiore, pectore \& ventre candicantibus. Alis fubviridi ad cæruleum vergente, albo; nigro, \& lutefcente colore tinctis. Cauda duplici minore nempe, alba, qux majoris fulcrum; \& majore quatuor pennis longitudine dodrantale anguftifimis conftante aterrima. Tibiis \& pedibus ex nigro \&zalbo maculatis, unguibus nigris \& acutifimo hamo armatis.

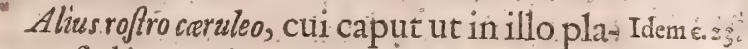
num, fed in cervice magis elevatum totum nigrum. Oculi nigri, circulo albo circumdante, \& inde lutefcente. Collum \& pectus coloris coccinei, venter \& cowæ candicant. Alx, tergus, \& caudx nigricant. Caudx longiores pennas, qux funt binæ longiflimx quinque nimirum palmorum, \& latifim $x$, tertia primum etiam lata, fed in exilia admodum filamenta definens, minores alix fultinent.

Alter eft Brachyurus fuperioribus omnino Idenic. is diffimilis, minor nempe, \& præter pedes \& roftrum, qux carnei coloris, totus niger. Cauda breviore. Oculis nigris, albo circulo cinctis.

Tertius eft fene Vropygio, \& hic vel Erythromelanus, in quo totum corpus prone \& fupine, item alarum principia coccineo colore fplendent:Reliquum alarum atrum eft: Roftrum pro corporis proportione exiguum , \& domefticorum roftro minus, colore qua capiti jungitur albo, cxtera nigro, acutum \& exile. Uropygium nullum. Inde ex ejus pennis opera plumaria conffciunt: vel Cyanerii thromelanus fuperiori lon-

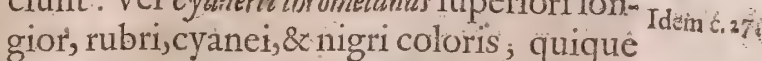
habet caput, collum, pedtus \& inferiora omnia coloris rubri faturati : ad colli laterà 
maculas binas, contiguas, fimilunares, magnas cæruleas, roftrum parvum, recurvum, nigrum, prope frontem album; alas admodum longas, nigras, ad latera cæruleas;

Idem c,28. pedes breves \& nigras.
2usartus Porpbyromelanus, cui caput, dorfum, Uropygium coloris funt purpurei faturati. Roftrum collurionis æmulum, fuperius nigrum, qua capiti adhæret album. Remiges alarum nigræ: Cauda quinque digitos longa, decem pennis nigerrimis conftans.

\section{P U N C T U M IV.}

\section{De Embriza Alba Eg Tratenfi.}

Gofner. in

Ornithol.

$\mathrm{H}$ IE Pafferini etiam generis effe videntur. Albam ita Gefnerus defcribit. Emberiza alba, qux mihi demonftrata eft media hyeme apud nos capta. major eft flava, roftro brevi, latiufculo, flavi nihil habet. Colore fimilis Alaudx, alioqui diffimilis, ventre albicante, à quo etiam Albam cognominavimus. In fuperiore roftri parte retro mucronem, tuberculum intus confpicitur. Digiti fufci funt; crura album \& puniceum colorem præ fe ferunt.

De Pratenfi fic idem:Emberizam pratenfem voco quam aucupes noftri. Wife Emberitz è pratis in quibus verfari folet appellant. Hæc, utpictura indicat, colore eft teftaceo, feu figlino, cruribus, pectore, ventre, alis \& cauda media. Utrinque enim in ea nigræfunt pennæ. Dorfum quQque nigricat, \& in alis fuperius maculæ nigrx funt fubrotund $x$ : inferius vero margines pennarum fecundum longitudinem nigricant. Roftrum fufcum, veriex niger, infra quem utrinque macula albicans retrorfum tendit : tum rurfus alix duæ nigræ \& albicantes per intervalla fequuntur. Hanc avem circa lacum Verbanum Ceppa vocant.

\section{T I T U L U S I I. De Avibus Granivoris Canoris.}

\section{- C A P U T I.}

De Carduele, Spino E. Paffere Canario.

Nomen.

\section{$C$} A R D E E I is, Carduelus, \&Cardelus Gazæ, Hermolao \& Gefnero Thraupis; Aldrovando ab aurea in alis vitta, Chrýfomitres. Aurivittes, Kirandi Jena, \& Avis Jovis; aliis Corydalis, Gracis

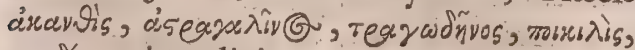
$2000 \delta \lambda_{s}$ etiam dicitur.

Defriptio. Avis eft parva, cui dorfum cinereum \& Schwenck- fufcum, Ale croceo colore, nigroque mix-
feld in Aviar. Sils- tim \& alternatim variate, albifque notatæ
dia. rubens apice fufco. Oculi ambitus exterior niger, hunc miniatus, miniatum cxfius circumdat. Nec tamen hæc colorum pictura in omnibus apparet. Femina alas habet cinereas, guttur album. Vifa nondum adulta ubique unicolor, ex cinereo ad ruffum tendens. Vifæ \& aliæ, quarum quæ- Aldrorandam in anteriori capitis parte $\&$ in mento thol. 1 . I 8 . aliquid rubri obtinent, dorfo, pectore, ven- c. 3 . tre, \& reliquis capitis partibus albefcunt: quædam totæ prorfuis albæ funt, capitis partem rubram fi demas, \& aliquat lutefcentes in alis pennas.

Sexus facile cognofcitur, fi coloris, ut fu- Sexus. pra attigi, vocis \& plumarum habeatur ratio. Vox fominis exilior, nec diuturnus cantus. Plumæ coftas obveftientes cinerex aut fufc $x$, maribus aterrimæ.

Victitat feminibus lapparum, papave- Nurimen. ris, rutx, dipfaci. Cannabino adeo pin- tum. guefcit, ut cantandi alacritatem amittat. de Villa. Quxcunque vero edit, roftro decorticat, ut pura medulla vefcatur.

Nidum in truncis arborum \& fpinis con- Generatio. Itruit, ter in anno, Majo nempe, Junio \& Augufto. Aliquando \& in hypocauftis pullitiem educit. Septem frepe ova, octo interdum, quinque aliquando ponit. Prxftant cæteris; qui menfe Augufto excluduntur. In dumetis nafcuntur, atriores funt, \& prunis aut malis aurantiis potius quam aliis arboribus infident.

Canunt omnitempore, fed maxime, cum $\gamma_{0}$. alias è fuo genere adventare cognof cunt.

Volant gregatim, \& ad duo millia quan- $v_{\text {olasus. }}$ doque.

Etatem ad X X. annosproducunt. Vi- Etas. fa Moguntix viginti tres egreffa, cui fingulis annis roftrum ac ungues pracidebantur, ut cibum potumque capere poffet.Depofitis geminis pennis canæ, quo locabatur vel prona vel fupina jacebat. Plus voce quam patina hominem delectant. Haud mali tamen funt alimenti, fi pingues, \& non nidificant. Affas iliacis \& colicis prodefle Kiramides authoreft.

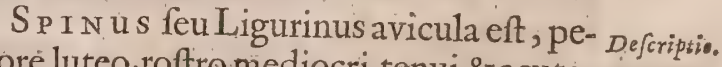
ctoré luteo, roftro mediocri, tenui \& acuto. Duas habet maculas nigras. Alteram in fronte, alteram fub mento. Mari capitis macula multo nigrior; idem toto corpore magis quam fominalutefcit.

In frigidioribus regionibus vel nun- Locks. quam vel raro apparet, nec in Italia quo-' tannis cernitur.

Iifdem quibus Carduelis vefcitur, nafci Vicus. inprimis \& comiza femine.

Nidulatur in montium fylvis. Ova fecundum nonnullos duodecim, fecundum alios quatuor aut quinque ponit. Amæniflime cantat; \& non tantum Carduelis, fed \& Vox. cantat; \& non tantum Carduelis, fed tur. dus Orni-
thol.1. 18. c. 4 . 
Volatiss. Volant gregatim, \& toto agmine facilli- fringillam excedit. Color in capite, dorfo mè autumno capiuntur. Sanguis ejus cum \& cauda nigrior quam Fringillix. Supina falifanguine non coit. Afrio vero, quod pars albicat. Pectus cum gutture nonnihil fpinas tempore verno depafcens, nidum ruboris habet. Alx duabus transverfis lidejiciat, infenfus eft.

Defcriptio. PASSER GANARIUS ab infulis Canariis, unde adfertur, ita dictus, avis eft vulgaris Pari magnitudine; roftro albo, parvo \& in acutum tendente; alarum \& caudx pennis to tis viridi colore. Mari pectus, venter, "\& pars fuperior capitis, quæ roftro adjacet magislutea funt, quàm foeminx.

Vicius. Pafcitur Phalaridis femine, faccharo, \& auricula muris, qua ad cantum excitatur.

$V o x$. Concentu eft valde amœeno \& acuto, quem fpiritu diu non interrupto runc in longum, nunc in altum varia vocis inflexione extendit.

Prxferundi quibus cauda longior, corporis magnitudo minor.

\section{A P U T II.}

De Fringilla, Montifringilla, \& Linaria. neis ex ruffo flavefcentibus diftinguuntur, media linea interjecta. In fómina, vertex, cervix \& dorfum plus habent ferruginei: alarum linéa fuperior adeo eft angufta \& brevis, ut ferè delitefcat. Non adeo fuave canunt, \& caveis inclufe aliarum alitum Pafferum inprimis voces imitantur:

LINARI A Pafferis eft magnitudine, Deforiptis fpecie admodum fimilis, colore teftaceo feu ferrugineo ad cinereum,vergente, eoque in mare intenfiore. Idem in pectore maculis refpergitur ruffis, fomina fufcis \& majoribus. Alarum rectrices pennx nigricant, fed ad latera \& in extremitatibus fuis candicant.

Cibus ipfi Phalaridis, lini, cannabis, ra- Nuírimerst parum, \& caulium femen, panicum, ave- tum. na fracta \& $c$.

Laborat interdum morbo, quem fubti- Morbis. lem dicunt, in quo moefta filet, pennx obrigent, venter folito tumidior venis rubris confpergitur, pectus ex carne appa-
ret.

Ring IL I A, feu quod frigus præ-
nunciet, feu quod plures in frigore convolent, ita dicta, Spiza eft Arigore modernis Græcis Fringillaro. In ea capitis \& colli pars prona ad fubcreruleum vergit ; quod hinc ad Vropygium fubvirefcit. Pectus \&x venter inter rubrum \& fpadiceum ambigunt. Fremina minus vegetis ornatur coloribus; pectus \& venter ex ruffo albefcunt. Vifa toto corpore candida. Vifa \& ex albido flavefcens.

Iocus. Locis gaudent hyeme moderate frigidis, Arit. H.A.
1. . c. . . 1. 9. c. 7. per hyemem recedunt, \& valido frigore ita offendintur, ut volare nequeant; \& manibus capiantur.

Generatio. In infimis arborum, \& fummis fruticum ramis nidulantur. Nidus intus ex lana \&aranearum telis, extus ex mufco conftruitur: Quinque aut fex ponere ova aucupes referunt.

Non uno eodemque modo canunt. Quxdam concife quafi quærulantur, quxdam in longum trahunt. Maribus vox alta eft \& plena. Fominis exilis \& fubmif fior Fringutire vel frigere authores dicunt, fi fuavius ut canat volueris, locuftam mandendam appone.

Ingenium. Difficulter obaftutiam capiuntur; facilius vel zephyro filante, vel fudo. Nam \& - demiffius tum volant, \&r melius allectricum voces audiunt. Qurdam nunquam manfuefunt, \& inedia comfumptre commoriuntur. Omnes primis captivitatis menfiTheophr. bus pre mœftitia obmutefcunt; nec nifi de fignis blanditiis exhilarantur. Mane fi canant,
tempett. tempeft. tempeftatem prefagiunt.

Defcriptio. MONTIFRINGILLA magnitudine

Exoriente canicula obmutefcit, ac plu- Vor. mas vellicando circa medium excutit, fic certum canicularis fyderis exortum indicat. Celebris eft apud Italos ejus aftutia. Unde proverbium egliè un Fanello.

Huc pertinet Linaria Rubra Gefnero à Gefner. íri coccinê verticis colore dicta, five illa $A$ - Ornithol. fter Oppiani,five aliud quid. Advolant aliquando turmatim, \& fere peftilentiam brevi futuram circa Norimbergam indicare putantur.

Nec non Linaria maritsa. Aldrovandi quæroftro lutea, vertice miniacea, pecto- Aldrovan re \& ventre candicans. Collo \& dbufo- dus 1. I 8 re \& ventre candicans. Collo \& dorfo ex ${ }^{c}+9$. luteo fufca eft. Alteri quam exhibet per tergus \& fuperiora prorfus leucophra, percurrentibus ftrijs deorfum vergentibus, color miniaceus magis fplendet, alæ funt longe pallidiores; Gula \& pectus leviter lutefcunt ; retro oculos macula fufca, rotunda data eft.

Qưx circa Argentinam Gyntel nominatur, per caput, dorfum \& caudam fufca eft, pectore ruffo, fufcis diftincto maculis, cruribus rubicundis, ventre inferiore al qicante ; femi nibus papaveri \& aliis vefcitur ; \& gregatim yolat.

\section{A P U T III.}

\section{De Alauda in genere, $\xi$ in specie.}

A LAUDA, feu Caffita \& Galerita,quæ tamen criftatis vocabula proprie conveniunt, Græcis veteribus róess, ropu-

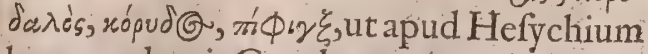
lego;modernis Cuzula, ๙९४ $\lambda$ ítí, \& in Creta, 
tefte Bellonio, Chamrchilados nuncupa- Cum frigus intenfum eft, \& nix agros teScaliger tur. Cirim non effe, tum cirri feu innulæ

Exerc.233. oblongx pulcherrim $x$, tum pedes rubri, qui in alauda non funt, Scaligero agente, evincunt. Formam non defcribam, obvia omnibus eft avicula. In pofteriore digiro pedis longiffimum habet unguem.

LoCHS..

In Andalufia non reperiri, Averroës tradit; nunquam arboribus infidere Ariftote-

Arit.H.A. les. Vif $x$ tamen in illis criftat $x$, firugo1.9.c.8. fum nec levem habuere corticem. In anAgricola. guftiis montium hyeme alicubi condun1.de Ani- tur: in Italia \& Gallia omni eas videbis mal. fu-
bter.

Nutrimen Vefcuntur granis, fed \& vermes degluPlut.lde tiunt, attelaborumque ex genere locuftaIfide. rum ova diligenter perquirunt: ideo à Lemniis coluntuir.

Generatîn. Nidum ex ficcarum herbarum radicibus humi ter in anno, nempe circiter Calend. Maji, Junii, \&z paulo poft Idus Julias conftruunt, eundemque auræ obverfum ita in fegetibus \& gramine recondunt, ut prætereuntium \& accipitrum minime obvius fit Arif.H.A. oculis. Gva quinque pariunt, quxà bufo1.6.c.r. nibus foveri falfum; quia auræ exponuntur. Superincidentes folis radiis parentum defectum fupplere videntur. Pulli exclufi implumes adhuc deducuntur ad paftum, ut predantium eripiantur injuriịs.

rox. Quantum ad Contum mira alacritate pennis exertis in aëre vocis modulatione, litæ ferenitati temporis, quafi applaudit. Nam nubilo pluviove colo, vix aut unquan canit, ut neque humi, fed inter afcendendum. Afcendit autem paulatim, fubito vero $\&$ inftar lapidis defcendens cantillat. Matutino vero potiflimum audiuntur, meridiano filent:

Inimicitia. Inimicitias exercent cum Pella ex ardeaArift.1.9. rum genere, cujus ova diripiunt, ut AriH.A.c.I. ftoteles vult; cum Acanthyllide, ut Philes \&. Elianus; cum corvis, quod ab iis Anton. devorentur; cum Accipitribus Alauda-

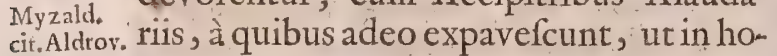
Alian.H. minum finus confugiant; cum Arcturo fyA.1.6.c.46. dere, quia in ipfius cum fole exortu, obmutefcere incipiunt, xgrotant, \& plumas vellicando excipiunt. Denique cum finapis femine, quod nulli non innoxium, alaudas conficit.

Morbi. Laborant morbo comitiali, \& alterius oculi coecitate, idque nono accidere anno Albertus experientia propria nixus teftatur.

$v$ fus. De ufu in cibis taceo. Juniores \& pinguiufculas nemo non appetit.

species. Species Alaudarum funt, $C_{R}$ IS T Ata \& Non Cristata. Illa eftvel Major vel Minor; quarum hæc Ariftoteli incognita, Schwenkfeldio Arborea, Fera, civávup(G, apicem pro corporis magnitudine longiufculum, \& pedes rubros habet. git in fterquiliniis \& prope horrea verfatur, per æquinoctium avolat, fi Longolio credendum ; nidum in foflis fenticolis fternit; nullam particularem cantiunculam habet; fed inepre aliarum quibus cum viatitat vocem refert: Congener eft ipfi Alauda Syl-

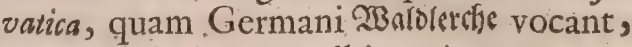
parte inprimis prona albicantior.

Major roftrum habet cavum; criftam, cujus radices inter utrumque oculum fituantur, aliquantulum nigricantem. Dorfum cinereum albo maculatum. Ventrem Bellon.1.5. albicantem, peetus cinereum albis maculis de Avibus confperfum. Caudx plumas nigras. Linguam exiguam fere furcatam, quia ramis raro infidet; ungues longiufculos. Habitat inagris, circa flumina, \&lacus; hyemis tempore ad vias. Nonvolat aliarum more, fed vento cogente, nunc ima nunc fumma petit.

\section{Non-criftata fuavius canit.}

Laudatur ad colicos dolores, feu cocta $V$ fuss: féu affa. Quidam cor alligari femori jubent: Galen. de alii recens tepenfque devorant. Confularis dic. facult. Afprenatum domus eft, inquit Plinius, in Diofcorid. qua alter è fratribus colo liberatus eft ave 1. 2. c.48. hac in cibo fumpta, \& corde ejus armilla aurea ínclufo; alter facrificio quodam crudis laterculis inclufo corde, ad formam camini, atque ut facrum perastum erat, obftructo facello. Thraces vivente adhuc Alauda cor exemtum finiftro femori pellendx colic 2 ergo circumdabant, ut Alexander Trallianus fcribit. Porta caufamin loquacitatem conjicit. Nimia enim garrulitate, flatus; ex quo morbus fxpe exoritur, eximitur.

Non Cristata, Hermolao, Sipontino, \& Grapaldo Terraneola, Nipho falsò Ariftotelis Tetrix, colore fimilis eft criftatæ, fed magnitudine minor. Caput habet nigrius fulvo colore intermixtum. Dorfum Arift.H.A. fpadiceum, cinereum, \& fubnigrum. $P e^{-1.9 .}$ c. 25. ctus pluribus maculis diftinctum. Ventrem fubalbidum. Pofticos digitos \& ungues ejufdem magnitudinis cujus \& pofteriores. Degit in planis locis, erica \& Junipero con- Bellon. H. fitis. Hyeme gregatim volant, xftate binæ. Avium 1.5. Alta petunt volatu, diutius in aëre hærent, ${ }^{c}{ }^{23}$. \& majora fpacia conficiunt. Amœnitate vocis inter omnes excellunt. Galli ex uno temperamento in alterum facile tranfire, \& pro ventorum diverfitate ; diverfimode etiam immutari, tradunt. Flante Auftro macrefcunt, Aquilone pinguefcunt. Captua . ra hyeme largiffima, nifi nives diutinæ fedeant, \& maxima fit frigorisinclementia. Ad hanc Calandra, Alauda pratorum, $\mathbb{E}^{*}$. Alaude congener fpectat.

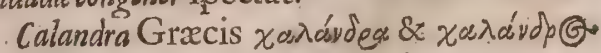
forte : tus; aliis, fed falfo Acredula, Charadrios, 
Gurgulio, ad Sturni magnitudinem accedit. Alaud $x$ de cxtero in omnibus fimilis. Collum qua jubæ Capiti connectuntur gracile habet, \& roftrum craflius. Vistitat duriufculis granis. Vocis modulatione audientes mirifice oblectat, ac omnes avium voces expreffiflime imitatur. Capta, vix unam diei horam fine cantu præterit.

Bellon. H. Alanda Pratorum Alaudis eft minor. RoAvium. 1.5 ftrum habet tenue, \& longiufculum. Plumas cutem contegentes omnino nigras. Caud $x$, in extremo albicantes. Humidor mit. In pratis nidificat. Difficulter educatur, fed educata fuavifime canit. Cum Accipitrem fupervenientem adfpicit, in arborum ramis latitat.

Alaude Congener illa Aldrovando dicitur, qux Bononix Petrone, Genuæ Petronella \& Chiapparone dicitur. Criftatr majoris magnitudinem $x q u a t$, vel fuperat. $\mathrm{Ei}$ demque colore fere fimilis eft. Pectoris \& totius ventris color magis ad fubflavum vergit. Ungues in tantam longitudinem non excrefcunt. Tibiæ \& pedes albicantiora funt. Humi frepe quiefcit vel curfitat; in arboribus vero \& fruticibusfumma femper cacumina petit, quibus diu immobilis infidens, fuaviffimas cantilenas modulatur:

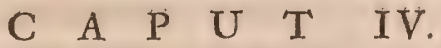

\section{De Cbloride, Citrinella \& Serino Gefneri,} \& Luteis earumque congenere.

Deforiptio.<smiles></smiles>

HL or Is Germanis Brunfincê, feu Fringilla viridis, magnitudine eft alaudx, aliquando tota viridis, aliquando valde lutea. Mas à foemina in hoc differt, quod hæc fpadiceo partim, partim, cinereo ubique coloratur, minufque multo lutei coloris, imo modicum admodum habet. Pedes ei \& crura mollicula, carnea fere fubftantia \& colore. Gula, venter, pectus, uropygium, \& alarum fuprema ora, pulcherrimo ochre colore flavefcit.

Victus.

Ariftoteles vermiculis vittitare fcribit. Arit. H.A. Verum pafcitur quoque feminibus, Carduorum majorum, Lapparum, raporum, \& phalaridis. Adeo aliquoties cicuratur, ut

Arift.H.A. una manu detenta, cibum altera porre-

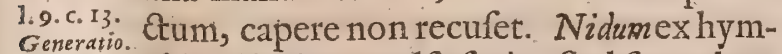
AI. H. A. phito ftirpitus evulfo facit. Sed ftragulum 1.4. c. 47. ex lana \& villo fubjicit. Quatuor aut quinAldrovan- dus Orni- que ova parit.

thol. 1. 18. Congener eft huic illa, quam Aldrovandus c.18. Cbloridam Indicam vocat, quxque prono, ventre nimirum \& pectore eft candidiffima, roftro fubviridiad fufcum vergente, capite toto dorfo \& Uropygio viridibus; pennis, alarum remigibus \& tota cauda. cæruleis, fcapis albis, pedibus nigris.

Citrinelia M Gefnefi, quan Gal- li Tarin vocant, Thracipedem Ariftotelis Bellonius effe opinatur.Color capitis dorfi caud $x$ intenfior eft quam in Ligurino, ideo ob flavedinem magis fufca videtur. Mas. plus flavi coloris in toto corpore \& prefertim in pectore circa nates habet, quam foemina. Vefoitur iisdem feminibus, quibus alix canoræ. Raro plures quam feptem, aut octo uno incubitu excludit, \& in cantus omnibus hujus generis excellit.

SER I N U S Gefneri Ligurinum magnitudine \& colore referr, pectore \& ventre ex viridi flavefcens; parte fuperiore, partim ejusdem coloris, partim fufca. Congener eft illa, quam GermaniHirngrylle vocant, magnitudine Ligurini, fed magis lutea.

Capitur in Helvetiæ montibus. Auceps Gefnet. ilit cum fexum utrumque domialeret, ita ut Ornithol. aliqua volandi libertas effet, pullos etiam ex eis habuit. Sed cum aliquando pro mare Gryllo marem Ligurinum adhibuiffet, ova quidem nata funt, fed ex quibus foris nihil provenit. Suavifime cantillat.

L U TEARUM duo funt genera; $V$ num, quod Ciam fimpliciter Itali vocant; Alterum, quod à colore paleari, Ciam Pagliariam, feu Pagliaricciam, Angli Gelgorftam dicunt.Capiuntur facillime omni aucupii genere. Vefcuntur granis hordei, triticei, pane; hyeme alimentum in equinis ftercoribus quærunt. Captæper duos vel tres menfes merum Cici ingeminant; fervitutis oblitx ad fuos modulos revertun tut. In caveis frepe cum morbo comitiali conflictantur. Media hyeme magno numero in Italia apparent, \& 8 in pratis ingentes earum catervæ confpiciuntur. Quæ de harum congenere addit Aldrovandus vide fi libet capite vigefimo primo, libri decimi octavi.

\section{T I T U⿺ $\quad$ L $\quad$ U $S$ III.} De Avibus Baccivoris.

\section{A $\quad P \quad U$ T $I$.}

\section{De Turdis in genere.}

Ais Latinis, feu per Onomat opo- Bellonius A ram, feu à colore, Turdus dicta, à Obfer ${ }_{c .} l_{i} x_{0}$

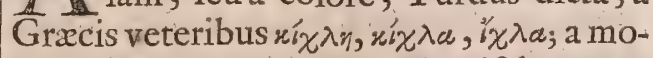
dernis Schynopoullos, ac fi lentifcinas aves diceres, vocatur. Genera ipforum tria prodidit Ariftoteles. Vijcivorum feu 涫oßógov picæ magnitudine. T $\varrho_{\iota} x a ́ d a$ à ftridore dictum, quantitate Merulæ; \& Ilias, omnibus minus, minufque maculis diftinctum, quod gregatim volat, \& nidos àluto hirun- Athentixizo dinum more conftruit, \& apud Gallos non Dipn 1. $\dot{s}_{\text {i }}$ extare putatur. Recentiores plura enume- $\mathrm{H}$ - $\mathrm{A}$. ratis annumerant. Nam \& Turdela Hermo- Arift. 1. gs lao eft genus Turdi alterum, quod in $\mathrm{Ve}_{-} \mathrm{c}_{0}{ }_{2} 6$. neta provincia Drexanos vulgo vocant, major Turdo, penna fubfufca, varia; \& 
Turnero illa, qux Saxonice §rachoogs//femine ab ipfis excreto provenire vifcum (commune hoc fereillis nomen, qux in no- Theophraftus \& Plinius prodidere, tam Theoph: valibus \& quiefcentibus agris immoran- falfo quam Saturia \& Orchides ex eorum de Cauf. tur) colore fufco, terreo, obfcuro, ut humi genitura nafci, falfim eff. Quot enim in c. 2. . .2 . fedens agnofci vix poflit, ex Turdorum eft arboribus Turdus ftercus excernit, \& ta- Plin. H.N. genere. Idem Germanorum ₹roffel / Tur- men vifcum non generatur? Quot in re- 1. 16. c. 94. Genera. . dum pilarem effe putabat, Scaliger fecunment.Cont- di apud Ariftotelem generis, duas. Jecies fatato, 1. cit; quarum una Trida à Vafconibus, altera Turdus dicitur, figura \& facie adeo diffimiles, ut nonnunquam in agnofcendo fallantur. Saxonum Ziepdrufchel colore Iliaco fimilis, quxque circa rubos verfatur, \& fructibus eorum victitat, minimum Turdigenus, \& Batis Ariftotelis quibusdam, Germanorum vere Silcin Biemer / Merula minor, roftro acuto, brevibus pedibus, ejusdem nonnullis Cyanus. Helvetii habent Tutdum fylveftrem. Carinthiorum avis dicta saintrofer / pedibus albis, Turdis minoribus annumeratur.DeAlbis, qui in Septentrione, non eft quod aliquid dicam.

Forma. Forma fi fpectetur, cinereus color eis fere peculiaris eft, huic quam illi remiffior vel intenfior. Omnes per collum inferius, pectus \& ventrem maculis æeftate confperArif.H.A. guntur, quas per hyemem deponunt. Un1.9.c.49. De Plinius, Turdis color aftate circa collum vac.20. rius, byeme concolor. Vifus tamen vifcivorus; nefcio quo anni tempore captus, qui ita plumbei coloris evaferat, ut quodam modo ad amethyftinum accederet. Vifus \& Turdus vulgò dictus, tribus diverfis coloribus diverfis niminum temporibus captus. Rofrum omnibus eft longiufculum, craffiufculum, rectum. Lingus lata, \& ad imitandum humanum fermonem parata. Pedes figura fimiles, \& colore non in omnibus eodem. Intefinum appendices non habet, nec gula verfus ftomaclium dilatatur, nec fuperius ingluviem habet. Nullibi non funt obvii. Daphnios, feu à Laureto illo Alexandrino, ubi baccis vefci poterant; feù Daphne delitiofo quodam Syrix fuburbano ita dictos, Clemens Alexandrinus celebrat. Advenas effe, \& quotannis in Italiam circiter æquinoctium autumnale transmare, verno revolare, AudcReRuft. thor eft Varro. Unde trimeftres Plinius 1.3. A. 1. 8. dixit; per hyemem latere fcripfit Ariftoc. 3. teles: nec tamen omnes, vel ex eo evidens, Gefn, in
Ornithol. quod in Helvetia circa Tigurum per hyeOrnithol. men abundent, hyeme in Italia loca maritima juniperis \& myrtis confita, frequenHesam. tent. Ab Ambrofio inter eas qux fub hye1.5. c.r. mis initium ad nos accedunt, numerenAldrov, tur; Bononiæ denique Martio etiam menOrnithol. fe copiofe habeantur.

Yicius. Quantum abVictum, delectantur baccis myrti, juniperi, fambuci, heder $x$; nec non olivis, ut eft apud Calphurnium Poëtam. Vnde Olivariorum nomen; fagi glandibus, infectis, lumbricis \& culicibus. Ex gionibus Turdinon funt, ubi vifcum naf́itur? Concoguitur in Turdi ventriculo granum cum labrufcarum longe duriora \& Scaliger in majora concoquantur gigarta : \& exhibitis Exerc. 68 . univifci baccis, nulla in excrementis reperta eft fpecies. De faginatione videantur Oeconomica.

In cacuminibus arborum nidificantes, $\mathrm{pe}-$ Generatioo. ne contextim in fucceffu, generant. Ova, decem à conceptu diebus pariunt \&r fovent. Increbuit alicubi mos, ut vafa ibidem collocentur.

Vox eorum trutillare, ut Philomele au- $v_{0 x}$ thor inquit. Sermoni affuet, tanquam e Scaliger in modulis fermocinantur. Habuic Agrippi-

na, qui omnium fermones imitabatur. Et Plin.H.N. mirum eftadeo furdos dici, ut vitium in ${\text { l. } 10 . c_{0} 42 .}^{2}$ proverbium cefferit. Invenere \&.in

MedicinaVfum. Myrtorum baccis farti \& $V$ fiss.

affi ventris profluvio laborantibus exhi- Plin.H.N. bentur. Tempore peftis in cibo, macera -1.30 .c. 7 . ti ,laudantur.

2uid de ufu in cibis dicam? Duriores qui- Bellon 1.9. dem concoctu, Perdicibus, Attagenis, de Avibus Phafianis \& Gallinis, Galenus facit: fed ${ }^{\text {c. } 3 \text {. }}$ quia idem Phafianos Gallinis concoctione \& nutriendi pares, edendi fuiavitate fit Galenus periores alibi fcribit; alibilaudatis cibarïs, Method.1. qux neque tenuem neque craflum fuccum ${ }_{\mathrm{Lib}}^{7}$ de cigignuntannumerat, vellocus prior men- bis boni $\alpha$ dofus eft, vel fibi ipfi contradicens, falli- mali fucti. tiir. Greci fane ova cum Turdis, lepori- Alex. ab nis carnibus, ac mellitis placentis fecundx Alex. 1: 5 . menfre frequentius inferebant. Iisdem Genial, dier. $_{26}$ Turdorum curmæ in propomatibus feu primis conæ ferculis in ufu. Eorundem Athen. in pectora in patinam Apicianam conjicie Dipn. I. 2. bantur. Et quantus circa eos Romanorum luxus, five copiam, five pretia fpectes.'Tanta Turdorum aliquando fuere aviaria, ut Plin.H.N. ex iis ftercorarentur agri. Lucullus alios ${ }_{\text {Varro }}^{1.17 .9 .}$ videbat Turdos in mazomo pofitos CO- $R_{0} R_{0} l_{3}$. ctos, alios volitare circa feneftras captos. Ex uno Ornithone quinque millia fcio veniffe Turdorum denariis ternis (id eft computante Budæo denis folidis Turonicis \& femiffe) ut H. S. faxaginta millia ea pars villæ reddiderit eo anno, inquit Var- varro $I_{3}$. ro.At nunc xtatis noftræluxuries quotidia- de R.R.R... na fecit hæc pretia, \&cc. Noftra ætate quoquo modo capti eduntur. Quibusdam jecur ovis integrum cum medulla panis contunditur, \& per linteum transmittitur: Hinc aromatibus ad faporem coloremque commendandum infperfis fervefcit. Turdi in jure carnium elixi, \& modice frixi imponuntur.

C A = 
colore pars fub alis tingitur. Interiota oris

G A P U T I I.

De Turdis in Jpecie.

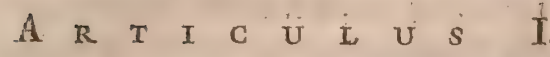

De Turdo Vifcivoro \& Trichadé.

Gefner. in Ornich.

$T$ Urdus Vifcivorus, Ariftoteli i $\xi_{\circ} \beta \beta^{\prime}$

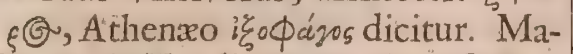
jor eft cxteris Turdis, \& paulo infra columbam. Capite, alis, \& ventre fufcus; plumistamen juxta caudam aliquid flaviadmixtum apparet. Cutem intra roftrum pallidum \& fubrubum colores mixti tingunt. Collum parte prona, venterque totusnigris punctis in albicantibus piumis, \& alicubi flavis variant. Pedes digitique, pofteriore Aldrovan- præfertim tibiarum nervo, flavefcunt. Alc.2. drovandis femel unum adeo, in cauda maxime, \& alarum remigibus albefcentem obfervavit, ut pene albefceret ; capite vero, tergore, \&fupernis alis omnino cinereus effet. Nullo non tempare apud nosvifuntur. Cibus ipfis abietis vifcum \& refina; xftate in primis; hyeme fructiferarum arborum femina. Sed \& baccis arborum, Juniperi præfertim \& Liguftri, inhiant. Dum finguli fingulas vifciferas arbores occupant, \& prope eas morantes, alios perfequuntur, facilius capi, prodidere nonnulli. Obfervata in iis à rufticis \& præxagia. Diu nempe duraturæ hyemis, fi circa hujus finem in cacumine arboris cantillent. Futuræ æftatis, fi in ejus medio confiderant.

TRICHA $s$, qui Pilaris perperam dicitur, \& à ftridore nomen fortitus eft, totus fere magnitudine \& figura éft Merulæ. Roftrum. habet fubflavum in extremonigricans. Os \& linguam flavo colore tincta. Collum pronum cinereum maculis nigris afperfum. Dorfum charopum, \& per medias pennulas nigricans. Pars circa Uropygium cinereis plumis obtegitur. Calldam nigræ pennæe conftituunt. Collum fipinum \& pectus varia funt. Pennæ alarum partim nigricant, partim ruffo colore tinguntur, \&zc. Nunquam aut raro in æftate in Anglia vifitur, hyeme tanta illorum multitudo, ut nullius avis major. Vefcitur baccis juniperi, Aquifolix, \& forbi minimæ. Apud Helvetios poftremo advenit. Acutè Arift.H.A. fonat, \& quamvis colorem mutet : vocem
1.9.c.20. tamen non variat. Volat gregatim, \& inter volandum obftreperus eft.

$$
\text { A R T I C U L U } 3 \text { I I. }
$$

De Turdo Illade, E़ fimpliciter dicto.

$T$ Urdus Tllas, Tyllas Alexandro, Myndio dicitur. Fufcus eft per totum dorfum. Pectus eft varii coloris, medius venter albicat; utrinque rubet. Eodem penitus flavefcunt. Nidificant in Bohemia vel Hungaria. Gregatim plarumque in dumetis degunt. Initio hyemis perquatuor decim fere diesante Pilares in Helvetiam advolant, circa Pafcharecedunt. Racemis victitant, vineifque multum damni inferunt. Ideo tempore vindemiarum capiuntur. Gefnerus in diffecti ventriculo menfe Novembri baccas fpinz albx quam Oxya cantham dicimus, repetit.

Quem Aldrovandus Tiurdum fimpliciter dictum vocat, is Bellonio Turdus primus Ariftotelis, \& Turdus vifoivorus minor dicitur. Crura in eo ex defcriptione Gefnerialbicant. Pectus, ventrem, \& latera puncta nigra infigniunt; illud fubflavo' \& ruffò colore in unum commixtis infignitur. Idem fub alis color merus. Tơta fere pars prona fufcefcit. Alx fufco ruffum mifcuerunt, \& maculas fubflavas habent. Venter candidus eft. Crura albicant. Proprium illis effe apparet, ut circum oculos maculentur. Sexum folo cantu difcerni poffe dicunt.

\section{NB. Genus. Turdorum exoticum wide in} Mantil 5 . Num.9.

\section{A P U T I I I.}

\section{De Merulis.}

$\mathrm{M}$

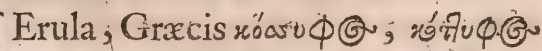

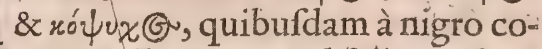
lore Nigretta; Latinis quod folivaga fic \& fola pafcatur, Merula dicicur. Duo ipfarum GeneraA iriftoteles ponit.Vulgarefeu nigrum, Generd. \& candidum, quod tantum circa Cyllenam Aritt.H.As: Arcadix nafci fcribit: nos \& in Norvegia; \& in novo orbe inveniri fcimus. Varro in-Varr.de R: ter res inufitates reponit. Addit \& tertium R. $1.3 .6,9 ?^{\circ}$ fufco colore, se minoris magnitudinis, quod Pafferem folitarium vel Merulam montanam quidam effe judicant. Vidit Aldrovandus totam ex flavo ad caftaneum vergentem, mutato forte priore colore. Magnitudinem ei Turdi Trichadis Ariftoteles tribuit citante A thenixo, colorem nigrum, roftrum puniceum vere an falfo nefcio. Albertus roftrum \& pedes crocea. Sed ut plumarum colorem pro temporis diver fitate mutant : ita \& roftum idem non fervat. Nam id anniculis, tefte Plinio, in ebur transfiguratur; at maribus duntaxat. Scaliger pullos nigrum habere, annicullos In Arifod buxeum affirmat. Sexus optime difcernitur. ${ }^{\text {telis }} \mathrm{H}$. $\mathrm{A}^{\text {? }}$ Fœmina namque fufca eft, roftro inferius tantum lutefcente, fupra plane fufcido. Gula pectufque totum ex albicante \& fufcefcente coloribus maculantur. Nominat Aldrovandus quandam Leucophalim, cujus Ornith. caput præter tres maculas oblongas nigras, 16. c. 6 , qux retro oculos confpiciebantur, prorfus candidum erat, roftrum \& oculornm 
iris lutea, pedes fufcefcebant. Cauda \& venter aterrimi coloris. Alx albo maculabantur. Apponit \& candidam totam, roftro duntaxat rutilo, \& pedibus lutefcentibus. Alix ex albo \&nigro funt maculatæ, mas minus quam foemina, cauda nigra, roftro $\&$ pedibus intenfe in mare rutilis, pallide in fœmina flavefcentibus.

Quantum ad Locum, verfantur in locis denfis confitis arboribus, fpinetis, anguftis montium angulis, \& lapidum fiffuris.

Arif:H.A. Mutant ut Turdi locum, \& hyeme in 1.9. c. 16. vicina demigrant apriça. Parafitus tamen apud Athænæum, fi algor fub dio perpetiendus fit, fe Merulam effe profitetur.

vietws. Vefcuntur iifdem quibus Turdi. Sed \& promis forborum, orni fambucique acinis. Caveis inclufæe etiam carnibus. Plantæ ex quibus precipue cibum decerpunt, funt Oxycedrus Dalechampii, Ilex Aquifolia ejusdem, Myrtacanta, philyrea anguftifolia, myrtus laurea maxima, myrtus exotica Plinii, \&rarea Theophrafti effigie alni.

Eeneratio. Nidos figura hæmifphærica oblongiuf; cula, admodum fcutelli cavos, ex furculis ramulisque exilibus, \& fibrofis radiculis luto inter fe contextis, fubftrata molliore materia conftruunt. Bis anno, omnium avium primx, ante exactam hyemem, in Helvetia menfe Martio vel A prili pariunt. Numerum pullorum nemo exponit. Nido Aldrovando allato quinque inerant. Perfarum Magos ex falvia fub ficu putrefacta, dum fol \& Luna fecundam folis faciem occupant, avem Merulx fimilem procreaffe, cujus aduftx cinere lampadi infperfo domus ferpentibus repleta videbaTipit. Me- tur, author eft Langius.

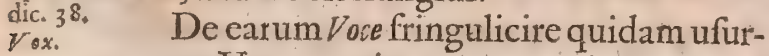
pat. Veteres ejus non exprimunt proprium, fed inter canoras ponunt. Quandam adeo in novem vocum modis exprimendis excelluiffe, ut nullus hominum perfecte eam imitari potuerit, Albertus author eft. Incipiunt autem vere canere; continuant per æftatem. Hyeme cohiben-

Arit.H.A. do vocem, Atrepunt \& tumultuofe vocu1.9. c. 49. la vocem Plinius hyeme balbutire, circa folPlin.H.N. ftitium mutas effe ait.

1. Io.

Amicitiam cum ea Rubecula colit. Sequitur enim eam, \& noctu, vel juxta ipfam, vel in proxima arbore conquiefcit. Ipfas Noctux ita infenfas quidam volunt, ut quotiefcunque clamantem audiverint, tanquam injuriam vindicaturx, advolent.

1.6. H. A. Mali Punici grano perire ÆElianus author 1.6.c. 46. Ma

Ingenism. Ingenium refipit, quod humanum fermoPhiloftr. nem, quamvis linguam ftrictam, roftrum 1. 7. in vita rectum, \& anguftum habeant, imitantur:
Apollon. \& quodLaurifolio annuum faftidium purgant.
De $V f u$ in cibis, hrc pauca dixiffe fuff- $V$ fus. ciat. In pectore ipfarum adufto haùd par- Horat. 1.2. vam collocaffe voluptatem Romanos. In- fermon. ter popinx vero profeflores clunefne ter- Plin.H.N. goribus fint praferendx, difceptatum. 1.10. c.50. Tarde tamen concoquuntur, parumque alunt, fi Platinæ credimus; interlaudatas Platin.1.5. cenferi debent, fiSalernitanis: Nonnulli de tuenda à Noctua captas praferunt. Alii pingues \& retibus vel laqueis captas eligunt:

Quantum ad Medicinam, bene illis qui laxa funt alvo præfcribuntur. Plinius inaffatas cum myrti bacci dyfentericis mederi fcribit, Porta Melancholix. Fimus ex ace- Porta 1. 3. to miftus, fi orizam avis comederit, extir- c. Ix.

pat lentigines. Caput ad brachium finifrum, cum leporis pedibus portatum, audaces facere, mendacium eft.

\section{A P U. T I V.}

De Merulis in Jpecie.

$A$ R T I C U L U S I.

De Paffere folitario E̊ ejus congenere.

DAffer Solitarius, quod cum nullo fuigeneris unquam, nfi tempore generationis verfetur vulgo dictus, quem tertiam Ariftolelis Merulam effe Gefnerus, $\mathrm{Ni}$ phus, \& Aldrovandus afferunt, Merulus Solitarius circa Tridentum ; Merulus ftercorofus, quod in latrinis habitare credatur Romanis, fi Alberto credendum ; Merula faxatilis Placentix dicitur. Avis eft Merula Gerner, in lo, parumper arcuato, capite pro corporis proportione parvo, fuperius plano, nigroque ad latera,nempe circum oculos, aures, \& in collo inferiore cæruleo. Fomina tota fufca eft, \& pectore maculislutefcentibus variegatur, mari plane diffimilis. In faxis \& teftis (non tectis, repépusov, nam que Arift. 1. 9. textus habet) diverforium habere Arifto- c. 19. les dixit. In parietibus aliis Pafferibus conjungi, \&cum eis ad paftum volare Albertus. In dumofis rupibus circa Larium lacum nidulari, neque cum aliis avibus degere, Gefnerus affirmat. Canorus eft, \& Mediolaniac Genevæ magno propter cantum precio venditur. Quem Bellonius.defcripfit , \& Charadrium effe primo afpectu putabat, Turdi Iliaci eft craflicie, Lufciniæ moribus preditis. Roftrum habet rotundum, acutum, fubalbum, in extremo nigrum. Pennes fub pectore $\&$ duabus coftiscolore dactylorum, maculis interftincto. Dorfum cinereum, fulvo maculatum. Forma.

Pedes Turdo fimiles, Caudam ut in Lufcinia ruffam, quam mox ut è nido eximitur, immutat. Mas quia pulchrior, coloris elegantia à foemina diftinguitur.

In rupibus folitariis nidificat, \& raro in Generatio. plano 
plano aut per valles cernitur. Certo anni torum laticudine plumas, reliqua macttempore fub tegulis feu imbribus degit. Ca- lofas, nigris in medio pennis, ambitu albis, nit noctu xque ac interdiu ad lumen can- fuperiore fufcas, alarum pennis, margine delæ maxime : Francifcus Gallorum Rex extrinfeco albicantibus. Fomina, quam Altanti ejus cantum fecit, "ut nullam preter drovandus defcripfit, erat corpore toto hanc audire dignaretur.

PASSERI SOLITAR IO congener eft illa avis, quam quidam Petrocos fcyphum, Germani Gtcinrofele \& 3 lauboget vocant, Bellonius Bellonius Cyaneum Ariftotelis, fed falio
Obferv.l.I c. II. (Ex Picorum enim genere eft, roftro et-

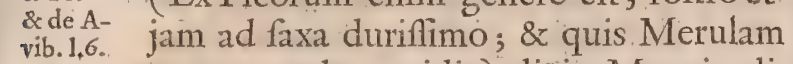
c.6. totam cxruleam vidit) dixit. MagnitudiSeiler. ad ne eft Stuini, pectore, cervice, \& lumbis Seiler. ad Cyanea: dorfo \& alis nonnihil nigricans.
Gefnerum. Roftrum ei fesquidigiti longitudine fubter nares fufcum, imo aculeatum fuperiore parte adunca, inferiorem ut plurimum contegente.

Degit in altiflimis, preruptis, \& nivofis fcopulis, in Creta, Citharea, Corcyra, Zacyntho, Eubxa, \& circa fluvium Athefin.

Generatio. Nidificat in deviis folitudinibus, pullosque, quos ternos aut quaternos excludit, ut à rupicapris etiam tuti fint, in cavernas deorfum condit.

Vox. Vox ipfi articulata, amœna \& varia. Media \& intempefta nocte expergefacta, ad aftantis provocationem claro fpiritu canit. Ante tempus autumni cum colore etjam vocem mutat, ac alis expanfis novos, fecum continuo murmurans, excogitat cantus, nec veteris oblivifcitur.

Color fuib hyemem niger è cæruleo evadit. Circa veris initium, in priftinum commutatur. Adulta vel è nido femel egreffa \& volatui adfueta, nullis aftutiis capitur. Moris denique ei, oculos hominum aliorum alitum more adpetere: Tamque diligenter res obfervare, ut plæraque, vocis aliquo articulo indicet.

\section{A R T I C U L U S II.}

De Merula Montana, Germanorum Torquata, Bicolore, E Saxatili.

$\mathrm{M}$

Erula: Germanorum MoN T A$\mathrm{NA}$, avis eft paulo infra Turdum majorem. Caput, dorfum \& alæ, ruffo quodam modice admifto nigricant. Pectus eft, ex plumis partim fubfulvis, partim nigricantibus obfcure maculofim. Os interius \&.lingua luteifeu melini coloris. Ventris color ex nigro \& cinereo miftis; crura ex glauco nigricante, \&ruffo, confant. Cauda eft atra.

Torevata, quix \& Montana, Saxatilis, \& Equina, quod in fylvis vermiculos in fimo equino quxrat, avis eft barbatula, magnitudine fere \& colore Turdi. Parte prona inter collum habet albas duorum digi-

fubnigro ; roftro circa nares, \& in apice ni-

gro, ad latera flavefcente, pennisremigibus alarum nec non ventris, extimis oris, noinnihil albicantibus, cxtera candicantibus. In ultimo gutture feu pectoris principio macula albifima pollicem lata ad hum meros pertingente, vel torque candido, ornabatur.

Merula Bicolor quod duobus potiffmum coloribus fufco aut fubnigro, \& lu teo rubefcente variet, dicta, eft avis $\mathrm{Mc}$ rula paulo minor, capite fufco, lineolis candicantibus variegato, roftro in luteo rubefcente, qui etiam color in tergore \& cauda intenfior ; in pectore \& ventre remiffior, videtur. Alarum remigibus fufcis, in extremis orisalbis, pedibus breviufculis, digitis pro proportione longis luteis, unguibus rubicundis.

SAXatilis, quam Turnerus ex Gracte lorum genere facit, quidam Cyanon Ariftotelis credunt, nonnulli Rubiculam $\mathrm{Sa}$ xatilem, Nucifragam, Merulam Alpinam vocant, avis eft cum Caryocatacte Gefneri eadem, merula major. Sturniferè infta: maculata, fupra nigricans, minus tamen in capite \& dorfo, quàm in alis, maculis ubique diftincta femilunaribus, qux pariter per tergus \& $x$ alas majores funt quam per caput.Prone à roftro ad anumufque lutea maculis ferrugineis albisque, qux \& ipfremagnitudine variant, percurrentibus. Alarum pennas majores habet nigras, \& in extremisoris candicantes. Caudam fupine nigram, prone ferrugineam, pedes fufcos. Vaga eft, nec invenufta.

\section{$A \mathrm{R}$ T I C U L U S III}

\section{De Merula Rofea, Exoticis, है Merule congenere.}

$\mathrm{M}$ Erula Ros EA, ab aucupibus, Aldr. OtItalis Sturnus marinus vocatur. ERt nith.l. IG. merula paulo minor; tergore, pectore, \& ${ }^{\text {c. I } 5 \text {. }}$ alis fupernis rofeis feu carneis, capite cirrhato, roftro qua capite jungitur nigro, cxtera carneo, alis \& cauda nigris, remigibus fere fubcaftaneis. Infermina, color eft dilutior, caput fi excipias. Reliqua enim pars colli, alæ \& cauda minus quàm in mare nigrefcunt. Plurimum adipis corpori adjiciunt, \& in cibo maxime commendantur.

Eхотіс a eft duplex, Braflica, \& Indica Bellonit do Apos. Brasilica ut à Bellonio defcri- Avibus. bitur, differert magnitudine à Merula. Roitrum illibreve. Color totius corporis, fi caut- 
caudam $\&$ alas, quxe atræ funt, adeo intenfe rubet, ut nullus intenfior rubor poffit excogitari. Cauda oblonga eft, cruraniAldrovan- gra. Illius, quam Aldrovandus exhibet, thol.1. 16 , pennæfuperius omnes ad fcapulas rubent, c. $\$$. dein nigre fuccedunt, has rufus rubræexcipiunt. Roftrum eft infigniter recurvum, intus luteum. Pedes, qui pro tibiarum proportione majufculi ex cinereo leviter fufcefcunt. A p o s monftrofa forte eft. Roftrum habet Merulæ in extremitate nigrum \& recurvum, infra qua capiti jungitur candicans. Caput, venter, dorfum, colore coccineo intenfo \& vegeto, alæ \& cauda nigro, unde Porphyromelanos dici poffet, tinguntur.

CONGEN:ER Merula eft duplex. Vna roftro, prope quod linea rubra confpicitur, nigro; capite, dorfo; \& cauda, ad fubcaftaneum vergentibus, extremis oris albicantibus. Prone pectore, ventreque toto \& cauda, lineis quibufdam cinereis per transverfum ductis albicat. Alterc Merulis erat minor, Pafferibus major, capite cinereó, oculis nigris aureo circulo circumductis, roftro pro corporis proportione robufto, luteo, craffiufculo, in extremitate nigro \& acuto. Dorfo ad caudam caftaneo obfcuro, pennis alarum qua dorfo junguntur albis. Qua ventri nigris. Remigibus in extremis oris cinereis. Similis Collurionicinereo videbatur.

\section{A P U T $\mathrm{T}$.}

De Sturno.

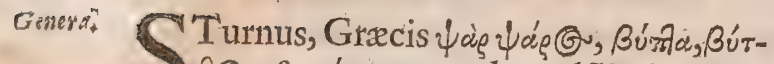
S), \& yó $\lambda \mu \iota s$, quod apud Hefychium \& Phavorinum leges, dicitur. Avis eftob colorum varietatem, \& confperfas per corpus maculas, elegans, \& bene, picturata à Poëtis dicitur. Non tantum autem albis maculis tingitur; fed rubefcit quoque, lutea aliquando; in alis, prope oculos, \& in infimo tergore viridefcit. Roftrum habet Picorum non abfimile, in fine fufcum. Caudam brevem \& nigram. Pedes fere croce-

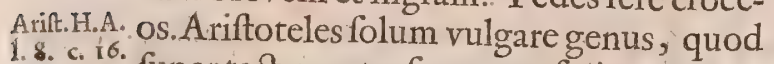
1. 8. c. i6. fuper tecta cantu fuo aures fatigat, agno-

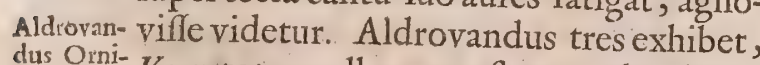
dus Orni- Vnum totum album, roftro quod ex luteo G 19. rubefcit, \& pedibus, qui leviter carnei, exceptis. Alteri caput, collum, \& roftrum erant alba; Maculx fupra oculos biræ nigra:ventercandidus, alarum principia maculis fubcæruleis varia. Remiges alarum \& cauda ut in Sturno vulgari. Pedes lutei. Tertiitotum corpus ex cinereo lutefcebat. Pectus punctulis confpergebatur.Roftrum \& pedes nigri coloriserant.

tocks of Victus.

Locum fiattendas, nullibi non inveniuntur. Avenis, pratis aquofis, ubiarmenta pafcuntur, \& agris gaudent. Turribus in- primis \& tectis hyeme latent. Sividum, pamphagi funt. Nam preter baccas \& uvas, quibus impenfe delectantur, \& pinguefcunt; milium quoque, panicum, cicutam, ftercora, \& lumbricos, imo fuspenforum cadavera, ideo $a b$ eorum efu Belgæ abftinent, depafcuntur.

Nidulantur iisdem fere locis, eodemque Generatio. pene modo, ut Pafferes. Ter anno parere dicuntur; \& uno tempore feptem velocto ova ponunt. Græcis dicuntur « thori Philomelx pifitare. Summo mane maxime funt obftreperi, nocte filent. Vifi qui omnium avium voces imitabantur. Et in Gallix urbibus habentur, qui fermo Brujer 1. is nem explanate, longiori etiam contextu, de re cibar. exprimunt. Habebant \& Cæfares juvenes Plin. H.N. $\begin{array}{ll}\text { ejusdem peritix unum. } & \text { 1. Io. c.24. }\end{array}$

Proprium ipfis catervatim volare; \& Volatus. quodam pilæorbe circumagi omnibus in medium agmen tendentibus. Vefpere po. tiffimum aggregantur, \& tanta multitudihe atque impetu quandoque volant, ut nuben facere, \& tempeftatis modo fonare videantur. Dicuntur fibi ipfis medicinam facere. Atterebat pedi luxato ova formi- Gefner. in carum, comminuta, \& fub alis calefacta, Ornithol. unus. Sic integer intra paucos dies evafit. Metuunt Accipitrem, eundemque fuperne vel à latere accedentem, alis eventant, fubtus volantem ftercoribus opprimunt. Semine alii intereunt; \& à canibus metu: untur.

Galenus eos inter cibos attenuantes \& $v$ fus. bonifucci refert; quod vel de juvenculis, Galen. 1.6 . vel de illis, qui in montibus degunt fu- tuenda. mendum eft. Vindemix tempore pabuli Alex.1.13. melioris copia non improbantur. Suaviores evadere, fi mox captis capita amputentur, Cardanus author eft. Stercus oryza \#ginera I: paftorum ad faciem exornandam facit. $28 . c . s$.

NB. Sturnt genus Indicum vide in 3. de fainita Mantifja. Num. 6.

c. 2 I.

\section{A $P$ U $\quad T \quad$ VI. \\ De Coccothrauftis.}

$\mathrm{D}$ Uplicem Coccothrauften Aldro- Defcriptio? vandus exhibet, vulgarem Gefneri, \& Indicam criftatam. Illa ita dicta, quod roftro fuo $\operatorname{coc} \cos \&$ interiora ceraforum grana confringere foleat. Circa Verbanum Lacum Fringilla Montana, Bellonio, àroftri magnitudine Grosbec dicitur. Putabat hanc effe Ariftotelis Pardalumquiddam. Auit.H.A: Falfo, ex collatione utriufque patebit. Par- ${ }^{1}$ Bellon. $c_{2}$, de dalus enim colore toto cinereus eft, ma- Avibus 1,7 . gnitudine par Sturno. Coccofthrauftes au- $c_{0} z a$. tem eft, fiBellonii defcriptionem fequemur,fturno paulo minor, roftro duro, \& magnitudine pro corporis proportione infignis. Capite fuperiore mali aurantii colo- 
re, cum macula fub gutture nigra, collo colorem. Cavex inclufa, non folum raro cinereo, dorfo fulvo, alarum extremitati- cantillat, fed ne infticutionem quidem ad: bus ex viridi lutefcentibus ficuti torques Palumbis, caudx extremitate alba fubtus fulva. Ventre, pectore \& gutture ejufdem coloris. Gefnerus ei tribuit, Alaudx aut Loxix magnitudinem. Roftrum durum, validum, breve, latum, quod inferius à pennis nigris ambitur. Colorem capitis, in foemina, charopum, vel ex flavo ruffum; in pectore \& ventre ex cinereo rubicundum. Pennas alarum fuperius nigricantes, in medio albentes, in imo coloris fere cærulei feu Indici. Collum pronum, \& utrinque ad latera plumis cinereis veititum. Dorfum ex fufco nigricans.

IEftate in fylvis capitur, \& tum in Italia in montibus agit. Sub Octobrem ad plana defcendit: In Germanis æftate rarius, hyeme frequentius cernitur. Nidificat in arborum cavis. Victitat nucleis ceraforum., qux roftro confringit; nec non olivis, \& aliis baccis. Non fervat accrefcente atate latur, \& ipeculum impetit.

Indicá incolis capitis viridis apud quos reperitur, dicitur Frufo, Lufitanis Cardi nalitius, quod galerum purpureum geftare videatur. Haber cirros in capite figura trigona coccineos, quo colore pariter collum, pentus \& ventèr refulgent. Alarum extremitates dilute purpurafcentes. Caltdam pro corporis proportione, longiuf culam, digitum auricularem latam, aliquantulum furrectam. Tibias breves \& al bicantes, ungues robuftos \& nonnihil recurvos. Victitest panico, amygdalis, \& alfine herba, \& cibum è manibus accipit.

Voces avium, lufciniæ maxime imitatur. Sxpe fe aqua immergit, unde temperiei calidiflimæ effe putatur. Vifa icone fua in fpeculo, mirabilibus modis fibilos edendos criftarn deponendơ, Caudam more Pavonum erigendo, alas motitando, gefticu-

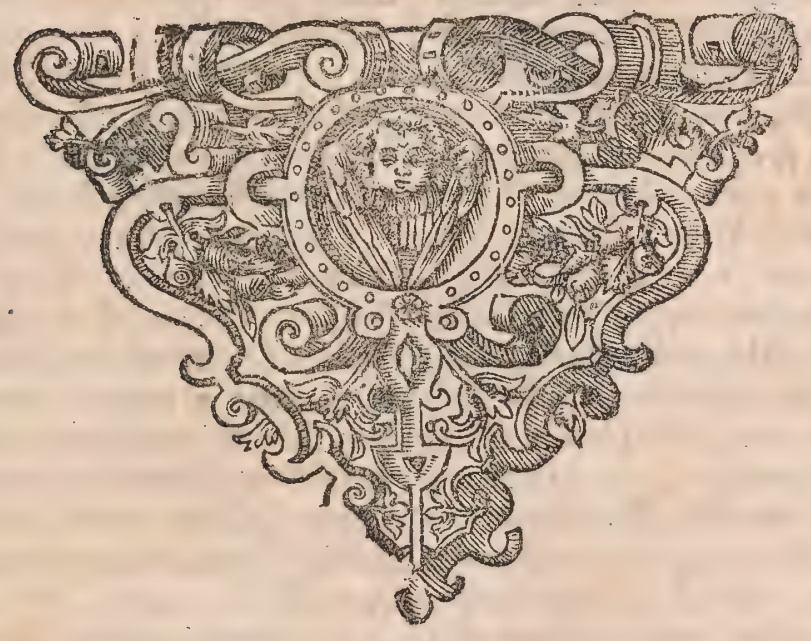




\title{
HISTORIA NATURAIIS
}

D E

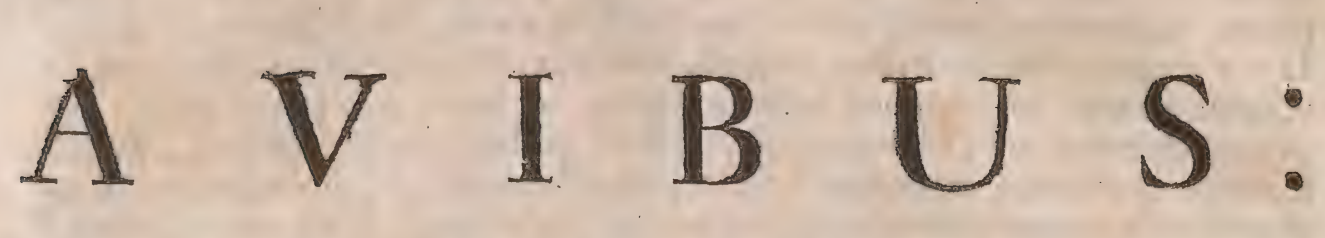

LI B E R III.

De Avibus Infectivoris.

\author{
T I U LUS I.
}

De Infectivoris non Canoris.

C A P U $\quad \mathbf{T}$ I.

De Picis Martiis.

Defcription,

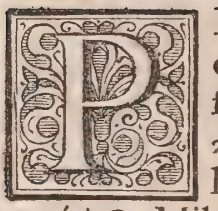

Icus Martius quod Marti fa cer fit dictus, opuóro $\lambda$ a $\psi \mathrm{He}$ -

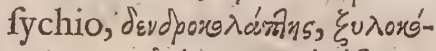

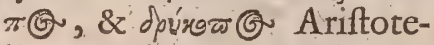
li, орит́твн(a Ariftophani, r xseresvisys vocatur. Genera ipforum tria

Arit.H.A. Ariftoteles recenfet; nos de pluribus inferius dicemus. An vero vel illa qux occidentalibus Indis Alcatran tefte Cardano dicitur, roftri \& corporis magnitudine celebris, cinerea croceave pluma diftincta, roftro duorum palmorum, in acutum tendente; vel Picutus dicta, cui roftrum toto corpore majus, ubi capiti jungitur tribus digitis latum, aduncum, quo \& arbores terebrat, \& à parvis fimiis fe defendit, quxque linguam loco pennx habere dicitur, ad Picos pertineat, penes eruditos fit judicium. Formam ipforum fi attendamus, habent omnes rofrum rectum, durum, rotundum, \& ad pertundendas arbores percommodum. Linguam iis A riftoteles tri-

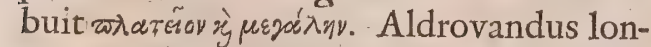
gam quidem in omnibus \& ad oćciput ufque extendi, \& fuper totum capitis verticem ceu in glomum convolvi, adeo ut cum exoritur, tanquam è multis involucris in longum admodum extendatur, obfervavit; latam minime; quin eft acutiffima, \& in extremitate quodammodo cartilaginea. Anatomen vide apud Aldrovandum. Crura quoque omnibus funt breviufcula, at admodum robufta. Digiti pedum ante bini, totidem retro, ique valde conjuncti, ut arborem quam fcandunt firmius apprehendant. Cauda rigida, \& duriufcula, cujus pennæ in extremitatibus ferme nudx, quibus haud aliter quam pedibus inter rependum innituntur.

Locum fi fpectes, in quibufvis reperiun- Lociss. tur regionibus, raro in Belgio, in Tarentino agro negari fcribit Plinius; fed Aldro- Plin. H.N. vandus omnia genera in Italia ali, maxi-Aldrovanmum fiexcipias, affirmat. dus Orni-

Victitant vermibus, culicibus nempe for- thol.1. 12. micis; quas exporrecta lingua velut in veru $V$ ienus. infigunt, \& latitantibus füb lignorum corticibus, \& medulla coflis. Ideò arbores tundunt, quarum percufi corticis fono pabu- Plin, 1.c. lum fubeffe intelligunt, \& tam vehementer eas interdum excavant, ut ipfas fternant. Quidam apud Ariftotelem amyg-Arit.H.A. dalum tertio ictu pertudit, \& nucleum l. 9.c. 9. comedit.

Nidificant in cavis arborum, olearum Generatio: inprimis. Tantoartificio nidum exftruunt, \& excavant, ut admoto circino rotundius reddi foramen à perfectiffimo Geometra non poffer ; \& ligna quibus inter fe confertis conftat, facilius manibus feparentur, quam ferro diffecentur. Pullos feptem vel octo educant, quos exire ex ovoà cauda Hylas, referente Plinio, tradidit. Quoniam pondere capitum perverfa ova pofteriorem partem corporum fovendam matri applicant. Nunquam humi confiftunt, vel in faxis confident, ne aciem unguium obtundant. Scandunt vero per arbores om-

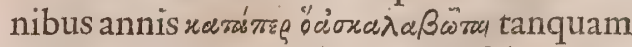
ftelliones, feu ut Plinius vertit, feles, non modo furfum per arborem reptando, fed deorfum etiam \& fub ipfis ramis, pedibus \& ventre furfum, tergore deorfum terram 
verfus converfo; quod Ariftoteli eft üta

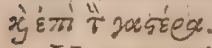

Yox. Humano ipfos fermoni affiefcere ScaliScaliger in
Exercitat 237. \& pauciora quam Picam reddere, addit Albertus Albertus perfecte aliquando loqui fcribit. lib. 23. de Validius quam foleret ftridens pluviam
Animal. Animal, prefagire credebatur. Hinc ei pluviæ avis apud veteres nomen.

Vfus. Vfus ipforum \& in cibo; ideo tota fere hyeme \& autumno Bononix in foro venduntur ; \& in Medicina. Nam cum fale torrefactum quidam ad internas ani eminentias applicant. Affatum vel elixum incantatione ligatos folvere; oculos, geftantibus vifum acuere; roftrum è collo fufpenfum, dentium, uvulæ $\&$ tonfillarum dolorem curare; Kiranidis funt deliramenta. Idem ferentes ab apibus etiamfi mella earum eximant, non feriri, Plinii. Clavum \& cuneum arbori, in qua nidificant infiPlin.H.N. xum, diu non hærere. Foramen vero nidi 1. Io. c. . 8.
At. H. A. lapide velligno obftructum, herba appofi1. I.c. 45. ta, feu illa linaria major, feu æthiopis, eundem aperire, pari fide affirmatur.

\section{A $P$ U $T$ I I De Picis in Jpecie.}

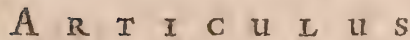

I.

De Tico Maximo, Majore, Vario minore Viridi noftrate, Ticoluteo Cyanopide, Viridimajore, \&o Murario.

$\mathrm{P}$ Icus MAX I Mu s, eft omnium longe maximus, cornicis interdum magnitudine, infra gallinam aliquid, \& excepto capitis vertice totus niger. Plumæ tamen in vertice coccineo vel flammeo colore egregie micant, \& velut cirrhum efficiunt. Roftrum habet longum; robuftum, digitum parvum, longum, cujus fuperior pars; qux juxta caput lata eminet, $\&$ duas ftrias, ut folium Cyperi, obtinet. Linguam oblongam duram \& in extremitate afperam. Digitos binos ante \& totidem retro. Ungues recurvos.

Picum MAjor em misegin Ariftoteles vocat. Magnitudine merulam vincit, fcribente Ariftotele. Is quem Aldrovandus depingit, rofrum habet canaliculatum, linguam longifimam, mufculofam, extremo apice duro nervo aculeatam. Caudam robuftam, \& ob fuperiores reliquas cooperientes plenas duro calamo donatas \& inflexu diflicillimas, renitentem. In tota ave triplex color confpicitur. Plume medio vertice rubicundx, \& faturo cocci colore confpicuæ funt, qux in foemella marialioquin per omnia fimili defiderantur. In oculorum ambitu, ventre toto, $\&$ alis in- da nigrialiquid confpicitur.

Picus VARIUS MINoR major per omnia fimillimus eft, \& prorfus videre: tur idem. Nifi rubræ illæ maculæ in vertice \& Uropygio deeffent. Dorfam ejus verfus lumbos magis quam fuperioris varium. Et ex albo nigroque promifcue naculatum, lineis interim obfcuris transverfalibus qux alarum notis refpondere videntur, confperfum eft.

PIcus Vir id Is rod.cos eft Ariftotelis, inter Picos quidem eidem non recenfi. tus, inter Picos tamen vel ob folam pedum \& Caudæ difpofitionem (duobus digitis ante \& totidem retro infignitur, \& caudam rigidam habet) numetandus. Turturem magnitudine equat. Roflrum habet nigrum, durum, robuftum, acutim duos digitos longum. Caput crafliufculum in fuperiori parte ex maculis partim miniaceis, partim nigricantibus variegatum. Oculos alia quxdam macula nigra ambit, fub qua rubræ illæ maculæ fuperioribus correfpondentes pallidiores funt. Dorfumi $\mathcal{E}$ ale virides cum luteo tamen intermixto. Mentum, pectus, venter, crura pallide virefcunt, adeo ut ex albo \& viridi permifce ri videantur. $\mathbb{E}$ ftate eum filere ajunt. Id co cum menfe Aprili quidam clamitan tem audivifet, hyemem adhuc metuendam predixit. Altifimas arbores volatu trajicit.

Offa ipfius tofta in pollinem redacta, \& in vino epota validum funt conra calcu lum remedium.

Picus Luteus Cyanopus ex Perfia adfertur. Magnitudine à fuperiore nihil differt; caput tamen \& collum craffius, \& roftrum prolixius obtinet. Peñnæ à medio vertice ad extremum caudre ufque aliquid ferruginei habent, rofirum vero omnino ferrugineum. Pedes fubcærulei, ungues nigri, cæetera lutea, nifi quod alarum penne omnes in extremo quodammodo ferrugine:e fint.

Pico Viridi Major I feuMaxi-aldrovart mo, Roftrum, quod in omni Picorum ge-dus Orninere rectum eft, incurvum, pedes ad fimi- thol. $1_{i}$ is litudinem aliorum; varias maculas in alis, tribuit Bellonius.

Picus Mur a Rius muris turrium de Avibus maxime adhæret, \& vermiculos in eorum rimis inquirit. Paffere domeftico paulo major eft, fturni fere crafitie. Roftrum Jiabet oblongum, tenue, nigrum. Caput, collum, dorfum cinerea. Pectus albicans. Alas partim cineras, partim rúbeas. Caudam brevem. Digitos pedum longos, tres ante, unum pro calce. Alas in volatu femper motitat, nec uno loco infidere novit. In foraminibus parietum nidulatur. Suavem vocem edit. 
A R T I C u L a s II.

De Pico Cinereo Jeu Sitta, Pico nidum $\int u$ Spendente, Chlorione Indico E Picis congenere.

$\mathrm{P}$ IcUs CINER E us Ariftoteli órzo"y

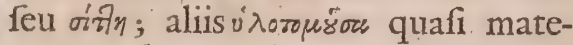
riem contundens, nomine omnibus communi; quibusdam oatoomíns \& rเvấdos, quod Uropygium motitet; modernis Græcis xвенъvigi's dicitur. Annumeratur Picis, quia eorum more fuper arbores repit. Caput ei parvum.; Oculi exigui; Roftrum longiufculum, nigrum, rotundum Collum, dorfum, alæ, nec non \& cauda fuperius è plumbeo ad cinereum vergunt: fub collo verò \& ventre è caftaneo ad ruffum. Cervixad latera lutefcit. Qua parte inter roftri principium \& retro oculos macula oblonga nigerrima infignitur. Vivit maceriem contundens. In foraminibus arborum, quas terra \& limo artificiofiffime claudit, angufto aditu fibi relicto, nidulatur, \& prolem numerofam progignit. Frangit Aquilæ ova. Res malefica ei tribuitur, quafi rerum cognitione calleat.

Arift.H.A. PrCuS N I D UM S U S ṔENDENS cum 1.9. c. 17. Oriolo Alberti, Ariftotelis Chloreo, \& Idem l.g.c. Plinii Chlorione, Galbula feu Galgulo, Ictero, \& Bononienfium Regalbula idem effe ab. Aldrovando creditur. Modernis Græcis oure $\phi a^{\prime} j$ s dicitur. Chloreum \& Plin. H.N. Chlorionem Ariftoteles $\&$ Plinius appella1.37. c. ro. vere, ut luteum \& viridem in ea reperiri
Aldror. Ornith. colorem innuerent. Junior virefcit; adul1. x. c. 39. tior aut faltem annua facta alis tantummodo exceptis tota evadit lutea. Magnitudine eft par Turturi; colore pro ratione $x$ tatis variat. In juniore roftrum eft fubfufcum. Adulta inter roftrum \& oculos maculam haber nigram. Junior minimè. Illa alas habet nigerrimas, quarum pennæ \& remiges maxime in extremitatibus fuis albefcunt: junior fuperiores pallidas, inferiores nigricantes.

Locus. Locum fi attendas Germanix effe peregrinam Gefinerus reliquit. Migratoria vero Plin.H.N. eft. Plinius \& Elianus hyeme eam videri 1. ro. c.25. negant; æxtivo tempore in confpestum venimal. 1.4. nire, exortu areturi fyderis difcedere, ' $\&$ c. 47. pullis editis Italiam relinquere, adjiciunt. In Helvetia menfe Majo apparere incipit, in quibusdam Gallix locis Martio.Dependens pedibus fomnum capit, quia fe tur Plin.H.N. tiorem fperat, fi Plinio credimus.

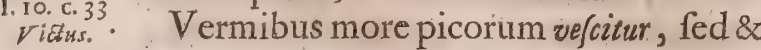
ficubus. Unde ipfi ov $₫ \Phi \alpha$ ' $y$ z nomen.

Generatio. Proprium ipfi nidum in arboribus fufpendere. Conftat ille ex mufco \& lanugine quandoque, ex fóno \& culmis nonnunquam, ex cannabe \& feftucis interdum.
Forma ipfi corbis vel calathi ficarii èjuncis intexti; vincula de quibus pendet funt, culmi, junci, fila è lino, ferico, fetæ equinæ \& cætera. Iconem in Aldrovando vide.

Cum cantillat orio velloriot fonat, im- $v_{0} \hat{x}_{\text {. }}$ minente pluvia fiftulæ inftar canit.

Vfus ipfius in cibo eft \& Medicina. Pin- Y fiss. guefcit mirum in modum. Emoritur fi ab $1_{1,30, c_{\text {, I }} \text {. }}$ idterico confpicitur æger, ipfa evadit. Ad Germanos accedens, non amplius nafcituras pruinas promittit.

Chlorio Indicus maxima fui parte, quin toto corpore luteus eft; fi coronam verticis \& caudx alarumque maculas cxruleas, \& roftrum pedesque qux' infigniter rubent excipias.

PICIS CONGENEREM Aldrovandus Marchioni Fachineto debet. Erat, quantum ex pictura conjicere licebat, $\mathrm{Coc}$ cothrauftis magnitudine; roftro luteo, acu to, Picorum haud abfimili; vertice, cervice \& toto dorfo viridi, Uropygio albo, pennis alarum veftitricibus viridibus, remigum fuperioribus albis, inferioribús, \& cauda cæruleis. Prona pars à roftri initio ad anum ufque coloris cinnaberis erat.

NB. Picarum genera exoticavide in Mantifja. N. 5 .

\section{A P U T III.}

\section{De Iynge Jeu Torquilla, Iyngi congenere; \& Certbia.}

DRopter roftri \& linguæ conftitutionem, Picis Jynx fubjungitur, quam

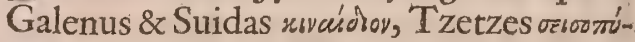
roy \& Cinclida, Athi montis incolær, tefte Bellonio, Alcionem, Theocriti interpres ozıréaiv, alii Turbinem, Gaza Torquillam vocat. Vincit magnitudine fringillam, Roftrum habet firmum ex plumbeo \& nigro permixtum. Lingue aculeum tam acutum \& validum, ut humanam cutim haud aliter ac acicula penetret. Ea infra arterix fummum fubit, \& fupra cranium reflexa, prope nares inferitur. Eft autem gemina ubi ab occipitio reflecti incipit, 2 in fyncipite rurfus utræque partes conveniunt. Digitos pedum utrinque duos habet. Digitorum utrobique longior alter, cum altero breviore conjungitur. Confpicitur in quavis regione circa arbores.

$V$ efciuur formicis, easque exerta lingua $V$ icius. velociflime aculeo transfixas venari \& devorare folet; nec unquam roftro attin-

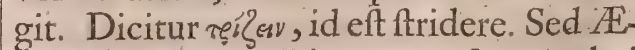
lianus obliquam tibiam voce fua æmulari ait.

Nidulatur in arbortm foraminibus, vil-Generatio? lis \& domibus. Octo vel novem ova uno partu excludit. Egerrime cicuratúr. Sị 
manu teneatuit, caput in utramque partem circumagic. Apud Gefnerum enutrita, acceffum hominis xgre fercbat, collum in fublime erigebat, roftrum fine morfu modo extendebat, modo retrahebat. Pluma capitis rigebant. Caudam erigebat \& dilatabat. Ufusipfius eft in cibis.

Aldrovan- JYNGI CONGENER, quem Aldrodus lib. I2. vandus defcribit, magnitudine erat par Ornithol. Jyngis ; colore capitis; dorfi, álarum, \& to-
c. 43. tius caudx ferrugineo; maculis luteis transverfalibus diftincto, pectore \& ventre albicantibus, \& lineis luteis per longitudinem exornatis. Tibiis luteis; digitis picorum more oblongis:

Cer t h I A, Ariftoteli is'psiov, vellut Robertus Conftantínus opinatur, $\mathrm{ab}$ aftu repoliov dicta, avicula eft exigua, Regulo paulo minor. Roftrum habet arcuatum, in fuperiori parte longius \& craffius. Guttur \& pectus candicans; dorfum \& alas fulvefcentia, nigris maculis ubique diftincta. Caudam brevem, rigidam, \& in extremitate acutam. Ungues valde aduncos. Victitat infectis minoribus. In cavis arborum nidificat, \& viginti quandoque ova ponit. Vocem ipfi claram tribuit Arifote-

Arit, H.A. les. Perpetuo fere nunc in hanc nunc in 1, 9. 6. 17. illam partem volitat. Toto anno eandem patriam incolit. Arborum ramis fringillaginis inftar fefe annectit, \& Picorum more arbores perreptat. Sagax ipfi in vitz officiis ingenium Ariftoteles adfcripfit.

\section{A P U T IV.}

\section{De Merope.}

$\mathrm{M}$ Eropis nomen Albertus Pico viridi, Niphus Grallo fuo, alii Paro majori, fed male impofuere. Convenit illi aviculæ, cujus vox multiplicem partitionem capit, ideo à $\mu \varepsilon \mu \sigma \mu \hat{\omega}$ óròs dicta eft;

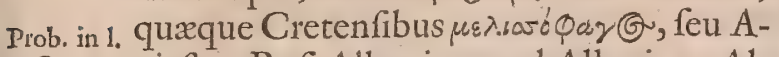
4. Georg. piafter, Rafi Alkenius, vel Alkerius; AlBellon.lib. berto Mufcipula, aliis Riparia, Parra, \& c. 27. Gangrena tefte Kiranidis interprete dicitur. Magnitudine fturnum fuperac, $\mathrm{Me}$ Arift.H.A. rulis par eft. Ariftoteles hoc tantum de illa
1.9. C.I3. habet. Pennas ejus inferiores pallidas effe, fuperiores caruleas, ut Halcyonis, poDefcriptio. Atremas pinnulas rubras. Plinius Ariftote-
Plin.H.N. lem fecutus, pallido intus colore pennarum, fuperne Cyaneo, priori fubrutilo effe dixit. Aldrovandus \& maris \& foeminæ defcriptionem tradit. Mari roftrum eft longum, durum, ad inftar falcis mefforix arcuatum, \& quafi triangulurm. Iris ita rubefcit, ut aliam omnem rubedinem fuperet. Fremine color ubicunque minus intenfus. Tergus quodammodo virefcens. $\mathrm{Lin}$ guam habet fublongam \& gracilem: oris rictum tam amplum, referente Alberto, ut multas mufcas in os ejus humoris infiden- tes capiat. Veficulam fellis anopílañ hiut more viridi maragdi inftar refertam.

In Creta infula tam vulgaris eft, ut nufo tichso quam non in ea confpiciatur: reperitur \& in Italia. Grocis per continentem, incognitam fcribit Bellonitis.

Victitat apibus; ideo Virgilius Mérópis $V$ ieziśs nidum prope alvearia prohibet, \& cicadis. 1.9. c. 40 . Sed nec lampranx caucalidis, \& raparum Georg.1.s. Ceminibus, vel tritico abotiner N Nidificat Arit, HiA in cavernis, interdum ad fex pedum altis Plin.H.N. tudinem, interdum ad quatuor cubitos, 1 . I c $c_{13} 3$. deforfisc. Et fex aut feptem pullos pas 1. g.c. 13: rit.

Volat gregatim, circa"imontes qui thy- Volatitus mum ferunt frequenter; \& cum reliqux aves quafi furfum ad oculos verfus volitent, ille retrorfum caudam verfum eum exercet.

Voceminftarhominis quodammodo edit, ro qui ore in rơtundum claufo fonet grul gru$\mathrm{ru}$, urubul, \& longe auditur. Ingenium \& Mores fi fpectes, migratoria eft. Pullos ne facile capiantur de loco ad locum transfert, \& author eft Ariftoteles offe qui confirment, Meropes parentibus fenefcentibus vicem reddere; imo eofdem quam primum facultas datur, liberorum opera ali.

Vfus ejus in Medicina aliquis. Fel fi cum $V$ wust gallis \& oleo omphacino mifceatur, firmam capillis nigredinem inducit. Frixa in oleo manus ab apum punctionibus immu nes reddit, fi credere fas eft. Eft $8 z$ alius Merops quem Germani Hirundinem marinam vocant. Eft fuperiore paulo longior, \& craffior. Roftrum habet nigrum, longum, acutum, \& proprius ad falcem mefforiam, quam in illa accedens. A roftro maculam nigram, qux per oculos retro ad colli initium ufque defertur. Alarum pennæ, variis coloribus infigniuntur. Primæ cærulex funt. Secundx ex cæruleo \& fla vo mixta. Tertix omnino flavæ, remiges nigre \& in extremitatibus rubre.

$$
\begin{gathered}
\text { C A P U T V. } \\
\text { De Regulo. }
\end{gathered}
$$

D Egulus, Græcis Trochilus, Orchilus

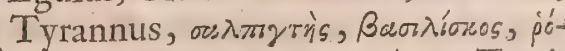

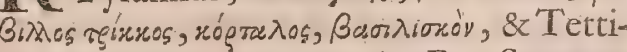
gon, in Creta inprimis, aliis Rex Senator, Parra, Bitricus, \& Acalanthis dicitur, qux omnia nomina Pafferi Troglodyti com muniter tribuuntur. Ariftoteles ipfi corpus Arift. H. As? non amplius tribuit quam Locuftx, \&e cri- I. S. c. 3 : ftam è pluma elatiufcula rutilam. Quem. Tldrovandus defcribit, à capite ad extremitatem caudx menfuratus, vix palmuni exfuperabat.Criftam in fronte erectam colore fere aureo gerebat; qux in mortuis non confpicitur, Caput, collum, dorfum, \& 
mediæa alæex viridi lutefcebant. Remiges; fe funt. Mafcula alba, quam criftatis hax nigricabant, \& ad latera flavefcebant. Pro- bet, in hoc non confpicitur.

pe carum exortum notabilis vifebatur macula. Guttur \& pectus ex albo flavefcebant, venter candicabat. Fremelle pallidioribus capitis funt confpicuæ. Minores etjam ipfis crifta pennulæ, quarum caput linea craffa fatis velut corona eleganter ambit. In alis duas habent albas maculas, parvam unam,longam alteram, cum mas hanc folam habeat.

Locus. Hyeme degunt in urbibus \& foraminibus, reliquo tempore in fylvis, inter fruteta \& juniperos.

Fielus. Vefcuntur vermiculis, quorum nomine

1. 8. с. 3. mufc $x$, formicx, coffi, \& fimilia infecta intelliguntur. Mufcis adeo ingurgitari quidam dicunt, ut aliquando de vita periGlitentur.

eemeratio. Bis anno pariunt \& ova feptem aut fex piforum ponunt magnitudine. Volant folitarix ; \& aliqui polt migratices recedunt.

Voz. Voxipforum zinzulare, ut Authori Philomela placet. Magni \& ficci in hyeme frigoris tempore, præcipue cantant. Parvitatem corporis ingenii folertix in ipfis natura penfavit. Aufu enim magno contra

Arift.H.A. Aquilam pugnare conantur. Cum fe pro-

1. 9.c.Ir. xime quafi manu capiendas obtulerint, caflo hominis conatu profugiunt. Multi uno fpecu in hyeme conduntur, ut parvus in tam minimis corporibus calor, focietate augeatur. Cum in veruculo igni apponuntur, tametfi nemo vertat, tamen per fe convertuntur : fcilicet, ubi ea pars, qux igni obverfa fuit, affata eft ; altera, qux non eft affata, quia gravior, defcendit. Motu infolito \& cantu quamyis fuavi geftientes, quia ariduli vaporofum aërem plaufibiliter excipiunt, \& adventantem humiditatem, qua refocillentur implorant, pluvias

Aratus in affuturas denotant. Exdem ingruunt, A-

phxnom. rato tefte, fi cava terræ fubierint. Unde floricomis hymenxis infeftos dixit Avienus, quia ifti fereno cœlo gaudent.

Datur \&alius Regulus non CRISTATus, qui quandoque in agro Bononienfi capitur. Similis hic, criftam fi excipias, edi
fuperiori Regulo. Roftrum ei gracile, ob- lati

longiufculum, facurrimo atro colore refplendens, interna capacitate, \&c utraque Poras ab Ariftotele numeratur; quanquam Verex, hoc nomen \& infecto volatili, quod Equos Vertex, collum, Dorfum colore bxtico ad infeftat, tribuatur. Si ea eft, quam Belloflavum nonnihil vergente. Oculi nigref- nius ob parvitatem Philofopho ita vocari centes, quos plumx cinerex ambiunt. Alx fcribit, \& depingit; habet.criftam capitis \& cauda exteriorifupernafuperficie ex fuf- flavam, roftum nigrefcens, fed in hisexco ad fpadiceum vergunt. Peetus, alæ in- tremitatibus aliquandoluteum, longiufcuternæ ac fupremæ, caudxque inferioris lum, \& debile: Caudam, tergus, alarum initium funt flava. Poltici digitiunguicu- plicas \& extremitates, lutea: crura, pedes, lus omnium eft maximus; digitus à medio \& ungues nigra. Degit in umbrofis nemoanticorum magnitudine fecundus, duo rum locis. Vidtitat beftiolis vivis, \& grana exteri antici minores \& xquales inter averfatur. Semper canit. 


\section{A P U'T VII.}

De Firundinibus in genere.

H Irundo, feu à voce fua, ut Varro credit; feu ab hærendo, quod tectis $x^{-}$ dium, vel trabibus, ubi nidificat, adhæreat,

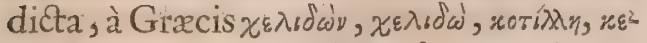

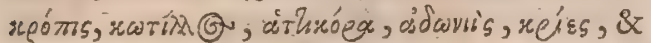
¿ $\lambda$ c $\lambda u$ zóva vocatur. Vagam volucrem Ovidius, Daulidem avem Plutarchus, Biftonis alitem Seneca, Pandione natam alii dixere. De Generibus Hirundinum non conPlin. H.A. veniunt authores. Ariftoteles, Domeficas, 1. 10. c.33. Apodes, E Falcuas agnofcit. Plinius, Domefi1. 1o. c.33. Aps, Rufticas, Apodes, \& Riparias. Gefnerus, Do-
Gefiner, in 6 is, Ornithol. fimecas, Sylueftres \& Riparias. Scaliger, vilgares Scalig. Ex. nigras, Subfuluas, fimili forma in ripis nidificantes. Quater illis grandiores, toto corpore atras, foedifima facie, cruribus brevifimis, crefliffimis, hirtis; \& Buteonis magnitudine, fed facie nullo modo ab his difArif.H.A. fimili. Dantur \& albx, feu quod præ ni1. 3.... 12. mio frigore albefcant; feu quod canefcant Arit, 1. de ante tempus, ut alia quadam animalia, feu coloribus. quod artificio tales eyadant. Si quis albas, Aldrovan- inquit Aldrovandus, defideret, ova earum dus Ornit. dum cubant, oliva illinat.

Defcriptiot. Dejcriptione longa opus non eft. Formx eft grat $x$, nigredinis decentiffim $x$, modic $x$ carnis, plumarum multarum. Albedo totum cingit ventrem; hinc $\pi$ ob $1 \lambda \eta$. Ariftophani. Color ceruleus, ad latera per caput alafque refulget, unde Cyanea Simonidi. Rubedo fub gutture potifímum \&pectore emicat. Unde Ovidius.

\section{Neque adbuo depectore cedis}

Exceffere rota, fignataque fanguine plima eft.

Plin. H.N. Oculi eruti renafcuntur, feu quod pullorum 1. I2. c. 37. acu puncti vifum recipiant, quod Elia… H. A. nus de alba in Samo nafcente ab AriftoteAl. H. A. le proditum ait ; feu quod laceratis eo1. 17.c. 2. rum oculis, alii fubnafcantur, ut nonnulli prodidere. Cauda eft bifurcata, \& longa. Pedes breves nigri \& debiles. InArif.H.A. terna fi fpectentur, fel aliis ventri, aliis inA. 2. c. ult, tefting adhæret. Ventriculus ipfis longior. In difectis pullorum qui primo partu exclufi funt, ventriculis luna crefcente, lapilli, chelidonii dicti, magicis narrati artibus reperiuntur. De colore non conTrallianus ftat. Nigrum \& album Trallianus, can-

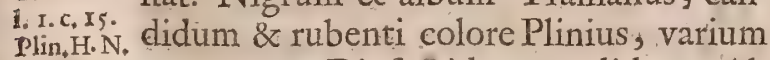
1. Ir. c. 17. \& parvum Diofcorides, prodidere. AlDiofcor, 1 drovandus, unum intus albicantem, ex2. c. 49 . tra melinum, alterum fubrubentem habuit.

Tocuss. In nulla non regione inveniuntur: A
Plin.H.N. Thebarum duntaxat, quod urbs illa fapius 1.10. c.24. capta fit, \& Bizix in Thracia, propter Therei fcelera, abhorrent. In ÆEgypto pereniant, noftre hyeme menfe Septem- bre feu Octobre vel conduntur, vel in itcina tepidiora loca abeunt. Inventre mul Avit. t. $A$

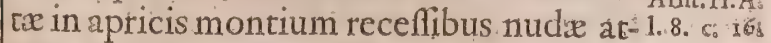
que deplumes. In quadam Germanix fuperioris fylva, incifa quercus putrida, plena Hirundinibus inventa eft. In Septen. trionalibus locis inter cannas defcenfuræ, fefe colligunt, \& frepifime in modum conglomeratæ maffæx à pifcatoribus extrahuntur, \& in $æ f$ tuaria deportatæ, caloris acceffu refolutx, volare incipiunt, fed exiguo tempore durant. Redeunt fub veris initium : ideo à Rhodiis fub hyemis finem in vitantur. Et Calpurnius illis vifis oves ab hybernis ftabulis educi jubet. Eafdem redire indicio obfervatum.Migraturæ cum Voffius die rubro filo pedi alligato dimiffæ funt, idem Idolol.1. 3 3 retulere reduces.

Victitant infectis, ut cicadis; ideo eas in $V$ icizus. xdibus haberi vetabat Pythagoras; api- Plut. 1. 8. bus, unde nidos earum alveis propinquos Sap. q. $\%$. tolli, Ariftoteles jubet ; mufcis, culici- Arif.H.A bus, papilionibus, \& aliis. Carne vefci, 1.9. c. 40. credidit Ariftoteles, an granis dubita Arift.H.A tur. 1.S. . 3.

De artificiofa Nidorsm ftructura, in fe-Generatio: quentibus dicemus. Quantum ad coitum cum cxteræ aves in eo à maribus confcen- . Il. H. A dantur, Hirundines, contrario quam aliæ modo mifcentur, averfer nempe: Bis an- Aritt.H.A no, quinque, femel ova , magnitudine oli- $1.6, \sigma_{*} s_{5}$, $v æ$, ferrugineis maculis confperfa pariunt, nec plura utero gerunt. Primi partus, in juria frigoris (prima namque parit) corrumpuntur; pofteriore pullos, fed cœecos proferunt. Fotus educatio fumma peragitur à mare \& foemina æquitate. Alterant PlinsH.N. cibum, \& à primo natu, finitur in ulti-1. Io.....33. mo. Nil amplius, qui accepto cibo lo- 1.3. . H. H. A. cum mutavit, accipit, donee in priftinum Oppian.ins redierit. Hefiodus citante Eliano, di- Cyne midium tantummodo fomnum perficere ait.

Vox ipfarum perfritinnire, thrinfare vel $V_{0}$. drinzare, zinzilulare, minurizare, àlatinis;

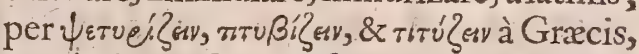
exprimitur. Canunt ftantes; aliquando in volatu clamant breve \& abruptum quiddam. Mane \& tempore coitus mägis ftrepunt.

Rarifime propter pedum debilitatèn \& brevitatem incedunt. Volucrum vero fo- Plin. H.N lis, flexuofi volatus, velox celeritas, quibus ${ }^{1}$ lo $_{0} c_{i} j_{3}$ : ex caufis neque rapinæ cæterarum ávium obnoxixfunt.

Ingenium \& in eo qui quidem quod cicu- Ingennium? rari nequeant pullis Chelidonia applicata, vifum reftituant, blattas ovis infeftas apio fugent, \& poftquam pullos à ferpente la niatos animadverterint, circa ejus maxil- Oppiaas las fe tamdiu, donec conficiantur, vol Halieut. vant; teftantur; fed in Nidortm ftructu plin. H.N. ra maxime. Hos luto conftrunt, ftra-1. 1. 10. c. 33 ;

$$
\text { L 2. mento }
$$


N A T U R A L I S

mento roborant. Si quando inopia eft luti, madefactis multa aqua pennis, pulverem fpargunt.Ipfum vero nidum mollibus plumis floccisque confternunt, tepefaciendis ovis, fimul ne durus fit infantibus pullis.

Irvafas Putantur pluvais prefagire, cum circa lagiam. cus ita proxime volitant, ut etiam ventre contingant; vel hac $\&$ illac volantes parietibus fubinde hrent; ; vel ufque adeo humiles feruntur, ut pedibus humum verrere videantur; feu quod tum mufcas \& alia animalia venentur; feu quod commotam furfum auram perhorrefcentes deorfum pavitent.

Afectus. Quantum ad Sympatbiam vel Antipathiam, vix aliquos videntur, vel amicos vel hoftes habere. Cum pafferibus tamen, qui initio veris earum præoccupare nidos conantur, pugnant, \& obfervarum Colonix, Hirundinem cum Pafferem ejicere non poffet, ftridore fuo multas convocaffe. $\mathrm{H} x$ cum impetu advolantes, luto, quod ore fingulæ gerebant, nidi foramen obftruxere. Paffer inclufus fuffocatus eft.

$V$ fus. $\quad V /$ us ipfarum pullorum inprimis fylveftrium in Medicina maximus. Cor cum melle devoratum, quartanas pellit. Lapilli, croceo linteo involuti, linoque ad collum fufpenfi, easdem tollunt. Caput matutino pafcenti precifum, \& luna plena lineo panno adalligatum; capitis medetur doloribus. Idem lapilli fi manu finguli teneantur, faciunt, fi Marcello credimus. Aqua hirundinum deftillata Epilepticos fublevat. Lapilli ad brachia alligati, fi Sexto credimus, eosdem fanant. Nec male fimus cum aceto \&z caftoreo à quibusdam iisdem exhibetur. Stercus cum felle taurino inunctum capillos denigrat. Fel \& fanguis mire caliginibus profunt. Idem, fi tepidò applicetur, oculum ißtu læfum reftituit. Celebris nidorum in angina ufus, fed \& crematarum ciniseandem difcutit.

\section{A $P$ P $T$ VIII.}

De Hirundinibus in pecie.

$A \times$ T I C $C^{\prime}$ U L U S I.

De Firundine Agrefti, Eo Riparia.

Plin.H.N. T Irundo agrefis, quam Plinius Rufticam 1. 10.c. 33. I vocat, in capite, collo \& dorfo, hirundinis domefticx eft colore: Sub roftro, gutture, \& toto ventre ad caudam ufque candicat. Pedes habet pennis obfitos. Sed \& maculam prope caudam albam tantre magnitudinis, ut dum volat, nihil in ea nigredinis, caudre extremitates, caput, alas, \& dorfum fi excipias, appareat. His notis à domeftica diftinguitur. Caudam quidem etiam bifurcatam habet; fed longifimis illis, qux in domeftica vifuntur, deftituitur. Raræe funt in domibus: Diverfos figu-Idem ibid. $r a$, fed eadem materia confingunt nidos: Totos fupinos, faucibus porrectis in anguftum; utero capaci; mirum qua peritia, \& occultandis habiles pullis, \& fubfternendis molles. In Agypti Heracleotico oftio molem continuatione nidorum evaganti Nilo inexpugnabilem opponunt; ftadii fere unius fpacio; quod humano opere perfici non poffer. In eadem juxta oppidum. Coptom infula eft facra Ifidi, quam ne laceret amnis idem, muniunt opere, incipientibus diebus vernis palea \& ftramento, roftrum ejus firmantes, continuatis per triduum noctibus, tanto labore, ut mul. tas in opere emori conftet. Ea militia illis cum anno redit femper.

Riparia Marcello Empirico Ripariola, Gazæ Falcula, Græcis Drepanis dicitur. Fœmina prone præter peetus candicat, fupine fufca eft: mas vero magis nigricat, collo toto, præterquam fub roftro; ubi macula eft, lutefcens. Hoc tantum cum Hirundinibus omnibus commune habet, quod pedibus fit curtis, multum volet, \& infecta in volatu capiat. Nidos non faciunt. Ripas excavant, atque ita internidificant. Aldrovandus illatis tantum plumis \& ftramentis nidulari audivit. Efftate tantum apparent, menfe Augufto cum Sol eft in Leone, \& cum imber inceffit. Eo tempore pariune, cumque pulli convaluerint, moriuntur. Plinius, migrare multis diebus antequam futurum eft, ut amnis auctus attingat ejus nidum, author eft. Huc referHirundinem MARINAM aucupibus Italis dißtam, quæ corpore eft major, pedibus longioribus, ventre toto ad pectus ufque candicante, capite, alis, \& dorfo fufcefcentibus. Roftro robufto, nigro; Rictu maximo eoque coccineo. Cauda bifurcata, pedibus aterrimis. A roftro per oculos ad pectus fere ufque notabilis linea atra defertur, \&velut torquem propepectus conftituit.

NB. De Hirundine exotica vide Mantifam. Nùm. II.

A R T I c u L u s II.

$$
\text { De. Apode. }
$$

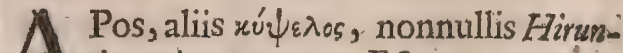
do marina vocatur. Eft toto corpore plumis egregie munita, unius coloris, qualis in murium pilis, confpicitur. Caput habet fupra admodum latum; collum brevifimum, rictum adeo amplum, ut integros fcarabeos deglutiat, roftrum exiguum, nigrum, las longas, caudam bifurcatam, crura brevifcula, ad digitos ufque pennis obfita, ad rependum potius quam infiftendum facta. Digitos utrinque 
binos, ut in Picis Martiis, unguibus acu- $\mid$ commorarilfidorus. Rarius arboribus in tis armatos, quibus quod rapuit adeo conftringit, ut id perfodiat.

Vicitat infectis per aëra volantibus, eaque nifi volans capit \& edit. Oculorum vero acie ita valet, ut per mille paffus mufcam Plin.H.N. obfervet, \& fubito infequatur. Volant plu1. ro.c. 39. rimum, \& gregatim, arcus tenfi figura, frepe alas non movendo. Hæ funt qux toto mari cernuntur, nec unquam tam longo naves tamque continuo curfu recedunt à terra, ut non circumvolitent eas Apodes. Cætera genera refident, \& infiftunt : his quies nifi in hido nulla, aut pendent aut jacent. Nidificant in foraminibus turrium. Vif $\&$ in fpeculis \& abruptis fluminum littoribus. Fœtus earum Bononix magno væneunt.

\section{A P.U T IX.}

\section{De Upupa.}

$\mathrm{U}$ Pupam avem, qux Græcis communiter $\varepsilon^{\prime \prime} \pi \circ \psi$, Orus Cucupham, alii

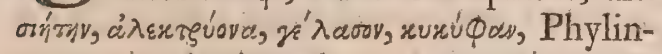

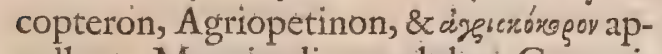
Paufan: pellant. Magnitudine paululum Coturnicem excedit. Color in ea cinereus atbus \& nigricans, quem mutat alltumno inprimis. Unde apud Efchylum dúo rog$\phi$ ìs $\phi$ áves dicitur. Rofrum ei nigrum, rotundiufculum, falcatum, parumper à latePlin.H.N. ribus depreffum. Capiti plicatilem criftam, reno@icas Græci dicunt, ex viginti fex plimis conftantem, dedit natura, qux per medium caputà roftro refidet, \& per capitis longitudinem pro avis arbitrio, furrigi-

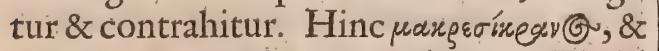
ropuráio (G) poëtis cognominatur. Fit id Aldrovan- beneficio mufculi, qui inter verticem cadus Orni- pitis \& roftri initium in quodam cavo loc. Ir. catus, totus continuts, à verticis extremo, $\&$ frontis carnofiore initio nafcitur, \& utrinque fupra nares, infima parte carnofior, \& rubicundus, extima \& fuprema, cui criftx plumulæ profunde implantantur, membranofus magis, ac cutaneus, definit. Lingua ipfi parva, trigona, initio lata, extremo, inftar æqualium laterum trianguli acuta, in profundolatitat. Apera arterio initio divaricationum, quibus in pulmones utrosque finitur, duo velut of cula, extrinfecus laryngis vicem fupplentia exhibet, quibus pellicula tenuiflima prætenditur. Annuli femicirculares in utrumque latus terminati, nequaquam interna parte coëunt, fed tota interior facies hiat, fubtiliffima membrana obtenta tantummodo cooperta, qux aëre \& fpiritu \& copiofo, vocis efforman$\mathrm{d} x$ ac edend $x$ gratia, concepto, in amplum diftendipoteft.

Arift. H.A. Montes \& fylvas incolere Ariftoteles teA, g. c. x. Atatur. In fepulchris, \& humano ftercore fidere, frepits in terra; maxime ubi immun dicies eft, experientia. Plurimo anni tempore, in montium anguftis, \& arborum cavis locis latitat. Ideo verno tempore deplumis folet confpici.

Vefitur myrtibaccis, vermibus, formicis, Yictis. mufcis. Uvis frepe tam immodice, ut ebria evadat. De Nidonon convenit inter Au- Gneratid. thores, nec fibi conftat Ariftoteles. Gefnerus fub ftipitibus arborum. Olaus $M$. in olatis $M$.

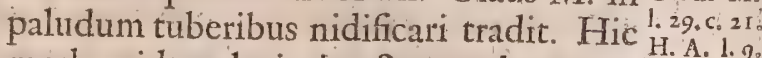

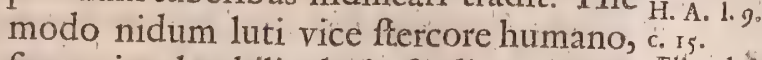
feu ut intolerabiliodoris foeditate hom $\mathrm{t}-$ Allian, 1.6. nes ab eodem fuget; feu re venenata ad c. 1. eundem animalia accedant, circumlinire ; modo, ftipites arborum fubire, \& fine ullo inftrumento in cavis parere, fcribit. Ter na ova Perdicum fimilia, fed minora, du- Anglicus riora, afpectu deformiora, \& odoratu gra- lib. In 92
viora, parit.
cap. no

Lente admodum volat.

Voxipfi per xeftatem alia, volatu mem, fi Alberto credendum; fi Polluci ${ }_{\mathrm{c} .1} \mathrm{I}_{3} \mathrm{~s} . \mathrm{l} . \mathrm{s}$.

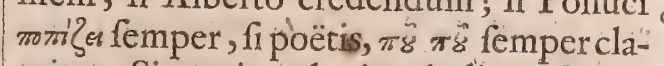
mitat. Si gemit, pluviam indicat. Si clamat, vulpem in vepretis hrerere innuit. Si ante vitium tempus canit, infignem vini copiam prænunciat:

Ingenio non deftitui certum, fi ex uva- Ingeninns, rum efu ebria adiantum herbam ori inferere; \& circumambulando fibi mederi,gramen adverfus $\beta$ arouvía edere; claufum nidum, herba quadam, prodente Eliano Elian. de aperire, verum eft. Senefcentes, inter pul- Animalib. los jam adultos plumas deponunt, \& vi- ${ }^{1}, 3 \cdot c_{2} 26_{0}^{\circ}$ fum amittunt. Ab iifdem, donec vires recuperent, pafcuntur. Vifus admota herba, reftituitur.

Invenit \& in Medicina ufum. Cor in late- $V$ fus. tis doloribus laudatur. Mira in fomniis videbis, fi fanguine tempora illeveris. Lingua obliviofo fufpenfa prodeft. Pennarum fuffitus vermes expellit. Corium capiti impofitum dolorem fedat. Ala dextra cum dente hominis ad caput dormientis fufpenfa, non expergifci, donec auferatur, fabulam effe credo.

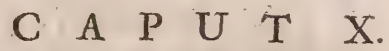

\section{De $P$ aris in genere, $E$ in pecie.}

D Arus, Egithalus, Parix, \& Parula dicitur.Tria ejus Genera agnofcit Ariftoteles; plura adjiciunt alii. Omnibus juxta oculos maculæa albæ funt. Unguibus etiam omnes reptare, \& facile, ubi yolant, adhrerere poffunt, ita ut nucem è filo illis fufpenfam adhrefénéntes comedant.

Semper fere in arboribus deguni; raro ${ }^{\text {Locns }}$ terram petunt. Ad Belgas \& Anglosquotannis fub initium Octobris accedunt.

Vefcuntur muribus, cute tantum detracta. Victus $\mathrm{L}_{3} \quad \mathrm{Ob}_{\mathrm{V}} \mathrm{V}_{0.5}$ 
Objectis, vermibus, apibus, nucibus, can- tudinis, ut retro per tergus fuper caput ponabino femine, quod dum roftro perfo- fita, hoc longitudine fua vincat. In foemirant, fonum fabri malleum in afferem adi- naomnia funt pallidiora, \& color tergoris gentisexcitant. Sebum eis exhibetur, ut in mare caftaneus, in hac ferme fufcefcit. lentore fauces demulceantur, \& fuavius canant.

Generatio. Nidificant in cavis arborum quidaim, nonnullæ nidos de arborum ramis miro artificio fufpendunt. Ova plurima edere fcriArif.H.A. pfit Ariftoteles. Gregatim \& impetuofe 1.9. c. Is. volant. Tinnire per noctem authorPhilomelæ fcribit. Veniunt apud Helvetios in cibum, \& regium morbum, patientis afpectu in fe, fi nonnullis credimus, recipiunt.

Species Parorum funt, Major, Paluftris, Sylvaticus, Ater, Creruleus, Caudatus, \& Criflatus.

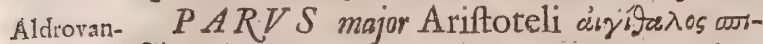
dus 1. 17. ¿ir

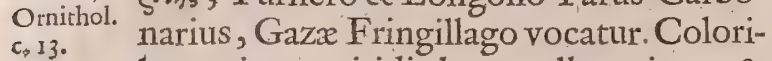
$\varepsilon_{0} 13$. bus quinque viridi, luteo, albo, nigro, \& cxruleo elegantiflime variat. Caput integit vitta, prx intenfo nigrore inftar corvi refplendens. Tempora \& oculorum ambitus albent. Lingua extrema in duas partes fiffa eft, quarum utraque denuo in exigua quafi capillamenta fubdividitur.Cauda eft bifida, partim cinerea, partim nigra, cujus extre- mæ utrinque pennæ dux, exteriori parte candent. Propter cantus fuavitatem alitur, eumque per totum continuat. Pulverizatus colicos \& nephriticos cruciatus tollit.

PARVS INDICVS tribus potifimum coloribus, oculos fiexcipias, cæruleo, albo, \& nigro, conftabat. Guttur, pectus, $\&$ totus venter candibat. Vertex capitis \& collum coloris erant cærulei diluti; Pedes nigerrimi.

PARUS PALUSTR Is in agro Bononienfi Paronzino, Bellonio, quartum Pari genus, Turnero Schæniclos Ariftotelis dicitur. Capite eft prorfus nigro, ut à Gefnero defcribitur; pectore \& ventre albicat. Dorfo \& cauda frigefcit, crura funt rofea.

$S \Upsilon L V A T I C V S$ macula per medium verticem rubente eft confpicuus, partibus utrinque nigris, crufculis fufcis, alis nigricantibus, reliquo corpore viridis, ventre dilutius.

$A T E R$ qui \& Carbonaribus, albam maculam infra oculos habet, aliam in occipitio, caput nigrum, ventrem luteum, crura fufca.

CARVLEVS ab Ariftotele tertio loco, \& abfque nomine peculiari pofitus, quod folus caruleo capite fit infignis, ita dicitur.

$C A V D A T V S$ Ariftoteli cesvòs, Bellonio Monticola, aliis, fedmale ćvóvvp(a) vocatur. Niger eft, parte prona, albus fupi$\mathrm{na}$, in mediis alis rubet, circa imum ventrem dilutius. Vertex ei albus, roftrum fufcum, cauda bifurcata; \& tantæ longi-

Incolit montes \& fylvas, \& raro, nifi frigido Arif.H.A. tempore invenitur. Vefcitur vermibus, ara- Bellon.1.\%. neis, \& fimilibus animalculis. Sed \& arbo- c. 25。 rum germina principio veris amputat. $\mathrm{Ni-}$ dum ftruit inter frutices, duos fere palmos cum dimidio longum, ex mufco \& araneorum filis compofitum, aditu femper angufto.

Species quæ Mourier Gallis audit, rotun* dum aditu gemino ad arboris alicujus truncum fufpendit, \& multa ova parit. Vifus ex lanugine illa, qux in falice vetufta \& populo, extra ex lino aut cannabe extructus. Quem Aldrovandus à Presbytero quodam Colonienfi defcriptum exhibet, avicula eft Wyritepfker, quafi vini promum Colonienfes dicunt.

Volant Pari caudati invicem, \& modo hanc, modo illam petunt arborem. Vox ipfis non ita incondita; altum vero veris inprimis tempore clamant. CRISTATO magnicudo eft Paro majore minor, montano par. Caput cum paucis punctis albis nigrum, crifta retro extenfa, corpus pronum fufcum, pectus album, crura cinerea: Degit circa abietes \& Juniperos.

\section{A P U T XI.}

\section{De Motacillis, \& Mufcicapis.}

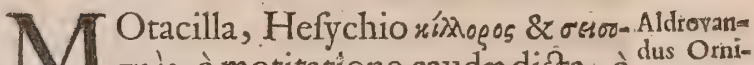

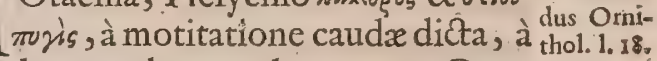
quibusdam cauda tremula vocatur. Com-c. 22. mune omnibus mufcis vef ci; \& circa aquas \& pecora, ideo verfari : combuftarum pulverem contra lapidem vefic $x$ vehementer laudari Faventinus \& Maffa reliquere.Species ipfarum funt Alba \& Flava, ad quas Spipole, Spardæ, \& aliæ Mufcicape referri poffunt.

$A L B A$, quæ \& communis Gazæ Albicula, Bellonio Ariftotelis Cnipologus, fed forte male, avicula eft oblonga, vertice, collo fuperiore \& pectore nigris, dorfo cinereo, roftro longiufculo, tenui, nigro, gula candida, ventre toto candido. Fœmella vertice eft cinereo, gula lutefcente, cæetera mari fimilis. Verfatur circa aquas: frep \& aratrum vermium caufa fequitur.

Flava duplexeft. Alteri caput proportione parvum, fufcum : roftrum longiusculum, nigricans. Cranium molliflimum, alæbreves, venter cum pauciflimo luteo albicans, qui color initio caudæinferius intenfior eft. Pennx in alis nigricantes, in medio per transverfum albid $x$, extrem $x$ torx nigrx; cauda bifurcata, reliquo corpore longior. $\mathrm{Ab}$ Accipitre perfequente fi evaferit, egregic cantare dicitur. 
Alteri roftum gracile, atrum, in extremo $\mid$ minor eft. Capite fupremo nigricat, unde parum recurvum, flavedo à gula ad podi- Melanocephalos Cretenfibus dicitur. Colcem ufque præcedente intenfior. Caput \& $\operatorname{lum} \&$ dorfum habet cinerea. Mas à fómi ${ }^{z}$ dorfum ferruginei ferme coloris, mentum ha difcrepat, quoniam ventre candicat; albicantè macula velut barba cana vefti- dorfo, capite, \& collo albicat; gerit \& al: tun.

Spipolarum, utaucupes Bononienfes Ornithol. appellant, tres defcribit Aldrovandus fpe1.18. cap. cies. Vna habebat caput leucophæum, albam fub mento maculam, pectus rubicundum: Dorfum cinereum, ventrem ex rubicundo \& albo varium. Alkera pectus maculis fufcis deorfum defcendentibus interfinctum, ventrem albefcentem, maculam retro ad oculos majufculam ad ferrugineum accedentem. Teria cui \& Boarinix nomen, tota erat ex albo lutefcens, roftro \& pedibus fufcefcentibus.

STOPAROLAS idem exhibet binas; unam pectore $\& x$ ventre fere candido; $\mathrm{Ca}$ pite, quod maculis nigris in vertice, conpergitur, collo, tergore, cauda fubfufcis: alteram roftro oblongo, recto, fupra tamen parumper declivi, fuperius nigro, inferius corneo : collo, pectore, \& ventre pallidis, Ornithol. oculis exiguis.

Mus é ICAPAR U M, qux forte Oppiano, quod circa boves volitent Bodũ̃u; plures exponuntur ab eodem fpecies; ex quibus illa quam Pigliamofche aucupibus Italis vocari fcribit, in collo maculam albam velut torquem habet; in medio alarum aliam : Altera, Magnanima quafi inunus fabri obiens dicitur, forte quod roftro fonorè tundat, dum Mufcas capit. Tertia quæ Gefnero Glarea, cruribus rofeis, \& ante hyemem avolat. 2uarta quam Germani sobturvoget vocant, forte quod imminente peftilentia fint frequentiores, folitaria eft, \& per arborés irrequieta volitat. Quinta Gallis Moucherolle dicta, quæ pafferi adeo fimilis eft, ut non nifi moribus dum vivit; \& roftro cum mortua eft, ab eo diftinguatur. In fylvis \& dumetis latitat; \& crura habet rofacea. Quidam Linariis eas comparant. Gefnerus eandem cum fua Prunella effe conjicit.

\section{A P U T XII.}

De Rubetra, Rubecula, Pyrrbula, E Thenicuro.

Atilt.H.A. 1.8. C.3 Scalig. ad
H.A.I.8.

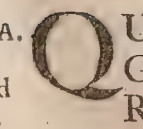

Uæ Ariftoteli Græce Baris, illam Gaza Latine Rubetram, Scaliger nit de ea inter Aurtilit. Non conveBaradam effe opinatur. Germani quidam Turdorum minimum genus quod rubi fructu victitat : Longolius Linariam feu Miliariam; Turnerus Anglorum Moretetteram, aut Stonchatteram; Bellonius Gallorum Traquetum, quod continuo alas motitet. Si hunc fequimur, fringilla paulo

bam peralas lineam. In Gracia, Greta \& Gallia continuo, migratoria enim nón eft, vifitur, \& femper dumetorum cacuminibus infidet. Unde forte ei apud Græços nomen, néc ad pagos vel vicos propius accedit. Solitudine gaudet, \& gregatim duntaxat, dum foboliintenta eft, volare confpicitur. Nidum tánta feruit induftria, ut difficulter quo intret vel exeat invenias.

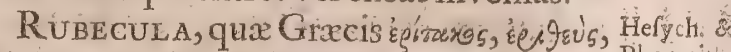

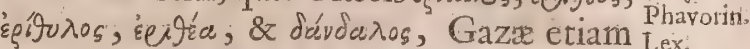
Sylvia, pectore eft aurantio ad ferrugineum accedente, lingua bifida, cauda duodecimpennis inftructa, quam fxpe motitat, poftquam fubmiferit abfque tremore ftatim erigit, \& fic ejus pullià Phinicuri, feu Ruticilix foemina, \& pullis, quibus ita fimiles funt, ut vix ab oculatifimo dignofci poffint, qux fimul atque caudam moverit non ceffant, donec ter aut quater fimul moverint; dignof cuntur. EEftate cum. prole ad defertiffima quæque loca fecedit, cum Ruticilla comparet. In fine Autumni perfectam in pectora rubedinem nacta; ad oppida \& pages confugit, quo tempore Ruticilla delitefcit. Nunquam fere in eodem faltu nifi una reperitur ; unde Phàvo-

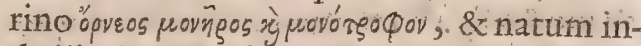
de illud, una arbor non capit duos Erithacos. Voce homines imitari, prodidit Por- Porphỳi. phyrius. Si cava terræ fubierit, pluviam ftin ab abprædicit. Merulam amore tanto profequi- nimal: tur, ut noctu fere in proxima arbore pro pe eam quiefcat. Dicitur \& morbo comitiali effe obnoxia.

PY R R H L A feu Rubicilla, Scaligero Aldhov: Byrriola pafferis eft magnitudine; gula, Ornith. pectore \& ventre, miniaceis feu purpu- $32, c_{0} 3$ reis (fœeminx pectus totum caftaneo cine- Scalig.ad reo colore diluitur) roftro brevi ac lato, Arilt.H.A. bituminis inftar fplendente, trigono fer. me. Lingua pro corporis magnitudine latiore \& crafliore ; cujus pars extrema quix palatum tangit, \& fapores dijudicat carnea eft \& nuda, reliqux cornea pellicula obteguntur. Degitxeftate in montibus \& fylvis ; fub hyemem ad plana defcendit, \& facillime capitur. Colorem per totum an num fervat. Vefcitur vermiculis; fed inprimis femine cannabino, \& primis illis arborum mali præfertim \& pyrigemmis; quæ ante folia \& flores erumpunt. Sed \& nucibus ac acinis rubentibus fambuci aquatici, \& folani perpetui, delectatur. Nidulatur in fepibus \& quatuor ova excludit. Voce fiftulam imitatur etiam fomina \& \& omnes cantus avium canendo \& fibilando expri mit forte \& humanum fermonem. 
Arit.H.A. PHOENICUR I feu Ruticillx, quam

1. 9. c. 49. Ariftoteles \&r Plinius cum Erithaco confundunt, plura fortaflis funt genera. Turnerus enim caput fcribit ei effe nigrum, Gefnerus macula alba infigne. Aldrovandus quatuor diverfas obfervavit, binas iisdem cx Gefnero adjecit. Tota æeftate nobifum degit, hyeme avolat, aut fe abfcondit. $V_{\boldsymbol{e}}$ foitur mufcis, nucleis juglandium concifis, ovis formicarum \& araneis. Nidulatur in arborum, murorum, \& pofticarum redium, ubi hominum minor frequentia, cavis. $\mathrm{Bi}$ na aut terna ova parit. Cuculi pullum, qui aliquando in ejus repertus fuic nido, alit. In fublimi aliquo adificio, primo inprimis diluculo, idque veris tempore, canit. Hyeme \& pullis exclufis filet. Inter incubandum prxtereunte aliquo clamitat.

\section{A P U T XIII.}

De Antho, Cannevarola Bononienfium, Denante, Es Lufciniola.

A N тн I avis, quem Florum Gaza vertit, facit mentionem Ariftoteles, eidemque fringill æmagnitudinem, pedes fiffos, pulchrum colorem, domicilium circa aquas \& pecudes; victum ex herbis Plin. H.N. \& vermiculis facilem, oculorum imbecil1. 10.c.42. litatem, hinnitum equorum, quem herbæ
\&. 74 . \&.74. pabulo, adventu ipforum pulfa imitatur, ad hunc modum fe ulcifcens, odium cum Spino \& $\approx$ Egitho tantum, ut fanguinem eorum credant non coire, multisque ob id veneficiis infament, tribuit. Quxnam illa hodie fit avis, non convenit inter fcriptores. Bellonius illam quæ Gallis Bruant dicitur, effe credit, illamque fringilla effe majorem, mares fere lutefcere, cauda flavefcere, cruribus \& pedibus nonnihil rubefcere, circa altas \& proceras arbores procul à pratis diffitas verfari, plerumque canabino femine vefci, ad minimum quinque pullos excludere, dum volat ftrepitum

Aldrov. edere, fcribit. Aldrovandus, qui modo I. 17. c.33. defcriptam avem Chloridem effe putat, fpipolam effe judicat, cum \& pulchra fit, \& omnia fere ea, quæ Antho Ariftoteles adfcribit, admittat. Circa amnes, inquit, \& prata uliginofa degit, \& fi ab equisibi pafcentibus pellatur,aufugit quodam cum garritu, quo, hinnitum equi quodammodo imitari videtur. Gefnerus denique illam Aviculam quam circa Argentoratum Ġaulammer vocant, Ariftotelis Anthum effe conjicit.

CANNEVAR OL A Bononienfium, quod in viridi crefcenteque cannabe \& niduletur, \& degat fic dicta, Germanorum Crafmufcho, \& Anglorum Titlingx, fi Aldrovando credimus, per omnia fimilis eft. Lufciniam tam exacte corporis figura exprimit, ut nifi pau-

lo effet minor, nec tam ruffefccret, prorfus eadem videretur. Tota parte prona, gula nempe, pectore, \& ventre ex albo flavefcit, fupinè capite, collo, dorfo, \& alis ex luteo fufcefcit. Roftrum habet lutefcens longiufculum. Caput planum. Caudam breviufculam infra lutefcentem, fupraad ferrugineum vergentem.

Oenanthe Ariftoteli \& Plinio memo- Ariff.H.A: rata, Gazæ vitiflora feu vitifera, velà co- 1. . . c. c. 49. lore fimili uvis germinantibus; vel quod 1. x0.c.29. vini tempore appareat, vel quod uvis delectetur, ita dicitur. Abdit féfub caniculæ exortum, eadem occidente confpicitur. Vitat interdum frigus interdum xftum. Quænam fit avicula ambigitur. Bellonius illam effe credit, qux Gallis, Cul blanc, Italis Culo bianco dicitur. Avis eft Sittre magnitudine; roftro, alis, cruribus, \& caud $x$ extremitate nigris; dorfo cinereo; lingua oblonga ac plana, pedibus parvis: cruribus oblongiufculis. Quia quicquid. fub ventre, infra, \& $x$ fupra Uropygium, $\&$ anteriorem partem caudæalbum eft, Cul blanc vulgo vocatur. Verfatur in parvis dumetis, neque in volatu perfeverat. Nidulatur in foraminibusveteris macerix, quandoque etiam in lapidicinis, quin \& in terra, ubibos aut aliquod jumentum veftigium impreflit. Vefcitur erucis \& vermibus terræ. Plures Couli blanci defcriptiones Aldrov: apud Aldrovandum vide.

Quam Bellonius Lusciniolam appellat, avis non eft obvia. Pectore, capite, dorfo, \& collo coloris eft cinerei. Pennæalarum, \& caudx fufc $x$; roftrum acutum, fubnigrum, gracile, in extremo \& intus aureum, celeriter per terram curfitat. Numerofe quando xeftus ingravefcit, \& potandi gratia in paluftria fefe conferunt, capiuntur. Huc refer illam, quam aucupes ItaliGiarolam vocant, magnitudine alaudx. Roftrum habet fragile, intus rubicundum. Riftum admodum amplum. Verticem, collum, dorfum, \& alas coloris varii. Linguam bifidam, Caudam adeo brevem, utvix ulla appareat, illamque bifidam, variam, anguftiflimis plumulis compofitam. In pedibus pofticus digitus admodum longus, parislongitudinis unguem annexum habet, ita ut ambo pollicem expleant, isque primum rectusfere totus, extremo tantum, admodum exiguo unco modice inflexo, armatur.

\section{T I T U L U S II}

De Infectivoris Canoris.

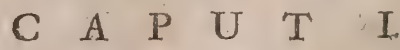

De Lufcinia.

Ner Infectivoras Canoras primum Lu= Nomen. Scinie, alterum Hypolaidi, tertium Atri- 
capille locum tradimus, Caufa in voce pa- intermiffu cantus. Denfante fe frondium

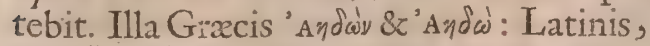
feu quod in lucis canat, feu quod ante lu$\mathrm{cem}$, feu qiod lugens Lufcinia; fed \& Acredula, volucris Attica, Ales Daulia, Pandionia \&c. dicitur.

Defcriptio. Formam non eft quod defribam, cum Arit.H.A. ubique fint obvix. Lingure fummo acumi1.9.,.15.
plin.H.N. ne caret, nec tenuitatem illam primam haPlin, H.N. bet, quam creter aves, atque hoc illi cum Atricapilla commune intercedit. Marifoeminạ corporis habitu fimilis, aliquando tamen ad cinereum vergens, quod \& junioribus competit. Illa quam Schwenkfeldius majorem vocat, tota fere cinerea eft, \& parum rubedinis obtinet. Sexum male ex corporis colore, mole, oculo dextro, qui mari major dicitur, collegeris : Mares adulti vere capti, quod tum in venerem ruentibus genitalia turgeant fere produnt; extra id tempus, qux frequentes, \& modulatos edit cantus, qui continuo fpiritu in longum trahuntur; qux unico fxpe infiftit pedi, \& diu immobilis permanet, mas eft. Curfitat per caveam foemina, \& cantum brevem concifum ac intermiffum promit.

Eocus. Locus ipfis diverfus. In fylvis quxdam vitam agunt, qux majores funt forte, quia $f e$ in his tutiores à ferpentibus credunt, in fepibus quædam, nonnullæ montana loca amant, paluftria nonnullx; plana alix. Hybernia iis caret fi Botero credendum; Batavia fi aliis; imo mori illatx dicuntur. Athenis tanta ipfarum copia, ut Philomelam Atticam Poëtx finxerint. Sunt \& prope Arduennam fylvam plurimæ. \#ftate adulta non diu apparent, \& fub autumno ufque ad dies vernos conduntur. Maximi vaneunt,quxin caveis hyemem pertulere. Cibus eis vermiculi, fed inprimis formicx, \&illarum ova. In caveis duris ovis \& mica panis vefcuntur.

partus. Nidum vere menfe Majo, vel etiam priArift. H.A. ma eftate, quandoque humi fub fepibus, 1.5. .9. \& arborum truncis, aliquando in ipfis fruticibusviridibus, \& denfis, ex foliis arborum, paleis, \& mufco oblongiufculum conftrunt. Cum plurimum fena ova pariunt; \& dum incubant, à cantu, fi Ariftotelem fequimur, ceffant; fi Albertum \& alios, Lufcinia pervigil cuftos, cum ova quodam finu corporis \& gremio fovet, infomnem longx noctis laborem ( folam ex

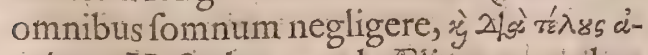
zqúrver Hefiodus apud Ælianum author

Alianus var.1. I 1,20 .

eft ) cantilen $x$ fuavitate folatur ; quo poffit non minus dulcibus modulis quam fotu corporis, ova animare:

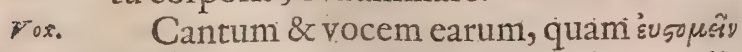
Sidon.E- Pollux vocat, Sidonius fibilare dicit, Plipirt. 1.2. 1. 10. c. 29, bus ac noctibus continuis xv. garrulus fine germine, non in novifimum digna miratu ave. Primum tanta vox tanto in corpufculo, tam pertinax fpiritus. Deinde in una perfecta Muficx fcientia modulatus editur fonus: \& nunc continuo fpiritu trahitur in longum, nunc variatur inflexo, nunc diftinguitur concifo, copulatur intorto; promitritur revocato, infufcatur ex inopinato. Interdum \& fecum ipfe murmurat: plcnus, gravis , acutus, creber, extentus, ubi vifum eft vibrans, fummus, medius, imus, breviterque omnia tam parvulis in faucibus, quitotexquifitis tibiarum tormentis ars hominum excogitavit : ut non fit dubium hanc fuavitatem premonftratam efficaci aufpicio, cum in ore Stefichori cecinitinfantis. Variant tamen. Nam in paluftribus, relaxante inftrumenta vocis humiditate nimia, tam fonoræ non funt. In Hifpaniola \&Infula S: Johannis, Martyre te- Mattyri ind fte, nunquam à cantu ceffant. In Scotia Occiden. non tam fuaviter ac in Italia canunt; \& Ind. circa Orphei fepulchrum, vocaliores à Paufano ini Thracibus credebantur.

Amicitiam \& cum Phænicuris colunt, Affectuss cum quibus etiam coire creduntur, \& cum aviculis mollioris roftri, ad quas caveis inclufas advolitant. Inimicitiam, cum collurione qui vifco implicatas capit; Accipitre qui eifdem infidiatur; \& vipera, à cujus fuppofitx oculorum fulgore in certiflimam perniciem trahuntur, defcenderites enim paulatim ex arbore in predam ipfi Mirabil in cedunt, ut Merula fcribit; quod tamen Cardan. 1 Cardanus negare videtur, exercent. Inter de var, rer, affectus corporis precipua pinguedo. Sxpe adipis mole obrutæe extinguuntur. Si aliquo alio liberos corripi contingat, formis carum ovis fibi ipfis medentur.

Ingenium fingularis in herum cicurata- Ingenizime. rumfides; fape emiffa, (tale Alcon Do- Apud Nenacife dono dediffe canit) - loga. 2:

\section{Scit rur fum remeare domum tectumgue fubire \\ Viminis, \&ु caveam totis preponere $y$ lvis;}

imo multæ venditæ vel dono datæ aliis prioris domini defiderio contabefcentes commoriuntur; \& obftinatus libertatis . amor, (fiadultæe cavex includantur, cantus \& cibi adfinentia, pro fervitute vena- Elian i in torem tefte $Æ$ Eliano, filentio ulcifcuntur) ${ }^{\text {variis. }}$ teftantur: Cantus maxime, \& Docilitas. Simplex ille, fi in folitudinibus degunt; varius \& multo apparatu compofitus, fi

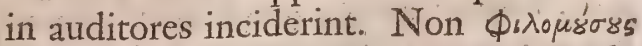
duntaxat, fed \& $\phi_{1} \lambda_{0} \delta^{\circ} \xi$ \%s cum Charmide

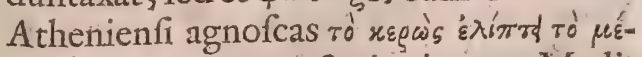
$\lambda$ (6. Nec minor pofteritatis cura. Meditantur alix juniores: verfusque quos incitentur accipiunt. Audit difcipula intentione magna $\&$ reddit, vicibufque reticent. Intelligitur emendatr correctio, \& in doM cente 
cente quxdam reprehenfio. Docilitas mira. Cæfares juvenes habuere Lufcinias GræMlin.H.N. co atque Latino fermone dociles; proterea meditantes in diem \&raffidue nova loquentes, longiore etiam contentu. Vifum jam frepe juffas canere copiffe, \& cum Symphonia alternaffe: ficut homines repertos, qui fonum earum, ad dita in transverfas harundines aqua foramen infpirantes, linguxve parva aliqua oppofita mora, indifcreta redderent fimilitudine. Fuere Gerner, in tres Ratisbonæ, Anno M.D.XLVI. qux, Ornithol. intra noctis filentium, quicquid interdiu ab hofpiribus colloquentibus inaudierant, Germanico fermone ita promere folebant, ut ab audientibus optime intelligerentur.

F fus. De ipfarum in cibo ufu non eft quod multum dicam. Plumis nudata vox eft prætereaque nihil, ut Lacon iile apud PlutarPuturch. chum dixit. Appofitam fuife in centenain Apopth. ria illa $\mathbb{E}$ fopi Tragici, cui quendam civem Romanum donatione unica xM. aureorum dediffe legimus. Patina, vel exinde colligas, quod centum aviculis, qux cantu aliquo excellerent, conftaret. Arrii etiam filios magno coëmptas efitaffe HoHorat. 1.2. ratius teftis eft. Medicinam fi fpectes. CanSerm. Sa- crorum oculi cum Lufcinix carnibus in Plin. H.N. cervina pelle alligati vigiliam præftant fu1.32.c.ro. gato fomno. Fel cum melle illitum vifum
FI. H. A. gato 1. I. c. 43. perfecte acuit, ut vult Kiranides.

\section{A P U T II.}

\section{De Hypoldide E Atricapilla.}

Arift.H.A. T T Y p o L a I D E M feu Currucam Ariצ. 8.c. 3. 1 ftoteli debemus; qui quidem $\mathrm{Cu}$ culum in ejus nido parere fcripfit; fed cum corporis formam non addiderit, par fere de ea ac Antho inter fcriptores concertatio. Niphus cantu \& magnitudine Philomelam imitari, \& quod in oculi Equi mortui concavitate nidificet, Hyppolaida vocari fcribit. Bellonius Lufciniæ in cantu fimilem, Gallis Fanette brune, facit. Tưnerus, Titlingam feu Lingettam Anglorum, quæ Lufcinia minor eft, colorefubviridi. Culices \& vermiculos in ramis arborum fectatur; raro humi confiftit; hyeme non cernitur, cuculi pullum pro fuo educat, \& fequitur, effe; \& Germanis Pafterem gramineum fagmufthe feu Brafenutcíc vocarilirequit. Gefnerus dictionem Germanicam Grafmufche per metatefin à Latinorum curruca factam effe conjicit, \& quatuor ejus genera facit. Majores vel colore funt fufco pre cæteris canoræ. Circa lacum Verbanum Piccafigas, id eft, Ficedulas, vocant, vcl pectore albo, capite cinereo. Ex. Lino nidum ftrunt, ftatur.
Atricapillis, maribus capue prima xate rubet, deinde nigrefcit, fominis femper rubet. Minores ventrem album, oculos albicantes habent, inter fepes fere degunt, \& hyeme difcedunt. Eliota Anglus Paferem fepium effe putat; quem Turnerus Pafferem Troglodytem interpretatur, Germanis amunfchlipffe. Aldrovandus nullam obfervavit, cui proprie illud nomen convenire exiftimaret. Schwenkfeldius,

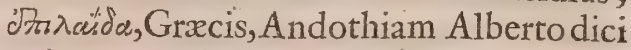
opinatur, \& fupina parte totam cineream, prona albidam, partim dilute cinereo colore refperfam, vertice punctulis nigris maculato, defcribit. Secundum eundem; nidum inter gramina rotundum fufpendit: ova Majo plærumque quinque, aliquando feptem, fubviridia, punctis minutiffimis varia, parit; eaque fi digitistangantur, non amplius fovet, fed relinquit.

A TR ICA PIL L A $\mu \varepsilon \lambda a \gamma r \rho^{\prime} \rho \varphi$ os $\& \mu \varepsilon-$

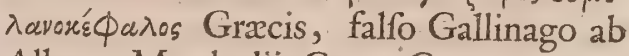
Alberto M., ab aliis Guger Germanorum, qui capite quidem atro.eft, fed pectore rubet; à nonnullis avis Phœenicuro adeo fimilis, ut nifi cauda differrent, quæilli rubea, huic cinerea eft, vix dignofci poffent, effe putatur. Quam vere Ariftoteli \& Pli- Arir.H.A: nio cum Sycalide, feu Ficedula, vel ut Plin. H.N. Scaligero placet Ficula \& Ficilla eadem 1. 10. c.29. fit, \& ineunte quidem autumno Ficedu-Scaligerad la, abautumno protinus Atricapilla eva- 1. $9_{0}$. dat, putetur; cum Schwenkfeldius Atricapillam vere \& Autumno deprehenderit, judicandum relinquo. Aliquot earum Schvenkexhibet Aldrovandus icones. Vna capite, ,eld. in Adorfo, cauda, \& remigibus alarum pennis tota nigra erat. Alterius vertex colorem caftaneum gerebat. Tertia notabili macula fupra roftrum in fronte notabatur. Quarta tota ex albo \& nigro variabat. Schwenkfeldius Paffere paulo minorem, vertice nigerrimo, collo dilute cæruleo, ventre albicante, podice fubflavo, pedibus glaucis, unguiculis fufcis, effe fcribit, \& fum$\mathrm{m} \mathfrak{x}$ lingux acumine carere addit. In Anǵlia non habentur, fi Turnero credimus. Nidificant in caveis arborum, \& plura quam viginti ova ponunt, fed numero femper impari. Non tantum vermiculis, fed \& forbi Alpinæ bacculis, vefcuntur ; imo \& uvis inhiant. Unde Ampelides vocantur: Pullos tanta fedulitate alunt, ut in nido etiam pinguiffimi exiftant. Optimæ Gel. Noct; funt in cibo autumno, propter alimentum ${ }_{c .}^{\text {Attic.l. } 15}$. tum in iis abundans. Phavorini tempore negabant ullam avem præter ficedulam totam comedi oportere. Diofcorides frequenter in cibo fumptas, vifum acuere te- 


\title{
HISTORIA NATURALIS
}

D $\mathrm{E}$

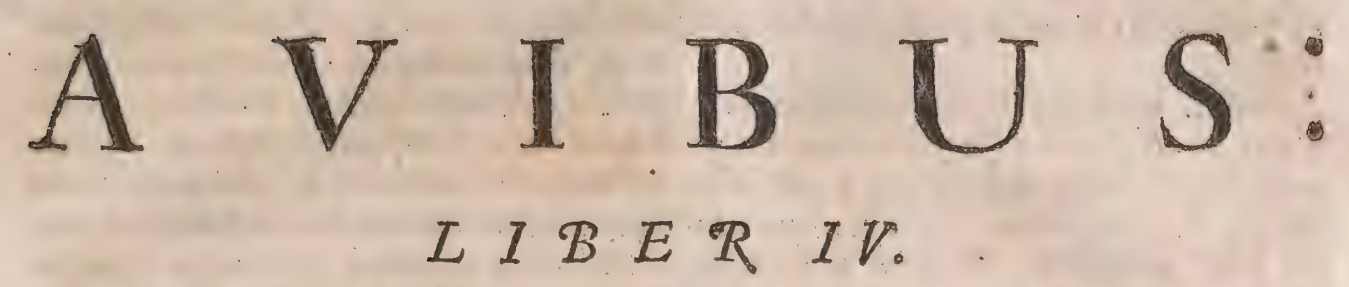

\section{DeAvibus Aquaticis, Palmipedibus.}

\author{
T I T U L U S I. .
}

\section{De Palmipedibus Tifcivoris.} Aldrovan- 5 phyrio dicitur; quemque thol.1. ig. diverfum à Pellecano Ariftotelis Gefinec. 2. rus facit. Alberto Ofina, Kiranidi Ramphius. Verrio Flacco Truo, Ifidoro $\mathrm{Ca}$ nopus Agyptius, Aldrovando Pelecanus Ariftotelis, \& Oppiani Pelicinus vocatur; \& nomen hoc quod collum mergens \& fpirans quafi ruditum afini edat, fortitus eft. Duo ipfius Genera. Albertus facit, fylveftre nempe \& Aquaticum; ex quibus hoc duntaxat doctifini agnofcunt. Videntur tamen \& in provincia Manzi in India Orientali effe toti albi, cum offe fupra caput, colore fanguineo, nifi nos $\mathrm{O}_{-}$ doricus de Foro Julii fallit; imo \& avis, E1. H. A. quam Alianus Indis Celam appellari fcri-

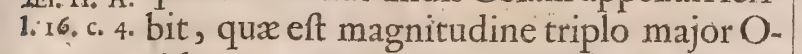
tide, ore permagno, ingluvie maxima, longis cruribus, fummis alis pallidis, $\mathrm{cx}$ teris pennis cinericiis, Onocrotalus Indicus dici poteft.

Defcriptio. Quantum ad Magnitudinem vifus Rhodi paulo minor cygno, multo anfere; vifus, cujus longitudo ab initio roftri ad pedes ultimos. extenfa, hominis proceritatem æequabat; ab. Aldrovando emptus hominem-jufta ftaturæ non adxquabat tantum, fed vincebat etiam: ideo quorundam pondus ad XXIV. libras duodecim unciarum. accedit: Corpus habet album. Roftrum coloris fufci, rubrum interdum, ut in Machlinienfi Onocrotalovifebatur, validifimum ac plane offeum; cujus fuperior mandibula, ut Aldrovandus in Ferraria allato obfervavit, tres digitos lata, duas Spithamas longa. Inferior palmi longitudine fuperiorem excedit, cum ab interiori parte capi tis ortum ducat; fuperior in curvum quendam hamum crocei fere coloris definit ; $8 x$ intus plantaginis angufti folix pentapleuri figuram exacte exprimit, extuberantibus per ejus longitudinem quinque lineis a fperis, \&ob longa tubercula referentibus. Sub hac infigne quoddam capaciflimum membranofum, rugofum, \& omni fibrarum genere proditum, coloris fere crocei percurrentibus ubique maculis nigris, \& facile dilatatu, dependet ceu uter quidam; receptaculum. Ingentis ftaturx hominem ocreatum pedem ufque ad genu immitte re in fauces \& educere potuiffe vidit Perot: tus; parvulum $\mathbb{E}$ thiopem in eodem inventum fcribit Sanctus. Crura ipfi Anferina, prx tanti corporis porportione breviufcula. Capitis plumæ albæ, mollesque, in radicibus fuis nigræ, in eccipitio longiores. Interiora, fi fpectes, in eo, quem Aldrovandus defcribit, quam foeminam effe ova ciceris magnitudine ad feptum confpecta oftendere;lien erat rotundus, nu* cis avellanæ magnitudine, aliquanto craffior. Ventriculus ex membranis craflioribus conftabat, digitos decem longus, duos latus, materia chylofa lutea cum quibufdam quifquiliis \& capillis, refertus (Gefnerus fuccum quendam viridem vermiculis fcatentem in fuo invenit.) Veficula fellis in concaro jecoris hixebat, $\&$ ab ea meatus velut canalis ad inteftinum duodenum porrigebatur. Inteftina fex ulnas longa appendices duorum digitorum longitudinis habebant. Gula crat longa, crafliufcula, carnofa, quix fubinde latior evadens, ubi ad ventriculum 
perveniffet, comprimebatur. Cor maxi- mafusaccedit. A Plinio \& Solino cum Fü mum, offalevia, alba, pellucida \& fine me- licis comparatur. Aldrovandus Arten- Aldrovis dulla. Vlne alarum mëmbrana quadam nam hodie nuncupari, \& in infula Sanct $x_{1 . \text { ng.c. } 3 \text {. }}$ integebantur infigni, ex qua tendones Mariæ de Tremitiduntaxat inveniri, creviginti quatuor oriebantur, tam tenuiter dit. CuiDalechampius adftipulatur. Hoc salnaf. ad

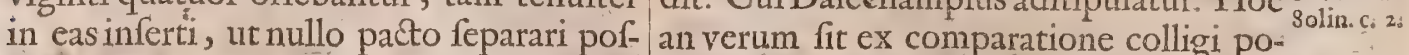
fent.

Eotus. Verfatur in aquis pifcofis \& diffufioributs. Vifus in $\mathbb{E g y p t o ~ a ̀ ~ S e p t e n t r i o n e ~ v e r f u s ~}$ meridiem tendere. Obfervatæ \& circa Gazanum Egypticivitatem greges; quæ verfus mare volitabant. Mittitur \& à Gallia Septentrionali; \& Marcellus Onocrotalum Ravennatem cognominat. Reperitur etiam in Hetruriæ maritimis, circa Herodisportum, \& Orbiteliiftagnum. Circa Lufannam in lacu Lemano femel tantum anno apparere creditur. Gefnerus in lacu ad Tugium captum commemorat.

terit. Magnitudine ifta eft Gallinæ fatis corpulentæ. Color ei füfcus feu cinereusobfcurus. Tota fere prone candicat. Roftrum êft luteum prædurum \& aduncum. Oculi ignei.Degit in cavis ut lucem folis declinet; noctu circa fcopulos non longe fuper aquam volitat. Pifcibus viititat, quos noctu tantum venatur. In cavernis fcopulorum \& terra nidulatur, \& vocem vagitui infan- Plin.H.N. tium fimilem promit. De Diomedeis vero ${ }_{\text {Solin. }}^{\text {l. ro. }} 44_{0}$ ita Plinius: Nec Diomedeas preteribo a- lybitt. co 2.

$V$ icius. Vittitat inprimis pifcibus, eofque dum Gefner. in venatur, non toto corpore mergitur, fed Ornithol. collum fubinde demittit. Cicuri fi libralem (quinquelibrarum pifcis haud magna ipfi efca eft) exhibueris, ita invertit, ut Bellonius roftro præmiffo deglutiat. Devorat \& cum de $A v i b u s$. teftis conchas, eafque calore interno intra ingluviem apertas, revomit, \& hiantibus jam têtis carnem ab ocreis feligit. Solum fcilicet vifceris hahet ductum; qui ab inPetr. Mar- troitu oris ad naturæ fecreta pertingit. Vi-
tyr. in De- fus dimidiam endromedem, qua miles $\mathrm{u}$ ead. "nus tegebatur, in fe projectam abforpfiffe integram, qux ex gutture interfectæ fine jactura educta eft.

Generstio. Nidum ex ramulis ad ripam fluminis alicujus vel ftagni ponit, ibique tot ova Anferinis fimilia, quot cygnus folet, edit, fotufque enutrit. -

V.oldats. Volant nonnunquam foli, nonnunquam gregatim : \& cum volant fonum alarum cient.

Vos. Wox ipfi ruditui Afini fimilis: fonum cum edit roftrum in aquam vel terrelutum infigit, fi Alberto credendum. Dicuntur (Bartholomæus Anglicus ex Ifidoro author eft) erecto ad colum roftro, Accipitrum metu, fed forte falfo, dormire; \& in Lycia ad flumen Xanthum, quotannis cum corvis, cornicibus, \& aliis carnivoris Prefagium prolitim committere. Si vicerint, abundantiam frugum fibi promittunt incohe; fi vincantur, ovium", boum, \& aliarum quadrupedum foecundum proventum.

$\checkmark$ fis. Ingluvie ea parte qua capiti adhrfic colligata, ad quam ejiciendam, Fgyptii pifcatores utuntur : qui humiditate corrumpi nequit, multo tempore utilis eft.

Avis Diomede ab infulis Diomedis fic dicta, de qua multa veteres fabulati funt, Servio, Stephano Grammatico \& Ifidoro Ardex genus eft : quibus Sal-

tes oculosque igneo colore, cxtero candidis tradens. Duo femper iis duces : alterum ducere agmen, alterum cogere. Scrobes exçavare roftro, inde crate confternere, \& operire terra, qux ante fuerit egefta. In his foetificare. Fores binas omniun frobibus. Orientem fpectare quibus exeant in pafcua. Occafum quibus redeant. Alvum exoneraturas fubvolare femper, \& contrario flatu. Uno hoc in loco totius orbis vifuntur, in infula, quam diximus nobilem Diomedis tumulo atque delubro, contra Apuliæ oram, fulicarum fimiles. Advenas barbaros clangore infeftant, Græcis tantum adulantur. Miro difcrimine, veluti generi Diomedis hoc tribuentes: Ademqne eam quotidie pleno gutture madentibus pennis perlucentatque purificant. Unde origo fabulæ, Diomedis focios in earum effigies mutatos.

\section{A P U T II.}

\section{De Laris.ingenere Es in $\int p e c i e$ de Laro albo.}

T Arus, quem Auguftinus Fulicam, alii Aldro.OrMergum, Herodium, Suidas \& alii nith.l.19. apud Græcos жє́т фov, quidam etiam Gaviam vocant; $a b$ Aldrovando defcribitur, quod fit avis à roftri acie ad alarum fere fi- Defcriptio. nem duas fpithamas longa, capite maximo \& craffo, ex albo \& cinereo variegato; pettore ejusdem fere coloris, illoque amplo; roftro, craffolutefcente, in extremo nigricante \& infigniter acuto; in cujus fuperiore parte narium funt foramina oblonga, rictu ampliffimo. Oculi iridem auri inftar fplendidam niger ambit circulus, hunc albus, album cinereus. Ale exalbo cinereo, \& ad caftanearum colorem fimil commiftis tendente conftant, \& caudam palmi longitudine excedunt. Cauda cinerea tota. Pedes lutei; pofterior digitus fatis confpicuus,ungue etiam armatus. Corpore eft levif- 
fimo, \& multis ac denfis plumis induitur.

Elian. H. - Frequentes in locis maritimis ftagnis \& A.1.3.c.20. fluminibus, cum ingens aliqua tempeftas coorta eft, confpiciuntur.

Tocus.

Preter pifces lumbricis etiam, cochleis, quas furfum raptas, ad faxa demiffas con- fringunt, Locuftis \& Phalangiis à quibus Tarentinos agros repurgant, vefcuntur. Delphinós etiam in littora dejectos devorant. Olivis denique in Liguria perniciem adferunt.".

Generatio. Nidulantur in faxis maritimis, à quibus Arift.H.A. potabilis aqua manat, \& bina ternave ova 1. 5.c. . xeftate pariunt.- Volant præcipites \& faciles leves quippe. Hinc Laro apud Homerum Mercurius confertur. Sed \& pennæ per-fe aliarum avium leviores putantur. Has enim pelamydum pifcatores, tefte Æliano, ad hamum linex alligant, ut propter earum levitatem ab occurrente aqua fenfim ac leviter agitetur.

Affectus. Amicitiam cum homine utilitatis gratia, quia pifcibus vefcuntur, \& Monedula, AI. H. A. ut Elianus prodit, colunt. Malo punico 1. 6. c. 6. interimuntur. Imminentibus ventis fublimes in aëre volitant, \& vento fefe obvertunt. Copiæ pifcium capiendæaugurium, fi ad pifcatores retibus pifcantes advolarint, facere creduntur.

$V$ fus. Cerebrum Lari ficcatum \& concifum infantibus Epilepticis odorandum quidan commendant. Pennæ proprietate quadam occulta, fimul atque mare intúmefcit, in pulvinaribus etiam eriguntur, $\&$ decumbentem fublevant.

Inter.fpecies Larorum, eft primus Larus A L в u s forte Gavia peralba Apuleii; qux fuperfluctus marinos natat, demergit fe prope ad Oceani fundum \& gremium. Duo ipfius funt genera prodente Bellonio, Majus \& Minus. Ille minor eft cinereo, pulchritudine corporis ad columbam accedit, quanquam male hanc vincere videatur. Nivis inftar candidus eft. Ro/trum habet teres, acutum, rubicundum, cujus coloris \& cauda eft. Recta cruribus infiftit, pofteriora corporis magis elevata geftans, ita ut inferiora in arcum quafi curvari videantur. Minor fummitatem capitis ni-gram habet; ftatim atque frigora ingruere incipiunt, in mediterraneis locis fupra flumina volitans apparet, \& cateris in volando diutius perfeverat. Captus intra biduum fere cicuratur; facileque nutritur, inteftinis nempe, carne \& pifcibus: Adeo clamofus eft, ut aërem clamore fuo percellat. Videtureffe Turneri \& Gefneri Cepphus, qui ex illius defcriptione, eft avis marina, magnitudine Monedulx, fed alis acutioribus, \& longioribus, colore tota albo, excepto nigro quem in capite gerit cirro: roftro etiam \& pedibus puniceis.Diuti- no clangore defatigata tandem keph pro- Schwenkfert. Schivenkfeld. Larialbi facit mentio- feld in A nem, cuin capite rubeo.

fix:

\section{A $\quad P \quad U \quad T$ III.}

De Laris Cinereis, Tifatore, $\mathrm{Ni}$ gro, Sterna \& Fidipedibus.

TARORUM CINEREORU 1 tria ponit inprimis Aldrovandus genera.

Primum columbam magnitudine parum fuperat, colore undique eft albo, in dorfo tantum \& alis cinereo. Caput fupremum, macula nigra utrinque ad extremum oculi angulum infigne omnino candicat. $R$ frum habet longiufculum, \& aliquantulum velut armatum, introrfun ad inftar thecx ejus, in qua novacula recônditur cavum, colore corneo. Os interius totum, \& linguam cujus extremitas bifida, rubentia. Ora extrema Palpebrarum rubra inftar circulioculos exornat. Crura interdum rubent, interdum fufcefcunt. Digitit'mem. branis rubris fepiuntur. Pofterior pedis digitus aciculx caput non excedit. Credunt quidam pennas capitis à Martio menfe per trimeftre quo tempore foboli dant operam nigrefcere. Reliquis novem menfibus candidas effe. Interiora fi fpectentur, Gula ampliffima, ventriculo longiufculo, crafliufculo, cujus interior tunica craffa rubra eft, preponitur. Hepar maximum flavicans bilobium, ventriculum infra amplexatur, fupra cor mucrone recipit. Lien eft longiufculus fanguinei coloris; $F$ el viride: $V e f c u-$ la in hepate continetur, \& inteftino ramulo jungitur. Ad inteftinum rectum appendiculæ binæ graciles, \& tenues antrorfum Schwenkreflexæf fectantur. Vefcitur pifcibus, infe- fiario Sile $^{-}$ ctis paluftribus, mufcis \& conchulis. $\mathrm{Ni}-$ fix. dulatur in denfis pifcinarum \& lacuum arundinetis; Majo \& Junio menfibus ova quinque columbinis paulo majora parit.

Alteri quod vix fpithamam excedit,dorfum \& alæ funt coloris leucophæi ad cæruleum quodammodo vergentis. Roftrum. pro proportione corporis exilius, arcuatum, nigrum, pedes, tibix membranaque digitos interfepiens coloris crocei.

Tertium eft capite nigro, roftro recto, \& in fine acuto, coloris miniacei; oculis \& pedibus ejufdem coloris; coftis alarum \& remigibus albis, dorfo \& in reliqua parte cinereis.

Larus P Is C A T o R, circa Argentinam privatim Sifctertein diatus, circa Oppenheimium Fel, minor eft, Laro cinereo, vertice nigro, roftro \& cruribus è fufco pal$\mathrm{M}_{3}$ lidis, 
lidis, totus albicans. Volatus eft celerrimi, \& dum pifces captat, etiam in aquam fe mergit.

Larus NIGER, à colore fic dicitur. Quamvis enim fic alis cinereis ultra caudam extenfis, cruribus levirubore notatis; oculis ex fufco purpurafcentibus, roftro tamen, capite, collo, pectore, \& ventre niSchwenk- grefcit.Schwenk feldius ipfi crura \& pedes feld. in A. latiufculos rubentes, nigricantibus.trans-
viario Silefix. verfm anterius maculis adfcribit: \& nidum in arundinibus pifcinarum fufpendere, ac menfe Majo parere, addit.

Quam Turnerus S T ER N A Mappellat, marinis Laris ita fimilem effe, ut fola magnitudine \& colore ab illis differre videatur, minorem duntaxat \& paulo nigriorem adijcit. Tempore quo parturit improbe clamofa eft. Apud Frifios dicitur effe vertice nigro, roftro \& cruribus rubidis.

Larorum FIDD I PED U M duo funtgenera. Vnum alis longis, utpote quæ trium fere digitorum longitudine caudam exuperant. Cuioculi, caput, collum, roftrum funt nigerrima: Pedum digiti infignibus mucronibus armantur. Alterum brevibus; cui magnitudo Merulx, caput nigrum, Alarum coftxalbefcentes, Pennæ fub cauda candicantes, pedes rubefcentes, digiti, membranulix quodam rudimento interjecto, quatuor.

\section{A P U T IV. De Catbarracta \& Ceppho.}

C A tarracta, Ariftotelis \& Oppiani, ex eo quod cum impetu ad predam capiendam decidat, ex hujus defcriptione avis eftinftar Lari minoris, fed robuftior, colore candido, \& Accipitri Palumbario Arit. H.A. fimilis; ex Ariftotele, Accipitre minor, 3.9. cirz: gula ampla, \& lata. Aldrovandus avem roftro acuto, craflo, fupra non modice adunco, prone per alas, dorfum, betico,albo', \& luteo mixtis variegatam, fupine totam albam maculis beticis diftinctam., tibiis, pedibus, \& membrana eos interfepiente cinereis, ponit. In mari victitat; fed \& fcopulis, littoribus, \& petris, quas chxrades vocant, fupra aquam eminentibus infider.Pifces captat exiguos. Ubi vero natantes confpexerit (perfpicacifima enim. eft, \& vel ad fundum ufque maris) altius fubvolat, \& contractis omnibus pennis, quovis telo celerius delapfa, ad cubiti fpacium immergitur, \& pifcem extrahit; nec diutius manet, quam jugeri fpacium tranfieris. Mirus incubandi mos ovis, fi Oppianocredimus. Fucum aut algam is fuper petram infternunt, fic ventis expofita relinquunt. Masilla unde marem procreandum conjicit, foemina unde forminam in fublime per aliquot dies fublata, in pela-

T U R A L I S

gus mittic ; motu concalefactis ovis, pulli excluduntur. Pullis luce afpecta, nulla in nidis mora, parentes volatu fequi conantur : à parentibus fufcepti, in mare demittuntur, mox extrahuntur. Acie oculorum in fenio obtufa,dum ad predam fe ferriarbitrantur, præcipitiis illufi intereunt.

CEP P H $s$ Ariftotelis, Fulica eft qui- Aldrơantz bufdam, Aldrovando, avis, habens roftrum- dus Ornicolore carneo, ad mandibularum Tatera c. I 2 . ruffo, in extremo quod aduncum eft, nigro, oculos exiguos ruffos. Caput,collium, pectus, ventrem, coxas, exalbis \& fufcis, intercurrente etiam betico \& luteo, maculis variegata: Crura \& tibias viridefcentes. Pedes \& membranam digitos fecantem fufca.: An fit Cepphus veterum, ignoratur. Nam de hoc, fi foramen corporis fpectas, id duntaxat habemus, Laro effe fimilem, cum quo defcripta parum habet fimilitudinis, plumis abundare, fed carnis effe exigux, ideo facile vento impelli. De Oppianus. cætero, apud mare victitant, cujus \& fpumam vorant. Thunnos, propter pifciculos, quos dentibus fuis difcerpunt, fequitur: Ad tonitrua adeo perhorrefcit, ut fonitu exaudito ex aëre in mare decidat. Spuma infperfa alliciuntur, capiuntur allecti. Aratus in Cum relicto mari gregatim in terram ad-Phoenom. verfo vento revolant, imminentis venti indicium præbent. Carnem habent probiodoris, partem pofteriorem, quæ fola. limum olet, fi excipias.

\section{C : A $\quad \mathrm{P}$ U.$T$.}

\section{De Anfere Baffano, Phalacrocorace, Cor- vo Sylvatico, Nycticorace Gefneri, জ Graculo palmipede.}

A Ner Bas a nus feu Scoticus, Gefner, in A incolis Solendgufe dictus, avis eft Ornithol. domeftico Anfere longior, fed minus lata, Heć. Boc̈Anferem tamen \& forma \& voce per O- fcript, Scomnia referens. Nullibi quam circa Caftel- tix. lum Bas, viribus humanis inexpugnabile, reperitur, ad quod incipiente vere appellunt. Tres vel quatuor primo tanquam fpeculatores advolant; has aliquot poft diebus reliqua multitudo infequitur,quod egregiorum virorum relationi debemus. Nidulantur in caftri prædicti rupibus; \& conftruendis nidis tantam lignorum copiam comportant, ut auferentibus, qui illic habitant, abunde in annum ex ea parte profpectum fit. Ova in rupibus depofita, fuperpofito pede altero, unde forte nomen à folea accepere, excludunt. Pullos delicatifimis pifcibus nutricant. Quod fi avolartes novum videre, illo abjecto, iterum fe magno impetu immergunt. Tanta autem pifcium ab ipfis evomitur copia, ut \& prefidiariis arcis in cibum cedant. 
D E A

Habent intefinum quoddam parvum, oleo fingularis virtutis refertum. If chiadem \& arthritim fanare creditur. Pulli capti \& affi halecis nidorem emittunt. Caro eft durior, \& vinum exigens, quod aliquoties experti fumus cum Anno MDCXXIII. in Scotia ageremus.

Ex adipe Unguentum fié, quod cum Comageno Plinii de bonitate certat.

PHAL A C R OCORAX, quem cum corvo Aquatico Plinii eundem efle vel exinde conjici poteft, quod calveat, quænam avis fit interHiftoricosNaturales non convenit.Gefnerus an fitilla, quæinBurgundia Crotpefcherot feu Corvus Pifcątor, cuil unus pes eft ad natandum palmipes,alter ad rapinam uncis unguibus armatur; fic cum pif́cem in aqua arripuit, nec facile propter pondus volare poteft, pifcem altero pede retinens, altero ad ripam navigat; dubitat. Alii Corvum aquaticum Plinii, Phalacrocoracem, Corvum Sylvaticum, \& Gracculum palmipedem, eafdem effe opinantur. Bellonius quidem fimillimam avem cum ea, cujus hic pro Phalacrocorace ex Aldrovando iconem dedimus, exhibet : fed corvum aquaticum, Cornicem marinam eafdem Ariftoteli aves effe, \& Phalacrocoracem, innuit. Gallis dicitur Cormorant, quo nomine Angli avem infigniunt, qvæ anguillas integras edit, per inteftina elapfas rurfus devorat, \& vel novies aliquando unam abforbet, priufquam retinuerit. Aldrovandus Phalacrocoracem fcribit effe capi magnitudine, roftro longo acuto \& rubefcente. Capite fere plumis nudo \& cute tecto, qux carnem fubftantia \& colore æmulatur. Ex collo velut jubre dependent, quales in capis cernuntur. In pedibus plumas quardam aureas geftat. Solus inter palmipedes Fibro excepto in arboribus fedet, in iifque nidulatur, $x q u e$ in aqua marina atque dulci degit. Magnum ftagnis damnum quod pifces devoret, adfert, interdum Anguillam mediocris maguitudinis ex aqua abrepta aërem defert, \& antequam devoret, diu cum illa colluctatur.

Corvum SYL vaticum hifceadjicio, non quod fit vel palmipes, vel aquatilis, fed quod ab aliquibus cum Phalacrocorace confundatur. Magnitudo ipfi eft Gallinx; color toto corpore niger, fi eminus videas; fin propius ad folem prefertim, cum viridi permixtus videtur. $R o-$ frum rubicundum, oblongum, \& anguftis terræ vel arborum foraminibus inferi aptum. A capite crifta retro tendit, haud fcitur an in omnibus aut femper. Pedes habet, ut Gallinæ longiores; crura oblonga obfcuxe rubentia. Digitos fiffos. Vefcitur pifcibus, ranis, locuftis, grylliș. In rupibus, turribus defertis \& pylis, unde Cimafrapp Germanis, nidislatur. Bina aut terna ova
I B U S

parit. Altifime voldr, \& primus fere om nium, circa initium Junii ni fallor, migrat: Pulli diebus aliquot antequam volare poffunt, nidis exemti ita facile cicurantur, ut in agros evolent, \& fubinde revertantur. In Iftria circa promontorium Polæ homine per funem demifo eximuntur, \& inter menfarum delicias habentur. Aucupes in fingulis nidis, fingulos relinquere folent, ut anno fequente libentius redeant.

Huc pertinet \& N Y C T I C O R A X Gefneri quamvis palmipes non fit, qui juxta aquas \& inter arundines verfari dicitur. Vefcitur pifciculis. Nidulatur in altis arboribus, ita vel quaterna ova parit.Inter arundineta abfona voce vomiturientis inftar clamitat.

Sednec GRACUTI PALMIPEDIs Ariftotelis, feu Corvi Aquatici minoris, hic oblivifcendum, quem alii Phalacrocoracem, alii Corvum Sylvaticum vel Mergum magnum nigrum effe judicant. Colore in toto corpore eft fubnigro, collum fi excipias, ubi nonnilil ruffi admifceri videtur. Roftrum aduncum acutum, prope frontem fubalbicans, cætero fubnigrum. Crura, pedes, \& membranæ, fufcæ funt.

\section{A P U De Mergisingenere.}

$\mathbf{M}$ Ergum, quem Græci Poëtrx Dy. pten, Poingam \& Bungam dicunt, A' Qúraw veterum effe, vel ex eo colligitur; quod omnes eandem avem effe tradiderint, \& plæraque de Ethyia à Græcis tradita, Plinius de Mergo interpretatus fit. Belloniustamen $\mathbb{E}$ Ethyiam veterum quan- Bellonius dam Merg I MAR IN I fpeciem, qux obferv. 1.ís. Cretenfibus Vultamaria \& Calicatizu di- c, r r. citur, effe judicat.

Magnitudine eft Querquedulx, albo Defcriptio: ventre, capite \& dorfo nigro, itemque alis \& cauda. Pluma ei inftar lanuginis, valide cuti inhærens. Roftrum marginibusacutis cavum \& plane fere, lanuginofis plumis bona fui parte obducitur, nigrum fuperiore, album inferiore parte, vertice lato. Frons tuberofitate quadam verrucatur, cui floccus plumarum niger innafcitur. Digito pedum pofteriore fola inter palmipedes caret. 'Utut fit, certe \& Salmafium hic confentientem habemus; hoc folo diffentit, quod Mergum \& Fulicam eafdem Salmaar. in effe contendat. Formam fi fpectes, de ea Solin. c. 2: quidem Ovidius.

Fecit amór maciem, langa internodiacrurum Ovid. Me
tamorph.

Longa manet cervix. Caput eft à tergore longe:

fed quis ille'fit, unufquifque conjicere tehtet: Noftri contra omne genus avium pedes habent in cauda, ita ut in terra ftan- 
tes inftar hominis corpus erectum proferant,ut Author de natura rerum fcribit. $A b$ Anatibus dentibus \& cruribus difcrevit Gefnerus. Magis enim duriac rigidi, utrinque tantum in marginibus, roftri; cxteris, quibus roftrum latum non eft, fed in acutum definit, nulli. Crura vel non æque abfoluta habert, vel breviora, vel non eodem fitu, vel pofterius, quamobrem incommode ingrediuntur.

tocus.

Verfontur plærunque in mari, fluminiAritt. H.A. bus, ftagnis \& paludibus : amant tamen \& 1. 8. c. 3. aprica loca, ut ficcefcant: Diutiflime in. nirgid. I. 5 . aquis, dum fe immergunt, morantur, \& Homerus fumma ac ab Homero allata natandi polOdyfi.1.5. lent peritia. Alam namque alteram fxpius ad ventum erigunt, \& ejufdem tanquam Pighius in veli adminiculo navigant, quod Pighius dic. prodidit. Soli inter amphibias inter volandum pifcontur.

Vitus. Congros, Anguillas, \& alios lubricos Oppian.in pifces deglutiunt, ingeftos, interdum etjam vivos, mox alvo, quod eis àventre mox recto inteftino cibi tranfeant, egerunt; quod Oppianus \& Plinius obfervavere. Schwenkfeldius in omnium quas fecuit ventriculis, plumas avicularum copiofifimas, quafi cum pifciculis, \& avena compactas invenit.

Partus. Nidificant à bruma ineunte vere. Sxpe Arit. H.A. in maritimis faxis, in arboribus interdum. plin.H.N. Utrumque fe juxta oftium Thinæ fluvii, 1. 10. c. 37. \& in Nortfolcia obfervaffe Anglus quidam fcribit. Ova ut plurimum bina ternave ponunt. Pullos ab ovis exclufos fi matrem perdiderint, adeo validos effe ajunt, ut ipfi cibum fibi comparent.

Nullam eas vocem emittere, arbitrati funt quidam. Lucretius de iis.

\section{Mergique marini \\ Fluctibus in falfo victum, vitamquepetentes Longe alias alto jaciunt in tempore voces.}

Ingenism. Cicurari poffe, tum ille qui Venetiis ab Scal. Exer- hero è cymba emiffus, non fine fpectatocit. 233. rum \& voluptate \& admiratione fub. aquis fibi cibum capiebat, fatur redibat ad herum, oftendit; tum illi in Oriente, qui ab hero, poftquam eis guttur filo, ne pifees captos devorarent, ligaffet, dimiff, \& pifces capiebant, \& in ciftas huic negocio Odoricus deftinatas injiciebant; Pifcatione heri ¿̇ Foro Ju- peracta, foluto gutture, fibi pifcabantur,
lii in irin. Virgil.Ge- pafti ad herum redibant, teftantur. Alii org.l. I. tempeftatem prefagire, cum maria furigin. $1_{1}$ 12. giunt, \& clamorem ad littora ferunt, dic. 7 . Perfius Sa-
tyra 6. feu quod vapores ab aquis ad imbriferam nubem erigendam furfum attolli fagaciter fubodorentur; feu quod pifces pleræque per eum coeli ftatum, è mediis aquis ad littora enatare foleant. Alii cum in mare frequentius fefe immergunt, feu propter aliam aliquam caufam, feu quod tranquillo mari metu belluarum progredi non audeant; in altum fub tempeftatem regreflis, audacter progrediuntur. Plinius pennas roftro purgantes ventum indicare alicubiinnuit. Alianus geftu alarum ex- Al. Ho $A_{0}$

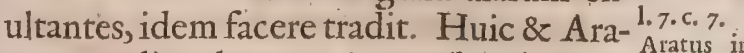

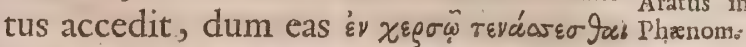

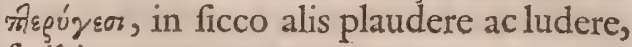
fcribit.

Vfus illorum in cibo nullus : quantum ad Medicinam. Magi contra quartanas devorari jubent cor Mergi marini fine ferro exemptum, inveteratumque conteri, \&in aqua calida bibi. Ventriculum in cibo fumptum ftomacho mederi falfiflimum comperit Galenus. Fel cum cedria inun- Galen. de ctum evulfos palpebrarum pilos renafci fimpl.1.1s. non patitur. Jecur fale affervatum ex hydromelite duobus cochlearibus potum, fecundinas pellere fcripfit Diofcorides.

\section{A P U T VII.}

\section{De Varius Mergorum generibus.}

$\mathrm{M}$ Ergorum varia funt genera.Mergus Gerner. in Rhenanus, quibufdam Monialis alba appellatus; qui omnium Mergorum Anatiformis maxime eft, corpore undique albo atro colore diftincto, prona colli \& pectoris parte cum ventre candida, fed paffim cinereis punctis aut maculis diftincta. Frequens eft apud Sueffiones \& Bellovacos, M A J o R, qui roftrum denticulatum anguftius, èfufco ad cæruleum dilutum vergens, extremitate deorfum incurvata; pectus, collum, \& ventrem tota alba: in dorfo fupremo egregias quafdam plumas alternatim albas nigrafque, inde etiam ad latera verfus pectus tænias fimiliter difcolores utrinque procedentes habet; \& gobiis inprimis atque troctis vefcitur.

GLACIALIs, quod per fumma frigora in aquis capiatur ita dictus, magnitudo Querquedulx, collum digitos octonos longum. Dorfum undique nigrum, alx nigre fed albo diftinctx, crura brevia fufca, membranis inter digitos nigris; quique per hyemem apud Helvetios, non minus quam Anas fera laudatur.

L ONG IROS TRUS, cui roftrum nonnihil rotundum, digiti longitudine; caput criftatum, collum fubrubrum, corpus prexter alas totum nigrum. Pedes crocei, membranælutex.

RAUCEDULUS, cui corpus \& alæ cinerex; gula \& venter alba, pedes nigri:

R U B E R cui pars fuperior capitis \& colli rubefcit. NIGER cui roftrum nigrum, collum fpadicis colore, corpus ur in 
D E A V

Fuligula, alæ cum tranfverfa linea alba nigrix.

Albus, cuiroftrum ruffum, caput cum collo nigrum, viridibus aliqùot punctis refperfum. Crura rubicunda.

CIRrhatus quihabet caput ruffum vel teftacei coloris cirrho retrorfum eminente. Dentes ferratos, duros, retrorfum flexos; Crura \& digitos pedum, interjentis membranis ex ruffo fufcis, rubentes. Roftrum tres digitos longum, inferne rubicundum, fuperne nigricans. Duobus foraminibus odoratus caufa pervium. Bellonius Fibrum feu Caftorem vocat. Afperam arteriam $\mathrm{ab}$ aliis aquatilibus diverfam habet. Nec enim eft rotunda, fed compreffa \& inæqualis, modo craffior, modo anguftior, s in medio duobus velut nodis extuberans. Cum adventriculi regionem pervenit, in cavitatem quandam ex membranis \& offe grandiufculo inæquali conftructam dilatatur. Semper in aquis manet, $\&$ in is fe diutiflime omnium continet. Urinando ad quadraginta aut quinquaginta pedes procedit. Caputinter natandun fublime attollit; S inter arundines nidulatur.

MERGANSER denique ut Gefnerus vocat, cui caput cum tertia colli parte ex viridi nigricat. Colium reliquum cum aliquo pallore album eft. Inferior colli pars nigrefcit. Plumæ ventris \& fupinæ caudx gilvefunt. Crura \& pedes cum membranis inter digitos minii colorem habent. Ventriculus eft corneus id eft firmifimus. Pondere interdum ad libras duodecim accedit.

Huc pertinet Mergus ille, quem Bellonius Gallice HER LE vocat, anatem magis quam anferem referens, roftro longo, terete, \& mucrone reflexo, colore fubrubro.

Item GU L o Germanis Seeritorr/ magnitudine Anferis, colore gilvo, gregaria, menfis lautioribus contemta.

Nec non Schel adrachus Anate major, varius roftro lato, adunco, dentibus acutiflimis pleno, ex gilvo fubruffo.

MOR FEX, denique tota nigra, roftro ferrato \& valido, qux fub aqua mergitur, \& anguillas capit. Eafdemque fi fe gravari fenferit, evomit. Gregatim in arboribus juxta aquas nidificat. Volatura caudam diu in aqua trahit. Saturata ad folem ut ficcetur, expandit. Fimus ficcat arborum ramos in quos inciderit.

NB. DB mergis exoticis vide Mantiffam. Num. II.
I $\mathrm{B} \cup \mathrm{U}$

\section{A P. U T VHIT.}

De Colymbis in genere \&ु in pecie.

A Vis qua Græcis Colymbus, Colymbis, \& Colymbas; Latinis Urinatrix dicitur. Unum tantum illius genus Ariftoteles commemorat; alii plura; Turnerus tria vidit: Primum totum nigrum, fi cirrum. quem in capite gerit, exceperis; Mergo, quo tamen triplo minus eft, quoad corporis effigiem non diffimile. Angli Doukeram vocant. Alterum Turdo non majus, Anati colore \& corporis effigie fimile. Anglis media Urinatrix dicitur. Tertium adeo nuper ab ovo exclufum refert Anferculum, ut nifi Roftrum hujus paulo tenuius effet, xgre alterum ab altero difcerneres. Non enim pennas, fed lanuginem quandam earum loco obtinet.

Gefnerus, Colynbos facit Maximos. Gefner, in Majores \& Minores. Maximus qui in Acronio lacu raro capitur, $a b$ inepto per aquæfuperficiem motu Fluder dictus, Anfere major eft. Roftro oblongo, angufto, acuto. Neque volare poteft recte, neque ingredi commode, nifi fimul pedibus alifque nitatur. Tam profunde urinari dicitur, utorgia rum viginti fpacio, quandoque reti aut mucrone ferreo fub aqua capiatur. Major duorum eft generum. Primus Anfere paulo minor, collo eft oblongo, dorfo nigro, col lo inferiore \& ventre albo, plumis fere niveis. Digitos pedum habet ternos, adhr. rentibus membranis latos, fed aliquo ufque divifos. Ungueslatiufculos præfertim. medium, teretes \& in mucronem attenuatos. Crura juxta anum fere retrorfum prorecta,natationi potius quam ingreffui apta, femora in ventre condita, inæqualem interdum tibiarum fitum. Alter criftatus feu cornutus eft, plumis circa verticem, \& collum fupremum eminentibus, fuperius nigris, ad latera ruffis. Aliquot ejus funt defcriptiones. Minor Germanis Succhelin, ut major Succhel, magnitudine eft columbx, digitis latis, adhærentibus membranis fufcis, non continuis tamen fed trifariam diffectis. Inferiore roftri parte tota fanguineo colore rubente. In femore multa officula tenuia, circa articulum agglutinata, dimidia oflis femoris magnitudine, ab una tạntum parte habet.

Bellonius etiam Majorem fub nomine Uriæ veterum defcribic, Anatis magnitudine, roftro longo, rubicundo, ac ferrato, Criftam habere videtur. .Nam cum nigro fit vertice,plumæoblongæab occipite pendent, quascum excandefcit, aut exhilaratur, attollit aut demittit. Voce eft horri$\mathrm{da}$, fed ad fui tutelam utili. Idem nec $M i$ noris oblivifcitur, qui adeo aqux familiaris eft, ut ei per terram gradi poffe, propter 
femora in ventre ita recondita, ut nullo | vocant, Recurviroftram vere dixeris, avis modo appareant, \& crura, quæ extrorfum eft magnitudine columbx aut paulo graciprotenduntur, ut omnino è lumbiscenferi lior, roftro nigro, furfum tendente, in pofit, natura negaffe videatur. Caudam extremo acuto, quinque digitorum fere habet nullam, nullumque Uropygium. longitudine Corporefupino toto albo; caAlas pro corporis proportione exiguas. Plumas lanuginofas. Digitos ab invicem feparatos,latos tamen. Roftrum rotundum exiguum, rubicundum. Crura parte pofteriore ferræ inftar crenatæ. Jecur tenellum, inteftina à reliquarum avium inteftinis diverfa, gracilia \& tenuia fi in pauca aqua deprehendatur, vix fe in aërem attollere poteft. Prope terram in cefpite aliquo paluftrinidificat. Addit \& Aldrovandus fuas defcriptiones, quas hic adferre non eft neceffe. Addidiffe fufficiar. Colymbos Athenæo inter omnes Aquaticas aves minimos effe, atro \& fordido colore tingi, Oppianus \& acuto roftro inftrui; Oppiano ColymIxeutic. 1. bos femper natare, \& ne fomni quidem diovando. vél cibi gratia in continentem exire, nifi partus tempore; cofdem adverfis ventis natare; ne illorum vi aliquando inviti in terram extrudantur. Circa medium $\mathrm{Au}-$ guftum propter pennarum mutationem volare non poffunt. Et tam celerrime merguntur, ut bombardx etiam ictum effugiant: Referri ad colymbos poteft, avis Anglis Coote dicta, forma \& colore Fulicæ fimilis, paulo minor, in cujus roftro parvum tuberculum rubeum eminet, qux fubinde ad fundum ufque urinatur. Non pifcibus tantum, fed alga, lineo, gramine, parvifque cochleis victitat. Et vulgo fertur, non poffe diutius volare, quam pedis cavo arreptam aquam retineat.

Athenaus Huc pertinet UR I A Anata multo miDipnor.l. 9 nor, roftro longiore ac tenui, colore fordido teftaceo. Gefnerus colore tantum, \& magnitudine à Colymbis differre putat.

B ReNTHus quænam fit avis dubitatur. Niphus monticolam effe credit, generisunci. Plinius pro eo Anatem vertit, quod \& Gaza fecutus eft. Albertus Merguli pifces venantis fpeciem interpretatur. Arift.H.A: Et forte eft, quia pifcibus vivere AriftoteIi. g. C. I. Jes reliquit.

Nec magis notum, quænam fit PHaLiARIS; Bellonius pro ea Mergum varium majorem fubftituit. Gefnerus Folægam Athenzus Italorum eam effe credit.Apud A thenæum Dipnof.I. 9 habet roftrum anguftum; corpus afpectu. magis teres quam Anas, colorem in alvo \& dorfo cinereum.

$A^{\prime}$ v o s e T T A Italorum, quam Lucarni circa lacum Verbanum Spinzago d'acqua pite \& cervice fuperius ex fufco nigricante; pedibus coloris cyanei diluti, digitis mem= branis junctis. Cruribus longis, ac ideo pofteriore digito, qui pro calce eft, $\mathrm{mi}^{-}$ nuto.

Vox ejuseft Crex. Crex.

TROCHiLus juxta tipas fluviorim oberrat, \& tanta fepius celeritate difcurrit, ut ${ }_{1.3 . \text {. C. I . } 1.8}$ curfus volatu ejus velocior fit. Obvia qux-1.8. 8. c. 25. que depafcitur, hirudines etiam qux fau- Arit. H.A. cibus Crocodili inhrerent, Cladorynchos ${ }^{1,9 . c_{0}, 6}$

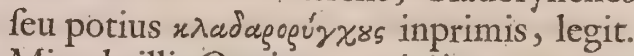
Mira de illis Oppianus, nimirum, mares à fominis, foeminas à maribus pafci.Ineunte vere priores foeminas,follicitare cantu vel ftridore potius peculiari, mafculos ad coitum. Fotu procreato feparari, \& ad fua pafcua redire. Tunc mares omnem fœturæ \& Veneris curam relinquere, fœminislaborem folum incumbere, eumque eas inter fe partiri: Alias ova in nidis fovere, alias foventibus cibum congerere. Pullos adultos ad littus ubi mares verfari folent perduci. Ibi fomellas cum fuo fexu remanere, mafculos ultro feparari. Gefnerus effe putat generis Gallinularum Aquaticarum; Aldrovandus Corriram feu Tabellariam vulgo dictam. Avis hrec eft varia, roftro recto, luteo, in fine nigro. Ridu magno. Oculis nigris albo circulo circumdatis, quem rurfus alius fpadiceus ambit. Cruribus longis, coxis brevibus, digitis membrana junctis. Si Corrira Trochilus non eft, Celeris eft.

\section{T I T U L U S II.} De Avibus Talmipedibus Herbivoris.

$$
\begin{gathered}
\text { C A P U T I. } \\
\text { De Cygno. }
\end{gathered}
$$

\section{C}

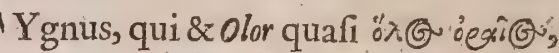
totus candidus, Græcis modernis Cy-

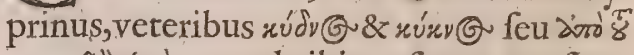

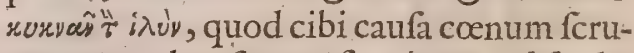
tetur, \& turbet, feu quafi $x \lambda$ úres quod fit clamofus; feu quod teres collum habeat, dicitur.Totus eft candidus. Horatius purpureum, \& pulchrum \& f plendentem, poëtica licentia nominaffe creditur. Roftrum habet parvum turbinatum, in extremitate obtufum, ferratum \& falcis inftar dentatum,colore ruffo; in cujus fumma parte qua capiti committitur, tuberculum rotundum, nigerrimum, \& roftrum in fe inflectens vifi- Homer. I. tur. Collum longifimum, viginti octo verte- liad. $b$ : bris conftans, unde $\delta_{8} \lambda_{6}$ x 
Jou velut pifcatorix ufum in aqua porrectum prabet. Pedes nigris notis partim cærulcis partim rubicundis \& albis diftinctos. Membranas digitis interjectas fquamulis minimis rotundis inæquales. Digitos vero veluti annuli quidam in latum interfecant; eorum medius omnium \& crafliffimus \& maximus eft, longus digitos decem, internus novem, externus feptem. Uno pede pro remo, altero pro corporis fui gubernaculo utitur. Linguam mediam, quod fupërius ponendum erat, fulcus denticulis palatum medium fecantibus refpondens dividit, \&ipfe prope radicem fcaber. Interna fifpectes, Intefina omnia quatuor dodrantes, \& palmum longa, multoque adipe, qui vicem emeriti obit intecta, in illo quem Aldrovandus fecari curavit, erant ; \& cum fimplici tantum in fe media fpira revolutione inflectantur, ne aliquid non plane diftributialimentipreterlaberetur,natura, coeca duo dodrantis fpacio inter anum \& ipforum initium interjecto, recto inteftino appendit. Arteria afpera admirandx plane eft ftructuræ. Nam Oefophagum fubjectum comitata, ad jugulum defceridens cum pervenit, non recta, ut in cxteris animantibus, ad pulmones tendit, fed fupra claviculas elevata, in coftam offis pectoris feu fterni, qux ex duobus lateralibus offibus, \& tertio fuperno his pro operculo incumbente fabricata, vaginx feu thecæ figuram \& ufum præbet. Ad hujus finem poftquam pervenit arteria, inferne in fe inftar ferpentis reflectitur, \& S. literam exprimit; moxque fub priore jam dicta portione ipfi fuperpofita, hanc capfulam denuo egreditur, \& claviculis mediis confcenfis, harum jugo tanquam fulcro innititur; atque ita fuftentata, denuo in morem tubæ revolvitur, thoracifque cavum fubiens, antequam ad pulmones fertur, prius quafi laryngem alteram efformat, tranfverfim fecta, ofliculoque quantum ipfa lata eft longo, \& quod tenui membrana obtenditur, hiulcam fiftulam, feu fyringem arganorum muficorum, quæinferiore fui parte fimili fiftum patulx funt, figuram repræfentat.Sub hac lar'ynge arteria in duas canales divaricatur; quorum finguli in medio ampliori capacitate protuberantes, recta in pulmones exiguos coftis retro totos affixos abeuntes, diftribuuntur. Talem ftructuram \& cantus, de quo poftea, \& refpiratio repofcebat. Ne enim, ḍum aliquando horæ dimidiæ fpacio toto capite $8 r$ collo pronis, vado alimo niam haufturus immergitur,periculumfuffocationis incurrat; ex ea arteriæ, quæ pectoris dictæ vaginæ reclufa eft, portione, fpiritus quantum fatis fuppeditatur. greges eorum in Pfro mari apparere pródidit. In fluviis Cayftro, Iftro, Tanai, Stry mone, Mrandro, Eridano, Mintio, Ta: mefi \& quidem magna copia degere, apud Ovidium, Senecam Tragodum, Theo- Ovid, Mecritum, Lucianum, Statium Papinium tamis . 2o \& $_{2}$ Mantuantum, Polydorum Virgilium, \& Sencec in alios invenies. Innumeris in agro Engolis- Agamen. menfi; Francifci primi opera, in fonte Te- Eidyl. It. nario educatos. Brujerinus teftis eft: fed Theb. ftagna vehementer appetunt; feu quod Polyd. i.r. quietiora nec natatum impediant, quod H.Anglor. Aeliano vifum, feu quod in illis major $\mathrm{kL}: \mathrm{H} . \mathrm{A}$. herbarum fuppetat copia.
c. 17.c. 24.
1. 15. de re Cibus ipfi herbx at fegetum grana, ova cib. c. 6 r. pifcium. Roftro cribrat coenum, \&algam $V$ ictus.. inprimis quærit. In Scotiælacu Spina, herbx cujufdam femine, qux ab iifdem nomen fortita eft, delectatur. Ea autem natura eft, ut agris injecta nunquam putrefcat.

- Tempore libidinis blandientes inter fe $p_{\text {arriss. }}$ mas \& foemina, alternatim capita cum fuis isect, Boe
tius in de
collis inflectunt, velut amplexandi gratia; friptionie colla mares applicant foeminis, deinde Scot: mas foeminam confcendit: Ubi coierint, mas confcius læa fam à fe fominam fugit, illa impatiens fugientem infequitur. At non diutina hæc eft eis difcordia, noxa ceffante reconciliantur; \& foemina maris perfecutione relicta, poft coitum frequenti caudx motu, roftrum in aquis mergens, fe purificat. Semel tantum anno initio veris pariunt. Quia plures \& fpeciofos foetus pro-

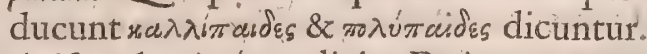
Ariftoteles 'zu tíxuss dicit. Pariunt ova tertio anno, illaque magna, oblonga, tefta dura obtecta.

Probenatant, velociter fylveftres, tar- Volatisiss de ob corporis pondus domefticæ volant. Hefuto HerAriftoteles longius in pelagus efferri fcri-cul.

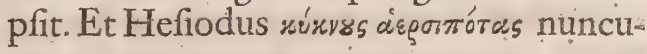
pat.

Cantum quod attinet, fcinduntur in fen- $V o x$.

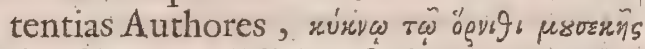
ềver dó cow, prodidit Paufanias, cum eo So- Paufan: crates apud Platonem, Ariftoteles, Cicero, Aritt. H.A.A. \& Philofophis; ex Poëtis Callimachus, Cicero l. 3 . Afchylus, Theocritus, Antipater, Euri- ${ }^{-}$Ovid. $1.5_{0}^{\circ}$ pides, Lucretius, Virgilius, Seneca, Ovi- Trift. Eleg, dius, Martialis, fentiunt. Diluculo ante ${ }_{\text {Sen }}^{t}$. folis ortum tanquam in aëre vacuo per id Hyppol. tempus audiendi clarius, in maris littori- Martial. in bus, nifi tempeftas diffuadeat canere; nec Oenpiist.ins cantus in fenecta morti vicinus (remifio- Ixeutic. ris tum) oblivifei. Favonium vel canen ${ }^{-}$vando: dum obfervare, fati certos, ne à quoquan Lucian. in interpellentur fecedere, apud Oppianum Plectro. legitur. Fabulofum id, apud Lucianum, l.1. o. c. 23 . Plinium, Alexandrum Myndium \& Scali- Myndius ger. invenies. Elianus vacillat, \& modo then $1 . \%$. zocus. - Locum fi atterndas, eft avis amphibia his adftipulari, modo in illos propendere Scalig, Ex. $\mathrm{N} 2$ vide ${ }^{232}$ 
1. I0. I.N. videtur. An funeris fui cantator fit, quod Myndius \& Brafavolus obfervaffe dicitur, nefcio. apud A- De Elephanto fane id proditum. Cantare, then. 1.9 . nullum fere dubium. Audivit in lacu Man232. tuano cantantes Pendafius. Prope Londinum in Tamefi feftivis cantibus fubeuntes Flian claffes excipiunt. Canorum quiddam laH.A.l.ro mentantium in morem quovis tempore c. r. obftrepere, obfervavit Aldrovandus. In Idem var. hoc denique duplex ille flexus, qui offis pectoris primum capfulæ inferitur; deinde altera revolutione in furculam inclinata recumbens, in pulmones decidit, factus videtur, 'ut vox in ipfo revoluti arterix anguilo, repercufo, majori cum clangore ercumperet, ac veluti morulæ exigux in eo anfractu quiete recreata, vires acquireret eundo.

Plin.H.N. Ingenium in volatu potifinium often1.xo.r.23. dunt. Liburnicarum more roftrato impetu feruntur, facilius ita findentes aëra, quam fi recta fronte incederent. A tergo fenfim dilatante fe cuneo, porrigitur agmen,largeque impellenti prabetur aure. Colla imponunt precedentibus, feffos duces ad terga recipiunt.

Etses.

Arilt.1.9.

.A.c.x. ducentefimum nempe attingere annum Alian. incredibile videtur.

c.I3. Inimiçitias interdum tantas inter fe alunt, Statius. ut alter alterum devoret, vel, ut Alianus Hliad. perimat. Necpullis, velovisparcitur. Ab Aquila fibi metuant. Attacti, non iniquo Marte repugnant: fed nec cum fulgure, ferpentibus \& draconibus ipfis convenit. Cicuta interiiffe non mirum, cum \& proci illius efu periiffe vifi fint.

Prafagium. Pluvias expectabis, fi rorem aqux infpergunt; fi profundos eidem immergunt humeros, ferenitatem. Apud Helvetios ingen frigens metuitur, fi hyeme in quodam lacu apparuerint.

VJus. VJus incibis laudatus apud veteres. Alexandrides inter aves lautas numerat, \&Dipnofophiftis apponuntur; nec minore quam Plut. 1. de Anferes habitos, precio ex Plutarcho poefu carnis. teft colligi. Recentiores nigram, \& duram, forte quia annofi adferuntur, carnem acHerberft. cufant. Mofcovitarum tamen Duces, quoin Mofco. ties carne vefcuntur, affos hofpitibus aplegat. ponunt. In Medicina, faciem purgat, \& eru-
Scan. hammon. gat adeps. Ova ad ignem facrum celebrantur. Pellis ventriculo appofita, concoctionem vi peculiari juvare creditur.

$$
\begin{gathered}
\text { C A P U T II. } \\
\text { De Anfere. }
\end{gathered}
$$

$A \cdot R \quad T, I \quad C \quad U \quad L \quad U S I$. De Anfere domieftico.

Plin. H.N. Nfer, Plinio alicubi Ganza, Grecis

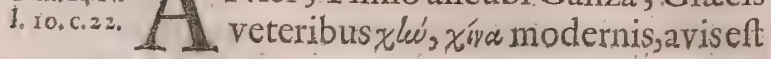

vulgo tam nota, ut defcriptione rion indigeat. Inferum \&r domefticum diftinguis tur, quorum ille minor Ariftoteli, varius effe à Columella manifefto errore proditur, cum apud nos varii candidos numero exfuperent.In regno Senegæcolore \& pennis multi jugis variantur. In Hifpania nova capite rubeo, olores candicie fuperant.

Vifus cum duobus capitibus, totidem- De $\int_{\text {criptitis: }}$ que linguis, collo unico, quatuor pedibus, quorum un um par alarum locum occupabat, alterum circa podicem. Alæ dux circa collum pandebantur. Proditus ab Alberto \& alter, dupli collo, quaternis pedibus, \& totidem alis, dorfo uno, adeo ut duæaves, altera alteram ferenis, viderentur. Frequentifima fcilicet in illis ob humorem \& itoliditatem monftra funt. In Atit. H. A teriora fi fpectes, teftes fub diaphragmáte lumbisannectuntur, hifce dio ex vena cava rami infident.Duovafa exinfima utriufque parte emerfa, \& deorfum per lumborum regionem recto delata, prope os facrum, coeunt, $8 x$ canalem teretem, qui in plures orbes circumvolvitur, \& cujus pars fuperior, tota carnea, inferior intus carcilagineá confpicitur, efformant. Penisloco extremam portionem datam, qux in coitu arrigatur, haud male conjeceris.

Locus ipfis fere ubique, eam Arabix Locuss partem qux Auftrum verfus affurgit, fi excipias. In Blœfia agro aquarum fere experte greges copiofi fpectantur, magnumque ex his plumx pretium. De victu non eft quod dicam. Tenella arborum germinxabfumit, viridariorum herbas penitus depafcitur, \& vitium pampinos rodit. Trifolio, fonugreco, lactuca, \& aliis delectatur.

Quantum ad Generationem in aqua coeunt; $p_{\text {artus. }}$ nec humi infiftentes; à coitu aquis fefe in- Varro de gurgitant. Singulis maribus tres olim defti- $c_{\text {. }}$. $\mathrm{R}$. nabántur foeminx, fex hodie. Tempusad-Aritt.H.Az mittendiaptiflimum à bruma, pariunt \& ju- $1.6 . c_{2}, 2$. venesabfque coitu,fed hypenemia. Coitus la de re $\mathrm{R}$. expertæ fi abfque eo pofuerint, plura qui- ${ }^{1.8 . C .1} 1_{3}$. dem, fed fterilia, minora, \& 2 minus jucundi, 1.5 .5 .633$. quam focunda faporis erunt. De numero $1,6, c_{, 2}, \mathrm{H}$. \&partus \& ovorum inter fcriptores non convenit.'Ter parere fcribit Columella fi foetus non excludunt. Bis Plinius, fi primú foetum Plin. H.N. gallinæ excludant. Ova plurima fedecim, 1.ro. c. 590 paucifima feptem, huic pariunt. Si quis furripiat, pariunt, dum rumpantur. Illi fingulis fortibus pariunt, primo quina, fequenti quaterna, noviflimo terna. Quintilius ad duodecim, \&ultra procedere ait. Carolus Stephanus, fi non incubent duodecim, $\&$ fingulis fortationibus plura. Recentiorum quidam ad centum \& ducenta afcendunt. Tempus parieridi aliis à Calend. Martiis ad folftitium : fi bruma coiverint, Plinio poft folftitium XL. prope diebus pa- 
tiunt. Si appropinquant partus, digito tanguntur ova, quæ funt prima parte locorum genitalium. Incubatus a foemina duntaxat abfolvitur, nec recedit, donec pullos excufferit. Commodiffime à Calendis Martiis ad folfitium cxercetur fecundum Palladium; à principio Novembris ad Decembrem exactum fecundum recentiores. Pulli intratriginta dierum fpaArirt.H.A. cium excluduntur, intra viginti quinque; i.6. c. $_{0}$ fi dies tepidiores funt.

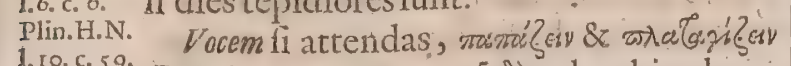

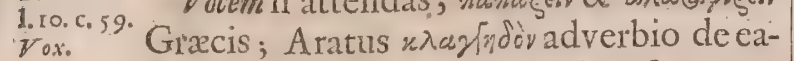
dem ufus eft. Gratitare, gignire, ftrepere, clangere, Latinis dicuntur.

Volatus. Raro volatum domefticx exercent, fed pedibus valent. Mirum in hoc alite, inquit Plin.H.N. Plinius, à Morinis ufque Romam pedibus l.ro,c. 22. venire. Fefli proferuntur ad primos, ita cxteri ftipatione naturali eos propellunt.

Affectus. De Affectibus corporis pauca occurrunt. Solus ex pedeftribus à cane rabido morfus, rabie non corripitur, fi Nipho credendum. Laborat pituita \& phtiriafi; illam pimpinella qux in pratis nafcitur avertit. Huic frequenti ablutione \& fideritidis ufu Plin.H.N. occurrit. Pullis eorum urtica contacta 1. 10 , c. 59. mortifera, nec minus aviditas, nunc fatietate nimia, nunc fuamet vi, quando apprehenfa radice, morfu frpe conantes evellere, ante colla fua abrumpunt: Difcordia cum Aquila, ne morte quidem interrumpitur pennie commixtre certent, \&Anferin $x$ ub Aquilinis abfumuntur.

Etas fexaginta annos attingit, fi Alber-

Etas. Flian. H. A. 1.5 to credendum Non dediflet fidem Carc. 29. ${ }^{2}$ danus, nifi carduelem tredecim annis in cavea educatam fciviffet, \& fylveftris anferis tam duram carnem, ut ne triduum quidem cocta emolliri poffet.

Ingeniwm. Quod folia lauri ne in extrema quidem Mizald de fame attingunt; rhododaphnes ne coacti Anim. 1.5. quidem edunt; quod humanum longe præfentiunt odorem, \& auditu cum apro certant; quod fe ab Anfere dejectum Falconem vidife Scaliger fcribit; vigil, cura Capitolio teftata defenfo, per id tempus. canum filentio proditis rebus, \& fama aPlin.H.N. moris, Argis di-lecta forma pueri nomine 1. 10. c.22. Oleni \& Glauces Ptolomæo Regi cithara canentis, qurm eodem tempore \& aries adamaffe creditur, ingenio debetur. Poteft \& fapientix videri intectus is effe. Ita comes perpezuo adhrfife Lacydi Philofopho dicitur, nufquam ab eo non in publico, non in balneis, non noctu non interdiu digreffus. Quod femper vociferatur, improbum dixit Virgilius. Si dum adpaTheophr. ftum feftinant, jugi clamore obftrepunt; de fignis tempeftas imminere dicenda eft.

Trempeft. ${ }_{\text {R fus. }}$ Reperere olim in cibis $x$ ftimium: Regum Egypti mentis folus cum vitulo ap- ponebatur. Alexander Severus fertis tantum diebus ad convivium recipiebat. AB Annibale Numidicis Gallinis præferebantur. Quod fi jecur refpicias, Romani eos ejusdem bonitate novere inquit Plinius. Fartilibus in magnam amplitudinem crefcit: exemtun quoque lacte mulfo augetur. Nec fine caufa in quætione eft, quis primus tantum bonum invenerit, Scipio Metellus vir Confularis, an M. Seftius eadem xtate Eques Romanus. Hodie in Gal. lia non minoris fit Anfer altilis, quam Ro mæ olim Lupus fcarus, aut Mulus. Eft \& Judxis ubique terrarum in deliciis. Nee damnofi interdum, hyeme \& juniores in cibum cedant. Aliorum excrementitia \& concostu difficilis caro eft: Tenerefcunt tamen, fi collo pertriduum fufpendantur, gravi lapide pedibus aligato. Septentrionales fale conditis, \& vento ficcaris, tum coctis, poft xtivale folftitium vef́cuntur. Meffalinus Cotta; quod conftat, Meffale Oratoris F. palmas pedum ex his torrere, Plin. $\mathrm{H} \cdot \mathrm{A}$ ? atque patinis cum gallinaceorum criftis 1, ro. c. $2 \%$ condire reperit.

Quantum ad Medicinam, Plumæex ventre tritæ \& infperfx, fanguinem fiftunt: Lingua peculiariter ad vefica vitia \& involuntariem mictionem facit." Sanguis ut tiliffime inter Antitoda mifcetur. Fel contufis oculis prodeft, fi hyffopo poftea \& melle inungantur, De. Adipis ufu vide Schwenk multa in Aldrovando. Puerperx in Bohe fel, in The mia butyro in cibis preparant, fi aqua aut les. rem intraverit, precipuum eft remedium. Cum iridis noftratis pulvere permixtus, \& umbilico in tefta nucis juglandis inditus, alvum infantibus folvit. Aliud reperit Syrix pars qux Comagena vocatur; adipem eorum in vafe æreo cum cinnamomo nive multa obrutum ac rigore gelido macera tum, ad ufum praclari medicaminis, quod. ab gente dicitur Comagenum. Diofcorides Commagenes non meminit. Deplumarum olim ufu ita Plinius. Candidorum alterum vectigal in pluma. Velluntur quicbusdam locis bis anno. Rurfus plumigeri veftiuntur; molliorque qux corpori quam proxima, \& è Germania laudatifima. Pretium plumæe eorum in libras denarii quini. Et inde crimina plerumque auxiliorum præfectis, à vigili ftatione ad hæc aucupia dimiffis cohortibus totis. Eoque delicix proceffere, ut fine hoc inftrumento durare, jam ne virorum quidem cervices poffint:

A. R T I C U L u S II. De Anfere Fero ingenere; de Vulpanfere,
E. Bornicla ave.

Nferis fylveftris plures funt differen: tiæ. Plinius Chenolopeces, \& quibus lau" 
$D$ Defrit tio. tiores epulas Britaninia non novit, Chenero- dam linguam ferunt. Cilicibus,id quidem tes ponit: Apud Albertum cinereos., qui tantum attribuit Plutarchus : fed ferisadpropter corporis levitatem altius volant. Grandinofos, feu ob candorem niveos. Qui præter extremas quinque remiges pennas albi funt. Eftate nufpiam conpiciuntur; hyeme ingruente fublimi volatu gregatim migrant : Arborum qui ex arboribus nafci creduntur, quibus color capitis ut Pavoni, Schwenk- abfque crifta tamen, invenies. Schwenkfeld, in A- feldius eosin arborum cavis, cornicum \& 2 fix. ciconiarum nidis, ova tredecim vel quatuordecim, illaque flaventia parere fcribit. Apud Oppianum Linurgi \& Cencbritre reperiuntur. Gefnerus Anferis Atllati, quem Itali Ciccum vel Ocam Sternam vocant, cui magnitudo inter Anatem \& Anferem, pondus leve, pectus maculis afperfum, dorfum \& alæ cinerea, meminit. Scaliger in Oceano Brafilix morinos, à colore atro, qui nunquam evolent, effe prodit. De Baffano feu Scotico fuperius egimus. Defcriptionem non morabimur. Caput fere Anatinum magis quam Anferinum. Utraque mandibula intus oras ferratas loco dentium obtinet. Palatum quibufdam denticulis acutis inftar limæ eft fcabrum \& afperrimum. Membrance qux digitos connectunt in extremo ferre inftar denticulatæ videntúr.

tocus. Locus ipfis maxime circa paludes. In Athyopia adeo frequentibus agminibus graffantur, ut tum morfu, tum ftercoribus omnia demoliantur. In Septentrione cubationis tempore, quo à meridionalibus plagis redeunt, copiofiffime vifuntur, cirCarol.Ste- ca Aprilis initium. In Bataviam, Hannophan.deR. niam, Artefiam migrationis tempore coR.l.t.c. I5. piofiflimi confluunt. Novam Hifpaniam merife Decembri prætervolant. In India pulcherrimi confpiciuntur. Totum ipfis corpus, preter pectus \& ventrem, nigrum. Oculos circulus coralli mulus aubit. Ex minore oculorum Cantha linea ejufdem fubftantix \& coloris extuberat, verfufque collum deducitur. Inde fex feptemve ramuli exigui utrinque ad medium colliufque defcendentis, devaricantur.

fcribi apud AElianum \& Marcellinum le- A1, H.A:

gimus. Tardius adveniunt quam Grues. 1. 5.c. 29.

Vidit aliquando Gefnerus.fexto Octobris permultas avolantium turbas, quæab. riente in Galliam \& Occidentem verfus per turmas triangulasvolabant.

Quantum ad ufum, caro propter exerci- $Y$ Jus's tationem minuseftexcrementitia. Cruda adhuc fuaviter olet. Linguæ affx bene aे calculofis in cibo fumuntur.

\section{A R T I C U: L U S I V: \\ De Vulpanfere, Capricalca, G Ber- nicla ave.}

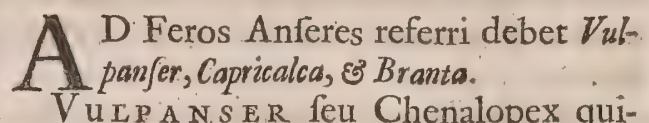
bufdam, eft avis pectore ruffefcens, aquatica, in cuniculorum foveis, interdum \& rupium cavernis nidificans, quam Angli Bergandram vocant. Gefnerus an Anfer Stellatus fit Chenolopex confiderandum reliquit. Aldrovandus nihil certi proferie poteft. Inter palmipedes quæ circa aquas verfantur, $a b$ Ariftotele numeratur. Ova hypenemia quandoque parit. In pullis tu- Arit.H.A. endis eandem quam perdix operam collo-1. 8. c. 3. cat. Et ab Aquilæ, felis \& cæeterorum ho- A1. H. A. ftium injuriis fefe defendit. In Cupediis 1.5 . c. $30^{\circ}$ olim apud Britannos fuiffe ex Plinio fupe- -1 1. 19. c. 16. rius diximus.

De CA P R I C A L C A occurrit. Corvo paulo majorem effe ac in deliciis haberi. Tæniis tranfverfis fufcis per collum pectus \& ventrem diftingui, caudam nullam habere. BR A NTA feu Bernicla \& \& Bernichia, Scotis Clakgufe, Gallis Crauant, \& Oye Nonnete, Ifidoro Barliata, Alberto Barbates, Hollandis atganfen dicitur. Bellonius Chenalopecem veterum effe putat. Minor eft fero Anfere, Monacharum ornatui, qux colorem album atro fuperimponunt, fimilis. Alis \& dorfo coloris

tartus. Coire poft hyemale folftitium incipiunt, initio veris ova ad fummum fedecim ponunt. Steriles evadunt, fi mites redditx fuerint:

$\checkmark$ olatus. Migratoriæ funt aves. Migrature vociferantur alte volando, forte ne qua earum Author de remaneat. Meridiem petunt cum SeptenNatura re- trio propellit; iftum cum Aufter, nec cefram. fant, nifi efurie coacti. Ordo ut Gruum cum filentio literatus; nec clangunt nifi rupto ordine. Vide qux de dontefticis ëx Oppianus Plinio diximus. Oppianus nec Ducibus, Ixeur.1, 2, nec fomni tempore cuftodibus deftitui c. Aldio- fcribit. Taurum montem fuperaturi Aquilarum metu lapillos roftris ad coërcenplumbei, cauda brevi \& nigra. Anferum ferarum more volat, ftrepit, paludes frequentat, \& fegetem depopulatur. De ortu magna eft inter doctos controverfia. Quidam coire volunt: alii ex putridis navium ruderibus; nonnulli ex pomis cujufdam arboris in infula Pomonia nafcentibus corruptis; alii 'ex fructu foliis conglomeratis fimili, qui cum opportuno tempore decidit in fubjectam aquam, revivifcit; convertiturque in vivam, oriri exiftimant. Ifidorus, Alexander $a b$ Alexandro, Olaus Magnus, Hector Boëthius ; Scaliger, Mejerus, Gefnerus, \& alii, communi famæa adftipulantur. 
D E A V

Batavi ex propria infpectione in Grônlandia Barniclas, qux ovis incubarent, pullofque educarent fefe inveniffe affirmant.

$$
\begin{gathered}
\text { C A } \mathrm{P} \text { U T III. } \\
\text { De Anate. } \\
\text { A R } \mathrm{T} \text { I c U L U } s \text { I. } \\
\text { De Anate in genere. }
\end{gathered}
$$

Descriptio. A Nas, Grecis antiquis v'rara vel vinta,

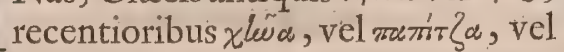
Pappos, avis eft apud nos notillima. Dorfum ipfi \& roftrum lata, pedes cartilaginofis membranis interfepientibus, ampli; crura brevia craffa, \& retroverfus difpofita, ut in natatione valentius inftantes; aquas propellere poffent. Gulam habent amplam; linguam plæræque interius afperiufculis utrinque eminentiis dentatam \& quafi plumatam: Mufculos circa corporis fuperficiem feparatos, interiores albidos: quod fi exteriores liveant, quod vi frigoris fieri videtur, bonam fecuturam xftatem ruftici apud Helvetios conjiciunt.

Aquis tum ut earum frigiditate congenitam intemperiem, qux calida eft, contemperent; tum ut pabulum quoque naturæ fuæ \& palato conveniens, illic quæritent, gaudent, inque iis maximam temporis partem verfantur.

In cibo herbarum aquaticarum radicibus $\&$ feminibus, vermibus, \& animalium aquaticorum ovis, lenticula inprimis paluftri, quam Crefcentienfis Anatinam, alii Pavarinam vocant, delectantur. Sunt qui Scaliger in pifciculis \& limo vefci, nec à venenatis Theophr. abftinere, quod Scaligero plácet, vode caur.

parins. Quantum ad Generationem tantx funt, Authori de natura rerum, falacitatis, ut plures mares folam fominam certatim coeundo, occidant. Menfe Martio \& in

fequente concumbunt. Pariunt juxta aquas \& rigua; pulli exclufi ftatim recondita quadam natura aquam profequuntur; \& mox ut ovum exeunt, tanta agilitate vigent, ut etiamfi matrem mori vel alienari contigerit, fine nutrice vivant. Super omnia autem eft earum ovis fubditis Gallin $x$ atque exclufisadmiratio; primo non plane agnoplin.H.N. fcentis foetum, mox incertos incubitus fol1. 10.c.55. licite convocantis; poftremo lamenta circa pifcinæ ftagna, mergentibus fe pullis natura duce.

Vocem Anatum Author philomelx per tetrinire exprimit. Scaliger quiritatricém appellat. Fœminx crafior eft, maris acutior.

Inceffis. Lente ob crurum brevitatem incedrant, ad natandum potiusapti:
B U $\cdot S$

95

Ingenium ipfis cum Anferibus fere com- Ingenixm mune. Aquilarum quomodo declinare foleant i尺tus AElianus defcribit. Merguntur 1 I. H. Á

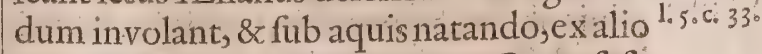
loco extra aquam eminent. Cum fefe aquis mergunt, plúmas; cum pennas rofro purgant, diuque \& multum alas excutiunt, ventos fpondere Theophraftus, $\mathbb{E}_{-}$Theophic lianus, \& Plinius tradunt. Ventris \& inte- de fignis. finarum in bubus dolorem, vifu natan- $\mathbb{E} . \mathrm{H}$. $\mathrm{A}$. tium Anatum levari, eafdem majore pro- ${ }^{1.7 .7 .}$. . . . fectu mulos \& equinum genus confpectu 1. $18 .{ }^{2} .25 \%$ fuo fanare, Columellx \& Vegetio pla- ${ }_{\text {R. R. } 1.6 .}$ cet. c. 7 :

VJus in cibis notus eft. Cato Cenforinus $r$ firs. xgrotis etiam tefte Plutarcho præfcribi in Clatatone. juflit; duram, concoctư difficilem, nec laudati fucci effe, apud Hippocratem, Galenum, \&alioslegere eft. Alii Anferinx præferunt. Alexander Benedictus in pefte damnavit. Fracaftorius lue venerea laborantibus prohibuit. Pectus \& cervicem laudat Martialis, cxtera danda coquo.

Ufum in Medicina fuperius etiam atti- Gel: Nod: gimus. Mithridates Ponti Rex folitus ea-Atticar. 1. rum fanguinem mifcere medicamentis qux digerendis venenis valent; ipfe talium medelarum ufu ab inteftinis epula rum infidiis cavebat. Idem, fanguinem à cerebro defluentem infufus fiftit. Adeps Plin.ti.n: per Clyfterem injectus dolorem fedat coli-1. 10. $c_{*} 6$ cum, \& emplaftro ad pleuritidem apud Myrepfum immifcetur. Fimum, Villanovanus utiliter morfibus venenatis imponi fcribit. Chinenfes adeo numerofa agmina alunt, ut frepe x x M. excedant, his in. evellendis noxiis oryzæ herbis utuntur. Quæ Campofulgofus, de Anate cum tredecim pullis, menfe Decembri, fefto Nicolai, in Gallia prope urbem Redonenfem, templum tempore Miffa ingrediente, \& aram circumeunte, ac unum pullum ibidem relinquente (nefciturquo is fe recipiat,) fcribit, an fidem mereantur,penes Lectorem judicium efto.

$$
\text { A R T I C u i u s II. }
$$

\section{De Anate Domeftica, Indica, Lybica, Es Cairina.}

\section{A} N A S Domes t i C A Gre-

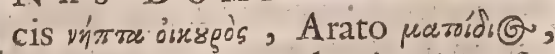
interdum alba, aliquando cinerea, fxpe compofiti ex utrifque coloris invenitur. Inter marem $\&$ foeminam hoc eft difcriminis, quod ille plumas in Uropygio verfus caput furrectas habeat: Quod tam acutam \& magnam vocem edit; \& tam diu caput fub aqua tenet, afperse arterix debetur, qua bifariam in pulmones devaricatur, veficam quandam duxam \& 
concavam, quæ ubi major apparet, dex- fub roftro punctulis fubcandidis interftintrorfum vergit, habet. Famis aliquando ctum. Corpus totum fere atrum. Crura \& peftis prefagæ domeftic , manfuetu- brevia fed robufta. Fominæ roftrum erat dinis oblitæ, Sylvas cum Gallinis, Anferi- minus tuberofum, qua capite connectitur, bus, \& Pavonibus petiiffe dicuntur.

A N A T IS IN D I C. E tres deforiptiones habentur. Prime caput quod auctum plumis', in fummitate criftam plumeam candidam per totam colli longitudinem; quam cum excandefcit, erigit, gerit, fanguinis inftar rubefcit. Totum collum, callofa \& incifuris diftincta caro eft. Roftrum totum cæruleum. Collum, qua corpori jungitur, circulo plumeo nigro, rara pluma alba, maculofa, per ima anguftiore, per fumma latiore, nitefcit : Extremæ alæ atque cauda cum fplendore ut in Cantharidibus vilefcunt. Fomina non ita variegatur,mari alioquin fimilis. Alterius caput albicabat. Roftrum, crurac auda, \& alarum longiffimæ pennæ atri coloris erant. Collum fupremum angufta linea nigra ambiebat. In Tertia nihil fingulare apparet, tuberculum rubrum rotundum fi exceperis, quod pofteriori roftri parti \& cruribus infidet. Id ipfi cum Anate maritima Rondeletii; cujus roftrum \& crura rofæ fylveftris colore rubent, caput non fine viridibus maculis, nigricat; commune eft.

\section{NB. De anatibus Indicis vide etiam Man- tiffam Num. Io.}

$L_{\text {Y B I C A ut à Bellonio defcribitur,me- }}$ dia eft inter Anatem \& Anferem magnitudine. Roftrum habet breve, latum, \& in extremo aduncum. In capite inter duo nafi foramina tuberculum cerafi inftar rubidum. Tempora fine plumis, cute corium rubrum præ fe ferente. Genitale fanguinis inftar rubrum, tam magnum, ut digitiunius craflitiem, quatuor vel quinque longitudinem xquet. Vocem interruptam tanquam male affectos pulmones haberet. Quam Aldrovandus defcribit, roftrum denticulatum habebat, toto corpore nigrefcens ; pectore duntaxat paulo albicante. Scaliger Indicam yocat; \& nullam emittere vocem; ova, qux unicoloria,fufca, rotunda pene funt, fi ad folem defpicias, eandem in fummo nigredinem, qux in earum roftris eft, habere, adjicit. Si duas noftrates fingulis maribus deftinaveris, magnum numerum ovorum pariunt. Sed pulli geniti nullam fobolem procreabunt, fi Auguftino Gallo credimus.

Anatem CAIR IN A M \& marem \& foeminam defcripfit Aldrovandus: Mas qui foemellix major, habet roftrum qua capiti conjungitur valde craffum \& tuberofum, in hamum tandem acutum \& curvum definens, nigricans fere, fed prope finem rubidum; caput atrum \& cirratum; guttur linea partim alba, partim rubra fatis lata difinctum. Macula illa, qux in maris roftro rubra, cinerei coloris erat, cui nonnihil rubri admixtum, \&x.

$$
A R \text { T I C U L U S III. }
$$

De Anatibus feris in genere, Eु in pecie
de Ouerquedulis.

A Natum Ferarum multæ funt diffe- Martyr. de rentix. Nam ut de illis taceam, de ut. Oceani quibus acturi fumus, funt in Infula S. Johannis in America albiffimx, capite rubeo. In Ancyra alix qux voce cornuum fonitumimitantur,libertatis ita amantes, ut per totum etiam triennium in corte nutritæ, fi occafio detur,erumpant. Cxterum latiroftris omnibus corneus quafi in extremitate unguis eft, quo cibos apprehendunt; dentium loco ftrix circa roftrum afperiufculæ, membrane pedum in extremo ferratx.

Videbisipfas paffim; in feptentriona- Locus. libus tanta copia, ut fere cunctas aquas Olans Maoperire videantur : in iis tamen inprimis, gept. Io 19 quibus fubterrane $x$ ven $x$ calidam exhala- c. 6 . tionem fubminiftrant, quas apertas circulari \& obliquo natatu fervare conantur; fi vehementia frigoris vincantur, vafum mare proftatione petunt. Migratorias effe, \&z ad Xanthum fluvium adverfus corvos pugnare, quidam credunt. Hyemis tempore aut in ripis fluviorum aut pifcinarum aggeribus, aut paludum frutetis latere, aut fylvarum propinqua, hortorumque præfidia petere, verifimilius effe exiftimo. Sane omni alicubi tempore confpiciuntur. Qux in Tugurino lacu verfantur, frepe ad vicinum fluvium Silum, tranfvolant. Quia minus ibidem à lupis \& vulpibus lreduntur.

Si frequentes \& conglobatas ferri ani- Prefagiwas madverteris, quanquam cœlo fereno, imminentem expectabis pluviam; fialas in continente concutiunt, ventum inftare exiftimes.

Præcipux ex illis funt QUER qux Rofcades \& Phafcades dicuntur, quxque in Minores \& Majores dividuntur. M I N ORES qux Querquedule proprie dicuntur, Anatibus funt minores, roftro, pedibus, \& cæetera fimiles. Gula ipfis alba atris notata punctis; venter candidus, al in cæío viridantes; pedes cum membranis nigris cinerei. Vivas ventre depluma- Schrrenk: to in colica malum ad fe trahere Abdomi- $\begin{gathered}\text { feld. in } \\ \text { Avenatia }\end{gathered}$ ni appofitas, experientia docuit. Species Siler. plures apud Aldrovandum invenies, ex quibus Laponice priores quæe ad fcapulam 
D E A V

funtpeninx, rofei obfoleti coloris, fed maculis femilunaribus nigris notatx erant. Sequentes partim albx, partim virides confpiciebantur; omnium longifimx cæruleo vegetiflimo decorabantur colore.

Ad has $A N A S$ circia, Kermell circa Arcentoratum dicta, Qwerquedula criftita, referuntur. Circia mergulo paulo major eft, corpore fufco, roftrolatiufculo. Calculis \& feminibus herbarum aquaticarum victitat. Kernell, , haber Roftrum Indici coloris, caput ruffum, punctis albis refperfum, verticem nigrum, gulam albam, alas cinereas transverfis duabus lineis albis diftinctas. Pectus ruffum, crura Bellon. in fufca. Criffatre quam Bellonius Colymbim Hiff.A- vocat, corpus eft rotundum viriditate gevium. mans; occiput Onocrotali inftar criftatum, oculiære polito fplendidiores; fub quibus juxta rictum lata utrinque vifitur macula. Crura brevia, pedes lati, pectus cum capite \& collo nigrum, venter plumbeus.

Boscades Majores funtafpeetu cinerex: Mas in collo radiantes quafi Pavonis pennas colore ex viridi \& cæruleo compofito habet, torquem circa collum album, \& in alis verfus ventrem colore fpledente funt, vel Minores, quibus caput viride, roftrum fubflavum, venter ex albo cinereus \& varie maculofus, crura ruben-

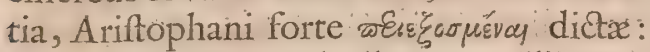
vel Majores, qux coloribus cum illis magna ex parte conveniunt, \& Stert-enten quod roftro fundum fodientes victum perfcrutantur, dicuntur. Amant glandes \& avenam. Congeneres ipfis Anates à victu Graminer feu Juncex, Schmit-enten dictx, roftro \& pedibus nigris, corporis colore dilutiore: Quam Bellonius Anatem Tor-

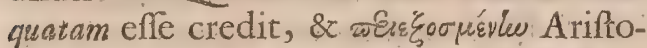
phanis, medix eft inter Anferem \& Anatem magnitudinis, moribus Anferinis, fed voce magis obfcura, qux ex ovis à rutfticis inventis \& Gallinx fubjectis prodiit, dicit; illam Gefnerus Picam marinam effe, pedibus palmatis rubefcentibus, \& ad pofteriora magis pofitis quam cæteris palmipedibus, roftro, tenuiore magis latitudine fe demittente, quam longiore proceffu fe extendente:, quatuor incifuris rubris à fumma, duabus ab ima parte fulcata, in colore pallentis ochre, effe afferit:

$$
\text { A R T I C u L:U S IV. }
$$

De alius Anatumferarum jpeciebus.

$\mathrm{P}$

Rxter Bofcades, funt \& inter Anatum ferarum genera, Glaucius, Anas fufica, Mufcaria, Platyrynchos, Fiftularis, Caudasuta, Nigra, Herle Tadorne, Puffinus \& Pe-
I B U S.

97

nelope avis, de iis quorum Aldrovandus lib: XIX. cap. 45 . mentionem facit, taceo.

Pro G L a u c I o, quem Athenxus ab oculorum colore ita dici, \& Anate mino? remeffe fcribit, Murillanem nobis Galli Bellbin: at cum Bellonius obtrudit. Cujus roftrum in drovand: margine ferræ inftar incifum eft. Collum cir- Ornith،

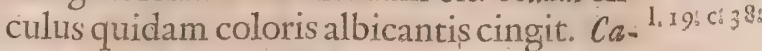
put totum ad mediam colliregionem ferrugineo faturato ornatur.Lingum habet adeo carnofam, ut prope radicem gemina videatur. Nullum fel, jecur in duos diftinctam lobos, 'quorum unus ventriculo incumbit, inteftinis alter. Victitat feminibus herbarum, qux in ripis nafcuntur, aftacis tenellis, limacibus, millepedibus aquaticis $\&$ aliis. Congenerem ipfieam, qux Gallis un Tiers, dicit, medio inter Morillonem \& Anatem marem colore.

FVSCA à colore dicitur. A media ma gnitudine, quidam MEDIA.M dixere. Gefnerus eandem cum Rot-halfa, unde Erythrocephaliquoque nomen meruit; $8 x$ veterum Penelope,quod fimiliter $\phi_{\text {atvisón }}$

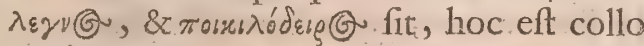
puniceo \& vario, facit. Triplicem ejus defcriptionem apud Aldrovandum invenies. Fœminæ caput non rubet, fed maculas aliquas flavas habet.

Muscartarum (dicuntur ita quod Gefinet. ing mufcas capiant) tria funt genera. Vnum quod laminam roftri fuperiorem habet plane croceam, dentes utrinque ferratos, membranaceos flexiles, eminëntes. Colorem pluniarum per totum corpus varium. Helvetius Muggrate. Alterum corpore magno, coloris elegantifimi in lacu Podamico circa Confantiam vifitur. Murente \& Moffente à paluiftri cocno vocantur. Tertium Mifcenis Pill-ente dicitur, roftro longo, molli\& cinereo. Mufcis fufcis fufpenfo gradu ingrediens infidiatur, \& vocem noctu lamentanti fimilem edit.

PlatyR ynChi feu Lati roftrx in plura genera difperguntur.Sunt qui roftrum clypeorum inftar convexum \& longum nigricans habent. Et quia inter volandum alis fuis ita perftrepunt, ut fonus crepitaculorum repréfentetur, 5 châfl-enter dicuntur. Quibusdam, qui safchenmant Helvetiis, inferiorem roftri laminam fuperiorem ita ut tota intra eam includatur, fubire, dentes $\mathrm{ab}$ utraquie roftri parte molles, flexiles, rectos, \& omnium longifimos effe, adjicit Gefnerus. funt quibus idem duplo fere quam in cæteris latius habetur : idque in mare nigrum, in foemella modo flavefcens modo maculis varium vifitur. Dantur \& $z$ platyrynchi pedibus rubris: $\mathcal{G}^{3}$ alii roftro nigro E plano, quorum defcriptiones apud Aldrovandum habentur. Pertinet ad eos, Clangula cujus mas fecundum oculos; qui pulchri funt, utrinque rnaculam

O

albam $y$ 
albam, caput magnum, \& in nigro viri- nigro, reliquo corporis colore plumbeo; danshabet; foemina \& virore \& macula roftro, cruribus \& pedibus fufcis. Marem deftituitur. Fuligula à fuligineo totius cor- defcripfit Aldrovandus exacte, quem poris colore ita dicta, cujus roftrum bre- vide.

viufculum latumque, linea alba, alas prope finem transverfim fecat. Cirrbata, Vollente à corpulentia, gallinæ magnitudine, cujus mas apicem in vertice gerit nigris pennarum cirrhis conditum, prope quem pennæ utrinque ex nigro virent.

F I S T U L A R Is, à fono acutiore quem fiftulx modo emittit denominata, roftrum habet colore ifatidis, circa unguem ductus quafi fila nigros, collum nigro rubroque varium, tergum partim plumeum, partim rubris nigrisque pennis temperatum. In Fœmellis nihil tale cernitur.

$C A V D A C V T A E$ roftrum fuperne nigrum, à lateribus ifatidis dilutæ imitatur colorem. In foemella cum maculis nigris cinereum. in alis pennæ infimx transverfim albx; medix in nigro gemmantes, viridi, \& damafceno, extremæ nonnul$1 x$ flavicantes, quæ fomellæ denegata funt.

NigR A à corporis colore ita dicitur. Linea alba per ejus alarum longitudinem excurrit: Roftrum nigro luteo \& rubro dictinguitur. Pedes rubefcunt.

HER. L E; ut Galli vocant; roftrum habet rotundum $\&$ in extremo recurvum, rubrum, utrinque ftriatum, colorem mali aurantii, Linguam ferratam, alas candidas, pedes rubeos. Gefnerus eum inter Mergos relegat.

LAA T A:R DONE corpus totum effet candidum, nifi alæ fuperius nigrefcerent, ubi \& linea rubra utrinque confpicitur. Roftrum habet breve, in fuperna parte rubicundum, à lateribus utrinqúe verfus narium foramina macula nigra notatum, extremitate in aliam unguis inftar definens. Crura paulo altiora. Torquem, qui pectus ambitrubrum, cumtota ventriculi regio candicet.

Puffinus avis eft marina, colore fufca; pennis caret, fed plumis tantum ceu lanugine quadam veftitur. Itaque fubvolare non poteft. Si quando ocyus locus mutare inftituit; alarum, pedumque extremitate nixus, aquas celeriter quafi prorepens praterlegit. Alga \& cochleis victitat. Sale conditur \& tempore quadragefimæe editurin Anglia.

Pene L OPEN avem Anati fimilem, magnitudine columbx, fcholiaftes Ariftophanis facit. Jon Фowvró $\lambda \varepsilon y$ vov, id eft, phœenicei coloris collum habentem ponit. Gefnerus illam effe putat, quam Germani Siottinls / Bellonius Canne à la tefte rouffe vocat. Capite eft rubro, gutture \& pectore

\section{A P U T I V.}

\section{De Fulica, Cotta; Eீ Rallo Italorum.}

GULICA, quam quidam Phænen, qux oflifraga eft, effe credunt; quidam ex veteribus, at Cicero, Erodion, nonnulli Cepphum Ariftotelis; alii nec forte male ás vuraw, cum à fuligine ita dica- De la Certur, putant, quæque Kiranidi Phalaris, virgil.GeAlbertø Mergus niger, \& pullus aquaticus orgicl. r. dicitur, avis eft magnitudine Gallinæ; co- Defcriptio. lore per totum corpus nigro, in collo \& capite nigerrimo, collo oblongo, fyncipite glabro figura ovali, alba pellicula, figura criftr gallinaceærefpondente, intecto, fpecie calvitii. Digitis pedum membranæ nigræ latæ, fed divulfæ adhærent', \&utrinque aut ab altera faltem parte fecantur. Internodia membranarum femicirculos fere conftituunt. Recta pedibus incedit, velociterque currit. Lingua quam Gallinæ mollior, ungues grandiufculi ac nigri. Alæ ad reliqui corporis convexum incurvatæ. Ventriculo lien adhæret, una ex parte gracilis \& tenuis, altera vero in extremo craffior, atque folex equi inftar inflexus, dimidix juglandis latitudine. Lobo bepatis dextro folliculus fellis auricularis digiti magnitudine annectitur. Pulmones Bellonius coftis adhrent. Intefinum rectum appen- apudAldicibus utrinque fingulis palmi longitu-1,19. co 13 . dine, extremo furfum reflexo, inftructum invenies, fi illud in fuperna parte afpexeris. Ova intus formata $8 x$ lumbis annexa jam inde ab hyeme etiam obtinent. Nullum fexus difcrimen, ut in cxteris avibus agnofcitur. Sunt tamen alix aliis interdum in ventre colore magis fpadiceo.

Locis paluftribus \& ftagnantibus dele- Locus ê ctatur. Maro marinas appellavit. Herbis $V^{\text {iEtus. }}$

\& quovis feminum genere vefcitur.

Nidulatur humi, \& ova magnitudine ${ }_{\text {Partus. }}$ ovorum Gallinaceorum ærtate ponit. Cum per ferenitatem relictis paludibus ${ }_{\text {Arat. in }}$ in ficco ludunt, vapores ab aquis ad im- Phoenom. briferam nubem erigendam, furfum at- Virgil.Getolli fagaciter odorantur, \& ventos præ- Cicero in fagiunt, ut apud Virgilium legimus. Progn. Procellas voce teftari, Cicero author eft. Obfcurus quidam, dum alas quatiunt, aquam; dum fe fubmergunt, fimulque alas quatiunt, ventum predicare tradidit.

Genus illud quiod Marcol Frifiis audit, cadaveribus pafcitur. Ova inter arundines parit; quibus ab incolis, uno relicto, abla- 
tis, \& nido perforato, reverfa alia \& alia, cochleis nutritur: pifcibus abtinet. $\mathrm{Ne}$ fraudes nefcia ponit, donec effreta exhau- gant eam diutius poffe volare, quam pedis riatur.

Quam Parifienfes Diabolum marinum vo- neatur.

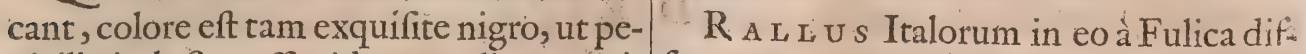
nicillo inductus effe videatur, albam capi- fert, quod roftrum habeat nigrum, plus tis maculam latiorem quam Fulica habet, albi in alis \& circa oculos coloris, crura fub. crura ad fe attrahit.

Сотт A Anglorum avis eft. Fulica ter digitos non ita diffectas. Mortrisruré paulo minor, forma \& colore fimilis. non procul Venetiis diftante magnis capiRoftrum tuberculo quodam rubeo infi- tur expenfis. A famulis; qui venaticorum gnitur, crura rubent, nulla fyncipitis con- canum vice cothurnis induti per aquas erpicitur macula. Urinando ad marisufque rant, fuftibus exturbantur. Hinc preda fundum, alga, limo, gramine, parvifque Falconum infidiis fiunt:

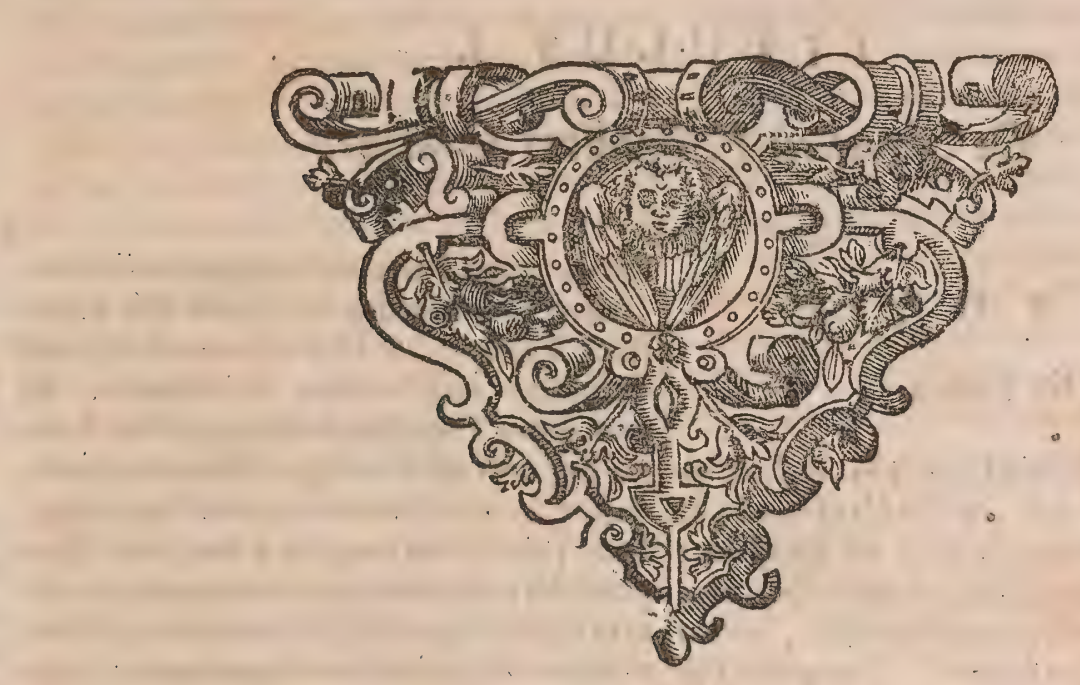




\title{
HISTORIA NATURALIS
}

\section{E

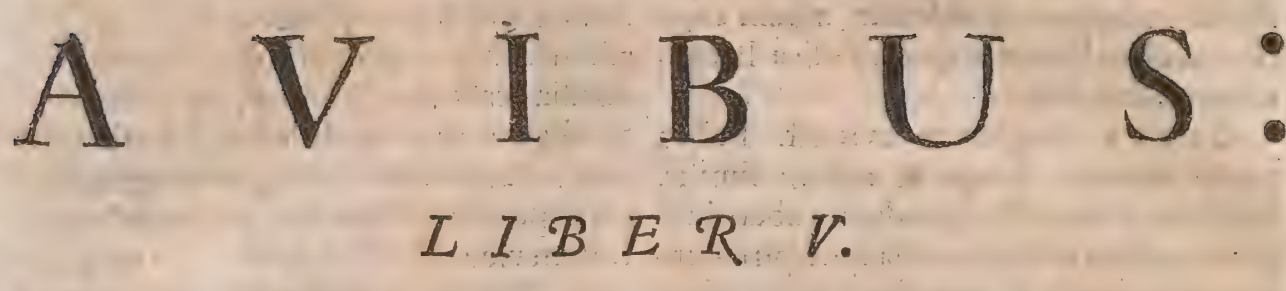 \\ De Avibus Aquaticis, Fillipedibus.}

\author{
T I T U.L US I. \\ De Aquaticis Fi.ßipedibus Carnivoris.
}

\section{$\begin{array}{lllllll}C & A & P & U & T & I\end{array}$ \\ De Ciconid.}

Defcriptio.

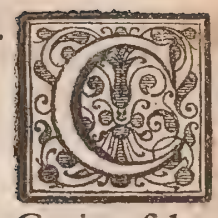

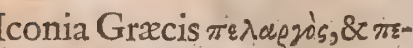
$\lambda a y o$ 's, quibufdam rixu $\psi, \&$ жs: $\varphi \alpha^{\prime}$, avis eft apud nos notiffima, pennis albis \& nigris, cruribus albis, roftro Gruino fubrubro \& craffo. Tempore PliPlin.H.N. nii affirmabatur linguam non habere, ha1. 10.c. 23. bere, illamque fubrubram \& breviflimam notum eft. Degebanit quoque olim in Italia, nunc nullas effe opinatur AldroAidro.Or- vandus.

nith. 1. 20. In Fiderate agro, nec nidum feciffe Locus. apud Plinium legimus; qui pariter eafdem amonum arbufto locum in Tranfpadana Italia non permeare; ficuti nec octavum citra lapidem $a b$ eo, refert. Sed \& in Britannia ignotas effe audivimus, creditumque vulgo nonnifi in liberis regnis verfari. Migratoriam effe avem certum eft, fed quonam è loco venirent, aut quo fe referrent, inçompertum antiquis erat. Ex longinquo venire non dubium, eodem quo Grues modo,illas hyemis, has ærtatis advenas. Extractus ex quodam prope Metim in Lotharingia lacu junctarum globus; quæ Cantupoful. thermis excalefactx revixerunt, fi CamMemorab. pofulgofo credimus. Sed \& ex Lario lacu
1. I. fpexi, quxad tria vel quatuor millia as cedere videbantur. Volabant illæ à Ruffia \& Tartaria, \& Hellefpontum agmine decuffato tranfverfum trajiciebant. Et cum fupra Tenedum infulam effent. Longo per anfractus tractu fe convertebant, donec in circulum omnes collegerentur. Inde priufquam longius à faucibus Propontidis pergerent, in minores aliquot turmas fupra vigintife diftribuebant, \& fe invicem verfus meridiem fequebantur.) $A$ bituræ congregantur in loco certo, comitatxque fic, ut nulla fuigeneris relinquatur, nifi captiva aut ferva, ceu lege; prædicta die recedunt. Nemo vidit agmen dif- Plin.H.N. cedentium, cum difceffurum appareat: nec venire, fed veniffe. (De incolis ubi moraturx funt, intellige ) utrumque nocturnis fit temporibus. Et quamvis ultra citrave provolent, nunquam tamen adveniffe ufquam nifi noctu exiftimantur. Pythomes comen vocant in Afia patentibus campis, ubi congregatx inter fe commurmurant: eam qux novifimo advenit lacerant, atque ita abeunt. Notàtum poft Idus Augufti non temere vifas ibi.

Vefcuntur ranis, anguibus \& pifcibus, $Y$ iäis. bis in ejus ventriculo diffecto avicula offa. reperit Schwenkfeldius. Bufonem non nifi fumma fame guftant. Hinc nocere iis, , omnibus quidem locis nefas du-Solin. in cunt, fed in Theffalia vel maxime, Polyhif, ubi ferpentium immanis copia eft, quos dum efcandi gratia infectantur, regionibus Theffalibus plurimum mali detrahunt. Capitale itaque occidiffe, ea- Plin. H: $\mathbf{N}$. demque legibus pona quæ in homici- 1. 10.c.23. dain.:

Nidulari in agro Varro innuit. In fum- $p$ artuse mis urbium tectis, ipfis etiam fumariis, 
certum eft, nec dubium aridarum aliquando arborum fummitates fectari. Primo adventu veteres nidos repetunt, falvos à fordibus repurgant, tempeftate læfos inftaurant \& conftabiliunt. In iis duntaxat Veneri indulgent. Ova, triginta non amplius diebus, foeminam quatuor Anferinorum tum magnitudine tum colore fimiles ponere, eaque quamprimum variatis utrumque plumis fovere Encomiaftes author eft.

Solin.,41. Incubatus fpatio menfis tempeftate benigna abfolvitur, \& tam impenfe nidos fovent, ut incubitus affiduitate plumas exuant. Tam flagranti amore foetus profequuntur, ut in incendio Delfenfi, cum fubtrahere non poffent, cum iifden alis contectis interire, quam deferere maluerint.

Vox earum eft apud quosdam glotterare. Quia fonus ille ex duabus roftri partibus duplici rea lamina, vel duobus officulis fe invicem collidentibus inter fe collifis fit, Crotaliftria à P. Syro vocatur.

Volatus. Nunquam Auftro flante volant, dum feruntur, pedibus curfum moderantur, porrectifque in caudam qux brevior illis contigit pedibus, per aëra contendunt. Dormientes uni tantum pediinnituntur, \& caput humero alteri imponunt.

Cum Cornicibus, Aquilis, Mergis \&z Vefpertilionibus inimicitias gerere proditum à quibuisdam.Prrefagam effe avem docuere exempla. Preffa obfidione ab Atțila Aquileja, urbem cum pullis deferuit. Inde augurium ab oppugnante fumptum eft, $2 x$ urbs in poteftatem redacta. Cum tempeftas imminet, utroque pede innixa, pennas triftior infundit, roftrum in pectus condit, \& vultum eo unde tempeftas ingruit obvertit. Ex earum cum carnivoris in nuo. Si penes has victoria, pecora feliciter fuccedunt. Si illx palmam abftulere, frugum fertilitas præfagitur: Quod vulnera origano fanant, \& Platoni foliis vefpertiliones à nidis arcent; quod roftro cum alvus non dedit, excrementa ejiciunt; quod denique lapidem lychniten, ferpentum aphiloitrat. verruncam nido imponunt, ut apud Phiin vit $A$ pollon.

SEl.H.A. 1. S. C.22.

Gefner. i Ornithol

Filian.

H. A. 1. c. 20. in mulieris Tarentinæ finum conjectus, quod ex Aliano \& Oppiano habemus; ad inftar crotali vel crepitaculi, quod ex Lycia conflictu de proventu judicatur an-

Edebantur ante Plinii xvum ; id Senpro- $V$ fos nius Ruffus, quem Horatius tangit, inftituife creditur. Nemo jam attigiffe velit, feu quod venenatis vefcatur, feu quot? flavam, duram, \& mali fuccicarnem habeat:

V.jumin Medicina fiattendas, Affam fi femel anno edatur $\mathrm{ab}$ arthritide præfervare nugatur Kiranides. Nec capras, nec oves pefte infici quidam fcribunt, fi exventriculo aqua intrito fingulis cochleare unum infuderis. Fimum ex aqua hauftum nonnullorum fide comitialibus prodeffe prodidit Diofcorides, refutavit Galenus, cum Diofcorid. adipe fuillo in Emplaftri formam mixtam Parab. 1.r. inveteratam podagram tollere, apud Aë-fimp.i. Io tium \& Myrepfum invenies. $\quad c, 17 \%$

Datur \& Ciconia , quæ quod dorfum Aëtius totum nigrum fi eminus fpectetur, ha- l.1 2.c. 4.4 t beat ; NIGRA dicitur. Reperitur in montanis \& fylvofis Helvetix locis. Forma \& magnitudine à Ciconiis proprie dictis Gefier. iti non differt, qua parte alx jünguntur cor- Ornithol. pori', oblonga cavitas retrorfum extenfa cernitur. Inteftina funt involuta. In femore diffecto nervi quatuordecim magnitudine differentes, quorum duo latifimi in genu partem cartilagineam fe inferebant utrinque. Vefcitur fcarabeis \& locuftis. Nidulatur in abietibus. In cibo ferinum \& pifcofum præ fe fert odorem. In feftatur pediculis.

\section{A P U T II.}

\section{De Ibide ES Thenicoptero.}

B $\mathrm{B}_{\text {Is }}$ in multis cum ciconia convenit, Defriptio.

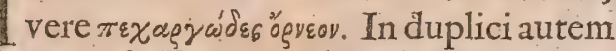
funt apud ÆEgyptios differentia. Candide, Plin.H.N qux ad Pelufium tantum non funt, cum 1. ro c. c.30 in tota habeantur Agypto; \& Nigre, quas Aritt. H.A Pelufium duntaxat alit, tota $\$$ gyptus abhorret. Capite ifta eft corvi aquatici, roftro mucronato, incurvo, fornicato, rubente, \& qua capiti jungitur, pollicis craffitiem fuperante. Abdito in pennas qua fub pectore, capite $\& x$ collo, cordis fignaturam exprimit. Simul ac nata eft, duas æque drachmas ponderat, ut Plutarchus prodidit. Majus pro corporis proportione cor habere, Gaudentius Merula author eft. Intequa ex Cubitorum, ex alie- Merula. \& recens Zingiberis radix Vefalienfi ho- na fide apud Elianum legimus. Compri-1. 3. Mefpiti allata, in gratitudinis exempla ibunt. mitur id defectione lunx, donec aucto rur- morab. Ciconiam foeminam adulterii, poftquam fus fplendore fulgeat. A:lian. H: hofpes prohibuifet aquam, compertam, à Egypto eft peculiaris, mortem fibi fa- A.1. 10 . maritis aliis difcerptam: Alcinoën in Cra- me exportata confcif́cit. Nullum non A- c. 2g. none Theffalix fominam, qux thorum lexandrix trivium iis plenum eft. Dicun- $x_{1}$ lian ; t. Domini abfentis polluerat, excoecatam, turtamen \& circa Licham in extrema Atanquam caftitatis teftimonialegimus. Ci- phrica, ubi lacus quidam dulcis eft conconiarum legum apud Ariftophanem no- fpici. Quam fe in Alpibus vidiffe referenmen, inde originem traxit, quod in fene- te Plinio. M. Egnatius Calvinus prodidit, etute parentes $\&$ alunt, \& humeris geftant. Nigram fuiffe fufpicamur.

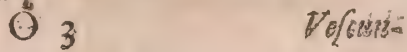


Victis. . Vefruntur ferpentibus, brüchis, \& lock1.r.de Nat. Atis: Illos volucres ex vaftitate Lybiz venDeorum. to Aphrico invectas interficiunt atque c. 29. confumunt. Nec hoc intra Agypti fines Ammian. tantum. Sagacitate enim excitatx, venMarcellin. turis in procinctum eunt univerfæ, \& prifcript, orb. ufquam terminos proprios externum maJofeph. . lum vaftet, in aëre occurfant catervis peftic. Io. lentibus. Ibi agmen devorant univerfum. Arift. de Mofes in Athiopas per loca ferpentibus c.6. $\quad$ infefta iturus, papyraceis inclufas fecum tulit.

Partus.

Quantum ad Generationem, Egyptii ore coire \& parere nugabantur. Nidificant in palnis metu felium. Ex ovo Bafilifcus nafciputatur, translato ex venenatis cibis in illud feminio. Vita ipfis longiflima adeo ut Hermopolis facerdotes immortalem jactaverint. Penna, Crocodilus, fcribente Eliano, \& Ovo immobilis redditur; fed omne ferpentum genus ad ejus contactum rigere, Philes tradidit. More lautarum mulierem tardo \& molli gradu ingreditur; cubile petitura fe purgat. Roftri aduncitate per eam partem fe prodiit (falfugine autem utitur) qua reddi ciborum onera maxime falubre eft.

Plin.H.N. PHÆNIGOPTERUM qui à colore 1.8. c. 27. ita dicitur, Lingulacam feu Glottidem Ariftotelis effe credit Bellonius, fi Scaligeri defcriptionem fequimur. Roftrum neque rectum plane, fed neque aduncum habet. Scythici arcus potius partem imitatur. Cinereum colorem nobilitant alarum punicex pennx; à quibus \& nomèn. Earum quoque nonnihil ad caudam, quam hujus generis longi cruris levibus breviflimam habet, ac veluti præcifam. Sub roftri initium ad colli commiffuram finus turgidus eft qualis in Ardeola. Crura pedefque alis habet concolores, fed adeo breves, ut cum in homine Galenus agnoverit longiffimos, huic omnium qux nota funt nobis animalium, brevifimos attribuere potuerit.Magnitudo eiArdex,Flammant nomen in Provincia. Habet \& alterius iconem Aldrovandus, qui ex cinereo phæniceo \& albo miftis coloribus fpectabatur. Superior mandibula, in medio notabili extuberantia infignis, inferiore longior erat, \& in acutiflimam aciem definebat.

Tocsss.

Heliod.

1,6 .

De loco nihil fere certi. Nil avem difertiflime facit Heliodorus; ex Flandria hyeme ad Narbonenfis Gallix provinciam volare fcribit Gefnerus; in mediis ftagnis marinis degere; pifcibus \& cochleis vefci, reliquit $\mathrm{R}$ ondeletius:

rfus. Apitium linguam Phónicopteri præcipui effe faporis pronunciaffe, Plinius $\mathrm{Au}$ thor eft. Heliogabalum vero palatinis fuis Lamprid. ingentes dapes extis \& cerebellis illorum in Helio- refertas exhibuifle, tradidit Lampridius.

\section{A $P$ U $T$ III.}

De Ardeis ingenere.

Q Uam Latini Ardeam feu ab ardendo, quod fimus ejus exurat, feu quafi arduam propter arduos volatus vo-

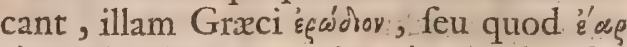
idpor, id eft fanguinem in coitu exudet; feu

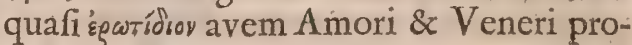
priam, dixere.

Genera ipfarum tria Ariftoteles \& Plinius Generd. faciunt, Leucum, Pellum, \& Alteriam, Sca- Arit.H.A. liger album, nigrum \& fubfulvum, quod 1.10. c.60. Pigrum Vafconia vocat. Aldrovandus in- Scalig. Exnumera obfervavit. Corpus ipfis leve, exile;macilentum. Collum longum. Roftrum longum, craffiufculum, robuftum, intus cavum, in extremo acutum. Digiti pedum terni longi, membranis modice juncti. Quartus retro pro calce fimiliter longus eft.

Degunt numerofecirca paludes \& ftagna Lotws. in Bononienfi, Farrarienfi, Mantuano, \& Ravennate agro; reperiuntur \& in Anglia quod ibi capitale fit eas occidere. In Gallia Ardearia inftituta habentur. Pulli vo. landi compotes ultra citroque commeant, deinde domicilia repetunt. In Infulis nom vi orbis quæ Ardearum dicuntur, tantam ovorum Hifpani invenerunt copiam, ut multos iis currus onerarent. Ab Agricola inter eas aves numerantur, qux calidiora loca quærunt. Confecta hyeme ad folita revertuntur.

$V e f c u n t u r$ pifcibus \& oftreis. Illos dum capiunt, folis radios ita excipiunt, ut vifa ipforum umbra refugiant. Hos cum teftis devorant, quas à colore interno apertas, revomunt. Anguillas quoque integras deglutiunt. Ad pedem tanquam ad illicium concurrere piffes creduntur. Si oleo ex ipfis per def́cenfum deftillato inungantur manus, pifces ita advolabunt, ur fponte capi poffint. Pifcatores Hirfchbergenfes il- Schwenklicium ex farina hordei, carnis cancrorum viar. Silef. ex chelis \& caudis, placentæ lini expreffo oleo parte una,vitellis ovorum tribus, pinguedine Ardex \& olei laurini ana unc. IIr. cum petrolei \& Camphoræ ana drachmis duabus conficiunt. Mirifice pifces illiciuntur.

In coitu angi, mares etiam cum vocife- $\mathbf{p}$ artus. ratu fanguinem ex oculis profundere, nec minus xgre parere gravidas, Ariftoreles, fed falfo prodidit. Vidit fxpe coeuntes Albertus, cruribus fuper dorfum fominx flexis, ita ut pedes maris ad caput fominæ fint, \& genua verfus excrementi fedem fuper dorfum. Motu alarum fe fuftinent \& femen infundunt: Nidificant in fylvis, 10 cis paludofis, alnis \& falicibus confitis ac fere inaccellis gregatim. Sic \& ab aucupibus, 
cupibus, \& à rapacibus immunes fe putant. Cancros ceu fafcinationis amuletum nidis fuis imponunt, fi ÆEliano credimus. Alia.H.A. Carvo adverfus infeftinantia nidos fuos 1.8.c.35\% animantia fe munire, prodidere nonnulli..

tolatus. Volant extenfis retro pedibus. Ideo illis Arift. 1. de Uropygium inutile; collo contracto; tam incefiu A- alte, ut fupra nubes tranfeendant, maxime
nimal. cum jam futuræ imminent pluviæ.

Inimicitias cum Alauda, ovorum fuoAffe dus. Inimicitias cum Alauda, ovorum fuo-
Alia.H.A. rum hofte, vulpibus, cochleis \& Rapaci$\mathbf{i}_{1} 5.6 .35$.

bus exercent.Sxpe cochlex è nativis egreffacteftis, in magna fecuritate pafcuntur; Ardex in vacuas involant. A Falcone depreffa, roftro fub alis condito ac furfum elato, irruentem excipit. Sxpeambx elifis interaneis hunti affliguntur enectx. Accipitrem excrementis fuis, quæ pennas ejus \& pedes inficiunt, \& exurunt, repelCrefcent. lunt. Fertur Falcones, quod CrefcentideAgricul. us prodidit, fi fanguinem Ardex guftave1. 10.c.15. rint, omne defiderium capiendi Grues amittere; fi carnem abfque fanguine, videri non teneri.

Prefagium De Prefagiis hoc fufficiat. Ventum vel Oppian,in pluvias innuere, vel cum capur pectori imAratas in ponit; vel cum notas paludes deferit, \& Aratus in ponit; vel cum notas a fel cum terrarelicta Plin.H.N. multo cum clangore adfeftinat; vel cum 1.r8...3.3. multo cum clangore adfeftinat; vel cum
Allia.H.A. obftrepero clangore à mari ad terram avo-
1.7.c.7. 1.7.c.7. lat; vel cum in mediis arenis triftis refidet. V fus.

Menfis in Gallia expetûntur. Sed cum caro illarum pifculentum quiddam redoleat, \& fibrofa fit, falubris effe non poteft. Quæ de roftri feu in pelle afinina fronti alligatiad fomnum conciliandum, feu cum cancri felle in eadem ad vigilantis collum Plin.H.N. fufpenfi, ad vigilias inducendas Plinius 1.30x.15* vel Kiranides prodire, inter fabulofa reputo.

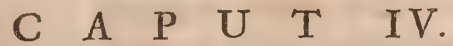

De Ardeis in pecie.

A. R I I I C C U L. U $s$

I.

\section{De Ardea Cinerea.}

A

$R$ dex cinerex tria funt genera, $M a$ jor, nempe, Minor, \& Congener.

ARdeA CINEREa Major quie Ariftoteli Pella, feu pulla \& fufca, cui fuperius dicta omnia fere congruunt; Roftrum habet longum, prope frontem craflúm, quod ita tenue pedetentim evadit, ut tandem velut in acum aliquam magnam definat. Capiti cinereus, cirrhus ex tenerioribus pennis infidet, quià fyncipite incipiens furfum fupra oculos per verticem erigitur. Digitus pofticus longiufculus eft, \& fere anticis longitudine rqualis
Nidulantur in excelfis a rboribus non procul à fluminibus, tam apud Anglos quam Gallos. Quia pifcibus pullos nutriunt, \& multi, cum ori inferuntur, in terram de cidunt, idem cum pluvia à multis decidiffe putantur. Francifcus I. Rex Gallorum tam cicures reddidit, ut à paftu redeuntes ad Ardearia fefe reciperent.

M I N O R prout a Bellonio defcribitur, roftrum habet nigrum, concavum ; Lineam in fronte $\mathrm{ab}$ uno oculo ad alterum candidam. In capite \& dorfo pennas, coloratas. Alas cinereas inter pennas verticis nigras exoriuntur candidæ exiless, afpectu jucundiffimx. Nidificat in rupibus.

Congener, Ardea, roftrum habet pollicis craflitudine, digiti minimi juxta nares latitudine, intus cananiculatum, inferne corneum \& rofeum. Plumas capitis, colli, dorfi, \& fuperiorum alarum ex cinereo fufcefcentes, extremas omnes macula ruffa notatas. Ventrem fere ex cinereo album. Crura fubviridia, \& pedes in digitos fiffos, quos tamen divaricationis initio breviufcula membra conjungit. Ad hanc refer; quam Gefnerus defcribit, cui roftrum eft fubflavi coloris, marginibus acutis, \& parte anteriore leviter dentium loco exafperatis, ferratifve. Caput \& col1 m candida. Crifta capitis è plumis nigris retrorfum tendit. Dorfum \& alas cinereas. Unguem medii digiti ab altera parte denticulatum.

\section{A. R T I C U L U S II.}

\section{De Ardea Alba.}

$A$ Rdea alba, Gracis $\lambda$ europód (C), Cice-Defcriprios roni Platelea, Plinio Platea, Alber- Plin.H.N.

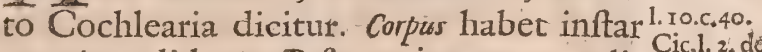
cygni candidum. Roftrum nigrum pauculis Nat:Deor notis ferrugineis fuperiori parte refperfum, fubftantia coriacex duræ, cochlear referens. In quibufdam ad carneum colorem proxime accedit. Fœminx fuperius imaculis rubeis confpergitur. In maris vero roftri medio, linea quxdam qualis etiam. in circumferentia confpicitur, à fronte ad roftri apicem ufque confpicua eft; prope oculos macula cærulea, qux in foemina lutea eft; vifitur. Quxdam maculis in collo \& dorfo pulcherrimis, colore coccineo confperguntur. Interiora fi fpectes in diffeeta apud Aldrovandum foemella, Lien erat exiguus, nigricans, rotundus, dextra parte, prope folliculum bilis non procul à ventriculo. Inteftina finuofa, uniformia, novem fpithamas longa. Cornullo pericardio veftitum. Ventriculus lævis, intus \& fimplex. Ingluviei loco pars ventriculi fuperiori orificio imminens, ampla capacitas. Aspera arteria cygnè valde fimilis, licetcontrario modo fita. Nam quemadmodum 
in Cygno ad fternum afcendens poft def- lum \& pectus, quod nigris maculis, ut in cendit; ita hre ad pulmones recta percur- Ardea deorfum defcendentibus confperrens, fuos flexus agit invicem oppofitos. fum cernitur, albicat. Cætera tota eft leuo $\Omega_{a}$ tibiæ aperta, medulla rubra erant ple- cophxi coloris, prone remiffioris, fupine na. Reperitur in Gallia, Anglia, Bohemia, intenfioris. Femora in ea, contra ac in relinon tantum marinis locis, fed \& paluftri- quis pennis veftiuntur.

bus. In Holandia non longe à Lugduno infinitos earum nidos vidimus.

Victus. Vefcuniur pifcibus, ranis \& ferpentibus, ut quidam produnt. Nec vel herbas aquaticas virides, \& ramenta radicum genicuAtift.H. A. lata arundinum, vel inteftina Gallinarum 1. 9. c. 18. afpernantur. Facile coëunt, in arboribus nidulantur, \& pariunt, ad quatior fotus alunt, quià ferinifaporis cultoribus commendantur. Gefnerus fibi guftanti Anferi non diffimilem vifam ait; \& apud Anglos in deliciis habetur.

Huc plurimæ alix Ardex referuntur.

I." G A R L E T T A Italorum, ut Gefnerus vocat, avis cum Ardea per omnia, co-

Gerner. in lore excepto, congruens. Quam Gefnerus

Ornithol. Ferrariævidit, roftrum habebat longum acutum; in crifta capitis dorfum verfus pennæ oblongæ ad duos cum dimidio dodrantes, circiter fex nafcebantur, quæaliquando magno vendebantur precio. Pedes nigricabant: inferius tamen fubito in medio cruris, niger color definebat, \& viridis è glauculo fuberat ad extremos ufque ungues. Minimus pedis digitus binis articulis conftabat; proximus ab eo ternis, medius quaternis, ultimis quinis. Cum hac N1dro. Or-eandem illam Aldrovandus facit, quæ nith.1. 20. habebat roftrum fupra nigrum, infra cxruleum, oblongum; caudam brevem, rariores aliquot in dorfo illafque oblongas pennas, quibus pileos \& galeas proceres exornant, tres in capite pinnas, breviores \& coloris albi, qux criftam efficiebant.

II. E GR E T T A Gallorum, qux \& Hxmatopus, Phonicopus, \& Cirris Virgilii. ut Scaligeri, pater \& filius, adftruunt, dicitur. Omnibus fere Ardeis minor eft; tota fere ex croceo, ad colorem caftanex vergens, prone intenfius, fupine \& fuper alis remiflius. Collo brevi; roftro robufto, longo, acuto, bicolore; qua caput tangit viridi, vel ex viridiad cæruleum inclinante; cruribus \& pedibus, rubri faturati coloris; cauda tam exigua, ut ea prorfus carere videatur.

III. SeVAIOTTA Italorum.| Cauda brevi, pedibus viridibus, roftro luteo in extremo nigricante. Apex capitis triginta plumis conftat, quarum medix albæ funt, extremx nigrx, in tergore pinnx elegantes coloris rubicundi in fuis radicibus albre.

Congener ipfi eft \& ifta rofhro maxime arcuato, colore prorfus leucophæo. Avis eft afpectu non invenufta. Prone ad col-

Ex Ardeis quoque albis funt, tum ea, quxe Garzeita bianca dicitur, roftro longo gracili, acutiflimo, digitis poftico omnium minimo, anteriorum medio longiffimo, inter oculos \& roftrum maculata, tum ea qux vertice eft croceo, pedibus pro proportione corporis longiffimis, fufcis, albicantibus annulis circumdatis. Ungue medii digiti cæterislongiore, ferrato.

\section{$A R T I C U$ L U S III.}

\section{De Ardea Afteria five ftellari.}

Ader ftellaris triplex genus eft, $M_{i-}$ Defcriptio. A nus, Majus \& criftatum. Minus oxvo's Ariftoteli, Taurus Plinio, Botaurus, Butorius \& Buttora aliis, dicitur, \& quibufdam Ornocrotalus effe putatur. Collo eft longo \& mire plumofo. Capito nigro, corpore reliquo fufco \& pallido maculis nigris denfiffime afperfo. Pedes habet longiffimos \& inter extremos ungues medii digiti pedis unius \& calcis ejufdem, fpithamæ longitudo intercedit; ungues longiffmos; \& ille qui calcis vicem in avibus gerit longitudinefefquiunciam fuperat.Medius digitus utriufque pedisquicæteris longior dentatus \& ferratus eft. Cauda illi breviffi$\mathrm{ma}$; fomachus; quo ingluviei loco utitur, capaciffimus, canino fimilis. Arteria alpera in eo tota continua eft, larynx nulla, nec quod huic analogia quadam refpondeat. Damnum hoc compenfare voluiffe Natura videtur, canalium disorum hinc inde in pulmones utrofque abeuntium ftructura. Ita enim fabricati funt, ut annuli cartilaginei minime totum abfolvant circulum, fed exteriori duntaxat parte medium ; interiori, ubi aliis avibus hi circuli fiffura tantum. modo in longum diffecantur, membrana quædam tenuifima, alteram canalis divaricati exacte medietatem abfolvens, plana \& $x$ quabilis obtenditur; quin \& hemicycli latus exterius componentes rari admodum, interjectis fubtilifimis membranis five tunicis, ad faciliorem \& majorem diftentionem facti funt, quo nempe largifimus, \& hoc facili tumefcere meatu conceptus aër, roftro in aquam inferto aliquandiu retentus, tandem per apertum. \& extractum, qua data porta, maximo impetu erumperet. Prolobo caret, at ejus loco amplifimum oefophagum habet.

Victitat ranis \& pifcibus, inprimis an- victus: guillis. 
paiss Nidum exarundinibus intertextum cum / frum ei oblongum tenue \& anterius falca ovis duodecim in lacu quodam fevidiffe, tum. Crura oblonga, pedes fifi. Nulla maipfamqueavem colore ita ad arundinem gis ad ibidem accedit. PuGNACES accedere, ut inter arundines fedens vix quotannis immenfo numero, ex Septendeprehendatur, reliquit Gefnerus. "At trione in Belgium, verno tempore fub cundim ex furculis in celfarum arborum Majum advolant, plures mares quam foeramis ftruere, \& ita aut quatuor ova ex- minx. Hinc inter mares tanta contentio, cludere, reliquit Bellonius.

ut fefe mutuo occidant, donec cum foemi-

DeVoce diximus, cuifimiles illi foni di- minis numero pares evaferint. Exclufis adeò prixclarè humanam vocem intelligere, ut fiquis eam fervum appållaverit, vel pigrum (nugantur olim è fervo in avem tranfiiffe) indignetur. Non facile hominem refugit; eo proximo, aut arundinibus fe abdit, aut aquæ immergitur.

Volatus. Non citius evolat, quam prius falierit. Ubi pifces frequentes novit, adeò quieta confiftit; ut planè videatur mortua : \& ne colli longitudine fe prodat, breve id incurvando facit. Capta ftat immobilis, \& venatorem apprehenfurum incautum vulnerat.

M AJo R ex Pella \& Stellari prognata effe creditur. Illam enim capite, pectoris maçulis, alarum colore, ipfa denique magnitudine refert. Reliquarum partium colore Stellaren minorem, rnaculas fiexcipias, Giruin ea non funt : imò pedibus adeò eandem exprimit, ut fimul pofitas vix peritifimus etiam auceps difcernat: $A$ picem quoque in vertice habet, ex quo dux longiufculæpennx exorientes, totum caput velut galeam, colore nigro exornant. Gefnerus Elaphin Oppiani efle conjicit, qux: pennas in dorfo varias \& maculofas hinnulorum inftar habet, \&linguam longiffimam, qua in aquam protenfa, fenfim adfauces, pifces ad confpectum adnatantes folet attrahere. Hanc Aldrovandus \& Cristatam feu Cirrhatam effe opinatur.

Congener eft hifce, quam idem Ardeam Nigram vocat, colore pertotim, collo excepto, quod albo torque circumdatur, \& roftro quod luteum eft, nigricante; collo longo, longis cruribus, digitis pedum longifimis, unguibus acutis, \& cauda brevi.

\section{A A P U U T $\mathrm{T}$.}

\section{De quibusdam Avibus ad Ardeas rem latis.}

\footnotetext{
A D Ardeas refero Falcinellum five Falcatam, \& Pugnaces, quas Belgæx Kemperkens vocant. F A I C I N E L L U S avis eft magnitudine, \& tota corporis fpecie Ardeam referens, eleganti colore, viridi fere, alicubi puniceo admixto, capite \& collo fufco. Superior pars colli anterius albicat, maculis nigris intercurrentibus, Ro-
} educatisque foetibus;una cum his unde ve nerant, revolant.

Ofto ipforum genera, feu formas potius defcripfit, \&:depingi curavit Aldrovandus.

Prima Perdicis inftar toto corpore maculis refpergitur. Caput Galeritæ velut apice infigne eft. Roftrum exile, in extre mo nonnihil recurvum. Lingua longa, acuta, fubatra: Caput, cervix, dorfum, alæ, venter, \& femora ex luteo ad caftanex fere colorem tendunt, \& maculis, quæ in capite adeo exiguxfunt, ut exigua punctula potius videantur, refperguntur. Altera criftam quoqe in vertice gerit. Ventre nigricat, candicat pectore. Mentum macula nigricans ceu barba quxdam exornat. In fronte albicat; in occipite, \& in reliquis partibus eralbo ad fufcum vergit.

Tertia tota fere eft ruffa, nigris naculis lunam xmulantibus undique excepta cervice infperfa, apice caret. Femora \& infernum Vropygium colore funt batico. Alarum pennæ majores nigræ, in fine, \& ad latera fere crocerz.

2 uarta colore fere curn ifta convenit, nifi quod venter fit fufćus, podex albicans; alas fubalbicantes maculx multx, magnix; transverfales, tortuof $x$ tranfeurrunt: $\mathrm{Ca}$ put nigrum magnæ pennæ velut galeam eleganter exornant; quas proculdubio dimicatura erigit.

Quinta ejusdem fere eft coloris,fed pènnas eas, quas erigit dimicatura majores, candidas, \& in extremitatibus fuis nigras häbet.

Sexte pennee illæx funt candidx, color plurimum diverfus. Toto enim corporé fufca eft exceptis femoribus \& cauda, quæ funt colore batico. Ante albas illas in collo furrectas, alias habet in vertice quæ $\mathrm{mi}^{\circ}$ nores fünt, \& nigra. Caput ex ênereo flavefcit.

Septima pennis omnibus váriat, viridibus, albis, rubris, amethyftinis, luteis, \& quod obfervatu dignum eft; nulla earum alterius colore permifcetur.

octavam auritan Natura fecic Roftro eft gracili \& oblongo, à capite per collum pennæundiquaque pendent, magnitudine xquales, fed in quibus varios cernere eff colores, qui velut varios torques formants modo ferrugineos modo rubros, modo albos. Collum habet longum, valde 
gracile, tenue, ad latera candicans, cxtera lutefcens, lineolislongis undiquaque confperfum. Gaput ad latera maculam miniaceam magnam habet, in qua oculi fiti funt. Aures afininis non diffimiles, crura duplo quam precedentibus breviora. Digitum pofticum admodum brevem.

\section{A P U T VI.}

\section{De.Porpbyrione, Ef Horione.}

Dipnof.l. D Drphyrion, à colore ita dicta, qua'm Cal-
Defriptie. Defriptio. L limachius apud Athenzum à Porphyride diverfam facir, quxque in agro Patavino Telamon vocatur, avis eft fecundum - Athenxum Galli magnitudine, colore cxruleo, roftro ad caput vehementius obftridto, phoniceo, longis cruribus, fiflis pedibus, in quibus quinque digitos habet, \& maximum illum, qui medius eft.Oppianus - ei criftam in capite, qualem fagittarii Perfe geftant, tribuit. Ifidorus pedem unum latum a d natandum, alterum fiffum ad ambulandum addit. Apud Aldrovandum duplex ejus exhibetur Icon. Prior habet roftrum craffum, acutum, purpureum, à fronad verticem fere ufque macula ejufdem coloris extenditur. Pars capitis quæ hujufmodi maculx fubjacet, \& collum pronum virefcunt. Ex remigibus alarum pennis, quædam in extremo albicant, quxdam funt fufcx. Reliquum totum corpus, cæruleo vegeto colore infignitur. Cauda fere caret. Digitis tantum quatuor ex purpureo fubalbefcentibus infiftit. Alter roftro, cruribus, pedibus, \& oculis defcripto eft fimilis, nifi quod ungues habet fufcos, \& macula in fronte purpurea ornatur; \& quod in illius capite \& collo viride erat, in hac cæruleum apparet. Cærulex pariter funt Plin.H.N. alæ. Reliquum caput, cervix, dorfum, pe1,10.c. 47 ctus, vertex, \& femora nigricabant. Laudatiflimi funt in Comagene. Nobiliorem vero Baleares infulx mittunt. Fert eas \& ultima Syria, ut Diodorus prodidit. AtheAthen Di- næus avem Lybicam, Diis ejus regionis pnof. 1. 9. facram indigitat.

Vithus Vefcitur pifcibus, \& in occulto quidem, ne à quo quam videatir. Non prius autem cibum capit, quam fe lavaverit; nec prius fe vel in pulverem vel in lavationem dat, Athen.Di- quam in ambulationem veniens certa fpaphof.l,, , cia confecerit. Sola hæc merfu bibit, ex
Plin.H.N. 1. 10.4. 46. proprio genere omnem cibum aqua fubArift,H.A. inde tingens, deinde pede ad roftrum ve1.8.c.6. luti manu afferens. Polemon apud Athenxum de cibo quem apprehendit, paucas

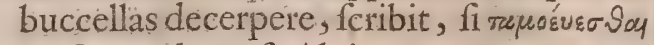
ita fumendum eft.Alvi excrementum, ut \& reliqux aves longi auguftique colli, humidius, quam caterx folent, rejicere, Ariftoteles autor eft.

\section{Ad volatum dirigendum loco Uropygii, volituts.} quod parum latum habet, pedes protendit ; \&.quia fpectaculo faltationis adeo delectatur, ut \&ipfa ad faltandum membra componat, haud difficulter eo modo capitur, fi Oppiano credimus.

Incredibilia fere de countic. tho ejus caftitate Au-'Affectus, thores. Nunquam in confpectu hominum conjugi mifceri, \& ne virum quidem uxori concumbentem videri poffe, retulit Oppianus. Tantum fenfum obtinere ftupri, ut fi id deprehenderit, vitam feu laqueo

feu inedia finiat, apud ZElianum, Athe- Plia.H.A.

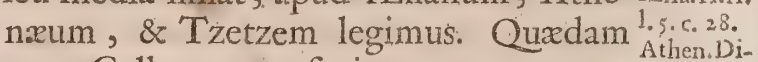
cum Gallo tantam focietatem contraxe- Athof. $I_{0}$. rat, ut cum ifte occideretur, convidto Tzetz. re privata, inedia fibi mortem confcifceret.

Nunquam cibigratia appofita effe vide- $V$ fus tur. Magnificis ædibus, ut $\mathbb{E}$ lianus haber, proludicra eft delectatione.

Cognata eft ipfi Hor Io N, avis ama- Ellia.H.A. torio affectu flagrans, magnitudine $\mathrm{He}^{1, .17, c_{.} 22 \text { : }}$ rodii, cruribus rubris, oculis cæruleis, fic à Mufica inftructa, ut naturx munere fuaviffime canat.

\section{A P U T VII.}

\section{De Helorio, Limofa Venetor. Barge Gal- lorum, \& Hamatopode Bellonii.}

T E L or I U S, Creci, de quo poftea, Athen.l.g. fimilis effe traditur. Clearchus eum apud Athenxum cum Trochilo \& Carulo

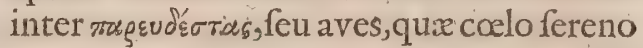
in littore pafci folent; meminit.

L i 1 o s a Venetorum, quæad lacum Verbanum Giraldel, circa Neapolim Leverfina, Germanis, ein Decerfun dicitur, Arquatx majori, de qua in fequentibus, per dorfum ef fimilis, maculis varia, tota parte prona, capite \& collo prafertim.

B A R G E Gallorum, quam IIgocephalum Bellonius facit, minor eft:Helorio, $\mathrm{CO}-$ lore vero non abfimilis, roftro breviore, reeto: Liene omnino caret. Fel jecori fimul \& ventriadherere confpectum eft, quod de Igocxphalo Arifoteles feripfit, Vi- Arit.H.A. ctum in faluginofis paludibus frequenter, 1.2.c. Is. rarius in remotis à mari, ubique noctu, quxritat. Vocem hircorim \& caprarum edit. Hominis acceffum non fert. Et apud Gallos in deliciis habetur.

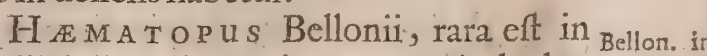
Gallicis littoribus avis. Corpore Ardeolx, obr.1. r. alis Lati, capite, collo, \& cauda extrema c. Ir. nigris. Interiore alarum parte \& ventrealbis. Gula magna admodum ampla \& robufta.Binos habet digitosfimul cohrentes; interiorvero $a b$ aliisfejunctus eft. Calcar in pedis calce, ut reliqux aquatica aves, non ha- 
bet Peder funt molles \& delicatuli. Digiti breves; ungulx ut in Tardis fornicatx.

$$
\begin{gathered}
\text { C A P U T VIII. } \\
\text { De Alcyone. }
\end{gathered}
$$

$\mathrm{H}$

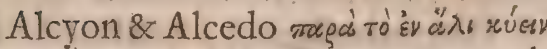
fic dicta, Avis Poffideonis nonnullis, Ceycis quibuldam, modernis Gracis

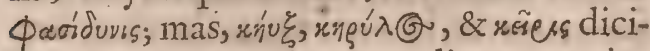
tur. Pauciflimis, inter mediterraneos inprimis, nota eft. Omnium rariffimum eft, inquit Ariftoteles, vidiffe Alcyonem, \& fere circa Vergiliarum occafum, brumamque apparet, \&ubi primum per portum non plus quam navem circumvolat, ftatim abit, \& nufquam preterea vifitur.Duo hujus Avis genera, Mutum, \& Vocale, ex Ariftotele quidam faciunt, fed falfo. $\chi \in \lambda^{\prime} \dot{\delta}$ ove cnim apud cum funtintelligend $x$. Turnerus \& illam inter Alcyones repofuit, qux Sturno paulo minor, corpus totum nigrum habet, ventrem album, caudam breviufculam, roftrum alcedone paulo brevius; quxque ante volatum, Alcedonis more nutat, in volatu gemit. Alcatraces quoque, qux in Peruvia marinis lupis, carabis, pifcibufque infidiantur; \& quia cadaveribus delectantur, adeo funt lethales, ut ad earum ufum neceffitate redacti, non fecus quam aconito toxicove victi intereant, inter earundem referuntur genera.

Formam fi attendas, non multo amplior Arift. H.A. eft Paflere, colore cxruleo \& luteo, \& fubapud Scal. purpureo mixto infignis. Tale corpus toc. 3 i. tum \& alix. Tum colli partes non feorfum pofitis coloribus. Roftrum fubluteum, longum, tenue. Mari adeo delectatur, ut pectus aquis afpergat, cauda in terra ficca impofita : non fpernit tamen \& aquas dulces.

Vitzitat pifcibus, quos ex alto fe in mare recta immittens capit.

Quantum ad Generationem fenes in coitu Parsus. Plin.H.N. extingui creduntur. Alix, utapud Plinium 1. ro. c. 32. legimus, foetificant bruma, pariunt ova Caffandra. quinque, qui dies Alcyonides vocantur, Plin. 1.c. 1.5.6.8. maxime : (hinc Siculi maris cives Scaliger vocavit ) In reliquis partibus eft quidem mitius pelagus, Siculum utique tractabile. Faciunt autem feptem ante brumam diebus, totidemque poftea fternitur mare Halcyonum foeturæ, unde nomen hi dies traxere. Nec tamen de tempore omnes affentiuntur. Columella enim in octavum Calendas Martii, quibus in Atlantico maxi fumma notatur tranquillitas eos conjicit. Sed \& in numero dierum diffentitur. Quinque ftatuit Simonides \& Ariftoteles; feptem Samius Demagoras, novem Philochorus, quatuordecim alii, De maris tum temporis tranquillitate, \& ventorum quiete molliore colo, apud Theocritum, Ovidium, Plautum, Plutarchum, Elia num, \&alios paflim invenies. Nidilocum Ambrofius arenam.; alii littus, quidam undas ipfas, hinc Statio, domus fluctivaga; Silio Italico nidus natans dicitur, ponunt. Saxo cuidam proxime aquam,

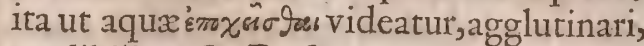
credibilius eft. Roftro autem fuo nec alio Plut,de asnidum fingit Halcedo, imo navis inftar mats fabricat, opus everti mergique fluctibus nefcium. Componit devincitque conferens invicem acus pifciculi fpinas, ac rectis aliis ceu ftamini tranfverfas alias veluti fubtegmen implicat, mox confertum recurvat, \& in orbem reducit; fic cooptat denique, ut opus navigii fpecie turbina. tum, ac qualo propemodum pifeatotio fimile evadat. Perfectum littori, quo fluctus extremi pertingunt, applicat. Hic unda molliter feriens, nondum firma fatis hiantiaque, procellarum verbere deprehenfa, farcire docet. Solide vero \& jam cohxrentia conftringit, figitque, adeo, ut nec faxo, nec ferro diffolvi diffringive facile queant. Magna cumprimis admiratione oftiolum dignum eft, fic modificatum figuratumque, ut hanc unam fubeuntem recipiat, coecum cæteris \& abditum, \& aliud prorfus nihil admittens, ne undarum quidem quicquam.

Mores ejus exinde metiare, quod thari- Mores. tum adeo diligit, ut non uno aliquo ftato Plut. $t_{0} c_{s}$ tempore, fed per totum annum confuetudine ejus utatur; fenem \& ad fectandum tardum, geftat \& nutrit, nunquam relinquens folum. Cum ad tepidum folem pen- Mizald. E nas inlittore expendunt, pluviam denotare ${ }^{\text {phem. 1. . }}$. dicuntur. Virgilius hoc inter catera ferc- Virgil.Gea nitatis figna numerat.

\section{A P U T IX.}

\section{De Ifpida, Es Rouferolle Gallorum.}

T Spida, quam nonnulli Alcyonem veterum velfimpliciter vel fluviatilem effe putant, Genux Martinus pifcator, no nonnullis aliis Italis Avis Paradyfi, fed \& Pifcator Regis dicitur.Roftrum ei eft nigrum, Difcritptio or rectum, in fummo acutum, tres digitos longum. Caput pronum cum cervice viridis coloris transverfis lineis ex albo cæruleis diftinttum.Virent \& ale, fedinterior pårs plumarum ad purpureum ferè viola. ceo dilutum colorem tendit, afperguntur lucidis aliquot punctis. Per medium dorfum à principio ufque ad finem caudæx, plumæ funt cærulei coloris diluti, \& ad album inclinantis adeò fplendidx, ut oculos et-jam vifu immorantes ofiendant. Pedes breves, rubicundi, in quibus duo longiores digiti ad mediam ufque partem connexi $\mathrm{P}_{2}$ pofted 
portea finduntur. Lingua perbrevis eftla- fum funt, in medio nigræ, in circuitu per tiufcula ac fubrubens. Oefophagus valde ob- interftitia fubruffix. Digitifunt fiffi, fed alilongus. Ventriculus in imo corpore juxta quatenus membrana conjuncti; quretiam anim. Adeps ruffa.

Eft \& aliud Ifpidx genus, quod ex India. adfertur. Regulum magnitudine vix fupe rans.Roftro oblongo, tenui, nigro, reliquo corpore ad caudam cæruleo, viridi \& nigro. Cauda pro corporis proportione longiufcula tota fere nigra. Pedum conftitutione cum fuperiore eadem. Solitaria eft, $\&$ in agro Bononienfi, Helvetia, \& alibi media hyeme circa ripas glacie concretas reperitur.

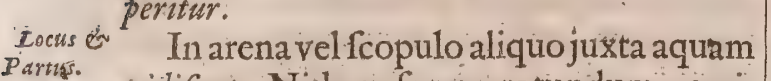
ridificat. Nidum forma totundum, eminente in angulum foramine exiguo, ex floribus arundinum, mollem conftruere ajunt.Pullosinterdum novem in nido uno reperiri.

Y Jus. Pellis ejus cum pennis affervata peculiari viadverfus timeas pollere creditur. Non tangi fulgure domum, in qua ejus nidus fufpenfus fuerit, nugantur quidam. Mofchi inftar cum pullis fuis fuaviter olere, Tragus prodidit. Sufpenfam pennas quotannis tanquam in vivo corpore mutare, falfum comperit Aldrovandus:

Rousserolle feu Roucherole Gallorum, Alcyone vocalis eft Bellonio. Roftrum habet ferratum Picæ Græcæ feu Collurioni fimile. Plumæ capitis longiores criftx quondam fpeciem præ fe ferunt. $\mathrm{Ni}$ dum fi quis inverfum afpiciat adarcen primo intuitu refcrre videtur. Sena ut plurimum ova parit, \& quinque fexve excludit pullos. Cantu adeo valet, ut omnibus canorus à Bellonio præferatur, tamque in eo indefeffa, ut dies \& noctes abfumat; tam feria, ut vacillet, totoque corpore tremat. Inter reliquas voces has inprimis proferre videtur Toro tret, fuis, huy, tret. Ariftophanes ejus cantum exprefliffe creditur.

\section{T I T U L U S II.}

\section{De Aquaticis fißipedibus Infectivoris.}

$$
\text { C A } A \text { U } \quad T \text {. I. }
$$

$$
\text { De Arquata, Crece \&5 'Totano. }
$$

A

Rquatum ab arcuato roftro fic dictam, Numenium veterum, qui forte à Neomenia, quod roftrifigura arcum lunx recens à novilunio crefcentis in cornua reprefentet, ita dicitur, effe Gefnerus credit; Bellonius Elorium Ariftotelis conjicit. Röfrum habet circiter octo digitos longum, poif tres digitos flecti deorfum incipiens, nigrum. Pennas coloris fufci varias \& maculofas, ex quibus maxime fulgent inftar ferici villofi, qux inter alas \& dor-

utrinque juxța digitos defcendit, \& in feriorem digitorum partem dilatat. Lingua pro tanta roftri longitudine breviflima eft, \& fagittre effigiem reprefentat; Femaina eft aliquanto minor, \& maculx illæ, quibus totum fere corpus refpergitur, in hac magis fufcefcunt. Omnium vermium genere vefitur, eofque in plantis quiburque quærit. Turmatim volant, voa pariunt quanta Gallinæ, quarerna, pallidà, menfe Aprili. Carnem habent ficcam, folidam, leporinæ fimilem. In Gallia in deliciis habentur.

$\mathrm{C}_{\mathrm{R}} \mathrm{E}$, quæ \& rerròs, quænam fit avis, vix à recentioribus obfervatum eft. Athenæus Helorio fimilem efle dicit; Ariftoteles vero crura alba habere, \& pofteriorem digitum qui pro calce eft minutum afferit: Herodotus ei Ibidis nigræ magnitudinem; Scholiaftes A riftophanis roftrum acutum \&z ferratum affignat. Bellonius avem circa Nilum vifam, cruribuslongis, roftro longo \& nigro, nigris quoque tibiis \& toto capite : collo tergore \& pectore candidis, quæè terra victum petit, \& in mufcas debacchatur; \& cum volat magnum edit ftrepitum, Crecem veterum effe opinatur. Pugnat cum Galgulo, \& Merula, Vireone,

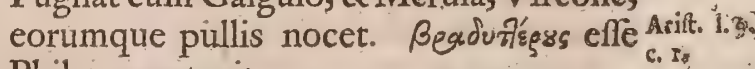
Philes annotavit.

Tot A U $s$ avis eft aquatica, capite nigricante, præfertim anterius; pofterius enim \& magis anteriori parte ruffum eft. Vertex cinereus, ut \& reliqua pars prona. Alarum ima pars alba, extima nigra eft, reliqux plumæ in ambitu varix ( funt \& albicantes. Carda palmi longitudine tranfverfislineis albis, nigrifque depicta; ut etiam limofx. Penne fuper caudam ad medium dorfum ufque albicant. Pars omnis fupina alba eft : in collo tamen, \& fuperiore alarum ambitu nigricantes macula vifuntur. Totius avis longitudo ab extremo (roftro) ad pedis extremum extenfr, dodrantem cum duobus palmis xquat. Roftri longitudo circiter tres digitos, colli totidem. Fidipes eft, verum duo majores digiti pedis aliquoufque membrana junguntur ut \& limofre. Pedes duos palmos longi ex pallido rubent, unguiculis muniti nigris. Corpus avis ea fere craffitic eft, qua Mergulus nofter roftri acuti.

$$
\text { C A P U T II. }
$$

De CalidriBellonii, Nigra, ơ Himantopode Plinii.

Alidris Bellonii avicula eft columbre magnitudine, criribus proceris adeo, 
ut equo infidere videatur, unde Cheva- quod leve, \& gracile eft, inftaraviunı pat lier, id eft, equitem nominarunt. Plumis luftrium fere, quas Gallinulas aquaticas optime inftructa eft, ideoque longe minus carnis obtinet, quam appareat. Roftrim \&crura rubra, longa, manifefto fane argumento aquaticam effe volucrem. Superior roftri pars nigricat, venter albus eft : caput, collum, \& pennæ fub alis, \&züropygio cinerex: quare Ariftoteli Calidrim dici arbitramur, cujus meminit his verbis: Quin etiam Calidris, cui cinereus color diftinetus varie. Radices plumarum ficut in Biftarda, \& la Cane petiere (Tetracem interpretatur ) rubent, fic in hac nigrex funt. In temporibus utrinque maculæ funt binx, nigrx, qux ceu umbram præbent fuperciliis, qux \& ipf alba macula infignia funt. Priores digitos membrana conjungit, ut in pica marina, (Pie de mer) Digitus pofticus admodum exiguus. Alæ, ut in pluvialium corpori junguntur, magnitudine corpori refpondent. Tam parva itaque ales proceris cruribus infiftens, alacriter, hilariterque incedit, prata ftagnaque \& ripas frequentat, \& plerumque aquam ingreditur ad femora ufque. Caro nihil ferinum redolet, fed delicatum quid, \& aromaticum. In furgeneris avibus, in deliciis habetur.

N IG RAM à rubra differre cercum eft. Nigra:enim ab ipfo ortu crüa \& roftrum atra funt, excepta fuperiori roftri parte, qux fubrubra eft. Color item huic nigrior: quin amputatis capite, cruribus, atque alis, reliquis corporis partibus Palumbis colorem inter cinereum, \& nigrum videbitur referre. Sin fermo fit de Caliduibus, qux jam pennas mutarunt, diftinguendufque color ab iis, qux prioribus etiamnum vefticintur, afferemus nos Pluvialem aliquando obfervaffe in autumno nigram, adeo ut poft mutationem plumarum eum non agnofceremus: nihilominus tam huic, quam alteri pedes nigri funt. Fotus earum menfe Aprili proftant, maculis undique Ortygometræe inftar (d'un Ras le) confperfi, cum alioqui hyeme tantum appareant. Ad hanc reducit Aldrovandus Gambettam Italis dictam: Qux eft capite, collo \& pectore cinereis \& maculis fufcis plurimis, undiquaque refperfa. Alarum pennx rectrices nigricant, corporis cinereæ funt, in dorfo \& alis ad ruffum vergentes, venter candidus eft. Roftrum nigrum: oculorum iridem ex luteo fubviridem niger circulus ambit. Pedes ex luteto rutili, quo colore potiflimum à nigraCalidri Bellonii difcrepat. HIMA N T OP us à flexitate crurum ita dicta, quam alii Hoemotopoda, à rubedine pedum vocant, à Gefnero ita defcribitur, Roftrum digitos fere quatuor longum eft, caput parvum, collum digitorim quinque, reliquum corpus, vocamus; digitorum fex; cauda quatuor crura quindecim. Color roftrinigricat, in capite, \& collo ptono fufcus : dorfo, \& alis niger, pauco fubviridi admixto, fi diligentius intuearis, cauda cinerea. Partes prone omnes, \& latera quoque albi coloris funt: Crura fanguinea digitis duntaxat ternis, ficut in Biftarda, Oenade Rondeletii, Morinello Gaii, Struthiocamelo, Pluviali, \& Cane Petiere Bellonii, ejusdem. que Pica marina: quiorum medius lon giufculus, breviffimus interior: jungitur autem medius cum exteriore brevifima membranula, tanquam palmipedum: $\mathrm{Po}$ plitum cavitas infignis eft, articulo tam flexili, ut in fceleto etiam tibia ab femur tota reflectatur: Videtur fane non curfu tantum valere, fed etiam volatu hac avis quoniam oblongx ejus alx funt, ita ut longiffimxearum pennæcaudam, feu uropygium, duobus, aut amplius digitis excedant. Oppianus hoc novum in eis, quod maxilla inferiore fixa, fuperior folum in ipfis moveatur notavit; fed in deferipto, nihil ab aliarum avium narura variat.

\section{A P U T III}

\section{De Gallinulis Aquaticis in genere \& in Specie, de quibufdam.}

Allinulx aquaticx hoc commune Thabent, quod eis fit corpus gracile \& adductum. Capue parvum, pennæ variæ: Roftrim longum, modice inflexum, nigricans. Ventrem \& fupinam eam capitis partem, qua inter roftrum \& collum eft ca ndida. Crura oblonga, digitum, qui pro cal ce eft admodum brevem; quxdam etiam eo carent. Plumas ad media tantum crura defcendentes. Vermiculis potius quàm pifcibus vefcuntur' quamvis \& ex his minimos comedant. Circa initia autumni in Helvetiam adveniunt; hyemis exitu de nuo avolant. Aucupium earum mane ante folis exortum, fit; aut vefpere, quo incipiente tam fublimi volatu evehuntur, ut non amplius appareant. Ob carnem fuavem \& teneram, in deliciis menfarum has bentur. Species ipfarum funt Chloropis, $E$ rytbropus, Ralla Anglorum, Rhodopus, Pheopus, Ochropus, Miclampus, Poliopus, Erythrid ochra, Hypoleucus, Gallimula Jerisa, b Scolopax.

CHLOROPUS eft triplex, Major; quärum altera Fulicam \& magnitudine \& cor poris figura refert, tota roftro longiufculo, furfum parumper elevato; altera Italis, porzana dicta, collo \& capite nigricantibus Dorfo cum fuperiore alarum parte cafta neo; inferiore ventre toto albido, femoribus plumis cinereis ufque ad genua coo- 
pertis. Tertia Gefneri, quam Glottidem Ariftotelis effë credit, colore eft fufco, cruribus viridibus. Vocem inftar fiftulæ argutam edit. Germanis ङొfutt dicitur. Prælongam exerit linguam unde ei nomen. Hanc initio blandita peregrinatione (cum Coturnicibus) avide profectam, ponitentia in volatu cum labore fcilicet fubit. Reverti inconcitatam piget, \& fequi; nec unquam plus uno die pergit, in proximo hofpitio deferit.

E; Y T H R O P U s vel eft Major, vel Minor, de utraque nihil fingulare occurrit. R A L L A Anglorum aquaticam intellige, cujus roftrum \& crura funt rubra ; plumæ undique magis cinerex, quamque male volare, fed egregie pugnacem effe, Bellonius prodidit. GMontana \& fylveftris in Ericeto degere folet. Ortygemetram effe credidit Bellonius; Perdicem rufticam Gefnerus.

$R$ Hорор U's nihil habet fingulare: Sed ne de aliis præter defriptionem, quam apud Aldrovandum \& Gefnerum invenies, quicquam. In Ochropode majore feptem diftincti coloresapparent, nec digitus pofterior pedis vifitur. Mediolingua in oblongum mucronem definit. cMinori collum eft quam cæteris altius.

ER Y THRA, quam Germani DRatteres vocant, vocem \& clamorem edit, quo fonus fullonum lanạs ferientium repræifentatur.

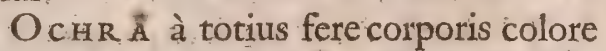
fubviridi, fed fordido \& obfeuro fic dicta eft.

De Hypole uco, quam Germani Syffertin appellant, nihil habeo quod dicam.

SER I CA ideo dicitur, quod color ater in ea holoferici inftar fplendeat.

\section{A P U T IV}

De Scolopace feu Perdice ruftica, Rufticula Jyluatica, Scolopace Jeu Gallinagine minori.

$\mathrm{S}$ C oL o P Á X avis, à roftri figura, quod inftar pali longum \& rectum habet ita

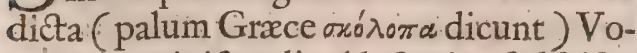
laterrano Ariftotelis Alectoris, fedfalfo; vulgo Græcorum ž $\lambda \lambda_{\text {ópvis }}$, Herodiano Sylveftris Perdix, Martiali Perdix ruftica, nonnullis Rufticula major, Alberto quod fuavis \& pinguis fit Ficedula, plærisque populis Beccaffa, Germanis Edhnephun \& Siterffrnepf/dicitur. Similes ipfi quasdam in Frifia aves facit Gefnerus. Ea, quæ Vulp nominatur vulgo, roftro \& pennis colore illi confertur, fed magnitudine vincit. Arift.H.A. Item Grutte dißta roftro. Magnitudine eft 1.9. c. 26. Gallinæ, colore Attagenis, ut Ariftoteles prodidit: Roftri, quod longum, anterius afperiufculu $\mathrm{m}$, pars fuperior ultra inferiorem extenditur. Linguam habet graeilem, oblongam, nervofam. Crura fere rofei coloris. Felle carere vulgo creditur, quod apud Bellonium legimus.

Nullibi non invenitur, in Gallia, Suecia, Lotuss Helvetia. Non ubique tamen iisdem in locis, nec femper Æftate in altis Pyrenæi, Helvetiæ,Sabaudix \& Arverinix montium jugis degit: Hyeme cibi gratia ad campos \& fylvas caeduas defcendit. Circa Brixiam principio Autumni, in Helvetia menfe Octobri capitur. A Germania inferiore $x$ ftate recedit, in fine Autumni redit. Aquas inprimis tepidas, loca pulverulenta $\&$ humida, fepes, \& hortos amat. Cibus ipfi vermes. Spiritu in cava immifo, unde fonus etiam procul audiatur, eos extrahere, proditum à nonnullis. Vifí, qui ex farina fagotritici cum aridis ficubus pafcebantur.Volatus debilitatem curfus velocitate natura compenfant. Cum proximam fibi aucupes Arit.H.A: exiftimant, longe receffiffe inveniunt. Ocis 19 , c. 26. lis eft obtufioribus, quamvis grandes habeat; odoratu potius cibum quærere creditur. Homine delectari ab Ariftotele relictum.

Habetur inter ciborum delicias, fed Gefner, in poftponitur Perdici. Aliqui depluma Ornishol. tum exenteratumque in furno torrent \& cremant, remedio calculofis futurum.

Rusticula Syzvatica, Rufticula paluftri majore, major eft. Gallinam enim fere xquat. Colore faturiore, roftro minus longo, ventre albicante, cruribus cinereis. Tendiculis feu laqueis capitur.

Sco o o P A x feu Gallinago minor, \& Scolopax minor, Molliceps Ariftotelis quibusdam; dorfum habet ejusdem fere cum Alauda coloris. Roftrim canaliculatum, maculofum, in extremo nigrum, qua. tuor digitos æquat longitudine. Alæ extenfe maculam albam in extremitatibus oftendunt. Qux ab Aldrovando exhibetur, roftrum habebat palmi longitudine canaliculatum, latiufculum, nigrum, tuberculis quibusdam afperum, in extremo acutum, cujus fuperior pars inferiorem aliquantulum longitudine excedebat. Linguia longitudine roftro fere par erat caniculata, in extremo cufpide acus inftar acuminata.

Frequentem in locis mediterraneis Gallia videt, nec Batavi eadem carent. In Germaniam circa æquinoctium vernum venit, fi Longolio credimus. Nec àmarginibus ftagnorum \& lacuum recedere idem affirmat. Migratoriam inde colligas. In diffectx ventriculo initio Decembris, fcarabxos, \&vermes albicantes, tènues, ob- 
longos,quales farinarios appellant,invenit |ifchion, five os coxendicis ab aliis àvibus Gelnerus. Neque in caveis, neque in avia- habet diverfa, etiamà Fulica. Caro Galrio vivere dignatur. Vocem audiram ( hæc linulx coctu facilis, ac tenera eft, offa fratalis eft, ut fiquis cultrum per ferram du- atu facilia, ingluvies ampla, jecur quoque cat ) pluviæ prognofticon quidam fa- fragile, cæterum inteftina, \& reliqux parciunt.

\section{A $\quad \mathrm{P}$ U $\quad \mathrm{T}, \mathrm{V}$.}

\section{De Gallinula terreftri, E़ alia Cbloro- pode.}

$\mathrm{H}$ Uc \& Gallinulam terreftrem \& aliam Chloropodem Fulica fimilem Bellonii refero. Illa circa Verbanum lacum Polle, à Germanis aucupibus .5oggefithar \& quod turmatim juxta fepes decurrant, dicitur. Gefnerus Rallum terrenum, feu Thoehilum terreftrem dicit. Corpore eft brevi, craffo. Digitis pro fua magnitudine longiffimis. Poftremus ad anteriores circiter dimidiam longitudinem obtinet. Vocemejus dicunt afperam ger, ger, ger ferpentum inftar. Capta fciuri vocem, fi fides referentibus, imitatur. Angliceu lautifimam inter fegetes capiunt.

De Galin ULA ChLOROPODE alia, ita Bellonius: Neceffario plane Gallinulam aquaticam ( (la Poulette d'eau) à Fulica, \& Fulica majori (de la Porle, \& Macroule) feparavimus: quoniam aquæ non innatat, nec palmipes eft. Pullettx autem aquaticæ, five Gallinulæ nomen à fimilitudine cum jam dicta impofitum eft, etfimulto minor fit, major tamen Ralla, adeo ut de utraque hac particeps efle videatur. Aucupes, quibus oftendimus, cum Fulicx fimilem effe cernerent, magnitudine tantum differre ajebant hancque ad perfectam necdum xtatem perveniffe. Unde nos diligentius peculiares aliquas notas difcriminantes inveltigavimus. In quibus ea præcipue fere eft, quod hæc Gallinula pedibusfit viridibus, \& non abfimilibus Botauri, neque etiam ita planis, nec denique lata membrana conjunctis, ut in Fulica. Cauda etiam Gallinulx longioreft. Macula frontis item minor. Colore Rallo fimilis quidem, fed ad Fulicx co-

lorem tendit : quare ex primo afpectu $R$ allum effe putabam, fed cum diligentius infpicerem, animadverti, palpebras oculorum candidas effe, quod Rallo non convenit, fed neque Fulicx. Caude binx pennæalbæfunt, utrinque nempe una. Sub peciore nonnihil ad cyaneum, five cæruleum vergit. Dorfum çolore eft caftanex intenfo. Alix item aliis nigriores funt, \& alarum plicas albas habent, \& aliam infuper albam lineam in minori ala, quam primæ plumæe ejus per calami longitudinem conftitumnt. Idem cibus reperitur in ejus ventriculo, qui in Rallo, \& Fulica: os fterni \& tes internæ, ut in Fulica: Affa ejusdem cum. Fulica faporis eft. Nidificat, \& pullos alit, \&ceducat, ut Rallus.

Huc pertinet illa quam $\mathrm{C}_{\mathrm{O}} \mathrm{k} \mathrm{R} \mathrm{I} \hat{\mathrm{A}} \mathrm{A}$ M vocant, avis roftro pro corporis proportione craffo, pectore, \&z al is fupernis albicantibus, cætera nigra.

NecPorzana Minor, quxMediolani Gírardina à Gallinularum aquaticarum cenfu eximenda eft. Roftrum habet breve, qua caput tangit flavum, \& in extremitate nigrum, pedes atros, ventrem album, pectus, dorfum, alas, colore fumido, albis maculis confperfo, alarum pennas majores nigras, \&c.

\section{A P U T VI.}

\section{De Trynga.}

D E Trynga, Juncone, \& Cinclohoc duntaxat A riftoteles prodidit, quod caudam motitent, lacus \& flumina petant. Irynga Turdo aquiparetur, Cinclus \& Junco minores fint. Hinc factum, ut diverfe Aves pro iis ab Authoribus obtrudantur, haud paucx tanquam congeneres referantur ad easdem. Turnerus eam totam pullam, ea parte, qux podicem tegit, qua. que candida eft, excepta, facit. Breves volatusfacere, in ftagnis quir nobilium $x$ des obducunt, \& in pifcinis apud Anglos plærunque degere, fi quando periclitatur, ad arundineta denfiora confugere, adjicit. Germani quidam Tryngam nigram totam, fidipedem, candido vertice ad roftrum ufque demiffo, pedibus altis \& nigris, caudam continue motitantem, \& loca aquofa incolentem ponunt, ad eandem Gefnerus avem qux Claronx 23 afferBroffer $/$ id eft, Turdus a quaticus nominatur, roftro brevi, cruribus altis, fidipedem, refert. Aldrovandus aliquot ad Tryngam reducit, quias alii ad Cinclum retulere.

Prima eiex illis quas Giarolos \& Giaroncet-Generá los in Italia vocant, Turdo magnitudine par. Roftro duos digitoslongo, nigro, in extremo nonnihil recurvo. Lingua acuta paris fere longitudinis. Capite fuperno, collo, dorfo, \& alis fufcis ad colorem ca. ftanere nonnihil vergentibus, oculorum ambitu, mento, pectore, ventre \& Uropygio albicantibus. Digitis tribus anterioribus ad medium fere palmum exporrectis, pofteriore brevifimo. Inter anticorum extimum \& medium membranula eft divaricationis initio, qux inter alios defideratur. 
Altera Pinarolo dicta, huic fere per rina dicitur. Ef quidem hæc ejusdem omnia fimilis, nifi quod roftrum habeat cum Alauda magnitudinis, roftro oblonnigrius, aliquando brevius, cujus fuperna pars infernam longitudine nonnihil excedit.

Tertiam Bellonitus ad Gallinaginem minorem refert, Gefnerus Samethünle effe putat, uterque Cinclum Ariftotelis effe opinatur. Corpulentia eft fere eadem cum Scolopace minore fimplicirer dicto: plum marum tamen colore differunt, \& roftro, quod utrinque quidem tenuie, longum \& acutum eft; precedentis tamen in extremo maculatum eft, \& crafliufculum. Maculis albis in capite \& univerfo collo maculatur. Pectus vero, totufque venter, femora \& plume fub cauda nivem candore æquant. Ripas potifimum \& loca, quæ bono aliquo odore recrean $t, \&$ mofchum redolent, frequentat.

Quartum inter cinclos repofuit Turnerus. Alauda eft major, colore in tergo nigro, ventre albo, tibiislongis. Vere circa fluminum ripas clamofa eft. Breves \& crebros facit volatus. Anglis Hirundo Aquatica dicitur.

Quinta ex Motacillis credita, SJilwende gen / \& \$ilwegicfen Germanis in Mifnia vocatur. Palmipes quidem non eft, fed roftrumlongum, molle, cinereum : crura alta habet. Duio.ipfius funt genera, Majus \& Minus. Hoc magnitudine Merulæ, tergo cinereo, ventre albo.

Flumina colit, \& in ripis vagatur. In arenis nidificat $\&$ incubat, interdum inter faxa ova ponit. Supra octo pullos uno tempore non excludit.

Viens Mufcis, vermibus, \& pifciculis vefci-

Imgrefiss. tur. Domi, pane \& malorum vefcitur putaminibus. Singulari in mufcis capiendis arte pollet. Lento enim fufpenfoque gradu'accedens, roftro elevato primum defignat, tum captam predam déglutit. Manfuefacta conclavia $\mathrm{ab}$ araneis purgat.

Vix. Vocem noctu lacrymantis inftar edit.

2uarte congenerem Merulam aquaticam Gefnerus facit, quam Germani $\mathfrak{3} n$ dh amfer / Lucarni \& circa Verbanum lacum Folotvel Folum d' acqua nominant : nec non cornicem aquaticam, Sturno paulo minorem, quam in Alcyone defcribit.

\section{A P U T VII.}

\section{De. Iuncone Eु Cinclo.}

$\mathrm{J}$ Unco zow'res \& xoúviresos, quod in juncis libenter degat, qux Græci $\sigma x$ inns nominant, ita dicitur. Ariftoteles Trynga minorem, Alaudx amicam facit. Addit, fluvios \& lacus petere, ac caudam motitare,Bellonius pro ea quandam oftendit, quę Gallis Alouette de mer, feu Alauda magiufculo; cruribus nigris gracilibus \& oblongiufculis, lingu nigra univerfum roftrum longitudine æquante; linea alba fub alis infignitur, \& dum volat ejusdem fere eft cum Galerita coloris:fed quia maritima eft, nefcio an pro Juncone fumi vel poffit, vel debeat. Aldrovandus aviculam, qux Paffere d'acqua vocatur pro Juncone ponit. Pafferis eft magnitudine, roftro nigro candiculato, fatis duro \& in extremo adunco. Lingua candiculata, $\&$ qua definit bifida \& duriufcula. Cauda tres digitos longa denis pennis conftante. Mas à fomina hoc folum differt, quod in hac colores fint magis obfoleti; in illo magis vegeti.

Congenerem facit eam, cui eadem fpecies, roftri pedumque conformatio, \& colore tantum variat. Collum pronum, \& pectus albicant, fed venter totus ex cinereo ad fufcum vergit. Catera fufca eft. Turnerus dum Parum fylveftrem pro Juncone obtrudit, vehementer fallitur.

C I IN C L U s Græcis rizr $\lambda$ (G), Suid $x$, nif

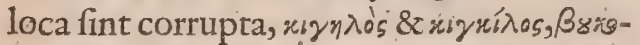
$\lambda$ ín Hefychio \& Varino, quod armenta fequatur, tertia eft exillis avibus, quxcaudam motitant, \& circaftagna \& flumina verfantur. Caudam motitare præter Ariftotelem, Ariftophanes in Tympaniftis prodidit. Volaterranus palmipedem effe fcripfit, fed falfo. Suidas gracilem \& nullo ferme corpore fcribit. Gefnerus cum rofto recto nigro \& longiufculo, ventre albo, pectore cinereo, cauda brevi ita ut eadem alarum longitudo fit, alis, dorfoque fufcis, cruribus ex ruffo fere luteis facit. Bellonius fecundam Gallinaginis minoris fpeciem Cinclum Ariftotelis effe putat. Idem Gallinaginum minimum genus, Cinclum minorem appellat. Tertia in quit Gallinaginis minoris fpecies primo generi magis quam fecundo fimilis eft. Roftrum enim ficut Scolopax major, craf fiufculum habet, $\&$ in extremo maculatum. Dorfum Sturno fimile. Aliquibus Deux pour un appellatur. Dux enim hujus generis, precio unius majoris væneunt. Aldrovandus de ea quam exhiber, an apud Aldror: mare etiam degat dubitat. Magnitudine Ornith, inquit Motacillam aliquanto fuperat. Color totius fere corporis inter fufcum $\&$ cinereum ambigit, fed alarum pennæ majores fubnigticant. Venter \& femora albicant. Roftrum nigrum tenue, \&longiufculum. Crura nigra, brevia \& exilia.

Congeneres ipfi dửas alias facit, quarum quoque Icones exhibet. Prior fub Cincli minoris nomine defcribitur. Altera iisdem quidem eft coloribus, fed caudam alban 
\&lineis nigris transverfim fecantibus ornatam habet. Roftrum quoque qua capiti jungitur crafiufculum, \& fenfim deinde magis magifque attenuatum. Quia pofteriore fui parte debilis eft, fuapte \& per fe nidum non conftruit, fed in alienis parit. Apud homines vivere non dedignatur. Captam maxime mitefcere tradit Philofophus. Videtur in Coryis Thracum Regis convivio apud Athenzum appofita, xizy-

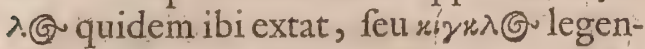
dum offe cenfetur.

\section{A P U T VIII.}

\section{De Vannello \&o Cercione Ave Indica.}

$\mathrm{V}$ ANNELL U S feu quod alis inftar vanni aut ventilabri commotis furepitum excitet, feu aliam ob caufam ita dictus, Fulica quibusdam, Stymphalis veterum aliis, fed falfo; quibusdam à voce, Bellon. de ${ }^{\circ} \mathrm{A} i \xi$, five Capella, Bellonio Parrus, Parus, Ávib.l.4. yel Parcis de quo apud Plinium, dicitur. Plin.H.N. Alcyoni congenerem. Gelenius facit; Plu1.r. c. 37. viali Gefnerus. Candidos reperiri audivit idem, nifi Lari fuerint. Sine crifta, iique aliquando colore fufco, \& maculis variis obfervati alibi. An Tremulus avis in provincia Salernitana dicta, quæ minor eft Gallina, coloris fufci, alte clamans, \& velocifime volans, quxque prope mare tefte Villanovano verfatur; \& cum fuper terra incedit, cauda tremit, unde ipfi nomen, fit ejusdem generis, difquirendum cum Gefnero relinquo. Exactifime à Bellonio deforibitur. Magnitudine inquit Plaridem vix excedit. Denfis admodum plumis contegitur, quæ in radicibus fuis qux corpus attigunt, omnino nigricant. Color enim alius eft in parte exteriori. Avis inverfa, fupinaque collocata, \& alis ejus extenfis magna plumarum pars in ventre; \& in femoribus nivei funt candoris. Ale in fuperiori quoque parte niveæ, in inferiori nigricant, \&cc. Hepar habet magnum, in duo partes utrinque divifum. Fel in ea reperire Bellonius non potuit. Inteftinum appendices habet.

Circa lacus \& amnes verfatur: aquas tamen non ingreditur, fed in planis \& erica confitis, utplurimum degit.

Vermibus, mufcis, cicadis, bruchis; fcarabxis \& aliisve fcitur. Albos lapillos deglutire, certum eft. Eftate fola volat, hyeme gregatim, \& tam frequenti numero, ut prata etiamfi ampliffima vix totum agmen capiunt. Alis eft obtufioribus, \& inter volandum magnum ftrepitum edit.

Vocem videntur Germani \& Galli per nomen ipfi inditum expreffife. Illi నivith hiDixhuict rocant.

Dum pullos fovet, ad hominem à quo nidum inquiri fufpicatur proxime accedit, $\&$ velut deditionem fimulat, donec â nido abduxerit, frepe multx unum hominem ita perfequuntur, ut eo facilius à nidis ab ducant.

Habetur in ciborum in Gallia delicis, $v$ fass. \& eodem quo lepus precio venditur $A$ deo pinguefcit, ut faginata videatur. Gefnerus boni faporis \& probi, fed levis \& tenuis alimenti effe comperit.

De Cercione quam Capellæ feu Vannello præmittere debuit, caudam enim motitat ita Elianus. In India avis ad Sturni magnitudinem accedens, variis coloribus picta nafcitur, qux \& humanam vocem effingit, \& Pfittacis vocalior, \& majore eft docilitate ac ingenio : non tamen humanum victum æquo animo fuftinet, fed libertatis defiderio famem potius quam fervitutem deliciis cibonum refer tam.amplectitur. Urbes, quas Alexander in India excitavit, \& Macedonibus inco lendas dedit, ut Bucephala cum adjacente agro, \& Cyropolis, alixque ideo Cercio: nem appellant, quod fimiliter caudam, atque Cinclus movet.

\section{C $A \quad P \quad U$ T $I X$}

\section{De Pluviali Gs Charadrio.}

DíL U.VIA I Is, Rhintace forte Plutarchi, quia nihil in ejus inteftinis excrementi reperitur, in agro Bononienfi Pivier, Gallis Pluvier, Germanis ßJutver \& Pufroll audit. Quomodo antiquis vocetur, ignorare fe fatetur Bellonius.

Duo ejus genera, flavefcens unum, cine- Geserie. reim alterum, quod Itali montanum. vo cant. Pulli Guillemot privatim vocantur. Illud Palumbi eft magnitudine.Roftro brevi, rotundo, nigro, acuto, \& in extremo nonnihil adunco, lingua triquetra, totam inferioris roftri canalem implente, prona parte fere cornea retufa.Pennix fuperne fufco albo luteoque colore ita diftinguuntur, ut ferratx appareant'; cauda quoque lineis fufcis luteis interfecatur:Boftico digito caret.Inter anticos tres membranula interjicitur, major inter medium \& extremum, minor inter eundem \& internum. Bellonius plumas ejus lutefcere fcribit, feu maculis luteis refpergi.

Frequens eft in Gallia, in Helvetia ra- Locis. riffima.Bononiæ non rara in foro venditur.

Rore victitare prodidere quidam, quod $r$ ichis. in ventribus earum nihil inveniatur. Nihil falfius. Ex humidis campis vermes eruit. Scarabros in diffecta. Invenit Bellonius. Lumbricos edere afferit idem, quia folum inteftinum jejunum habet. Ideo in eo nihil invenitur. Migratoria eft. AEftate nulla in Gallia cernitur, vere paucæe: Non minore numero, quam quinquagenario volant. Volature ventum fequuntur', 
raroadverfo tendunt, ut Bellonius prodidit.

Vox ipfis huit, huit fibilo qui porrectis labiis edi folet fimilis. Noctu folæ degunt; fummo mane diverfis in locis fpargæ confpiciuntur, quartamque aut dimidiam milliarii partem occupant. Imminente die, ut fimul conveniant, fibilum, fefe mutuo vocantes emittunt. Uni in toto grege tanquam Regiobeditur. Huic vox maxime fonora. Ad auditum undique confluitur. Aucupes Appellatorem vocant. Inter $\mathrm{Cupedias}$ in Gallia ponuntur. Ita ut in hominem delicati cibi nimium appetentem, ne Pluviali quidem oppofita contentum fore, alicubi tanquam proverbio dicatur. Apparanda non exenteratur.

leiro. Ot- Pluvialem Cineream Ariftotelis Parda-

65.

65. tota fere fit cinerea, quod de Pardalo prodidit Ariftoteles; tum quod maculata, unde Pardalo nomen. Pluviali fimpliciter dicta eft aliquanto major. Roftro paulo craffiori \& longiori, poftico digito admodum exiguo. Tota fere cinerei eft coloris, \& multisundique refpergitur maculis, qux inter cinereum, \& caftanex colorem ambigunt. Alre caudam qux brevis eft, excedunt. Magna ex parte gregatim volat , nec fingularem videris, quod apud Ariftotelem legimus. Vocem frequentem nec gravem emittit.

Huc refer illam, quæ Plwvialis Major, Aldrovando. Roftro eft procero, fupina parte per pectus, ventremque candicat. Majores alarum pennæ nigricant, pedes funt longi, \& ad cæruleum vergunt. 'Digito pofteriore fere caret.

CHAR ADRIUs Gażx Hiaticula, quod circa fluminum alveum \& rivorum hiatus verfetur, qualis Ariftoteli avis fit, ignoratur. Nam colore \& voce pravum effe,noctu apparere,interdiu aufugere, quod de fuo Philofophus reliquir, multis avibus

Arint.H.A. competit. Er cum -Ariftoteles Icterum i.g.c. II. Chloreum feu Galgulum vocet, haud verifimile videtur, eam avem Charadrium effe, quam in Perfide \& raro quidem reperiri; atriis regum requiri, quod multi ei propter auxilium quod ictericis præftare Helidor. 1. creditur, Albertus ex Heliodoro, Eliano 3. Hiftor. \& aliis afferit. Aldrovandus pro Charadrio aviculam exhibet corpore toto ex cinereo fufcam, Roftro brevi, fi cum aquaticis, longo, fi cum aliis conferas. Capite toto nigra vitta cinctam, cruribus oblongis \& gracilibus, colore ad rutilum accedente, fronte \& collo candicantibus, pedore nigrefcente. Quia ințerdiu latet, noctu progreditur,

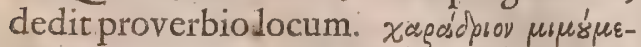
v(G), qui rem utilem occultat, dicitur. Ietericos folo afpectu fanare multi produnt. Philes Rubetam fpectantem icte- riciaaffici, rurfus Charadrion, liberarintgatur.

\section{T I T U L U S III.}

\section{De Avibus Fißipedibus Herbivoris.}

\section{A P U T U N I C U M.}

\section{De Grue.}

A Vis quam Gruem Latini àgruendo, Martialis. Poëtx Palamedis avem, quod is Trojano bello, quatuor literas $\phi \xi x \& g$, ordinem aciei, \& tefferas à Gruibus didiciffe dicatur, vocant, Græcis communiter zsesvós, quod colore cinereo \& quafi cano tanquam $\gamma^{\prime}$ '́c appareat; Tyrrhenis Tiris, \&

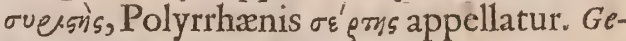
nera ipfarum apud Tartaros plura Venetus Venet. Reobfervavit. Sunt quædam alis nigris: aliæ rum Oricandide, pennas oculis aurei coloris plenas c,64. habentes. Nonnullix parvæ, pennis longis rubro nigroque colore perunctis inftructx; quædam denique magnæ, grifei cinerei coloris, oculos rubros \& nigros habentes. In Cuba duplo noftris funt grandiores. In alia Americæ parte rubras coloré coccineo Columbus obfervavit.

Dedefcriptione non eft quod fimus folli- Defcriptio. citi. Collum ipfi duos dodrantes longum, quod Philoxenus feu os Eurixidis F. feu Athen.Dis Cytherius, gulæcirca pifces mancipium, pnofil.r. fibi optabat. Anterior ejus pars ad latera nigricat, prona albet. Vertex cum macula rubente niger. Omnia reliqua cincrea præter majores alarum pennas. In alis rea tro verfus caudam pulvæ \& crifpæ funt, quas auro \& argento ornatas juvenes pilis affigere folent. Arteria afpera penitus in carnem ad os fternon inferitur. Ideo non mirum ex tam longinquo audiri.

Nulla non in orbis parte vifuntur, uni- Locus verfum enim fere, caloris amicx, peragunt. Circa Hebrum, Strymonem \& Cniftrum magna ipfarum copia. ExThracia, ubiæitate vivunt, hyeme ingruente traji-

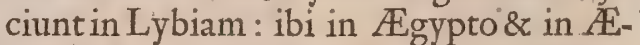
thiopia hyemem tranfigere $I$ Llianus prodi- $A$ lian. $\mathrm{H}$. dit. De Tartaria fuperius diximus, quæ ve- A.1.3.c. P.13. ro de Pygmxis Plinius habet, fabulofa 1.4.c. 1I. funt. Cibus ipfis fruges, \& herbæ.

Illd \& Suidas innuit, cum dicit, yéegyot $V^{i}$ itus.

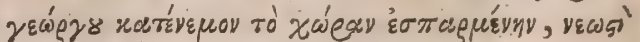
$\pi v e^{\prime} y \omega$ oit agrum noviter tritico fatum; \& Mantuanus Manituan. cum fcribit.

Strymonie de more Gruis, que femina campi 1.I. de COIact a legens aqua tepido fub fy dere libra.

Hoc apud Claudianum legitur. E Nilo Pygmea Grues poft bella remienfo Ore legunt rubrigerminacura maris:

Putantur tamen \& ferpentibus interdum. vefci. 
partus. Moventur in Fenerem cum obvio vento | narum notis infcribiaẻra, certun eff. Dú

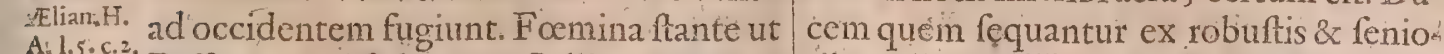
Pafferes, non fedente ut Gallinx, coëunt. ribus eligunt: Ubi cum defatigatio, quia ova bina, interqux lapidem fortuito etiam non habet, ubi nitatur, coeperit, proxiinventum deponere folitas, Albertus Co- mam iis qux acquievere fubftitutint; ealonix per annos aliquot obfervavit, nec plura pariunt. Quomodò exclisdant, à nemine quantum fiam hactenus prodirum eft.

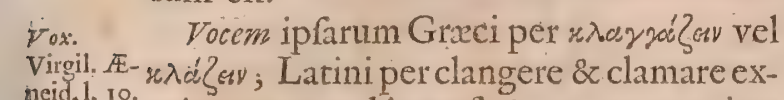
meid.1. ro. primunt, quod intenfo \& magno cum imAriftoph. peti prolata vociferentur. Ariftophanes

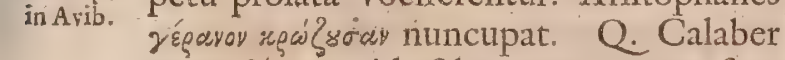
mavu $\phi$ งó $28 s$, id eft longum \& protenfum fonum edentes dicit. finiunt. Honorius anno octavo fenefcere tradit. Leonicus Tomaus quadraginta Aritt. de continuisannis unam domi aluit. Ariftogen.1.5. teles pennas Gruum in fenestute nigrefce6.5. re tradit. Seu quod pennarum earum natura albicet, plusque humoris fenefcentibus iis conftituatur, quam ut facile putredini pateant : feu quod terreftris humidi ipfarum natura à calore imminente non fatis concoquatur. Solinus fulvas reddi fribit. Ingrediendo pedes ante fe jaciunt, \& implumes tam celeriter aliquando currunt, ut curfu hominem vincant.

Nec minor Volatus velocitas. Cyrus per intervalla locorum fuos tabellarios ita difpofuife legitur, ut fatigatis recentes \& nocturni diurnis fuccederent; fic volantes Grues fuperarentur.

Plutar. in De Migratione mira ab Autoribus proArittotele. duntur. Ex Grecia Mrmacterione in A.1.2.c.r. quem $\mathbb{E}$ Equinoctium incidit, difcedere Tzetzes. notavit Plutarchus; ex Helvetia XI. Seprembr. audivit Gefnerus. 'Thraciam relictam ad Hebrum fluvium conveniunt, \& in turmas difponuntur. Maxima nata luAtrato ter exercitu, corruit; fepulta ad iter in Egyptum accinguntur. Volant alte, feu ad profpiciendum, quod Plinio \& Ifidoro placuit, feu ut, confpectis in tempeftatem plut.defo-nubibus in terram fefe referant. Exacte femalium, cundum ventum fervant, raro contra impetum nifi fugiendo nituntur. Et in tergo pręter volantium colla \& capita reponunt. In volatu trianguli formam efficere animadverfum ab Ariftotele. Ejus autem fummo Cicer.4. de angulo aër $\mathrm{ab}$ iis adverfus pellitur : deinde Nat.Deor. fenfim ab utroque latere, tanquam remis Plutarch. ita pennis curfus avium levatur. Bafis trian1.c. Lucan.l.s. guli tanquam à puppi ventis adjuvantur. Tempeftate mota; vel in triquetram figuram conducto agmine cufpide ejus circumfluum aëra findunt, vel immix́ræ glomerantur in orbes, vel contenta in finum falcatzque feruntur. Literam ypfilon quibusdam exprimere; $A$ vel $\Lambda$ aliis creduntur. Unam fequi ordineliterato, \&pen-

que vicifitudo in omni curfu fervatur. In Arit. Hi extremo agmine per vices qui acclament, $3^{l, g, c, 10}$ difpofitos haberit, \& qutui gregem vocé contineat. Excubias habent nocturnis femporibus, lapillum pede fuftinentes; qui laxatus fomno \& decidens indiligentiami coarguit. Cæxteræ dormiunt cäpite fubter alam condito, alternis pedibus infiften tes, Dux cum aliis erecto providet collo ac prodicit. Lapidem deceffuras deglutire auri indicem poftquam deciderit utilem, féu ut ita facilius ventorum turbini pondere refiftatur, quod \&lianus voluit; feu ut de via feffr, \& quietem parantes, jactu terram \& aquas explorent, quod $A$ riftophanes Byzantius credidit, prodidere quidam. Roftro eum fufcipere, ne in volatu navis inftar fluitent, Maximus' Ty rius fcripfit; ut vocem Taurum montem Aquilis plenum cohibeant, alii: Falfum Plin.tA. id Ariftoteles reliquit: lapides pedibus l.ro.c.iz: complecti, cum digitis is incurvantur ex lyhift. $\dot{c} t \mathrm{t}$; Alberto habemus. Certum eft, inquit Plinius, Pontum transvolaturas, primum omnium anguftias petere, inter duo promontoria Criu metopon \& Carambim, mox faburra (fed non ut alantur, quod Elianus fabulatur) ftabiliri. Cum medium tranfierint, abjici lapillos è pedibus, cum attigerint continentem è gutture \& arenam. Cum ab $\$$ gypto in Europam a volant. Duces non adhibent.

De Antipatbia hoc duntaxat occurric, ab affectatis Aquila infeftinari. Ita inter fe interdum ira exardefcere, ut dimicantes capiantur. Vifús aliquando mas foeminæa àd internecionem ufque undecim vulnera inflixiffe, quod pullos quo minus fe fequerentur, abftraxiffet, fi Alberto fides eft. Qux de Pygmaorum cum Gruibus pagna ab Ariftotele, Philoftrato, Menecle \& aliis produn-Ariat. $H . \&$. tur, fabulofa effe ex Strabone cognofces. 1.8. e.r. Adventus earum, Arationis tempus indi- Georg. cat. Si vel vociferantur, vel per apertum $\begin{gathered}\text { Hefiod, in } \\ \text { Die. }\end{gathered}$

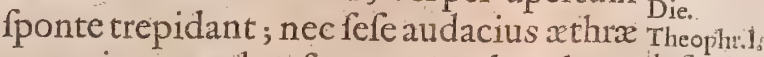
committunt vel vefpere, \& ad multum de fignis tempus volant, tempeftatem minantur. ${ }^{\text {temperts }}$ Si mane \& gregatim volent, ferenitatem promittunt:

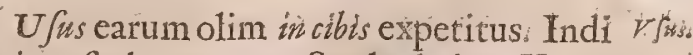
ovis vefcebantur, ut Strabo habet. Varro

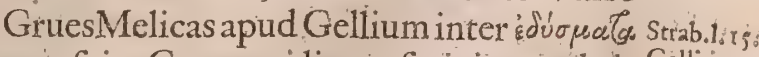
repofuit. Grues oculis confutis in tenebris Gellins.
faginatos Plutarchus teftis eft De fuis temi- Plut.1. $6_{0}$ poribus Plinitis. Cornelius Nepos qui Di- ciu Carms vi Augufti principatu obiit', cum fcribe- ${ }^{\text {vor. }}$ ret turdos paulo ante faginari cxptos, addidit, ciconias magis placere, quam.

$$
\mathrm{Q}^{2} \text { grues }
$$


grues : cum hrc ales inter primas expeta-

Plin.1.c. tur: illam nemo velit attigiffe. Sed \& hodie hybernos apuid Gallos cibos nobilitat.

Bruier. 1. Inaffant caryophillis per foffas \& pipere.

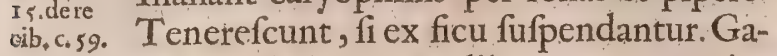
lenus, Egineta, \& alii carnem earum interfibrofas \& duras repofuere. Anaxandri-

Athent des, cum Iphicratis nuptiarum cum Thra-

1.12. cix Regis filia convivium ridet, Gruem ibifuiffe, qua frontem diftenderet, hiante podice, difciffis lateribus, dicit.

Quantum ad Medicinam, Torminofis in cibo profunt. Jus vocem clarificat, \& fperma auget. Caput, oculi, ventriculus exufta in pulverem fiftulis \& varicofis ulceribus infperguntur. Adeps omnes duritias cum Anferino diffolvit. Pulmonis vulturinidextræ partes venerem excitant viris adalligatæ gruis pelle. Penna ferpentes ftupidos reddit.

Flin.H. N. Et hæc de Grue in genere fufficiant.Spe1. 30. 6. 15. ciem quod attinet, quia B A L E A R I C A M Plinius Cirrhos in capite more Pavonis gerere fcribit, Aldrovandus eam fubftituit,
A T U R A L I S, \&c.

quam Bellonius cuidam Ardex generi ad: fribit. Vulgaris eft Gruis magnitudine; \& eodem plane corporis habitu, roftro ê cinereo fufco, vertice nigro, in quo cir-rhus erectus nafcitur, plurimis tenuibns \& fubtilibus aurei coloris pennis. Utrinque in temporibus maculam habet oblongam, candidam, ex cujus inferna parte utrinque oriuntur palearia rofei carneivé coloris. Collum, pectus, venter, cruraque tota ex cinereo fufca funt. Circa caput viride invenitur. Alas erigit, \& quandoque velociffime currit. Vefcitur herbis viridibus, quandoque furfuribus \& hordeo. Sub noctem altos parietes aut arbores more Pavonum quærit.

De J A P P ONENS I nihil fingulare OCcurrit. Tota fere candicat, roftro, collo inferiori, pedibus \& alis internis exceptis. Vertex capitis imfigniter rubet, ac nigris maculis refpergitur. Media pars colli inferior nigricat. Sub alis pennæ dependent fatis magnæ, multis infignir $x$ appendicibus, nigrx; crtera tota avis nigricat.

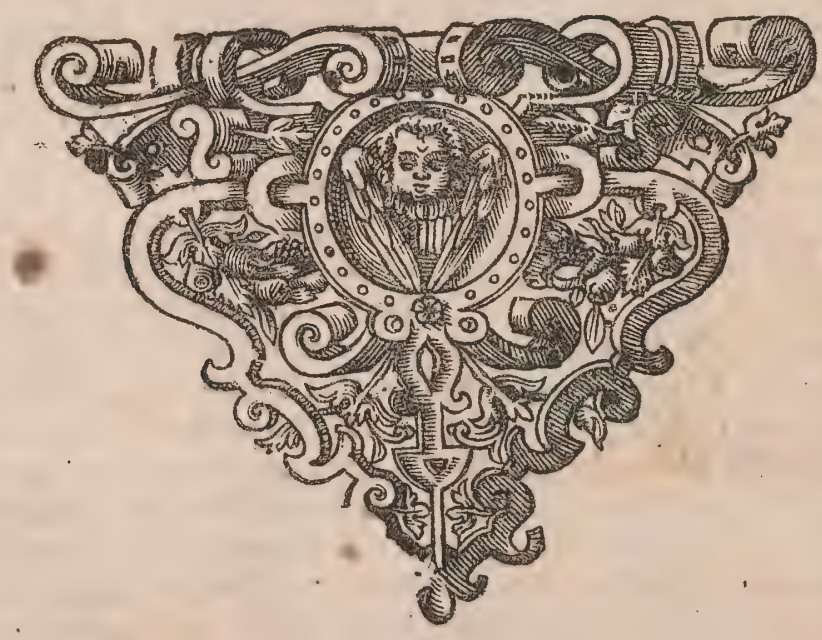




\title{
HISTORIA NATURALIS
}

D E

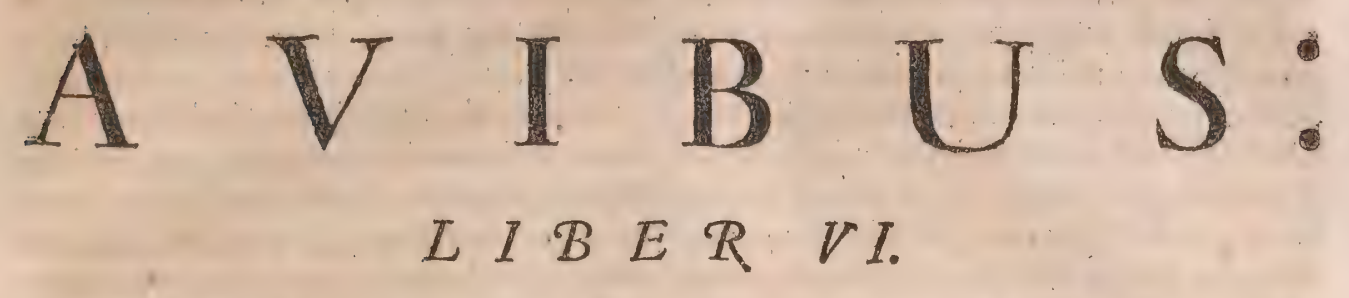

\section{De Avibus Exoticis, Americanis inprimis.}

\author{
T I T U L U S I.
}

De Avibus Exoticis.Terreftribus.

$\begin{array}{lllllll}C & A & \mathrm{P} & \mathrm{U} & \mathrm{T} & \mathrm{I}\end{array}$

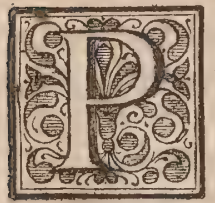

Oterant \& iftx fuperioribus inferi, nifi accuratam, plærarumque defcriptionem $\mathrm{Au}$ thores nobis invidiffent. $\mathrm{Hac}$ quia deftituimur, dicendum promifcue de illis erit, ne aliquid in hiftoria Avium fcitu dignum omififfe videamur. Si quid occurret, quod fuperioribus annecti poffit, Additamentis $\mathrm{D}$ E o volente inferetur. Incipiemus à $\mathrm{M}_{\mathrm{A}} \mathrm{N}$ u $\mathrm{co-}$ D I A T I $s$ five avibus Dei, ut Moluccani vocant. Hx aliis interdum Apodes Indicæ: interdum Aves Paradyfi, feu ob corporis fpeciem, feu quod ubi locorum nafcantur, unde veniant, quo fefe recipiant, ignoretur, vocantur; quamvis \& ad Phyfonem fluvium quxdam obfervatx fint, quibus idem, ob miram corporis fpeciem, \& plurimam colorum diverfitatem, nomen inditum erat, \& in Ægypto fufc \& fubrutilæ Monedulis minores, fub eodem nomine videantur. Magnitudo certa non poteft illis adicribi, quædam hirundine paulo majores vifæ funt. In Java columbarum magnitudine obfervari, à fe $\mathrm{Pi}$ ca maxima non minorem vifam, Scaliger reliquit. Omnibus peculiare eft, ut pedibus careant (quamvis Ariftoteles nullam abfque pedibus avem dariafferit, \& Pigaffetta pedes illis palmum unum longos affignet) \& in cauda veluti fila quxdam vel nervos obtineant. Caput ipfis non rotundum, fed preffum, nucis juglandis ferme tnagnitudine. Roftrum non om nibus æque magnum, neque ejufdem etiam coloris. Ala \& cauda expanf $x$, Accipitrinis Milvinis- que maginitudine refpondent: Pennæe fun tenuiffimx, \& præter tenuitatem pennis Pavonum fominarum ex toto perfimiles. Alx in arctum contrahi, vel in latum diffundi pro animantis lubitu nequeunt, fed naturaliter uno tantum eodemque modo perpetuo confiftunt. Dorfo fila gemina an nectuntur, tres \& amplius palmos longa , neque exacte rotunda, neque perfecte angulata,fed figura inter quadratum \& rotun dum media. Intus continuata ac perpetud, pinguedine totæexpletæ funt. Falfo perpe tuum volatuin exercere, quod non nifi mortux in terravel mari inveniantur, traduntur; nec verius affirmatur rore duntaxat pafci, \& ova in mafculorum dorficavitate incubari \& excludi. Sane quiete neceffario indigent, \& filis illis in cauda facile ramis arborum annectuntur, nulla hactenus in vifarum dorfi obfervata cavitas; \&cum tum. alte volent, tum animalia fint perfecta, quomodo rore, qui prope terram nafcitur; nec folidum alimentum fuppeditat, illas ali dixeris? Magni à Moluccarum Regulis funt, qui fe, fi illarum pennas portent, in pralio vulnerari non poffe, etiamfi in pri ma acie collocati fuerint, credunt.

Species ipfarum quinque defcribit Al-skecied drovandus. Prima hirundinem magnitudine, \& forma, fi corpus fpectes, pene xquar.Pennarum ambitus difcolór eft, fed admodum venuftus, \& vifu undique jucin* diffimus. Caput quale Hirundinis, \& pro corporis parvitate majufculum : cujus plu$m x$, qux fuperiorem partem à prima cervicis vertebra ad roftri ufque initium exornant, breves funt, craffe, durx, fpiffe, colore huteo egregie micantes, \& ad inftar pu rifimi auri, radiorumque folarium more refpondentes:reliquæ, quæ mentum contegunt, molliores, tenuiores, \& ex cyaneo

$$
\text { - Q.3 mire }
$$


mire virides, ut in Anatum mafculorum capitibus, dum lucidifimo fideri obvertuntur, confpicimus. Roftrum quam Hirundini prolixius. Alarum pennx forma Ardearum fimilesfint, tenuiores tantum, aclongiores; fufcx, inter nigrum, \& ruffum fulgentes: qux una cum cauda in orbem expanfx, rotæ fimilitudinem exhibent. Etenim plane immobiles funt, \& veluti infixa quxdam fpicula cuti adhærent. Cæterum minores quoque aliæ pennulæ, exque profecto haud paucx juxta fingulas majorum pennarum, qux alas conftituunt; origines, exoriuntur, qux fupra majorum principia extenfx, ea obtegunt, dimidio quifquiliatæ, ruffæx, coccineæve, cxtera crocex, \& fulvo auri colore fplendid $x, m u l-$ tum mehercule gratix ac venuftatis aviculæ ob eximiam illam \& fingularem colorum difparitatem conciliant.. Corporis reliqua moles tota pennis fulvis in ruffum vergentibus obducitur, ita tamen ut aliquid adhuc inter eas difcriminis advertas. Nam qux in pectore \& ventre collocantur, \& frequentifimæ funt, \& pariter latifim duorum triumve digitorum amplitudine fulvo funt colore, \& eo quidem nitidiffimo, haud fane alio quam jecur ipfum fplendentes. Quxvero dorfo infiguntur, rariores, neque ita frequentes funt, atque infuper amplis divifuris pennarum omnino Ardearum tergo adhærentium fimilitudine hiant : neque etiam ad tam infignem latitudinem accedunt : aut præftantem illum hepatis colorem adæquant, quinimo puniceo potius colore, carni $x$ mulo, obfcuriore etiamnum relucent. Fila illa gemina quæ dorfo annectuntur, quodammodo nigra funt.

Altera caputhabebat album fere, maculis luteis, aureifque perfufum, oculos pariter luteos, cilia rubicunda, roftrum inter luteum, \& viride medium, duos digitos longum, in fupina parte quodammodo recurvum, linguam rubicundam, longinfculam, acutam, Picorum haud plane diffimilem, ad lancinanda animalcula perquam idoneam. In pectore aliquo pacto rubefcebat. Venter, dorfum, \& alæ candicabant, hx tamen fuperius ubique, $\&$ in fine erant ferruginex. Dorfum primo ad flavum quodammodo tendere videbatur; pofteaquam vero uropygium attingit, ad rubicundum, feu ferrugineun colorem vergebat. Alarum longitudine, utpote, qux quinospalmos adæquant,primam fpeciem fuperabat. Caudxe pennæ, ubidorfo inferuntur, candicabant: cxtera ferruginex erant. Ejus dux pennæ reliquas duorum palmorum longitudine vincebant, \& reliqux etiam quam in prima longiores aderant. Carebat hrec avis geminis illis filis, qux omnibus è dorfo enafci fupra dixi: quare velitinerislongitudine, vel temöoris vetuftate decidiffe ea judicandum eft, non autem fominam ideo dicendam, ut peiperam vulgus hactenus fibi perfuafit. Duarum vero longiflimarum illarum pennarum fortaffis ad velociorem motum ufus fuerit.

Tertiam ob corporis longitudinem Hippomanucodiatam, quoniam longiorem videre mihi nunquam contigit, appellare placuit, qux videlicet à principio roftri ad caudx, \& alarum extremitatem tres dodrantes longa erat; \&ad duos palmos, cum alæ complicatæ funt, lata. Roftrum erat fatis aduncum, in fupina maxima parte, tres digitos longum, inferna vero paulo brevius. Tota vero avis erat alba preter nempe collum, \& ventrem, quorum color eft caftaneus. Superior capitis pars ferruginea, quem colorem flavus excipit, ut hunc viridis. Prope dorfum pennæa admodum prominebant longitudine duorum, vel trium digitorum. Erat præterea unicum duntaxat Avi filum, idque afperiufculum, \& admodum flexibile, quare alterum cafu quodam amiffum fuiffe exiftimare debemus.

Quarta à roftri principio ad alarum extremitatem ufque commenfurata duos do. drantes explebat. Roftrum pro corporis exiguitate longifimum, nigrum \&x quodammodo aduncum. Capitis, colli, \&alarum penna nigrefcebant,ubi tamen roftro adnectebantur, flavefcebant. Cirrhum prope cervicem tres propemodum digitos al tum habebat, rigidum, coloris flavi, quique ex fetis potius, quam pennis conftare videbatur, atque eo maxime à fubfequenti Manucodiata differebat.

Ultima magnitudine eft Turdelæ, miræ levitatis, alis oblongis prædita, teneris \& vifui perviis, \& pennis (fi pennæ dici poffunt potius quam fetæ: deplumes enim funt, duarum longis, anguftis, nigris, duritie cornea; pedes nulli, perpetuo volat,nec ufquam quiefcit, nifi in arbore aliqua, longis illis fetis ramo implicata pendens. Nulla navis tam celeriter pergit, \& tam procul à continente, quam non circumyolet.

Huc $R_{\text {H Y N T A CE ctefix pertinere vi- }}$ detur, qux ovi magnitudine, gallinacei forte, in Perfis nafcitur. Hefychio \& Pha-

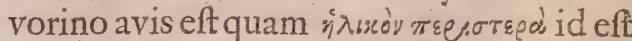
columbx magnitudine. Nonnullis Pluvialis avis dicitur, nec folido cibo ve fcitur.

\section{A P U T IT}

De Avibus Daje, Guitguit, $M$ aja, $X_{\text {ochi- }}$. tenacatl, छ Iajaubquitototl, Єఠఁ.

Mericanis nominibus utimur, quia A de Exoticis nos acturos recepimus. 
Poffent \& Latina imponi; quod Nierembergius fecit; fed metuimus, ne Lectoris judicium turbetur. Unicuique ad fua genera unamquemque revocare licebir. Avis $D$ AII $E$ columbam non excebit. Nidum quatuor fpithamas altum, locis fabulofis, cauda ac pedibus excavat. In eo ova per imbres anferinis majora, \& pugnum fere lata, quinquagena plurave, citra ullum albumen, crafte \& pinguis fubftantix, ponit. Excluduntur hæc citra incubantis parentis opem atque teporem. Exclufi pulli ftatim evolant. Avis eft commode edulis. Oya affa coctaque boni \& pinguis funt alimenti; frixa mali \& concoctu difficilis.

Guit Guit minima eltavicula, Regulo fimilis, viridi colore, \& fuavi natriNierenb. mento. Ea eft naturæ rerum vis, ut hæc tanNature ta avis ac fere nulla, audeat perfequi corxo.c, $\sigma_{0}$ vorum examina, eofque cogat ubilibet latitare, \& fe adverfus illam in arundinetis tueri. Corripetam Nierembergius dixit.

$\mathrm{M}_{\mathrm{A}}$ \& colore fulvus eft, \& in colli poftica parte caput (dictu admirandum, \& nulli alii animali conceffum ) ventriculus, primumque nutrimenti receptaculum, fi Idem. lib. Authoribus credendum. Gregatim in $\mathrm{Cu}$ c. 7. ba volant, \& Oryzz cujus maximus apud eas gentes proventus, fata devaftant. Cedunt menfis, \& grati multique nutrimenti effe dicuntur.

X С С IT EN A C A T L columbæeft par, roftro craffo acuminato \& nigro, Oculis nigris, iride lutea, alis caudaque albo \& nigro colore variatis, tænia nigra à roftro ad dextrum ufque pectoris procedente, alis vero circa priores partes etiam luteis, ac univerfim reliquo corpore pallenti, fi demas pedes \& crura quæ fufca funt, \& ungues ipfos, qui ex albo nonnihil pallefcunt, Vivit juxta arbores floridas, quarum melligine vict itat. Educat fobolem, habeturque à Tototepocenfibus apud quos eft frequens, maximi.

Iden. 1.c. J A J A U C I T O T O T L corpufcúlo fturc. ro. num xquat. Viridi, cyaneo, fulvo \& cinereo variegatur. Dum illi ab extrema cauda pennx prodeunt reliquis longiores, priori parte depiles, in'extremitate cyaneis ac nigris ornatæ pilis." Videtur ad Pafferes Indicos referri poffe.

\section{A P U $T$ III. \\ De Avibus Tuputa, Tentron tototl, Tritono, \&ु Hoact 2 in.}

Nierenib. Hift. Nat, Exot.1.10
C.I 4 .

$\mathrm{N}$ Nfolens in $T$ U P U T A natura. Viva tota vermibus farcitur. Hos pro carne habet, his fingula membra imbuta : preter hos \& pellem nihil carneum. Cutem non perforant denfis exornatam pennis. In carectofis \& herbofis locis verfatur, ad proceras arbores naufeat. Hxc ab Hernando habemus, fi eximix fidei is author eft.

QUAPA CH Tо т OTL octo nucias lon: ga eft, ac toridem cauda, Roftum è cyas neo nigrum, longiufculum incurvurnque, oculi nigri, iris alba ; pectus cinereum, ac inde ad caudam ufque venter niger, cauda ex nigro fulvefcens, alæ vero collum atque caput fulva. Rifus humani eft æmu la, hinc Ridibunda quibufdam. Et propterea inaufpicati ominis infamia Indis erat infenfa.

TENTZ ON Totot L appellaturavicula Paffere minor, colore fufca, pilis quibufdam ad roftri radicem circumcirca pro: pendentibus, barba inftar. Inde nomen ufurpavit.

TR I T o N U s pulcherrima, \& mirifico Nierétibs, colorum ornatu variegata proditur, Patria 1.10. H.N ipfi Hifpaniola. Tribus vocibus canit.Scilicet pæne indivifibilibus modulis variat cantum, $a b$ avita voco in alias fubitu dilapfa, ut videatur una omnes edere, unoque fpiritu multoos formare tonos, tanquam fi à tribus gutturibus fabricarentur.

H o A c i $Z$ I N Gallinx Indicx fere eft magnitudine, roftro incurvo, pectore candido in luteum inclinante, alis caudaque maculatis per intervalla pollicis, colore candido \& pallenti, dorfo ac fuprema parte collifulvis, fed utrifque in fufcum colorem inclinantibus, proterea etiam $\&$ temporibus ufque ad roftrum \& oculos. Unguibus nigris, ac fufcis cruribus. Ge ftat criftam è plumis è candido in pallidum colorem vergentibus, fed dorfo earum nigro. Vefcirur anguibus. Vivit in calidis regionibus, qualis eft Yautepecenfis, magnaque ex parte arboribus juxta flumina confitis infidet. Apparet Autumno. Vox ei magna, \& ululatum quendam reprefentans. Inaufpicata $a b$ incolis habetur. $U$ fum in Medicina invenit. Offa dolorem cujufvis particulæ humani corporis lancinatione fedant. Suffitus quoque plumarum, mentem reftituit his è morbo aliquo ea parum confantes evafere.Pennarum cinis in tra corpus fumptus, morbo Gallico affectis opera mirabili medetur.

\section{A P $\quad$ U $\quad T$ IV.}

\section{De Ave Emeu.}

Vem Emeu feu Eme Clufii potius verbis, qui eam accuratifime defcripfit; quam meis depingere malo. $\mathrm{H} \mathrm{c}_{\text {, }}$ inquit ifte, dum furrecto capite incedebat, quatuor pedum, \&zaliquot unciarum altitudinem excedebat: nam collum à fummo capite ad dorfi initium tredecim pæne un cias erat longum, ipfum corpus binos pedes latum, femora cum cruribus ufque 
ad pedum inflexionem decem \& feptem uncias longa ; corporis autem ipfius longitudo à pectore ad Vropygium trium pedum ferme erat. Penne feu verius plumæ totum avis corpus cum infima parte colli, dorfo \& pectori proxima, atque femora tegentes, perpetuo erant geminæ, ex eodem parvo brevique tubulo prodeuntes, \& fibi invicem incumbentes; fuperna quidem paullo craflior, inferna vero tenuior, \& delicatior, illæque variælongitudinis; ut in frmilis avis exuvio, quod Chriftianus Porretus Leydenfis pharmacopxus diligentiffimus, habebat, obfervabam. Qux enim in infima colli parte breviores erant, qux in medio corpore \& lateribus longiores, fexvidelicet aut feptem unciarum, qux autem in extremo corpore circa oropygium (nam cauda carebat) novem uncias longx \& reliquis duriores. Quanquam omnes du$r \mathfrak{x}$ aut rigid $x$, attamen non lat $x$, fed anguft ; \& rarioribus lateralibus pilis ex adverfo fitis preditæ, nigricoloris, qux tamen circum femora ad cinereum fere tendentis, nigro permanente nervo, ut in reliquis : eam vero formam, \& fitum habebantillæ plumæ, ut à procul afpicientibus non plumis fed villis duntaxat tectumejus avis corium exiftimari poflit; quale urfinum eft, \& alis carere, tametfialas haberet, fed fub plumis latera tegentibus latentes, \& quatuor majoribus pennis nigris præditas, ut in exuvio obfervabam, tametfi illæ abruptæeffent, nec de illartum longitudine ceati aliquid pronuntiare poffim; caules tamen confracti fatis craffi, durique \& folidi erant, atque in extimam ala partem alte penetrabant. Ale vero pars fuperior corpori contigua pennas five plumas veftitrices, illis fimiles, quæ adhuc in pectore retinebat; adhoc enim datas hujufmodi alas cenfendum, ut currentem adjuvent, quia hanc avem non effe volucrem, necà terra tolli poffe arbitror. Crura in ambitu quinque unciarum craflitudinem fuperabant, crebrifque corticibus feu fquamis latis tecta erant, prafertim fupra pedis inflexionem. Pedes habebat craffos, duros, tribus craffis digitis preditos, prona parte velut fquamis tectos, fupina prorfus callofos: quorum medius, qui reliquis longior, tribus articulis conftabat, interior uno, exterior binis. Omnium ungues valde magni, binas pæne uncias longi, crafli, duri \& cornei: Ejus caput exiguum pro avis magnitudine \& fere glabrum, coloris ex atro crerulei cum colli fuprema parte, in quo apparebant rari pili nigri: oculi paullo fupra roftri fiffuram magni, ardentes \& truces, leonis oculis pæne fimiles, quos cingebant nigri pili, quemadmodum \& meatus illos aurium parvos \& detectos, quos pæne oculos habebat. Roftri prona pars quemadmodum arcuata erar, pauloque fupra mucronem binis foraminibus, narium ufum præbentibus, prædita:à cujus medio ad capitis ufque verticem porrectum diadema affurgebar cornex fubftantix, tres fere uncias altum, coloris ex flavo fufci, quod cum plumario defluvio cadere, \& cum plumærenafcuntur, novum crefcere intelligebam. Supina roftri pars, ab ejus fciffura ad extremum mucronem quinas uncias longa. Anterior colli pars quatuor prive uncias infra roftrum, bina velut membranacea palearia, feu barbulas, propendentia habebat duas uncias longa, coloris rubriminiati. Poftea fimiliter colli pars deplumis, à capite fecundum longitudinem rubriminiati coloris erat; deinde infirma ejus pars aliquot, rubris plumulis, quibus nigræ intermixtæ tecta. Cæterum tametfi hæc avis aliquas notas habere videatur cum ftruthiocamelo communes, velut exiguum caput, natura prene calvum, quodque fine delectu vorat quidquid objicitur. Pedes tamen bifulcos non habet, fed tribus digitis præftitos, ut ante diximus, fine calcari, otidis five tard $x$ pedum modo: ideoque adeo firmos \& robuftos, ut in illuftriflimi Cômitis horto, (quem cum ipfo Comite ingreffus eram ut avem confpicerem ) arborem humani femoris craflitudinem æquantum prorfus contufam viderim, \& ejus corticem fublatum ab hujus avis, comite, id afferente, pedibus \& unguibus : etenim non roftro antrorfum, fed. oblique fe convertens, averfis retrorfum pedibus, eos, cum quibus pugnabat, impetere folebat.

Licet vero quæcumque objiciebantur viđus. voraret, ut aurantia mala integra, \&rfimilia: ordinarius tamen ejus cibus erat fimilagineus, five primarius panis, quem in magna craffaque fragmenta divifum, objectum vorabat, maxime enim recentibus gallinarum ovis delectari intelligebam, qux integracum ipfa tefta glutiebat, fi autem parum firma effet valetudine, illa ipfa integra per anum rejiciebat, deinde rurfus ea vorans retirebat $\varepsilon z$ concoquebat. Mihi autem affirmabant, hancavem fuiffe marem, \& ex poftica parte penem, cameli inftar, interdum exerere effe confpectum. Audio porro, illas naves quxe anno à Chrifti nativitate millefimo fexcentefimo tertio ex Moluccis in Hollandiam redibant, binos fimul aves quidem attuliffe, fed in itinere mortuas projeciffe; tametfi earum exuviæ five coria, ob raritatem, cenfervari potuiffent: illius avis aliquot ova nihilominus relata certe terna aut quaterna codem anno Amftelredami confpiciebam à mercatoribus redempta, \& paullo etiam ante unum Leydæa apud Porretum videram, omnium, mea opinione, maximum \& pulcherri- 
mum:dinenfi enim per longitudinem ambitus'quindecim unciarum erat; per cransverfum autem, duodecim, aut paullo amplior, ut propter amplitudinem pro quodam vafe non minus haberi poffet, quam ftruthiocameli ova, quibus, tefte Plinio, veteres nonnunquam utebantur, \& adhuc noftra ætas ejus rei gratia ufurpat; nam non femel videri meminiftruthiocameli ova argento excepta \& inclufa, poculorum vicem præbere. Hujus tamen avis ovi tefta non erat valde denfa, nec alba veluti ovorum ftruthiocameli, fed extrema parte virefcentis ex cinericio coloris, \& perpetuis, faltem creberrimis, quafi tuberculis fatura viriditate preditis ornata: illorum autem quæ Amftelredami confpiciebam, unum ejufdem prene erat cum illo magnitudinis, formæ \& coloris, quædam vero magis orbiculata, aliqua minora, nonnullorum etjam color dilutior, \& minus elegans. Porro mihi relatum, hujufmodi aves Moluccarum infularum non effe peculiares, fed etjam in Sumatra five Taprobana;vicinoque - illis infulis continente reperiri.

\section{A $\quad P \quad U-T \quad V$.}

De Avibus, Xochitototl, \& Auris.

$\mathrm{X}^{\circ}$ Осніт тотот L, forma. æmulatur pafferem noftrum, multicolor eft penna, pallet, nigrefcit, candet : partim quoHerrera exiguis feminibus vefcitur. Ex arborum raDeade 3. mis nidum conftruit pendulum. Ibi incu1ib.3. c.9. Novi orbis

bat ovis.

A UR A aliis Gallinaffa aut Gallinafo, in maritimis locis Zamuro, Peruanis Suguntus; Mexicanis Tropillotl,dicitur.Corvinum eft genus, \& ad magnitudinem $A$ quilæ accedit, quibus vix Gallinas fuperat. Color illi niger, Roftrum Pfittaci inftar. Frons depilis plicatili cute obtegitur, circumftant pili rari \& nigri fimiles $\mathbb{E}$ thiopum. Crus hobet fufcum. Aduncum unguem \& atrum. Hornandes incertæ originis effe credit, nec fciri ubi nidificent \& educent prolem. Frequentifimas omnibus Hifpanix novæ angulis hodie fcimus. Pernoct ant in arboribus \& rupibus, mane advolant ad urbes, \& ab editioribus locis plateasfpeculantur.

Vistus: Quicquid immundum eft aut exanime devorant, nec à ftercore humano abftinent, foeda ingluvie famofr.

Pavius. Pullos Acofta albos effe fcribit; adolefcentes in corvinam nigredinem degenerant.

Folatus. Gregatim volant, \& fublimipetæ funt Nec clamant, nec canunt raro murmure contentæx. Ingratus ab eiș odor. Si quis infequatur, exonerant fe ut leviores vola- tuifint, parifeftinatione evomendo quic quid glutierunt.

Vfum invenere in Medicina. Caro fi eda vjir. tur, Gallicum morbum juvat. Pennx exuftæe cinis vetat pilos nafci, $x$ que ac ftercus formicarum, vulnera quoque medicatur: Stercus drachmx unius menfura potatum prodeft melancholicis. Cor fole exficcatum impenfe odorum eft. In aliquibus Provinciis lege lata pona infligitur occidenti has aves. Reginam Aurarum.

Coz QV A U K T L I Indi vocant. Accé-De Laer 1 . dit magnitudine gnefiis Aquilis, alii galli- 5 . Indix næ Ægyptix parem faciunt: Corpus univerfum præter collum \& eas partes qux juxta pectus funt, ex nigro purpurefcens, fulvum eft ac pullum. Alx circa exortum nigrx, cætera cinerea; defuper vero mixtim fulve nigra, \& nonnihil in purpureum vergentes: Roftri extrema (qux Pfittaci Nierembs effe judices, tam eft indiftincta fimilitudo) ${ }_{\text {bel. Io }}^{\mathrm{H} \text {. Exot. }}$ alba funt: Cxtera fanguineo colore tincta. 56 . Amplum eft narium foramen, oculi nigri, iris fulva, rubex palpebre, frons fanguineo colore perfufa, ac plicatilibus rugis torva, quas tamen nonnunquam explicat, qua in re vocatos Gallo-pavos æmulari videtur, \& pilis quibufdam veluti retorridis rarifque. Ethiopum pilis haud abfimilibus. Cauda eft Aquilæ, inferne cinerea, foris vero nigra. Crura rubra, ungues unci.

Indignea eft Mexicanxprovincix. An Locius at guibus, müribus, lacertis, fed morticinis $V$ ollatus. maxime \& humano ftercore victitat. Sublime volat \& nimium extenfis panfifque alis, vix volatum intermittens. $\mathrm{Vi}$ incredibili obfiftit ventis, contra nititurque adverfantibus, eifdem fedibus perftans immo bilis. Unde ipfi apud Mexicanos nomen.

Caroeft inutilis, nutrimento, quantum Vfus. compertum eft, à nomine, nifi Medicine gratia deguftato. Audio, inquit Author nofter, hujus avis plumis admotis mederi Indos ulceribus, carnibufque elixis durante affectu devoratis; quas etiam ajunt morbo Gallico præfentaneo quodam remedio mederi.

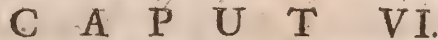

\section{De Avibus Garagay, \& Quetzaltototl.}

A A A A Y qux dicitur, avis eft ra- Niermb: I pax, Milvi magnitudine, capite ex ${ }_{\text {H. Exoto, }}$ extremitate alarum albo. Crocódilorum \& teftudinum ovis infenfa eft. Odoratur illa fub arena in ripis fluminum condita, eruit \& vorat. Solivaga eft, nifi quod Auræ aves eamfequantur, ut potiantur furto, auro enim fcalpere terram nefciunt, ut effodiant ova.

QuET ZAL T о T OTL, criftata eft pica columbrve magnitudine, pavoninis magna ex parte plumis ornata, roftro incur- 
vo \&luteo, \& pedibus nonnililluteis, cau- $\mid$ Ex plumis miræ fubtilitatis imagines inteda tzanatl plumis prælongis veftita, atque xunt indigenæ.

D: frriptio, virentibus nitidifque pavonini coloris, iridis foliis forma fimilibus, opertifque, alis fuperne nigricantibus, inferne vero, \& qua parte pavoninas attingunt, quæ in mediofunt, inclinantibus in virorem, quafi cavente natura meliorum pulchitudini. Crifta conftat plumis fplendentibus pulcherrimis, peetus collumque inferne rubris \& micantibus, ac pavoninis fuperne, qualibus etiam tegitur dorfum, nec non ex partes qux fubter alas funt, interque crura, fed dilutis exilibus, \& mollibus. Plumx alarum prælongæ funt, virore tinctæ diluto, \& in acumen definentes. Pennæ tegentes humeros virefcunt, fed fubter funt nigræ, quævero alas interftant, nonnihil incurva ac unguium colore:

L̇orks.

in Parali- Quauhtemalan verfus Horiduras. Loca pom.

aprica amant, nec compertum cicurarivel ali in domibus voluiffe.

$V c$ cuntur vermiculis, pineifque quibufdam fylveftribus, ex his quas Mexicani matzatli vocare confueverunt. Arbores excavare, \& in earum cavitatibus fobolem educare dicuntur. Sonitum proferunt Pfittacis non admodum diffimilem : verum fibilaedunt alacria, terde die, mane, meridie, \& fub occafum Solis ceciniffe obfervatum eft.

Volatus. Agminatim volant, \& vifco hærentesne plumis detrimento fint, non contorquentur, quafi naturæ duæ divitiarum fuarum cognitionem haberent.

$V$ fus. Et fane maximi plum $x$ apud indigenas habentur, \&aurum precio fuperant. Liongiores ad criftas \& cætera corporis ornamenta, cxteræ ad textilia opera ufurpantur. Plumis captas exuere, nudas dimittere dominis, quibus loco prædiorum funt, \& ad hæredes tranfeunt, licet, ne quifquam occidat, cavetur. Vere Reginam plumarum dixeris.

\section{A P U T VII. \\ De Avibus Tzinitzian, Totoqueftal, Ave montana, \&s Longa.}

Nier emb. ZINIt ZIAN parva eft avis, columH. Exot, 1. so, c. 65.

incurvum \& pallidum. Columbinum put \& collum, fed qux plumis virentibus ac nitidis veftuntur, pectus \& ventrem rubex, preter partem caudx proximam, qux cyaneo candentique colore promifcue tingitur. Caudam fuperne virentem, inferne nigram Alas partim albas partim fub nigro-atras. Crura ac pedes cinereos: Vivit in calidis juxta Oceanum Auftralem, vefcitur fructibus. Alitur in caveis
Tото日EETAL columbina magnio DeLaer. tudine minor eft, viridis omnino: Cauda 1.7.c. 4 . pennæ longifimæ funt, magno pretio habitæ \& receptæ in commerciis. Depilata dimittebatur. Capitis reus erat qui occidebat.

Avis Montana Indis Tepetototl, \& Tecnecholi, Hifpanis Phafianus, anferis eft magnitudine, colore nigro fplendenti, plumis tamen nonnullis inferne candentibus, circa caudam in poftremis alis; cruribus pedibufque cinereis. Roftro incurvo partim cinereo partim luteo, ac circum radicem velut tumenti,plicatili crifta, oculis nigris, fed iride pallenti.

Alitur frumentaceis frugibus aliifque fimilibus. Mite animal. Nam apprehenfo domefticorum pallio cibum exigit, \& claufam januam ubi aliquo intrare opus fit, pulfat. Horum fi liberum fequitur, reducem cum applaufu excipit.

Edulis eft ac pinguis caro, nec diffimilis illi chortalium Indicarum.

Avem Long A M Indi Hoitlallotldicunt. A roftri acumine ad caud $x$ ufque exortum, quæ f pithamam quoque longa eft, dodrantem prolixa confpicitur. Roftrum defuper nigrum, fubter vero cinereum, quadrantem longum ac mediocriter craffum. Cauda virens fed pavonino fplendore. Plumæ totius corporis ex albo fulvefcunt, fulvefcuntque prope caudam è nigro: fed qux corporis veftiunt fuperiora, nigræ funt maculis candicantibus confperfx. ${ }^{\circ}$ Calidis regionibus vivit. Humipeta eft, ac modici volatus, fed adeo pernici curfu, ur equorum velociffimorum agilitatem longe excedat.

\section{A P U $T$ VIII. \\ De Cygno Gucullato Clufii, Jeu Dodone Lufitanorum.}

CYgnum Cucullatum, feu Gallum gallinaceum peregrinum Clufii. (Hol-Clufius landi 930 algh/vogel/ feu naufeam moventem Exot. avem vocant) Mauritii infulæ, quam Luftani- Ilha de Cirne dixere, debemus. Magnitudine cygnum fuperat aut æquat. Caput habet magnum, membrana cucullum referente tectum. Roftrum crafium,oblongum, parte capiti proxima fubflavum, extremo mucrone nigrum. Prona pars adunca eft \& curva, in fupina quæ fubcærulea, macula mediam partem inter flavam \& nigram occupat. Raris \& brevibus pernis tegitur. Alarum loco quaternas \& quinas duntaxat longiufculas nigras pennas haw ber, pofteriore corporis parte, quæ præpinguis \& valde craffa, pro cauda qua- 
tomeant quinx cripip convolutxque pen- fobolcm educat: Antequam ningat clami nulx cincracei coloris confpiciuntur: Crurum qux craffa potius quam longa, fuperna. pars genu tenus nigris pennulis tegitur, inferior cum pedibusfubflavi eft coloris. $\mathrm{Pe}$ desin quatuor digitos dividuntur. Terni longiores antrorfum fpectant, quartus brevior retrorfum converfus eft. Omnes inftruuntur unguibus. De Crure ejus genutenus refciffo, ita Clufius: Erat, inquit, non valde longum, fed à genu ufque ad pedis inflexionem paulo plus quam quatuor uncias fuperabat : ejus vero craflitudo magna, ut cujus ambitus fere quatuor uncias xquabat, crebrifque corticibus feu fquammis tectum erat, prona quidem parte latioribus \& flavefcentibus., fupina veto minoribus \& fufcis. Pedis ctiam digitorum prona pars fingularibus iifque latis fquammis pradita, fupina autem tota callofa. Digiti fatis breves pro tam craffo crure. Nam maximi five medii ad unguem ufque longitudo uncias binas non admodum fuperabat, aliorum duorum illi proximorum vis binas uncias æquabat, pofterioris fefcunciam : omnium vero ungues crafii, duri, nigri, minus uncia longi, fed pofterioris digiti longior reliquis, \& unciam fuperans. In unius ventriculo lapilli inventifunt, unus planus \& orbicularis uncialis magnitudinis, alter inæqualis \& angulofus, in maris littore lectos \& devoratos Herbertus verifimile eft. Herbertus cum Lufitanis in Itinera-
rio. tio. tatem ferruginei coloris plumis tegi, alteram nudam effe, addit.

\section{A $\quad \mathrm{P}$ U $\quad \mathrm{T}$ IX.}

\section{De Avibus Ceoan, Cenotzqui Ë Tauxi.} Eoan feu avis nivea turdo vifcivoro paullo major eft. Circa pectus ventrem atque alarum exortum fulvefcit, permixtis ad caudam cinereis plumis. Alarum extrema caudaque ipfa cinerea funt, fuperne vero univerfum corpus è fufco nigrefcit. Roftrum quod parvum eft atque exile, cruraque fulvefcunt. Mentum candet, infertis tamen aliquot nigris pennis. Sermonem humanum xmulatur, veluti irridens tranfeuntes, quos tamen ubi licet, infequitur.

Avi Cenot $z$ Q un dict $x$ color illuftris variegatione. PeAtore fulvus, crure pallidus, ungue niger, ventre notis candidis \& atris permixtus, fub finem albis notis confperfus, cauda fubtus niger \& $x$ candidus, fuper fulvo nigrore maculatus. Caput nigrum eft fafcia cinctum cinerea. Roftrum parvum cinereum fuperne atque inferne, fed fuperne juxta exortum linea anbiturlutea. Quovis coelo gaudet, montana colit, \& roris tempore

tat, poftea filet. Ita convolvit huc \& illuc caput, contorto in varias partes collo, ut codem fitu immota perftans, cuncta circumfpiciat.

PAUX I gallinaccum xquat aut fupe- Nieremb: rat. Nigra eft, maculis nonnullis albis \& l.c.capt: $75:$ nigris perfperfa, collo nonnihil provecto; capite amplo, quod aliis criftatum, aliis pro plumea crifta lapis aut globus infurgit, (1apidem vocant, licet non nimis durus ) ovo fimilis aut major, ferruccineo colore, Hernandus tumorem quondam radici roftri affigi, quia parte eft tenuior, pici firma, lapidis duritia, \&z cxruleo colore, fribit. Alitur frumentaceis feminibus \& libenter manfuefic.

Huc pertinet alia Avis Ciconix magnitudine, colore cinereo: Criftam geftat uncias octo longam, è multis fubjectis aggeratam plumis ejufdem coloris, \& in amplitudinem orbicularem, precipue circa fummum dilatatis atque excrefcentibus. Vifam in horto Hifpaniarum Regis defcripfie Hernandus.

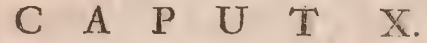

\section{De Avibus Picicitli, Polyglotta, छs Chicuatli.}

$\mathrm{P}$ Icicitliavis eft parva. Cinerea tota nifi capite \& collo, quorum utrumque nigrum; folum oculos nigros candens ambit macula. Eft ignobilitate quadam originis nobilis. Nefciunt adhuc Tetzcoquenfes ubi fatificet: Muta eft. Educat domi,brevi perit. Palato \& ftomacho eft acceptabilis.

PoL y G L O T T A quam Indi Concontlatolli feu quadringentas linguas vocant, fturnum non fuperat. Subtus albefcit, fuperiore parte fufca, pullis \& candentibus intermixtis pennis, maxime ad caudam \& caput, quod imagine quadam coronæargentex redimitur. In caveis ad blanditias auditus, ad oftentum nature fervatur:Vincitomnes aves fuavitate \& arbitrio gutturis, nullius non imitatur, nullius non fuperat. Calidas regiones amat, temperatas tolerat. Contenta eft quovis cibo: Similis eieft Tzanpan. Aliqui fufpicantur fominam effe ejufdem fpeciei, paribus magnitudine, cantu, forma, nifi quod plume inferne albx fint, cinere $\&$ nigrx:fuperne, pulla, nigrx, albx:

CHICUATLI noftratem rufticulam exæquat: Roftro eft longo, tenui, \& pullo, ac treniis juxta utrumque oculum lu= teis \& incurvis. Inferiora corporis pallida funt, nigris quibufdam plumis circa $6 \mathrm{l}=$ lum interfertis. Iris lutea, ac nigri oculi. Cxtera ex fulvo, fufca, \& cinereo per- 
mixta. In montibus verfatur. Calidis fri- tius, quod maxime virum, vivit, quamgidifque regionibus capitur. Pane \& ver- flores herbarum durant fuperftites, poftmiculis alitur: Humipeta eft, \& in vimine- quam marcuere, ad pinus aliasve arbores; um alteriufve materie conjecta carcerem, quadam nature providentia fefe confert, haud vulgariter garrit. Pingue \& non omnino afpernandum prabet alimentum.

\section{A $\quad P \quad U \quad T \quad X F$.}

\section{De Avicula Tominejo.}

Gomara Hift. general. Indiar. c. 194 . Oriedus

Hittor, general, i.r 4. de Laet, Brafilienfes Guonambuah, ut cap. 4. Lerius \& Thevetus teftantur. Ovicdus PafAuguntin.
Cerato Hi- ferem mofquitum vocant, produntur. Tam ftor: Perua- parva eft, ut quidam ei magnitudinem nerius.in crabronis, alii cicadæ, nonnulli extremi Hifforia pollicis articuli, \& evulfis pennis vix dimiBraflize. Thevet. fingul. Franc.

Antar. cap. 43.

Jofepl. Acolta Hift.

Narul. \&

Mor. Ind.

1. 4.6 .37 .

Zoctus: dix ejus partis, alii fcarabei Lucani aflignent. Oviedus in monetario trutina qua aurum appendi folet cum nidulo fuo pofitam, bina tantum pondera. Acofta unum duntaxat dicir, Hifpanis Tominos dicta, id eft XXIV. grana, unde Tomineii nomen, pependiffe vidit. Capitis \& colli plumæ miram elegantifimorum colorum quocunque obvertas varietatem repræfentant. Pectus igneum quendam auro fplendidiorem inprimis. Reliquum corpus fubcinericium eft. Oviedus nigerrimum colorem tribuit. Roftrum habet oblongum, illudque acus qua veftes farciuntur, exilitate. Linguam roftro dupla longiorem. Pedum \& unguium exilitate, cum illarum avicularum pictura, quæ ornatús gratia in librorum marginibus interdum adjici folet, comparari poteft.

Invenitur in Peruanis montibus \& Brafilia. Melle, rore, \& florum fucco alitur. Rofrtamen non infiftit, at in præalto milio quod Auatiab incolis dicitur, \& aliis fimilis magnitudinis plantis infidet.

origo. Duplex earum proditur origo. Namalix quidem ex ovis excluduntur uti reliqux volucres. (Conftruunt autem è xyli flocco nidos) alix, quod haud dubio fabulofum, ex mufcis transformari vulgo creduntur. Sunt qui dicunt vifam efle partim mufcam partim avem : primum ejus colorem nigrum, mox cineraceum, deinde rofeum, tandem rubentem. Nullus Hifpanorum cantus mentionem facit. Soli Levius \& Theretus Galli valde canoram effe, $\&$ in cantu adeo afliduum ut nemo qui non audiret \& confpiceret, ex tantillo corpufeulo tam fuavem \& fublimem cantum prodire poffe fibi perfuaderet.

Volatus. Volat celerrime, editque inter volandum quendam inftar apiculæ ftrepitum, ut

画椟。 eique fe roftro affixo fervat appenfam, donec fex plus minus quam transactis menfibus, acdecidentibus jam pluviis, vernantibus agris, denuo revirefcat, fimiles vices pluries fubitura. Gomara exfpirare menfe Octobri, pedibus exaliquo ramo appenfam aprico loco; renafciautem Aprili fcribit. Hinc Renati nomen. Servata eft frepius avis affixa ftipiti intra cubiculum, \& cum fex menfes exanimis jacuiffet, quo tempore natura fibi comparatum eft, revixit, ac dimiffa in agros volitarit.

Quam Clulius defcribic, \& Urufiam ac Tominejum vocat, an eadem cum jam defcripta fit, ignoro. Erat, inquit, hæc avicula, ut ex pictura obfervabam, à roftri mucrone ad pennarum caudx extremitatem tres uncias longa. Caput vero cum integro roftrouncialis cum femiffe erant longitudinis: alæ ad extremam fere caudam porrectx, parem habebant longitudinem: dorfum vix unciam latum erat, ejus \& alarum color ex cineracco fufcus, ventris cineraceuis. Pennæ qux in cauda obfcure rubefcentes, earum extrema pars nigra. Capitis, colli gutturis plumx elegantiffimi coloris ex auro rubro \& flavo mixti, qux Soli expofitx, admirabilem varietatem, prout obvertebatur caput, oftendebant : roftellum nigrum tenuifimum \& maxime acutum, pedes valde exiles, nigri, quatuor digitis ut reliquarum avicularum prediti, quorum tres in anteriorem partem porrecti, quartus in pofteriorem, \&c. Videtur tamen effe ex iftis. Diverfe enim fpeciei funt iftæ parvulx aviculæ, \& promifcua nomina communicantur invicem. Urufia Solis radium fignificat.

Ajunt pulverem ejus intra corpus fum- $V$ fass ptum epilepfiæ mederi. Pennæ præfertim qux in collo \& pectore nafcuntur, aureis ftaminibus à phrygionibus intexuntur.

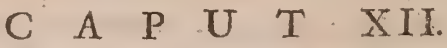

\section{De Avibus Cuntur, Es aliis quibuf- dam Infulce Maragnana.}

$\mathrm{C}$ Untur avis eft mole vafta. Vifx qux John. cee expanfis alis XV. aut XVI, pedes occu- Laet.Indie Occid. lib. parent. Pedes habet gallinis fimiles, caret ro. c. 5 . aduncis unguibus. Roftro tam valido inftruitur, ut eo vaccinum tergus perforet. Plumis albis nigrifque mixtis ornatur. Criftam parilem inftar novacula, \& non fervatam inftar gallinacei. Inter Carnivoras cenferi debent. Dux illarum vaccam occidere \& comedere valent, nec ab hominibus abttinent. Non modo ovem 
dilaniant, fed \& juvencam. Pauciores funt: Plures fi reperirentur, pecus univerfum in Peruvia deftruerent. In Infula Maragnana quatuor inprimis occurrunt.

De Lner. Prima quam ouyra Ovaffou (obferva, Ind.Oc- barbaros Toupinambautios univerfas aves cid,1.16. uno \& communi nomine appellare Oura five Ouyra ) vocant. Aquila eft pæne duplo major. Plumis veftitos elegantilimis, Roftro valido, Unguibus inprimis acutis. Vifa penna ex alis hujus avis extracta, qux ulnam noftratem longe fuperabat, elcgantifimo colore, \& rotundis maculis diftincta, inftar Gallinarum quæ ex Africa advehuntur. Tanti eft roboris, ut ovem integram abripiat atque dilaniet, homines facile profternat, \& necc à cervis abftineat.

Altera eft Moyton feu Mouton pàvonis noftratis magnitudine aut pallo major, pre alta crifta fpectabilis, \& per univerfum fere corpus nigris albifque plumis eleganter variegata. Carnes illarum cibo funt opportun $x, \&$ multre ejus vifuntur fpecies.

Huic Toucan accedat, palumbi magnitudine, roftro oblongo atque lato, ingluvie fub pectore tres quatuorve digitos transverfos lata, crocei coloris elegantiffimi \& miniatis plumis circa oras diftincta, pectore candido, dorfo exquifite rubente; alis atque cauda nigris; pulchra afpectu $\&$ carne palato admodum grata. Hujus \& $x$ alia fpecies appellatur à barbaris Ovaycho, cui roftrum eft paulo diverfum \& è rubro flavefcens.

2 wartum, locum avi owru dictr damus, perdicis quidem magnitudine, fed galli gallinacei in modum criftata; plumis rubris, nigris atque candidis infigni varietate. Sunt ibidem \& plures ejufcemodi rapaces aves Aquilis aut majores aut paullo minores, fingularis adhæc forme, \& plumis variorum colorum eleganter dinftinctx

Sunt \& quxdam Perdicum forma, fed majores paulo, cæruleis plumis ornatæ, \& crirulea ova ponentes. Tata Ouyra Ovaffon, \& Tata Ouyra miri, itemque Arou mara fingula funt columbarum noftrarum magnitudine, fed fingulari plumarum varietate \& elegantia.

Iandou ftruthiocamelorum eit fpecies. Proceritate ftaturam humanam fuperans. salian denique Turcici Galli magnitudine, roftro \& cruribus ciconix, licet volare nefciat: tamen tam pertinaciter currit, ut venáticos canes effugiat.

\section{A P U T XIII.}

De quibusdam Brafilie Avibus.

Trer cateras Brafilizaves, quarum alis bi mentio facta \& adhuc fiet, cenfentur
Gumbe-enger, Iangin, Quereiva; Tutarat Gurapanga, Macucagun, \& Mutu.

GUR A NHA-ENGER A magnitudi-c. 7 . ne eft Fringillæ, tergo \& alis cxuleis, pectore \&r ventre flavo, diademate fupra caput flavo. Cxterarum fere omnium cantum imitatur, \& mille modis vocem fleAit \& mutat. Varix ejus reperiuntur fpecies, qua omnes aviariis inclufe fummopere delectant.

T A N G A A Pafferis eft magnitudine, colore nigro, capite fubflavo, non canit. Epilepfiz quia obnoxia creditur, ideo illius carnibus abftinent barbari. Narrantiidem aviculas hafce inter fe choreas ducere, \& una mortux inftar humi procumbente, inconditum murmur \& ftrepitum edere. Hac confurgente, \& cundem ftrepitum edente, omnes una avolare.

QuE REIV A totum pectuis, pulcherrimo colore rubro tectum eft, alx nigro, reliquim corpus cyaneo. Propter exquiftam plimarum elegantian maximi fit à barbaris.

TUCA N A , quam Lerius \& Thevetus vocant Toucan, picx magnitudine, Havo' pectore, reliquo corpore nigro. Roftro ingenti \& minimum palmum longo, extus flavo, intus late rubentc. Cicuratur ita ut fub tecto pullos fuos excludat.

Qu I R A P A N G A eft tota alba, \& cum: modicx fitmagnitudinis, ftentoream habet vocem, \& quæ inftar tintinnabuli, ad dimidiam pæene leucam exaudiatur.

MACUCAGUA phafianx avi non abfimilis, Gallinas Europxas magnitudine fuperat; \& triplici cute munita eft. Ova quotannis bis tredecim aut quindecim ponit. Graditur quidem humi, fed petit ad confpectum hominum arbores. Largam delicatamque carnem habet. Multx illius fpecies reperiuntur, qqux capiuntur facile.

M. т u Gallinx eft fpeciesadmodum domeftica. Criftam inftar galli, nigriatque albis punctulis interfinctam gerit. Ova illius funt grandia, alba, \& ita dura, ut inter fe collifa inftar ferri tinniant. Quare barbari Maracas fuas ex illis conficiunt. affa illarum canibus funt lechalia, hominibus nihil nocent: An eadem fit cum Moutone de qua fuperiore capite actum eft, ex comparatione liquebit.

Huc pertinet quedam ex tapacibus $\mathrm{ma}$ gnx molis \& tam clamofa, ut ad dimidiam leucam audiatur, tota nigra, pulchris oculis, roftro galli gallinacei, cui cornu im=pofitum palmi piene longitudine, quod is quilinguæ vitio laborant, ad collum appenfum occulta, quadam naturx vi mederi, experientia comprobatum volunt.

Coronidis loco hifce Bambiayæe in Gu- De Láeto ba infula frequentes accedunt. Paullum Indix Oc R 3 fupra 
fupra folum feruntur magis quam volant, ita ut incolæe ferarum inftar illas venentur. Carnes coctx jus croceo colore inficiunt, faporis alioquin pergrati, \& phafianarum avium æmuli.

\section{T I T U L U S I I.}

De Avibus Exoticis Aquaticis.

$$
\text { C A P U T I. }
$$

De Pafereftulto, \&5 Anfere Magellanico.

Nierenb.

Hit. Exot.

I. IO.c.4.

$$
\text { 1. }
$$
Affer ftultus nomen ex eo accepit, quod manus apprehendentium nec fugiat nec timeat, admiratur folum aut ftupet. Præter frontis partem roftro adjacentem, qui cinerea eft, palmipes, roftro tres unciaslongo, tenui, obrotundo rectoque, fed prope extrema nonnihilincurvo,pedibus quoque qui cæterorum palmipedum funt, \& cruribus nigris, pupilla etiam nigra, \& membrana oculos tegente in ambitu cinerea.

Vefcitur pifciculis. Voce imitatur graculum. Magnitudine picam, forma Larum. Nobilis eft avium infulæ Mauritii manfuetudo. Appellentibus nautis perinde infidentac arboribus. Eadem fecuritas venatus eft. Accedunt ac fubeunt manus.

A NSER MAGELLANICUS àloco ita dicitur. Batavi forte à pinguedine Penguinem vocant. Defcribam eum verbis

Clur. Exo. Clufii. Marina eft hæc avis, inquit, \& ex Anferum genere, tametfi roftro diffimilis. In mari victitat : pinguis oppido eft, prægrandis anferis magnitudine; nam adultioresineo genere tredecim, quatuordecim etiam, fedecim interdum, juniores vero octo, decem \& duodecim libras pendere obfervantur. Prona parte, nigris pennis tectx erant. Supina \& in ventre albis: Collum; quod craflum \& breve habebant nonnullie, albis pennis tamquam torque cinctum. Earum cutis crafla \& denfa inter fuillæ. Alarum erant expertes, fed earum loco binasparvas coriaceas pinnas habebant, \&x latera tanquam parva brachia propendentes, prona parte brevibus, anguftis \& rigidis pennis confertim tectas, fupina autem minoribus \& rigidioribus, iisque albis, quibus nonnullis locis intermixtæ nigræ; minime quidem aptas ad volandum, fed quarum adminiculo velociter natarent. Maxima enim ex parte in aqua verfari intelligebam, \& terram duntaxat perere fotificationis vel pullationis tempore, \& plerunque quaternas aut quinas in una fcrobe latere. Roftrum corvino majus habent, non adeo tamen elatum, \& valde brevem caudam, pedes nigros, planos anferinorum pedum forma, non adeo tamen latos. Erecte \& fublimi capite incedunt, demiflis in latera pinnis, tanquam brachiis, fic ut procul intuentibus homunculi aut pygmxi appareant. Pifcibus duntaxat ve $\int i$, referebant Diarix; non ingrati tamen faporis effe illarum carnem, nec pifcem fapere: fcrobes vero valde profundas in littore fodere, cuniculorum inftar; totum folum adeo cavum interdum efficientes, ut perillud gradientes nautx, fxpiufcule genutenus in eas fcrobes inciderent. Hi funt fortafle anferes, quos Gomara ait fine pluma effe, nunquam è pelago prodire, plumxque loco villo longoprotegi.

\section{A P U T II.}

\section{De Avibus Iocbualcuacbili, Xocbitena- catl, Es Tlauquecbul.}

A Vis quam Chillenfes Iochualcuacbili Nieremb.

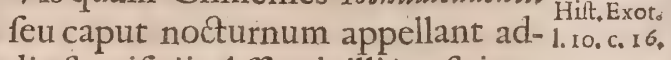
mirandi eft opificii. Affurgit illi à roftri exortu corona quxdam, aut orbis in tres divifus cufpides, fuperiori parte mediocriter craflus, \& è luteo rubefcens : ab antetiori alarum bini aculei contorti exeruntur. His armis avicula imbellis adverfus fortiores defenditur. Nullius vitam natura contempfit. Avis eft littoris Oceani Septentrionalis alumna, falforumve lacuum, è quibus victum fumit. Inventa apud flumen $\mathrm{Tu}$ fpe, vix xquat fturni noftratis magnitudinem, fed collo conftat tenui \& longo, capite parvo, \& in longum producto; prolixo roftro luteoque, prolixisque cruribus, \& pedum digitis atque unguibus: ungues autem lutei funt, digiti \& crura cinerea cum inferiorum femorum parte, nam fuperior fulva eft cum anteriori alarum parte, quarum pofterior cyanea eft. Reliquum corpus nigrum, quibusdam tamen fulvis circa ventrem permixtis pennis:

X OCHITENACATL; eft columbx Nieremb. magnitudine, roftro præ corpore móle ${ }^{1.10 . c .9 .}$ maximò, fuperiori parte luteo, inferiori vero fubnigro, \& in purpureum colorem vergente, oculis nigris, fed iride rubefcente exluteo, ac reliquo corpore cxruleo cinereoque. Vivit circa litora Oceani Auftralis; pifcibus, quos rapit, vefci fo. let.

TLAUHOVECH U I dicituravis peregrinæ gulæ: vivis duntaxat pifcibus vefcitur, mortuos non attingit; raptu gaudet, fpecie fimilis eft platex aut pellicano, fed coccineo pulcherrimoque univerfi fere corporis colore, aut exalbo rubefcenti, lato atque obrotundo circa finem roftro, cinereoque pupilla nigra, iride rubra rugofa, fronte galli pavonis, auræve, depili 
D. E A V

depili prene capite, candentique cum univerfo fere cóllo, \& parte pectoris, \& fafcia -nigra latiufcula, caput à collo diftinguente. Circa littora maris aut fluminum vivit.

$$
\begin{gathered}
\text { C A P U T III. } \\
\text { De Avibus Acolin, Duachilitone, छ } \\
\text { Acacalotl. }
\end{gathered}
$$

Nicremb.

A Colin, Coturnicis eft magnitudine Hitt. Exot. feriora, pedibus longis juxta aquarum

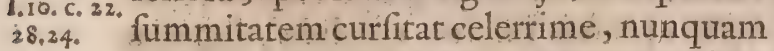
fere volat. Verfatur in lacu Mexicano. Vefcitur pifciculis \& ipfa efca vulgo. Bene Coturnicem aquaticam dixeris:

Qu A CHIL T ON E M, feu Averifotiquafrinicapitis, aliqui Jacacintli vocant Color illi purpureus, ex nigro interfertis pennis. Roftrmm initio pallet. Adolefcentibus rubet calvities juxta roftri exortum. Fulicani imitatur. Lutea crura invirorem affurgunt, in quatuor definentia digitos pallidos, citra ullam membranam. Oculi nigri, iris fulva.

Lacuftris avis eft. Pifcibus vefcitur, $\mathrm{i}-$ praque noon ingrata palato. Intempefta no-

* cte \& fub primo mane gallinaceorum ritu canit.

ACACALot L mas feu coryus aquaticus à cauda extrema ad roftri ufque acumen quatuor fere fpithamas longa , \& mediocris amplitudinis; crura fefquifpithamea, roftrum arcus inftar incuryum, duos palmos longum, ac mediocre tenue: pedès in quaternos finduntur digitos nigerrimis munitos unguibus: crura minus nigref cunt digitis, roftrum cyaneum eft, ac caput exiguum. Plum inferne fufcx infertis rubris, fupcriores vero promifcue purpurex, fübnigirx, virides atque fplendentes : cernix eft feptem digitos longa. Caput collumque pennis fufcis; albis \& viridibus teguntur ac paulifper fulvefcentibus, Oculi funt nigri,iris vero fanguineo tegitur colore. Cæxterum ab externis oculorum angulis ufque ad roftrum, uncix unius intervallo deplumis \& glabra eft, pellis rubefcenfque inalbo: Alx viridi fplendentique fubtus pellucent colore, \& qui pro variis folis repercufibus evariet atque mutetur; fupernæ vero prope exortum pafferefunt, deinde vero viridi atque pavonino fpectabiles colores. Indigena Mexicanx plagæe avis eft: verfatur circa lacus, ac pifcibus victitat: Mafculus fortaflis eft ejus àvis, quam recentiores vocant Arcuatam, aut illi faltem congener. Educat filios veris tempore juxta lacuftria loca.

Bonum priftat alimentum, nec valde injucundum, craftum tamen, atque (ut lacuftres aves decet ) pifcofi odoris.
I B U S

\section{A P U T I V.}

De Avibus Xomotl; Acototloquicbitls \& Acacacaboactli.

$\mathrm{X}$ omot $t$ palmipes eft, dorfo \& alis defu- Nierctiof per nigris, pectore fufco. Criftatam $3.5 \cdot 3.6$ : iracundia facit. Pennas intexebant Indi. fuis veftibus.

Acotot Loev ICH TL feu Pafer aquaticus mas ; pafferem fimilitudine \& forma fimulat Roftrum tamen nigrum; crura \& pedes fulvi, inferiora corporis plxrumque candida. Gatera fulva, candore aliquo \& nigrore variegata. Reperitur in Mexicanis plagis. Juncetis \& carectis infidet, ibique nidificat. Non minus occinit quam Solpergit. Ab ejus exortu ad occafum contumaci garrit fonitu mures imitante.

A CA CAHOATLI feU. Aoris dquatica rances fondns. Halcyonum fpeciesilla eft inquit Nierembergius, quam noftri marinetum Pifcatorem vocare folent, circa aquarum fluenta vißtus gratia à congenita quadam verfantem natura. Anate fera paullo minor eft; colloque \& roftro fithameo: hoc tres digitos latos prominet, me dio, cum fortitur craflitudinem, in acien definit, acmorfui eft peropportunum. Superne vero nigrum eft, inferne album, \& pallefens circa latera. Oculi nigri funt, iris rubra prope pupillam, deinde pallida, ac demum candens. Ab oculis ad roftriufque exortum fafcia procedit viridi pallefcens. Crura pedefque in digitos fifi virefcunt extrinfecus, intrinfecus vero inclinant ad pallorem, color totius corporis magna ex parte albus eft, fulvis pennis infertis; rum fupernamagis fufca funt, inferna vero candida. Ale infernse cinerex, ac defiper circa extrema nigræ, moxè fulvo rubefcentes, deinde pallefcentes ex fulvo, ac demum fulvefcentes ex fulvo, ac demum fulvefcentes circa dorfum. Pifcibus victitat : mitefcit minimo negotio, nec eft cantu infuavis, indulgenter tamen ac blande vermiculis \& aliis animalibus exiguis, quix in paludibus gignuntur, eft alenda. Carne etiarn vefcitur, \& aliis non paucis; ubi fieri aliter non poflit. Craffieft nutrimenti, neque diffimile ei, quod anates feræ prefentare folent. Indigena eft Mexicanæ plagx, \& vere educat inter juncta fobolem. Mirum eft , cum fit cervix pro ratione reliqui coloris longiflima, in quam brevitatem illam. Củm libet contrahat, quod frequentius facere folet. Cards pufilla eft, nigraque, \& nihil præ fe ferens fplendoris, qux in majorem procedit amplitudinem. Patrio nomine appellant tolcomictli. Similis omnino effet hæc avis compari, nifiro- 
ftrum defuper nigricaret, fubtus rubefce- modo eminenti, \& paulifper candida. $p_{i}$ ret, velut pedes \& crura, nec per univer- ctus è fufco vergit in cinereum : venter alfum corpus fulvum, nigrumque promi- bus eft, ac pedes plani : crura fulva, \& penfcue cerneretur.

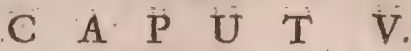

De Avibus Tacacintli, Xlepapantototl, 6. Hoactli.

Nierenb. H. Exot. 1 . Io: c. 43 . 44.45 .

$\mathrm{J}$ Acacintli feu roftrum jpice mayzii, tres pæne fpithamas eft longa, virentibus cruribus, capite ventreque cyareis, $f e d$ in purpureum vergentibus, alis promifcue fulvis nigrisque, lufcis oculis ac roftro, fed in coccineum prope exortum vểrgente, quod tres prene digitos latas longum eft, anteriori parte capitis depili \& calva: Pifcibus juxta lacus \& flumina vivit. Edulis eft ejus caro, fed nec bono, nec grato alimento.

X́́zepartototo Anatis fere fpecies eft, importuna Mexicanæ paludi, roftrum tamen in acutum finit : nullus illi negatus color.Pulchritudinem varietas dedit, pulchritudo nomen.

Nec contemnendi fpectaculi eft $\mathrm{Ho-}$ A T TI, five Tов С TLI, id eft, avis ficca, lacus Mexicani alumna, ternas fpithamas à roftri ipfius acumine ad caudam poftremam longa, ac gallinæ noftrx magnitudine. Crur a prolixa, pedem, roftrum cum uncia trientem, craflitudine vero pollicem $x$ quans. Superne id nigrum eft, lateribus autem pallens, ac inferne nigrum \& fubfufcum. Oculi funt magni, iris lutea, \& palpebræ rubex : vertex plumis nigris tegitur, itemque crifta infigni, fimiliter nigra: collum, venter, corpusque univerfüm candet: fed canda cinerea eft, velut \& defuper alæ, nam infernx funt albidiores, fuperiores alarum partes virore quodam fplendent. Dorfum, etfí candidis tegatur piumis, pennis tamen nigris in virentem fplendorem inclinantibus veftiri folet. $P e-$ des qui in digitos fiffi funt, \& crura quoque, pallefcunt. Alba fafcia circumcingitur caput, à roftri exortu ad 'oculos ufque procedente Lacus Mexicani advena eft, vocaturque $a b$. Hifpanis indigenis, velut \& quædam alixaves, martinete pifcador, ob pifcium quibus alitur capturam. Arundinetis educat fobolem, gravem infert morfum, ac gravem fimiliter vocem edit.$$
\text { C A } P \text { U } \quad T \text { VI. }
$$$$
\text { De Avibus Heatototl, Achalalactli, \& }
$$ Amalozque.}

Nieremb. H.E.1. Io. c. 47.43 . næ circa ea ortx: cauda orbicularis, \& variata inferne candido, pulloque colore, fuperne vero fưfca. Alê fubdus candentes, cinerex ac pullæfunt, defuper nigræx, candidis tamen quibusdam infertis pennis; reliqua vero eadem qua aquaticis eft natura.

Similis alteri $H \mathrm{E}$ А т т то т $\mathrm{L}$, qux anate domeftica paulo minor eft, roftro atro, tenui, obrotundo, ac prope extrema contorto, plumis inferne candidis, fiperne vero juxta femora fulvis, lineis tamen nigris intercurfantibus; circa refiduum vero, \& caudam fulvis. Ale funt fubtus cinerex; fupernæ vero fufcæ, nigre atque albx. Caput eft nigrum criftatumque, fed ab occipitio tenix albx utrimque procedunt ad oculos, quiatri funt, \& lutea conftant iride, cum cæetera fint fimiles avibus incolentibus paludes.

Suus quoque torques argenteus honeftat $A$ CH A L A L A C T L I, feu arem pifcium vibraticem. Alii vocant Michalacti.Columbina eft magnitudine, \& forma, roftro nigro acuminato, tres digitos longo, \& procorporis proportione craffo; caput crifta orna- * tur ècolore cyaneo in nigrum tendente, longaque. Venter candidis tegitur plumis, \& collum torque candenti infignitur: ales inferne albefcunt, fed portremis partibus videntur fufcx, \& candicantibus maculis interfinct $x$, fuperne vero ficut reliquum corpus funt cyanex, extremis partibus nigræ, \& albis undique refperfæ maculis. Cauda partim nigra, partim cyanea eft, fed maculis albis per intervalla quoque variata.Crura rubea funt,pedes diverfi in digitos, in atros ungues definentes; oculi nigri, \& iris candefcens. Advena avis eft huic Mexicanæ regioni, verfaturque juxta fontes \& flumina, pifciculis \& aliis aquatilibus victitans edulis, fed reliquarum avium paluftrium fapore atque nutrimento.

Neque exiguus decor eft AMALOzeve, feu avi rubefcentis colli. Paluftris ea eft, noArati turturi magnitudine par, cruribus pedibufque in digitos fiflis, atque ex albo rubefcentibus nigris unguibus, roftro medio circiter longo, exili \& nigro, atris oculis, \&riride rubra, pectoris \& ventris, \&alarum inferna alba funt; fed cauda, quæ mediocrem magnitudinem nancifcitur, fulvo \& nigro colore eft infperfa : at collum pectufque torques bini, minimi fere digiti diftantes intervallo, nigrique cingunt, quorum anterior undiquaque circuit, pofterior fuperna deficit ac difparet parte. Exutroque latere maculæ binæ candentes, pari amplitudine, fupra oculos verfus collum, illud fere attingentes, difcurrunt. Su- 
pẻrina corporis, adeoque ipfa cauda, albo, ma difcrepantur, tempeftatum preiìuncie, nigro, fulvoque funt colore; alæ vero de- \& qux in alto tantum Oceano verfantur, fuperfulvo \& fufco. Indigena eft avis, la- conftituunt. Primo eft Hafflert feu Equus cus Mexicani alumna, ac veris tempore marinus, ut inconvenienter appellant, edukans fobolem. Eftur caro, qux eodem qux magnitudine gallinam mediocrem, quo cœterarum aquaricarum eft nutrimen- forma falconem utcunque xquat. Cinerito. Vefcitur ipfaculicibus, pifciculifque \& $x$ cio eft colore, maculis albis paftim intervermibuslacuftribus: vehementius perfere- ftincta, rofto incurvo velut falconis fed pit quam pro corporis ratione, nec tamen breviore. Adejus confpectum exhorrefcepoteft garrulis avibus adnumerari.

\section{A P U T VII.}

\section{De Avibus Farrenfibus.}

I Nfulæ Farræà plumarum copia nomen adeptæ videntur. Cum enim avium fint foetura frelices, nod mirum \& plumarum abtândare copia. Cxterum aves qux ibidem reperiuntur, in aliquot diftinxit claf Hojerus in fes Hojerus.

In prima CL A S S E Lundam, Alkam, '\& Lommiam invenies. Illa mole corporis Anate eff inferior, roftro rubente \& latiufculo, pectuscandida, tempus \& alas nigra, pedes rubra. Revertitur primo vere. In pracipitibus celfarum rupium cavernis nidificat. Ova gallinacels tum colore tum magnitudine paria edit. Quo fub autumnumabeat ignotum.

Alka illa aliquanto majoreft, roftro lato \& nigro, itemque corpore, nifi quod fub pectore \& extremis alis albicat. Pedes nigri, caput denique fufcum, nifilinea alba ab utroque oculo ad roftri partem pröximam duceretur. Nidificat in editifimis fcopulis. Ova exalbo \& nigro maculata ponit.

Lomwie quxilla major, corpus totum eft nigrum excepto pectore quod albet.Pedes nigri,roftrum nigrum acutum, oblongumque. Ova in editioribus fcopulorum marginibus excludit, cyanei quidem coloris', fed lineamentis undique diverforum colorum mirevariegata ac velut picta.

In altera CLASSE, duas diverfas fpecies ponit, qux quod pedes ad incedendum inutiles habeant, nunquam terram ingrediuntur, \& mole corporis minorem $x$ quant Anferem. Prior Ildbrimel vocatur. Caput ejusfufcum, fub eollo circulus albus, pectus candidum. Tergum \& alæ nigricant, maculata pafinîn punctis albis, pedes nigri. Forte eft mergus Farrenfis maClur. Exo. ximus Clufii. Creditur in undis marinis 1.5.c-5. Alcyonis more foetum próducere.

Altera eft Goifugel.roftro admodum lato \& incurvo. Capite oblongo atque nigro. Alis exiguis, pedibus nigris ad incedendum ineptis. Oculorum margines candido circulo tinguntur. Rarifime \& nonnifíliquibus annis vifitur, nec ubi foettræ operam det, ignotum.

Tertiam CLAs S.EM tres fpecies for- re \& littora legere pifcatores folent. Certi tempeftatem in propinquo effe noxiam.

Altera dicitur stormfinck paflere paulo major. Tota eft grifea, five maculis., roftro admodum exili. Pegafum pra fuperiore rectius:dixeris: Siquidem fuper ipfos fillctus incredibili pedum velocitate transcurrere, ac nimbi inftar ferri folet. Videtur illi cognata quam Oviedus Patines à Oried.

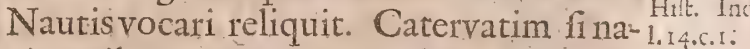
vigantibus appropinquet, deponenda effe fubito vela innuir.

Tercix nomen eft Barnfard. Magnitudine hæc Pafferi par, fub pectore candicans, collo dorfoque nigricans, roftro nigro \& nonnihil latiore, pedibus rubris. Tam velacem fe natando præftat; quam Stormfinka currendo.

Inquarta $\mathrm{C}_{\mathrm{L}}$ A S S E dux diverfe Anferum fpecies cenfentur. Prior Helfingegans capite \& collo nigro, circulo albo cincto, pectore albo, alis gryfeis, tergo cyanei coloris, pedibus rubris, magnitudine Anati refpondens dici.

Altera Erandgans anfere fylveftri pæne minor, capite \& pectore grifeis, collo rubro circulo cincto, alis, collo, pedibus rubris. Rarifime in Farris confpiciuntur,nequeibifrtificant. Unde veniant, \& quo migrent, nemini cognitum. Mutationem magiftratus ubi apparuerunt ímminere, fuperftitio ex longa experientia credidit Ultimum locum fibi skur vendicat, avis aquilino generi \& corporis mole \& rapacitaterefpondens. Roftrum habet curvum. Sed non admodum latum, pennas corpus tegentes grifeas, fola alarum extremitate albicante, pedes grifeos. Pifce vefcitur; fed \& in omne genus avium graffatur. $F œ-$ tum negligenter ex ovis grifeis, grandioribus, anatinis fimilibus, qux exilibus nigris maculis notata funt, in apertis campis producit. Aliter eam deforibit Clufius, \& Clufits eandem fere cum vulture aquatico Ovie Exoticor di exiftimat.

\section{A P U T VIII.}

De Avibus Lomsbay, Vulturibus aquaticis, Flamencos dictis, Go aliis qui-

$$
\text { busdam. }
$$
Ax, corpore funt magno, alis parvis, ${ }^{-H o l l i n}{ }^{-1}$ ut mirum fit, tam gravia corpora attollere 
poffe. Frequentes circa portum Lomsbay liquanto Africanis. Longailli crura, infein infula Aurangia, volant, unde \& nomen invenere. Nidulantur in præruptis montium locis. Unicum duntaxat ovum pariunt. $\mathrm{Ab}$ hominibus nihil metuunt, etiamfi in fuis nidis comprehendantur.

Niermb. VULTURE'S AcY A TICos facit Oî Exot.l. viedus mole tam grandes quam magnus 10. C82. Larus eft. Roftrum habent Larorum, fed magis mucronatum. Pedes diverfigeneris, finiftrum anatum \& anferum inftar planum, dextrum curvis unguibus inftructum. Vefcuntur pifcibus \& avibus, iidemque cum illis qui Aftures aquatiles ab $\mathrm{Hi}$ fpanis vocantur, de quibus Hernandes in Paralipomenis agit, effe putantur. Frequentes funt in Hifpaniola \& infula quæà Divo Johanne nomen accepit.

Avisquam Hifpani F $L$ A M E N CO vocant, grui eft forma non abfimilis. Juniores habent plumas candidas, ubi adoleverunt, mira elegantifimorum colortim varietate diftinguuntur. Gregatim volant,

Detaet. fed haud alte. Juxta littora infulx Cubx at-

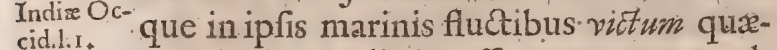
c.11. runt, falfis undis ita affuetæ, ut quum ab Indis domialuntur, (nam \& cicurantur) fal potui earum neceffario admifceatur. Idein 1.r. Habent \& infulx Bermude maritimas, qua c. 20 . in fubterraneis cavernis cuniculorum inftar, nidulantur \& ova fua ponunt, magnitudine \& colore gallinarum ovis pariajipfe carne funt obefä, \& grati nutrimenti.

Idem 1. ro. Colophonem ifti de Exoticis Avibus pro-

c. 5. mifcuæ hiftoriæ imponant illæ in Peruano ciconiis majores. Plumis fine ulla mixtura candidifimis, cruribus altis. Rariores funt. Binx ut plurimum incedunt. Et pifcibus victitant. De reliquis quix ad fua genera referri poterant, vide Notas.

\section{T I T U L U III.}

\section{E}

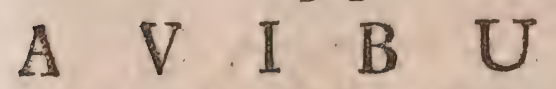

B R A S IL I A N I S:

\section{Ex Georgii Marcgravii Hiftoria} Naturali Brafilix.

De Avibus Brafilianis ingenere notetur: Vix ullibi elegantiores Aves reperiri quam in $\mathrm{Brafi}$ lia, fivarietatem plumarum \& colorum pectes; verum null a fere fuave canit, it a ut cantulonge à noftratibus fuperentur.

\section{A $\quad \mathrm{P}$ U $\mathrm{T}$ I.}

Nhandugvacu. Iacand, varice ejus Jpecies. Curicaca.

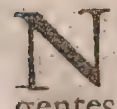

HANDUGVACU, Brafilienfibus, E M A Lufitanis; Struthio avis. Ingentes hic reperiuntur, minores tamen ariora fefquipedem, fuperiora pedem circiter longa: Tres habent in pedibus digitos anterius verfos, unguibus nigris, craffis, haud acutis preditos; pofterius unum digitum, fed rotundum, groflum, unde difficulter in area levi aut tabulato poffunt incedere, fed facile labuntur. Collum geftant incurvatum, ut Cygnus vel Ciconia. Longirudine circiter duorum pedum: $\mathrm{Ca}$ put anferinum, oculos nigros habent pulchros; roftrum compreffum, non admodum latum, duos \& femis digitos longum. Alas habent parvas, \& ad volandum ineptas, quarum tamen unam inftar veli erigentes citifime curfum promovent, ut vix, ac ne vix quidem à cane venatico fupérari poflint. Plumas habet gryfeas pertotum corpus, ut grus, in dorfo longiores \& elegantiores, \& corpus plumis tectum fere rotundum apparet. Casdam non habet ejusmodi criftis praditam, ut vulgo pingitur, fed pluma funt per dorfum expanfre ad anum ufque.

Tefferas luforias, aliaque ferramenta lubenter deglutit, fed non concoquit, at in" tegra per anum reddit: Vefcitur fructibus \& carne.

Frequens in Capitanix Serigippo campis, itemque in Capitania Rio Grande. In Pernambuco non vifitur. Caro illius bona ad comedendum.

$J$ A C A N A Brafilienfibus,gallina aquatica, 23 atcrlytn/diverfæreperiuntur illius fpecies, colore differentes. Hrc elegantiffima, magnitudine Columbæ, fed cruribus multo longioribus, flavi coloris, cui viriditas immixta. Cxura inferiora plus quam. duos digitos longa, fuperiora (maximam partem nuda ut aquaticis ) paulo minus: quatuor habet in pedibus digitos, quorum medius è tribus antrorfüm verfis, duos digitos longus, reliqui duo paulo breviores , quartus retrorfum verfus, pedem, aut etjam ampliuslongo: omnes autem unguibus femidigituni longis \& ffavis armantur. Cauda brevis ut gallinæx fylveftris; penn in dorfo, alis \& ventre ex viridi \& nigro mixtæ, fub cauda albx; verfus collum; \& in toto collo $\& x^{a}$ pectore ejufdem coloris cum plumis qux in collo pavonum aut columbarum quorundam vifuntur. Caput habet parvum, ut gallina fylveftris, quod tegitur membranaceo quodam tegumento rotundo, coloris ut gemma Turcois. Rofirum rectum gallinaceum, plus uno digitolongum; ab initio ad medietatem egregii miniati coloris reliqua pars eximii flavi, cui aliquid viriditatis admixtum. Frequentifima in paluftribus Brafilix locis ubique. Caro illarum edulis, fed haud magni pretii,funt enim plerumque macræ. Alia fpecies appellatur à Brafilienfibus 
Agua pecaca, priori figura \& magnicudine par; verum colore diverfa \& inferior.? enrice illius funt ut in dorfo prioris, ale magis brunefcentes: Carent autem mitella, at in qualibet ala interius habent corniculum directum, quibus fe defendunt.

Tertia fpecies prioribus figura \& magnitudine æqualis, colore autem differens, totum caput, collum, dorfum, cauda, nigri funtcoloris, initium alarum brunni: reliqua viridis; extremitates remigum brunni: pectus \& infimus venter itidem brunni coloris, uti \& crurum fuperiorum medietas fuperior. Roftrum rectum, crocei coloris, cum cuticula ruffa in exortu illius \& parte capitisanteriori. Crura nuda, tedes cinerei. In qualibet ala, antica parte habet corniculum fimile flavum.

Quarta fpeciesitidem figuræe eft ut reliqux. Roftrum illi flavum, mitella cutacea in initio capitis prope roftri exortum rubens, proceffus habens adlatera extenfos more gallinarum Numidicarum. Totum caput, collum, pectus \& infimus venter plumis veftiuntur nigricoloris, dorfum, cauda, $\&$ initium alarum ruffum, feu dilute brunnum; remiges alarum pennx thalafici coloris cum extremitatibus nigris. Sed hx remiges teguntur ruffis illis in exortu alarum, nec videri poffunt nifi cum avis volat. Crura longa, digiti pedum longi, quilibet quatuor internodiis, cinerei coloris. Quxlibet ala in anteriori parte habet corniculum acutiffimum coloris crocei.

C U R I C A C A Brafilienfibus à clamore dicta, Ma arino Lufitanis, avis Numerio, judicio Clufii, fimilis : magnitudo illi mediocris Anferis : capitis autem magnitudo ut Anatis : collum fex digitos longum, tres craffum, aut paulo plus : Roftrum fex digitos longum, incurvum plane ut enfis Hungaricus,' coloris ex igneo fufci.: Corporis longitudo à collo ad podicem undecim digitorum, caudx novem, definentis cum fine alarum. Cruna octo digitos longa, pedes duos \& femis; rubri inftar anatis fed non plani, quatuor digitis \& unguibus nigris, tribus anterius, tho pofterius verfo. Caput \& collum habet plumas albas flavo mixtas, $2 x$ in fuperiore parte paulum oblongas: Oculi illi funt nigni, circulo ruffo: Circa oculos \& fub origine gutturiscutis nigra: Totum corpus nigris pennis vefttum, excepto dorfo, capite \& ventre, ubi cinereæobfcuræ, \& in medio alarum albæ, cano mixtx, ut in ciconiis. Reliqux pennæ corporis, initii \& fmis alarum, \& totius caudx nigræ: Tibic fuperiores ad medietatem ufque carent pennis, nam aquatica eft avis.

Carnem bonam Habet; quam frepe comedicoctam \& frixam butyro:

Alia fpecies reperitur huic fimilis, fed multo minor, \& magnitudine fere gallinæ, qux vocatur matui tui.

Frequens eft ad Flumen S. Francifci, in Itapuama \& alibi.

\section{$\mathrm{C} \quad \mathrm{A} \quad \mathrm{P} \quad \mathrm{U}$ T II.}

Ijiepiranga. Iacapu. Iambu. Gallina Africana. Guiratangeima. Iupujuba, Sayacu. Ani. Guird guainumbi.

TIE Iranga Brafilienfibus, A vis alaudx magnitudinem paululum fuperat, \& cantum pafferis noftratis xmulatur: Totum corpus, collum \& caput egregie rubicundi feu fanguinei eft coloris: ale vero \& cauda fplendide nigti; præterquam in initio alarum, ubialiquid rubicundi admixtum eft. Cruna nigra inferiora quidem nuda, fuperiora autem nigris penis veftita. Roftrum inftar pafferis, fuperiori parti nigrum, inferiori verfis acumen nigrum, 'reliqua verfus caput album. Penne in capite breviores, quas crifpare interdum folet more Pafferum. Omnes pennx totius corporis ihterius funt nigre, exterius rubre, ita tamen complicatx, ut exterius totæ rubræ appareant. Cauda longitudine ferme tres digitos xquat. Digiti pedum quatuor \& ut in plerisqueavibus difpofiti.

Aliahujusfpecies reperitur pafferis magnitudine; qux penais per totum corpus veftitur ex cinereo cxrulefcentibus, alx tamen quodammodo ad thalafinum colorem accedunt. In ventre \& inferiori parte colli feu gutture albicat, vel potiusargenteo colore nitet. Cruna cinerei coloris, ut \&roftrum, quod ipfi fimile Fringillx. Digiti pedum quatuor fecundum communem avium modum.

JACAPU, Brafilienfibus; Avis magnitudine Alaudx, cauda extenfa, alis brevioribus: cruribus brevibus \& nigris; unguibus acutis ad quatuor digitos: roftro paulum incurvato \& nigro, femidige tum longo. Totum corpus vefticur pennis nigris fplendentibus; fub gutture tamen nigredini illi macula coloris cinnabrii funt admixtx.

J A $\mathrm{M} \mathrm{B} \mathrm{u}$ Brafilienfibus dicta avis eft perdix, noftratibus quidem, magnitudine par, uti\& figura. Penne autem per totum corpus obfcure flavefcentes, verum furco mixtæatque maculatæ.

G A L L I N A A fricana ex Infula do Majo, magnitudine noftratium gallinarum, figura corporis fere ut perdix: collum item coronatum portans, \& c caudam perdicis habens inferius dimiffam : pedes gallinaceos: roftrum flavium: \& in capite mitellam cutaceam fufcam: ad latera porro capitis alba, ut \& ad quodlibet latus prope roftrum cri- 
ftam rubram ad latus protenfam. Totum corpus veftitur pennis nigris, qux elegantiffimis maculis albis variegatx funt, in alis quidem oblongis, in reliquis autem partibus rotundis; funtque in dorfo minores, quam in reliquis partibus. Huic fimiles vidiè Sierra Lyona advectas, fed eorum collum circumiligatum feu circumvolutum, quafi linteamine membranaceocoloris cinerei carulefcentis. Caput tegit criftra obrotunda, multiplex, conftans pennis eleganter nigris. Punctula albicantia per totius corporis a mbitum, quafi umbra thalafinina variegantur.

Congenfibus hre avis dicitur Quetele.

QuIRATANGEIMA Brafilienfibus; Avis paulo major Alauda, Picæ variæ $x$ qualis. Corpus habet circiter tres digitos longum, collum fesquidigitum: Caput parvum, roftrum rectum, acutum, digitum longủm, crura pedesque, ut reliquæ aves communiter: Cawdarm longam, rectam, quatuor digitos longam: Color roftri niger, excepta inferiori parte, ubi inferitur quxaliquid fufci habet: Caput nigerrimum \& collum ufque ad initium pectoris. Colli fuperior pars à capite fere ad initium dorfi uranica eft : per initium dorfi transverfam habet máculam nigram ufque ad alas extenfam : alc autem funt nigerrimi coloris, verum in medio fecundum longitudinem habent maculam albam fesquidigitum longam:Carda quoque tota nigra: reliquum corpus coloris uranici: Crum fubcærulea. Oculorum pupilla fubnigra, albo fubflavo.

Nidificat in altis arboribus Acaya, idque libenter prope $x$ des. Nidos egregios exftruunt hæ aves, cylindracex figuræ, \& appendunt magno numero extremitatibus ramorum; qui conftant è virgultis. Clamant fere ut picx variæ noftrates.

Jupujuва feu Ja вu Brafilienfibus, ejufdem formx cum precedenti, \& codem modo in eadem arbore nidificans Guna eft fomina altermas ) cauda paulum breviori. Corpus habet totum nigerrimis pennis veftitum : in utriufque alx medio maculam flavam digitum longan ; in extremitate dorfi, \& prope anum tota eft flava (vidi quoque totaliter nigras, dorfo fangunei coloris) cauda inferiusab exortu ad medietatem flava, reliqua medietas nigra, fuperius nigra in totum, folum in ea ad latera utraque ufque ad medium pennam habens flavam. Crun nigra \& pedes. Roftrum fulphurei coloris: oculi Sapphyrini, pupilla nigra : linguam cxruleam habetanterius fiffam feu duplicatam.

Prope ædes domini Ingenii Tupucuraj arbor Uti fita, in quaplus quam quadringenti nidi harum avium pendent, maxi- moque numero funt hx aves, yux ter quo: tannis ibi pullos excludunt: nidus autem quilibet ex arido gramine, \& pilis equinis aut fuillis mixtis eft compofitus, coloris fufci, figura cucurbitæ angufte cum fuo alembico, longus in totum fefquipédem circiter, \& ab infimo ad unum pedem altus' cavus ut burfa, reliquum fuperius ad femipedem fimplum eft, \& fua extremitate pendet à ramulo extremo: omnes autem nidiex ramulis minimis extremis arborum dependent.

S A Y A C U Brafilienfibus, Avis Fringillæ magnitudine: totum corpus veftitur pennis, coloris è cinereo \& thalaflino mixti, in alis autem \& dorfo thalaffinum admifcetur, ita ut Sole illuftratx egregie fplendeant; roftrillum nigrum, oculi quoque nigri in totum.

A N I Brafilienfibus; Avis Turdelx magnitudine, totaliter nigra, pennis, roftro, oculis, pedibus Candam longam. erectam habet, fex digitos longam: Rofrum altum, latum, digitum aut paulo plus longum : inferior pars directa fere, fuperioralta, lata, femilunaris figura, \&compreffx, ita ut acumen fere fuperius habeat. Crura \& pedes fatis exiles, \& in is quatuor digiti, duo anterius, duo pofterius verfi,more pfittacorum. Clamat elata voce yiviiy uno tono, in medio elevatiori.

Frequentes funt in fylvis omnibus, verum cibo inutiles.

Guir a Gua in umbi Brafilienfibus Tupinambis; avis magnitudine Columbrad vifum, quia plurimas plumas habet, fed revera corpus non fuperat magnitudinem Turdelæ. Cäput paulo majus habet quam Turdela: roftrum nigrum, duos circiter digitos longum, cujus fuperior pars paulolongior inferiore. Eft autem roftrum fuperius \& inferius in latere ferratum inftar ferræ, infervitque dentium loco. Crura habet brevia, haud multum digitum excedentia, nigra; quatuor in pedibus digitos, quorum unus retrorfum vergit, tres antrorfum, fed primus verfus interiorem pedis partem brevior, medius longiffimus, \& tertius iterum brevis, fed non æqualis cum reliquis exortus: primi enim exortus eft ad pedem, fecundiitidem, tertii vero prope tertium articulum medii, habetque primus tres, fecundus quatuor, tertius ibidem tres articulationes, qui retrorfum vergit duas. Ungues nigri deorfum incurvati. Cauda longiflima, directa pennis paucis rectis, digitum circiter lata, fed decem longa: \& quidem dux tantum pennx extremam caudam conftituunt, qux ad duos digitos plumis carent, in extremitatibus autem rurfus plumas habent ad duos digitos. Corpus totum fex circiter digitos lon- 
gum eft. Perne clegantiflimx: nimirum in nefciens vix poflit agnofcere, quäs irafcens, capite quafi mitram gerit ex pennis Sap- aut etiam alias in criftam erigit.Roftrum lia phyrinis, qux prope exortun roftri Tur- bet infigne, non crafum, incurvatum, fescoidis colorem referunt: in medio autem hujus mitrx macula vifitur nigra magnitudine grofli Mifnici. Infra oculos (qui flavi funt,pupilla nigra) etiam nigras pennas habet Sapphyrinis mixtas: guttur.inferius, totum pectus \& tocus venter obfcure luteum habet colorem; fuperior colli pars, totum dorfum, alx \& cauda viridis feu graminei eft coloris, fed cui (prefertim in alis \& cauda) thalaflinusadmixtus, ut in col, lis anatum \& pavonum; à genibus ad ventrem crura fuperiora pennis virentibus funt pirxdita. In medio collo inferius quafi pro infigni gerit tres vel quatuor pennulas nigras, \& circum eas Sapphyrinas, qux maculam quandam feu notam conftituunt:

\section{A P U T III.}

\section{Iaguacati guacu. Mitu. Mitupo- ranga. Ibijaw.}

A guacít G Guacu Brafilienfibus, Papa Peixe Lufitanis, nam pifcibus victitat. Avis Turdelæ magnitudinem æquat; figura corporis ut Picus major. Roftrum habet nigrum, rektum, \& in extremitate acutum, tres ferme digitos longum : Oculos nigros \& crura breviflima nigra : fuperiora crura ex parte carent plumis; in pedibus digitos quatuor, (unum retrorfum ) inxqualis longitudinis, duo enim. verfus exteriora pedisbreves funt, tertius interior longe brevifimus \& remotior. Vngues nigri. Cavida duos digitos longa s. excedens alarum fines. Penne totius corporis fuperiores, nimirum in capite, collo, alis, cauda funt ferruginei coloris \& fplendentis: Circa collum tranfverfim, annulum habetex albiflimis plumis; guttur, inferius collum, pectus, \& totus venter pennis veftiuntur albis, prope utrumque oculum etiam maculam habet ex albis pennis : in cauda autem albx pennx interferuntur guttatim, ut $\&$ in alis, fed que vix videntur, nifi cum alas explicant \& volant.

Mrtu vel My т U Brafilienfibus dicta avis ex Phafianorum eft genere, major gallo gallinaceo Corporis longitudo à collo ad exortum caudx eft decen digitorum: collilongitudo fex digitorum, totaliter nigris pennis eft veftita, excepto ventre \& fub ano, ubibrunni coloris eft, fere ut perdix. Tenuiores funt pennx ad collum, caput, \& in pectore, \& holofericum. villofum nigrum pulchritudine æquant. In fummo capite habet pennas nigras complicatas in planifimam quafi mitellam, ut quidigitum fere longum; inferiorpars ejus parva, fuperior ferme quadruplo major: Roftrum auteni coloris eft egregii incarnati, verfus acumen tamen albicat. Crurd habet gallinacea decem digitos longa, nimirum quatuor à pedibus ad genua; $\&$ fex fuperius, atque hæc veftita pennis nigris : digitos item quatuor gallinacès, qui in exortu ufque ad primam juncturam cucicula fibi invicem annectuntui, ut in aliis quibufdam avibus. Caudam habet pedem longam, infar gallo-pavi, quam femper in latum mover, Kit, Kit, clamando, utilli. Caput bene formatum, anferini magnitudine : Collum fex circiter digitos longum : oirulos habet magnos, egregios, nigros, \& pone aures maculam cutaceam albefcentem ut gallinæ. Hanfuefcit facile. Lubenter in alto fedet ut gallopavi, fcanditque arbores, ut illi. Carzem denique habet admodum bonam. Reperitur \& alia ejufdem fpecies, quam Mituporanga vocant Brafilienfes, folo roftro 8 pennis capitis differens; hxc roftrum habethaud longum, fatis crafium non tamen ita altum ut Mitu, neque fic lunatum: ejus extremitas utrobique nigra, reliquim totum crocea cute veftitum, qualem \& circa oculos habet. Oculi nigriegreffi : collum \& caput nigerrimas habet plumas inftar holoferici; \& in fummitate capitis crifpatas atque cochleatim tortas habet pennas ufque adinitium colli; has erigere in criftam crifpam potcft. Reliquum totius avis nigrum, cui nigredini hinc inde aliquid viridis tranfplendet. Circa anum albas obtinet pennas. Crura cinerea; figura ut-Mitu. Cauda nigra, fed extremitatesillius pennarumalbæ. Et hæc quoque avis optime manfuefcit.

I в т а u Brafilienfibus, Noitibo Lufitanis: Avicula Hirundinis magnitudine: $C a-$ put habet latum \& compreffum : oculos $\mathrm{ma}$ gnos, elegantes, nigricantes, pupilla atra fplendente ellypticæ figuræ, exterius autem oculos ambit circulus ex albo flavefcens: Roftrillum minimum habet, quod non excedit craflitiem dentis aranei, nec tam eft longum : nares tamen patentes in roftro: os ampliffimum, quod claufum non poteft videri, acquando roftrillum aperit; os ad oculos diducere poteft, ita ut digitum fere fit amplum ; Lingwam habet minimam. Crum alba, \& fecundum corporis molem parvula, vix femidigitum longa; quatuor in pedibus digitos, tres anterius, quar. tum retrorfum verfum, unguibusincurvatisnigricantibus. Secundum longitudinem in unguiculo digiti medii cujuslibet pedis verfus interiora habet piniam quaf. multim 
multipliciter fectam, feu dentatam, vide- finem alæ definiens. His alis expanfis volaturque unguiculus quafi plumatus verfus re diu poteft, ac in aëre quafi pendula mainteriora, fed non funt plumæ, verum cu- nere; inter volandum ftrepitum edit intacea materia \& afpera. Couddm habet ele- ftarbruchi, feu rectius hur; bur, bur, inftar gantem, quam in latum poteft explicare, rotælinteariorum quæcircumvolvitur:adduos digitos longam, cum ejus extremi- modumque tenues apparent \& tranfpatate etiamalx definunt. Perras in toto in- rentes pennæ alarum expanfarum. Color feriori corpore habet ex albis \& nigris mix- plumarum aviculx per totum caput, coltas, ut Nifus : In capite, dorfo, alis \& caul- lum fuperius \& ad latera, per dorfum toda nigricant, \& albedo infperfa grata varie- tum \& initio alarum eft refplendens miritate : nonnihil quoque flavedinis albedini fice, nec à pictore bene exprimi poteft; admixtum: uno verbo, nigra eft \& punctu- nam viriditati, qualis in Pavonum \& Analata fubtiliter hinc inde:

Reperitur \& fpecies hujus magnitudine Noctur, ejufdem coloris \& conformationis. os quando aperit, pugnum humanum facile admittit.

\section{A P U T IV.}

\section{Guaimumbi varia Jpecies.}

G

U A I N U M B I qux \& Guinambi, item T. Aratita \& Aratantaguacu vocaturà Brafilienfibus, à Lufitanis Pegafrol, à noftratibus poteft appellari \$locmen Spectt. Hujus autem multex hic reperiuntur fpecies.

Prima: Totius corporis aviculalongitudo ab initio capitis (ubi roftrum eft infertum) ad exortum caudx duorum digitorum. Capitis magnitudo una cum pennis magnitudinen cerafi dulcis mediocris xquat. Colli longitudo tres quartas partes digiti, corporis longitudo unius digiti eft $8 z$ quadrantis: Magnitudo autem corporis cum pennis olivam grandem vix æquat, Raftellum habet fefquidigitum longum, fibrotundum, xquale, tenue, \& valde a= cuminatum, rectum, paululum tamen verfus extremitatem dorfum verfum; color hujus niger, excepta inferiori parte prope exortum, ubi rufefcit. Linguam habet duplicatam, feu bifectam, tenuiffimam inftar ferici fili tenuifima, albam, longam, ita ut illam longe extra roftellum poffit exferere : Ocellos parvos nigros. Crura \&pedes minimos brevefque, nigricoloris; in pedibus quatuor digitos, tres anterius, unum pofterius verfum, longis, femilunaribus, acutifimifque unguiculis nigris preditos. Candam liabet directam, digitum longam, .quatuor ut plurimum pennis confantem. Alic autem qux duorum digitorum longitudinem habent, ad extremitatem caudx fere pertingunt, pennx fingulariarte à hatura funt compofitx. $\mathrm{Ab}$. exortu enim alarum ad tres quartas partes digiticirciter duplex ordo pennarum eft, minus longior altero, \& fuperpofirx funt fibi invicem pennx, quafialx breves fuper longas. Hinc poft has pennas, alæ pennæe (quarum circiter decem funt) fequens interior femper longior fit antecedente exteriore, ita it intima fit omnium longifima

turm collo, aureus, ig̊neus, flavus mire admixtus eft, ita ut Sole illuftrante mirifice fplendeant. In gutture, inferiori collo, pectore \& toto infimo ventre, cruibufque fuperioribus albx funt pennæ, quibus in collo inferiori eximui coloris fimul fparfim admixtx, in ventre albis fubjacent nigrex. Alarum initium miro colore conftare dixi, reliqua pars tota brunna eft, feu fpadicei coloris fplendentis. Carda pennis conftat coloris inftar chalybis politi cærulefcentis. Victitat floribus folum, ideo capta viva detineri non poteft, fed moritur. Frequentes autem in floribus arboris, qux Menfe Januario potiffimum floret, \&xpoteft aliquis vel fexaginta uno die fclopeto figere. Inveniuntur \& fuper aliis arboribus variis. Toto autem anno, magno numero in filvis inveniuntur, \& prefertim matutino tempore ingentem ftrepitum excitant. Non autem canunt, fed clamant, Screp, sicrep, screp, uno fono \& continenter, fere ut pafferes. Volantes velociter alas movent, \& cum vix videantur, \& per longum temporis fpatium in aëre velut quietæe, vel fe moventes hærere poffunt alarum ope. Flores roftellis carpunt inter volandum. Nidum faciunt in ramis arborum folidi Hollandici magnitudine. Orva ponunt albiffima tefta, duo ut plurimum, ovalis figuræ; pifo haud majora.

Secunda: Pulchrior priori, ejufdem magnitudinis \& figurx. Roftellwm tamen brevius, nimirum duas tertias partes digiti longum, ejufdem figurx \& coloris cum prio re ; Lingua eadem, ut \& ocelli, crura, pedes, cauda \& alarum figura. Plumarum color in capite, collo fuperiori, dorfo, alis, cauda fimilis priori; at in gutture, feu collo inferiore, toto pectore \& infimo ventre ufque ad extremum corporis, tam eleganti \&-fplendente viriditate cum auréo colore tranfplendente funt plumx, \& mire refplendeant. Prope anum macula eft fatis magna (refpectu aviculx) conftans plumis candidiffimis.

Tertia, minor reliquis omnibus: $\mathrm{Ab}$ initio capitis, feu exortu roftri ad exortum caudx duos \& femis digiros longa. collum unum fere digitum longum : Gaput haud magnum. Corpus fefquidigitum longum. 
Roftelium paulo plus digito longum, ni- lim habet paulum curvattim, digitum longrum, fubrotundunx, acutum ac fere-reEtum. Crura \& pedes, ut reliquarum. Pennarum corporis \& alarum etiam eadem dipofitio, fed color diverfus. Caudam longiorem habet reliquis omnibus, paulo plus tribus digitis longam, pennis conftantem, quarum ea qua exortui ejus vicinior, brevior, fecunda femperlongior; eftque cauda furcata, 8r avicula volans eam in duo ampliffimacornua expandit, ita ut extremitates cornuum fefquidigicum à fe invicem diftent. Totum Capit \& collum hujus avicu. læx ex nigro ferico colore elegantiffime cxruleum tranfplendet, ut in collo Anatum. Totum dorfum \& pectus viride, aureum, \& thalafino tranfplendens, ut in fecunda fpecie, atque etiam prope anum talis macula eft è plumulis albis. Alarum color epaticus eft. Cavda ex nigricante corulenti inftar politi ferri coruleo imbuti.

Quarta, paulo minor tertia: Corporis figura \& plumarum difpofitio eadem, fed alio colore, nec non differens roftro, \& crurum colore. Roftellum fefquidigitum longum, deorfum incurvatum inftar enfis Polonici, fubrotundum, ubique æqualis craflitiei, \& in extremitate acuminatum. Superior ejus pars nigra eft, inferior flava, excepta extremitate qux etiam nigricat. Caput fuperius, collum fuperiori parte, ut \& alx, colore funt, ut prima fpecies, guttur, collum inferius, totum pectus \& infimus venter ex albo rufefcentis funt coloris. Caudam habet plus digito longam, definentem cum fine alarum, conftatque pennis ex nigricante virefcentibus, qux in Extremitatibus albæ. Crsira eodem modo difpofita habet, ut cxterx fpecies ;

- fed haud nigra, verum alba feu flavefcentia, fimilibus digitis, \& unguiculis fenilunaribus, acutis, \& nigris.

Quinta, magnitudine par tertix fpeciei: Roftello nigro, paulo plus quam digito longo, \& paulum deorfum incurvato, ocellis nigris, uti \& cruribus \& pedibus. Guttur, collum inferius, \& totus venter nigris holofericis veftiuntur pennis, cui nigredini quafi paulum coerulei tranfplendet. Prope anum macula eft albis plumulis. Extremitates autem nigri, nimirum ad latera colli, pectoris \& ventris mire thalafino, aureo \&rviridi mixti refplendent. Totum caput fuperius, collum fuperius, \& totum dorfumornantur pennis, aureo, igneo \& viridimixtis, ut \& initium alarum. Reliquum alarum ferreum eft, feu fufcum. Cardo paulo plus digito longa, eleganter brunnis, cui coeruleus tranfplendet, pennis conftat, circa oras autem pennæ illæ habent colorem; qualem chalybs politus cœsulefcens.

sexta, quintx magnitudine par. Roftelgum, inferius album, fiperius nigrum. Totum caput, collum, dorfum \& venter, ac initium alarum infignis coloris refplendentis pennis veftiuntur, nimirum plurimo aureo, dimidio fere igneo, \& minimo viridi mixto. In fumma, fplendet ut Sol. In ventre pennæ albæ paucæ mixtæ. Crura nigra funt. Ale nigricantes. Cauda fefquidigitum ferme longa, clegans \&lata, conftans pennis quibufdam infignis illius coloris, quo reliquum corpus, quxdam ex viridi \&aureo mixti coloris, \& per oras albre, quxdam in uno latere, feu medietate albx altero virides, cuitranfplendet âureus.

Septima, paulo minorquinta \& fexta fpecie. Roftellum habet non omnino digitum longum, coloris per totum corpus cinerei fere, ut paffer, cui hinc inde mire refplendens rubrum inftar Rubini perlucet.

octava: omnium elegantifima:Roffellum rectum, nigrum habet, femidigitum longum ; Linguam longam duplicatam : magnitudo \& conformatio eft ut fecundæe fpeciei. Totum caput fuperius \& collum fuperius miro rubini colore fulgent, ac fi rubinusradiis folis illuftraretur. Guttur autem \& collum inferius merum aurum Hungaricum politum, \& radiis folis illuftratum exhibent, ita ut impollibile fit perfecte fimilitudinem horum colorum reddere, multo minus à piotore reprafentari. Initium dorfa holoferica nigredine tectum eft, reliquum fufcis pennis, quibus tamen aliquid obfcuræ viriditatis admixtum. Totus infimus venter ejufdem cum dorfo coloris pennis veftitur; Als fufco ut in reliquis fpeciebus : prope anum maculam habet albam. Cruna exilia nigra. Cauda digitum, \& paulo plus longa, pennis conftat brunnis rufef centibus (feulemort) quæ in extremitatibus per oras fufcefcunt. Casda lata, quam inter volandum egregie explicat. Alarum extremitas cum cauda definit.

Nona, figura \& magnitudine, ut prima. Roftellum fuperius nigrum, fubtus ruffum. Totum corpus, exceptis alis, infigni illa fplendet viriditate cum aureo tranfplendente, quali fecunda fpecies in ventre. Ala fufcx. Cauda digitum longa, latiufcula, pennis conftans coloris, ut ferrum politum cœrulefcens.

Sortitur autem avis hæc varia apud Brafilienfes nomina, preter generale Guaimum$b i$, ut Guaracyaba, id eft, radius Solis, \& Gvaracigaba, id eft, capillus Solis. Fr. Ximenes fcribità Mexicanis appellari Huit zit zil. Avicula eft, inquit, quæ habet plumas pictas variis coloribus, è quibus mixtis \& compofitis cum artificio, \& admirabili in duftria faciunt Barbari imagines Sanctorum \& aliarum rerum, atque ita conjungunt, utoptime fimilitudinem repriefen- 
tent. Hujus aviculx ea natura ef \& pro- | macula : Cauda etiam nigra. Crura \& pedés prietas, quod non diutius vivat, quam flo- fufci. Elegans eft aviș.

resplantarum durant, cujus melle victitat, JA C U R U T Braflienfibus:bufoLufiquibus decidentibus, roftello fuo fe affi- tanis. Noctua eft, magnitudine rquat Angit arborum truncis, \& fex menfibus ita immota manet, donec flores renafcantur: quod tam multis teftimonis confirmatur, ur de eo dubitari non debeat. Ajunt pulverem linjus aviculse haufum, curare arthritidem coralloidem. Hæc ille. Vidimus plures ejufmodi icones artificiofe ex hujus avicula plumis concinnatas ita dextre, ut coloribus pictæviderentur; fi autem Soli obyertas, mirabilicer fplendet.

\section{$\begin{array}{lllllll}C & A & P & U & T & V\end{array}$}

\section{Iacupema. Iacamacait. Iacurutu, Soco.} Matuitui.

$\mathrm{J}$ A cupema Brafilienfibus; Phafiani eft fpecies; paulo major gallino minore domeftica noftrate. Caput illi gallinaceum haud magnum; Roftrum gallinaceum; oculi nigrefcentes, collum feptem circiter digitos longum; corporis autem longitudo ab exortu colli, ad exortum caudx novem circiter digitorum: Candam habet longam \& latam, longam nimirum pedem. Crura longa, fuperiora plumis veftita \& quinque digitos longa, inferiora tres, aut paulo plus. In pedibus quatuor digitos gallinaceos, quorum medius è tribus anterioribus duos digitos longus. Plumis tota avis veftitur nigris, quibus brunni aliquid mixtum. Ac capitis quidem plumas in criftam erigere poreft. Cingunturque illæ nigra alis albis in ambitu. Guttur fub capite, \& ad fefquidigiti longitudinem, in collo plumis nudum eft, \& rubra cute tectum. Collum totum inferius plumulis albis in nigris difperfis eft variegatum, ut \& totus infimus renter, acalarum medietas pofterior: fuperiora crura \& cauda folis nigris conftant, cui aliquid brunni mixtum. Crura inferiora \& pedes elegantis rubri coloris. Cicurantur. Carnem habet bonam. Hæc avis à clamore fuo nomen accepit, clamat enim Iacu, Iacu, Iacu.

J A M A C A I I, Brafilienfibus. Avicula Alaudx magnitudine. Corpus tres digitos longum, collum plus digito, crura duos digitos, cauda fere quatuor. Caput habet parvum: Roftrum digitum longum, directum, paulum deorfum inclinatum, acutum, nigrum quidem, at inferius prope exortum paululum cœrulefcens. Caput nigris veftitur pennis, uti \& collum inferius, fuperius luteis: totum dorfum, pectus, \& infimus venter luteis, ale nigris, in quorum medictate albx infertæ, quæ máculas albas faciint, in qualibet ala unam: ad exortum alanum tranfverfim per dorfum tendit nigra feres: Caput habet rotundum inftar felis: Roftrum aduncum, nigrum ; fuperiori partelongius. Oculos magnos, elatos, rotundos, \& fplendentes inftar Cryftalli; in quibus interius circulus flavus verfus extrema apparet. Latitudo oculorum aliquanto major groffo Mifnico. Prope aurium foramina plunias habet duos digitos longas, quæ inftar aurium in acutum definunt \& 2 attolluntur. Cauda lata ef, neque alx pertingunt ad illius extremitatem. Crura pennis veftita ufque ad pedes : in quibus quatuor digiti, tres anterills, unus pofterius verfus, atque in quolibet unguis incurvatus niger, plus quam digitum longus, \& acutifimus. Penne totius corporis variegatæè flavo, albo \& nigricante pereleganter:

Soco Brafilienfibus, avis Aquatica, cujus multx hic obfervari poffent fpecies; hæc cujus Iconem addimus, magnitudinem habebat Ardex minoris. Roftrum obtinet rectum, nigrum ; 8 in extremitate acutum, duos \& fenis digitos craffum, ubi craflifimum. Caput illi inftar Ardex, uti \& collum pedem longum. Oculi nigri circulo aureo. Ala \& cauda fimul definunt: Cauda enim brevis,nec fupra quinque digitos longa. Crura fatis longa, fuperiora quippe quatuor, \& inferiora totidem digitos: in pedibus porro quatuor digitos, videlicet tres anterius, unum pofterius ver. fum. Crura autem fuperiora ad medietatem funt nuda pennis : cætera fufca cute tecta. Caput \& collum brunnis quidem pennis, fed qux punctulis nigris variegatx funt, veftiuntur. Per totum collum inferius ad pettus ufque tendit linea plumis albis, nigris \& brunnis mixta. Dorfum \& ale nigris quidem, fed qux minutifimis punctulis flavefcentibus variegatæfunt, vertiuntur; Venter quoque ad eundem modum: fub alis denique nigrx; \& albo maculatre funtpennx.

Ma тuгти i Brafilienfibus, Avis Alaudx magnitudine. Roftrum habet rectum, nigrum quidem, at in exortu inferius croceum. Oculos elegantes nigros. Totum Caput fuperius, collum, dorfum, alx \& cauda fuperius coloris funt obfcure gryfei, \& \& remiges alarum nigricantes. Caput inferius, guttur, pectus, \& infimus venteralbicant, ut \& crura fuperiora, qux mediam partem pennis veftita, more avium aquaticarum: Supra exortum roftri in fronte maculam habet albam, \& annulum album circa collum, \& inferius femiannulum obfcure gryfeum, huic contiguum : nam guttur totum album eft, collum fuperius to- 
tum obfcure gryfeum. Crun funt fubluteo- $\mid$ nigræx, rubini colore tranfplendente in niLa s. digiti autem pedum aliquid fufci ad- gro: Pellis detrahitur huic avi, ac caro ejus mixtum habent. Tres folummodo digitos cocta comeditur; pinguis eft \& ficca, boni habet in pedibus, omnes anterius verfos, faporis, prefertim fi coeta butyro frixetur. qui in exortu cute ex parte junguntur: Un- Comedi frepiflime. guiculi nigri.

Avishæc ad littora maris \& ripas falforum fluminum difcurrit:

\section{A $\mathrm{P}$ U $\mathrm{T}$ VI.}

Iabiru. Iabiruguacu. Manucodiatá:

I A B IR u Brafilienfibus, Belgis vulgo Negro. Avis hac magnitudine fuperat cygnum. Corpus illius quatuordecim digitos longum: Collum totidem, \& brachii humani habens craflitiem. Caput fatis magnum, Oculi nigri, Roftrum nigrum directe extenfum; \& $r$ fuperius verfus extremitatem paulum incurvatum; undecim digitos longum, duos \& femis latum; verfus exteriora acuminatnm ; eftque fuperior roAtri pars paulo altior, \& major inferiori. Caretlingua, \& fub gutture ingluviem habet mediocris magnitudinis. Crura longiffma, duos nimirum pedes : fuperiora enim unum pedem $\&$ digitum longa, \& mediam partem pennis nuda; inferiora undecim digitos. Sunt autem crura recta, nigricantia, \& quafifquamata, digitum medium craffa. In pedibus digitiquatuor, tres anterius, unus pofterius verfus; quorum medius quatuor digitos longus, cxteri paulo breviores. Tota avis veftitur albis pennis inftar cygni auc anferis. Collum fere totum, nimirum octo digitorum, longitudine à capitenumerando, caret pennị; ; ac hujus medietas cum capite tegitur nigra cute, reliqua aiba cute: Sed puto in cute hrfiffe pinnulas albas, \& fuiffe abreptas. Cauda lata definit cum extremitate alarum.

JA B I R U G U A C U Petiguaribus, Nbandu opoa Tupinambis: Belgis Deurbanel. Roftrum habet magnum, feptem \& femis digitos longum, in extremitate teres \& inferius incurvatum; caret lingua, \& roftrum inferius canum eft. In fummitate capitis mitram offeam coloris albi, \& cinerei mixti gerit. oculinigri, \& pone eos aurium foramina ampla. Collum decem digitos longum, cujus medietas, uti \& caput, plumis, ac cute fquamofa cinerea eft tecta, cujus fuamæalbicant. Corpore æquat Ciconiam; Cardam habet brevem \& nigram, cum qua alæ definunt. Crura fuperiora ex parte albis veftita pennis, catera tota cinerea, \& quidem fuperiora crura longa funt digitos octo, inferiora fex, aut paulo plus : digiti pedum quatuor, ut in priore. Totum corpus \& collum albis veftitur pennis, \& à collo longiufculx pennx propendent \& sircum. Ale albx, remigesillarum pennæ
Manucodiata, \& quidem Rexcreditus; ad afpectum Columbam, fed revera hirundinem rquabat. Caput habet parvum, oxulos parvos, roftrum rectum, fatis crafum, acuminatum, fefquidigitum longum : Collum digitum longum; Corporis autem longitudo à collo ad caudæ exortum vix trium digitorum \&z femis. Ala fu pra feptem longx; Cauda lata \& fex digitos longa: Cruna duo habet, quodlibet inferius duos digitos longum; quatuor digitos in pedibus, tres antrorfum, unum retrorfum verfum, more communi; medius anteriorum paulo longior cxteris; pofterior etiam fatis longus; quilibet ungue $\mathrm{lu}$ nato, feu adunco accipitrino forti præditus Suntque crura \& pedes fatis craffi, ac ad rapinam comparati. Ala \& cauda pennas habentlatas \& fortes digitilatitudine. Totum dorfum, infimus venter, alx, cauda ele gantis funt brunni coloris; fuperius ad rofrum pennulas habet holofericum leve referentes, viridi \& fufco mixtas; inferius ad roftrum fimiles nigri coloris. Collum fuperius flavi, feu aurei eft coloris, inferius viridis cum aureo tranfplendente. $P e_{-}$ ctus faturate brunnum; fub alis in lateribus inter alas \& crura, exoriuntur multæ pen$n x$, pedem plus, vel minus longæ, elegantis ftucturx, qux fupra caudam longe extenduntur : funt autem prope exortum flavi, feu aurei coloris, reliqua ex albo flavefcentes, brunno umbratæ, feu dilute. intermixtre: inter has pennas duo quafi fi: la extenduntur; quodlibet longum duos pedes \& amplius, ac verfus extremum incurvata, obfcure brunni coloriss Crund fufca funt, unguibus magis albicantibus. $R o-$ frum coloris eft ex viridi \& coeruleo mixti, verfus acumen tamen albicans.

Hac eft illa avis, quam alii Paradifeam vocant: cujus aliquod reperiuntur.jpecies.

\section{A P T VII.}

Guirapunga utraque. Guiraquerea. Ids camaciri. Cariama.

CUIR A P A N G A Brafilienfibus; A vis I cujus fonus longe auditur, Turdelæ majoris magnitudinem fuperat, \& columbæ fere æquat. Roftrum habet digitum longum \& latum, anterius acutum, cujus fuperior pars paulum prominet firper inferiorem, ac deorfum eft incurvatum, nigrum, naribus patertibus, os illi amplum, quod aperire poteft ufque fub 
oculos, ita ut oris apertura cum roftro trian- tenfas anterius \&ad latus. Corpus haudlongulum formet. Linguam habet brevem. gum, fed rotundum fere eft. Pedes quatuor Oculos è nigro coerulefcentes: Sub gutture digitis more communi conftant, quoautem; quod latum habet, \& in collo infe- rum medius longior reliquis; \& unguiculo riori, multas digitum longas propenden- fuo (quos omnes habet nigros) pectine tes particulas carneas nigras habet, figu- corneo fubtiliter ferrato dotaius eft. Alas ra fpiculi haftx, vel quafi ligulx. Caput ob- longas habet, nimirum femipedem. Caufcure brunnis pennis veftitur. Totum col- da octo digitos longa, conftans in extrelim, pectus, venter, dorfum \& crura fu- mitate duabus pennis longioribus reliperiora leucophxis teguntur pennis, (qui- quis. Tota avis ex fufco cinerei coloris cum bus potiffimum in dorfo ) nigricantes admixte, ac verfus caudam etiam virefcentes. Caudam habet tres digitos longam, leucophæis ac nigricantibus pennis pauca viriditate admixta. Ala (non multum poft exortum caudx definentes) in initio funt nigræ, reliquam partem nigricantes, quibus obfcure virefcentes pennæ admifcentur. Crura inferiora nigricant, funtque plus digito longa; digitos quatuor habet cum cæeteris communes, nigris unguibus: $P \dot{e}$ Itus bifidum eft, feu convallem habet per medium fecundum longitudinem, tracheam amplam, unde etiam fortem clamorem poteft edere. Duplicem autem fonum edit promifcue, una vice quafi quis fecuri percuteret cuneum ferreum, in filva (cock, cick) altera autem quafi quis campanam fif fam tangeret Kur, Kur, Kur, \&c. Clamat autem folum media ætate, Decembris\& Januarii initio per quinque aut fex feptimanas, reliquis menfibus non auditur; unde Lufitanis Ave de Verano vocatur.

Guir a Punga, fomina; Turdelæx noftrx majoris magnitudine eft \& figura, \& eodem modo carnofa. Caput habet latiufculum, roftrum quoque latum, haud longum, oris hiatus amplus quandoaperitur. Roftrum nigrum. Oculi fatis magni. Cauda tres digitos aut paulo plus longa, nec alæ ad illius finem pertingunt. Tota avis veftitur pennis nigricantibus, quibus fufcæ \& dilute virentesfunt mixtæ: magis tamen fufcus eft in dorfo color, in gutture, pectore, \& ventre magis dilute virens, \& mixtus ut noftrx turdelæ. Avis eft pinguis \& copiofa carnis. Crura \& pedes nigricant, cxtera nihil differunt à communi norma.

Quirapererea Brafilienfibus; Avis Alaudx magnitudine, fed quia longas alas, \& caudam habet multo longiorem, videtur major. Caput latum, compreffum, ac fatis magnum habet. Oculos magnos \& nigricantes; roftellum parvum, triangulare, compreffum, \& fuperiore parte aduncum os amplum, longe amplius roftro, quod apertum triangulum efformat. Ad utramque autem extremitatem roftri fuperioris ad latera digiti fere longitudine, in quolibet decem, aut duodecim circiter fetas craffas fuillas habet promaculis obfcure flavis aut albicantibus mixtis, more Nifi.Circa totum collum autem pone caput annulum habet obfcure aureum. Cruna cinerea feu fufca. Digiti exigua pellicula connectuntur, non ita lata, ut in anatibus, nam non eft avis aquatica.

JACAMACIR I Brafilienfibus, Avis Alaudx magnitudine. Roftrum rectum,zcutum, nigrum habet, duos digitos fere longum. Linguam brevem. Oculos cœruleos. Alas breves, qux paulo poft exortum caudædefinunt. Carida autem tres \& femis digitos fere longa, recta, feptem aut octo pennis conftans. Crum fuperiora pennis veftita, inferiora nuda, cute flava \& viridi mixta. Pedes itidem. In quolibet pede quatuor habet digitos, duos anterius, duos pofterius verfos; eftque uterque interior, tam anterius, quam pofterius, dimidiam tantum partem longus pre exterioribus. Unguiculi nigri.

Totum caput, collum fuperius, totum dorfum, alæx, cauda fuperius colorisfunt viridis cum aureo \& igneo mixti,ita ut mirifice refplendeat; ejufdem coloris annulus etiam circumdat collum. Sub gutture autem, in pectore \& infimo ventre, \& fub cauda obfcure flavi coloriṣ eft, utcera vetufta.

Cariama Brafilienfibus, Avis Ardexe majoris magnitudine; ex aquaticarum eft genere: In capite fuper exortu roftri criftam plumatam gerit nigram cinereo mixtam, erectam. Roftrum breve, fuperius paulo aduncum, ex obfcuro flavo fufcum, Ocm los habet elegantes aureos, pupilla nigra, longis fuperciliis nigris. Ale definunt paulo poft exortum caudx. Crun habet longa, fuperius mediam partem pennis veftita, cretera nuda \& obrcure flava: digitostresin pedibus, medium longiflimum exteriorem breviorem, interiorem adhuc breviorem. Suntque digiti ad partem cute connexi. In poftica parte pedis digitum parvum habet, altiori loco pofitum, \& calcaneum rotundum, moreStruthionis. Vngues digitorum breviufculil, lunati, fufci. Totum corpus pennis veftitur gryfeis, feu cinereis fufco undatis, ut in falconibus, \& obfcure flavo mixto: extremitas alarum \& caudæfufca eft, obfcure flavo, \& gryfeo undata: in pectore $\&$ inferiore ventre plus habet gryfei, Caudam demiflam, collum. 
fectum gerit. Clamor ejus inftar gallo-pavi pennx funt fufcx \& nigris undis variegatæ: focminx, \& longe auditur: Carne eft valde In pedibus digitos habet quatuor flavos; probata.

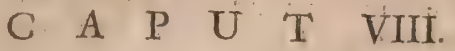

Guara. Urutaurana. Maguari. Guaraunà. Ajaja.Picui pinima. Pica Cureba. Tuidara. Guacaguacu. Tapera.

G u $\triangle$ R A Brafilienfibus (in Marahoon Trequentifima, \& Rio pe Ieneiro) avis eft aquatica \& terreftris, Albardcolie magnitudine. Roftrum habet enfis Polonici figura, longum, ex albo fubcinerefcens. oculos nigros. Collum \& corpus inftar Albardcolx. Ale definunt cum cauda, quæ breyis \& demiffa. Cruralonga, quorum fuperior medietas pennis veftita, reliqua nuda. Digiti pedum quatuor communi modo longiufculi, btevibus unguibus, prope exortum cute inter fe connexi : crura autem nuda cum pedibus coloris exalbo gryfei, uti \& roftrum.

Tota avis veftitur pennis elegantis coloris coccinei; remiges tantum alarum nigras habent extremitates. Hæc avis primum exclufa coloris eft nigricantis, hinc evadit cinerei, deinceps albi, fenfim autem rubefcere incipit, \& fecundo rtatis anno coloris eft in totum, quem Columbin vocant, quoque magis fenefcit, elegantifimum illum colorem coccineum acquirit. Victitat pifcibus, carne, adjuncta femper aqua.

Brafiliani è plumis hujus avis varia componunt corporis ornamenta.

UR UTAURANA Brafilienfibus:\& Vrutaui cuquichu Caririri, Avis Aquilx magnitudine. Roftrum liabet nigrum, cujus fuperior pars adunca, prope exortum tamen flavim; Oculos eleganter aureos, pupilla nigra, quos cuticula cinerea obducere poteft, licet palpebras non claudat. Caput aquilinus quidem fed fuperius compreffum, feu planum, in cujus fummitate duas habent pennas nigras, duos circiter digitos longas, cum duabus parvulis ad latus quodlibet: illasautem quando vult, in altum furrigit, atque iterum componit, Ale pauto poft exortum caudx definunt. Cauda ei lata inftar Aquilæ. Caput fuperius fufcis tegitur pennis, quarum ore fubflavefcunt. Totum collim fuperius, \& ad latera brunnis (ut perdix:) totum guttur cum collo inferiori eft album, ita tamen, ut albedo adlatera pennis nigris fit variegata. Totum peotus \& infimus venter, crura fuperiora $\&$ inferiora ufque ad pedes pennis veftiuntur albis, quibus nigrix fquanatimadmixtre funt. Ale \& carda fufci funt coloris cum umbra mixti, atque oras habent fubtilesalbicantes. Remiges alarum unguibus lunatis fufcis. Clamat $G e b, G e b$, ut pullus gallinaceus qui matrem perdi dit.Rapaxavis,crudam comedens carnem: Projectam fibi avem, five vivam, five mortuam, unguibus arripit, \& roftro egregic deplumat, dein dilacerat, \& carnem ofiaque deglutit; unam harum diu vivam alui in munimento Mauritii ad Flumen S: Francifci.

An ñotatio. Icon hujus avis haud male convenit cum Icone Nycticoracis Gefneri;non tamen Nycticoracisveterum, fed vulgo fic dicti circa Atgentinam, \& alibi circa Rhenum, avis pifcatorix) nifi quod in Capite trespennas habeat.

Maguar I Brafilienfibus; Avis Ciconix fimilis figura \& magnitudine, arque etiam ex parre colore. Collwm habet pedem longum. Rofrum rectum, acutum, novem digitoslongum. Cruri longa \& nuida, ut ciconia. Caudam brevem, cum qua alx definunt. Rofrum in exortu ad medietatem ufque ex viridi flavefcens, reliqua medietas extrema ex coeruléo cineirea Oculos habet parvos, argenteos, pupilla nigra, \& circa eos cutem cinnabriam, ac fimilem etiam inferius prope exortum roftri, feu inter roftrum, \& guttur:quam more Senembi, irafcens dependere finit fub gutture

Totum Caput, collum, \& totum corpus albifimis veftitur plumis; ac inferiori parte colli penne alba illa funt longiufcula: Cauda autem quoque alba, at fuperius nigris aliquot pennis tegitur. Ale in exortu albis teguntur pennis, fed prope dorfum nigris:nigrediniautem perfplendet viriditas. Crun funt rubra, ut \& pedes, quos cum Ciconia communes habet.Roftro crepitat, ut ciconia noftras. Caro illius edulis.

GuAR a una Brafilienfibus Rufticola aquatica, magnitudine Iacw: Rof trum habet teres, paulo deorfum inclinatum, flavum at in extremitate fufcum, quatuor \& femis digitos longum, croporis auten illius longitudo eft totidem. Crunt fuperiora mediam partem pennis veftita, fex digitos longa : Digiti pedum quatuor ita difpofiti, ut communiter; quorum medius tres digitos longus, cxteri breviores.

Tota avis veftitur pennis fufcis multa umbra mixtis. Caput autem \& collum totum ejufdem coloris, \& preterea albo punctulatum, ut in Iacit.

Carnem habet fatis bonam, quam frepius comedi.

A I I A Brafilienfibus, ColberadoLufitanis, Belgis ilepelar. Avis figura conveniens cum Europxis, folo colore different. Anferis magnitudine. Roftro inftar cochlearis lato, albo: Collo longo, pedibus latis. 
Tota alba eft, fed in dorfo \& $r$ alis dilute incänati coloris perfplendentis. Caro illius edulis, \& free comedi. Frequens eft ad Flumen Sancti Francifci, \& alibi paflim in locis paluftribus.

P'icue PIN I Ma. Brafilienfibus. Columbxe filveftris fpecies, paulo major Alau$\mathrm{da}$, Roftellum habet columbinum, fufcum. ocellos nigros, circello aureo. Totum caput, *collum fuperius \& ad latera, dorfum \& alæ pennas habent obfcure cinereas, feu lividas, oris nigricantibus lunatis. Longioresautem alarum pennæ, feu remiges, qux inter volandum videntur; ruffi funt coloris, uno latere nigricantes, ut \& in extremitatibus. Caudalongiufcula ex pennis conftat è cinereo fufcis, quarum \& quxdam nigrx, \& medietate exteriore albx. Venter albas pennas habet oris lunatis fufcis. Cruia \& pedes columbini albefcentes. Carnem habent bonam, \& funt admodum pingues.

Pica Cureba Brafilienfibus; quoque Columbx filveftris eft fpecies; coloris cinerei cum ruffo mixti; pedibus \& cruribus rubris.

Avicula (cujus nomen Auctor nom prodit) pafferis magnitudine \& figura, tota nigra, "capite tamen albo, \& cauda ex multo nigro \& gryfeo colore mixta. Clamar zip,zip.

T U I D A A Brafilienfibus; Ululæeft fpecies; Germanis Schlcict Eutn / Belgis 菲erthmule. Capite rotundo, nafo elato, \& plumis compexis conftrato; fub nafo roftrum habet aduncum, album : oculos autem nigros. Tota avis faciei fuperficies, cordis, uti pingitur, habet figuram, plumilis obfcure ex albo flavis, cum pauco nigro mixtis, quafi fimbria circumdata effent: Plume totius avis mixte albo \& pallide flavo ac gryfeo: Ala undatæ, uti \& cauda. Corpis fubtiliter punctatum cum fufco. Defcribitur \& à Gefnero.

GuACA Gua cu Brafilienfibus, Lufitanis Gaivota, Belgis meeuwe. Avis gallinx vulgaris magnitudine, roftro recto, longo, craffo, flavo. Caput fuperius nigris tegitur pennis, ut \& ultima medietas alarum \& Cauda. Guttur, totum collum, pectus \& infimus venter, ac initium alarum funt alba. Ova ponit in arena, gallinaceis figura, magnitudine \& colore fimilia : quæ quidem bonifunt faporis, fed caro avis nullius eft pretii.

T A P ER A Brafilienfibus, Adorinha Lufitanis; Hirundinis fpecies, noftratibus fimilis, ejufdem magnitudinis, \& eodem modo circumvolitans. Roftrum breve, latiufculum habet \& nigrum. Os amplum, quod aperire ultra oculorum regionem poteft, ut Ibian junior: Oculos elegantes, nigros. Alas longas, definentes cuim fine caudx, qux latiufcula eft; Crma \& pedes ut noftra- tibus. Totum caput fuperius, colluni dorfum, alx \& cauda pennas habent colo: ris ęx fufco cum gryfeo mixti ; remiges alarum \& extremitas caud $x$ paulo magis fuf cefcunt reliquis partibus. Sub gutture \& in pectore gryfei eft coloris cum albo mixti. Venter eft albus, uti \& fub cauda albet. Crura \& pedesfufci.

\section{A P $\quad U$ T $T$ IX.}

\section{Tfittacorum majorum \&ீ minorum variajpecies.}

\section{$\mathrm{P}$}

S I T TACORUM in Brafilia maxima eft copia \& fumma varietas; quos $\mathrm{Bra}$ filienfes communi nomine vocant $\mathrm{AJu}$ $\mathrm{R}$ u. Ariftoteles lib. IV. Hiftor. A nim. cap. $\mathrm{X}$. fcribit; Ea que ovapariunt, an fomnient incertum est, manifeftum vero ea dormire. Ego utrumque adfirmo cum Jul. Scaligero in Commentariis, \& quodille de fuo Turdo \&Accipitribus, ego de meo Pfittaco, quem Lauram vocabam, nam fxpius de nocte feipfum expergifcens femifomnis fublocutus eft. Idem Lib. VIII. cap. X. fcribit, Pfittacum à Gricis etiam aif vocari. Pfittaci nidificant in cavis arboribus, ubi foramen extra rotundum faciunt, ac ova duo aut tria columbinis fimilia imponunt fine nido aliquo ficto. Ova fi tangas, wihilominus excluduntur, nec Pfittacus ea deferit. Pullos excludunt medio Junio \& fine: plumati autem pulli inveniuntur apti ad eximendum fine Julii, \& medietate Augufti. Pfittaci juniores primum exclufi vermes crafiufculos habent, in quolibet narium foramine unum, ac preterea in fümmitate capitis tuberculum, in quo itidem vermis craffus latet. Omnes autem vermes brevi fponte excidunt, ac locus per fe fanatur. Fiunt varii coloris à Tapuyis, deplumando juniores, \&cutem variis coloribus inficiendo, Lufitani vocant Papagios cantrifeitos. Nullus Pfiatacorum Brafilienfium, preter Curicos fe manibus tangi in corpore permittit.

Primajpecies A JU R U c U R A u elegantiffima eft. Supra Roftrum in capite mitellam habet eleganter coruleam : Guttur, latera capitis \& fuperior illius pars eleganti flavo veftiuntur, totum corpus lato viridi. In alarum extremitátibus pennæ una medietate nigræ, altera crocex, partim etiam in extremitate corulex, partim hinc indevirides. In fumma, eleganter variegatæ. Cauda viridis, fed quando illam explicat; fimbriata nigro, rubro, cœruleo. Crura \& pedes cinerei coloris. Roftrum ex cinereo fufcum. Oculi nigricantes, circulo aureo. Lingua omnibus lata \& craffa.

secunda fpecies priori fimilis, paululum 
aliter variegatur coloribus, nimirum in incarnati coloris. Crun \&pedes cinerei. fummo capire mitella flava, cui albedo mixta, fuperoculos \& in gutture clare flavo. Circa roftrum fuperius macula eft thalaflina.

Septima: T.uIPAR a Tupinambis,ma gnitudine Alaudx, in totum dilute viridis coloris, catda brevior, ita ut cum alis definat.Roftro incarnato; cruribus gryfeis.

Tertia pecies; A JuR u c U R U CA. Mi- Prope roftri exortum in fronte, maculam. tram habet in capite ex coruleo \& pauco habet femilunarem miniatam, quafi coronigro mixtam, in medio mitræ maculam nam, qux \& inferius eft, in cujuslibet alæ flavam. Infra oculos flava, \& in gutture medio lutei, feu Uranici coloris. Nidiffcoerulea eft macula. Viriditas in pectore, cant in cumulis à formicis relictis, qui in alis \& dorfo paulo faturatior, in extremi- arboribus reperiuntur:

tatibus alarum \& cauda dilutior. Extremitates pennarum alæ flavæ \& rubræ, \&Indico colore mixtx. Cauda inferius ex flavo \& viridi mixta, fuperius dilute viridis. Crura è cinereo corulefcentia. Roftrum fuperius cinereum, in extremitatibusnigrum, ungues pedum nigri.

T U I; vulgo Perroquet.

Prima pecies: Magnitudine Hirundinis : in totum viridis coloris : cauda longiffima, rofftro nigro, adunco.

Secunda: Tui aputejuba, viridis in totum \& quidem dilutius in reliquo corpore, in ventre flavefcens, in alis obfcure viridis. Cauda longiflima : magnitudinis ejusdem cum priori; Oculis magnis, fubnigris, circello ex pennis circa oculos luteo, \& fupraroftrum, quod nigrum \& aduncum, in capite maculam habet magnam ex pennis Auraici coloris.

Teritia TUI TIR I cA, paulo majores funt Guineenfibus, in totum viridis coloris, quitamen in dorfo \& alis plerumque faturior, in reliquis partibus dilutior: roftro incurvato incarnati coloris. Ocklis nigris; Pedibus corrulefcentibus; Cauda paulum ultra extremitatem alarum protenfa. Admodum hi manfuefcunt, \& cibum ex alicujus ore capiunt, \& manibus fe tractari finunt. Item inftar Pfittacorum garritum addifcunt.

Quarta: Magnitudine Sturni, ejusdem coloris cum fecunda fpecie, fed breviori cauda.

2uinta JENDA Y A: Sunt magnitudine Merulx aut minoris Turdel $x$, roftro \& cruribus nigris, oculis nigricantibus, circulo aureo,exterius albo: Dorfum, alæ \& cau$\mathrm{da}$, ut \& anus viridibus pennis veftiuntur, quibus thalaffinus mixtus: Extremitasalarum quodammodo nigrefcit. Totum caput, collum \& pectus flavi coloris funt, cuiluteus intermixtus.

Sexta. TuJETE, magnitudine Alau$\mathrm{d} x$, in totum dilute viridis coloris. At initium alarum egregie cœruleum eft, \& omnium pennarum in alis oræ corulex; ita ut complicatx, quando quiefcit avis, maculam longam coruleam prope oram lateralem alic oftentent. In dorfo ad exortum caudæu ufque etiam macula cœrulea eft. Camda brevis. Rofellwm incurvatum,
Pfittaci \& Tui femper catervatim volant nimirum bini ac bini juxta fe invicem. Sylvæhis plenæ funt, \& fxpe quadringenti \& quingenti fimul volánt's ftrepitum magnum clamore excitantes. Confident in altifimis arboribus: nidificant potiffimum in mediterraneis. Caro boni faporis, fi affetur, maxime Perroquet.

A R A R A CA N G B Brafilienfibus, Pfittacus maximus, majores funt corvis nofratibus. Caput magnum, fuperius planum, \& latum habet. Oculos pulchros, cxfios, pupilla nigricante: Oculos autem exterius a mbit membrana alba, ut \& maxillas \& roftrum inferius : hæc fubter oculos femilunari forma eft producta. Roftrum incurvum, magnum, fuperius albicans, inferius nigrum. Linguam habet ut Pfittacus, \&codem modo edit. Voces etiam quasdam. fonare difcit. Roftrum fuperius tres circiter digitos longum, altum feu latum. Crum $\&$ pedes, ut Pfittacus, habet nigros. Totum caput, collum, pectus, venter, crura fuperiora, \& cauda inferius, ut \& initium alarum fuperius elegantibus rubris pennis veftiuntur, per medietatem autem alx tectx funt viridibus, extrema autem medietas alarum ufque ad finem coruleis ornatur. Extremitas dorfi prope anum fuperius, \& cauda coruleis conftant; quibus aliquot brunini coloris admifcetur. Carda longa eft decem circiter digitos, \& longe prominent últra finem alarum.

Ararauna Brafilienfibus. Figuraal teri fimilis, fed alterius coloris. Roftrum nigrum, oculi cæefi1; pupilla nigra. Cutis circa oculos alba nigris pennulis variegatur quafi acu picta effet. Crura $2 x$ pedes fufci coloris. Caput anterius fupra roftrum mittellam habet viridibus pennis; fub roftroinferiori ambiunt guttur pennæ nigrx: Colle autem latera, reliquum guttur, totum pectus \& infimum ventrem tegunt penna: flavi coloris. Extremum caput, collum pofterius verfum, totum dorfuim \& alas exterius cœrulei. Extremitatibus alarum plumæ flavæ funt admixtæ: Cauda conftat longis pennis cœruleis, quibus aliquot flavæ immifcentur. In genere autem cœe rulex pennæ interius funt nigræ, $\&$ quodammodo etiam nigredinem ad latera de fefpargunt: 
A N A C A Brafilienfibus: Perroquet; magnitudine Alaudx. Roftrum fufcum . aduncum. In capitis fummitate epatici coloris pennx, ad latera circa oculos brunni; guttur cinereum; Collum fuperius \& latera viridia.'Venter habet pennas ex brunno rufefcentes. Dorfum viride maculam habet dilute brunnam. Cauda quoque dilute brunna. In alarum initio fauguinea macula five fimbria eft : reliquum alarum viride, extremitas thalaflini coloris. Cruna fuperius viridibus veftita pennis, inferius cute cinerea, unguibus nigricantibus. Elegans plane avis.

MARACANA Brafilienfibus, avis Pfittaco plane fimilis (cujus \& fpecies) fed major, plumx totius ex gryfeo fubcorulefcunt, clamat utPfittacus. Fructus amat, Murucujaimprimis.

MAR A CA A Brafilienfibus, itidem Araræfpecies minor: magnitudine Pfittaci, figura Araræ, cauda longa tali, roftro, \& cute circa oculos. Roftrum nigrum, cutis circa oculos alba punctulata plumulis nigris. Oculiflavefcentes, pupilla nigra. Totum caput collum \&alæ faturate viridis coloris ut in Amurucurica ; fummitas capitis dilutior \& quodammodo cœrulefcit. Cauda fuperius viridibus \& in extremitate corulefcentibns, inferius faturate conftat pennis. Ale interius etiam rubri, exterius virides, \& extremitates corulex obfcure. In exortu cujuslibet alæ maculam habet miniatam. Super roftri exortum, fuperius maculam habet parvam fufcam: Crura \& pedes fufci. Clamat oe, $O e, O e$.

QU I JuвAT U I flavus eft totus, magnitudine Tuiapara; roftro incurvato gryfeo, Oculis nigris. Extremitas alarum obfcure viridis eft: canda longa flava cruna coloris incarnati. Facile \& valde manfuefcit.

Paragua Pfittacuseft niger, magnitudine Ajurucariu, pectore dorfo \& ventre medietate anteriore infigniter rubro. Oculis nigris, circello rubro. Roftra fufco, feu obfcure cinereo Cruribus \& pedibus obfcure cinereis.

TAR A B E Brafilienfibus, Pfittacus eft viridis: major quam Paragua, Capite rubro \& pectore atque initio alarum Roftra \& pedibus obfcure cinereis.:

A J u R u C A T I N.G A Brafilienfibus,Pfittacus magnitudine pulli gallinacei mediocris, totus viridis, oculis rubris, \& circa oculos cute alba. Roftro albo, \& cruribus albis: Caudam habet longam, viridem:

A Ju R U A P:A R A Brafilienfibus, in totum convenit cum pracedenti, fed minor eft: cit: $=i$

\section{Ipecu, Urubu. Tamatia utraque. Guiraje = moja. Gurrgru nheengeta.}

Pecu Braftienfibus, Cortapao Lufitanis, Avis magnitudine columbæ. Colli longitudo duorum digitorum, corporis autem quatuor, \& cande idem quatuor, crurum fere fesquidigiti; in pedibus quatuor habet digitos, duos antrorfum, duos retrorfum verfos, ut in Pfittacis. Caput veftitur pennis cinnabrii coloris, in quo \& criftam habet inftar columbx: Collum ad roftrum ufque inferius nigrum, ut \& fuperius; In utroque autem latere linea eft alba, craffa, qux divifim ad dorfum protenditur. Ale exterius totæ nigræ, interius al$\mathrm{b} \mathfrak{x}$; Cauda nigra ; in ventre \& cruribus fuperioribus pennæ funt nigræ, \&albæ. Rofrum illius rectum, acutum, fesquidigitum longum, quo arborum cortices exfcindit, ut Picus.

URUEU Biaflienfibus, vulgo cin Metue fchen-efici; Avis rapax, magnitudine Milvi \&Nifi, pedibus gallinaceis fubalbicantibus, cauda longa, $\&$ alis ea longioribus. Penne totius corporis funt nigre cum pauxillo ravi coloris hinc inde mixtæ. Caput habet parvum, figura pene gallinarum Indicarum, cute tectum paululum rugofa. In fummitate autem capitis fecundum longitudinem quafi dividitur cutis, \& in finiftro latere capitis infra oculum "crocei eft coloris, fupra oculum coerule $i$, in fummitate item, réliqua parte ex ruffo fubbrunni. In dextrolatere capitis circa oculum fuperne \& inferne croceicoloris, in fummitate itidem, reliqua parte ex croceo albicantis. Roftrum habet fatis.longum, exterius aduncum, acutum, \&ad medietatem úfque à capite cute obteckum ex croceo corulefcente. In mediate roftri fuperius narium foramen unum amplum transverfim pofitum, extremitas roftri, quxe cute caret, eft alba. oculos habet elegantes rubinifere colore, $p$ pilla rotunda nigra : $P$ al pebre funt crocex: Linguam carinatam, in ambitu denticulis acutis preditam. Fœtet ejus caro inftar cadaveris : nam \& cadaveribus vefcuntur, \& in maxima copia ftatim advolant in Capicania Sirigippo, \& Flumine Sancti Francifci, quando quis beftiam aliquam mactat. Foeda avis, femper macra; nunquam fatura.

T.A A T. A Brafilienfibus; Avis Alaudxmagnitudine, feu Pici. Tota punctulata, \& varicgata maculis ut Turdus minor, Germanis vulgo Ein ?roffet : in ventre albas habet pennas, maculis fufcis : fub gutture autem flavefcit uti \& circa collum. Roftrum habet longum rubrum, fupe- 
D E A V

rius paululum fufcum; cujus fuperior pars paulo longior, quam inferior. Supra nares fubtiles aliquot extant pennulx inftar pilorum. In pedibus quatuor habet digitos unguibus aduncis. Caret cauda. Caput illius majus quam proportio corporis requirat, uti \&roftrum.

T A M A T I A itidem Brafilienfibus diEta, avis aquatica, forfan gallina. Nifi roftrum obtinet, magnitudine Yaffana afu: dorfo incurvato incedens \& collo incurvato. Caput habet magnum, oculos magnos nigros, prope exortum roftri exiftentes. $R o-$ frum duos digitos longum, plus uno latum, inftar anaticis quidem, fed anterius acuminatum : eftque fuperior ejus pars nigra, inferior flavefcens. Crura fuperiora pernis nuda, fatis autem longa : Digiti in pedibus quatuor, quorum tres anterius, unus pofterius verfus, more gallinarum, funtque longi ut in Waterboen. Crura \& digiti coloris ex virefcenti flavi. Cauda brevifima, \& non longior quamin Yafana. Caput nigris pennis veftitum, reliquum corpus brunnis; in ventre autem albicantes pennæ intermifcentur.

Guira jenoja Brafilienfibus, Avicula magnitudine Fringilix. Roftellum habet vix femidigitum longum \& nigricans, osellos nigros. Totum caput, collum inferius, peclus, infimus venter $\&$ dorfi medietas extima pennis veftiuntur coruleis: Collum fuperius \& dorfi medietas anterior nigris: Ale quoque higrx, fed quibusin initioillarum infperfx cœrulex; reliqux nigræ funt, fed oras habent coeruleas. Cauda fesquidigitum fere longa \& itideminigra, definuntque alæ paulo poft initium caudx. Crura fufca; in pedibus quatuor digiti vulgari modo.

Guira R U NHEENCETA, Brafilienfibus; Merulæa aquaticx magnitudine, aut paulo major. Roftrum habet rectum, compreffum, nigrum, plus dimidio digito longum : Oculos Sapphyrinos, pupilla nigra. Crura qux fuperius veftita, funt pennis cinereis, inferius nigra cute teguntur, utipedes, in quibus more vulgari quatuor funt digiti, unguibus acutis nigris.

Totum caput, collum, pectus \& infimus venter pennis veftiuntur albis ad gryfeum dilutum accedentibus, dorfum autem leucophxis five cinereis. A roftro in utroque latere per oculum ufque ad finem laterum capitis, macula oblonga tendit nigra. Ale nigrax, non tamen obfcure. Cauda nigerrimas habet pennas, quarum tamen extremitates funt albx, \& fuperius quoque aliquot albis teguntur.
I B U S.

C A P U T X I.

Cocoi Ardea Jpecies: alia Jpecies. Guiratinga. Ardeola. Iacarini. Guirativica. Guiranbeemgatw.

Oocor Brafilienfibus, Ardex fpecies eft elegans, Ciconix ferme magnitudine. Roftrum habetrectum, acutum, fex circiter digitos longum quod in exortu ex flavo vireicit: oculos cryftallinos, circello aureo : circum oculos cutem cineream. Colli longitudo quindecim digitorum, corporis decem; casde, cum qua ale definunt. Cruta fuperiora mediam partem plumata, octo digitos longa, inferiora fex \& femis, cute tecta cinerea; digitos in pedibus quatuor, vulgari modo, quorum medius digitum longus, cæteri breviores unguibus lunaribus, fufcis. Guttur \& totum collum funtalba, fummitas capitis \& latera nigri coloris cum cineréo mixti. Ejusdeni coloris criftam elegantem gerit erectam; atque ab ea dux elegantes plumæe deorfum pofterius dependent, coloris ex nigro fubcinerei, quælibet quinque digitos 2 femis longa. Anterius collum fecundum longitudinem maculatum eft plumis è nigro \& cincreo mixtis. In colli parte anteriori \& inferiori, elegantes habet plumas longas, albas, fubtiles propendentes, quas in pileis geftare folemus. Totum dorfum, alr \& cauda cinerei funt coloris diluti cum pauxillo albo mixti; fupérior medietas crurum fuperiorum, albis veftitur pennis. Perdorfi autem longitudinem cinerex plumæ extenduntur fubtiles, elegantes, figura fimiles illis in collo. Caro ilo lius bona eft, \&frepius comedi.

Reperiturhic \& alia Ardea, Anatis domefticx magnitudine, ant paulo major. Roftrum habet rectum, acutum, medietato anteriore, tam fuperius, quam inferius, dupliciter ferratum, quatuor \& femis digitos longum. Caput \& collum habet Ardex: Oculos nigros, circulo aureo; Collims pedem longum; Corpus quinque ditgitos \& femis, caudam quatuore cum qua definunt alx. Crura tota novem \& femis digitos longa, fuperiora mediam partem pennis veftita: quatuor digiti in pedibus vulgari modo. Roftrum fuperius eft fufcum, prope exortum autem virefcit è flavo. To tum caput \& collum fuperius pennas habent longiufculas, pallide flavas, nigro undatas; fub gutture albicat. Collum inferius, pectus, \& infimus venter plumas habentalbas fufco undatas, quod in ambitu flavo eft fimbriatum. Totum dorfum \& alæ teguntur pennis fufcis flavo undatis, \& remiges alarum pennæ funt è nigro \& cinereo, aqualiparte, mixtæ, extremita tibus albis, Cauda conftat ejufmodipennis, 
qualibus extremitas alarum, fed transverfim albo lineatis. Crura \& pedes funtobfcure gryfei coloris, ungues fufci. Caro comeditur, fapit ut aliarum Ardearum.

QU I R A T I N G A Brafilienfibus, Garza Lufitanis, Ardex fpecies, Alberdeolæx magnitudine \& corporis figura. Erecte incedit, collo longo, roftro extenfo, recto, acuto, flavo, quatuor digitos longo, cujus pars fuperior nigra, inferior alba: $\mathrm{Cru-}$ za alta, ut Ardex, fex circiter digitos longa, pedum digiti ad vulgarem modum : crura exterius (ut \& digiti) funt flava, interius ex viridi \& fufco mixta: Per totum corpus albifimis veftitur pennis: In collo elegantiffimis plumis albis, quæ fubtiliores funt plumis Struthionum.

Aquatica eft avis. Crura fuperiora fine pennis.

ARDEOLA columbx magnitudine vix par : Collum habet longiffimum. Roftrum rectum, acutum, fuperius fufcum, inferius ex albo flavefcens, duos \& femis digitoslongum, linguam brevem, acutam. Oculos mediocres, circello aureo, pupilla nigra. Caput parvum, Collum tenue, ac feptem digitos longum, eum corporis longitudo vix fit quatuor. Crura longa, quodlibet quinque digitos; fuperior medietas mediam partem nuda. In pedibus digitos quatuor communi modo difpofitos, unguibus lunatis acutis. Color talis eft: prope oculos, ubi roftrum inferitur, cutis melini coloris eft. Caput fuperius veftitur pennis chalybei coloris pallide fufcis infperfis : totum collum cum pectore \& infimo ventre plumas habetalasleucophxis mixtas \& pallidis, ut variegatus appareat. Dorfum nigrum eft, ex parte chalybeo fufcum cum cereicoloris pennis mixtum. Alarum pen$n \mathfrak{x}$ longæ virentes, in extremitate maculam habentalbam, reliqua fuperficie ex fuf́co, chalybeo,cereo,\&leucophro eleganter variegata. Cauda duos digitos longa, quam tegunt alarum extremitates, quæ cutm illa definunt. Cruna fuperius leucophæo \& cereo mixta. Nuda pars \& pedes cute melina tecta funt. Ungues leucophæi. Erecta incedit avis \& decenter.

J A C A R IN I Brafilienfibus, Avis carduelis magnitudine. Roftellum habet craffum, cinereum. crura \& pedes cinereos, cum quatuor digitis more vulgari. Totum corpus nigris veftitus pennis, fed in quibus refplendet color inftar chaly bis politi. Ale interius albicant. Oculi corulei, \& pone illos amplum foramen loco aurium.

G UIR A T IR I C A Brafilienfibus, Avis Alaudx magnitudine. Roftrum habet craffum, rectum, fuperius fufcum, interiusalbum, \& paululum incarnatum. Crmracinerea cum quatuor digitis more vulgari. Totum saput cum gutture, \& colli in- feriore \& media parte egregie fanguinei funt coloris: Oculi cœrulefcunt ; aurium foramina ampla. Latera colli, totum pectus \& infimus venter albis veftiuntur pennis. Collum fuperius habet nigricantes, quibus paucx albæ mixtæ. Dorfum gryfeum eft (infperfis nigris paucis) ut \& initia alarum : reliquum alarum nigrum, ut \& can$d a$, qux tres circiter digitos longa : Oræ laterales in alis funt albx.

Guiran HEemgat U Tupinambis; Avis pafferis magnitudine. Caput fuperiusluteum, \& guttur: Collum, pectus, \& infimus venter flavi coloris, alæ ex virefcenti \& flavo mixtæ ac fufco diftinct $x$, uti \& cauda, ocelli \& roftrum funt nigra. Crura fufca; hic mas egregie canens ut Fringilla, vulgo Bincke.

Fomina ejusdem magnitudinis plumis pafferis veftitur, necita canit, fed clamat 'tfchrip, 'tfchrip, utpaffer.

\section{$C \wedge P U T$ XII.}

Curucui. Caracara. Tijeguacu. Teitei. Guiraguacu beraba. Guiracoereba. Guiraperea. Iapacani. Cabusre. Andira aca. $U_{R}$ u c U I Brafilienfibus; Elegan:
tiffima avis, fere magnitudine Picx. Roftrum habet breve, latiufculum, coloris fulfurei os anplum, \& quando aperit, triangulatum. Oculos pulchros coeruleos circulo aureo; \& fub quolibet oculo maculam cutaceam albam, ut gallinæ: in palpebris fuperius \& inferius pilos nigròs duriufculos. Collum haud longum. Crune brevia, \&ad pedes fere plumata pennis nigris. Cardam habet quinque \& femis digitoslongam, latiufculam. Sub roftro inferiori in medio, \& ad atrumque latus quafi barbam fetis compofitam nigris, fed in quibus tranfplendet coeruleus; ut in Anatum collo : fub gutture autem plumæ tantum nigre. Totum pectus \& infimusventer egregie miniati funt coloris; totum dorfum \& cauda fuperius ex cœruleo \& igneo fplendide virefcunt. Extremitas caude oram habet nigram : inferius autem cauda pennas habetalbas, nigro transverfim eleganter ftriatas. Initium alarum etiam infigniilla viriditate fplendet, media pars canefcit, nimirum plumis nigricantibus. minutifimis punctulis canis confperfis, ut anates effe folent. Ultima pars, fcilicet longx alarum pennæ ex fufco nigrefcunt. Crura, ut dixi, fere tota veftita, nigris pennis, cxtera cum pedibus fufca funt è cinereo. Digitos habet difpofitos ut Pfittacus. Perme fubter alas funt canx.

CA R A A R B Brafilienfibus, Gaviaons 
Lufitanis, Nifi fpecies, Avis magnitudinis | Avis Fringillæ magnitudine. Koftellum ha ${ }^{\text {t }}$ Milvii, caudam habet longam novem digi- bet nigrum, tres quartas partes digiti lontos; alarum longitudo quatuordecem di- gum, acutum, \& paululum deorfum flegitorum; qux tamen nondum ad finem xum. Oculos nigros. Linguam multipliciter caudx pertingunt. Color pennarum totus fiffam: In capite fuperius mitellam thalafeft ravi coloris cum albis \& flavis punctulis. finis pennis, reliquum caput, guttur, \& Cauda albo \& fufco eft variegata. Caput Ac- totum corpus inferius, pectus, \& totus incipitrinum, roftro adunco, mediocriter fimusventer, cum dorfi medietate poftemagno, nigro. Crur habet lutea , pedibus riori cöruleis feftiuntur pennis, lacteaccipitrinis, unguibus femilunaribus ni- fcentibus, \& à pectore per initia alartim ad gris acutiffimis \& longis. Avis gallinis val- dorfum, ubi incipit coruleus color, linea de infefta.

Habui aliam ejusdem magnitudinis, \& colore pennarum ut præcedens, fed pectus \& venter erant alba. Oculi aurei, \& cutiscircum eos flava. Crura lutea.

Tijf gu a cu Brafilienfibus, Avicula pafferis magnitudine, aut paulo major: Roftellum habet breve, triangulare, latiufculum, nigrum. Ocellos fapphyrinos: Cruna \& pedes cerei coloris, unguiculis fufcis, digiti difpofiti more vulgari. Tota avicula veftitur pennis coracinis: at in fummitate capitis maculam habet clypeiformem fplendentis fanguinei coloris. Totum dorfarm autem fere \& utramque alam fuperius ad partem obtendit macula nigro-cœerulea. Cauda brevis \& nigra.

- TeI ťe I Brafilienfibus quam etiam vocant Guiranhemgeta \& Guraindi. Avicula Rubecula magnitudine. A viario includiturpro cancra ave, fed pipit tantun ut Rubrica, Germanis Bimpel. Vefoitur paco \& mamao. Roftrum habet breve, crafliufculum, nigrum. Caput, collum fuperius, alæ; \& totum dorfum, \& cauda nigris veftiuntur pennis, quibus aliquid cœrulei, admixtum, ita ut fplendeant inftar chalybis. Guttur, collum inferius, peatus, totus infimus venter, \& crura fuperiora funt lutea: ad exortum roftrifuperioris poft nares maculam habet è pennisluteis. Crura \& pedes fufci funt coloris; \& hic eft mas.

Fomina proportione \& magnitudine plane refpondet mari, eodem roftro, \& iisdem cruribus; fed color plurimum differt; eft enim viridis, ut Acanthis. Germanis, Zeifdrn. Alx ac caput cum collo fuperius paulum fufcefcunt $\&$ corulefcunt mixtim. Delectantur hx aviculx quinque aut $f e x$ conjunctim aviario includi.

GurRaguacu Beraba Brafilienfibus. A vis Carduelis magnitudine: $\mathrm{Col}-$ lum inferius, dorfum \& ventris extremitás Iutei feu aurei eft coloris. Caput fuperius \& collum, dorfi medietas anterior, alx \& cauda dilute viridis. In alarum extremo fufcx pennæ mixtæ funt. Sub gutture ad oculos ufque maculam habet magnam, nigram. Roftellum habet rectum, acutum, flavum, fuperna parte paulum nigticans. Crun \& pedes fufci coloris.

G U I R A CoER EBA Brafilienfibus. tum alarum : totum antem collum fuperius cum medietate dorfi anteriore profunde nigris fubrilibus holofericis veftitur plumis. Cauda fefquidigitum longa eft \& nigra. Ale magnx, qux ad medietateslaterales flavefcunt. Flavedo autem illa tegitur, nec videri poteit, quando avis confrdet, quando vero volat, alæ ex nigro \& flavô elegantër ftriatæ videntur. Inter̂ius alæ ferme totaliter flavæ funt. Cruta fuperiora pennis nigricant, \& cœerulea quodammodo funt: Inferiora nuda, \& cinnabrii coloris una cum pedibus, unguiculi in pedibus nigri. Habent autem pedes digitos quatuor, vulgari modo difpofitos.

Guir A'PERE'a Brafilienfibus; Avís Alaudx magnitudine. Roffrim habet breve, craffiufculum, nigricanis. Caput fupe rius \& collum, totum dorfum $\&$ infimus venter, pennas habent obfcure flavi coloris, ut cera citrina : Caput inferius guttur \& collum inferius cum pectore nigras, quales \& paucz in ventre flavis funt intermixtæ. Cauda duos digitos longa, \& prxterit alas. Conftat autem cauda \& alæ pennis fufcis \& nigricantibus, quarum quælibet cum laterali extremitate thalafina, ita ut fufcæalix thalafino videantur ftriatæ. Cauda itidem, Crina fuperiora etiam eèrei coloris; inferiora cum pedibus obfcure cinerei. Digitiquatuor modo vulgari, unguibusnigricantibus.

- J A P A C A Ni Brafilienfis, Avis magnitudine Bemtere aut schanepue. Roftrum haber nigrum, oblongum, acuminatum, \& paulum deorfum incurvatum. Oculos aureos, pupillanigra. Caput veftitur pennis nigricantibus, collum fuperius, dorfum, alæ ex umbra \& nigro mixtis. Carda fuperius albo maculata eft. Pectus, \& totus infimus venter ac crura fuperiora ex albo \& flavo mixts, aclineis feu ftriis transverfis nigricantibus intertexta. Cruta fufca. Digiti in pedibus quacuor vulgari modo, unguibus acutis \& nigris.

C A в u R E Brafilienfibüs; Noctu民 fpecies: Avis magnitudine Turdelæ. Gaput habet rotundum, roftrum breve, aduncum, flavefcens; duo foranina narium. Oculos pulchros, magnos, rotundos, flavós, pupilla nigra. Sub oculis, \& ad latera roftri v multos 
multos habet pilos, longiufculos, fufcos. Crura brevia, totaliter pennis ventita, flava, uti \& pedes. In iis autem quatuor digitos, more vulgari, unguibus femilunaribus, acutis, nigris Caudam latam, prope cujus cxortum alx definunt. In toto capite, dorfo, alis, cauda, coloris eft umbræ dilutx : ac in capite \& collo minimis; in alis majoribus maculis albis yriegatur. Cauda vero albo eft undata. Pectus \& infimus venter albicant, \& maculis umbræ dilutæ variegantur. Facile manfuefcit. Collum ita circumagere poteft, ut roftri acies exacte dorfi medietatem oftendat. Ludit cum hominibus inftar fimiz, \& varios mimos facit adfpectu fuo, \& crepitus roftello; præterea pennas ad latera capitis erigere poteft, ut cornicula, feu auriculas reprefentent. Victitat carne cruḑa.

A ndira Aca Brafilienfibus, Vefpertilio cornutus. Multi hic reperiuntuir in Palmis nuciferis degentes; paulo majores noftratibus, prepingues, cinereicoloris, mollibus \& longioribus pilis, auribus latis. In fingulis pedibus habent quinque digitos, acutis unguibus armatos. Dentes candidi, \& fupra nafum corpufculum, ejusdem cum auribus longitudinis, fatis grande ex materia qualis illius rictus, flexile feu mobile. Alarum longitudo æquat femipedem Rhynlandicum.

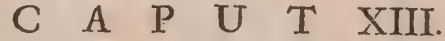

Macuacagua. Columbe filveftris pecies. Ands filveftris. Urubitinga. Mareca utraque. Tyjeguacu parvara. Tangara utraque.

$\mathrm{M}$ A cu c A G U A Brafilienfibus:Gallinæ filveftis fpecies, magnitudine Gallinx noftratis vel etiam major. Roftrum habet nigrum, plus fefquidigito longum, anterius paulo incurvum, ut perdicis : In roftri medietate duo narium foramina ampla. Ocislos nigros, poft eos aliquanto fpacio aures more gallinarum.Corpus craffum , Ale cum eo definunt, nullam enim habet çaudam. Crura inferiora nuda, duos \& $\mathrm{fe}-$ mis digitos longa. In pedibus tres habet digitos antrorfum verfos, craffiufculos, unguib us brevibus, obtufis. Calcaneus rotundus, ut in Struthione, \& paulum fupraillum breviufculus digitus verfus interiora, ungue obtufo. Totum caput \&collum punctulatum eft obfcure flavo \& nigro, fúb gutture albicat. Pectus, venter \& dorfum obfcure cinerei funt coloris. Ala umbræ coloris per totum undatæ nigro', præter remiges pennas, quæ totaliternigræ. Cruna fuperiora pennis veftita, uti venter, inferiora cœrulefcunt cum pedibus, ungues gryfei. Carnofa admodum eft avis, \&
NA T U R A L I S

tantum carnishabet, quantum dux gallinæ domefticæ vix habeant; eftque boni faporis. Sub cute craffa $\&$ pingui cuticulam habet, aliam qua caro tegitur. Victitat variis fructibus qui ex arboribus filveftribus decidunt. In ventriculo illius inveni fabas filveftres, femina Araticu. Humi currit, nam pedes inepti ab arbores fcandendum. ova ponit Gallinaceis paulo majora, coloris cœruleoviridis.

Co l u м в \& filveftris fpecies ex Infula. S. Thomæallata, noftratum magnitudine \& figura: fed roftro fuperius adunco, \& coloris in medietate anteriori tota corulei, cum albo \& pauco flavo mixti, in pofteritate tota fanguinei. Oculi nigri, circulo cœruleo. Pennis tegitur per totum. viridibus, ut Pfittacus. Remiges alarum exviridi fufcefcunt, ut $\&$ extremitas caudx. Sub ano flavo habet pennas. Crum \& pedes eleganter crocei coloris, ungues autem fufci.

A NA S Silveftris, magnitudine Anferis. Roftrum habet nigrum; Cruri fufca, uti \& pedes. Tota nigra eft, exceptis principiis alarum, quæ alba; Nigredini tamen illi viridis color tranfplendet.Criftam in capite gerit nigris plumis conftantem, \& maffam carnofam corrugatam, rubram fupra roftri fuperioris exortum. Cutem quoque habet rubram circum oculos. Caro bona \& copiofa. Figuntur plerumque in altis arboribus confidentes; nam poft lotionem in aqua frigida altas fubeunt arbores, captandiaëris \& Solis caufa.

UR U BITINGA Brafilienfibus ( fed. dubito adhuc de hoc nomine, nam nobilior eft hæc avis quam Urubitinga ) Avis Aquilæ fimilis, Anferis fementris magnitudine. Roftrum habet craffum, aduncum, nigrum, \& circa nares cutem flavefcentem. Oculos magnos, fplendide aquilinos. Caput groffum. Crura \& pedes luteos; in pedibus quatuor digitos vulgari modo difpofitos; Unguibus lunatis, longis, nigris: Alas amplas: Caudam latam. . Tota veftitur plumis fufcis \& nigricantibus; Peralas autem undatim quafi cinereus mifcetur. Canda novem digitos longa, ad fex alba, in extremitate ad tres nigricans, in extremitate tamen rurfus minimum eft albi. Egregix ftaturæeft avis.

MAR E C A itidem Anatis Filveftris fpecies, fed parva. Roftrum habet anatinum fufcum, ad cujus exortum in utroque latere macula rubra. Caput fuperius eft leporini gryfei coloris, latera capitis fub oculis tota alba. Totum pectus \& infimus venter ligniquerni fecti colorem obfcure xmulatur, variegati præterea punctulis nigris. Crusa \& pedes nigri. Cauda gryfea. Abe elegantes, in exortu ex gryfeo fubfufcentis coloris, remiges autem funt in uno latere 
prioris coloris, tota autem medietas extrema dilute brunefcentis, qualis in pedibus effe folet, im medio autem coloris viridis tranfplendentis,cum fimbria nigra, qualis in anatum collis. Caro valde bona.

MARECA alia fpecies, ejufdemcum antecedente magnitudinis \& figuræ. Rofrum habet nigrum fplendens. Summitas capitis, collum fuperius, totum dorfum umbræcoloris cum fufco mixti.Sub gutture albicat. Oculi nigri, \& ante quemlibet macula parva rotunda, plumis ex albo flavefcentibus. Totum pectus \& infimus venter obfcure gryfei coloris cum aureo mixti. Cauda nigra. Alarum pennæ fufc $x$, quibus viride tranfplendet: \& medix pennæ alarum eximia viriditate \& coeruleo in fufco tranfplendent, hic \& undam nigram habent, extrenhitas autem remigum tota eft alba. Crum \& pedes infigniter rubri feu miniati coloris. Affata avispedibus apprehenfa manus \& linteamina tingit colore miniato-fanguineo. Boni faporis habent carnem, fed paulum amaricantem.

Tijeguacu Paróara Brafilienfibus; Avis Alaudx magnitudine. Rofrum habet breve, craffum, fuperius fufcum, inferius albicans. Caput fuperius, latera ejus \& guttur ac collum inferius habent pennas flavas, fanguinei coloris pennis punctulatas ( $\&$ hæc foemina quidem, masenim hæc tota habet fanguinea.) Collum fuperius, \& totum dorfum cinereas, umbra aliquatenus mixtas. Ale fufcas oris albefcentibus præditas, ut \& cauda; fed alæ teguntur cinereis, dorfum maximam partem exceptis extremitatibus. Latera colli, pectus \& totus venter, \& crura fuperius albis teguntur pennis. Crura inferiora \& pedes fufci funt coloris; quatuor digiti more vulgari pofiti. Ocellos habet nigros.

TANG AR A Brafilienfibus. (Reperiuntur ejus aliquot fpecies colore variantes.) Prima elegans, magnitudine Fringillx. Roftrum habet rectum, craffufculum, nigrum. Oculos nigros. Crurt \& pedes ex cinereo fufcos. Supra roftri exortum fuperne maculam è pennis nigris. Totum Caput \& collum fplendentibus viridibus feu thalaffinis pennis veftiuntur. Initium dorfi inftar collaris ambiunt nigerrimx pennæ. Dorfum autem fub alis ufque ad exortum caudær veftitur plumis luteis. Totus infimus venter egregie cœrulefcit. Alæ nigrze funt, \& earum extremitates laterales. corulex, ita ut totaliter cœrulex appareant complicatæ, \& fola extremitas nigra videatur. Initium alarum exterius etiam thalaflinis pennis nitet, \& cuique alx fuperius in dorfo, feu in extremitate fuperiori laterali flavx pennæ funt mixtx. Caudam habet latam, fefquidigitum circiter longam, nigram pennis, fed quarum extremi- tates laterales cœrulcx funt. Extremitas caudæ eft nigra. Includitur cavex, \& clamat zip, zip, feu ut Rubrica Germanis (3)ympel. Vef citur farina \& pane.

secunda.pecies : figura \& magnitudine pafferis noftratis. Roftellum habet ex flavo fufcum, latiufculum, in extremitate acutum, cujus inferior pars multo brevior filperiore. Ocellos nigros. Totum caput, egregie miniatis tegitur pennis, totum reliquum corpus cum alis \& cauda fplendide nigris. Crura fuperiora albis pennis, $\&$ in latere exteriori maculam ablongam miniatam habent, quafi fanguine maculata. Crura inferiora \& pedes cinerei funt. In pedibus digiti quatuor more vulgari. Cauda brevis digitum longa, \& alæ prope illiūs exortum definunt.

\section{A P U T XIV.}

Anbima. Pitangua guacu. Attinguacu camacu. Guira acangatara.

A Nhrma Brafilienfibus:Avis aquaA tica ex rapacium genere, major cygno. Caput haber haud magnum, Gallinaceo fimile \& roftro nigro: cujus fuperior pars paulo longior inferiori, \& in extremitate deorfum incurvatum. Oculos pulchros, aureos, pupilla nigra, \& exterius nigro circulo.In capite prope exortum roftri cornu gerit erectum, extremitate fua antrorfum verfus incurvatum, paulo plus quam duos digitos longum, crafitiei chord $x$ majoris in Viola majore, rotundum quafi tornatum effet, coloris albicantis, feu offei. Circum cornu plumellæ fubtiles breves eriguntur albæ \& nigræ. Collum habet plus feptem digitislongum, reliquum corpus ad caudx exortum fere fefquipedem. $A$ las ampliffimas, utpote quarum plumarum longitudo fefquipedem fuperet. In cujufque alx antica parte duo cornua recta triangulata ex ipfo offe alx enata obtinet, craffa minimi digiti apicem, \& conicæ triangulate figure. Ent autem quodque anteriorum digitum longum, poiteriora paulo breviora coloris fufci. Caudan habet decem digitos longam, inftar anferinæ latam. Crura fuperiora quatuor digitos longa, \& quoad medietatem inferiorem pènnis nu$\mathrm{da}$ : Inferiora quinque digitos longa, fere duos craffa. In quolibet pede quatuor digitos obtinet more Gallinarum difpofitos, quorum medius trium anteriorum quatuor \& femis digitos longus, reliqui duo, tres \& femis : pofterior autem fere duos. Quilibet unguem habet corniculatum nigrum, digitum longum, \& in pofterioribus digitis paulo longiorem. Cute fufca \& fquamofa teguntur \& digiti, \& crura nuda. Capitis vertex plumulis varie- 
gatus eft albis \& nigris: ad latera, in guttu- veftiuntur. In capite longiufcalas habet re \& colli medietate fuperiorinigricat, in- pennas, quas inftar duorum cornuum poferior medietas colli \& pectus variegantur teft furrigere. Elegans avis ob longitudialbis, cinereis \& nigris pennis. Venter in- nem caudx.

ferior albas in totum habet pennas, ad la- GuIR A A CANGATARA Brafilientera fub alis, \& in dorfo funt nigræ, fed fibus. Avis picæ variæ magnitudine. Roquibus albæ hinc inde permifcentur.Canda frum habet digitum longum, cujusfupeeft nigra; Ale etiam nigre exceptis oris rior pars paulum adunca, totum autem extremis (prope offa) ubi ex albo flave- obfcure flavefcit. Oculos cryftallinos, circufcentibus pennis variegatæ funt. Terribi- lo fufco. Collum duos digitos longum, Corlem clamorem edit vyhu, vybu vociferan- pus tres. Cauda longiflima, nimirum octo do. Nunquam fola invenitur, femper par, digitos, conftans octo pennis rectis. Crunt mas \& foemina junctim incedunt, \& una fuperiora pennis veftita, \& fefquidigitum. mortua, altera à fepultura nunquam dif- longa, ut \& inferiora.In pedibus digitiquacedit. Corn quod in capite gerit, remedium eft contra venenum, fi in vino per noctem infundatur. Idem remedium eft contra fuffocationem uteri, \& in dfficili partu. Hæc quam defcripfi, foemina eft; mas duplæ magnitudinis. Nidum fuum facit è luto ad caudices arborum fuper terram, figura furni.

Pitangua Gua cu Brafilienfibus, Bemtere Lufitanis, magnitudine xquat Sturnum. Roftrum habet craffum, latum, pyramidale, paulo plus digito longum, exerius acuminatum. Collum breve, quod fedens contrahit. Corpus fere duos \& femis digitos longum.Caudam latiufculam, tres digitos longam, crura \& pedes fufcos, quatuor digitos more vulgari. Caput, collum fuperius, totum dorfum, alæ \& cauda coloris funt è fufco nigricantis, pauxillo viridi admixto. Collum inferius, pectus, \& infimus venter habent flavas pennas, fuperius autem juxta caput corollam (quafi monachicam) albi coloris. Sub gutture ad exortum roftrialbicat. Clamat alta voce.

Quxdam harum avium in fummitate capitis maculam habent flavam, quædam exparte luteam. Vocatur à Brafilienfibus Cuiriri, alias per omnia Pitanguaguacu fimilis.

A tinguacu Camacu Brafilienfibus: Avis Turdel $x$ fere magnitudine. $\mathrm{Ca}$ put habet fatis groffum, collum mediocriter longum ; Corpus tres digitos longum: Roftrum paululum aduncum, coloris ex viridi \& flavo mixti. Oculos fanguineos, pupilla nigra. Crura cinerea mediocris longitudinis, fuperius pennis veftita. In pedibus digitos quatuor, vulgari modo. Candam longifimam nimirum novem digitos longam, decem circiter pennis conftantem, quarum quxdam inferiores funt breviores fuperioribus. Totum caput, collum, dorfum, alæ, \& cauda pennas habent brunnas feu fuligineas, qux in cauda paulo faturatiores funt reliquis. Extremitas cujuslibet pennæ caudæ femidigitum longa, alba eft, \& inter album \& ruffum nigro umbrata. Guttur, pectus, \& infimus venter ac fuperiora crura cinereis pennis

tuor, more pfittacorum, \& quidem verfus interiora funt duo breviores, verfus exteriora duo longiores in quolibet pede. Totum caput pennis veftirur, qux in medio fecundum longitudinem ( $\mathrm{p}$ xime fcapum) fufcx, in lateribus flavefcentes, ut crifta. Collum \& alx è contrario pennas habent in medio flavefcentes, \& ad latera fufcas. Extremitas alarum fere plane fufcefcit. Totusventer, dorfum, (exceptis alis) crura fuperiora, \& exortus alarum, ad trium \& femis digitorum longitudinem pennis conftant ex albo pallide flavefcentibus, reliquum caudx fufcefcit, extremitas autem albas oras habet. Cruma inferiora, \& pedes thalaffini funt coloris. In capite longiores pennæ in criftam eriguntur. Ingentem in fylvis excitat clamorem.

\section{A $\quad \mathrm{P} \quad \mathrm{U} \quad \mathrm{T} \quad \mathrm{X}$.}

Matuitui. Aracari. Anbinba. Ipecati apoa. Pullus gallinaceus. Innominate tres.

\section{$\mathrm{M}$} A ти т тux Brafilienfibus, Avis fturni magnitudine. Brevi collo, pectore forti, cruribus brevibus, cauda duos \& femis digitos longa. Roftrum habet rectum, forte, cujus fuperior pars paulum prominet acumine inclinato, cinnabrii coloris. Totum caput, collum fuperius, dorfum, alr, \& cauda conftat pennis fufcis pallide flavo maculatis; apparentibus partim punctulatis, ut in Nifo. Sub gutture flavas habet pennas. Pectus \& venter albis veftiuntur, quæ fufco funt punctulatæ. Crura obfcure cinerefcunt.

A R A C A I Brafilienfibus: Avis magnitudine picæ Martix.Roftrum habet quatuor digitos longum, fesqui latum, feu altum, tres \& femis craffum, ubi craffiffimum, pailum deorfum incurvatum, inftar gladii Turcici, \& in extremitate acutum, inftar pfittacini, eftque fuperior pars paulo longior inferiori. Roftrum fuperius \& inferius plis mediam partem ab extremitate numerando ferratum dentibus : fuperior pars roftri major inferiore; eft autem roftrum canum, levifimum, levius fpon- 
gia ; fuperius albun, linea in fummitate craffa nigra fecundum longitudinem diftinctum: Inferior tota eft nigra; totum inferitur in caput triangulatum, \& ubi infertio eft linea triangulatim alba circumfcriptum. Linguam habet quatuor digitos longam leviflimam, afpectu plane pennam referentem, aut etiam plumata eft \& nigra, (fi pennam habere lingua dici poffit.) $\mathrm{C} d-$ put non ita magnum habet, latum, compreffum. Oculos magnos, pupilla nigra, circulo flavo, reliquas extremitates nigras. Collum haud longius Pfittacino، Corpus à colli exortu ad caudam ufque quinque circiter digitos longum. Cauda inftar picæ latiufcula, \& fex digitos, vel paulo plus longa. Crura \& pedes nigricantes ex viridi, Pfittacorum fimiles, duos digitos habent anterius, quorum unus longior altero, duos retro, 1 tidem inxqualis longitudinis; ungues incurvati, fufci, feu nigri. Crurum fuperiorum longitudo duorum digitorum, inferiorum fesqui. Totum caput \& collum ufque ad initium pectoris nigras habet plumas, \& ubi definunt, circulariter finiuntur. Pectus vero \& infimus venter totus eleganter flavis veftiuntur pennis, cum pavonino mixtis: Per Pectus autem tranfverfim linea digitum lata fanguinei coloris ducta eft $a b$ uno latere ufque ad alterum. Totum dorfum, alæx, cauda, \& crura fuperiora veftiuntur pennis ex nigro viridicantibus, uti in noAtratibus pifcis color effe folet. Extremitas dorfi ante initium caudx etiam fanguinei coloris, plus uno imperiali in circumferentia. Ale definunt ad exortum caudx, \& interius è cinereo funt fubfufci coloris. Roftrum interius eft nigrum. Avis hæc quafi fuum nomen profert, clamando acuto fono, fed non admodum clangofo Aracari:

A NH I NG A Brafilienfibus Tupinambus Mergi aquatici fpecies elegans, corpus, excepto collo, anatis domefticæ Europex habet magnitudine. Roftrum rectum, haud crafium, acutifimum, tres digitos longum, $\&$ per roftri medietatem anteriorem tam fuperius, quam inferius duplicem ordinem acutiffimorum hamulorum retro verforum. Caput parvum, longiufculum, ferpentini xmulum, paulo plus fesquidigito longum. Ocellos nigros, circulo aureo. Collum tenue, teres, pedem longum, corpus autem tantum feptem digitos, crura brevia, fuperiora duos digitos longa, pennata, inferiora vix fesquidigitum; quatuor digitos, tres anterius verfus, membranis junctos more anatum, 'aut corvi aquatici, quartus digitus brevior ad latus inferius extenditur, itidem membrana reliquis connexus; unguibus lunatis omnes acutiffimis. Caudam latam, decem digitoslongam, duodecim pennis conftantem, alx circa medietatem caudx definunt.
Roftrum gryfeum eft, \& poft. exortum paulum flavefcit. Caput totum \& collum plumis fubtiliffimis tegitur ad tactum holofericum referentibus; Coloris in capite \& collo fuperius ex gryfeo fubflavefcentis: fub guture, \& in collo inferius gryfei coloris, ut pelles illæ ( $\mathfrak{c}$ crchfelle vocant) ex quibus mitrre fiunt muliebres, \& ad tactum; \& adfpectum illius pellis pilos refert: Totum pectus, \& infimus venter, \& crura fuperiora plumis mollibus veftiuntur coloris argentei. Initium dorfi pennis fufcis, fed quarum quælibet in fui medio maculam. habet oblongam ex albo pallide flavam, ita ut punctulatim appareat:reliquum dorfi nigras habet pennas. Alas obtinet longas, quarum initium totum ejufmodi brevibus pennis tegitur, uti initium dorfi, $\mathrm{fe}-$ quitur ordo mediam partem, id eft, uno latere canarum, altero nigrarum: Remiges autem nigræ funt. Cauda nigris fplendentibus pennis conftat, quarum extremitas gryfea. Crura \& pedes ex obfcure flavefcente gryfei funt coloris. Solertiflima in capiendis pifcibus : nam, more ferpentum, contracto prius collo, ejaculatur roftrum in pifces, ac unguibus eos præhendit. Carnem illius comedi, fed haud melior eft, quam caro Lari.

I PE C A T I A P O A Brafilienfibus: Pata Lufitanis, id eft, Anfer, nobis Anas filveftris magnitudine anferis, octo vel novem menfium, figura plane ut noftrates anates. Venter \& interior pars caudx, collum totum cum çapite pennas habet albas, dorfum uf que ad collum, alx, fummitascapitis nigras, cui viriditas mixta, ut in noftrarum anatum collis. In collo \& ventre albis pennis nigræ paffim funt infparfæ. In his differt à noftratibus, quod fit primo major: $\int e$ cundoroftrum anatum quidem, fed nigrum, $\&$ in extremitate aduncum. Tertio fuper roftrum criftam gerit carneam, craffam, latam \& rotundam fere, nigram ${ }_{j}$ albis maculis infignitam. Crifte altitudo eadem; inter criftam \& roftrum (in fummitate nimirum roftri) foramen tranfverfum magnitudine pifi eft, ab utroq; latere confpicuum, quod. narium vice fungitur. Quarto pedum \& crurum color non ruber, fed è cinereo fufcus. Carnem multam \& bonam habet, nam fxpifime comedi.Reperitur paffim ad fluvios.

Alium habui per omnia fimilem priori, excepto, quod longiores ill x penne in alis, infigni brunno fplendebant colore, puto marem hunc effe, alteram foeminam.

$A_{N}$ o T A T I O. Gefnerus pene fimilem dedit iconem fub nomine Anatis Indicx, cujus picturam fe à Cardano accepiffe memorat, Sed color pennarum nonnihil differt ab Auctoris noftri defcriptione:

Pu L L u s gallinaceus monftrofus, magnitudine pulli recens exclufi. caput has 
bebatanaticum, fuperius tamen magis in $\mid$ Cauda inferius albas habet pennas, transacumen definens, roftrum anaticum, la- verfim nigro ordine undatas. Crura brevia, tum, cujus fuperior extremitas deorfum in- fufca funt; digitis quatuor; more Pfittacoflexa. Ocellos parvos, collum breve; alas rum difpofitis. Reperitur hic \& alia ARDE EE parvulas juxta priora crura pofitas: qua- fpecies: tota alba, roftro croceo, recto, tuor crura gallinacea, carebat pectore, acuto: Oculis nigris, circulo aureo, cruquippe eo loco, quo pectus effe debebat ribus \& pedibus nigris. Roftrum habetquinduo crura habens, quodlibet fuperius tres que digitos longum, collum longifimum, quadrantes digiti longum, inferius qua- nimirum quinque digitos fupra pedem. drantem; \& in fingulisquatuor digitos gal- Corpus feptem digitos longum, caudaim linaceos. Pofteriora duo crura ejufdem quinque, cum qua alæ definunt. Cruri fupefiguræ \& longitudinis cum anterioribus mire pofita erant, finiftrum quidem more naturali, dextrum vero in exortu fuo finifroerat adnatum, \& quafi furfum vergebat, eo modo quafi duo finiftra crura fuiffent, \& unum dextrum loco finiftri in exortu fuiffet adglutinatum : atque ideo urypigio carebat, quia nullum intervallum inter crura hæc pofteriora, \& caudx loco ipfi finiftro cruri exterius longiufculi pili canefcentes erant adnati. Pedes habebat gallinaceos, \& digitos eodem modo difpofitos:fed quilibet pes totus inverfo ordine pofitus erat, ita, ut inferior pars effet fuperior, \& fuperior inferior, unguiculique etiam furfum non deorfum vergebant. Totum caput, collum, venter, alæ, dorfum, \& fuperiora crura non veftiebantur pennis, fed pilis nigrisfemidigitum longis, quifub ventre \& gutture paululum canefcebant. In fumma, plane monftrofus pullus. Cruna inferiora \& pedes fufci coloris, uti \& roftrum, vitalia vifcera habebat gallinacea, fed inordinate difpofita. cor magnum.Vivebat cum excluderetur.

Avis (cui Auctor nomen non adfcripfit) magnitudine Alaudx, figura Matuituy. Roftellim habet rectum, nigrum: Oculos nigros; crura communia fufca : Caudam latiufculam, \& alias longiorem. Totum Caput fuperius, collum fuperius, dorfum, alæ; \& cauda, rufefcentis funt coloris, ex rubro, umbra \& albo mixti. Guttur, collum inferius, $\&$ infimus venter albi funt coloris.Per oculum utrumque à roftro tranfverfim maculam habet oblongam fufcam. Clamat Gip, Gip, ut junior gallo-pavus fere.

Avis (cujus nomen Auctor non prodit) magnitudinePatæ, \& ejufdem frguræx:Roftronigro, craffiufculo; capite nigro, pectore \& ventre cano; dorfo, alis \& cauda fufcefcentibus, cruribus fufcis. Clamat $Z i p, Z i p$, ut Paffer.

Avis (quam Auctor non nominat, (ed tantum admonet effe (peciem Curucui, de qua cap. I2.) magnitudine Picx fere. Roftrum habet breve, craffiufculum, paulum deorfum incurvatum, gryfeum feu cinereum: Oculos nigros, circulo croceo; Caput, collum, dorfum fuperius, \& cauda fuperius coloris nigri cum viridi cœruleo perfplendente, ut in chalybe polito: : Ale fufcx; Totum pectus \& infimus venter egregii coloris miniati: veftita, inferiora fex digitos. Digiti pedum communi modo fe habent, quorum medius anteriorum quatuor digitos longus, reliqui breviores, omnes unguibus lunatis preditinigris.

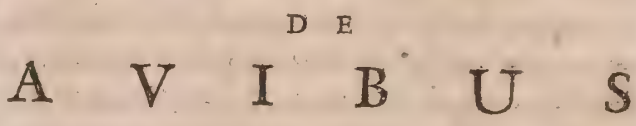

\section{A QUATICIS BRASILIANIS.}

Nter Aves marinas qux in Brafilia reperiuntur, feptem funt notatu digniores.

Prima eft QuIRATINGA grui magnitudine par, plumis candidis, roftro prolixo atque acuto, crocei coloris; cruribus oblongis è rubro fubflavis. Collum ipfius veftitur plumulis tam fubtilibus \& elegantibus, ut cum ftruthionum plumis certent. Altera eft C A R I P IR A, quæ quod in bi- Nieremb. nas partes bifurcatam caudam diftinguat, H. Exor, i. interdum explicans interdum contrahens, 'DeLaet. fartorix forcipis inftar, Raboforcado ab Ind.Occid. Hifpanis dicitur. Reperitur paffim in utraque India. Plumas ejus quod longo tempore durent, fagittis fuis adhibent Barbari. Ximenes adipem ad cicatrices faciei delendas, \& arthritidis dolores fopiendos, fingulare effe remedium narrat. Et fibi donati alarum remigium ita ut volant diftentum, amplius quam mortalis ullus diftento utroque brachii poffit complecti, occupaffe fpacium, addit. Non facile capitur, nifi forte in deferta aliqua infula, in qua pullós excludit.

Tertia CALCA MAR columbx eft magnitudine fed volandi nefcia. In fluctibus ova ponit \& excludit; quos etiam alarum atque pedum remigio fecat pervelociter. Malacia \& pluviis imminentibus tanto numero naves circumfluitant, ut à nautis faftidiantur.

2 uartam AYAYAM nominant, pic magnitudine, longo roftro cochlearis inftar, plumis candidis rubris maculis eleganter fuffufis, fingulari in pifcibus capiendis induftria.

Car a cur a eft quinta, exilicorpore, fubcinerei coloris, pulchris oculis, iride eleganter rubente, ita vocalis, ut majoris longe molis quisopinaretur. Ante fo- 
lis forte ortum \& fub occafum auditur, ccrto, ut volunt, ferenitatis futurx indicio.

Sexta eft GuAR A, picx magnitudine, oblongo roftro, \& anteriore parte recurvo, longis pedibus. Primum exclufa nigricat, deinde evadit cinęrea; ubi autem volare incipit egregie candicat, fenfim autem rubefcit; donec xtate plumæ illius colorem induunt purpuræ æmulum, 'quem ad fenectam ufque retinent. Victitant pifcibus, carnibus, \& aliis eduliis femper aqua temperatis.Pariunt quoque fubtectis. Gregatim volant, \& foli expofitx pulcherrimum prabent fpectaculim. Ex plumis diademata \& alia ornamenta à barbaris conficiuntur.

Ultima eft Gu IR A T E ON TE ON quafi dicas avem frpius morientem \& rurfusrefurgentem. Epilepfix enim obnoxia eft admodum, alioquin candidis \& pulcherrimis plumisveftita.

\section{A. P P E N D I X. De Avibuis Fabulojis.}

\section{A $\quad \mathrm{P} \quad \mathrm{U}$ T $\mathrm{T}$. De Gryphibus E़ Harpiis.}

D Lacet \& de Fabulofis aliquid adnectere, ne \& in hifce quicquam nobis defideretur. Præcedat Gryps fue G R y P H u s, cujus nomine major forte Aquila, ut fane in Oriente \& Septentrione niajora noftris animalia gigni experientia compertum eft, venire poteft. Ejus formam fi fpectes, fingitur effe quadrupes, antica parte, feu capite; alis, roftro, \& pedibus aquilam referens; poftica leonem. Magnitudinem Philoftr. aliiLeonis, aliilupi tribuunt, MandevilApollonii. lius octies Leone majorem reliquit. DorIflian. 1.5. fum pennis integitur nigris, anterior pars A puleii. 1. rubris, alæ candidis. Montes Riphoos feu Ir. Mile- Hyperboreos, haud procul ab ipfo Aquifiac. c. $27 . \quad$ Bactrianos inveniuntur. "

Nidos ex auro quod effodere conftruunt,

Barthol. \& ova duo Aquilinis majora duriora, caliAnglic, 1. diora \& ficciora, ponunt. Volatum avium

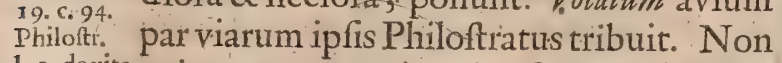
1. 3. devita enim pennatx, inquit, funt, fed rubra Apollonii. pelliculaalarum coftr tanquam digiticonSolin.c.25. nectuntur.Dicuntur aurum in Scythia AfiPolyhift atica cuftodire, ideo inter ipfos \& Arimafposinternecinum vigere odium. Tractat Elianus. de eo $\mathbb{E}$ Elianus, \& quomodo aurum illud 1. 4. c. 27. auferant incolæ defcribit, fed \& equis peculiariter infeftos effe rumoreft. Videtur

M. Paul. huc M. Pauli Venetiavis $R$ u c dicta per1.3. . 40. tinere, aquilæ effigie, fed magnitudine immenfa. Vifitur certis ẩni temporibus in infulis ultra Madagafcar fitis, tanti roboris ut fola, fine aliquo adminiculo ele- phantem capiat, \& in fubiine raptum rurfum ad terram labi finat, quo carnibus ejus vefcatur. Pliræque alarum pennæ paffus XII. funt longx, ea craflitie, qux longitudinis menfurx conveniat. Fides fit penes Authorem. Navigationes \& præteriti $\&$ hujus feculi, omnino de taliave tacent.

HARPYIS nomen à rapacitate inditum. ExElectoo Oceani filia genitas He- InTheonis fiodus prodit. Ponti \& Terre filix aliis dicuntur. Tres fuife Virgilius dicit, Ocypeten, Aëllo, \& Celano. Hyginus AlopenAcheloën \& Ocypeten appellavit; Ho- $^{-}$ merus quartam nomine, Thyellam addidiffe creditur. De forma fic Virgilius. 政

Proluvies, uncoque manus, \& pallida femper Orifame, \&c.

Collocantur in Strophalidibus infulis. A- Ovid. $\omega_{1}{ }_{3}$. pollonius fugatas conjecifiefe in fpecie, qui ph. $^{\text {Mermor-1 }}$ in Creta fub Arginunte vifebantur, tradit.

De ipfarum rapacitate, ingluvie, \& foeditate vide Valerium Flaccum, Virgilium, val. \&ralios.

$$
\text { C A P U T ... II. }
$$

Dẻ Stymphalidibus, Sirenibus $\mathfrak{E} S_{e-}$ leucidibus aribus.

Tymphalidibus, à Stymphala palude nomen datum eft. Magnitudine grues $\mathfrak{x}$ quant. Ibibus catera funt fimillimæ, ro- Paufan, in ftra tamen, ejufdem nempe duritiei, ut hominum fcuta perforare, firmiora habent, \& non ut Ibes obliqua. Plinius eas cirrhatas facere videtur. Marinas eas Ifidorus fa- Plin. cit. Apollonius circa Aretiadem infulam ${ }_{\text {Ifido }}$. c. 37。 collocat. Timagenes \& Pifander in Scyn-1. 12. Orithiam avolaffe tradit.Paufanias Arabięquo- - in. $^{\text {in. }}$ que deferta incoluiffe ait. Vefcebantur humana carne. Hercules eas ex Stymphalide palude abegit, feu crepitaculi æreí fonitu, fed quod multas fagittis confecifet.

SIRENES qua forma fuerint, non convenit inter Authores. Alii eas fuperiori parte virginis forman intuliffe, inferiore. in pif́cis caudam defiiffe:alii infera aviciam Alian.ling fpeciem habuiffe fabulantur: Nonnulli in de Anim: fuperioribus fpeciem pafferum, in inferio ribus mulierum eis tribuunt. Boccatius pedes gallinaceos affignat: Euftathius vero à Venere, quod virgineam fibi delegiffent vitam, in aves transformatas tradit. Bina funt quibufdam, Aglaopheme nempe 8 Thelxiepeja: tres alias Parthenope, Leucofia, \& Ligia. Sunt qui quatuor \& quinque fuife fingunt. Sed nec de eorum ortu eadem traduntur. Quidam è fanguine è cornu Acheloi deftillante natas volant. Nonnulli ex congrefu ejus cum Mufarum aliqua, de Venere fuperius diximus. Habitavere primum juxta Pelorum Sicilix promontorium, poftea in Capreiș. Plinius Surren- 
tum Campanix oppidum, una cum promontorioMinervæ, earundem fedem fuifte fribit. Finguntur tam fuavem harmoniam voce, tibiis, \&lyra edidiffe; ut \& mare \& ventos mulcerent. Cantu vero fuo navigantes occidiffe paffim apud diverfos Poëtas legere eft. De eorum cum Ulyffe colloCicer.1. 5. quio videapud Ciceronem carmen.

de finib. SEIEUCIDES aves vocantur, quarum adventum Cafii montis incola, locultis fruges eorum vaftantibus, à Jove precibus impetrant nec unde veniant, quove abeant, compertum, nunquam confpect $x$, nifi cum præfidio earum indigetur. Voracita-

Plin.1: 1o. tem eis antiquitas tribuit. Ingeftas locuftas e. 27. nullo negocio per alvum excernebant.

\section{A P $\quad$ U $\quad T$ III.}

\section{De Pbonice, Cinnamomo \&s Seménda.}

Herodot: DHónix fabulof́a eft avis. HerodoHift. $z_{\text {. }}$ tus nonnifi pictum fevidiffe teftatur.

Plin.H.N. Plinius unum in toto orbe, nec vifum malib.

gnopere fcribit. In ejus defcriptione variant Authores. Herodotus non tantum ei A quilæ magnitudinem tribuit, fed \& toto Ttetz. 1. 5. etiam habitu eidem fimilem facit. Adii Pa${ }_{6}$ Hit. Chil. vone majorem fcribunt. Herodoto pennæx rubore perfunduntur. Plinio vero \& Solino circa collun auri fulgore micant. Cxtera purpureus dicitur, cœruleam rofeis maculam pennis diftinguentibus criftis, faciem, fauces caputque plumeo apice cohoneftante.Idem Claudianus, Baptifta Mantuanus \& Lactantius produnt.

toous. Locum ipfi quidam Arabiam affignant. Amb. 1. 5. alii Heliopoli civitate Ægypti primo vi23. fum reliquere. Quidam fub æquinoctiali Plin. 10...... 2. ad Orientem \& Meridiem reperiri fcri1. ro.c. 2.
Solin. Po- bunt. Claudianus, \& Lactantius inacceffa lyh loca habitare cecinerunt.

Tacit.1.14
Anim. Nec de victu convenit. Plinius primum $\checkmark$ ictis. atque diligentifimum togatorum.Manilium de eo prodidiffe author eft, neminem extitifle, qui viderit vefcentem, quidam

Athenx. 1. rore victitare dixerant. Ovidius thuris la14. Dipn.
Partus. Nidiffcatione ejus \& in parentem amore ita

Taci. lib. Tacitus: Confecto annorum numero ubi mors 44. Annal propinquat ; fuis in terris fruere nidum, eique vim genitalem adfundere, ex quaffotum orivi, o primam adulto curam Jepeliendi patris, neque id temere, fed fublato myrrbe pondere, tentatoque perlongum iter ubi par oneri, par meatui fit, Subire patrium corpus, inque folis aram perferre atque adolere. Idem Herodotus, ex quo ille defumfiffe videtur.

Etas. Annorum illorum numerus varie definitur. Maxime vulgatum quingentorum fpacium, funt qui affeverent mille quadringentos fexaginta unum interjici. Plinio fexcenti fexaginta placent; Philoftrato fexcenti, Herodoto, Solino, Meli quin- genti quadraginta. Alberto trecenti quin quaginta; Chæremoni Egyptio, fex fupra feptem mille. Deterris quoque variatur. Jarchas Indus apud Philoftratum prope Nilum aflignat. Alii in Athiopia, ut Chæremon Agyptius, \& Orus Apollo. Alii in Phœenicia, ut Lactantius.

Nido materia aromata, Cinnamonum, Caffia, thurifque furculi. Ubi illum confcendit, folaribus fefe exponit radiis, alarumque continua ventilatione ignem excitare fingitur: fic fe cremat. Ex cremato novum oriripullum convenit inter omnes; quomodo vero id fiat, ambigitur. Plinius ceu vermiculum ex offibus \& medullis veteris Phoenicis primo procreari, ex eo pullum nafci fcribit. Philoftratus nulla vel offium vel medullarum mentione facta, ex cinere vermem, ex verme novam alitem generari nugatur. Oppianus ex cinere pullum exoriri refert. Orus ex effufo è patris vulnere, quod fponte fibi nimia ad. terram allifione infligit, fanguine procreari affirmat. Sexum illi nullum attribuitantiquitas, fed inter vitix remedia repofuit. Nam Plutarchus cerebrum ejus dulce effe plut. 1.de tradit, nefcio à quo guftatum, \& Plinius fanititueninterprima à Magis ex cinere ejus nidoque ${ }^{\mathrm{da}}$. medicinas proditas effe fcribit. Heliogabalus in conviviis Phonicem promittebat, aut $\mathrm{M}$. auri libras pro eo.

Ci n a MO Mus feu Cinnamologus, avis hactenus nobis incognita eft. Hero- Herodot: dotus grandem effe dixit. 'Vicentius Bel- inEuterpe: lunenfis paffere aliquanto majörem, coloris partim flavi, partim corulei, roftrilongi ad flavum vergentis fcriplit.

Locus ipfi ab Antiquis in Arabia affignatur. Dyonifius Periegetes terram ignorari una cum Herodoto memorat. Albertus in Ethiopia eum locat.

23. da A-

Nidum ponit feu in excelffifimis arbo-nimal. ribus, earumque ramis, feu in montium preruptis, illumque ex cinnamomi furculis exftructum. A romate hoc cum potiri Arabes volunt, boum, afinorumque defunctorum membra minutatim concifa, juxta nidos ponunt, \& abfcedent. Fruftra aves in nidoscomportant, quibus fuftinendis illi impares decidunt, \& ab incolis colliguntur.

De SEMENDA non eft quod dicam. Ald:ovaniMulta quidem fed parum verifimilia de dus Orniilla Indica commentaria produnt. Caput thol. $1 . x_{2}$. ipfius, quod effe putabat, quod Aldrovandus in Mufro Ducis Florentini vidit, erat curvum, \& valde craffum, colore in anteriore parte albicante, in pofteriore purpureo obfcuro, figura ovali. Roftrum habebat palmum longum, admodum acutum, intusquidem cavum, fed fine tribus illis fiftúlis, quibus muficam harmoniam à Semenda edi, quidam fabulati funt. 
M A $\mathrm{N}$

D E

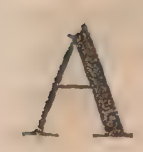
V I $\mathrm{B}$ U

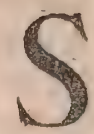

\section{Exoticis ad noftrates accedentibus.}

\section{De Aquilis.}

Nieremb. Hift.Exot 1. $10 . \operatorname{co} 30$, $\$ 31$.

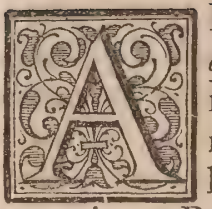

D Aquilas pertinent Itzquarbtli \& TlacoquaubtliIndorum, nec non Lconis Africani Ners. Ventuftum illud aqui$1 x$ genus, \& infignito capite regium. Roftro eft ad radicem luteo, deinde vero nigro, nigris unguibus, pedibus pallidis, cruribus ventreque è nigro \& candido permixtis; collo fulvo, dorfo \& cauda nigris ac fufcis, corona criftave nigra. Magnitudinem circiter æquat vulgaris arietis, \& vel ferocium audaciam animalium, adeo ut hominesetiam ipfos, poftquam cicurata eft, levi ex caufa aggrediatur \& involet : mitefcit tamen, \& aucupio non minus ac reliqui accipitres, quorum genus videtur, idonea eft, atque infervire folet. Avis digna qux à Regiis aucupibusalatur ac circumferatur.' Vilior eft tlacoquauhtli, feu aquila virgæ: frigidas amat plagas:afturis magnitudine, fufca $\& x$ cinerea, rapax avicularum, murium, lacertaIeo Afri-rum, colotorum, quibus vefcitur. De Nefir can. Afri- fuo ita Leo A fricanus : Avis eft omnium ca' 1. ult. earum, quxin Africa reperiuntur, maxima, grue procerior, crafliorque, predita roftro, collo \& cruribus : adeo fublime volat, ut oculorum aciem effugiat, \& confpeito alicujus animalis cadavere, fupra terram jacente, illico in illud irruat. Raro fola, fed gregatim volare folet. Longæva eft, nam pleræque confpectx funt calvo \& deplumi capite, tanquam vulf $e$ fuifent capitis pennæ : inde colligerelicet, prænimio fenio pennarum defluvium pati:ea de caufa fuos nidos veluti recenter natæ repetunt, unde à fuis pullis educantur: Coronate in provincia Chiapx habentur, ut apud de Laet in Novo orbe habemus.

\section{De Noctuis.}

Nieremb. Hift. Exot. 1. 10. c.3 $\& 40$ coletlgenus eft bubonis auriti, fpectaculo dignum, nigro \& fufco colore variegatur, huic oculi magni \& aürei.

\section{I. De Strutbio-Camelo.}

Pecies quxdam Strutbiocamelormi in De Laer Infula Maragnana invenitur. Proce- $\mathrm{vi}$ lib. 16. ritate ftaturam humanam fuperant, 8 ma- c. 14. ximæ funt velocitatis. Magis fupra terram feruntur quam volant. Barbari yandeu vocant.

\section{De Pfittacis.}

D Lacet hic quxdam de Pfittacis ex Hernando, Ximene, Clufio or Nierembergio adjicere. Ille primus ita fcribit, de Tozne$n e:$ Pfittaci id genus, viridi \& luteo colore micat, oculi rubeo, roftrum vero candenti \& nigro, fufco pede, fed in candidum inclinante. Propenfius eft, aptiufque ad fermones humanos exprimendos cxereris, ac frequentius apud Hifpanos. Alterum genus Cocho vocant viridi colore, rubro \& candenti capite, ac minoris molis; quod loquax eft, nec admodum diffimile precedenti, etfi fono diffet. Hos Pfittacos vocant Hifpani catherinas. 'Tertium 2uilitoton, tinctum virore, talandrix vocatæ, aut galeritæ non criftatæ magnitudine. Frontem candida macula infignitum, roftro candido \& nigris pedibus. Humanas voces imitatur, \& gregatim cum congeneribus volat, cum reliqui compares tantum reperiantur. Omnes vero in excelfis arboribus nidificant. Primum de quo diximus genus, certas ftatafque arbores, quas nunquam deferat, eligit: qux cum in hreredes tranfeant, dominis illarum haud funt parum utiles. Sunt \& quas Haitini 2uacamayas vocant, Mexicenfes vero Alo. Totx rubex, præter humeros \& caudam, qux cyanea funt, \& gallinæ cortalis noftræ circiter magnitudine, roftro magno candenti $\&$ refimo, pedibus nigris, ac carne fimiliter nigra, ex quibus nonnullix offenduntur, quæ fermonem humanum doctæx mulentur, ruftice tamen \& incondite : filiofque fuos more aliarum avium domefticarum educent in domibus ubialuntur. Offendas \& alios virore diluto tinctos, nigrante roftro pedibufque, humeris \& cauda virore tindtis 
exaturato,nec præfatis minores: Vivunt hi fpeciem etiam videre memini in arce $\mathrm{C}_{2}$ juxta montium cacumina, excelfafque pi- faris Ebers dorfiana ad Danubium fita innus. Acclamant vehementer, volantque fra Viennam, tum etiam Lugduni Batavobini. Sunt $\&$ montani incondita forma, quinon cicurantur aut aluntur domi. Nullius eorum caro eft edulis, nam \& atra eft, \& guftus injucundi. Omnibus eft commune, utramque maxillam movere, quod nulli aliorum contingit animalium. Sunt \& alia genera, de quibus alii Auctores latius.

Ximenes fic habet de Hifpaniola loquens. Innumeri funt $P$ fittaci virides cum purpureis maculis, quorum tria in hac infula genent, majores, mediocres, minimi. Majores ab Indis vocantur Higuaræ. Hi in eo diftant $a b$ aliis reliquarum infularum, quod maculam albam fupra roftrum geftent, non viridem aut miniatam. Valde locutuleix funt hæ higuaræ, fi humanos doceantur fermones. Minores vocantur xaxavis, \& viridiores funt, à paucifque interftinguuntur miniatis plumis. Hi inquieti \& turbulenti, mordaciores, iracundiores, \& garruli, licet rudes humanis loqui vocibus, quas nunquam difcunt.Decem ex his invadunt \& fugant centum higuararum. Nulla inter hos pax. Diverfis gregibus pervolant quacunque pervadant, garriunt. Higuaræ integriorem \& corpulentiorem edunt fonum, xaxavis acutiorem \& tenuiorem : \& licet ignari humanis vocibus loqui, placent tamen in caulis affiduo garritu \& inquietudine. Tertia pecies minimorum eft, nec excedunt pafferes mole, viridefque funt. $\mathrm{Hi}$ filent, \& pacatiores funt : viror dumtaxat in illis placet.

Clufii Hiftoria hxc eft. Inter Neotericos autem, nemo mea opinione exactius \& diligentius de hoc avium genere commentatus eft quam Ulyffes Aldrovandus Bononienfis, qui totum librum 40. Tomi primi Ornithologix fux ei dicavit : Ille enim Philofophica methodo tradidit quicquid ad Pfittacorum hiftoriam pertinere poteft, \&x quatuordecim diverfas eorum fpecies defcribit, tredecim vero icones exhibet, quarum duo priores maximæ funt, \& corvum magnitudine fuperant ; tertia \& quarta columbx funt magnitudine; quinta, fexta, feptima, octava, nona, \& decima mediocris funt magnitudinis, caudamque brevem habent, faltem non adeolongam, ut tres fubfequentes, qux longiore cauda funt præditæ: decimaquarta brevem ctiam habet caudam. Priorem illam elegantem, qux Pectoris \& ventris pennas flavas habet, tum \& eas qux alas dorfumque tegunt, tum etiam easquæ in cauda cœruleas, non femel videre memini, \& iconem habeo vivis coloribus expreffam, atque illam ipfam effe arbitror, quam Joannes Lerius cap. XI.Hiftorix fux Americanæ, Canide à Brafilianis appellari fcribit. Alteram rum apud Sionem Lucium Daniftam binas aves ejus generis, quas poftea Magno Duci Mofcovitarum dono mittebat. Reliquæe vero fpecies, (præter tertiamquæilli alba criftata eft, \& decimam quartam, quæ erythrochloros, etiamque criftata) mihi etiam confpectix, dum plerumque alix ab ipfo non defcriptæ, tam breviore cauda præditæ, \& majufcula corporis mole, quam minoris generis, qux longiores caudx pennas habent, \& collum velut torque rubro atque atro ornatum. Humana verba exacte exprimere folitx : quibus fimilem unam habuit nobiliffimus virPhilippus Marnixius SanctAldegondius, quam fxpe cacchinum humano more extollere audivi, cum ab adftantibus Gallico fermone compellaretur hoc modo. Riez perroquet, riez; id eft : Ride pfittace, ride. Sed quod magis mirum, Gallico fermone etiam fubjiciebat illico, tanquam ratione predita, haud dubite tamen ita edocta.Ole grand fot qui me faict rire, hoc eft. O magnum fatuum, qui me ad ridendum provocat Illaque verba iterum ac tertio repetere folebat. Sed inter reliquas unam; pfittacis primæ fpeciei magnitudine æqualem, apud. Illuftriffmam Dominam Mariam de Brimem, Ducem Croyam \& Arefchotenfem felicififimæ memoriæ, priufquam ex Hollandia excederet, cui fane parem in coloris pennarum varietate \& elegantia videre non memini. Et enim licet omnes fere pennæ corpus tegentes rubro çolore effent infectre, caudx tamen pennx, qux valde prolixx, partim rubre erant, partim corulex; at qux in dorfo \& alis verficolores ex flavo, rubro \& viridi, quibus cœruleus color etiam permixtus. Caput circum oculos albi coloris erat, finuofifque lineis nigris, quemadmodum caudx caput, diftinctum erat. Pfittacum, qui fimilis effer, apud nullum Auctorem defcriptum memini. Ea porro avis Annam Illuftriffimæ Ducis neptem, nunc Comitem Mergenfem \& Dominam de Grosbetee, adeo diligebat, ut quocunque per conclave fpatiaretur, illam fubfequeretur, nec quemquam veftem ejus attingere confpiceret, quin morfu illum appeteret, ita zelotypia quadam laborare videbatur. Ceterum pfittacus ille majoris generis, quem Lerius capite fupra memor ato à Brafilianis Arat vocari fcribit, valde elegans etiam effe debet: nam alarum remiges pennas, \& caudx, qux fefquipedalis longitudinis, media ex parte coccinei coloris effe refert, altera prorfus elegantis cyanei tubo feu nervo, qui medias pennas per longitudinem fecat, diverfos illos colores diftinguente, reliquas 
vero totius corporis pennas prorfus cœru- $\mid$ cis fuis tabellis quidam perfuadere conan= leo colore tinctas effe. Addit utrumque tur : at in arborum cavis, eofque orbicular genus illud majorum pfittacorum. Arat forma, fatifque duros ac firmos. Ceterum videlicet \& Canide, magna effe in rftima- cum fub extremum annum Chrifti milletione apud Brafilianos, quia illorum pen- fimum quingentefimum fexagefimum nas ter quaterve in anno vellunt, ad ve- quartum effe Olyflipone apud Sebaldum ftem, pileos, clypeos \& aulæa conficien- Linfium Germanum Ulmenfem, memidum, tametfi domefticum non fit, quia ta- ni filium ipfius Rodericum ex Fernammen in vaftis arboribus medios vicos occupantibus frequentius verfarifolet quam in filvis. Præeter binos illosingentes, idem. Lerius tria aut quatuor Pfittacorum genera apud Brafilianos inveniri ait.: Primum videlicet etiam majufculorum, \& crafliore corporis mole præditorum cui Aicurous nomen indunt Brafiliani Tououpinamboutii, caput ornatum habens verficoloribus, flavo, rubro, \& violaceo extremis alis fua verubentibus, \& caudx pennis oblongis \& flavis, reliquo corpore prorfus viridi : hoc genus rariflime ad exteros transferri, nullum tamen facilius \& perfectius edoceri ad humana verba pronuntianda, quam iftud. Additetiam, Brafilianam quandam mulierem in pago, binis milliaribus ab Infula in qua ipfe cum aliis Gallis habitabat, diftante, fimilem pfittacum in deliciis habuiffe, qui eo intellestu \& ratione præditus videbatur, ut comprehendere \& difcernere poffet, quidquid ipfa diceret quæ illum educaverat. Nam cum ; inquit, animi recreandigratia, in illum pagum profe. eti, ante illius mulieris $æ$ des interdum tranfiremus, compellare nos ipfa folebat his verbis: Vultis mihi pectinem dare vel fpeculum, \&illico efficiam ut meus pfittacus coram vobis cantet \& faltet? Si ejus petitioni annuebamus, fimul ac quxdam verbaavi pronunciaverat, pfittacus non modo in pertica, cui infidebat, faltare incipiebat, fed etiam garrire, fibilos edere, \& Brafiliorum adepugnam fefe parantium vociferationes imitari. Breviter, quando in ejus heræ mentem veniebat ut diceret, $\mathrm{Ca}$ ne, canebat; Salta, faltabat; fin vero xgre ferens, fe quod petierat non impetraffe, paullo acerbius avi diceret, Auge, hoc eft. Sile, immobilis filebat, nec ulla ratione cum ad linguam aut pedes movendum excitare poteramus. Secundum genus Marganas à Brafilianis appellatur, quale eft corum pfittacorum, qui in Europam inferri folent, nec magniapud illos pretii, propter abundantiam non vero minus iftic frequentes funt, quam apud nos columbx. Pfittacitertiigeneris, ab ipfis Touis, appellati, majores non funt fturno, \& univerfum corpus tectum habent pennis impenfe virentibus, caudæyero pennæ, quæ valdæ longæ, flavum colorem admixtum habent. Illud etiam addebat fe obfervaffe, pfictacosillius regionis nidos ex arborum ramispropendentes non conftruere, ut topographibuco Brafilianorum, ubi commorabatur, eo appellere \& navem mercibus onuftam advehere, in qua etiam aliquod mancipia, \& nonnulli pfittaci quarta fpeciei ab $\mathrm{Al}$ drovando defcriptx, atque alii etiam $\mathrm{mi}$ nores, fturni magnitudinem non exccdentes, prorfus viridis coloris pennis tecti, fed omnes brevi cauda præditi, \& albo roftro: idque genus valde frugibus noxium referabat. Eos in itinere maizigranis alueret, cujus multas fpicas eum adhuc habere obfervabam. In fecunda navigatione, quam Batavi in Indiam inftituerunt Orientalem, in Java vicinifque quibufdam Infulis pfittacos obfervabant longe illis elegantiores, quos è Brafilia advehere folent, eofque à Lufitanis, qui in Java \& Moluccis verfabantur, noyras appellari intelligebant : \&illos quidem corporis mola non valde magnos, fed adeo elegan. tis coloris, ut venuftiores depingi non poffe exiftimarent. Pectus enim \& ventrem pennx rubri coloris floridi fplendentifque tegebant, dorfum aurei coloris pennx, alas vero viridis \& cærulei commixtorum colorum pennx ornabant, fub alis fuave rubens color fplendebat. Valde autem ingens erat iftic illarum avium pretium, ut non minoris xftimarentur, quam octo aut decem thaleris Germanicis. Linfcotius fcribit, Lufitanos fepius periculum feciffe, an Olyfliponem transferre vivum aliquem poffent, fed nunquam voticompotes factos fuiffe, quod nimis tenelli \& delicatuli fint: Batavi tamen eam Induftriam adhibuerunt, ut unum vivum Amfteldamum ufque retulerint, qui tametfi non effet è felectilimis, centum tamen \& feptuaginta florenis ejus Provincir, hoc eft, paulo plu* ris quam feptuaginta thaleris venundari potuit, quemadmodum in diario illius navigationis adnotatum comperio. Is in itinere pleraque verba Hollandica, qux à nautis audiverat, pronunciare didicerat, adeoque cicurem ipfum ejus herus reddiderat, ut roftrum in os $\&$ aures ejus infereret fine noxa, pilofque barbæ ipfus compo neret; at fi quis alius manum admovere vellet, illico morfu illam appetebat, haud. fecus quam canis quifpiam. Anno porro Chrifti quinto fupra millefimum \& fexcen tefimum mittebat mihi Jacobus Plateau pfittaci cujufdam iconem vivis coloribus expreffam, cui cum fimilem hactenus non viderim, neque apud quempiam adfcri- 

veam, qua conclufus erat, aliquo animali, furrigebat, ut criftatus quodammodo videretur. Erant autem illæ rubefcentis coloris, \& extima parte corulei elegantifimi. Ventris pennæ fimilis fere erant coloris, fufco tamen infuper fuffufx colore. Dorfi pennæ virides \& alarum remiges pennæ fub çœrulex : cauda frequentibus pennis viridibus, fed nonlongis conftabat. Pretermittere nequivi, quin pfittaci pufillum, genus ex Ethiopia locifque Manicongo vicinis, proximis his annis à Batavis nauclerisallatum, fimul \& maris iionem, (foemina vero multo eft elegantior, utriufque enim fexusallatus) Lectoris oculis proponerem. Corpufculi moles fringillæ magnitudinem æquabat, hoc eft, duarum unciarum cum femiffe longitudinem habebat $a b$ infimo collo ad uropygium ufque. Omnes pennulx corpufculum tegentes viridis erant coloris, fed in quibus manifeftum apparebat difcrimen: nam qux in dorfo faturatiores erant, quæ in ventre dilutiores. Remiges alarum pennæ trium unciarum longitudinem habebant: \& tametfi prona parte, eo videlicet latere quo brevioribus villis erant præditæ, quoque fefe invicem tegebant, viridi faturo colore effent tinct $x$ altero tamen, quod longiores villos habebat, \& tota fupina parte fufci erant. Caudx pennæ elegantifim $x$ erant $\&$ pæne binas uncias longæ, paulo minus femiuncia latæ, colore ea parte, qua uropygio infixæ, viridi cum flavo permixto tinctie, deinde rubro eleganti, demum nigro, poftremo viridi : \& tres ifti poftremi colores ab invicem diftinsti, veluti in quorumdam pfittacorum viridium, majore corporis mole præditorum, caudx pennis videre eft:iftx autem vix confpiciebantur, nificum caudam explicaret, quia ab aliis ejufdem longitudinis tegebantur, quæ prorfus virides. Collum breve \& crafliufculum : plumulæ caput tegentes breves admodum \& virides præter eas quæ verticem fupra roftrum, quæque totum guttur tegebant; nam illæ rubrum, elegantem $\&$ floridum colorum habebant. De mare loquior, quia fominæ pennulæ dilutius rubebant, neque tam amplum fpatium occupabant, quam in mare. Oculi erant nigerrimi : roftrum craflum $\&$ firmum, fuperna pars adunca \& mucronata, ut in reliquis pfittacorum generibus A T U R A I I S

Ejus color fubrubens, crura brevia femunciæ longitudinem vix æquabant, cinerea ceique coloris fquamis erant tecta, ut aliorum vulgarium pfittacorum pedes, iique in quatuor digitos divifi, quorum bini anteriores \& imparis longitudinis, bini pofteriores \& illietiam impares, brevioribus quidem articulis duobus præditi, hi interni, longioribus autem tribus, \& hi externi. Ungues albi \& fatislongi. Valde exilem habere vocem, \& dumtaxat pipireobfervabam. Gaudet Confortio. Cum edebat, altero pede cibum non tenebat ut alii pfittaci, fed roftro carptim cibum arripiebat. Cibus autem magna ex parte phalaridis femen : illo enim libentius vefci obfervabam, quam ullo alio feminis genere. Mihi autem quidam confpecti funt adeo edocti, ut panem aqua tinctum carptim morlicando ederent. Potus eft aqua. I1lud præterea in hac avicula animadvertebam, quod foemellæ fenefcentes vix edere volebant, nifi cibum jam à mare carptum, \& aliquamdiu in prolobo retentum, \& quafi coctum fuo roftro reciperent, ut columbarum pulli à matre ali folent.

Apud Nierembergium de Guacama- Nieremb: yan hæc leges. Guacamayan genus pfittaci Hift. Exor. eft pulcherrimi, qui cum pueris ludit. In- c.63. \&64. compofitæ formæeft, folo veftitu in pretio habetur, neque prætermittenda induftria \& mirificus inftinctus hujus alitis. In Potofi quidam pittacus, quem lorum vocant, admirandi ingenii. Vocabat Indos occurfántes patriæ fuæ nomine Colla, leuca, Huayru, Quechua, \&c. quafi qui ipforum mores \& veftimenti ritus dignofcerret. Diflimulatam Indam nobiliori natu \& pæne Regio dignovit. Cum vidiffet illam,dixic: Huayru, Huayru, Huayru. Ignobilior ifta natio eft, quam illa cujus generis fe fimularet fæmina. Finxerat fe Pallam è Re gia ftirpe. Matrona partim pudens, partim irata, fputo \& maledicto avem affecit. Hifpali etiam alius pfittacus agnovit Medicum indignum nomine \& arte; quem, quoties cunque occurrebat, convitiis variis profcindebat è feneftra, donec lite impetravit Medicus ne fufpenderetur ibi. Alius Pfittacus tabernarii vinarii folitus audire illum domi querentem vinum non vendi, quod acetum effet. Didicit hæc verba, atque ad januam fufpenfus garriebat repetito præconio, Acerum eft. Acetum eft, quod facile fuit ementibus credere : donec herus madefaciens (aquam enim odio habent hx aves ) \& caftigans pfittacum dictavit, Optimum merum, Optimum merum, quod pfittacos fic animadverfus didicit, \& poftea ad januam idemtidem publicabat, optimum merum effe. Multi pfittacorum fimpliciflimi, ut ad crocitantem pfittacum ex arbore, in 
cujus ramis auceps latet, multitudo ingens ma. Cujus pulvis falutaris eft hydropiconvolitet, capique facile patiantur: nil cis:

enim vifo aucupe terrentur, fed ut laqueo

trahantur ad collum conjecto expectant, nec aufugiunt uno captato, \& in mantica, qua procincus eft Venator ipfis cernentibus repofito. Pfittaci faciem univerfim exprimit, quem quoque cantu ad amufim xmulatur Noyna, quæ ex Moluccanis Infulis in Indiam importatur, pennis tamen rubris crebrioribus veftita eft. Illarum una viginti aut triginca pardavis in India vænit, qux poftquam cum pfittacis \& afpectus amoenitatem, \& garritus jucunditatem communem habeant, hoc fibi peculiare quoque vendicant, quod educatorum fuorum, aut alias quoque adftantium capita \& barbas, ut $\&$ aures dentefque linguis fuis blande defricent aut allingant, quas partes ftudiofe quafi ad vivum emungunt, \& emundant, adeo utillarum altoribus ex his gefticulamentis oblectationis emergat haud parum. Taceo, quiod acutius attendenti coloris jucunda varictate pfittacos haud leviter exfuperare videantur.

\section{De Picis.}

Nieremb. R Reter enumeratas Picorum fpecies Hift: Exot. 1 . dantur adhuc apud Americanos duo 1.10. cap. Pice nempe Salutiferi \& Imbrifeti.Ille Heub-
48. 49. quecholtototl, feu avis capiti fimilis dicitur. Nobilis eft à capitis dolore levando.Merula major eft, roftro longo nigroque, fed in ferna partelonge breviori, vertice ac pære to to collo defuper rubeo, infernis partibus omnino cinereis; alis vero acdorfo nigris, fed albis transverfifque lineis variatis. Degit Pavatlanicis agris provincix Totonacapx. Pici fpecies eft arbores perforans, cujus capitis plum $x$ rubefcentes applicate \& conglutinatx, capitis feruntur curare dolorem; five in eam fententiam venerint, quod vertici avis adhæreant, five id ita fe habere experimento aliquo deprehenderint. Hic Quatotowi audit. Upupx magnitudine \& fufco colore variatur. Roftrum, quo excavat arbores perforatque, tres digitos longum eft, firmum \& candens, \& inferne brevius. Caput eft parvum, ac rubris contectum plumis, crifta quoque rubra infignitum, ac tres uncias longa, fed fuperna parte nigra. Alterutro colli latere fafcia candida defcendit ad ufque circiter pectus. Crura pedefque livida funt Vivit non longe à mari $\mathrm{Au}$ ftrali. Nidificat in arboribus excelfis : vefcitur cicadis, thaolli, \& vermiculis: imbrium tempore educat, hoc eft à menfe Majo ufque ad Septembrem: edulis tamen non eft, nec alium ( quod acceperim )* præftat ufum. Pici Martii datur in Nova Hifpania fpecies maxi-
In Nova Galacia Pice funt exiles, nec De Latefo pafferibus multo majores, fed tanto nu= ${ }_{\text {cid, } 1.16 \sigma_{6} s . t}$ mero, ut integram fegetem, ubi femel ari ftis incubuerint, profternant atque con= culcent, neque clamore aut aliis terriculamentis deterreantur. Eft \& Pica Xochi= tenacatl dicta columbæ magnitudine, roftro præ corporis mole maximo, fuperiori parte luteo, inferiori verofubnigro, \& in purpureum colorem vergente, Oculis nigris, fed iride rubefcente exluteo, ac reliquo corpore coruleo cinéreoque. $\mathrm{Vi}$ vit circalitora Oceani Auftralis; pifcibus, quos rapit, vefci folet: Iconem vide apud Nierembergium Hiftorix Exoticæ pag。 209.

\section{De Sturno.}

A. D Sturnos videtur pertinere quæ Nierenbís Pterophornicus Indiarum, \& Acolchi di- Hift. Exot. citur, de qua fic Nieremberg. Alarum infigne commendat acolchichi, feu avem humerorum rubeorum, impetravitque $a b$ Hifpanis honorificum nomen; qui aves commendadoras illas vocant, quod æmulentor Equitum militarium infignia. Simili rubore ad latus fulgentia.Sturnorum, quos Hifpani tordos vocamus videatur fpecies. Magnitudine, colore, \& forma pares funt, \& cum eis ubicumque verfantur, quanquam humeri primo fulvi appa. reant in rubrum vergentes, \& cum xtate. procefferc, in fulvum omnino mutentur colorem. In caveas conjecti, voces reddunt humanas, \& lepide garriunt. Quavis reoblata vefcuntur, fed pane maxime atque Indico frumento. Calidis frigidisque eas aves reperies regionibus, ab Hifpanis colonis rubeorum humerorum commendadozas, ut dixi, vocatos, fed numerofis agminibus funt oppidanis admodum molefti, eosque audacter incurfant, præcipue regionibus fervidis \& $\mathrm{ma}$ ritimis. Malum infuavemque præeftant fuccum, \& in arboribus non procul ab oppidis hominumque commercio nidificant, \& fata, in quibus forte confedere, devaftantarque depopulantur.Cantant luduntque, feu caveis includantur, feu libere per domos permittantur incedere.

\section{De Coturnicibus.}

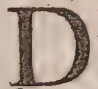
E Coturnibus ita idem Nierembergius. Corturnices vocabat Nova Hifpania Colin, quarum genera ex Francifco Hernando dabo. Noftratibus funt fimiles, etfi ad perdicum fpecies fint citra dubium referendx; Multa genera apud Novos Hifpanos reperiuntur nonnulla fufca \& criftata, qux quaishtzonecolion $X 3$ nun 
nuncupant, mediocris magnitudinis; alia fufca quoque, fed criftarum expertia, \& paulo minora, alia omnium maxima fulvaque, fed capite albo \& nigro, colore variato, extremis vero alis dorfoque candentibus, pedes vero ac roftrum nigra funt. Hifpanis, ut dixi, coturnicibus affimilantur. Omnia \& bono \& grato conftant alimento, fi tamen jugules duobus tribufve diebus, antequam affa apponantur menfis. Exhibetur earum caro etjam male habentibus : nec eft apud Indos ulla alia poft cohortales, qux illi poffit anteferri, aut alimenti falubritate aut guftu. Canunt noftratium inftar, etfi aliæ aliis fuavius. Caveis includuntur: vefcuntur Indico noftrove frumento, \&funt quamplurimis hujus plagx locis familiares. Alibi idem Auctor de Coyolcozque feu colli fonali inquit: fpecies eft colin, feu coturnicis Mexicanæe, inter quam plures alias, de quibus loquemur feorfim. Ergo coturnicibus vocatis à noftris fimilis hæc eft, magnitudine, cantu, nutrimento, volatu \& moribus. Sed diverfo colore, qui fuperne eft ex fulvo candidoque commixtus, inferne vero tantum fulvus, etfi verticem \& collum nigrantes albæque plumæ occupent; \& tænias $\mathrm{ab}$ utroque latere adeoque à collo ad utrumque collum efforment atque conftituant. Oculi funt atri, \& fulya crura:Indigena avis eft, campeftribusque locis, velut \& noftras, frequeris, ac fimili etiam alimento, quod ad illud perdicis Hifpanicx ( eft enim ejus fpecies) proxime accedat. Colcricuiltic, feu coturnicis fimulacrum, coturnicis quoque noftræ fpecies eft, albis, nigris coccineisque variata plumis, \& protractis defuper potius lineis quam circumfriptis maculis, fubter vero potius maculis frequentibus, quam lineis, pedes cruraque cyanea funt; fed cantu, magnitudine, moribus, cæterifque cunctis præcedenti omnino fimilis. Sturno eft Acolin magnitudine par, cruribus pedibufque viridi pallefcentibus, . \& in quatuor divifis prolixiores digitos. Roftrum eft luteum, \&longiufcuIum pro corporis proportione, ténueque \& mucronatum, oculi nigri, iris fulva, caputque parvum. Inferna corporis candida funt, lateribus fufco maculatis colore, fuperiora vero \& cauda, quæ breviufcula eft, fulva funt, fed maculis nigricantibus diftincta, \& candidis lineis quafvis pennas circumambientibus, ejufdemque coloris punctis nonnunquam confperfis. Lacus incolit, pifcofumque eft, nec' tamen admodum ingratum præftat alimentum. Vermiculis, mufcis, \& aliis parvis animalibus qux volitant circa paludem, victitare folet. Indigena eft Mexicanila- cus. Caput mira colorum varietate micat Quod medium atra linea fecat, ac velut cinerex alix latera, maculæ vero parvæ \&candentes canthos extérnos : collum pectufque cinerea funt, cætera è fulvo in viride potius inclinant.

\section{De Perdicibus.}

Unt in Peruvia Perdices quas à fono De Laet. rutu vocant. Duorum generum. Alix cid, I. 1o. majores, qux mole accedunt ad Gallinas, cap. 5. \& tantum in folitudinibus reperiuntur. Alix minores quam Hifpanienfes; fed carne longe optima. Utræque funt colore pardo, roftris \& pedibus albis. Ibidem funt aviculx plumis rubicundis, quos Hifpani ob fimilitudinem nominant Lit fcinias, quanquam cantus harumfit adeo ingratus, ut mali augurii olim dixerunt barbari.

\section{De Turdis.}

Enus Turdorum Chrappam incolit, Nieremb: I quos vocant pafferes fabros. Nigri Hit. 10. C.57. funt, folum in pectore \& capite rubri. Fructu quercino dumtaxat vefcuntur. RoAtro perforant corticem pinnum, glandem fingulis foraminibus aptiffime accommodant, ut manu extrahi nequeat, fic omnem pinum ornatifime cingunt glandibus incifis, Mox pedibus hærentes cortici, tendunt roftro glandem, \& vorant. $A$ lia fententia Gomatx eft de Pafferibus, quos vocant Hifpani carpinteros. In Dariene fcribit nafci palmas, quarum truncus per extrema attenuatur: in medio nidificare quofdam pafferes excavato roftris nidos. Hos pafferes vocatipfe Pitos, \& putat effe quos Plinius Picos dixit, Hifpani Fabros. Addit ex Aliquorum fententia, vim recludendinidos ferro impeditos non effo alicujus herbæ , fed ipfius pici, cujus tactu infringi metallum.

\section{De Anatibus.}

\section{C} Enus eft Anatis quam Acitlifeu aqua- Nieremb. tilem leporem confueverunt vocare Hift: Exot. Mexicenfes. Hæc cum defcripta delineataque à quibufdam recentiorum eadem prorfus effet, nifi caput longe majori infigniretur crifta, atraque, venter colore argenteo fplenderet, \& collum inferne niveo, fuperne vero è nigro vergente in fufcum. Lacubus innatat, ac juxta eosperpetuo verfatur : nam neque volandi potis eft, neque per terram commode incedendi; femoribus ita reliquo corpori connexis atque coalitis, ut natatui non inceffui queant infervire. Pifcibus quos involat vefcitur, indeque victitat. Prolem in juncetis atque arundinetis educat, nec anatum noftratium vulgarem vincit 
magnitudinem. ckafculus aliquanto longioreft, corpore, collo ac crifta ampliori. Roftrum fœminæ brevius eft, nigrum \& utrimque juxta oculos plumis fulvis redum, cum mas candentibus tegatur. Hæc eftavisilla, quam Indi fabulantur ventos evocare, ubife petiab aucupibus fentit, quibus flantibus turbatifque undis evertantur monoxyla, illamque infequentes fubmergantur, fi quinque prius fagittis excuffis arcu non contingat attingatque trucidari. In ejus diffectix corde reperiri gemmam arbitrantur ad multa utiliffimam, \& maximo habitam in pretio, nec alii quam Deo confecrandam. Verum hx sugx funt, \& mendacia ab horum hominum profecta credulitate. Infuavi parumque falubri, velut \& alix aves paluftres, nutrimento conftat: atque ideo à nullo fagacioris palati in cibos admittenda.

Eft \& apud Indos genus quoddam anatis fere (hirundinem Hifpani Indigen $x$ appéllant) tempatlaboac domefticæ magnitudine, quareidem ufurpavit apud Indos nomen; roftro lato eft \& longo, undequaque nigrante. Lingua alba, cruribus palmifque ex pallido rubefcentibus, collo \& capite viridibus purpureis, \& nigro fplendentibus colore, adeoque pavonino aut heliotropix gemmx; oculi nigri funt, \& pallens iris, pectus candens, reliquum vero corpus inferre fulvum, \& binis maculis juxta caudam utrinque candentibus infignitum, fuperne vero femicirculus quibusdam in ambitu ex albo, tendentibus in fufcum; intra vero è nigro in viridem fplendentem.' Alæ initio cyaneæ funt, mox candidx, \& tandem virenti micantes fplendore : earumdem tamen extrema alterolatere fulva funt, alterovero fulgida atque viridia : cauda defuper fubtufque per ambitum candefcit, ceterum inferne nigra, pavonacea vero fuperne. Advena eft lacui Mexicano, \& quale alix lacuftres aves folent præftare alimentum. In Afia quoddam eft genus anatum, quod non immerito quis inter cornicines retulerit, ita voce cornuum fonitum imitantur, quæ inflare folent per difpofitos equos iter facientium duces. Eft ea avis, quamvis inermis. Audax \& ftrenua: quam etiam malos Domones terrere, Turcis perfuafum eft: certe libertatis adeo retinens, ut etjam per totum triennium in corte nutrita, facultatem nacta, libertatem faginx anteponat, fedefque naturales \& fuetosalveos volatu repetat.

\section{De Mergis.}

Nieremb. $A \mathrm{D}$ Mergorum hiftoriam pertinent Hit. Exot. A Mergus Americanus, \& Mergus maximus Farrenfis feu ArEticus. Ille exiguis eft alis, ideo monftrofa. Hic ita à fro defcribitur. Avis marina eft, \& palmipes, anfero domeftico major, aut certe magnitudine illi xqualis : nam à collo qua parte pectori conjungitur, ufque ad oropygium, binos pedes longa erat : cor poris ambitus binorum pedum longitudinem fuperabat. Alæquatuordecim unciaslongx; cauda brevis, vix trium unciarum, collum fere octo uncias longum, ejus ambitus paulo major, caput breve, tres uncias latum, roftrum nigrum, mucronatum, quatuor unciarum magnitudinem fuperabat. Lingua pæne tres uncias longa, nigra, mucronata, cartilanigea, quodammodo carinata, fuperiore parte qua roftri parti connexa erat, parvis dentibus introrfum recurvis utrimque prædita, media autem parte afpera: palatum fimiliter quatuor exiguorum \& brevium. dentium introrfum fpectantium ordinibus conftabat, quibus efcam retineret \& conficeret: nam roftrum dentatum non erat. Totum corpus denfis pennis tectum habebat, qux in pectore, toto ventre, \& alarum fupina parte breves \& candidx, in dorfo autem alarumque prona parte longiores \& nigræ, fingulx tamen circa extremum, geminis maculis albis infignitæ, qux in dorfi quidem lateribus longiores, majoribus, qux vero circa collum in medio dorfo aliifque fupra caudam, minoribus, fic ut alix aliis incumbentes, invicemque tegentes ad maculas illas ufque, eam fere varietatem reprefentarent, qux in meleagride five Numidica gallina confpicitur. Collum velut torque cinctum erat, ènigris pennis conftante : caput etiam fimilibus pennis tectum : qux tamen oculos \& roftrum ambiebant, parvis maculis albis erant diftinctx; fub gutture etiam aliquas parvas pennas albas nigris permixtas habebat : prona fimiliter colli pars fupra torquem illum nigrarum pennarum, ad uncix longitudinem parvis pennis nigris, latera tamen alba habentibus, erat ornata, quemadmodum \& ea pars qux infra torquem in pectoris ateribus, infra podicem, nigrarum pennarum transverfam lineam habebat, quas albæ fubfequebantur, deinde fub cauda aliæ nigrx albis maculis notatx. Crura habebat in extremo corpore fita, paullo longiora tribus unciis, plana, nigra; pedes quatuor uncias longos, plufquam treslatos, nigros tribus digitis preditos (quo. rum interiores tribus articulis conftabant, breviorefque erant, medii quatuor, exteriores quinque ) nigra membrana fimul connexos ad ungues ufque, qui plani. Singuli etiam pedes, in pofteriore parte paullo fupra inflexionem, parvum articulum inftar calcaris habebant. Circa Farrenfem Infulam, quæ inter Norvegiam \& Islan- 
diam fita, captam hanc avem fcribebat /res factx, circulum egregic repræfentant. Hojerus, fortum in undis educare, nec ni- Collum cum ventre albicat, dorfum cum fi procellofo mari ac circa Autumnum, aliis cineritii eft coloris, extremitas tanhiemifve initium confpici, terram vero dem in albạs definit plumas. Pedescum nunquam attingere, nec volantem un- adnatis membranulis, femicirculis diftinquam effe confpectam, adeoque nec ala- Ctis albicant, ubiin quolibet pede unicum rum ufum habere ad volandum, nec pe- tantum unguem animadvertere licet. De dum ad incedendum : quo fit ut nonnifi Hirundine Exotica aquatica hrc habet : Quis capite extet (eo referente) quando fe con- non in volucre paluftri fummam colorum fpiciendam præber. Huic non valde diffi- varietatem miretur. A capite enim inmilis videtur mergus ille marinus, cujus choando, fuperior pars, candet, inferior meminit Gefnerus in Paralipomenis ad rubro intermixto coruleo colore fplendeHiftoriam de Avibus pag. 767. nifi illi in fcit. Venter inferior floccorum nivis indorfo cinereas plumas nigris maculis con- ftar albicat. In dorfi principio pennæ duæ fperfas tribueret. Huic fimilis eft aqueus lepus, cujus jam meminimus: Iconem vide apud Clufium.

\section{De Firundine.}

C

Laudat agmen Avis cucullata aquatica. Hirundo Exotica aquatica \& Gallinago filveftris aquatica. Quas in fuo Gazophylacio rerum Naturalium defcripfit, \& ære exprimi curavit Nobilifimus D: Doctor

Befer. in Beslerus, Amicus nofter plurimum honoGazophy- randus. De illaita fcribit: Animal hocce capitc monftrofum, in aquis natare ex decubitu naturali conjicere licet.: Comam quam in fronte cernis, ferruginei eft coloris. Ex parte maxillarum plumæ flavefcentes repullulant, qux in extremitaté nigrio-

nigricantes, albis punctis diftincti exfurgunt. Alias dorfum univerfum, una cum cauda ferruginei coloris; alæ quidem nigricant, punctis tamen niveis ornamenti inftar diftinguuntur. Pedes exporrecti fubfufci coloris, roftrum nigricans, ad furbulx formam effigiatum, quo pifces quafi hamo excipere folet.

\section{$X I I I$. De Gallinagine.}

D E Gallinagine Sylveftri aquatica, ita idem paucis : Rara hrceft avis, in locis paludofis victum quxritans, colore atro $\&$ rufo, per totum corpus inftar holoferici fplendefcente, roftrum oblongum, quodammodo incurvatum, crura alta \& fufca, digitos longos habet.

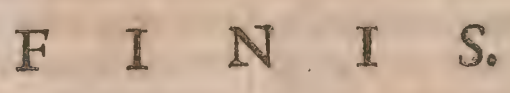




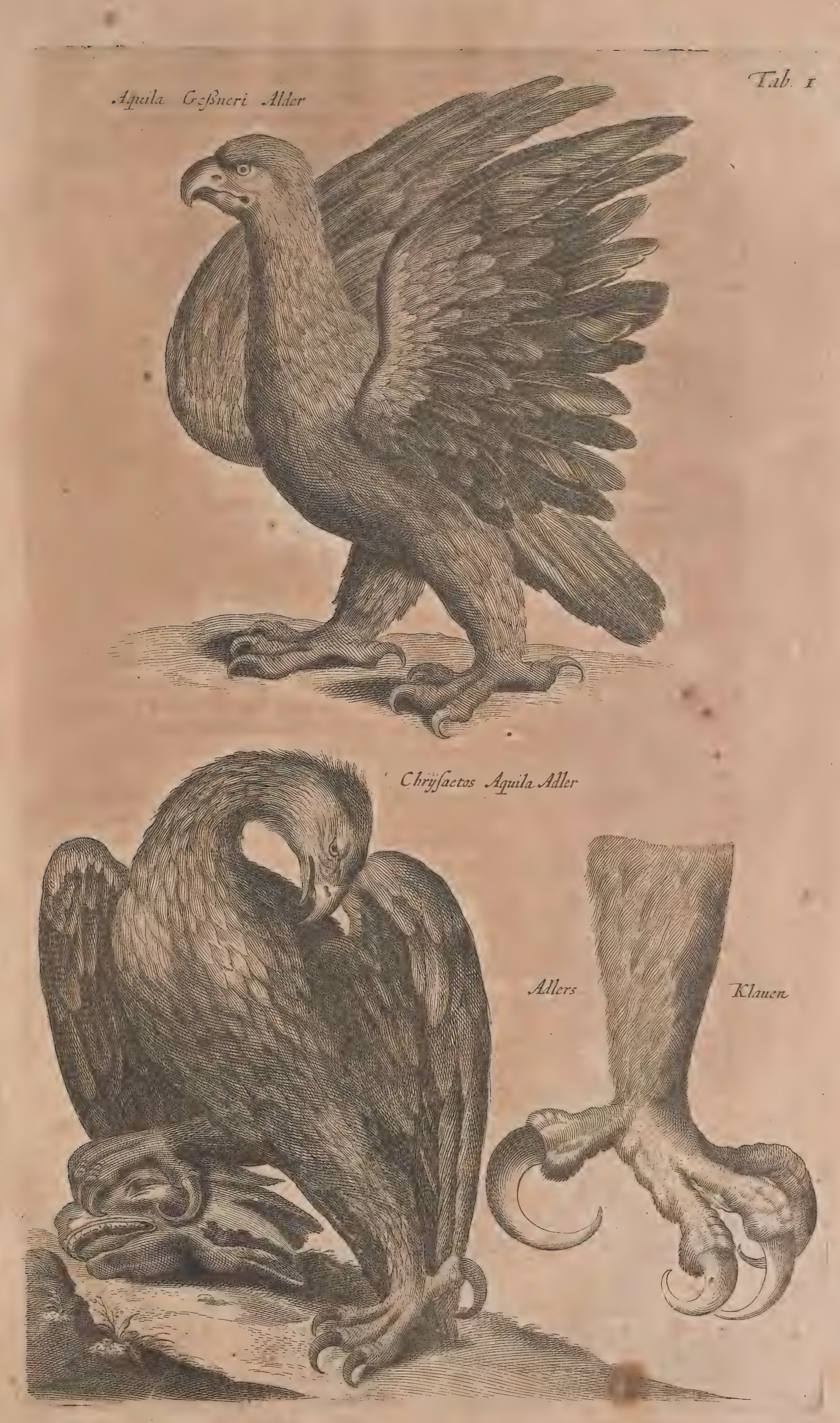




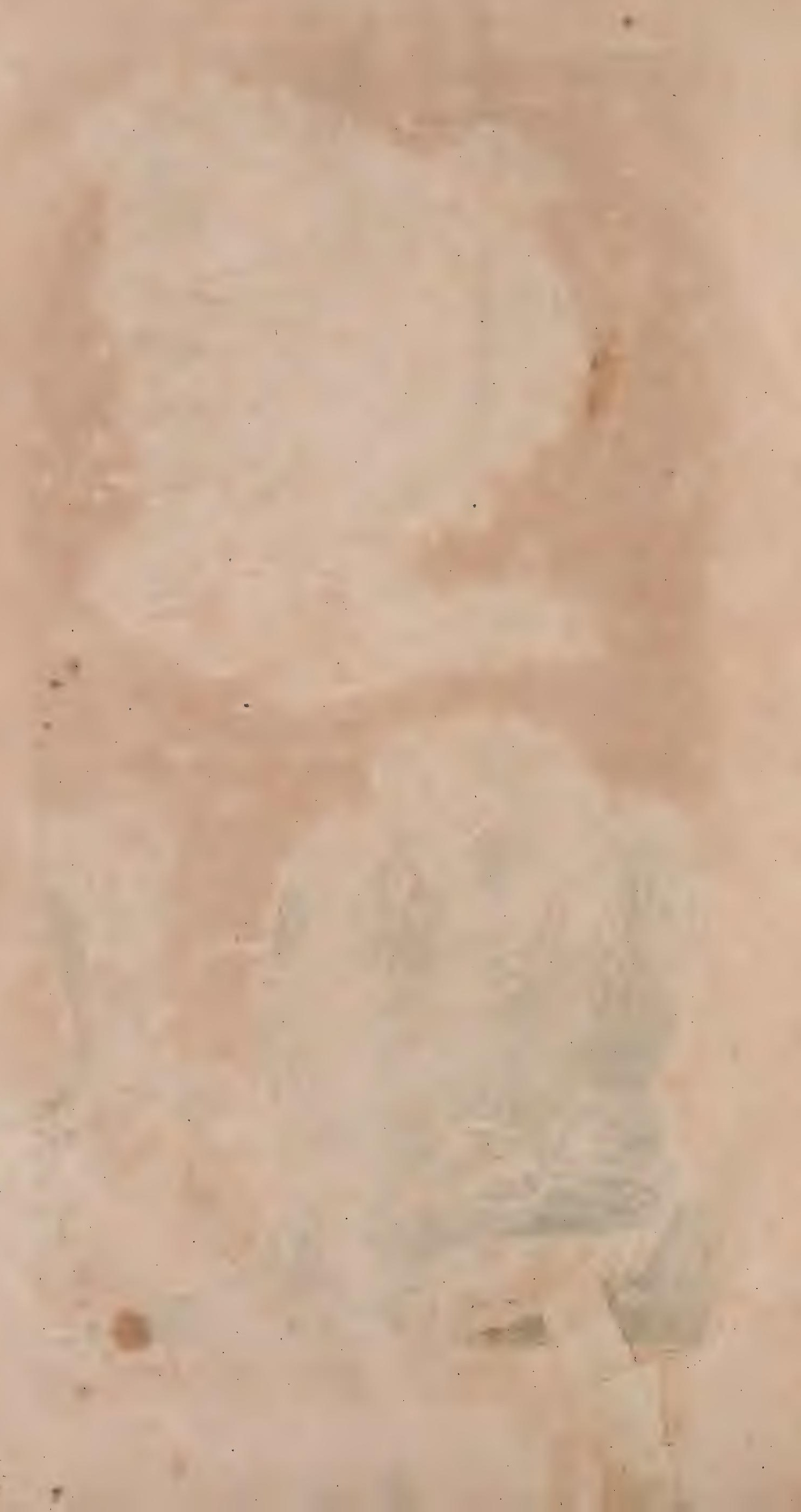




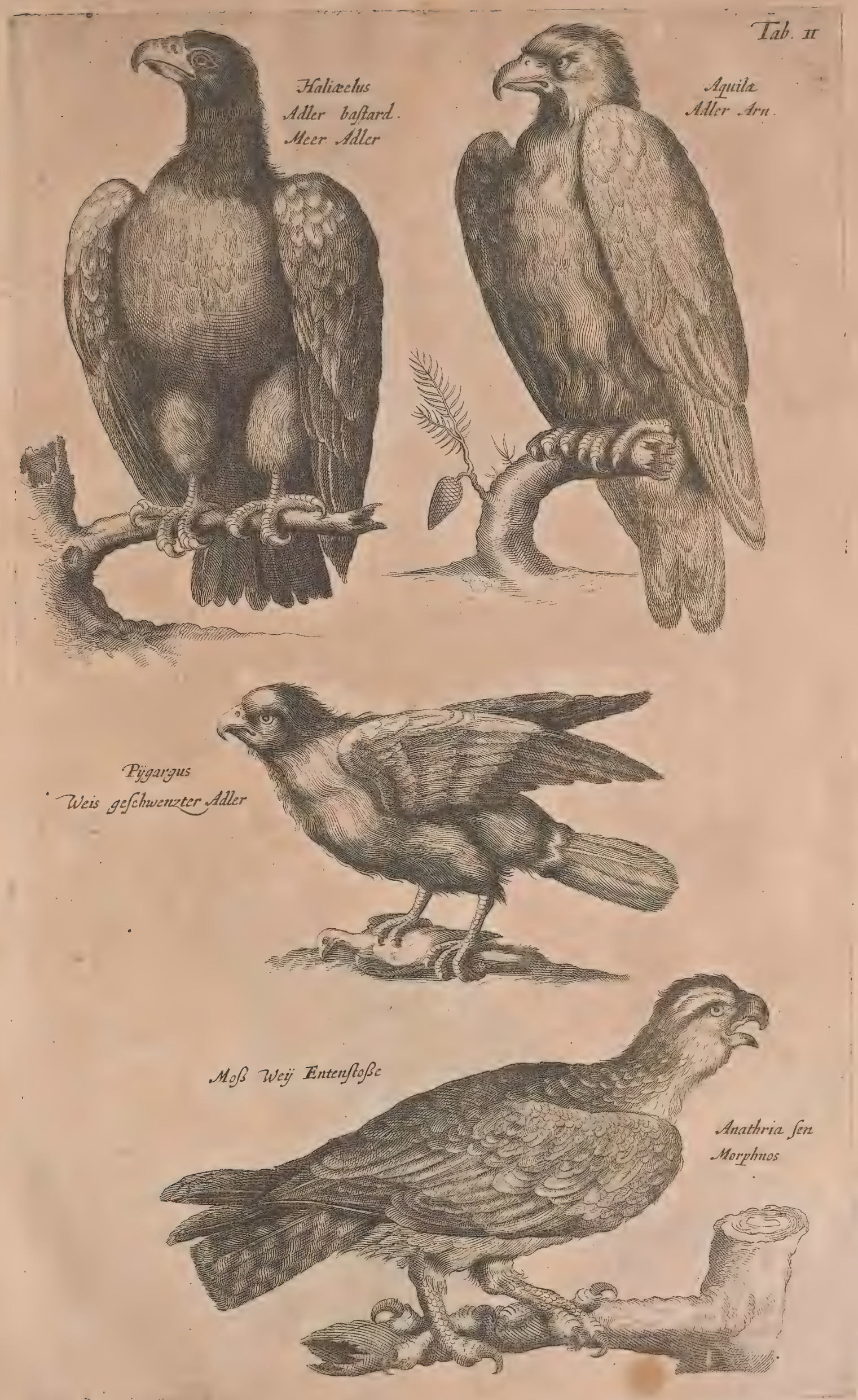



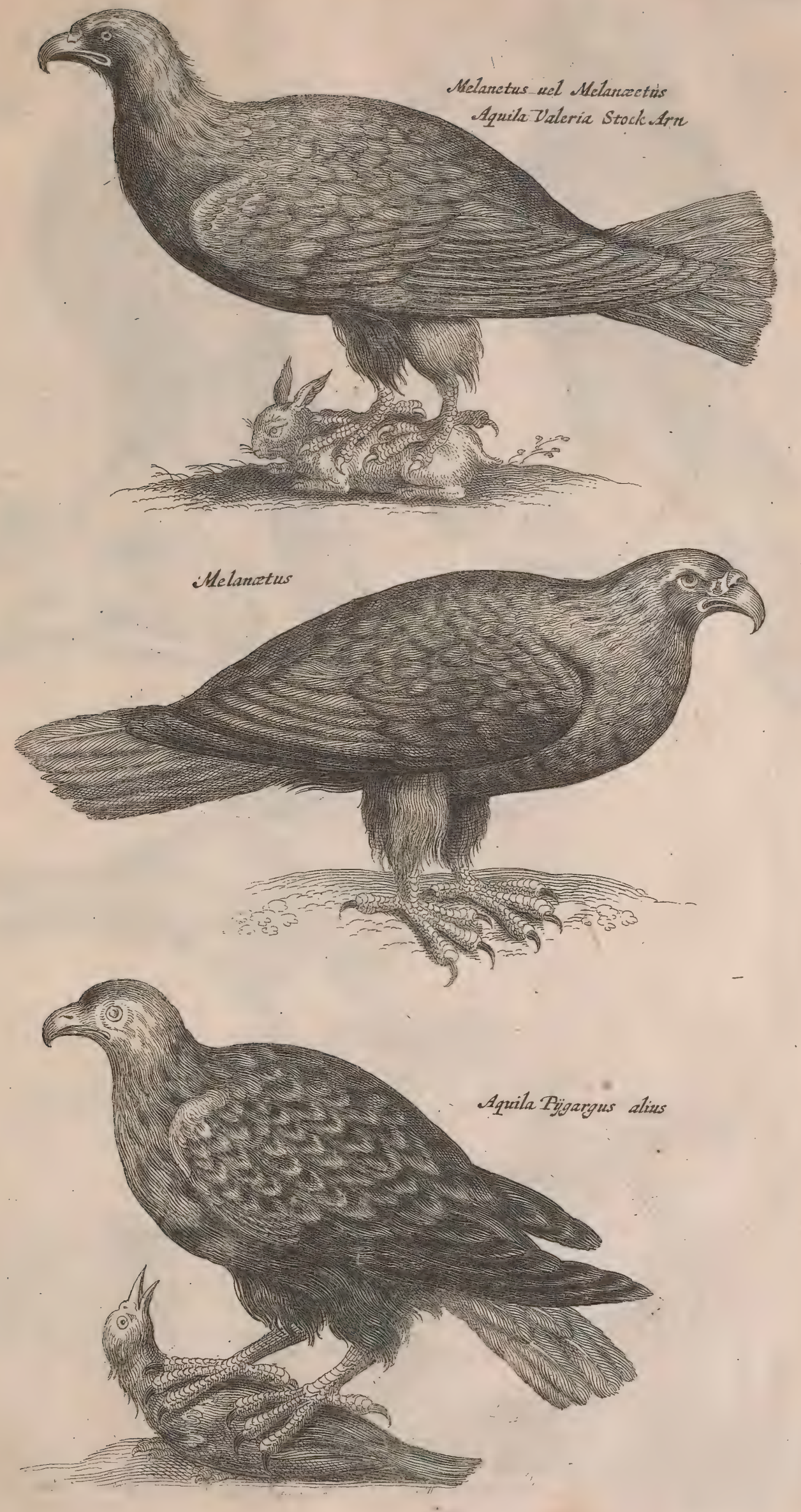

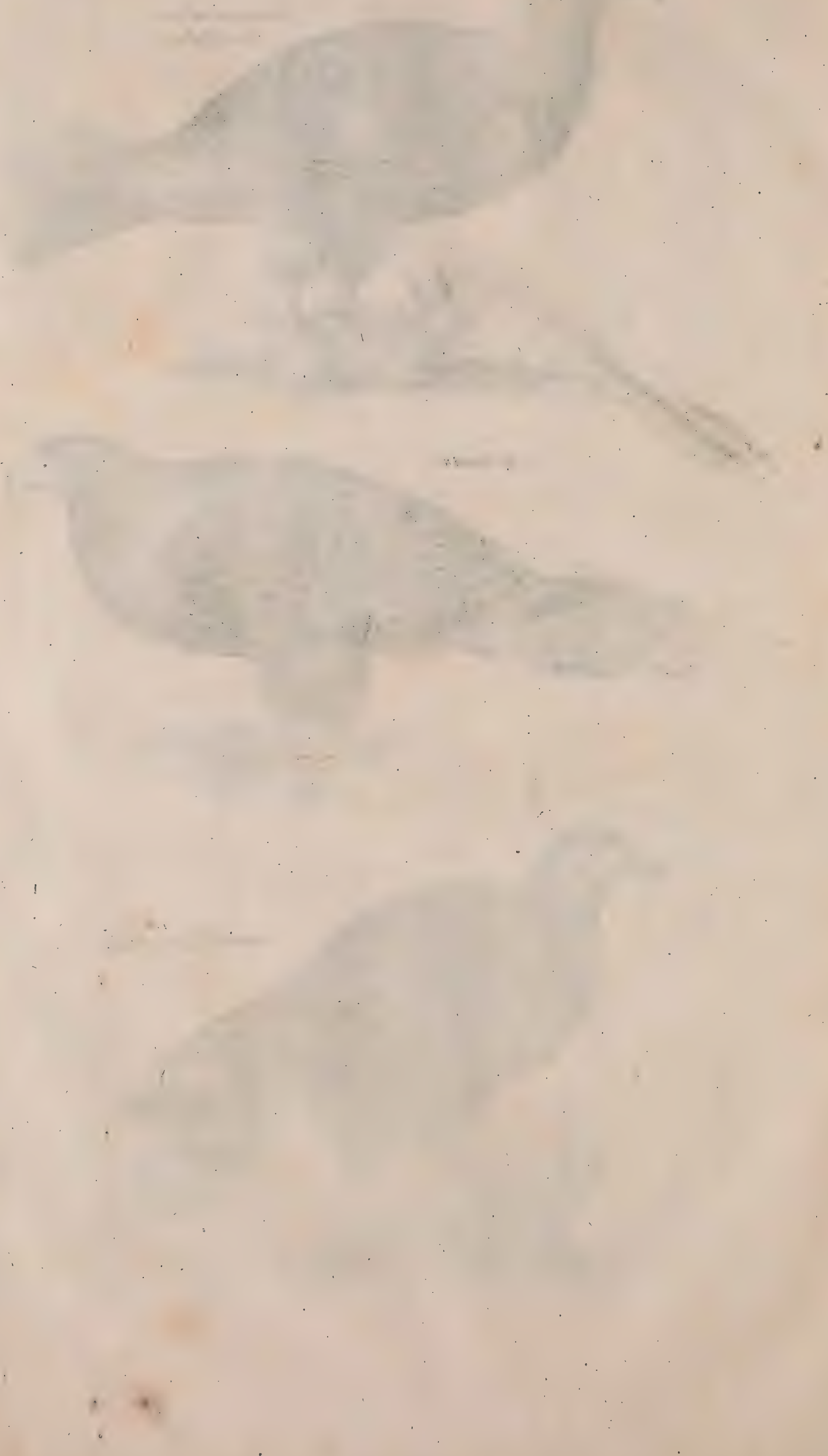

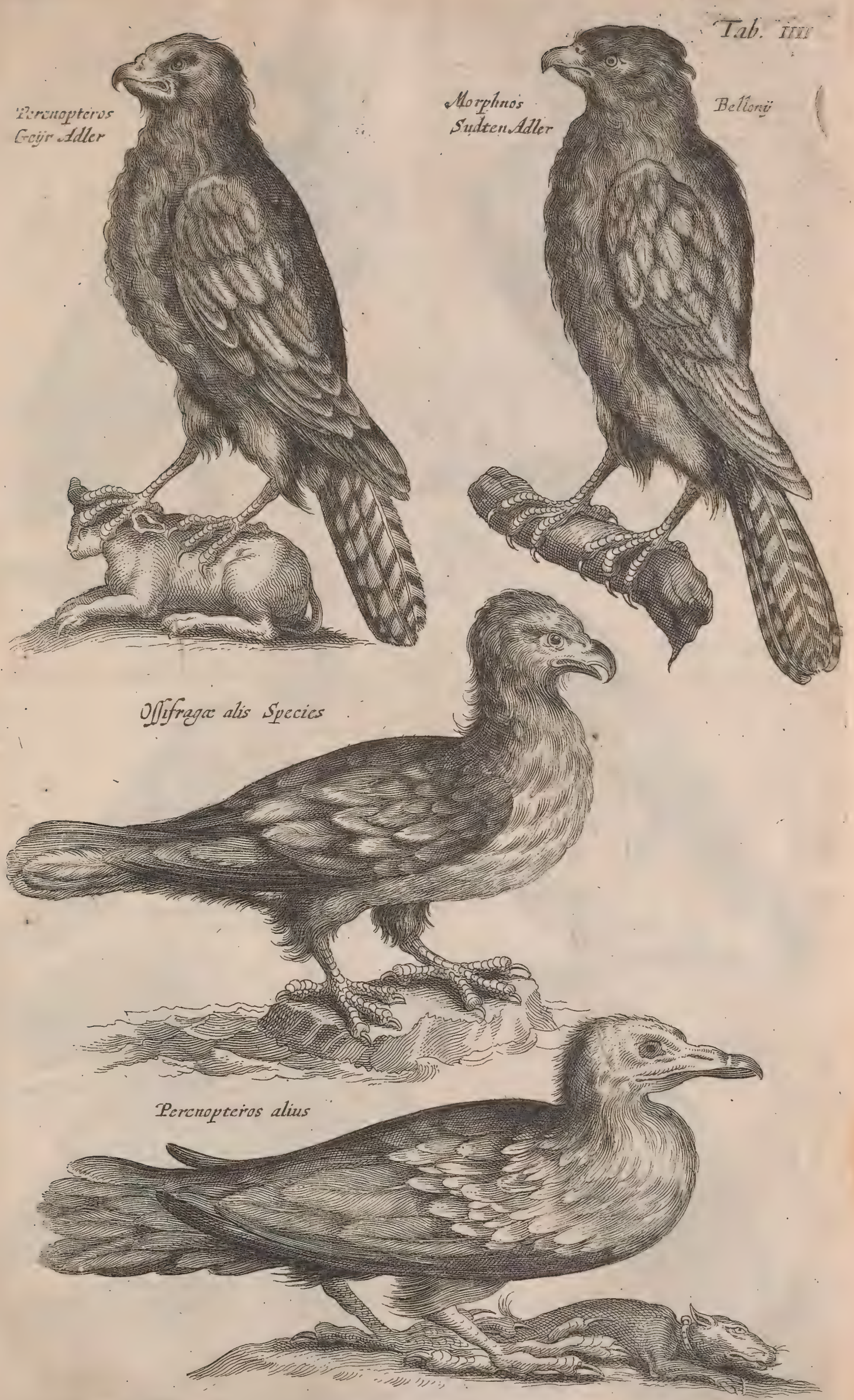



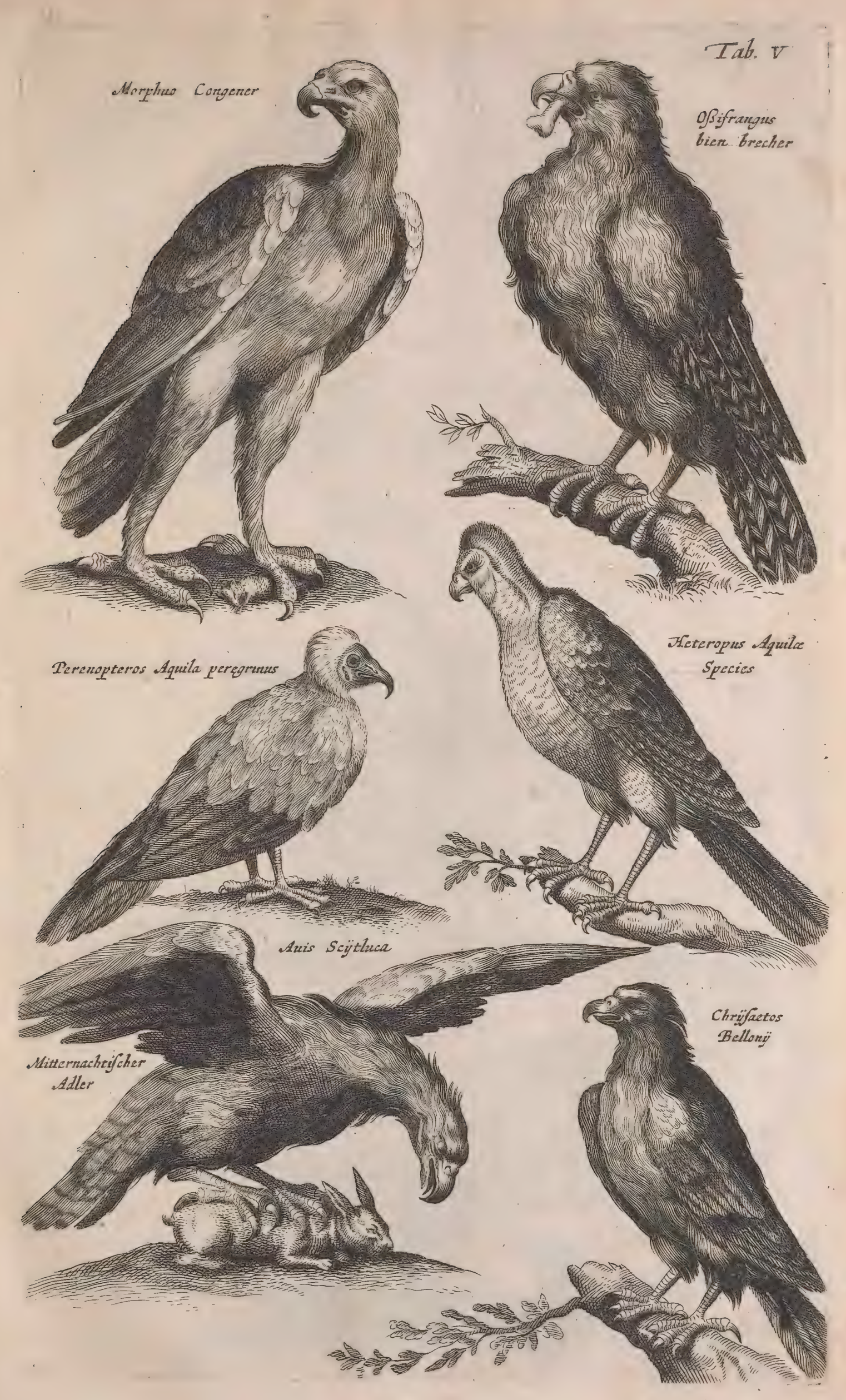





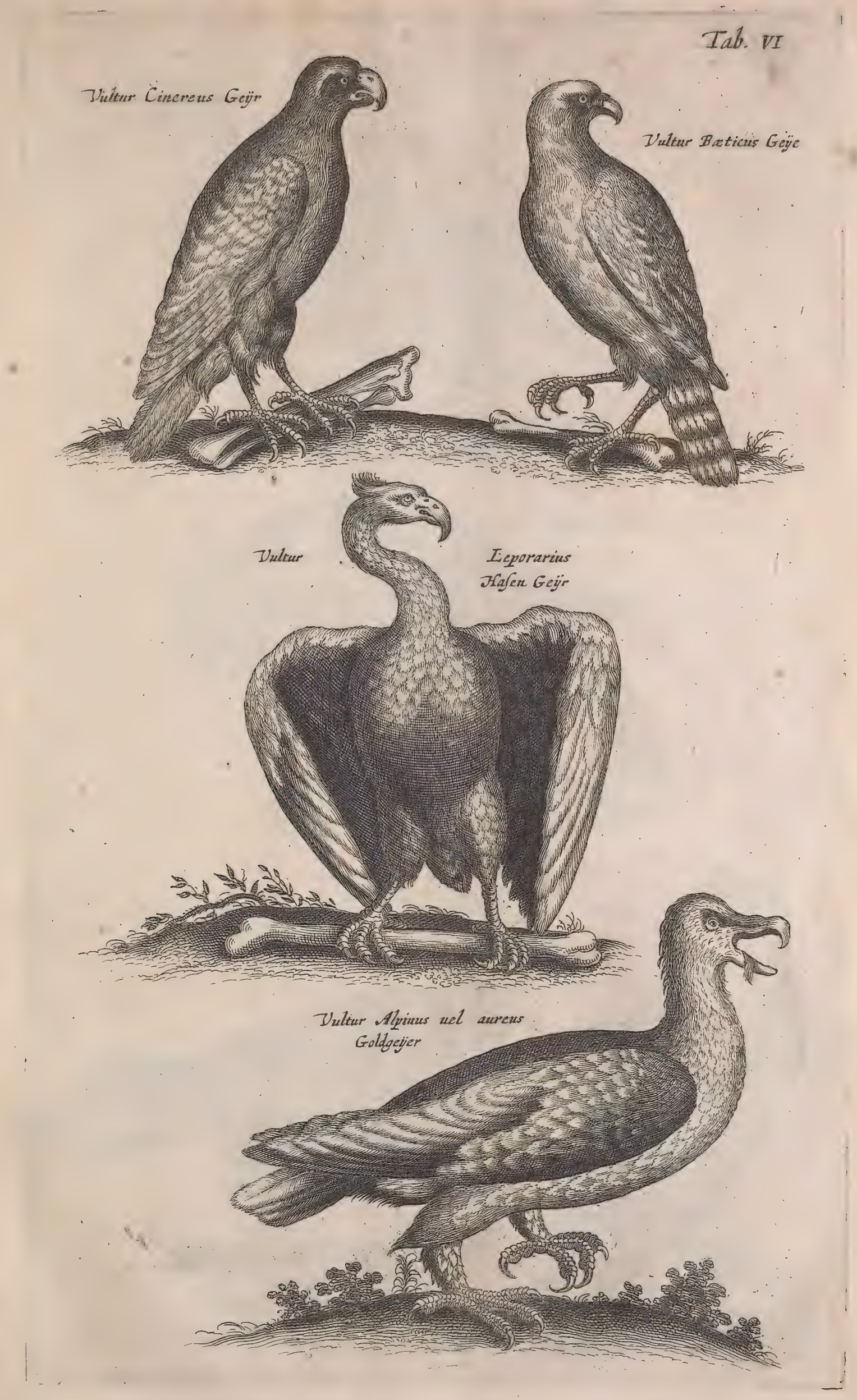




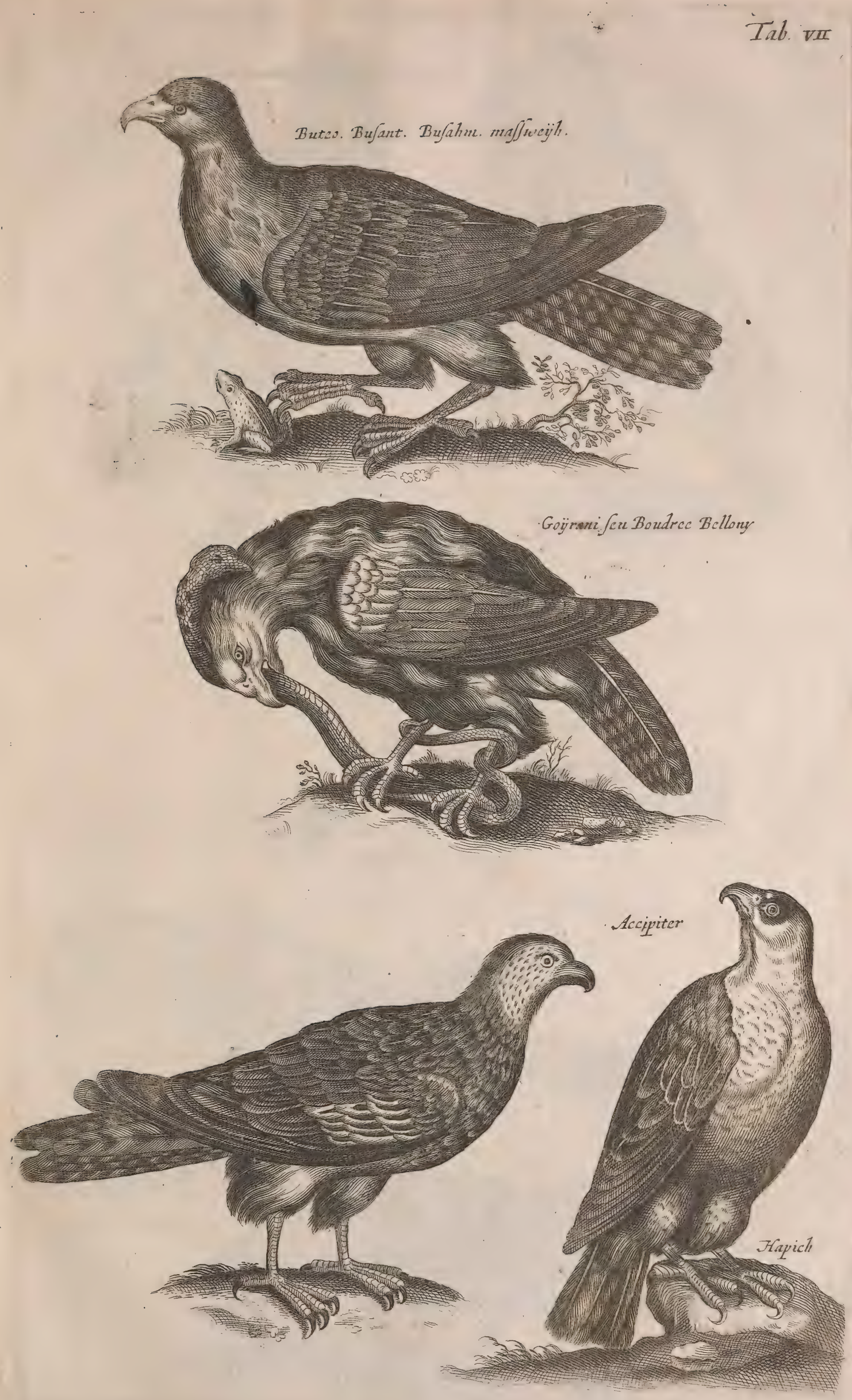


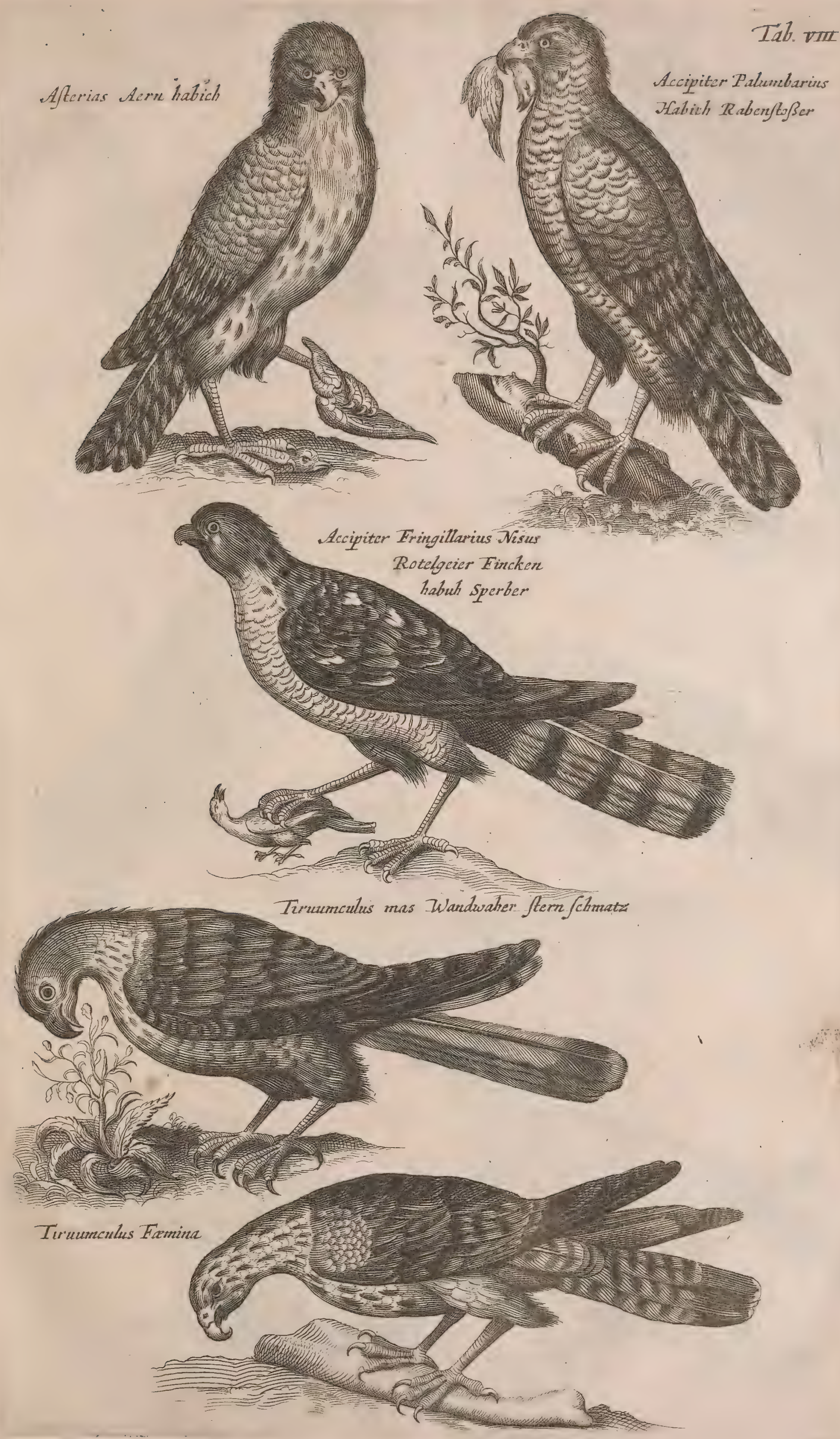


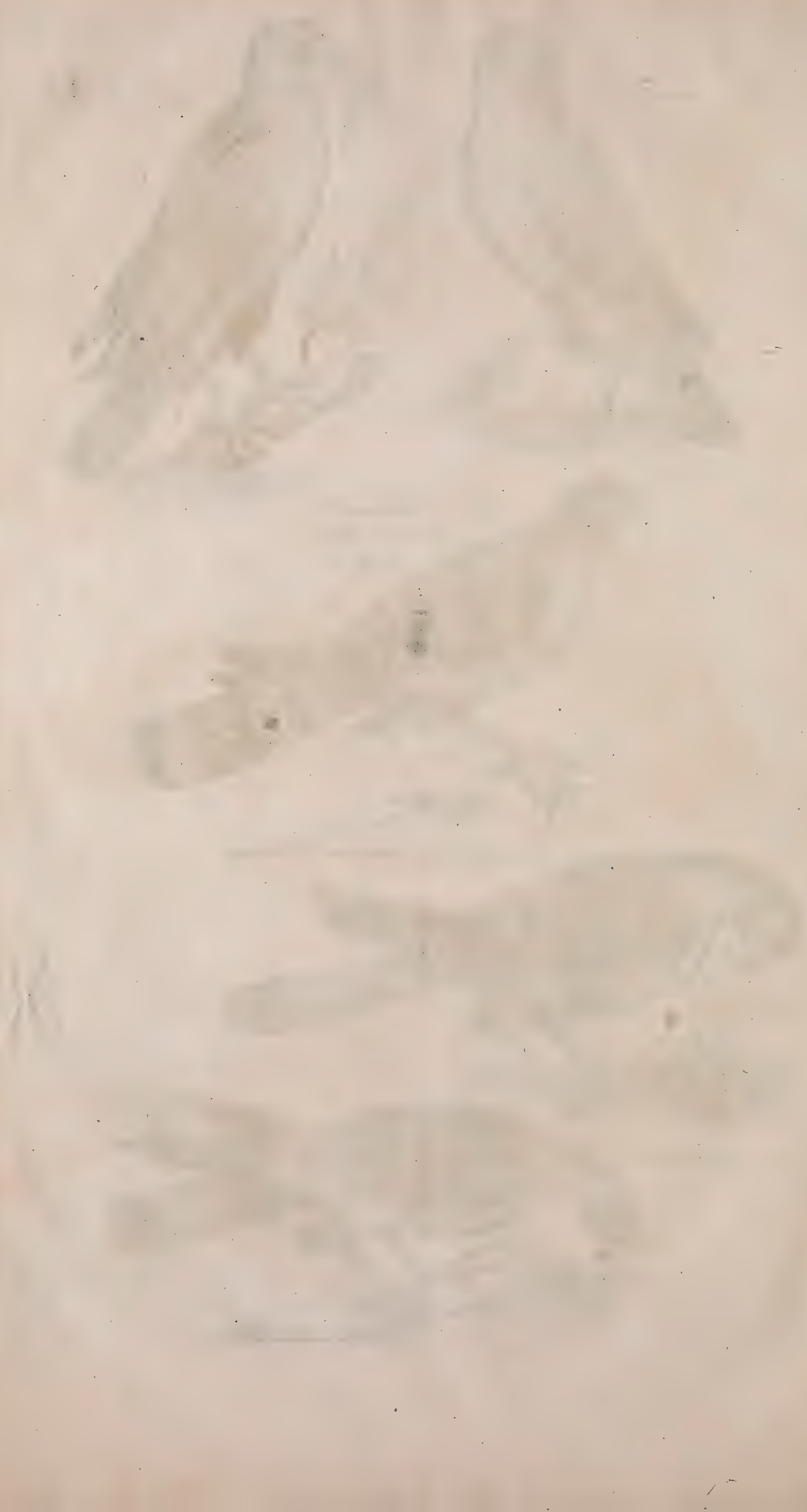




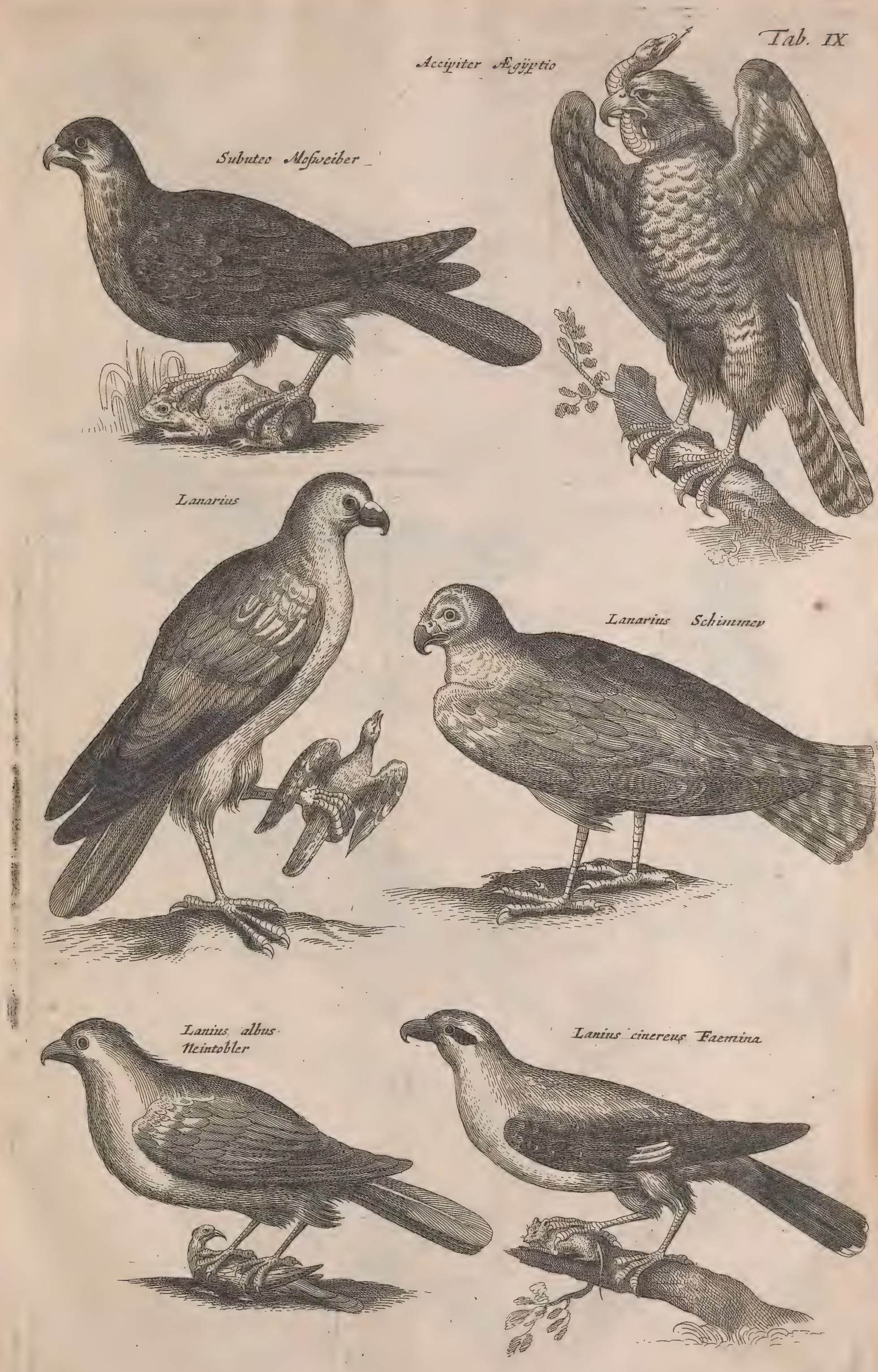





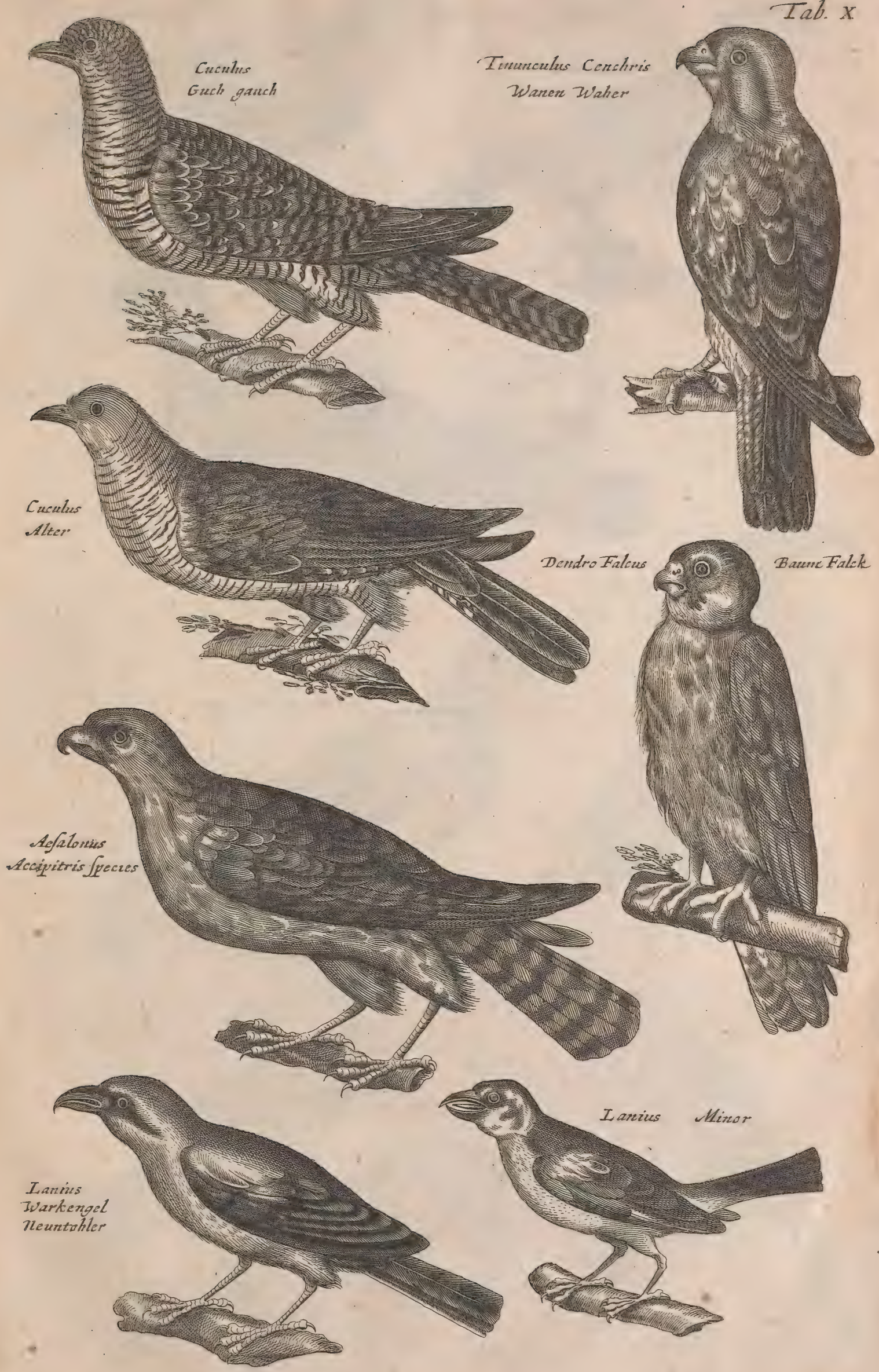





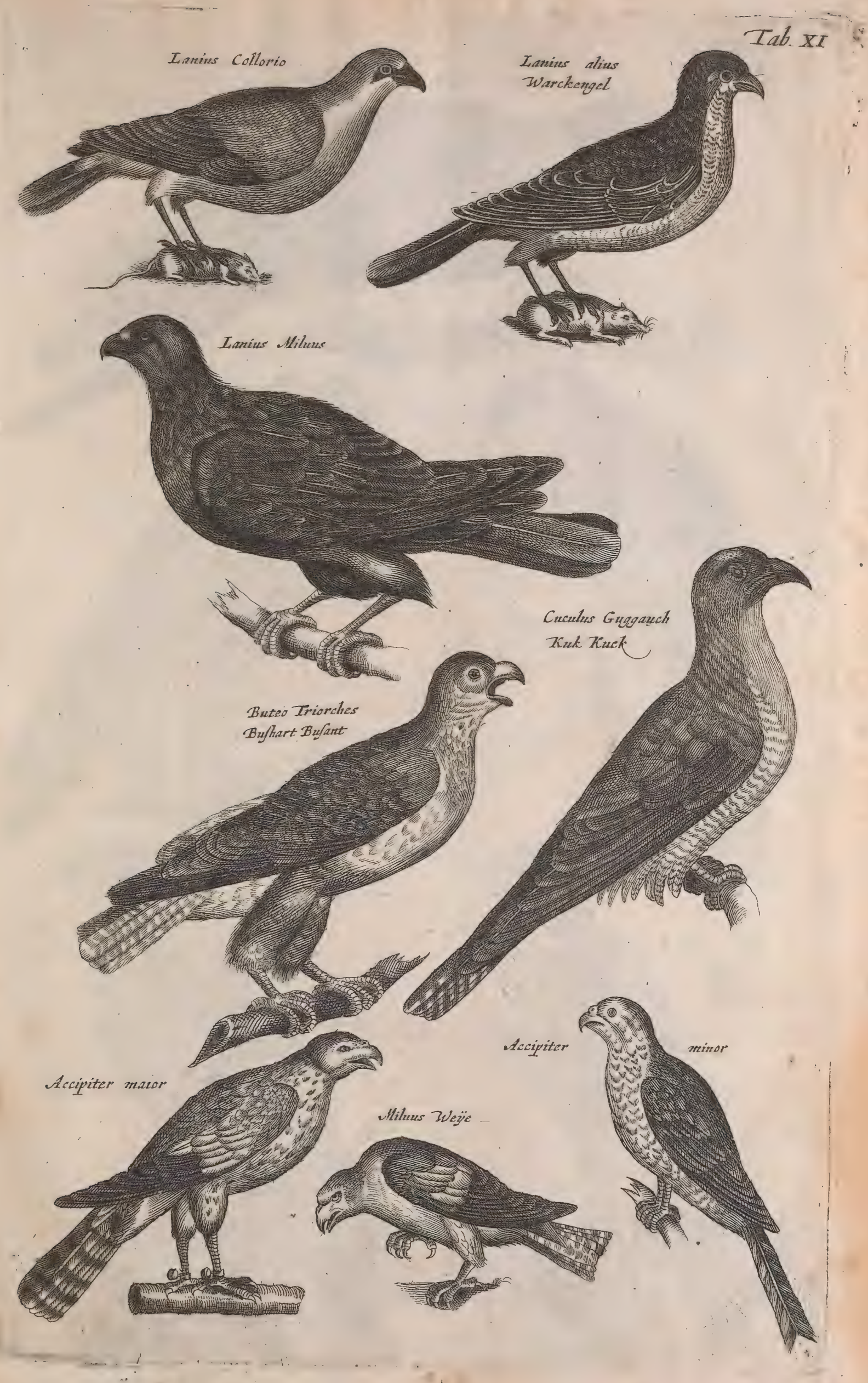


w
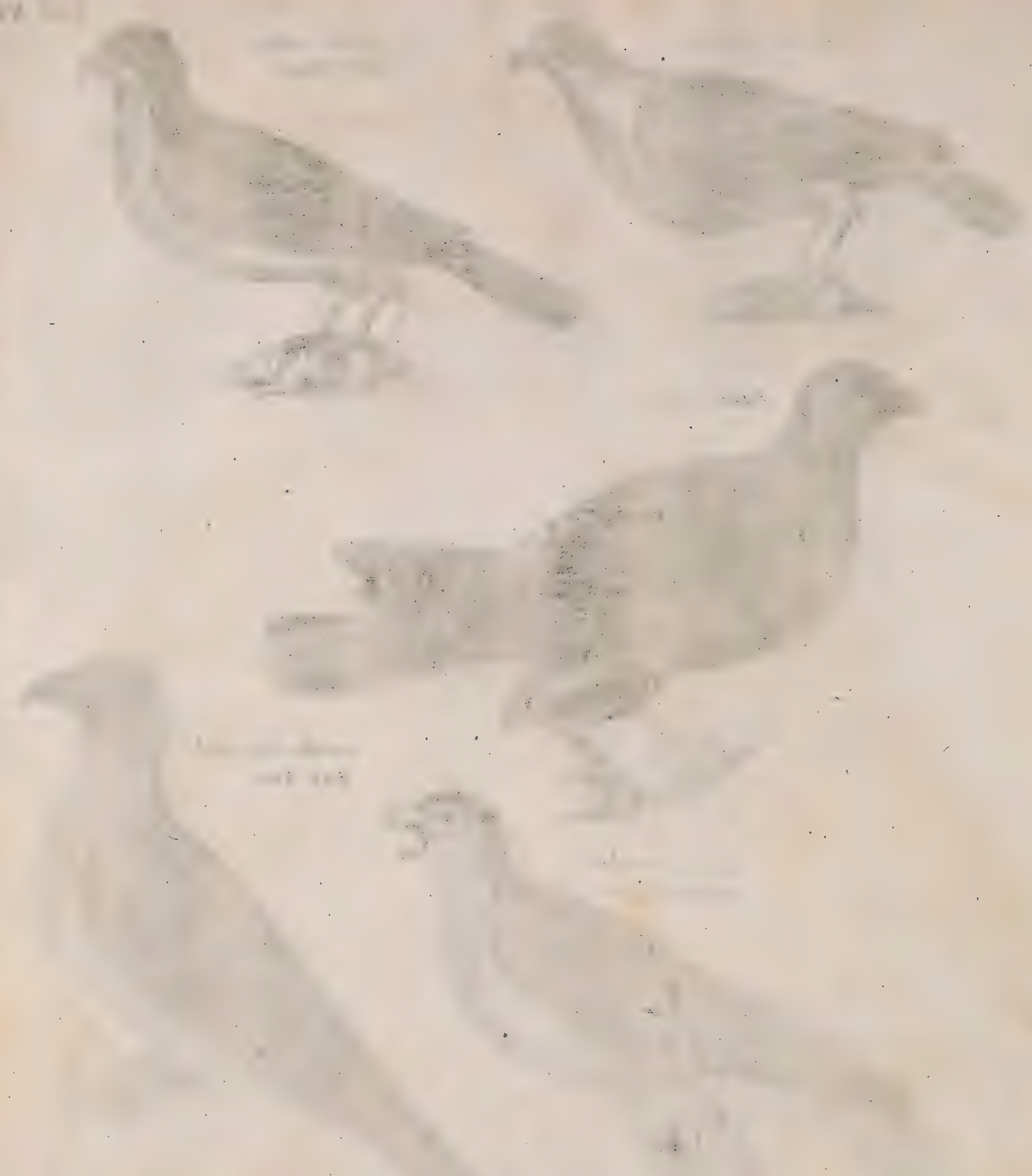

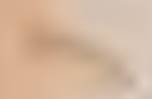

.

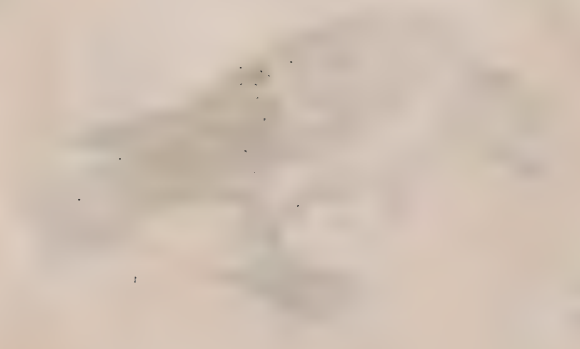




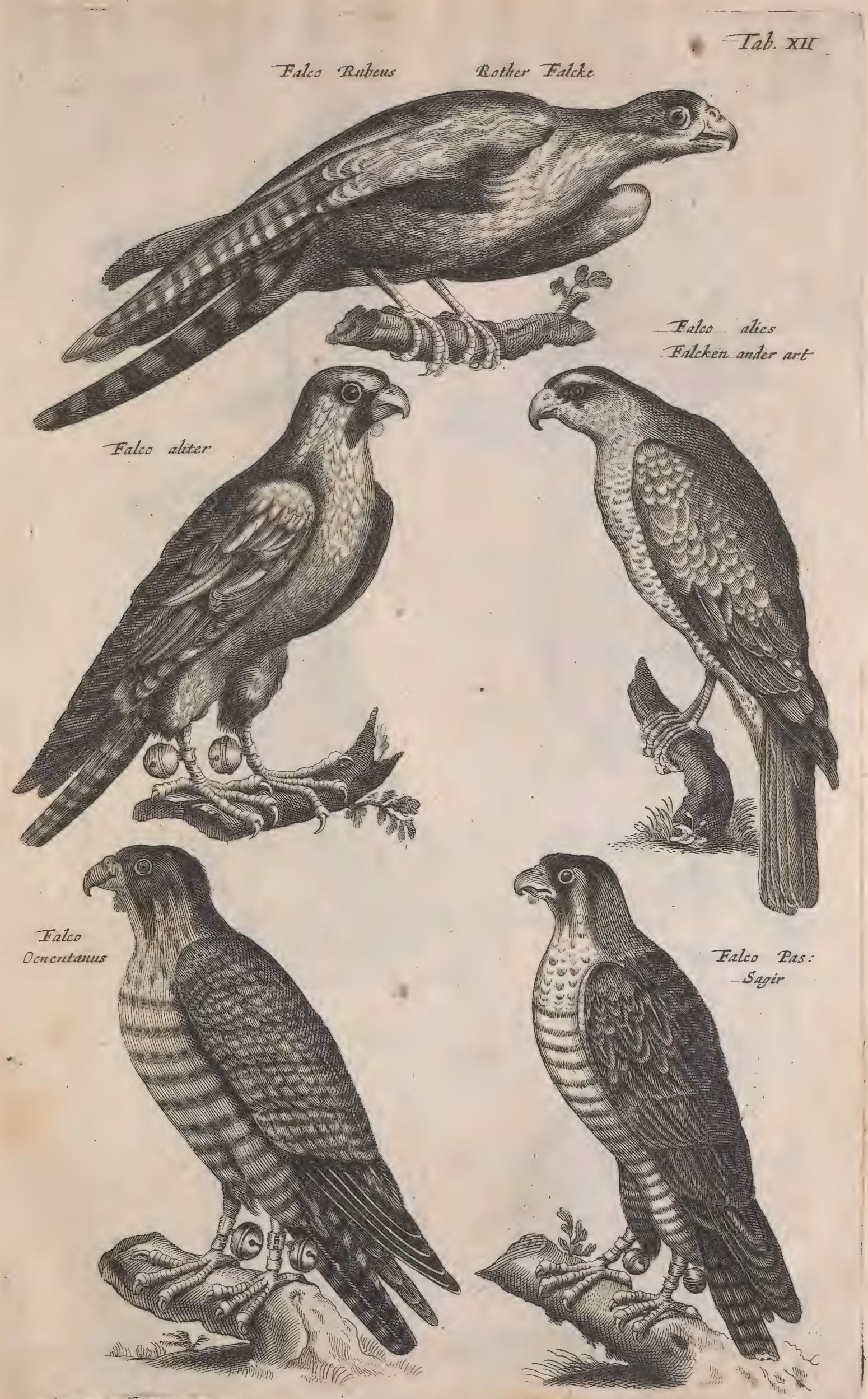




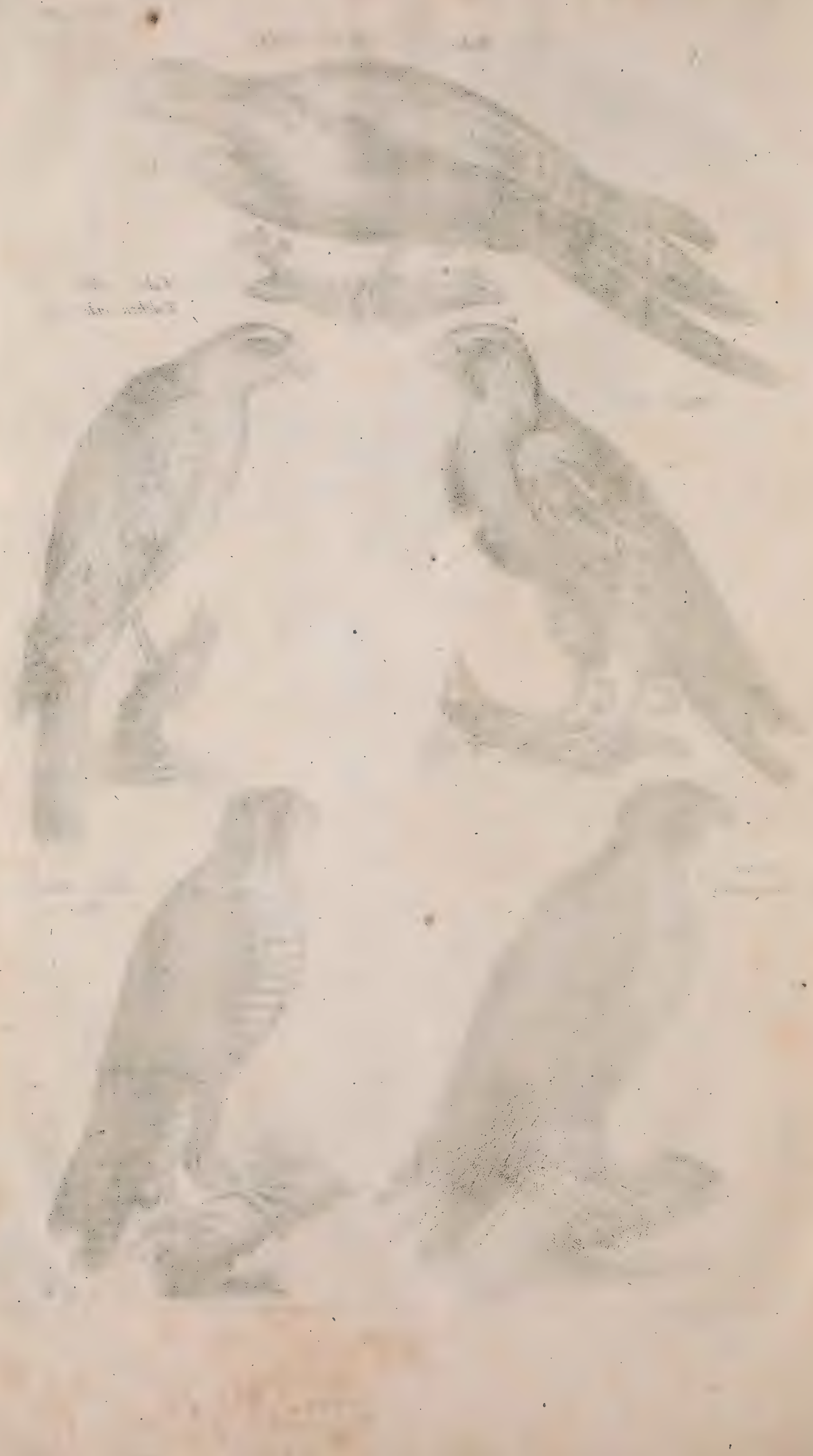




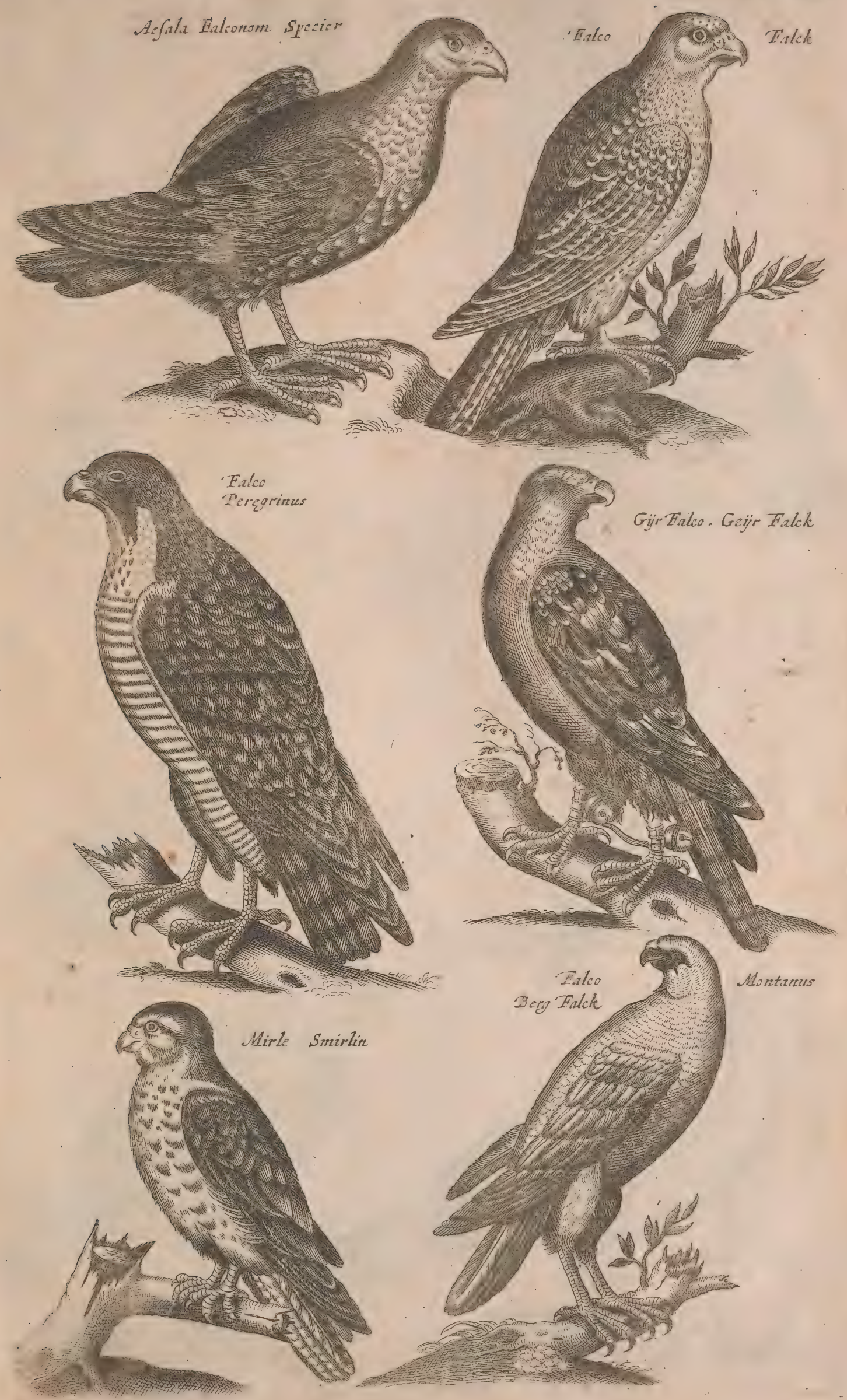



4)

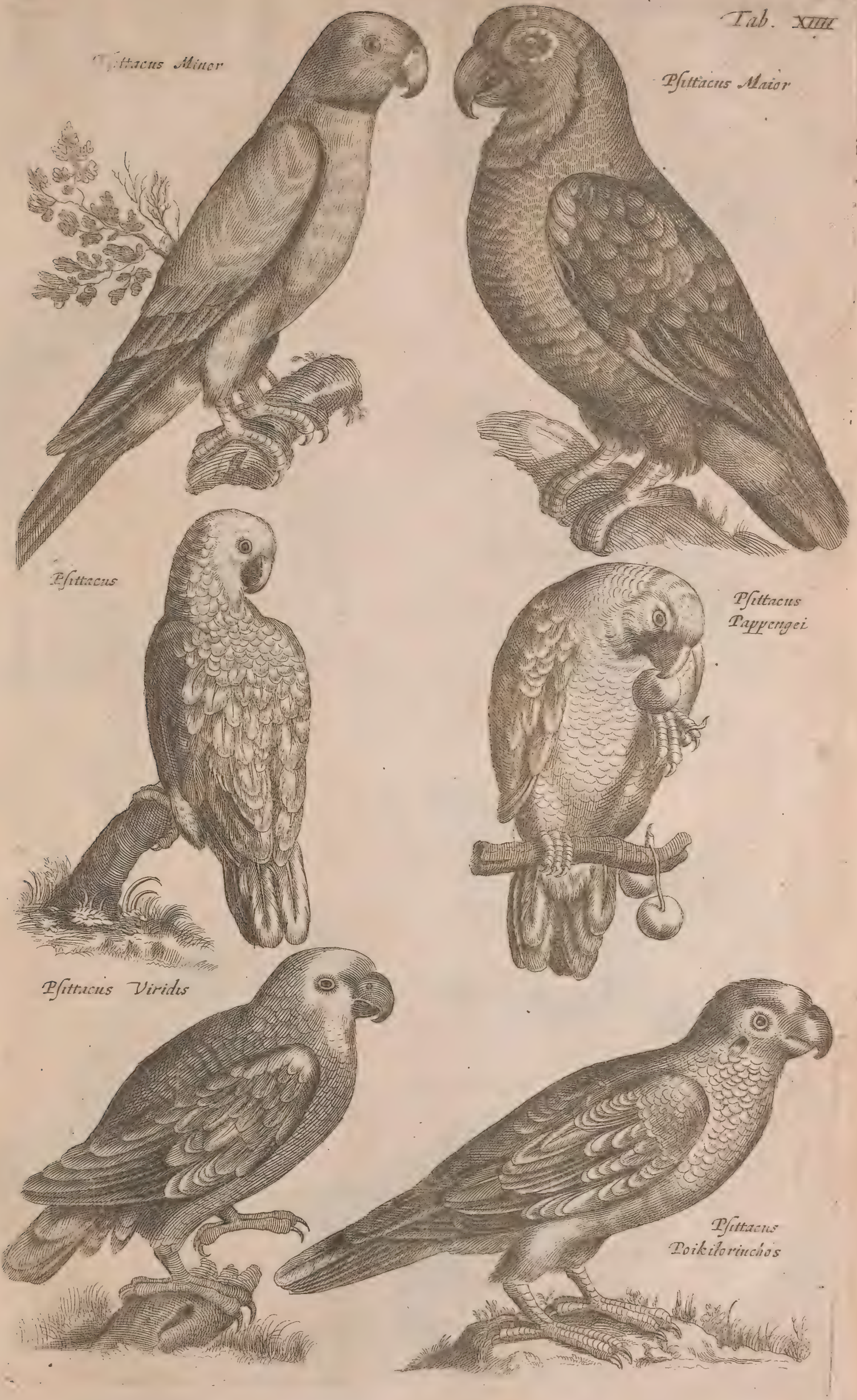





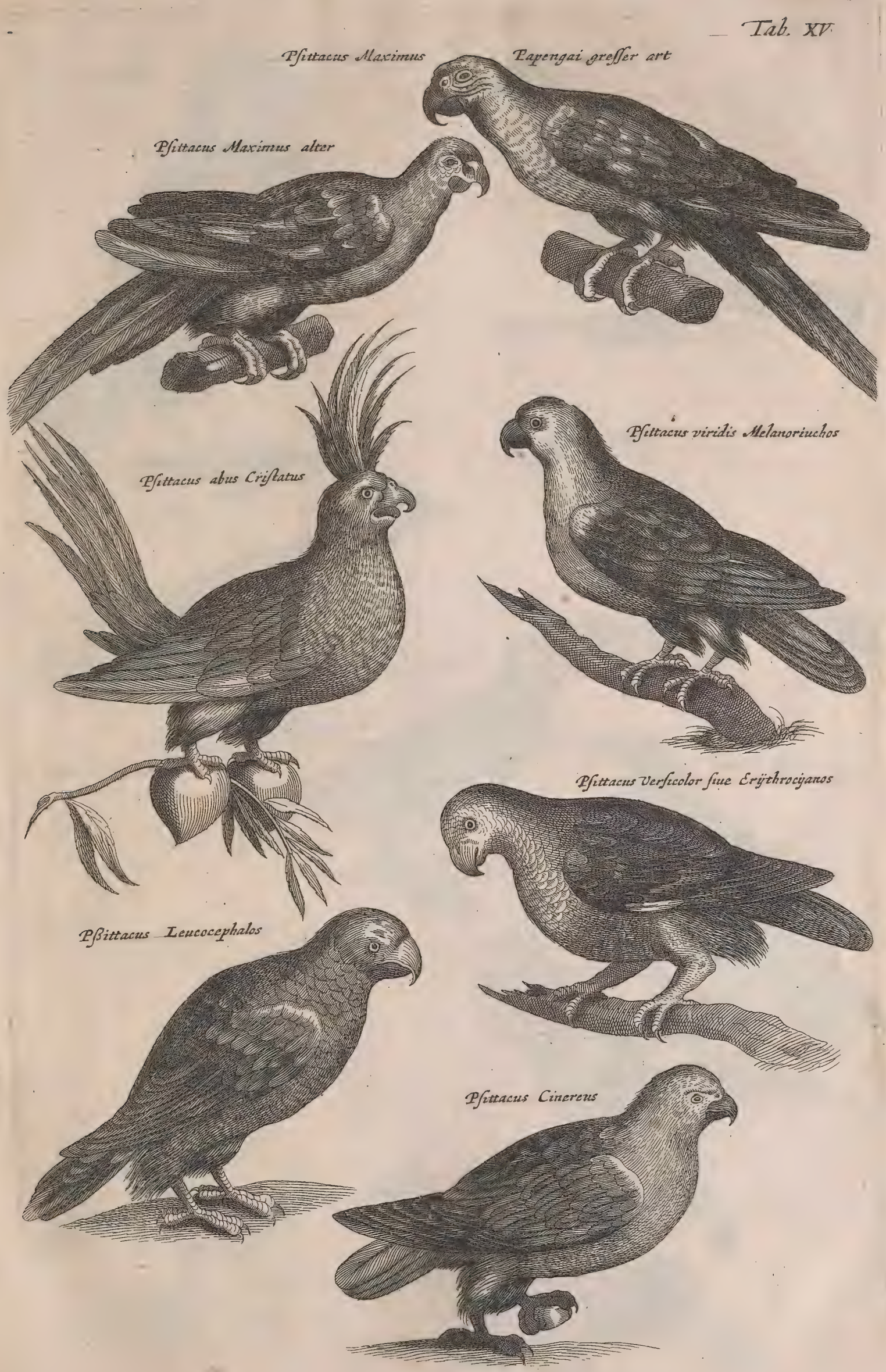


t

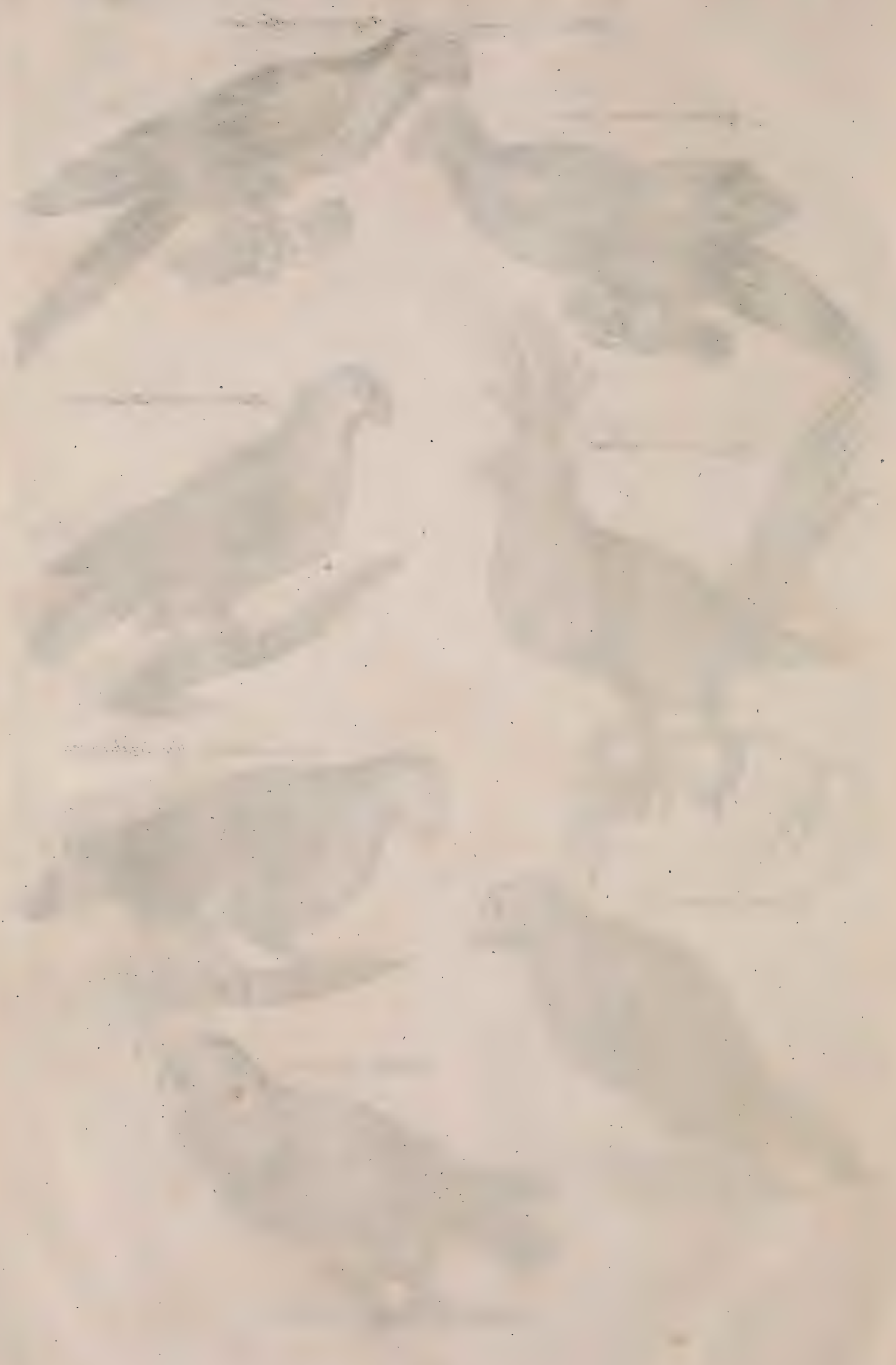


Tab. XVI
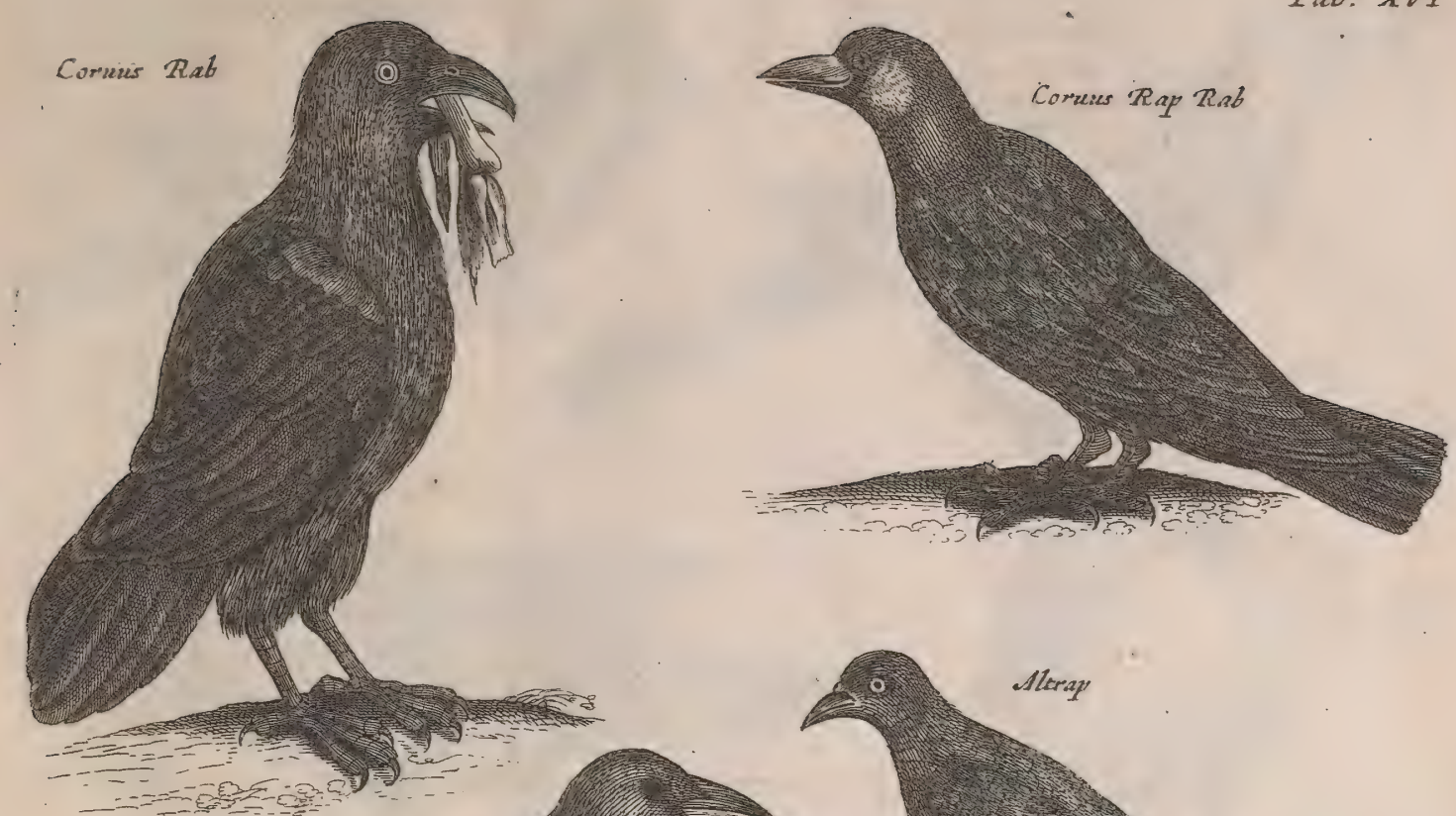

Cornix Kirae

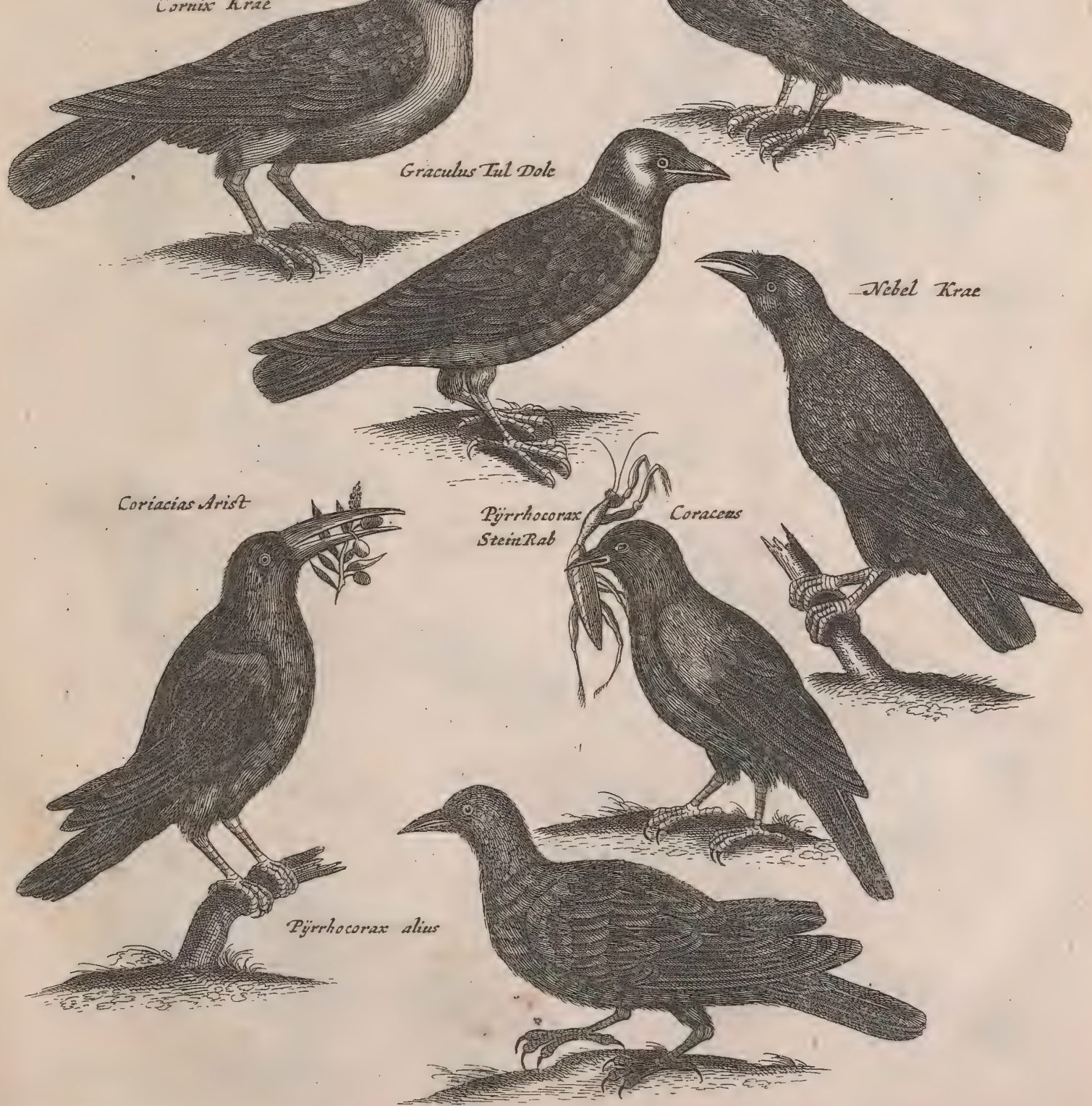





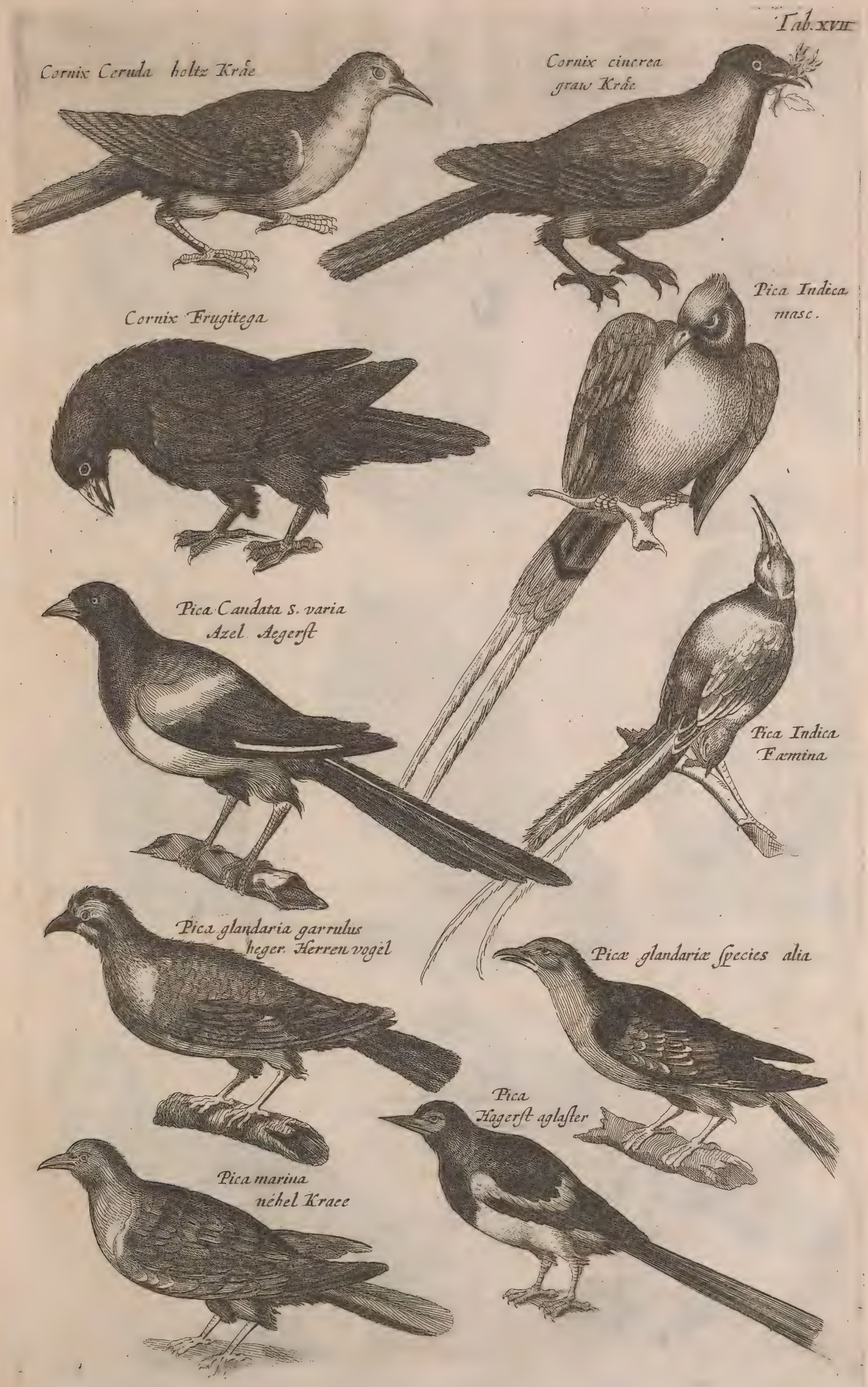


w

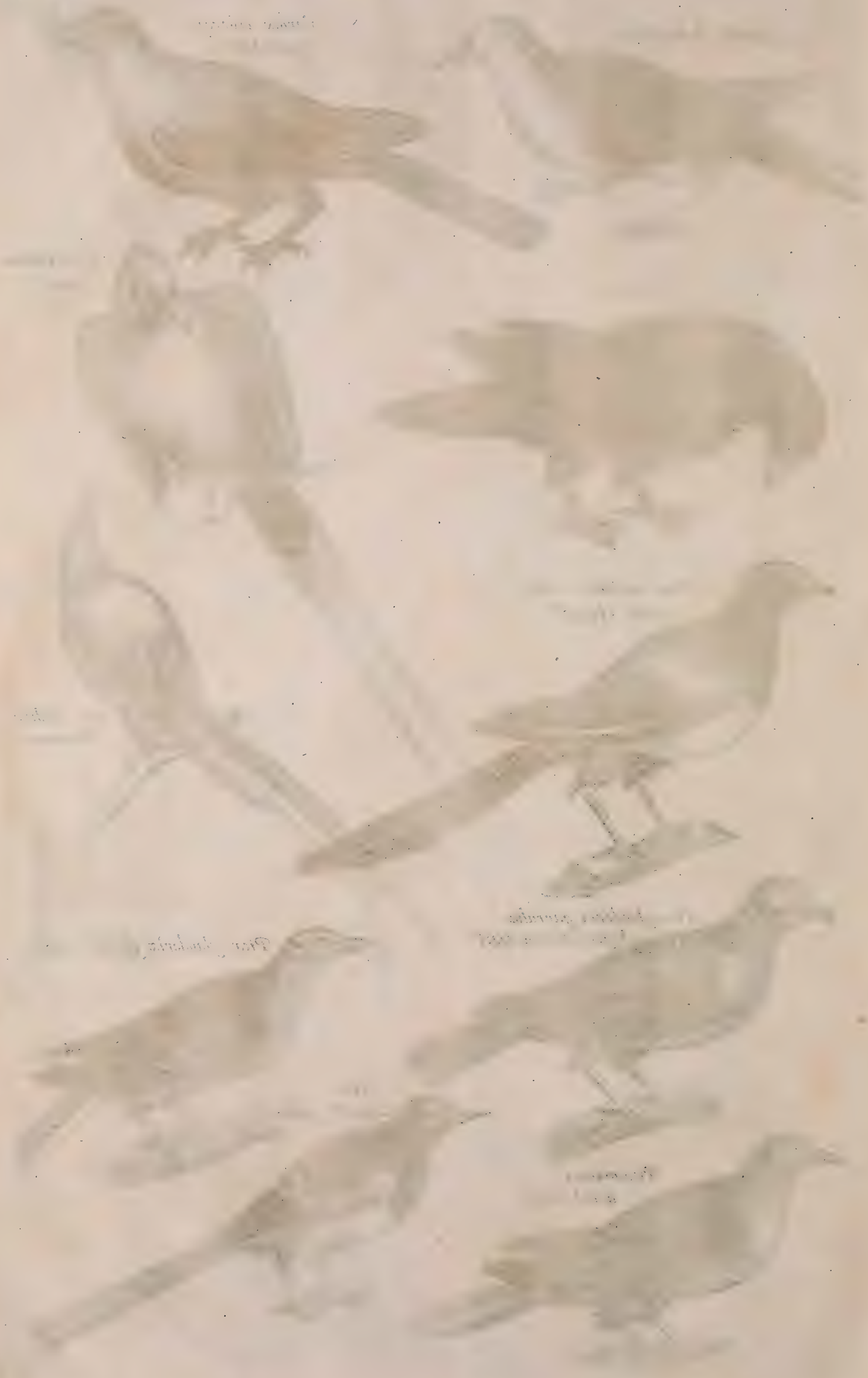



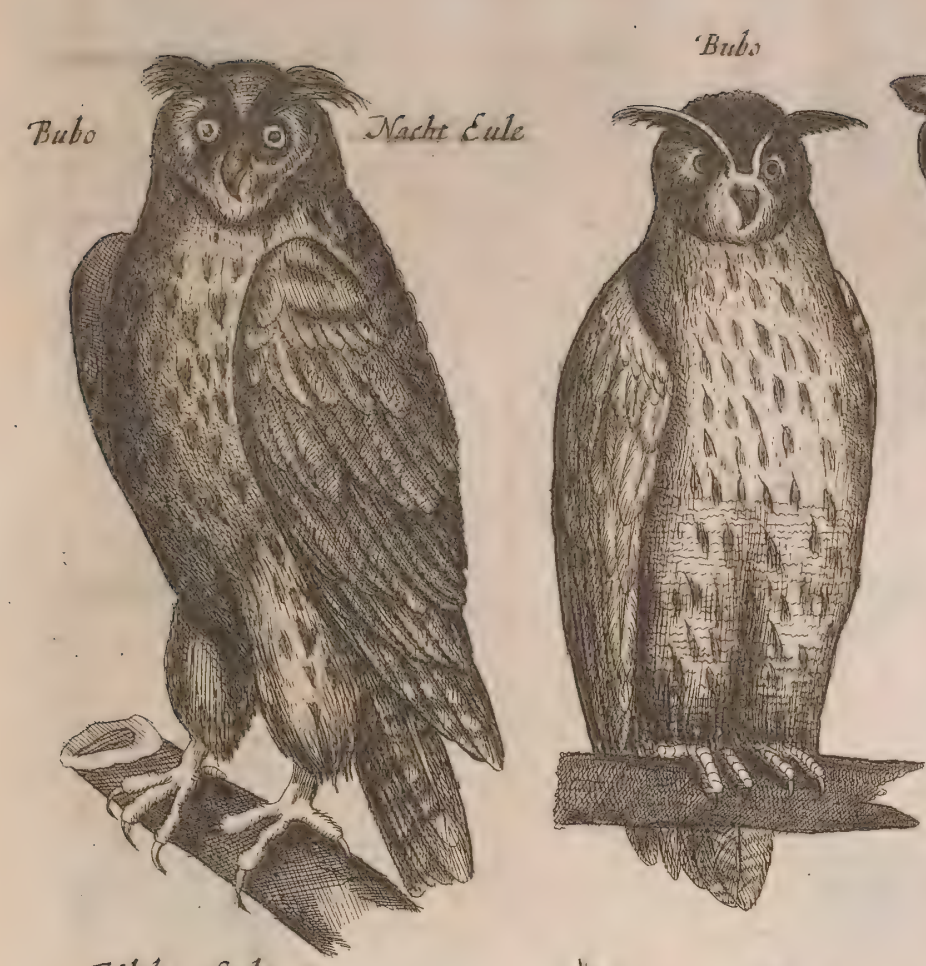

T.ab ximt

Vluta Ente
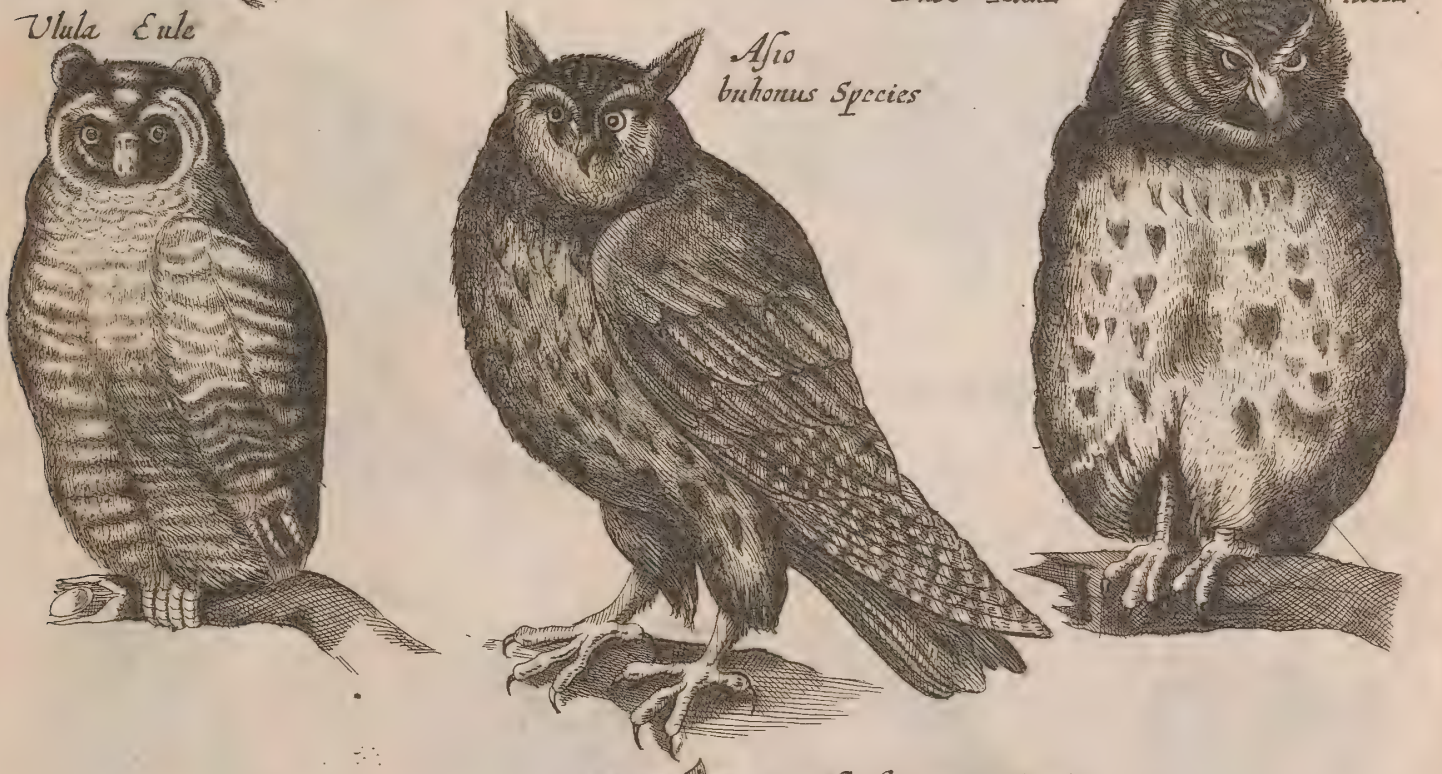

Bubo Kanz

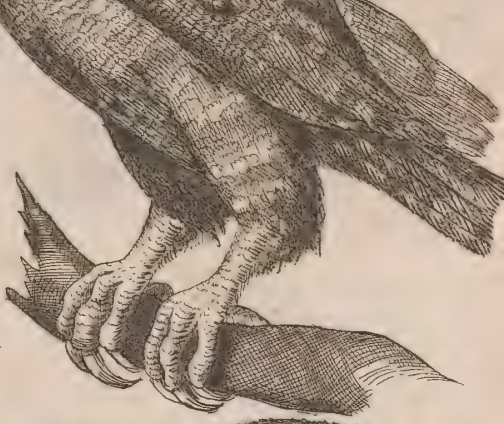

$4 \times 1 \times 5$

$(2$,

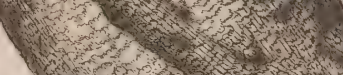

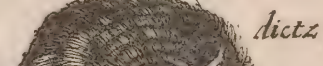
Bubo Berghn Ifutu liww

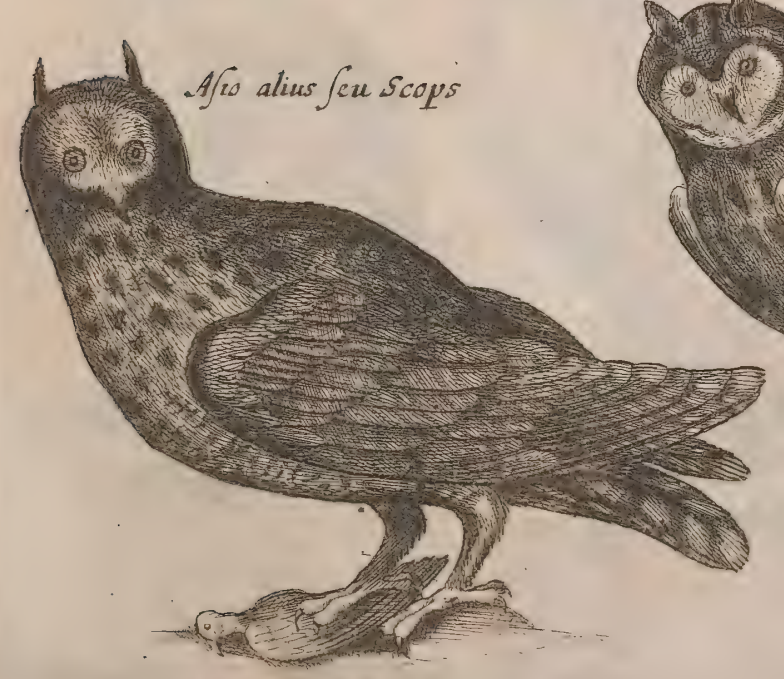

Afro Ceu Otus Dhrul 


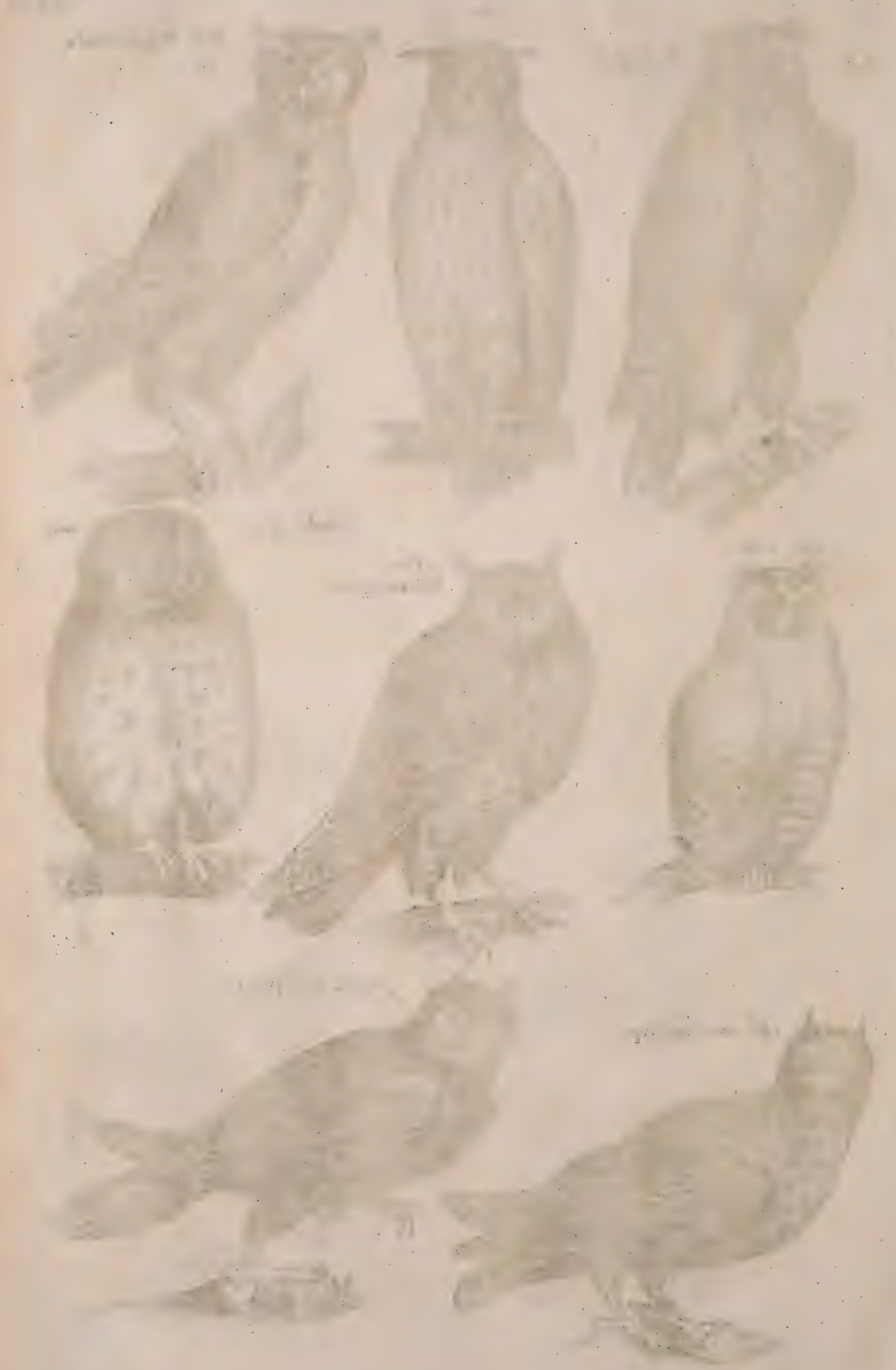




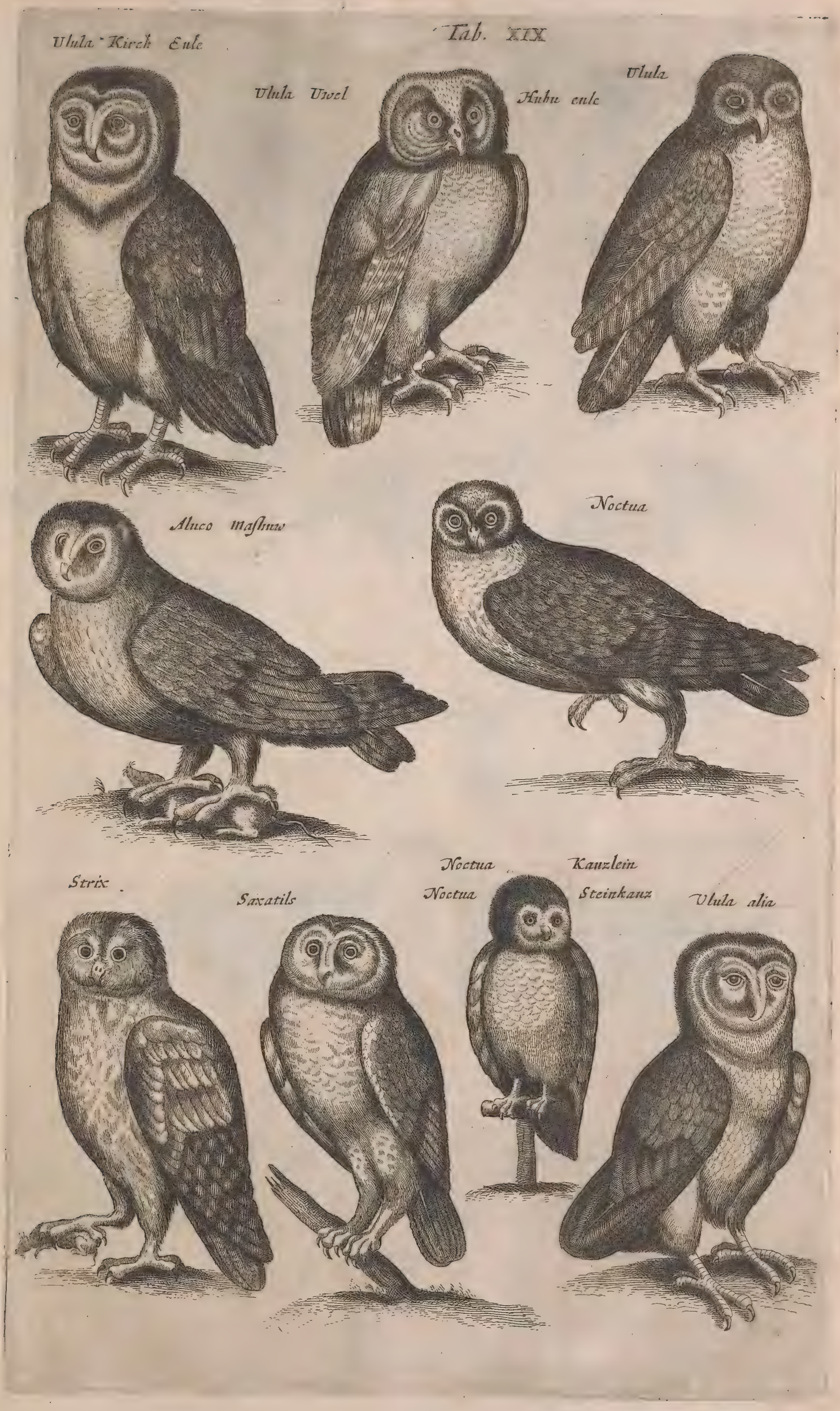





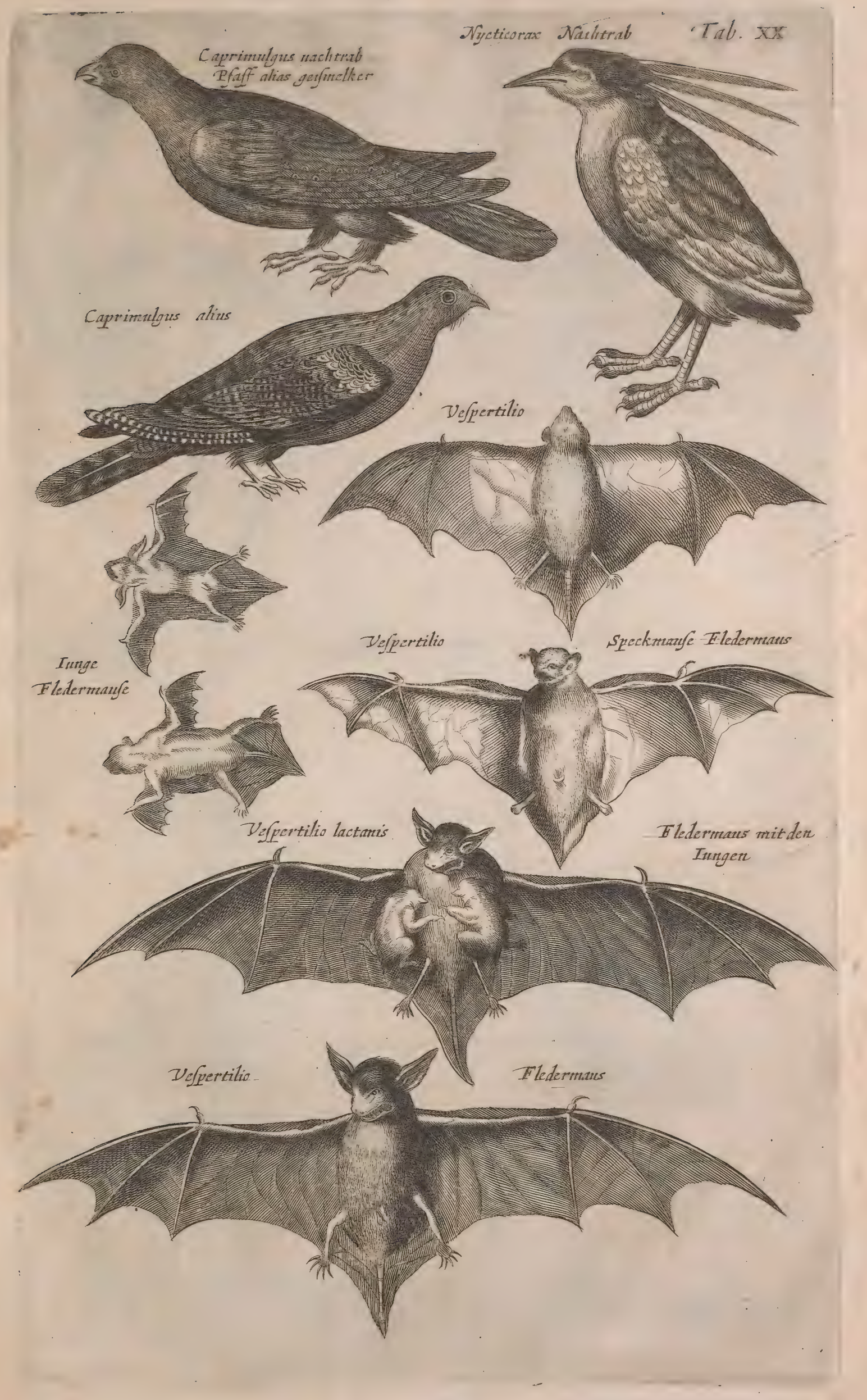




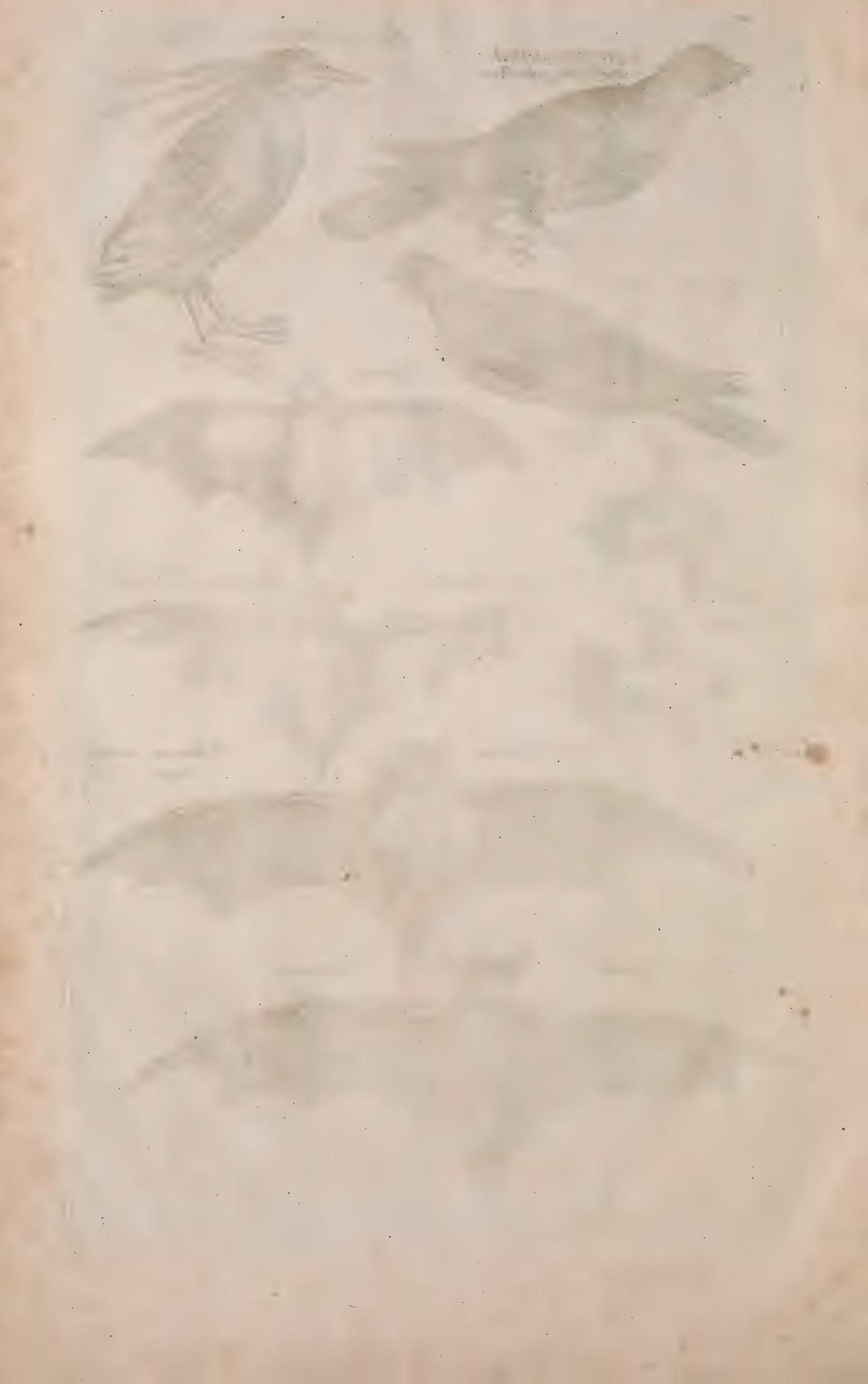



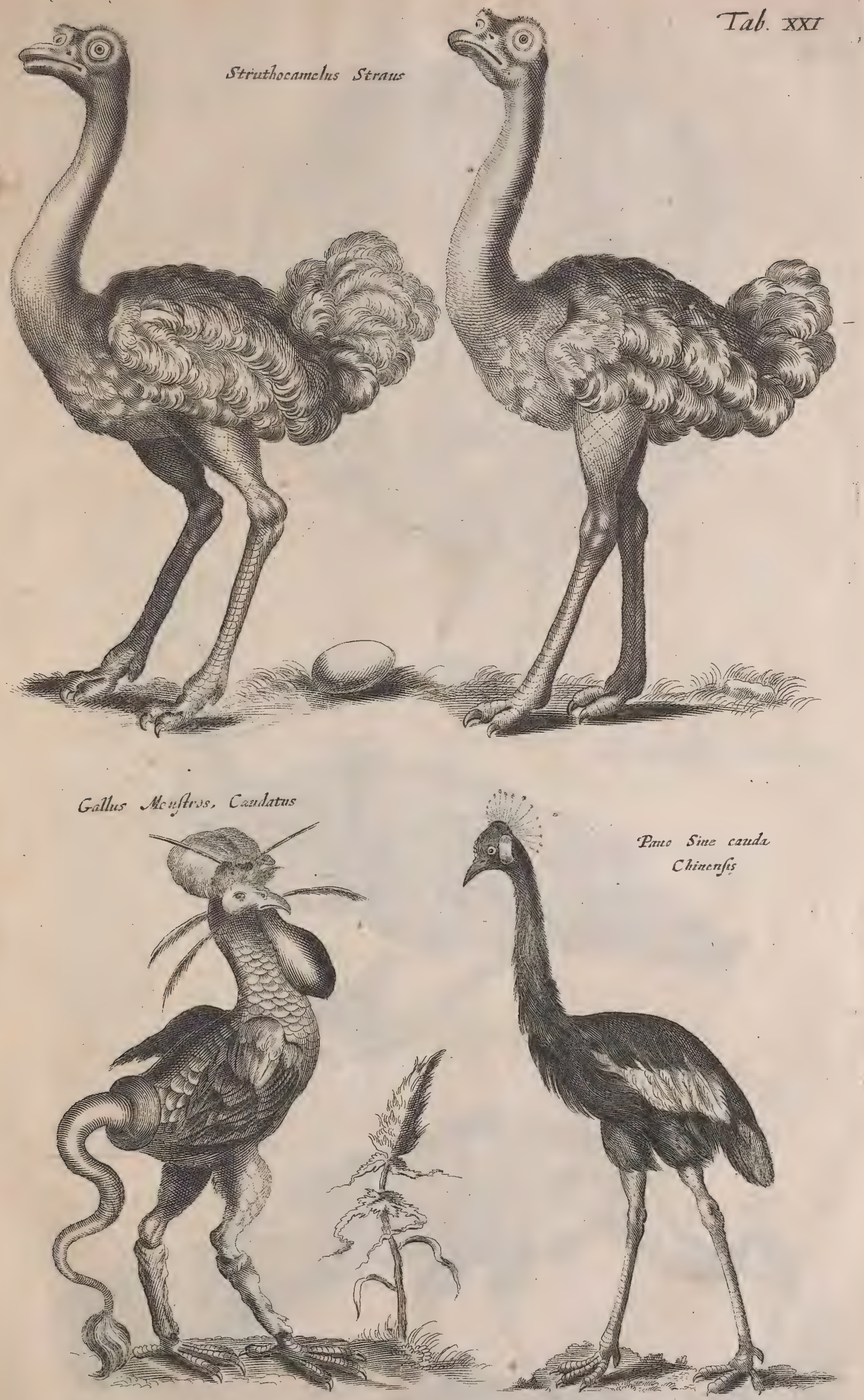



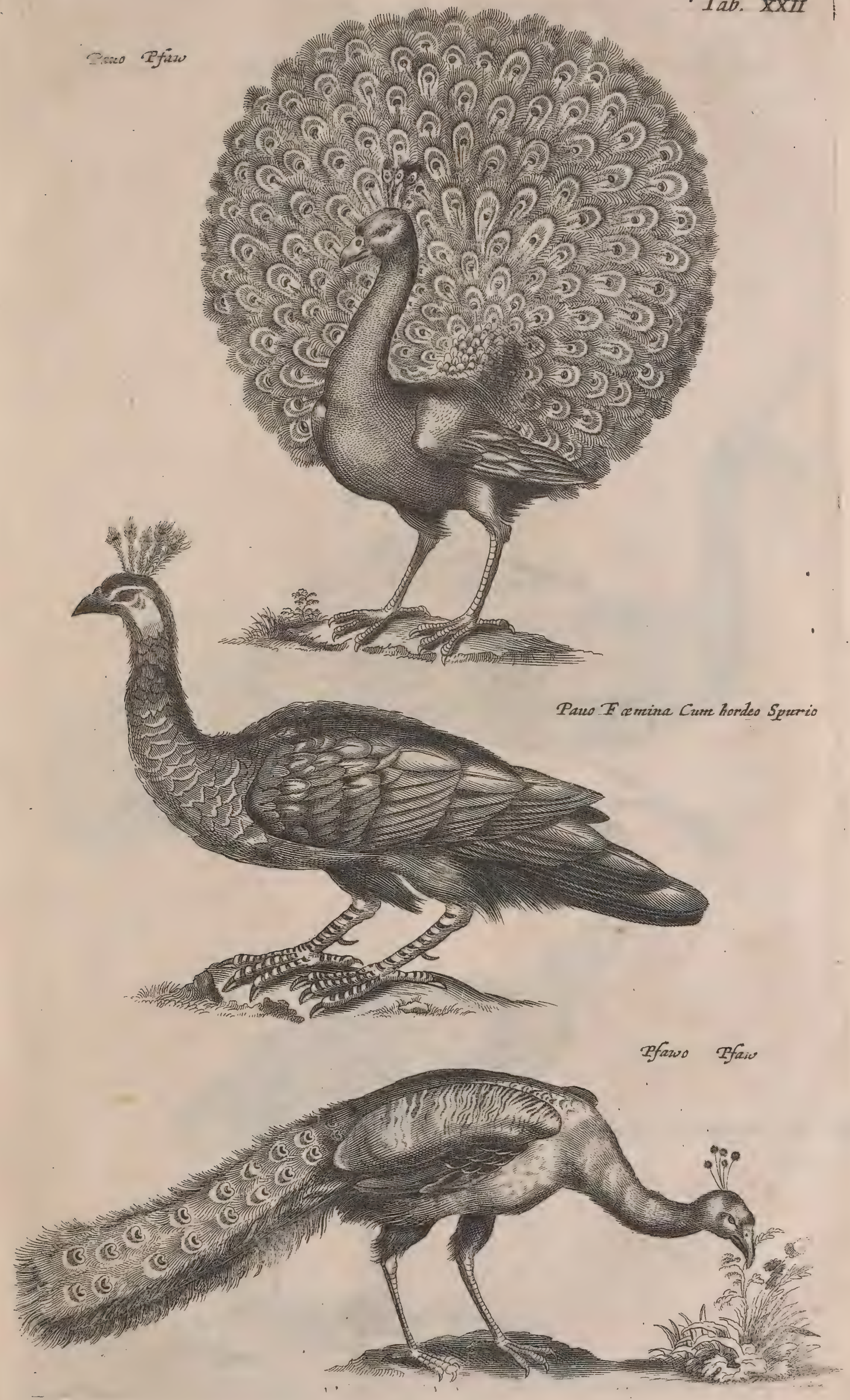

Tab. xxII 

Pano albus cum tritico multuli -

(a)

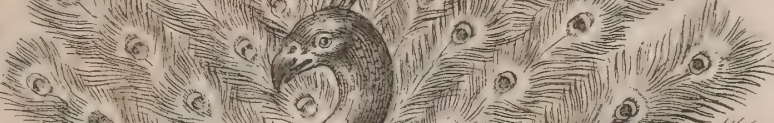

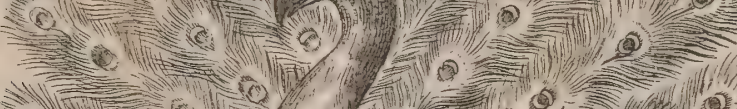

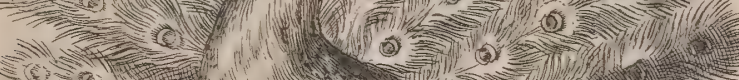

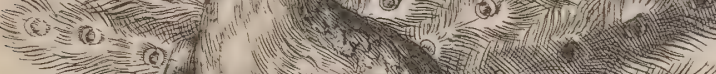
* th c) M 2010 Now

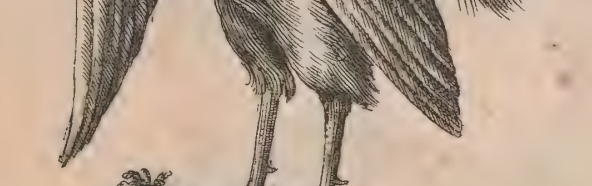

Paus Iapenonfis mas cum locuftas
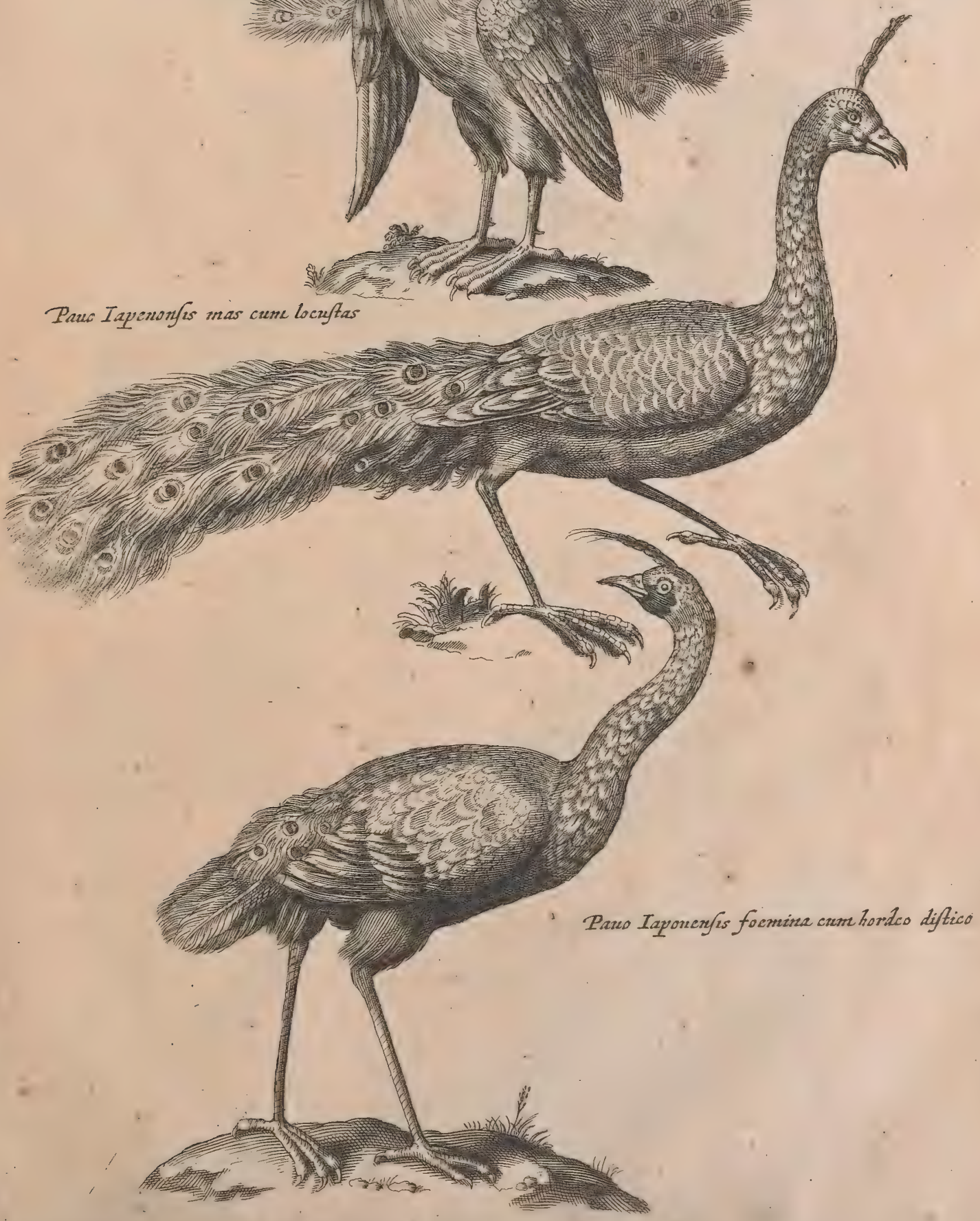



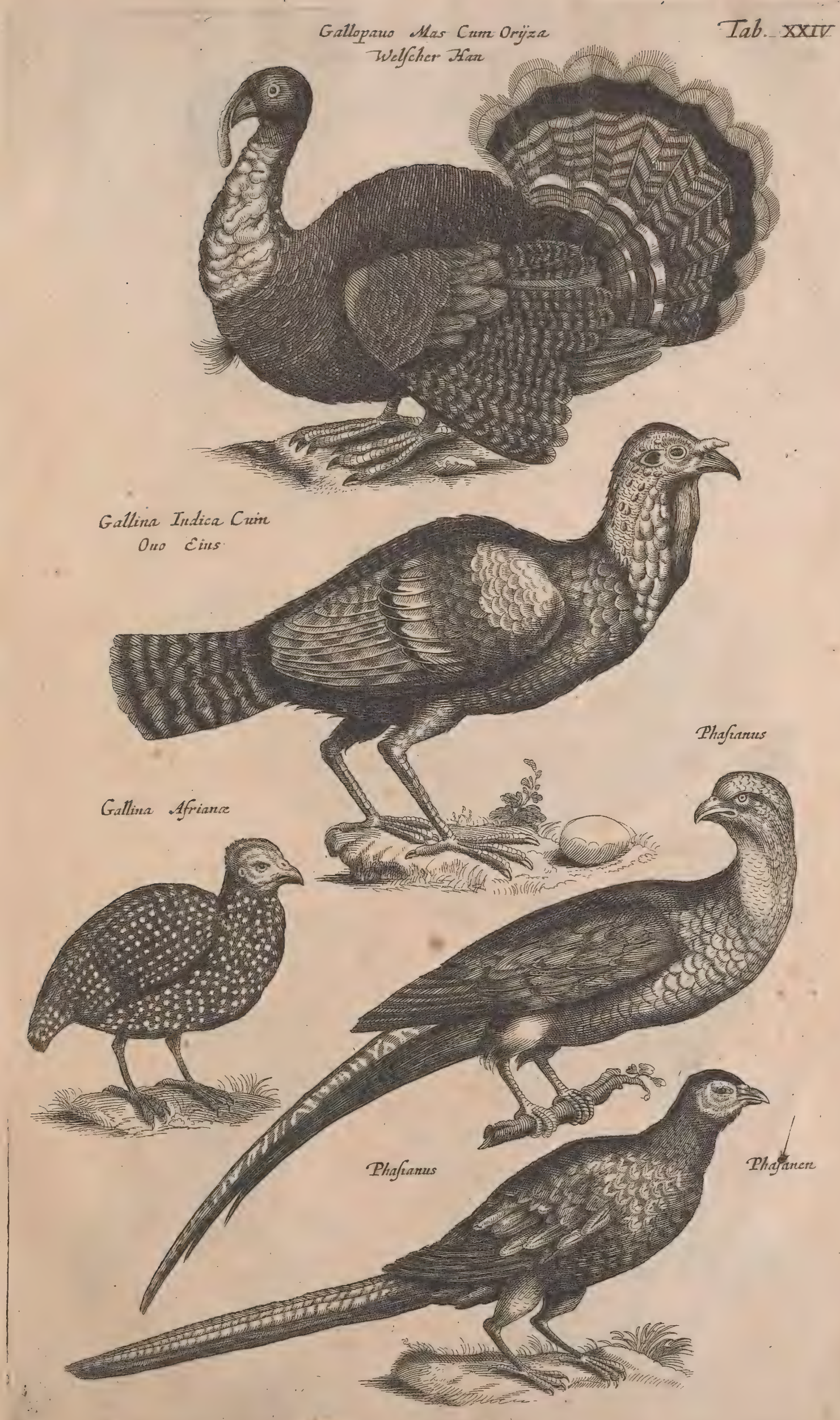





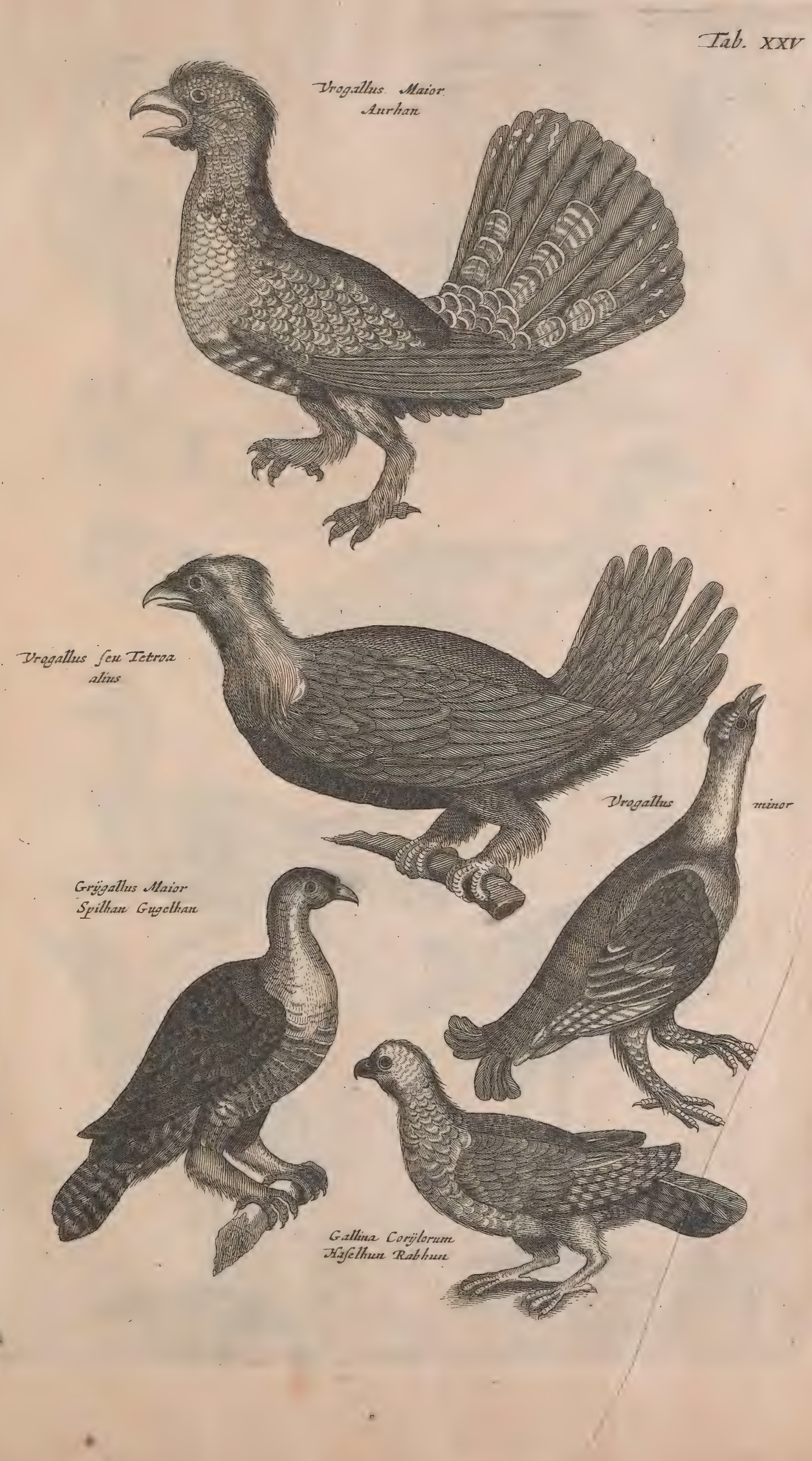





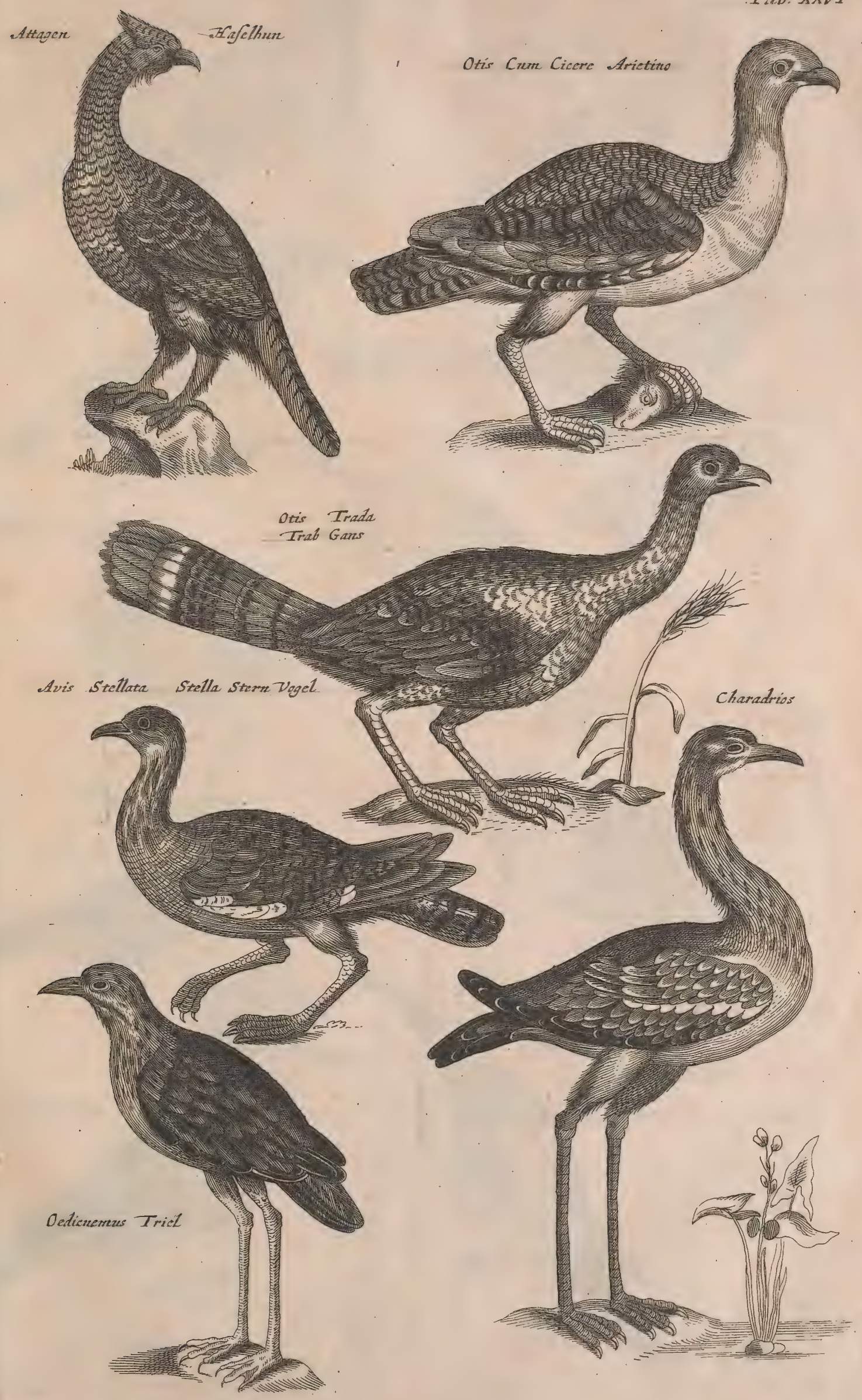




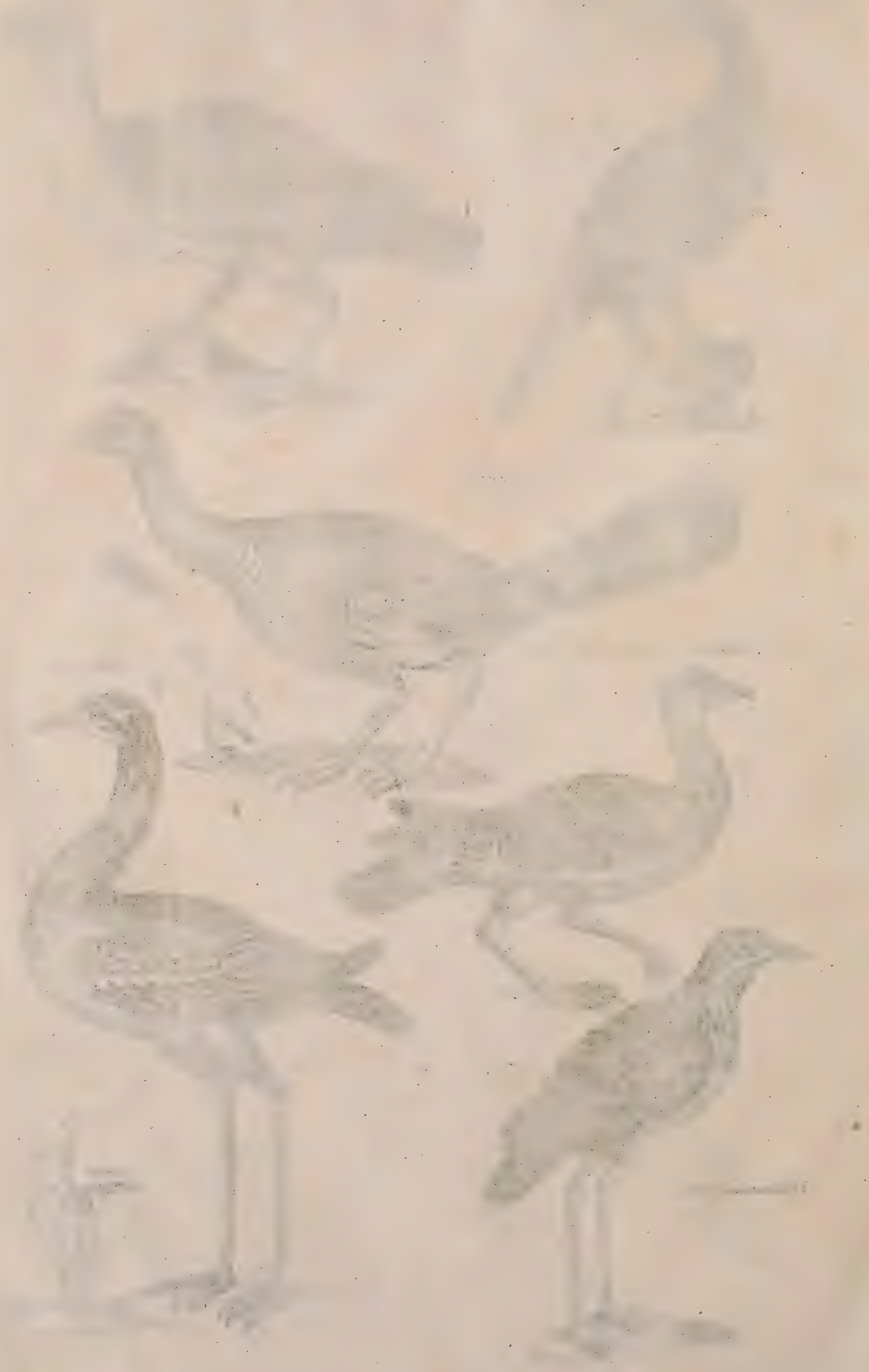




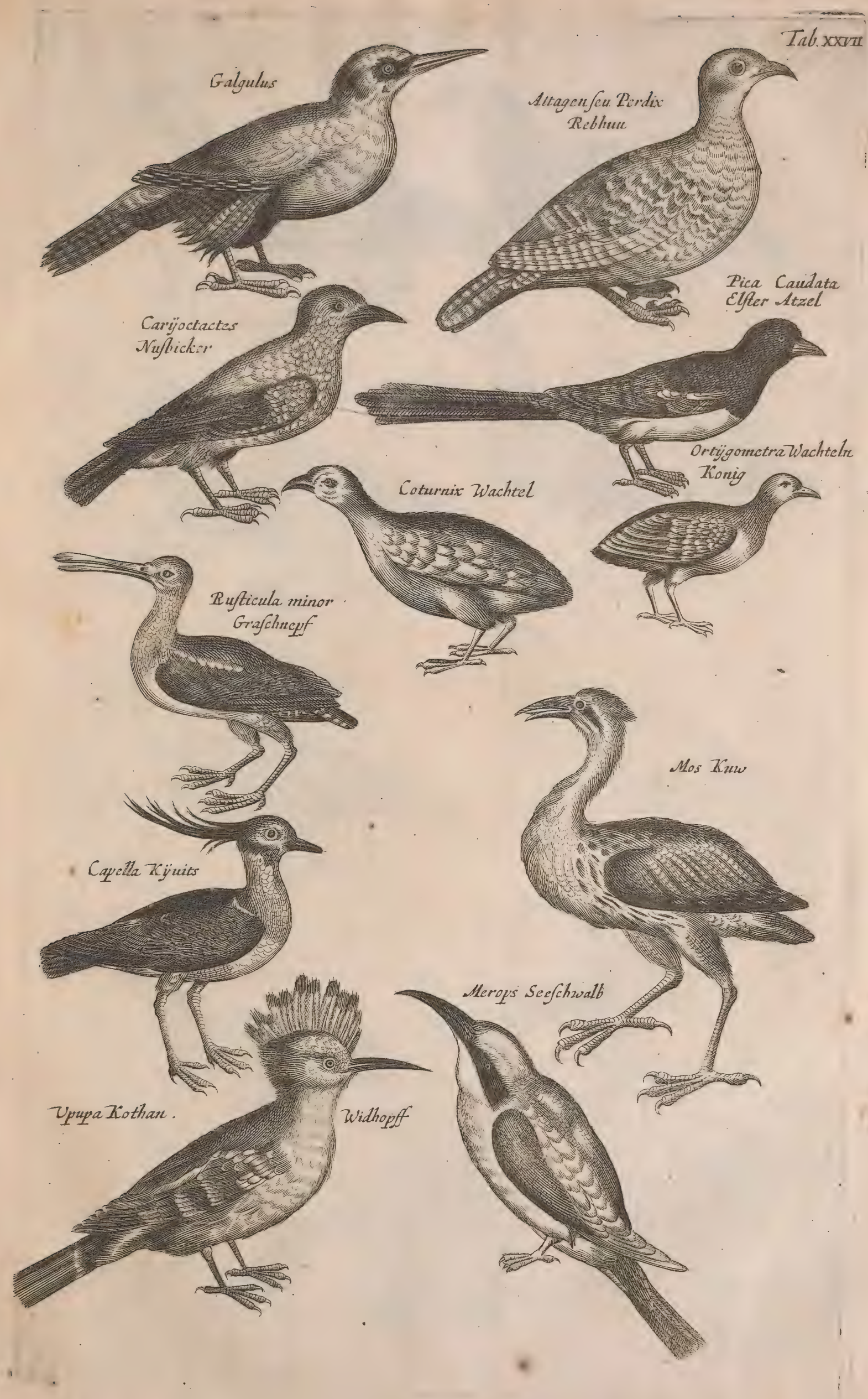




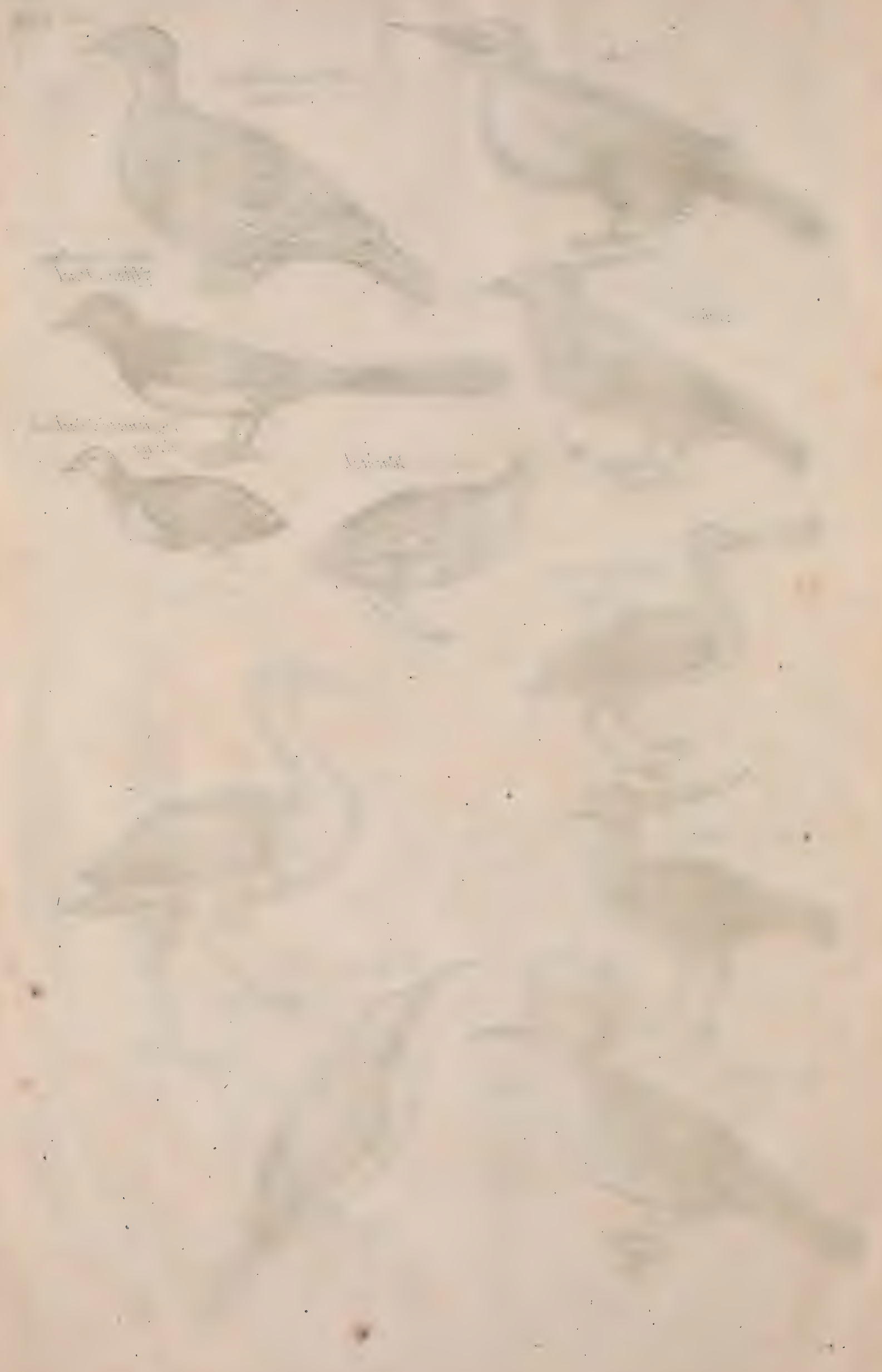




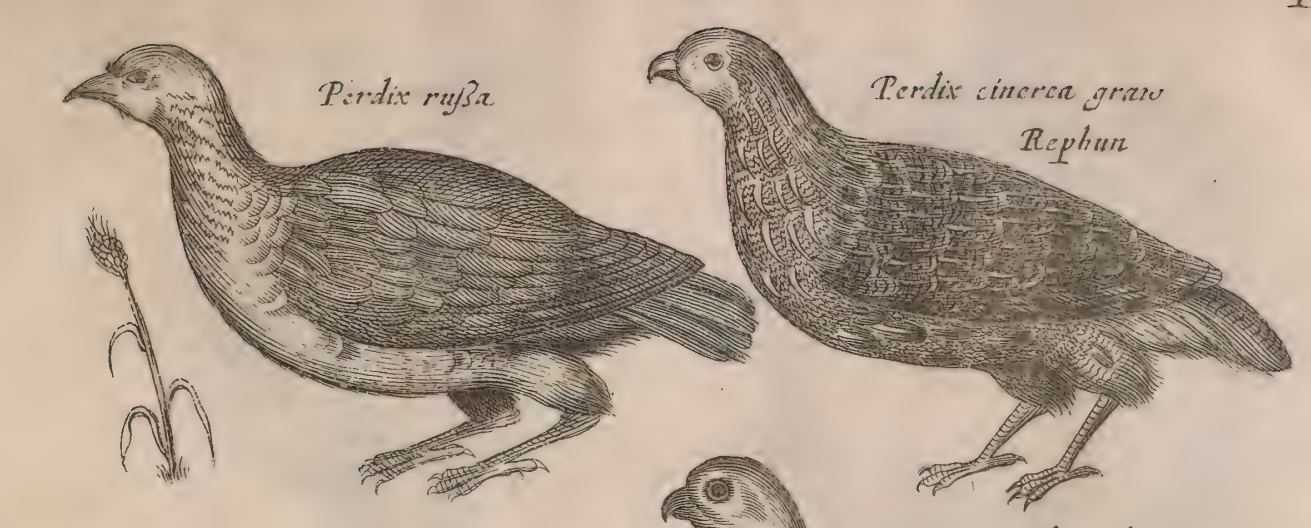

Tab.xxum

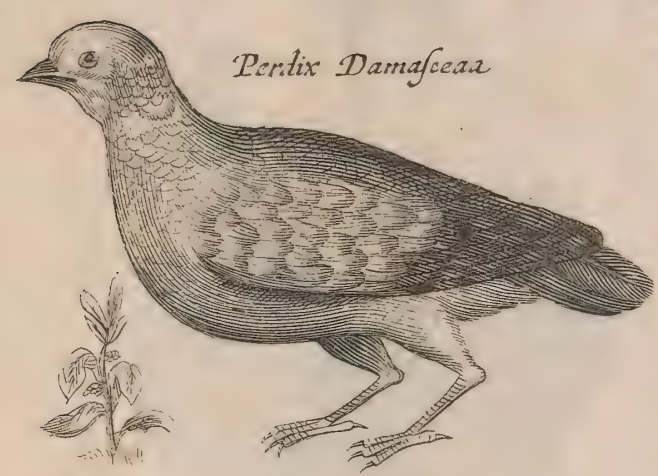

Iagopus Schree hure
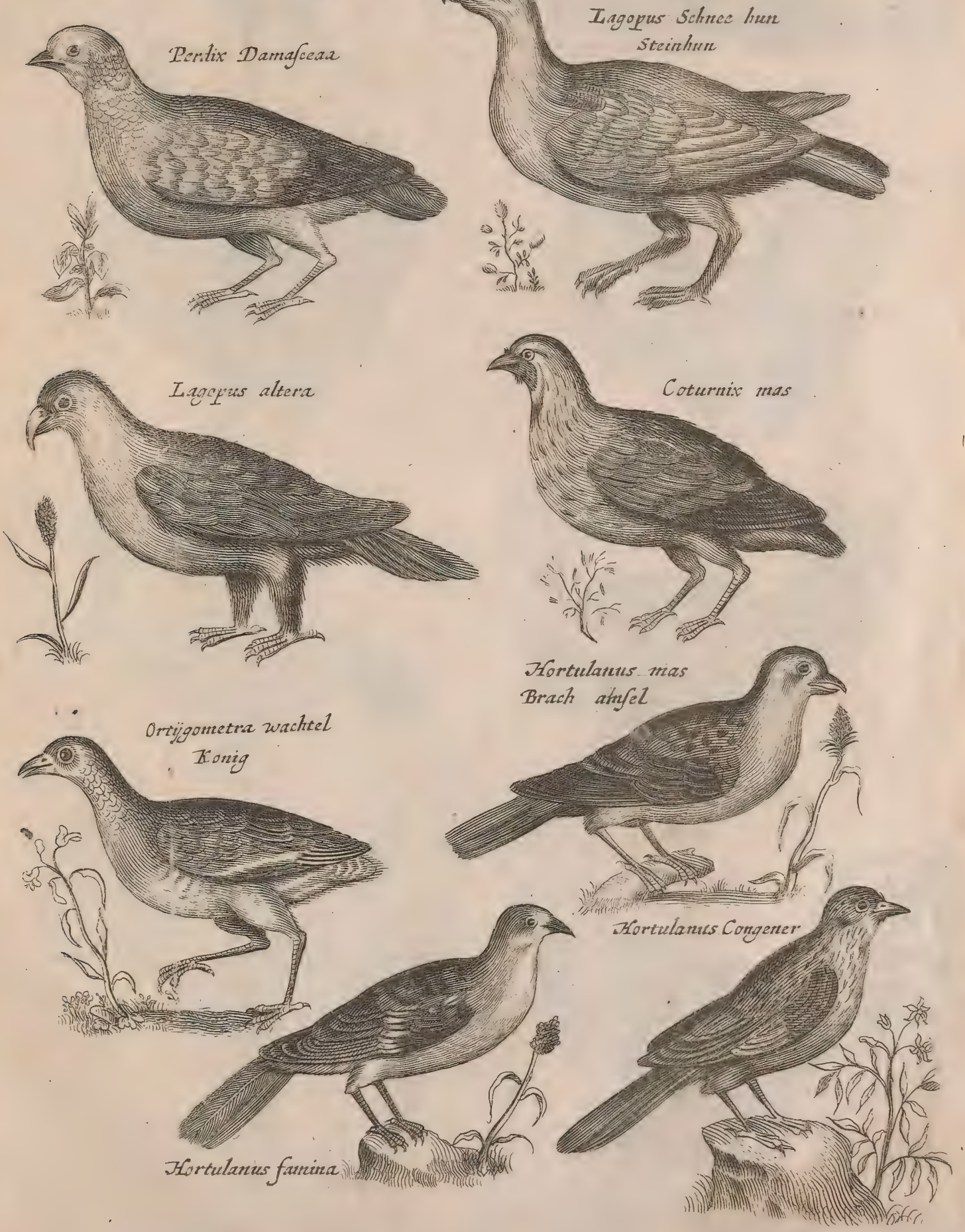



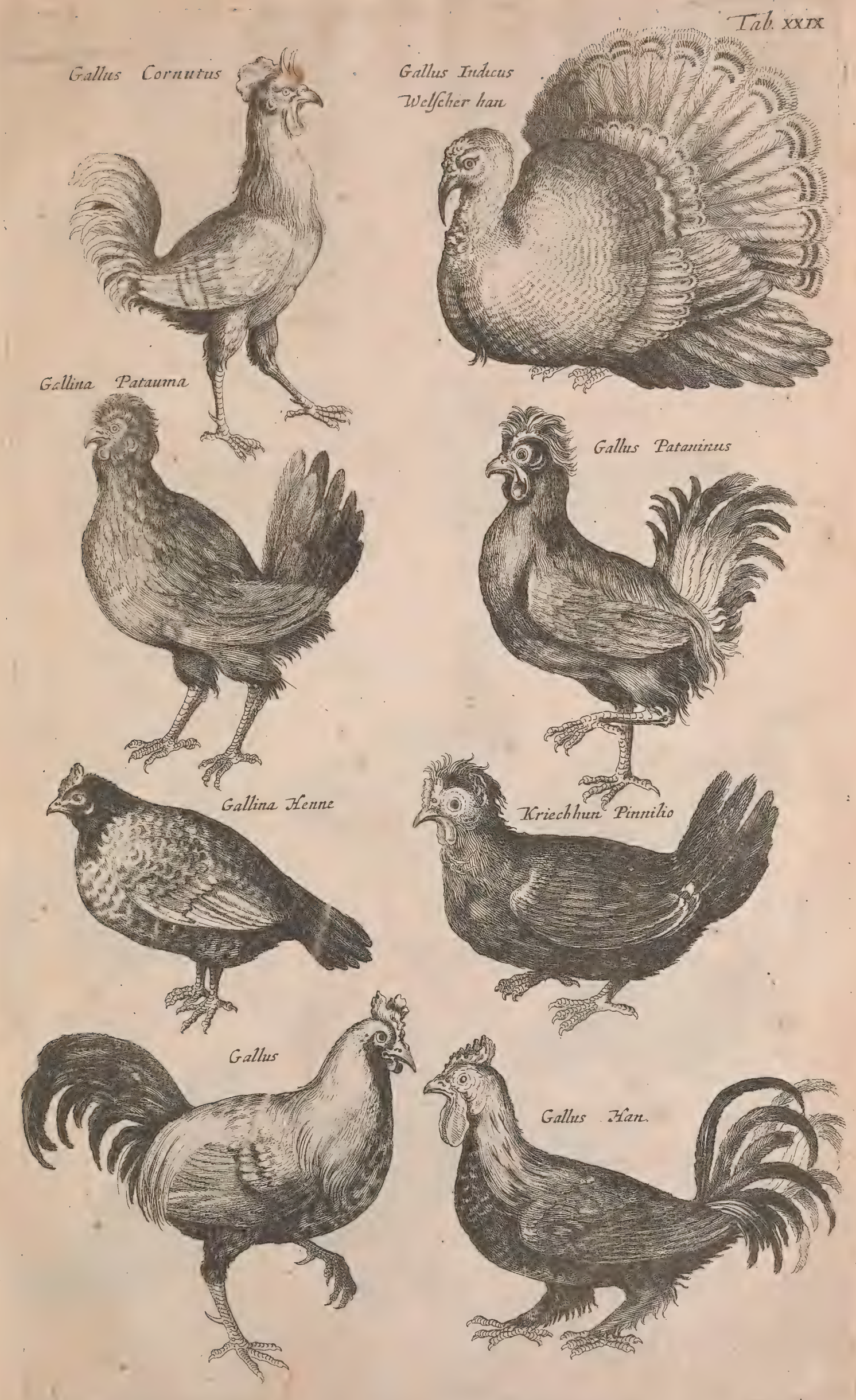





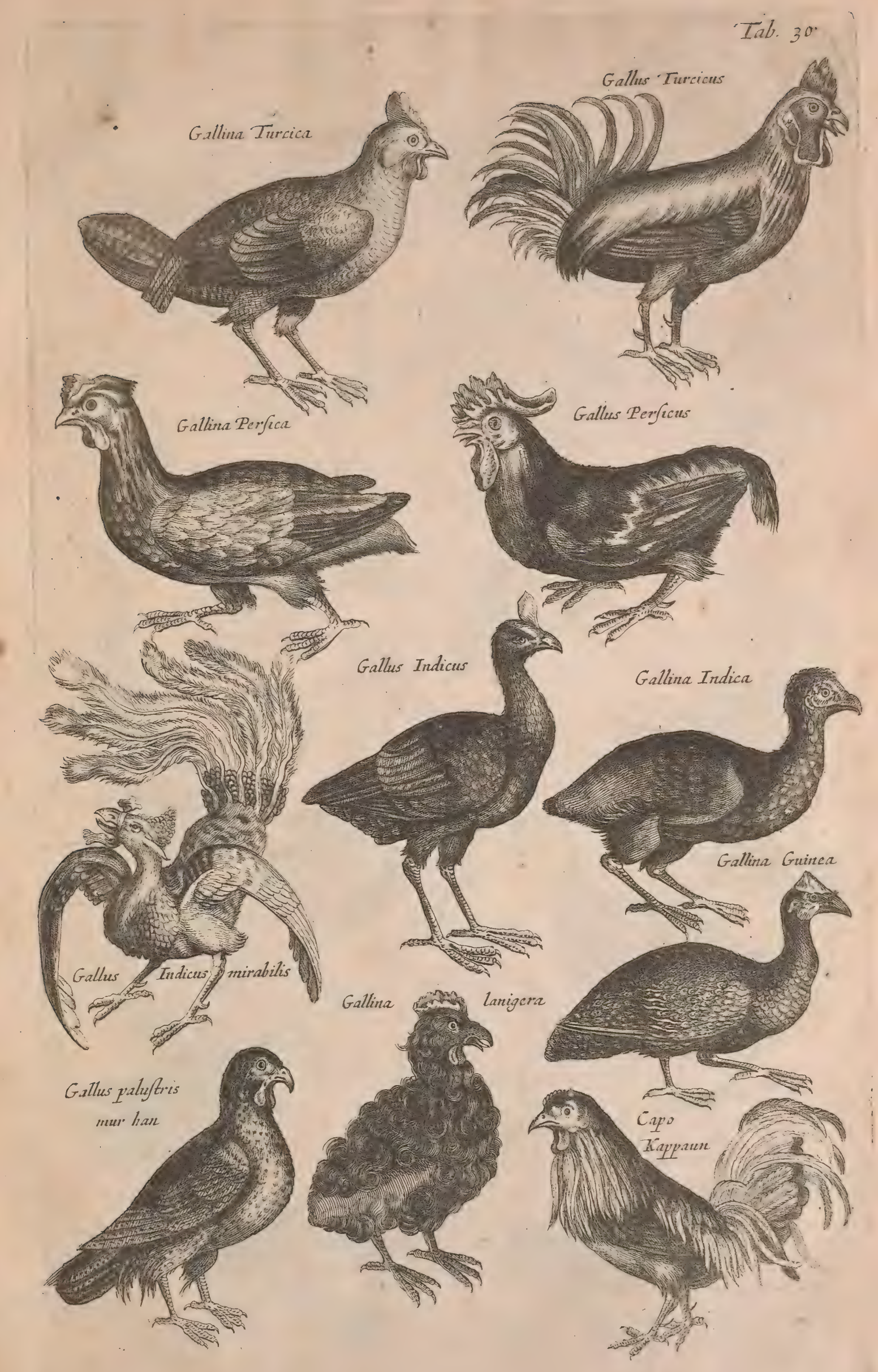





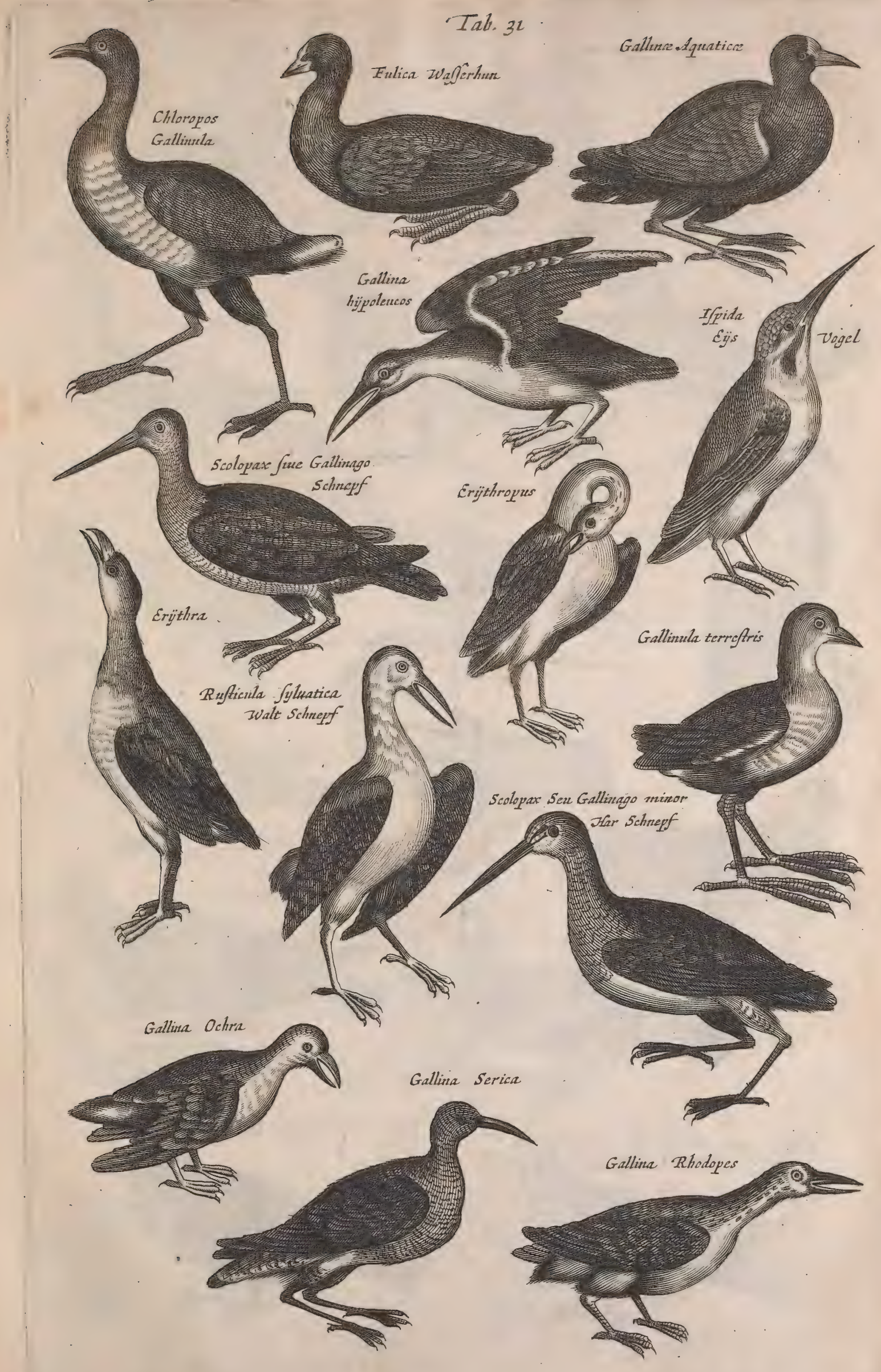




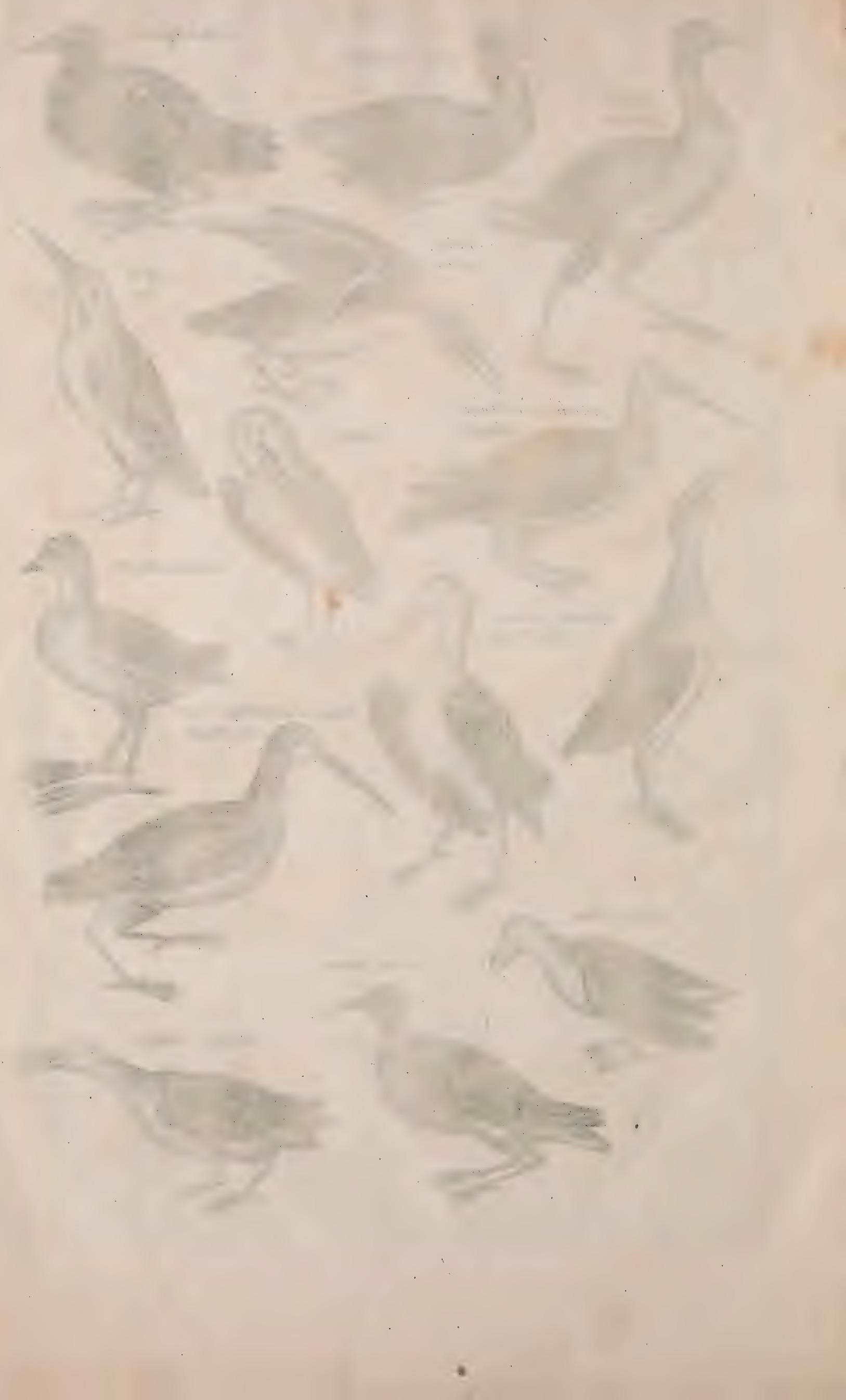




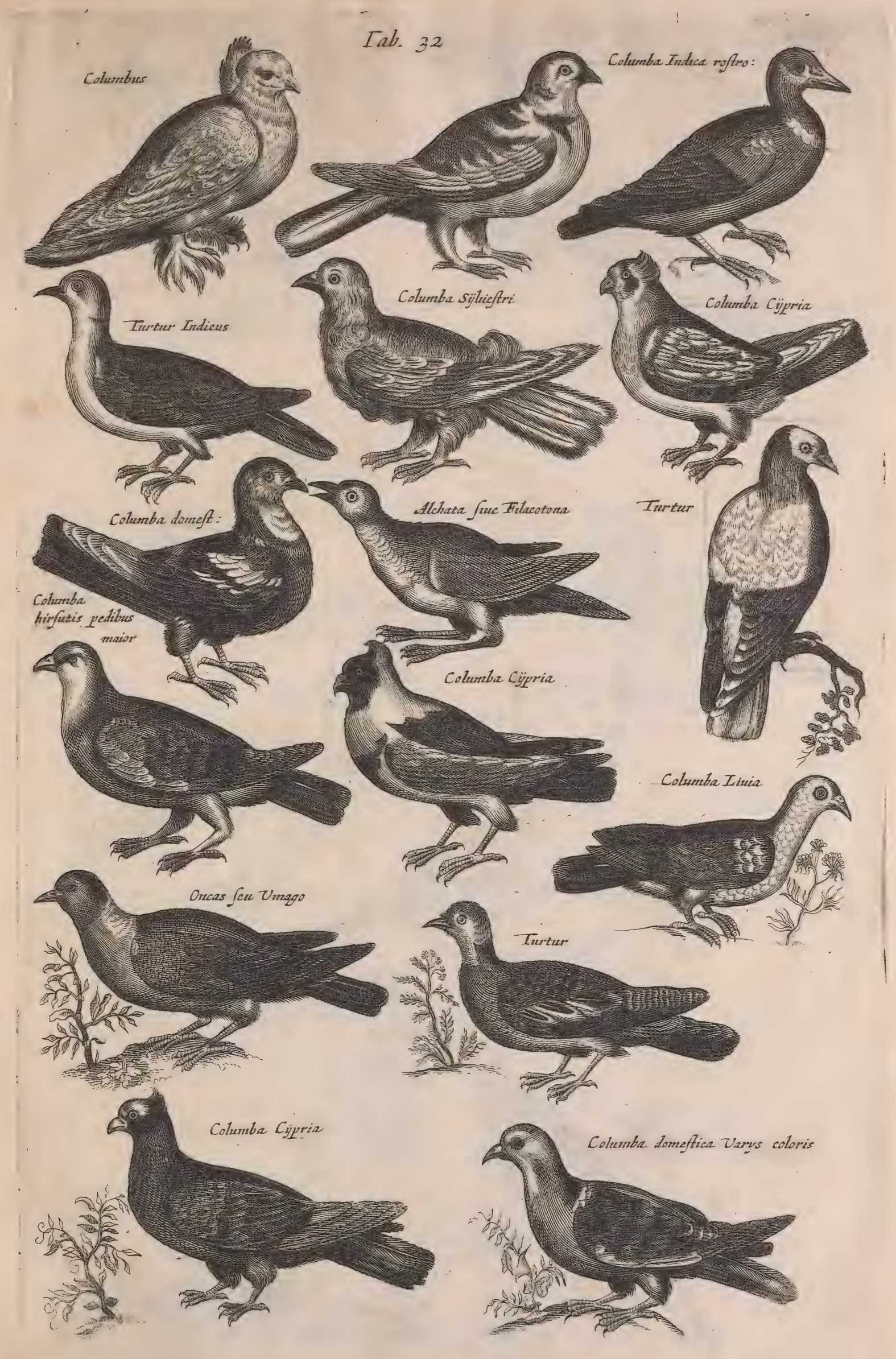





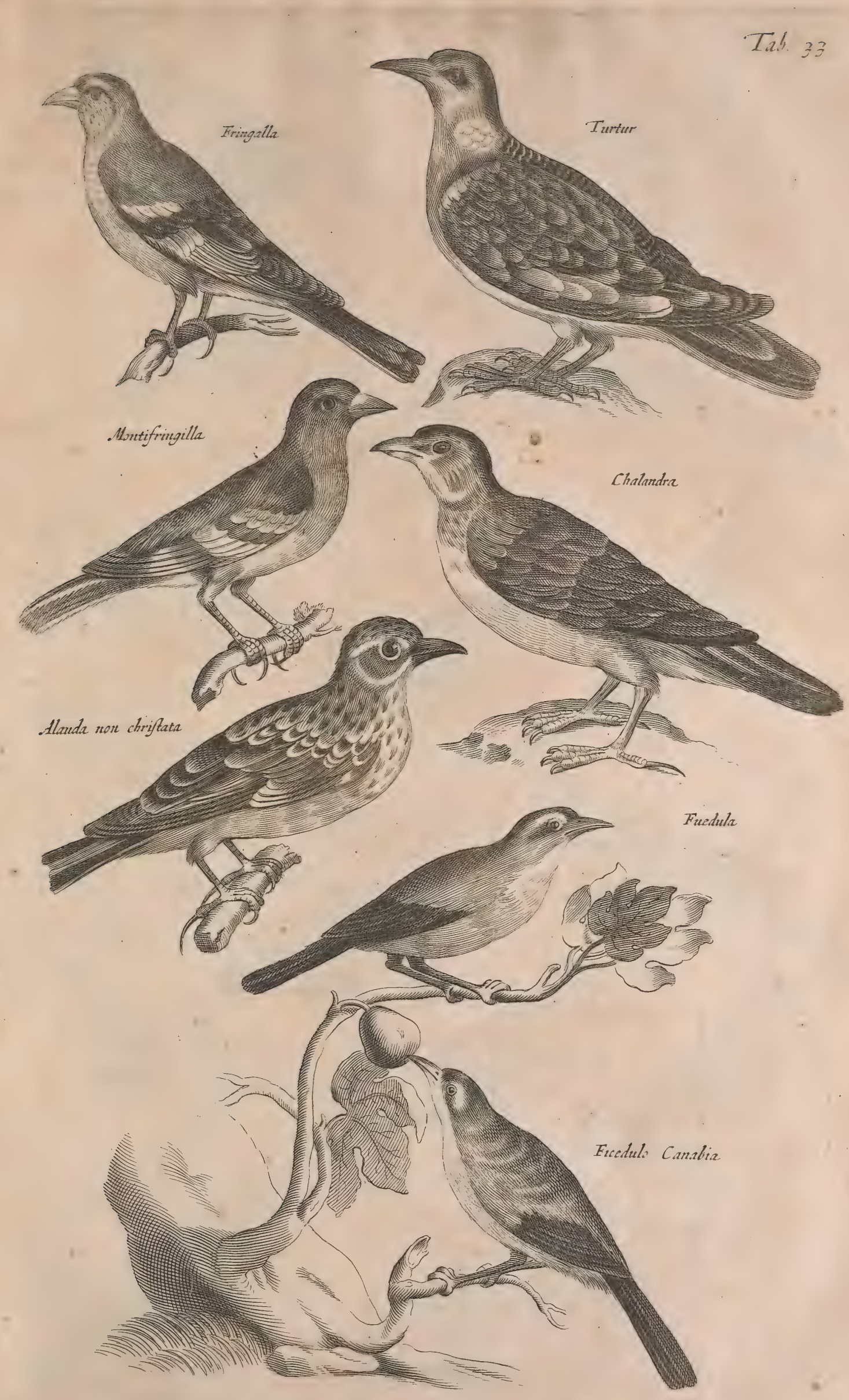





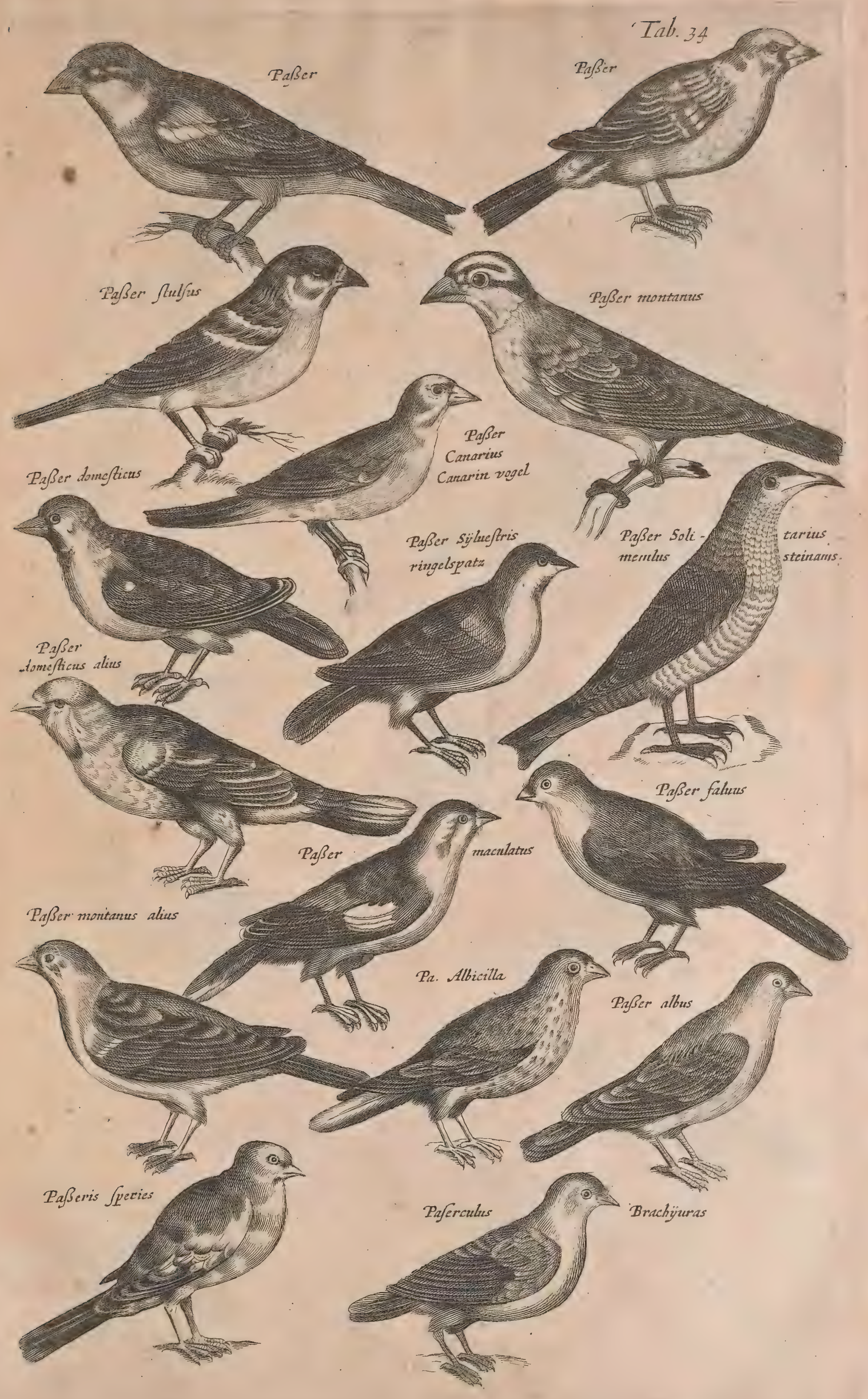





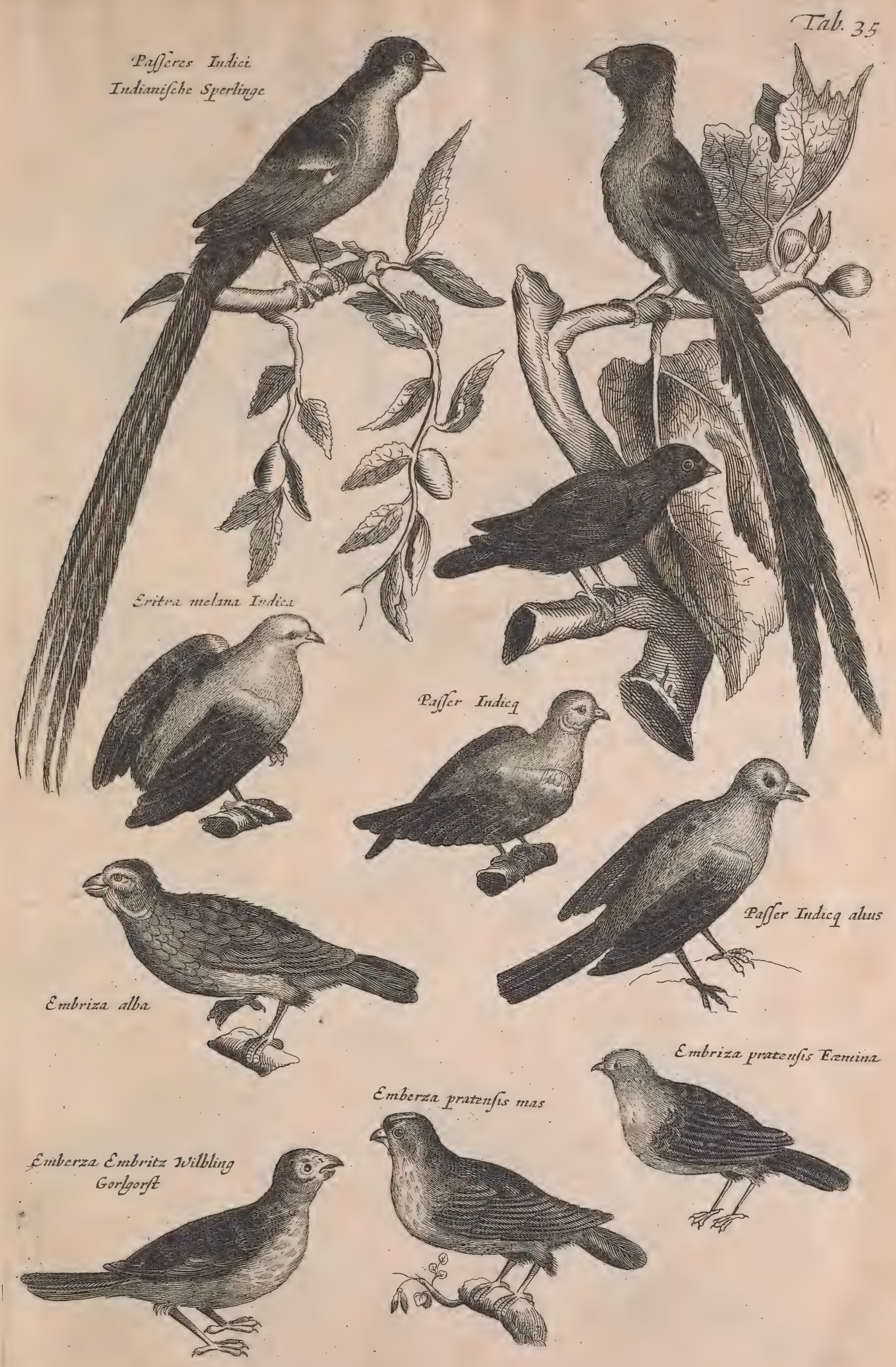





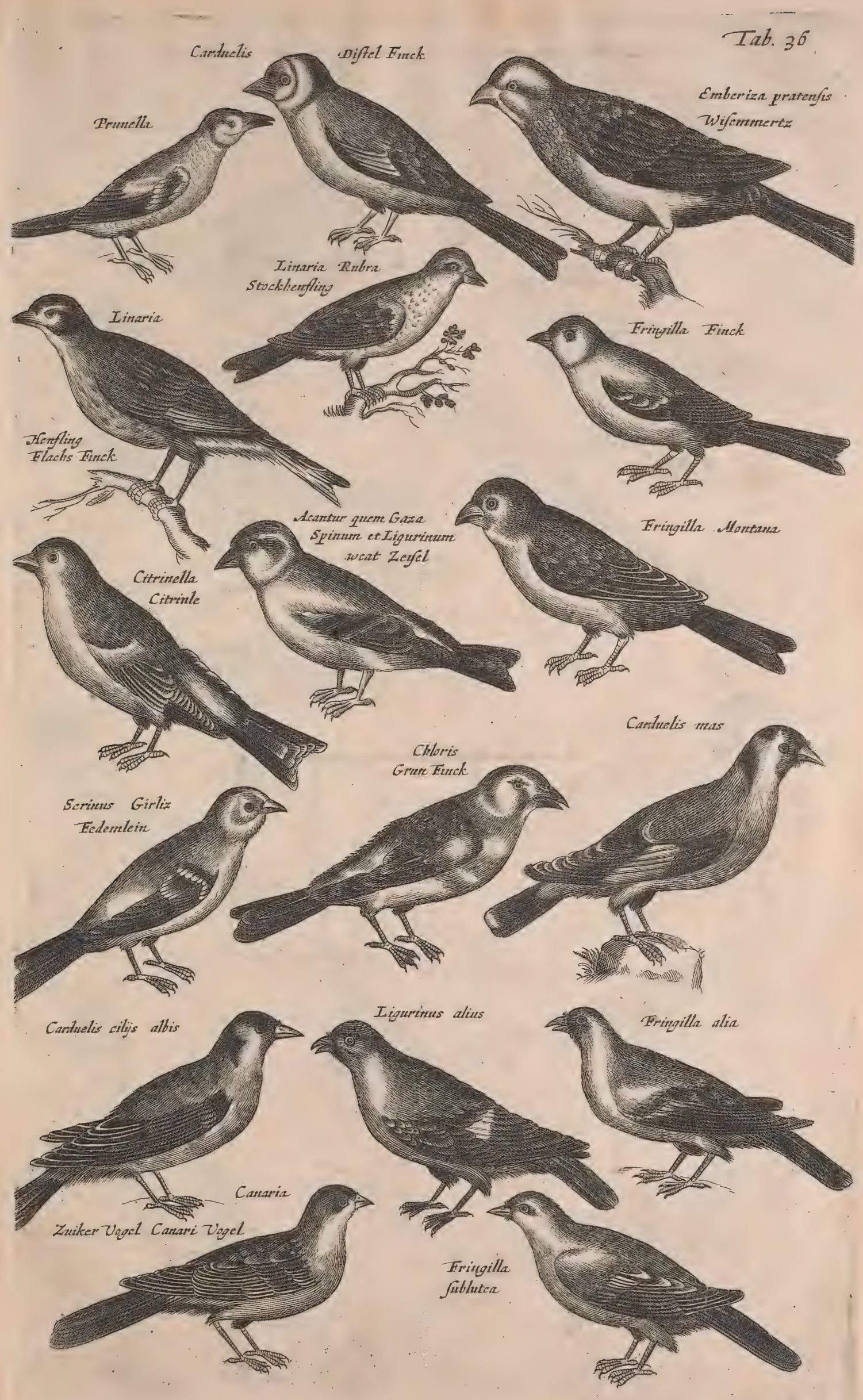




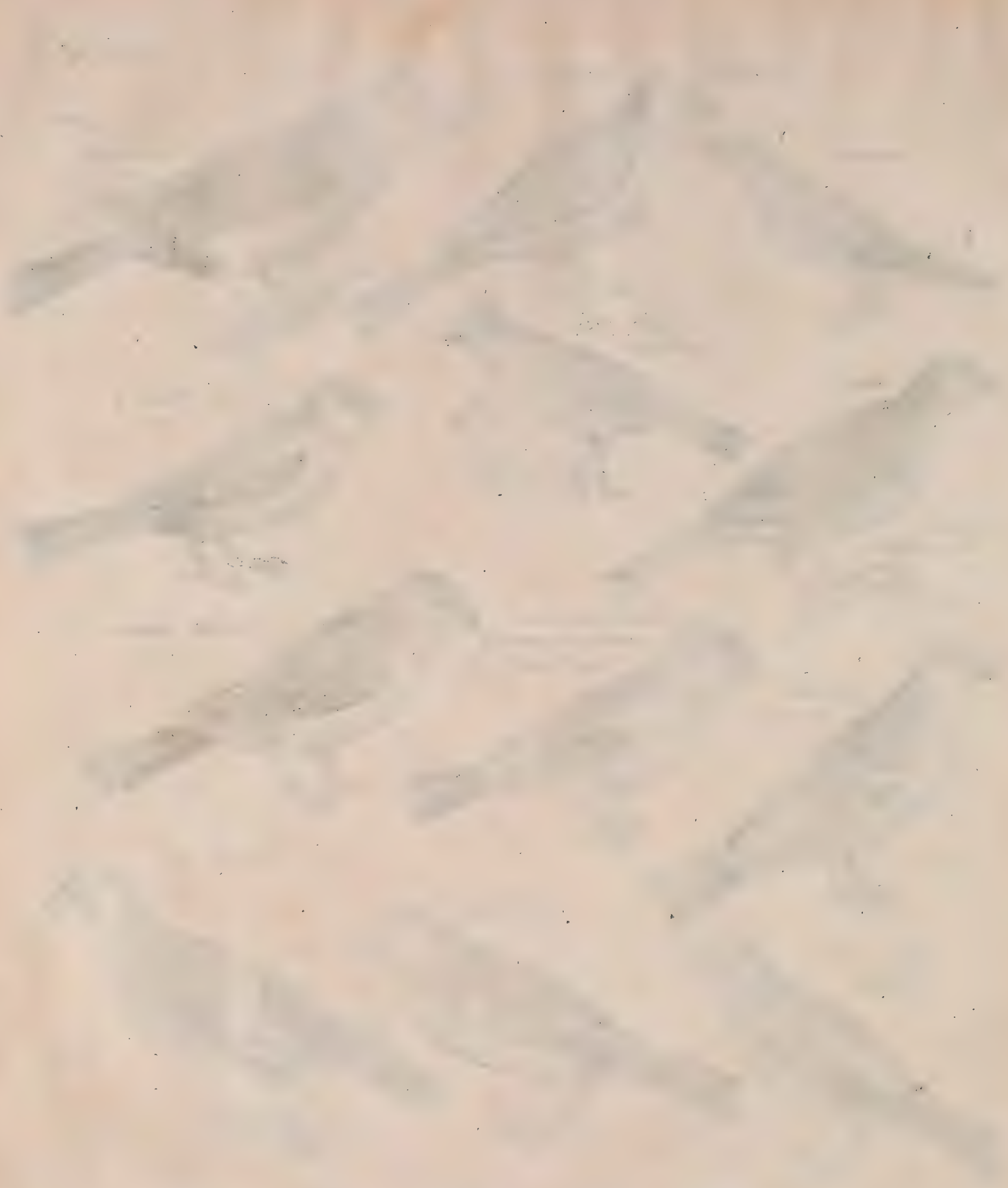




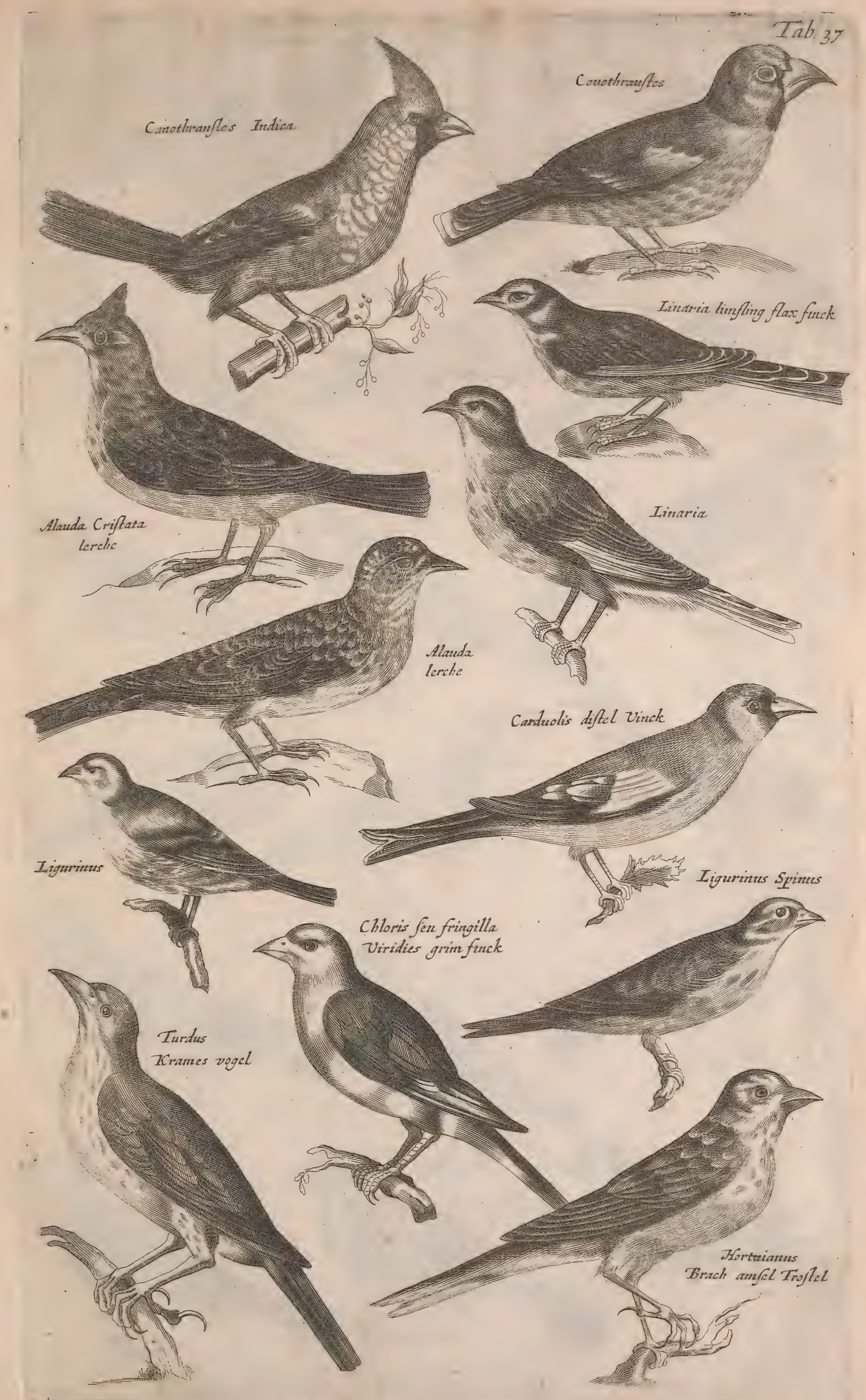





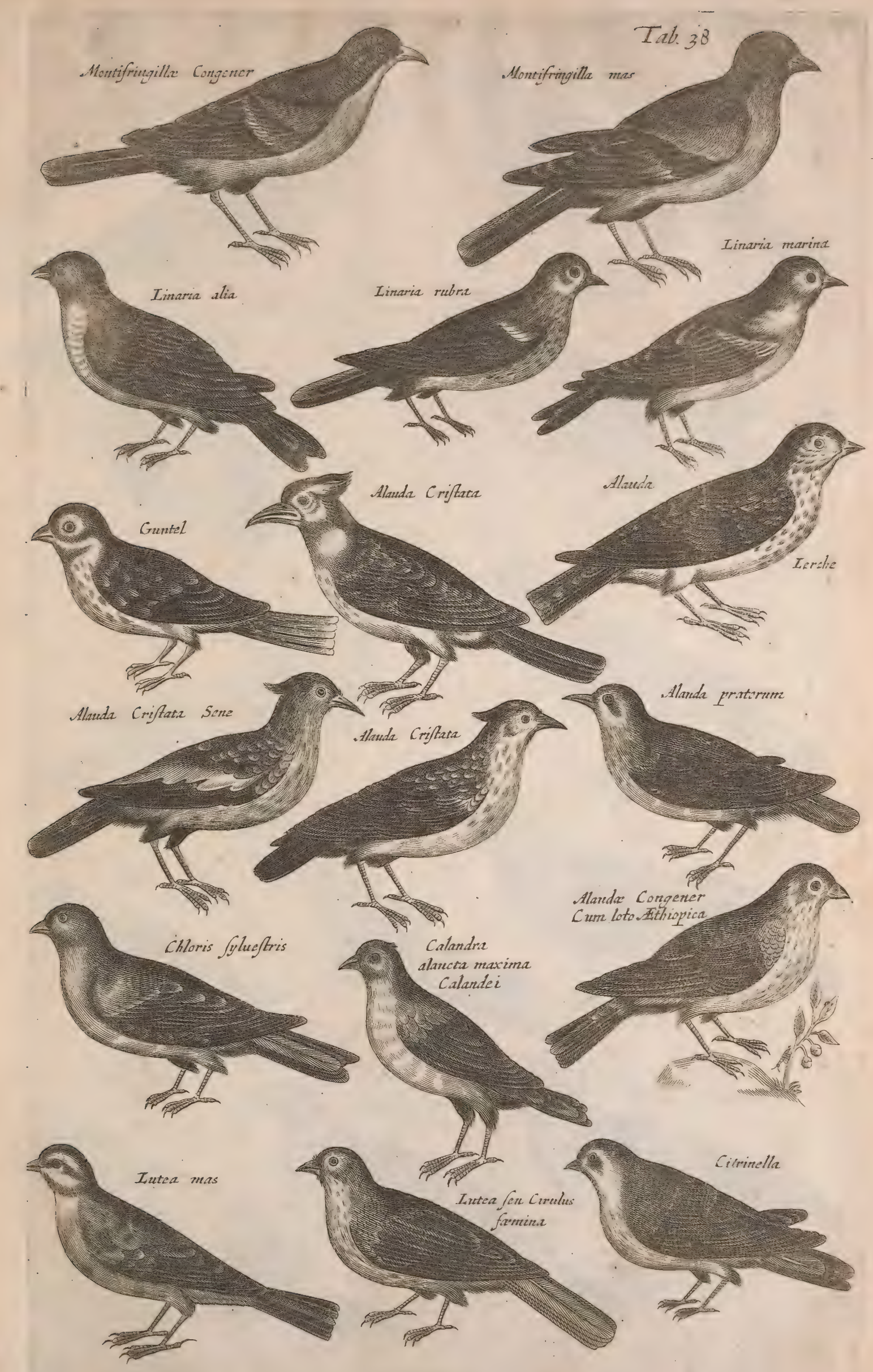





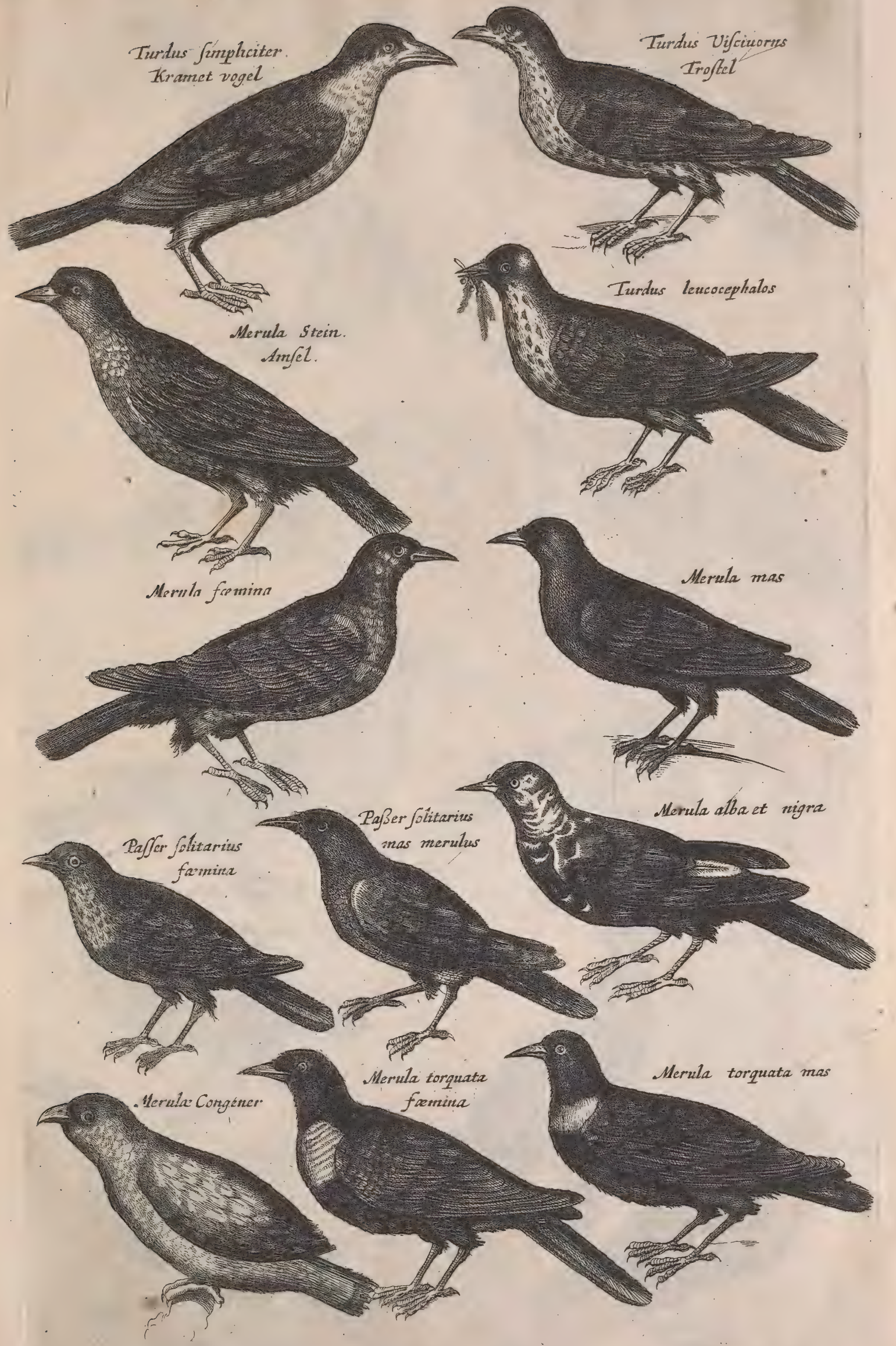





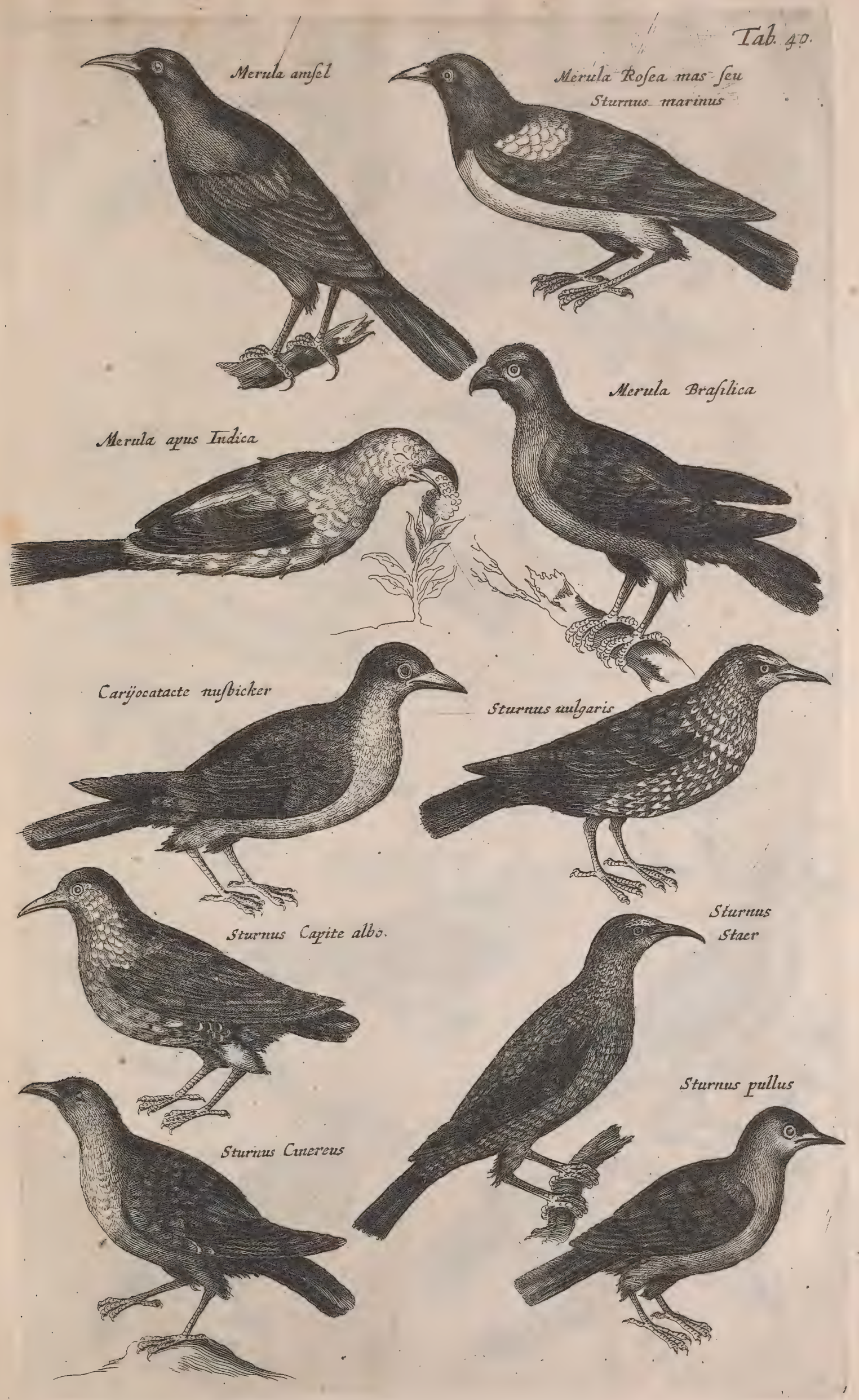





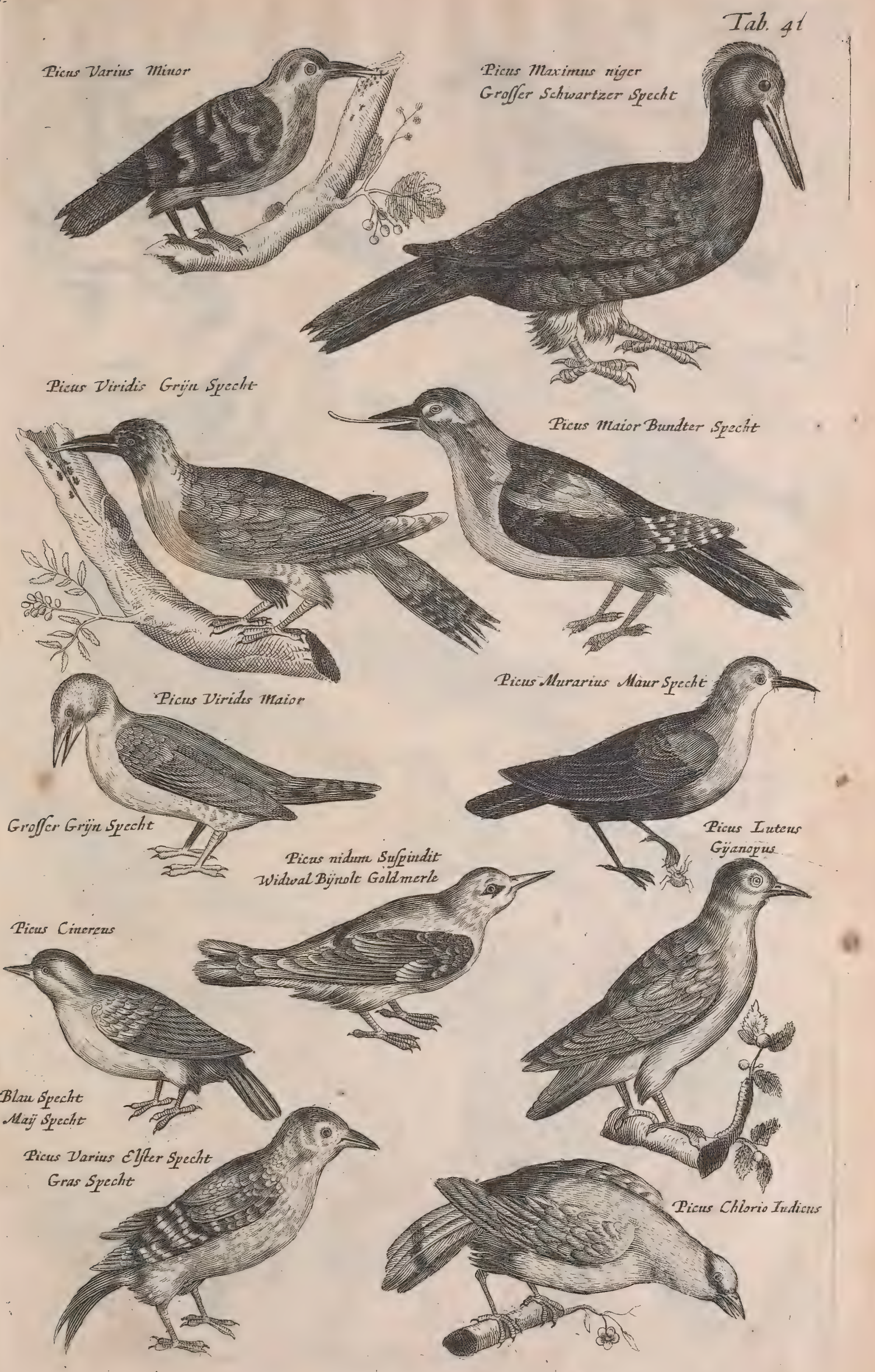



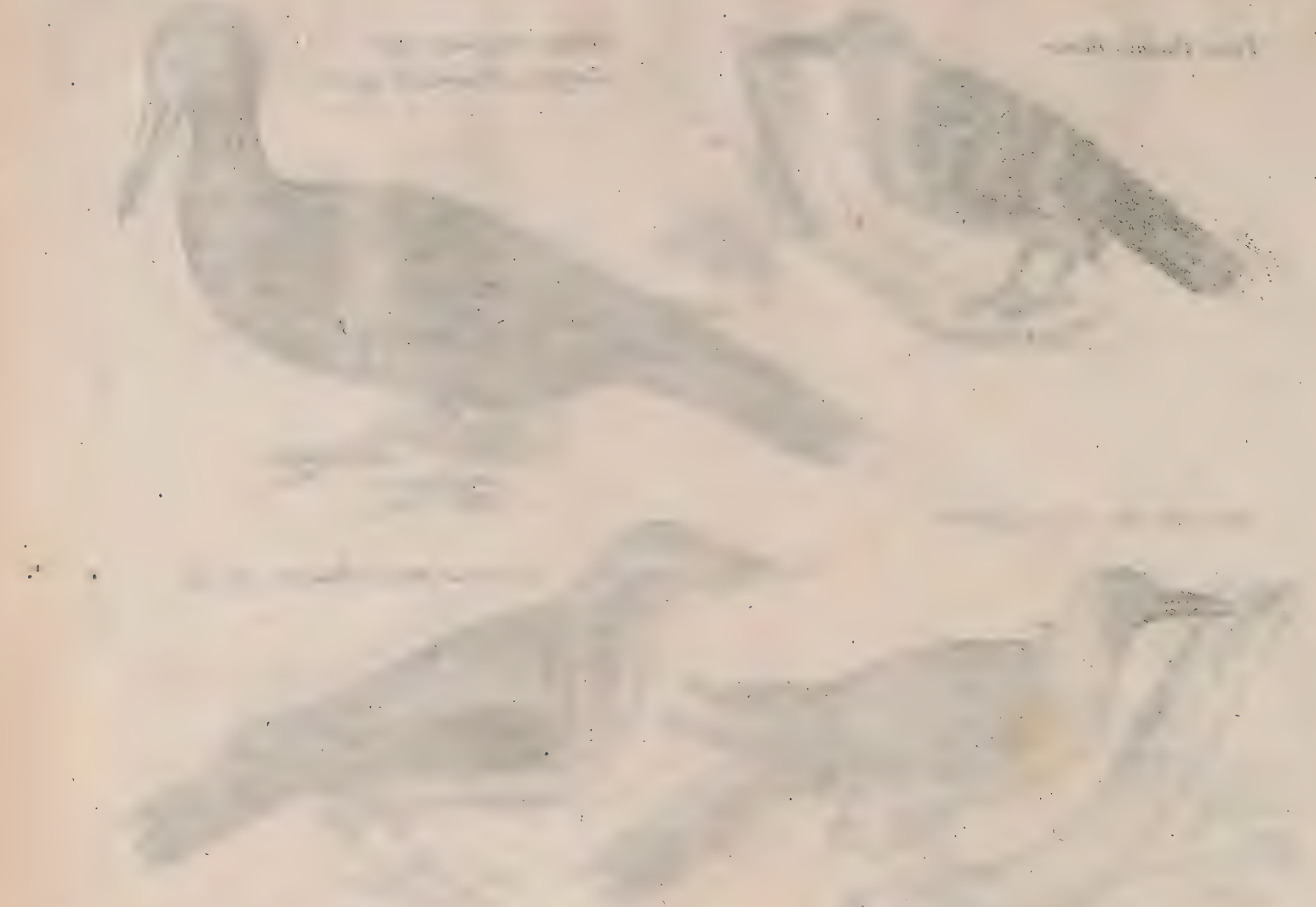

$\therefore \therefore \therefore, \cdots, \ldots, \cdots, \cdots$
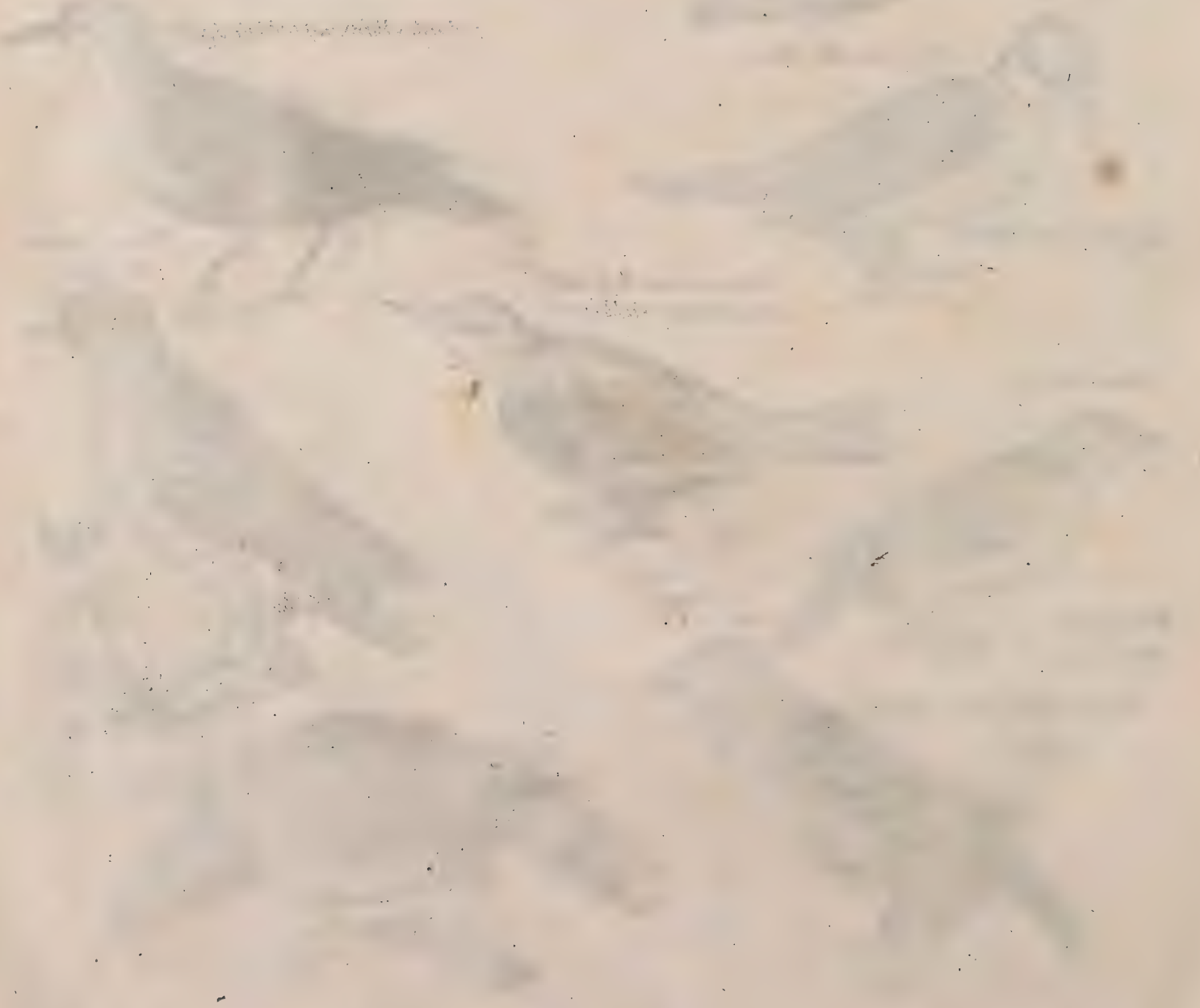
Tab. 42
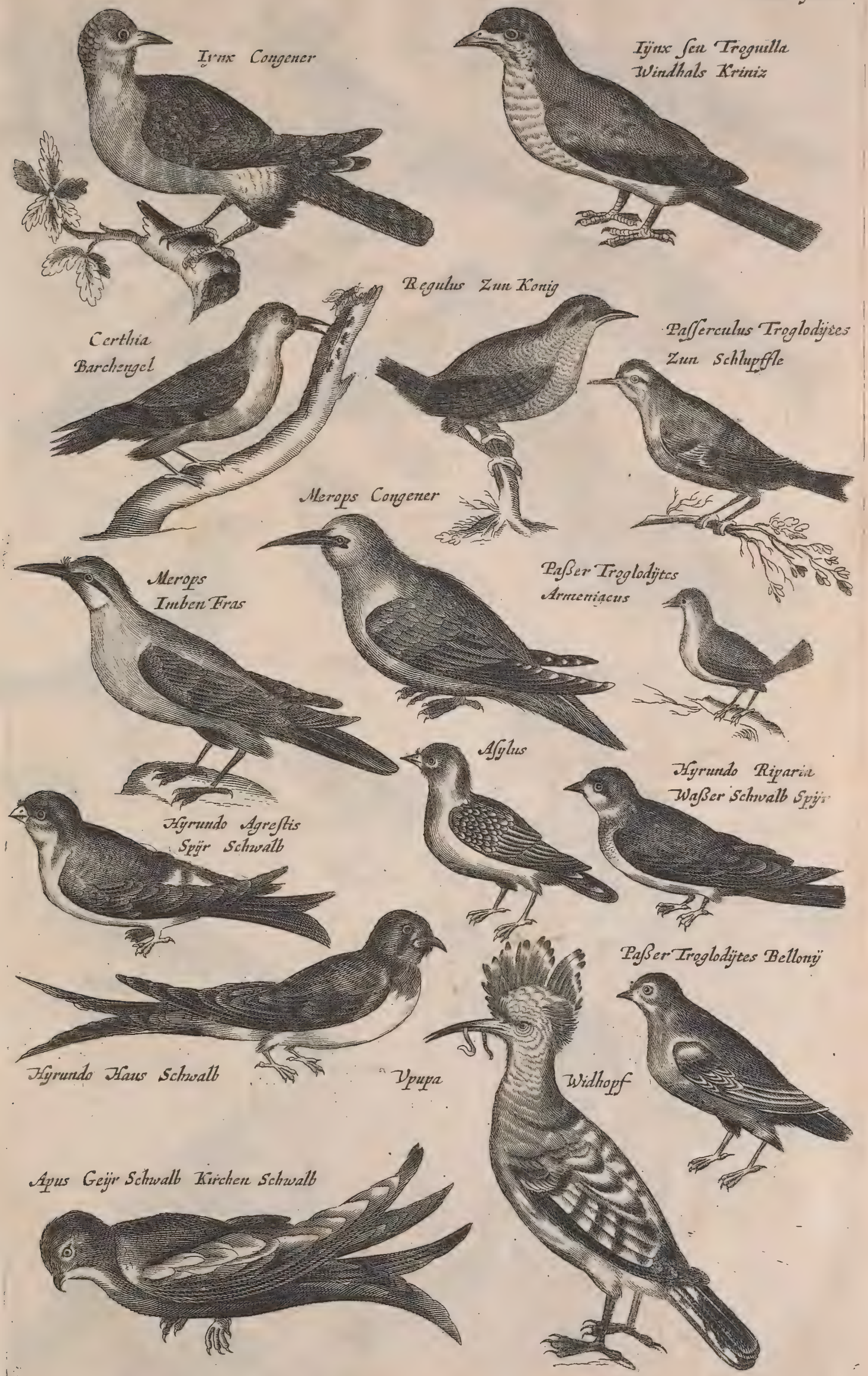


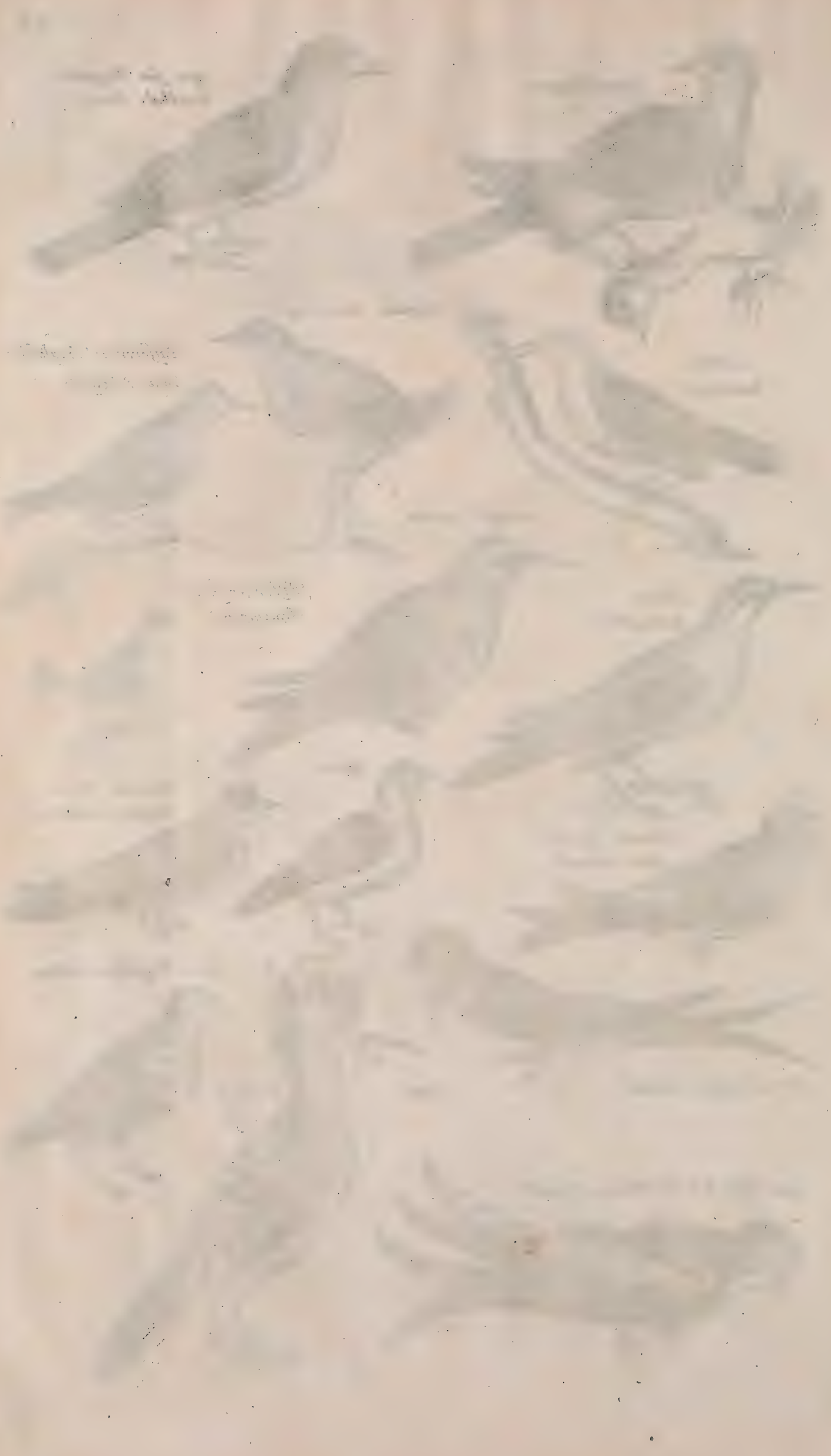




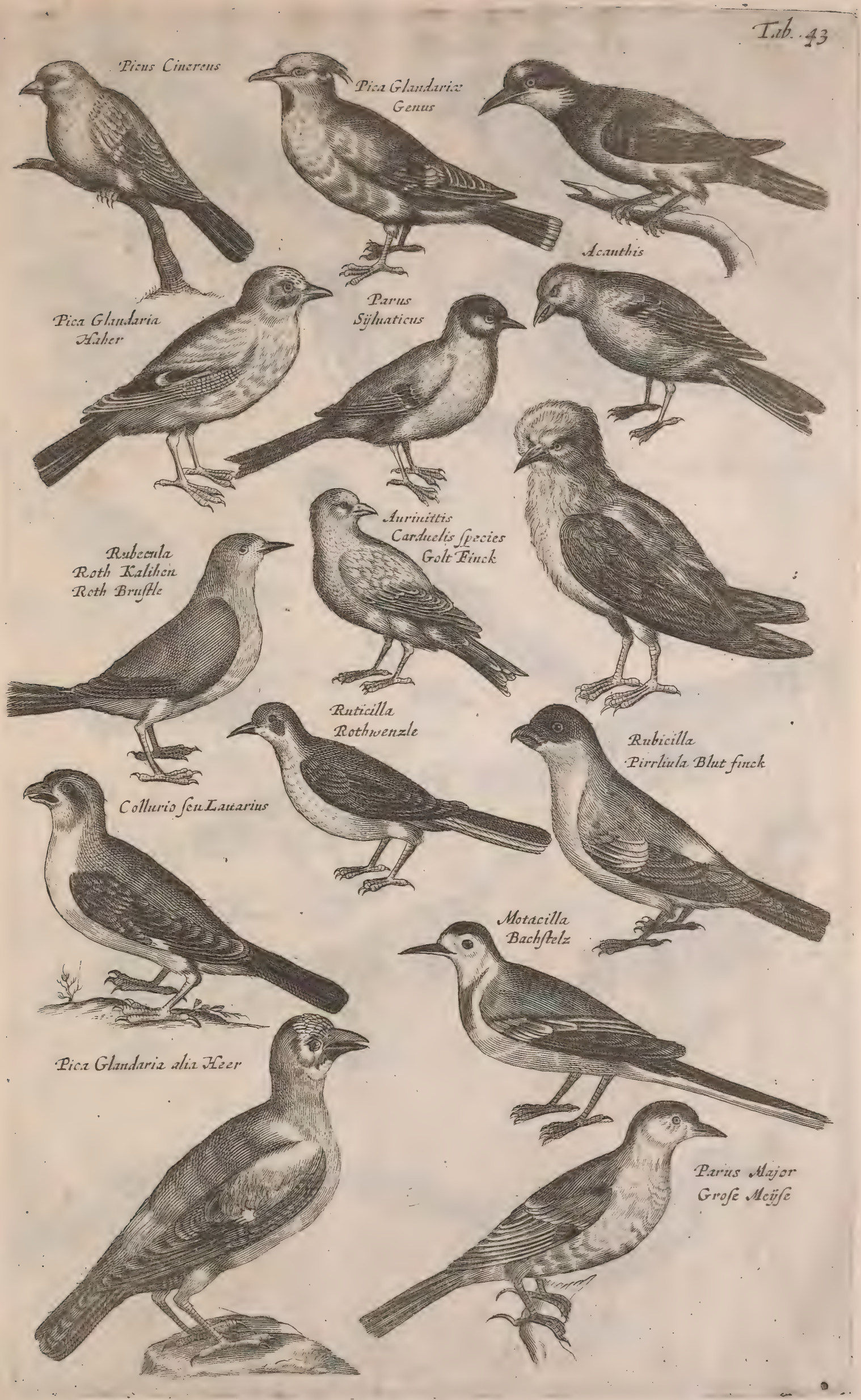



Paris Cerculens minor Blanu meif?

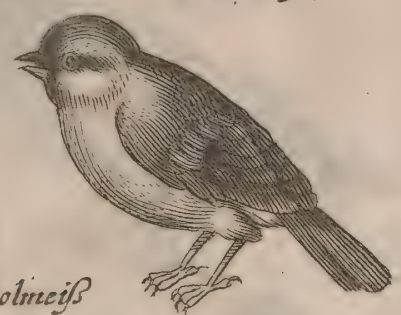

Parus ateritiolncis
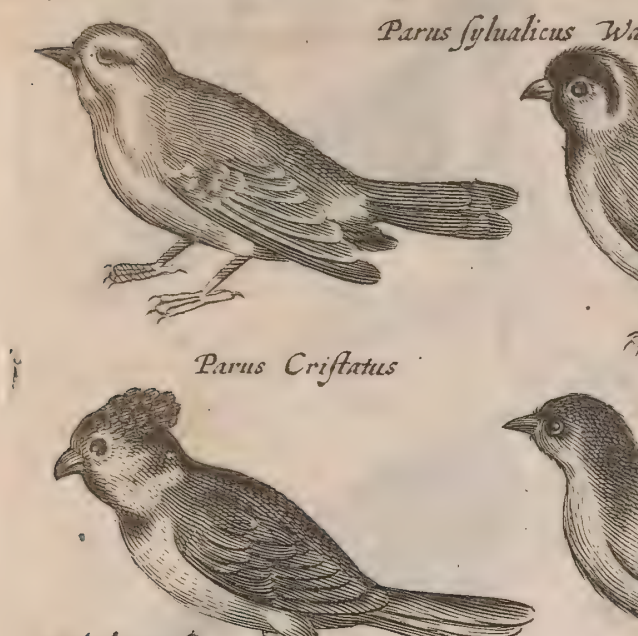

Tobel mais

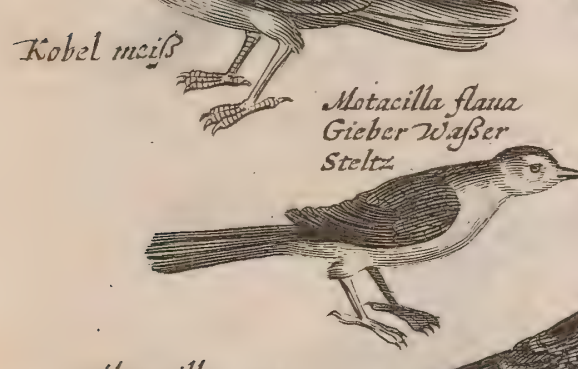

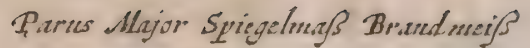

T.d. 44

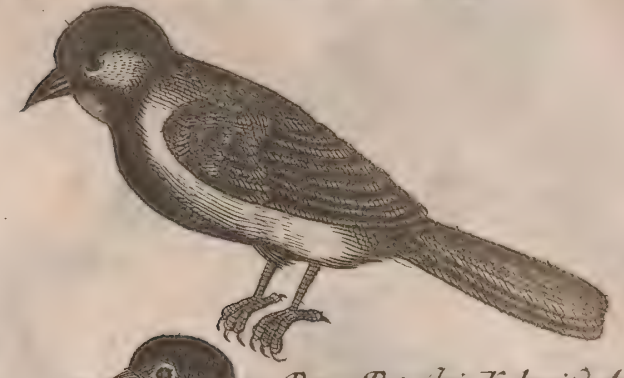

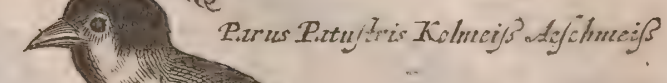
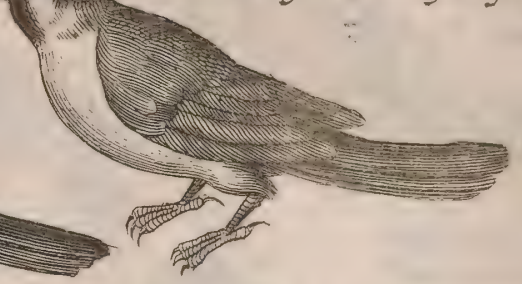
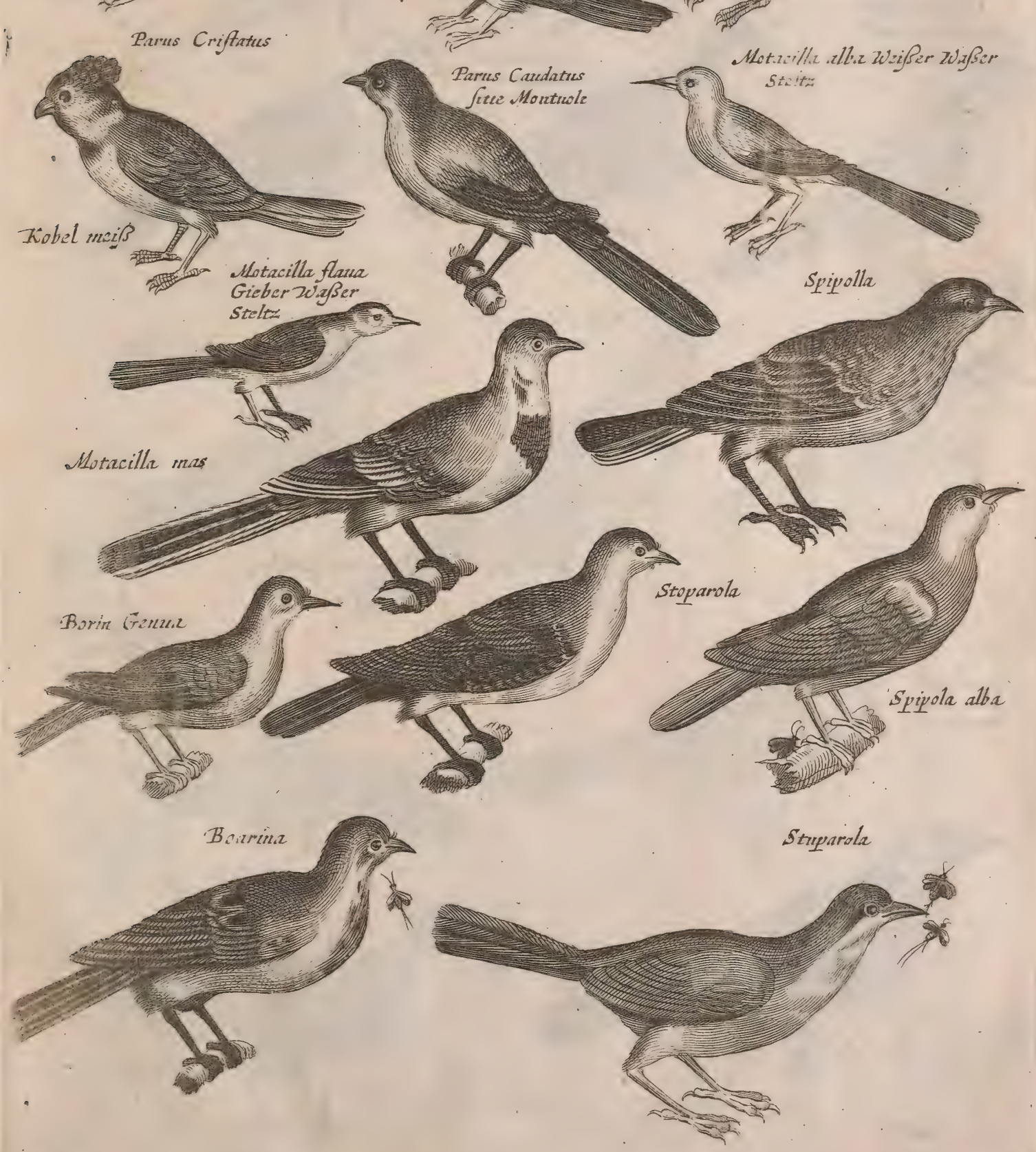


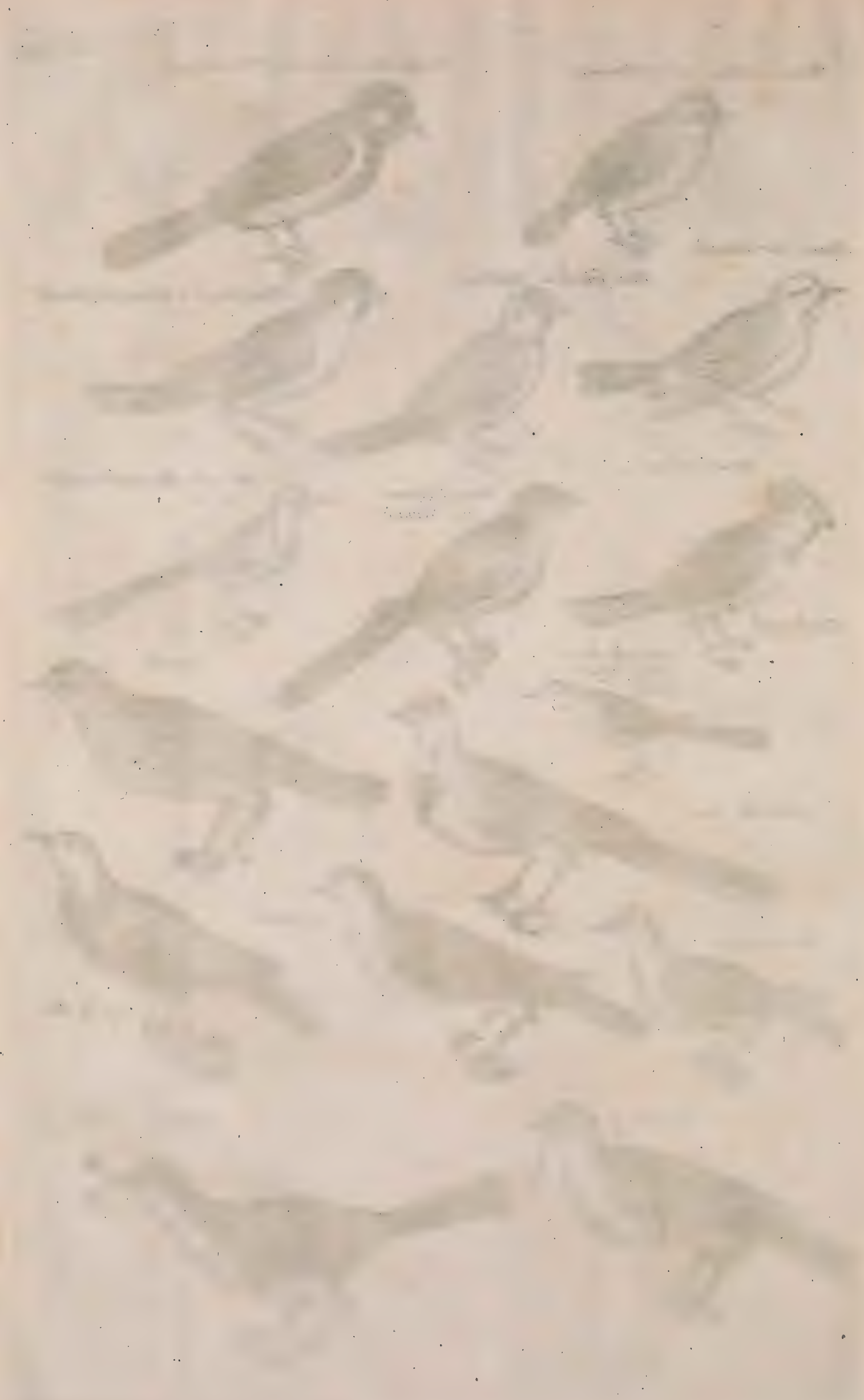



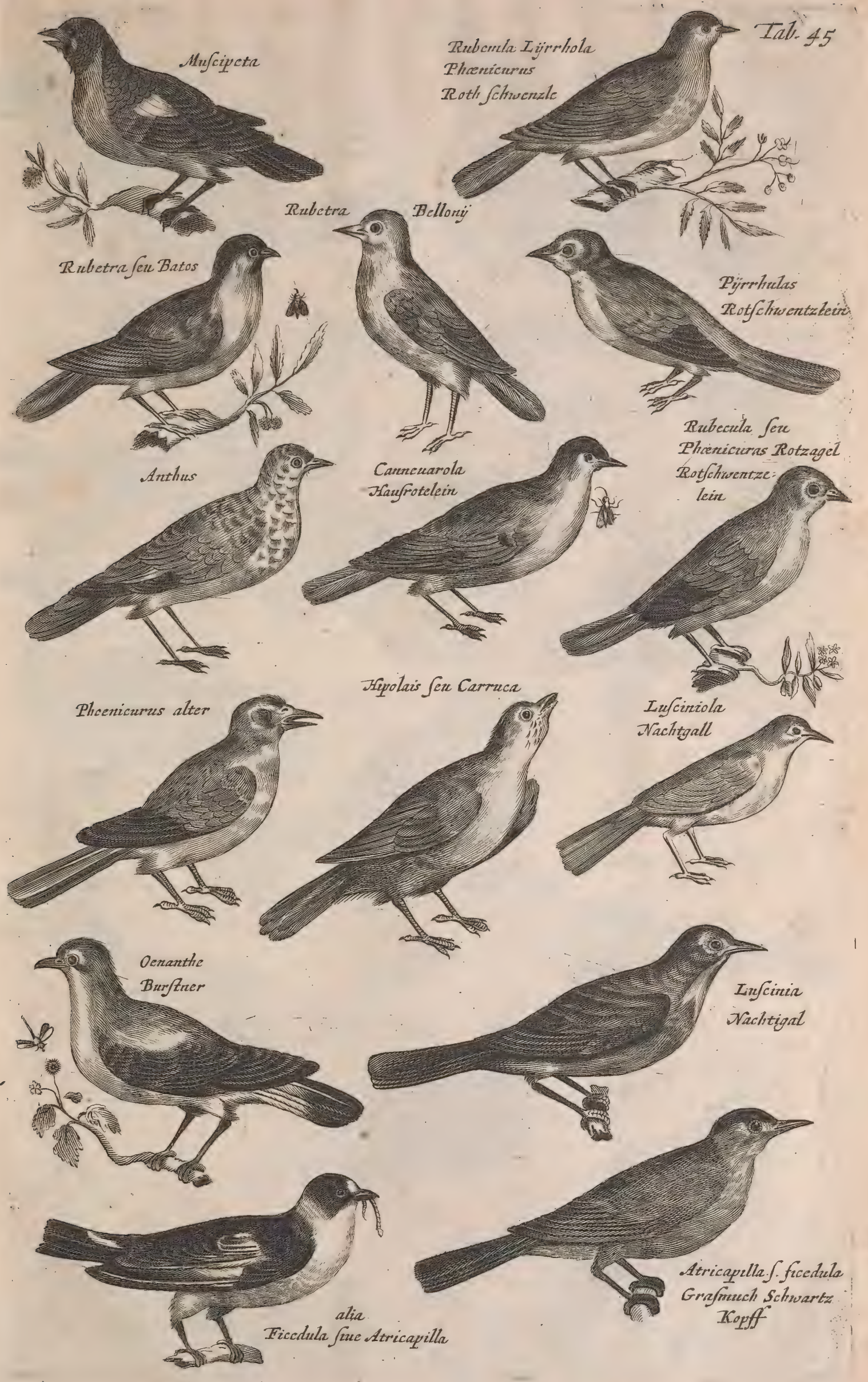
.

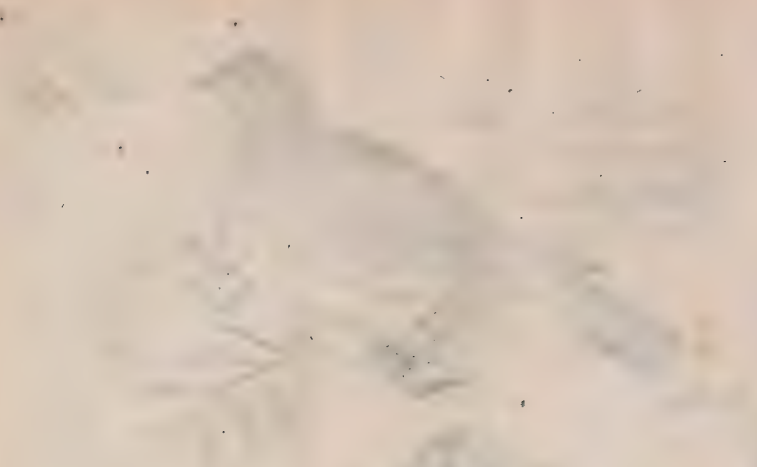

$$
\text { in }
$$
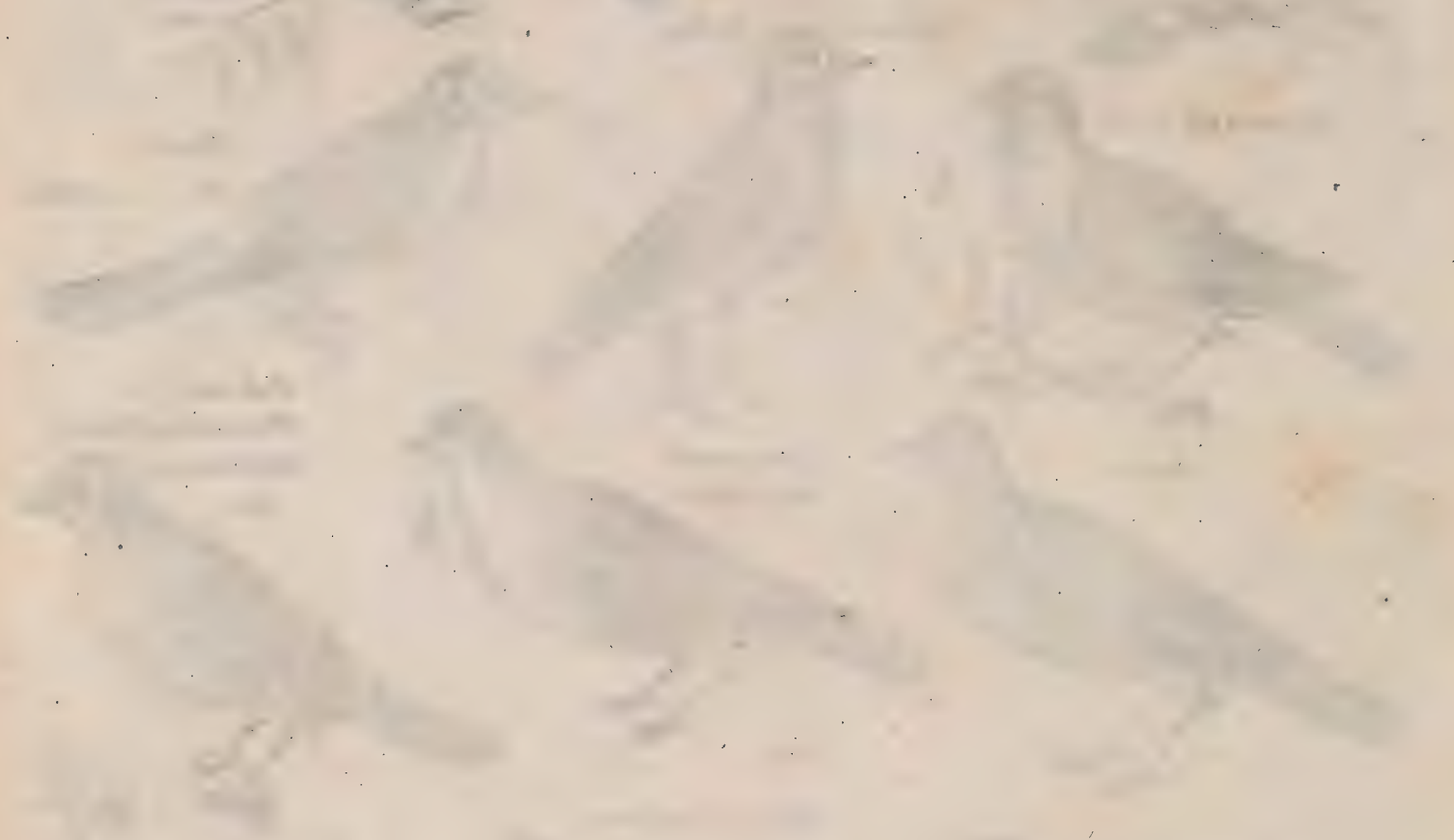

-

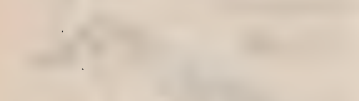

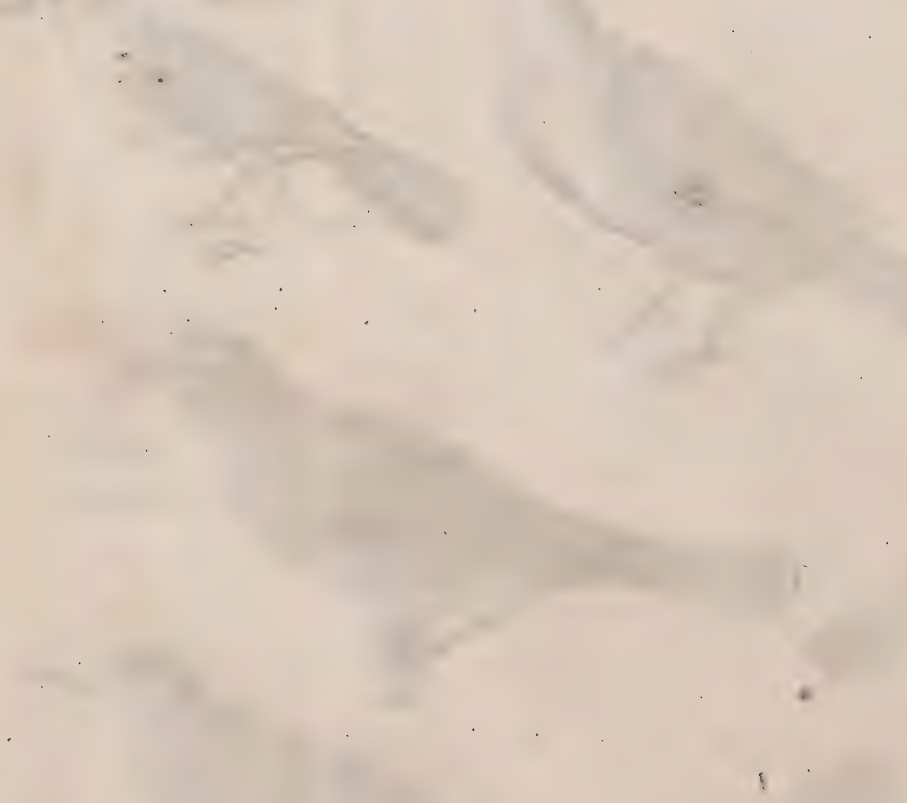




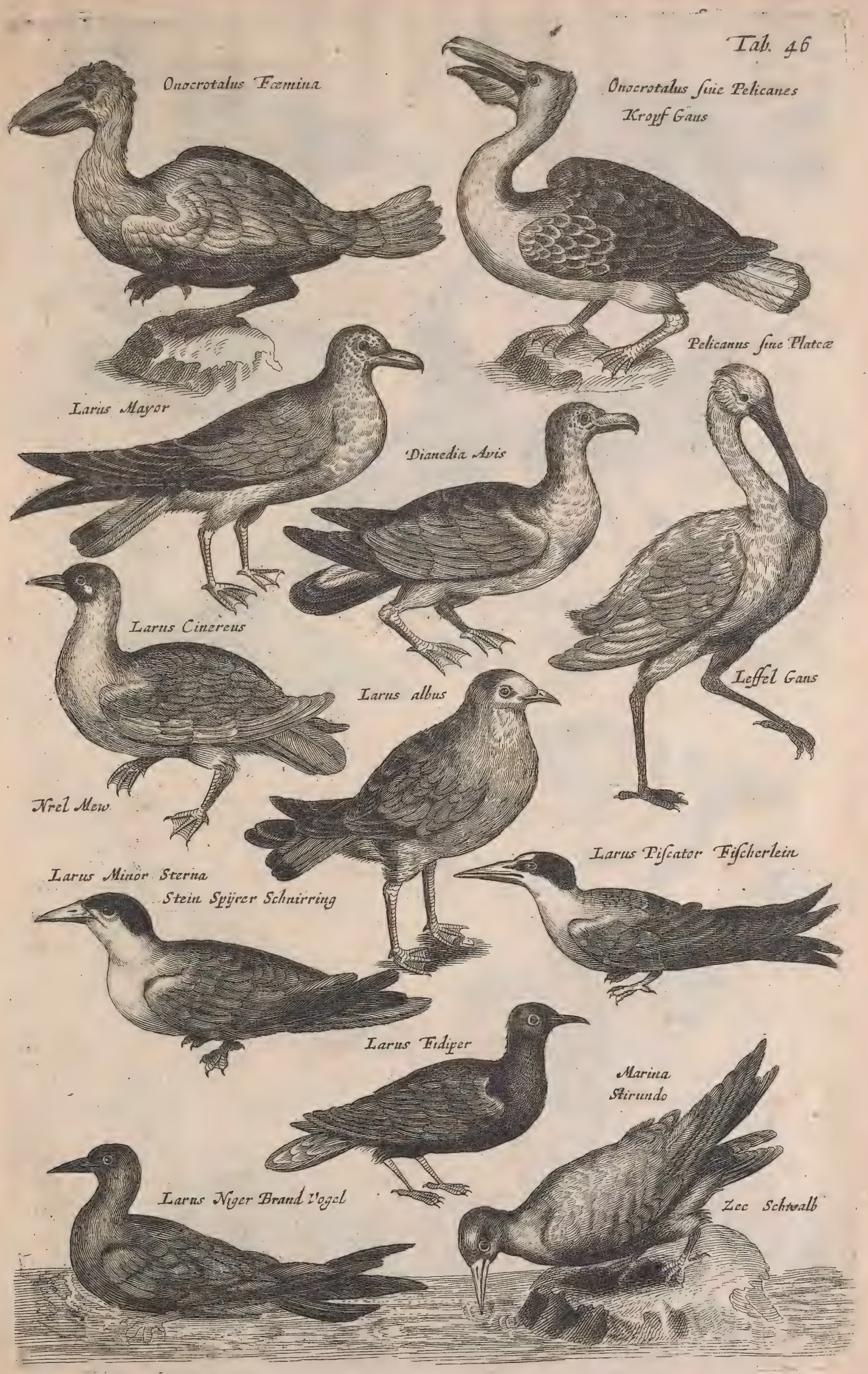



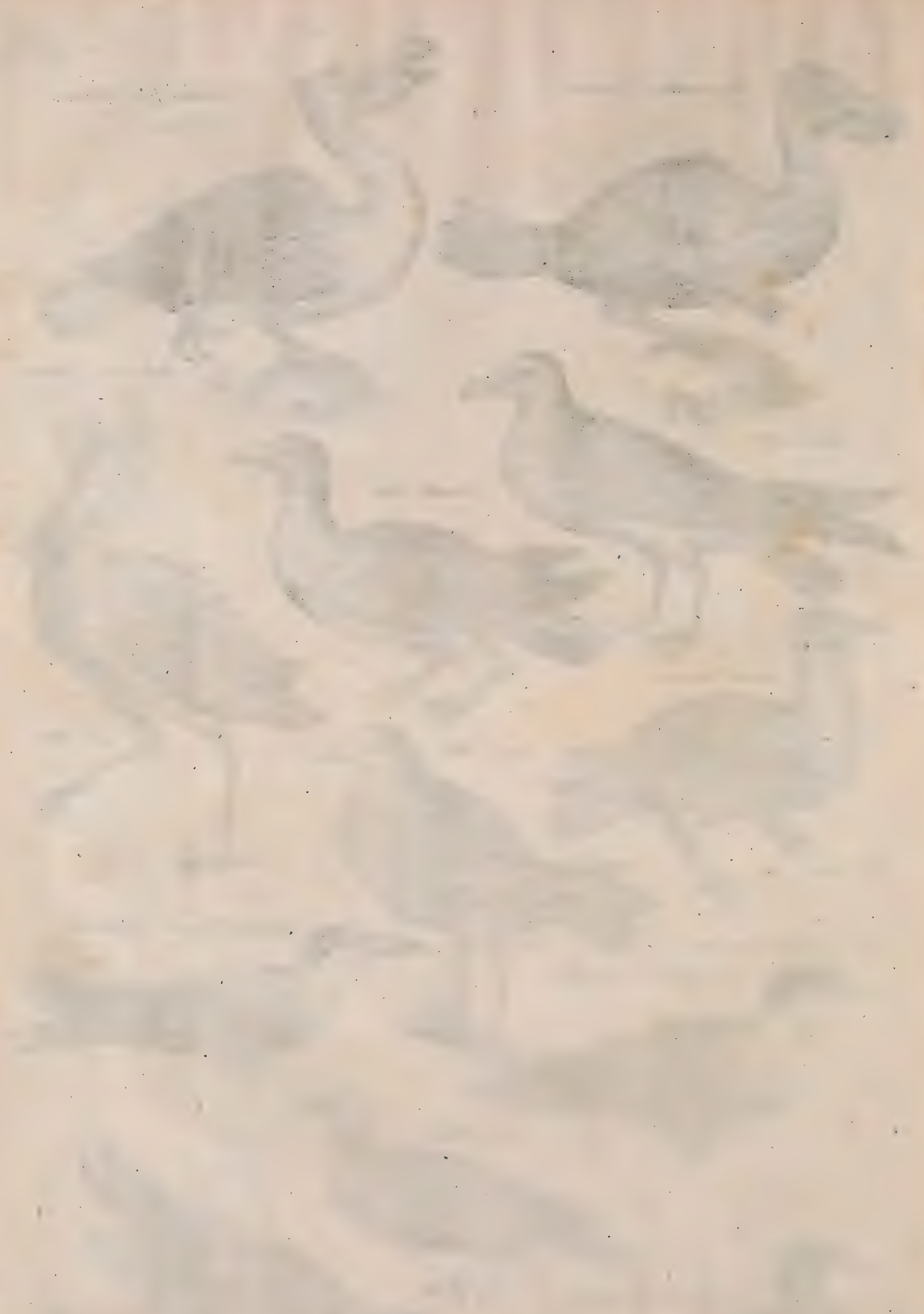

. 


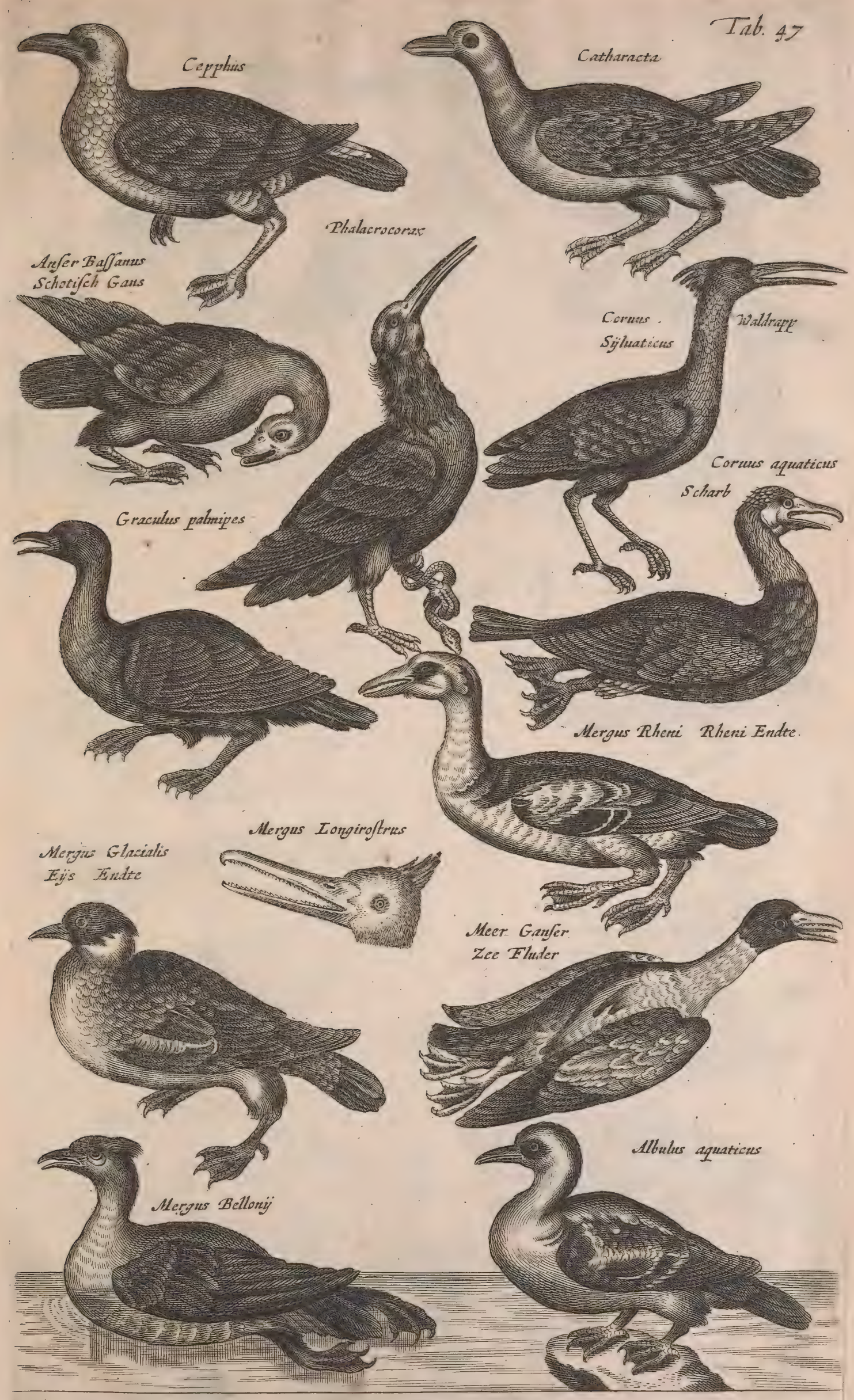




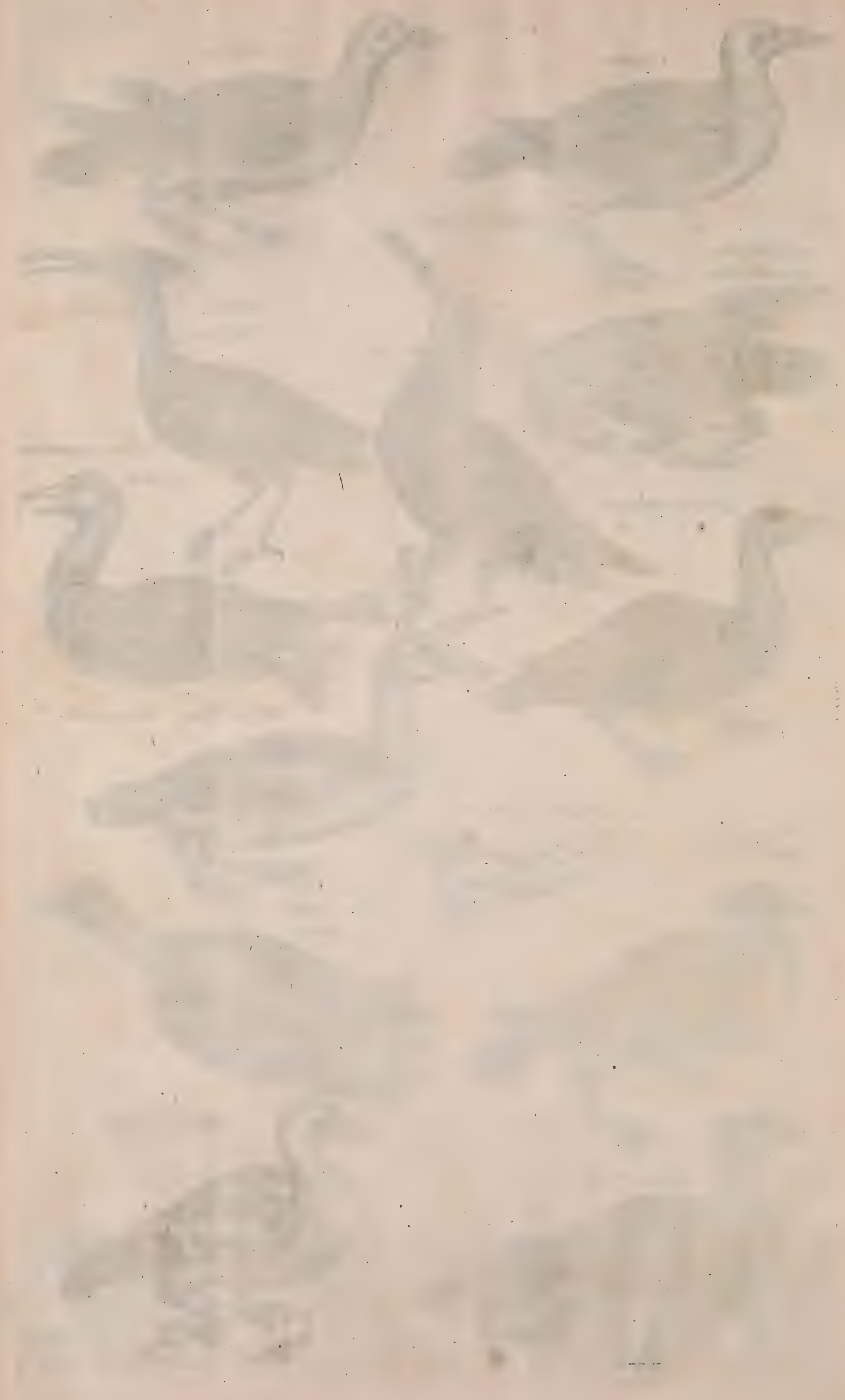




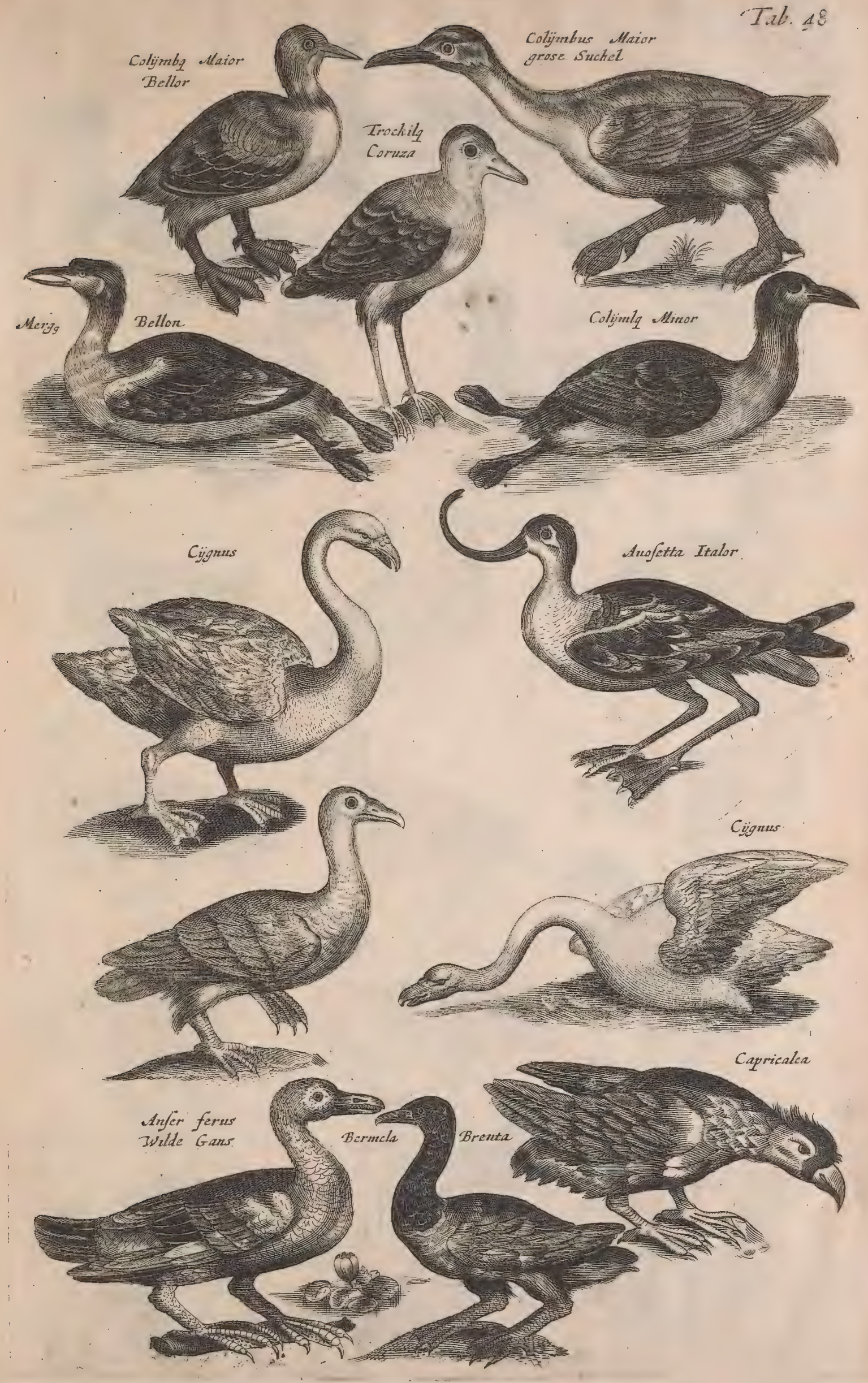



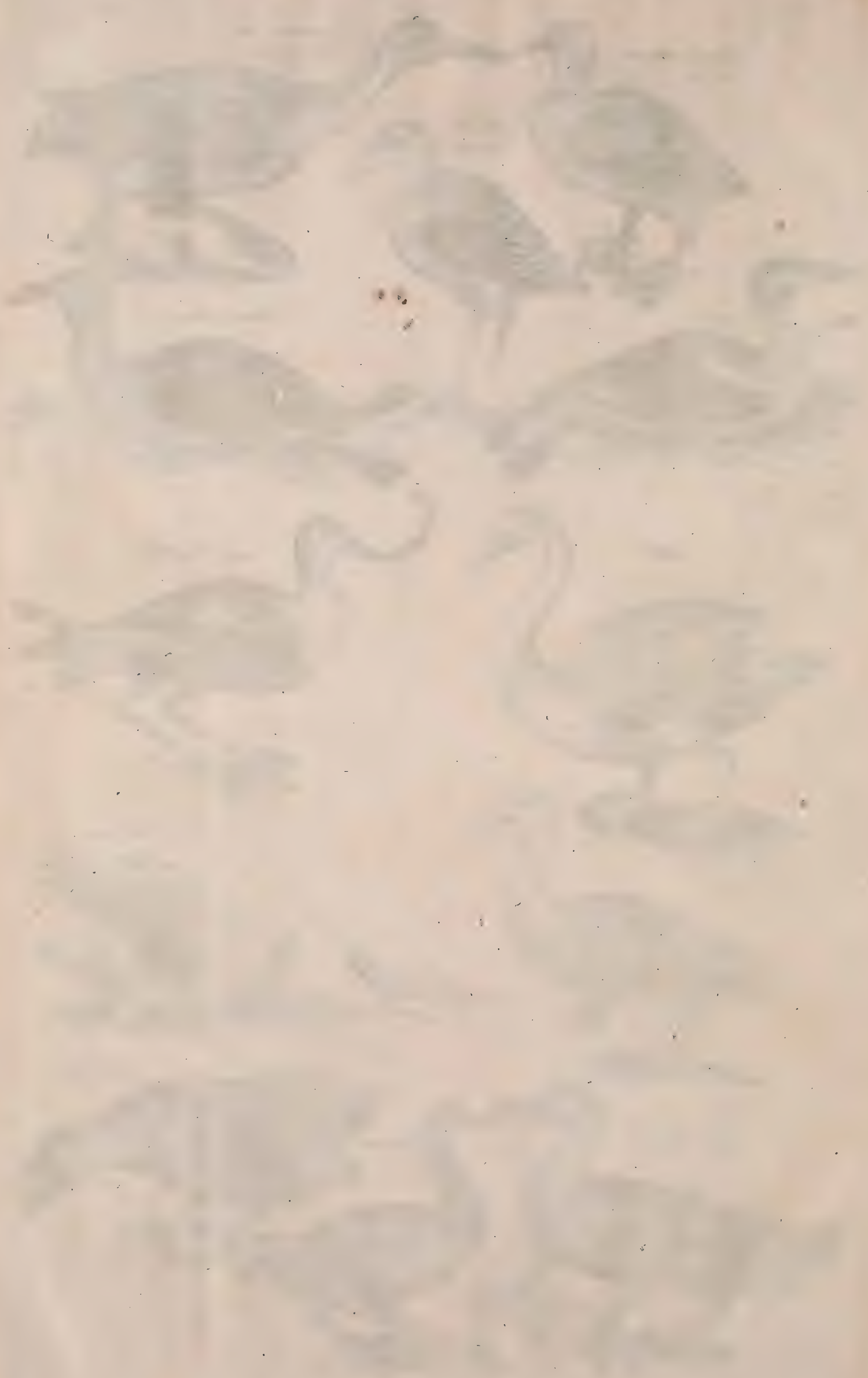


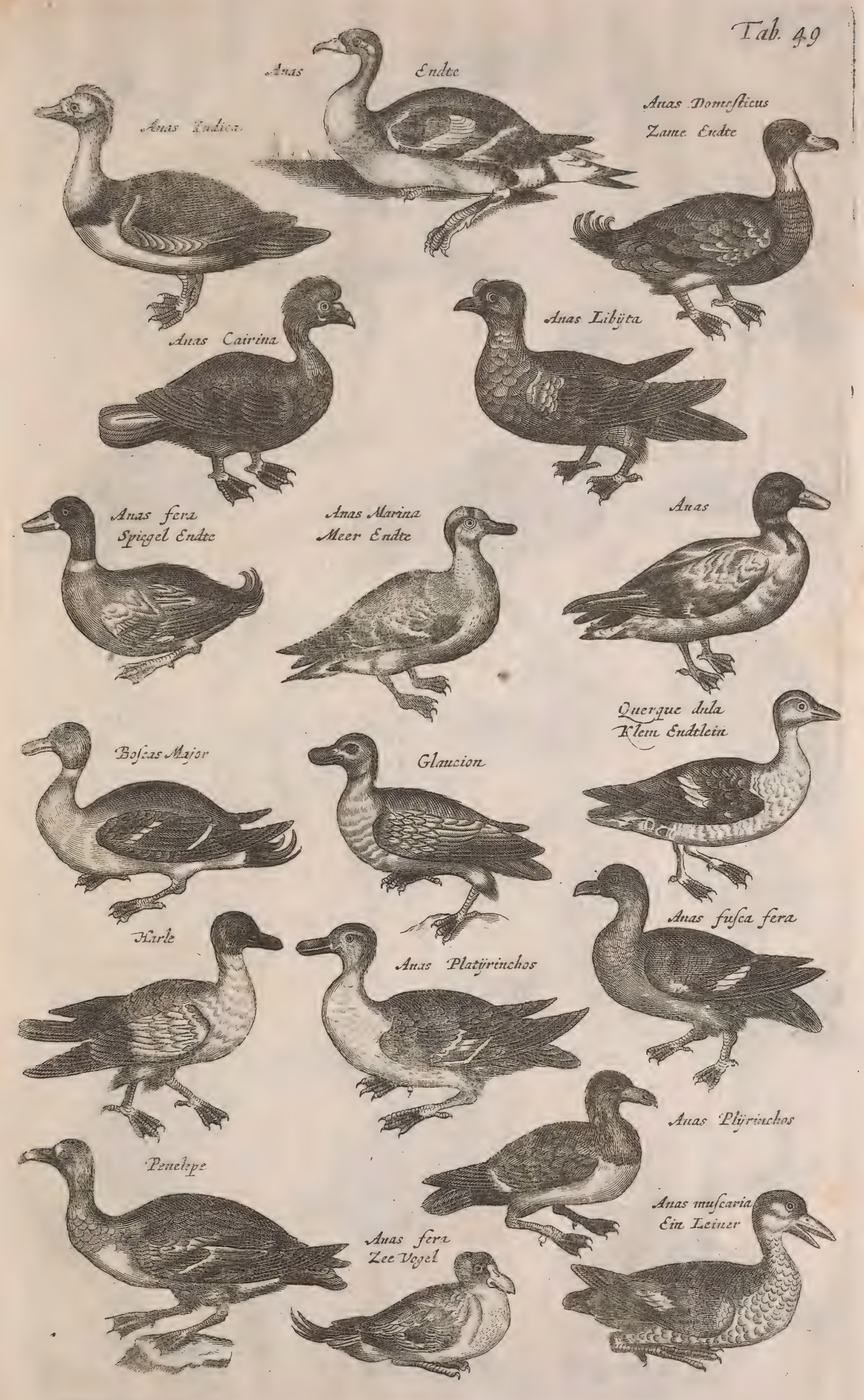




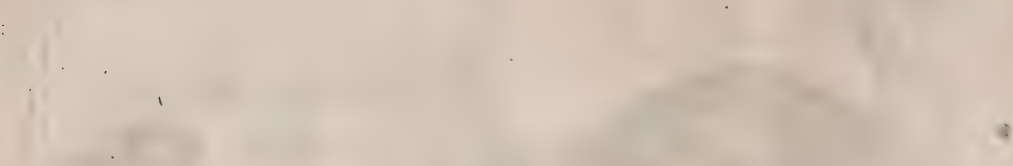
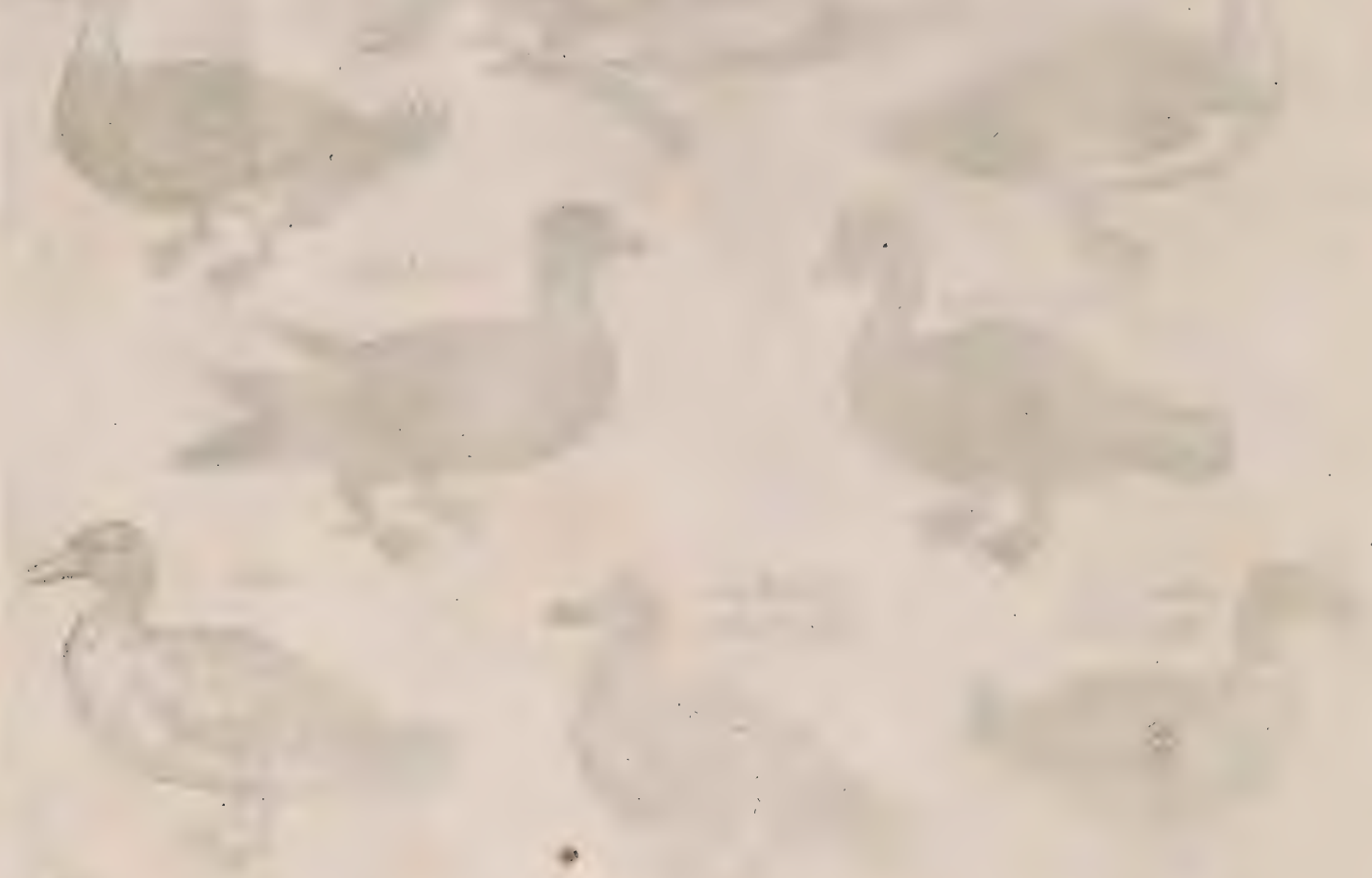

.
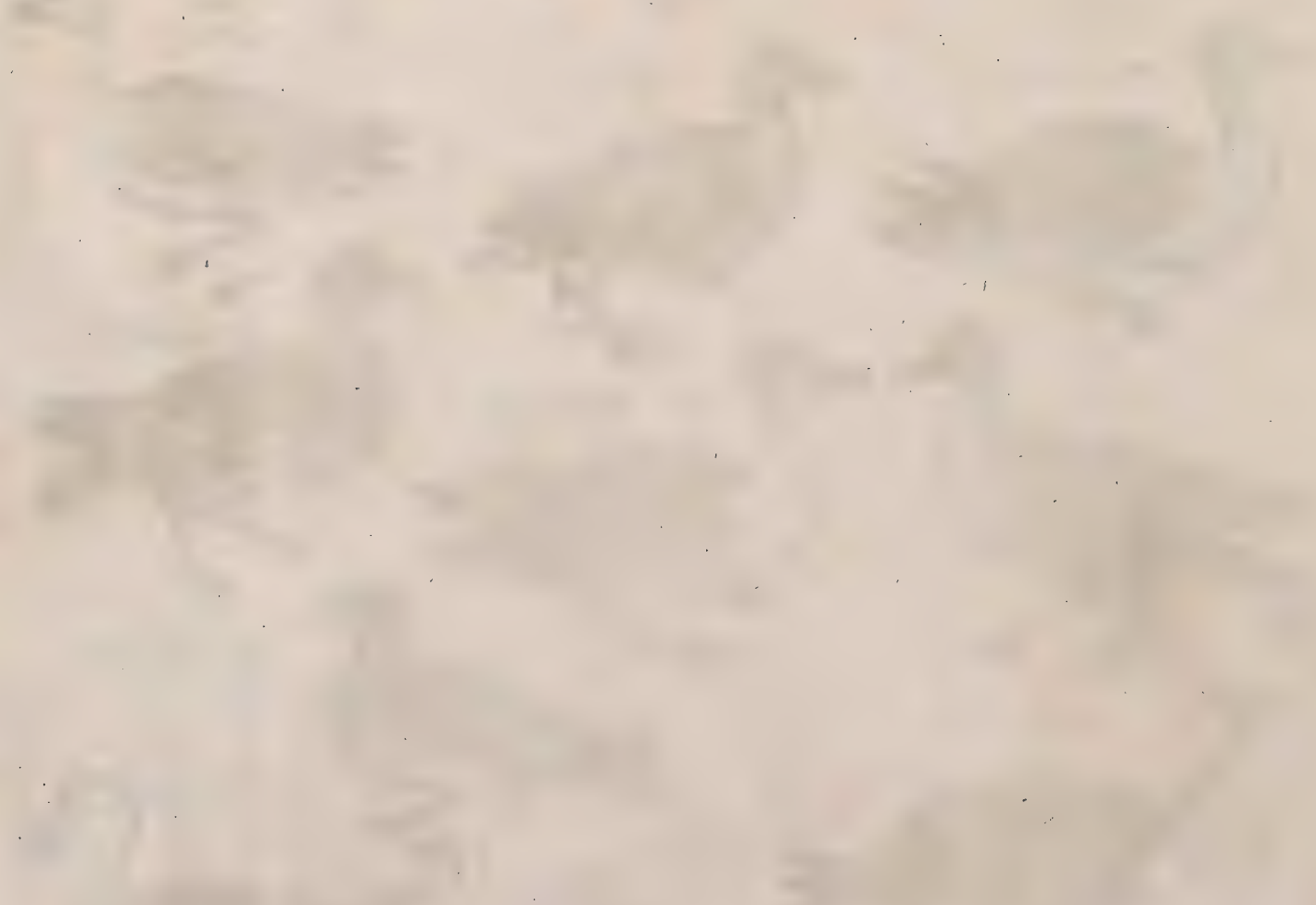


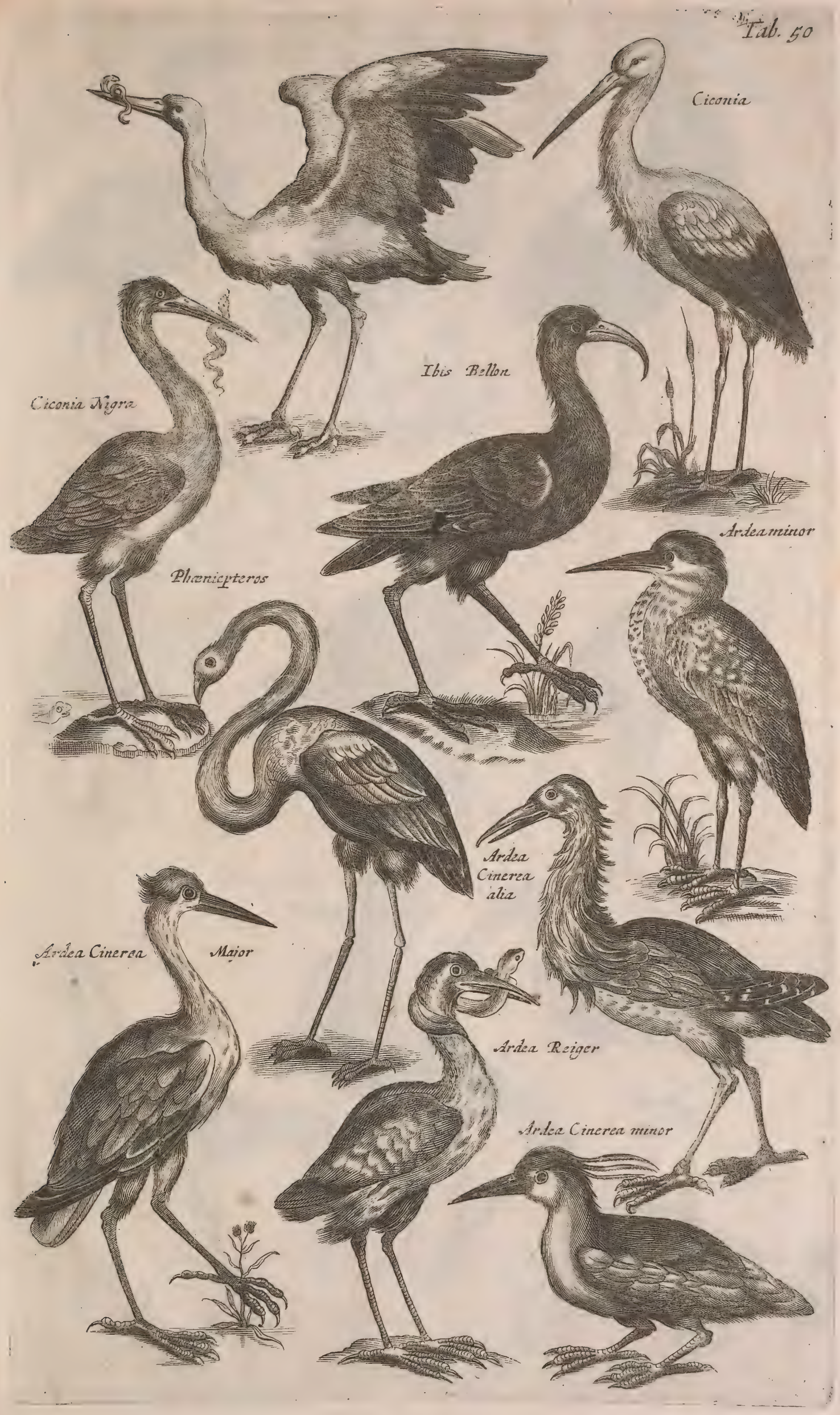





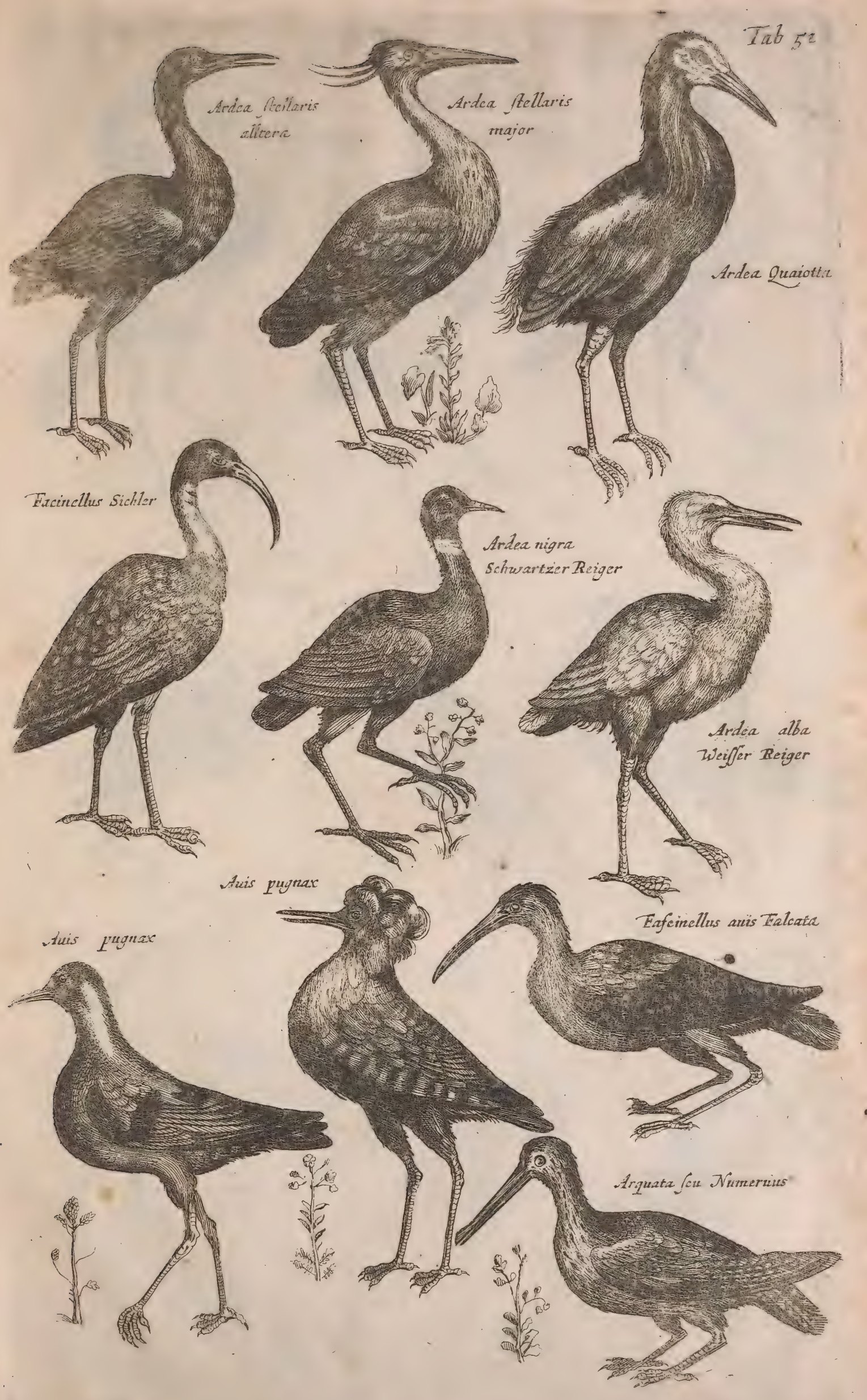




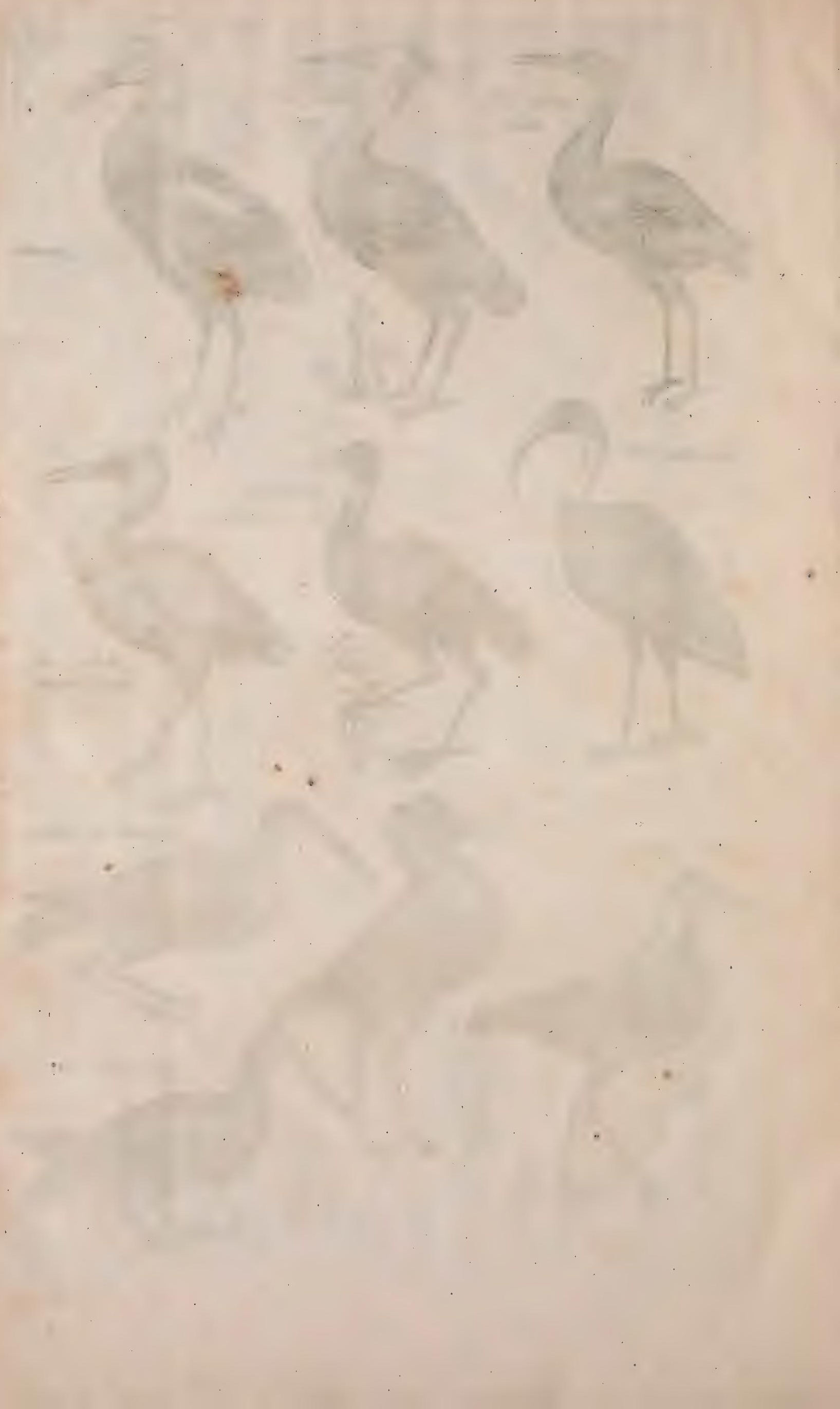



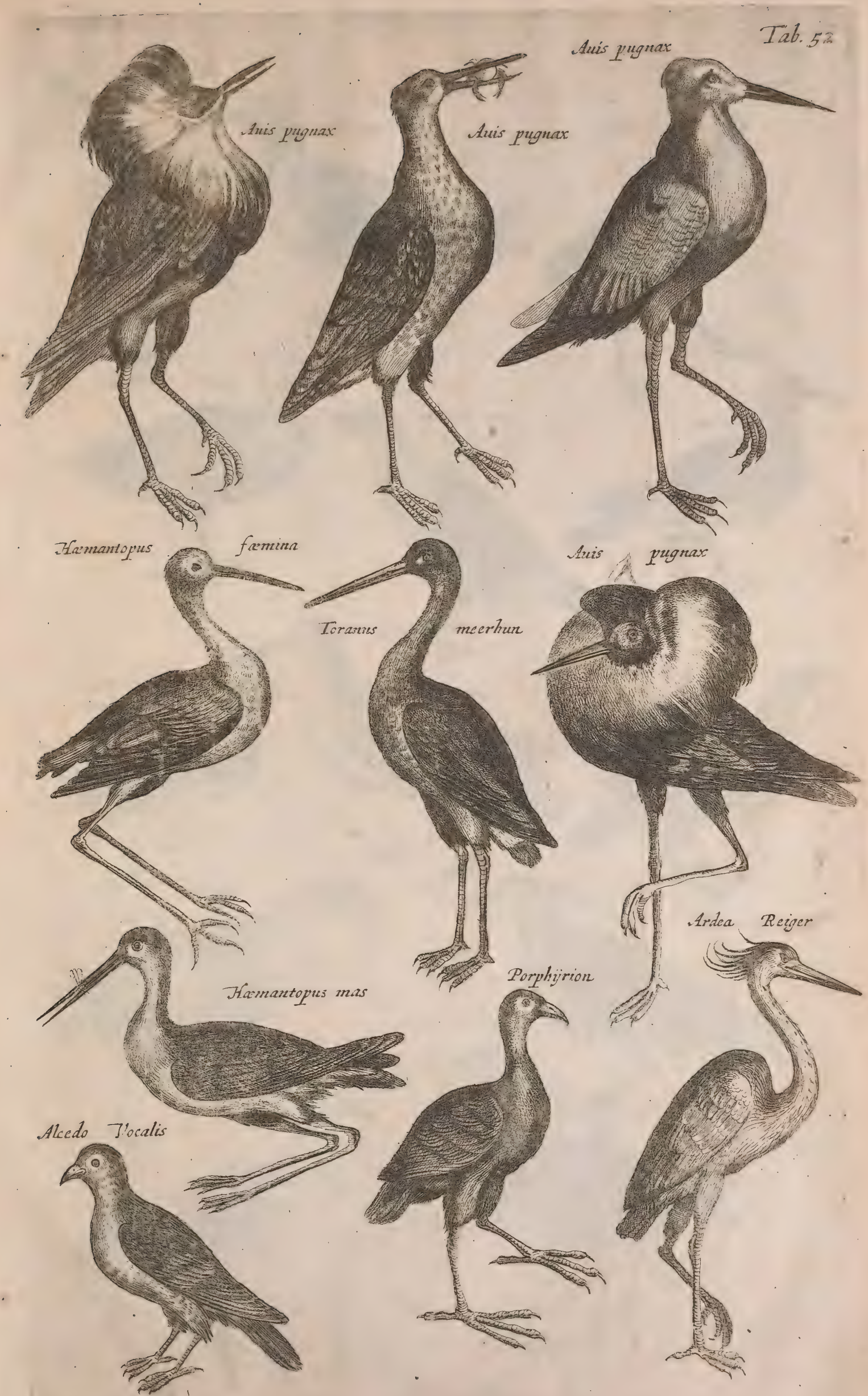


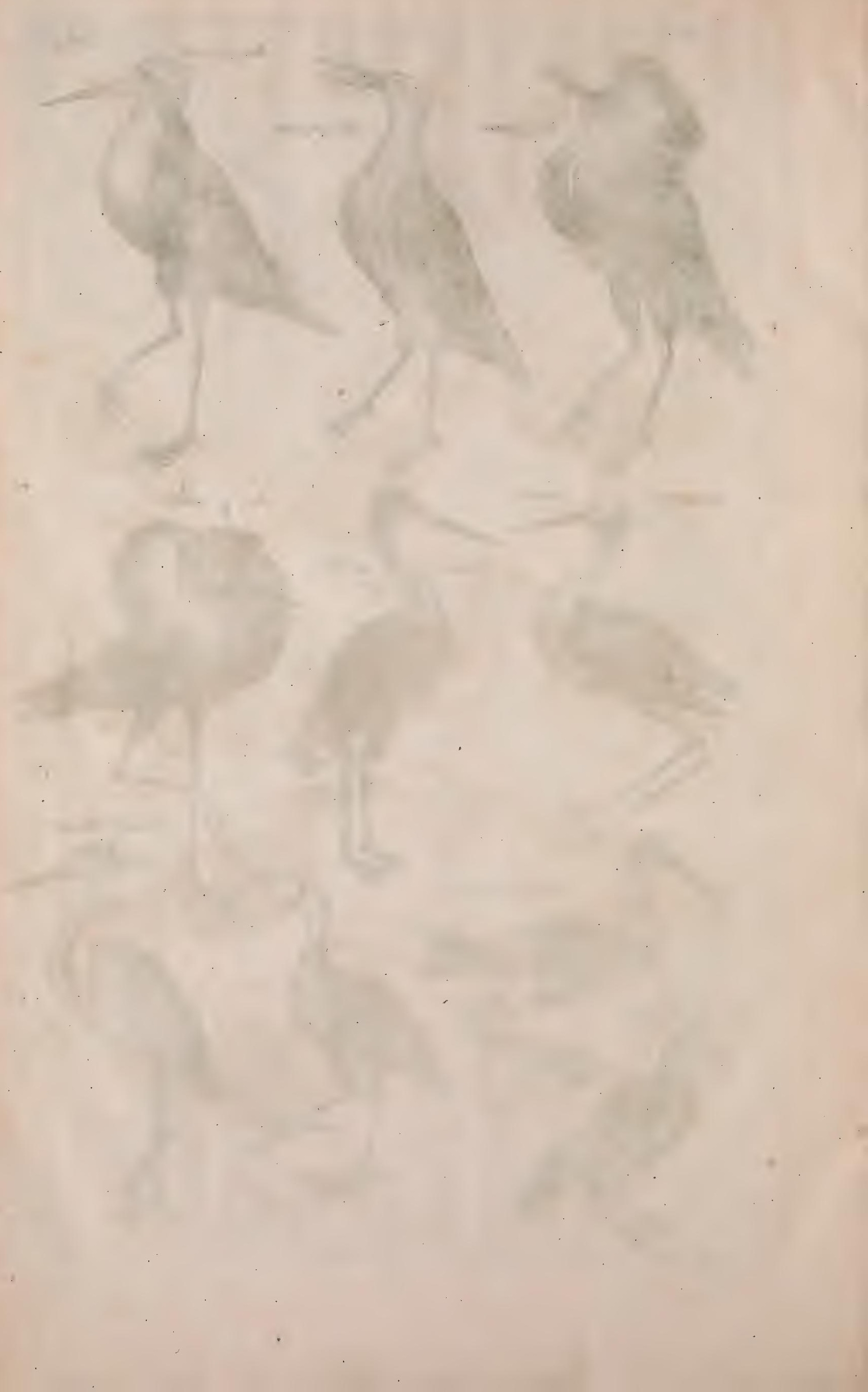




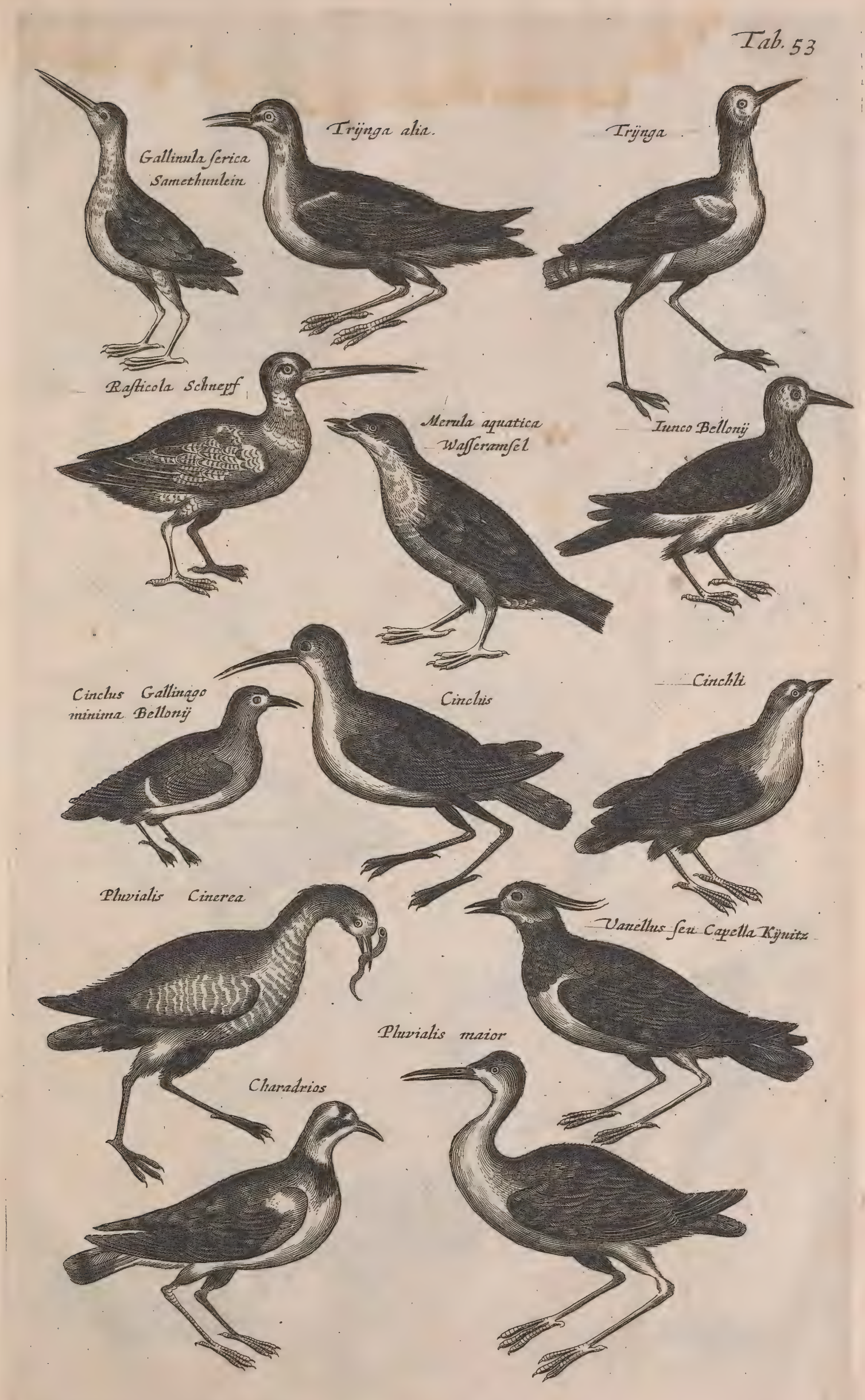




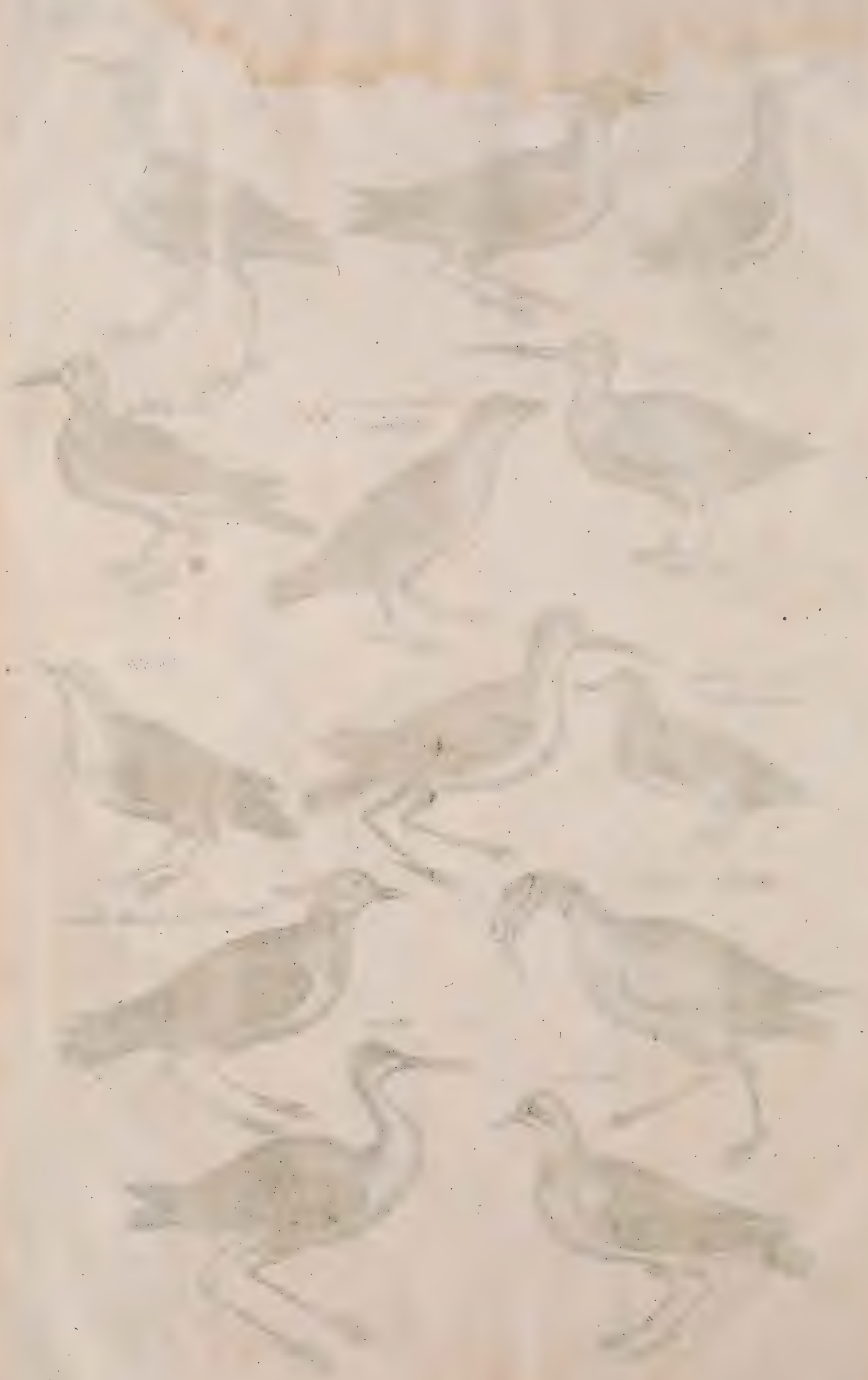




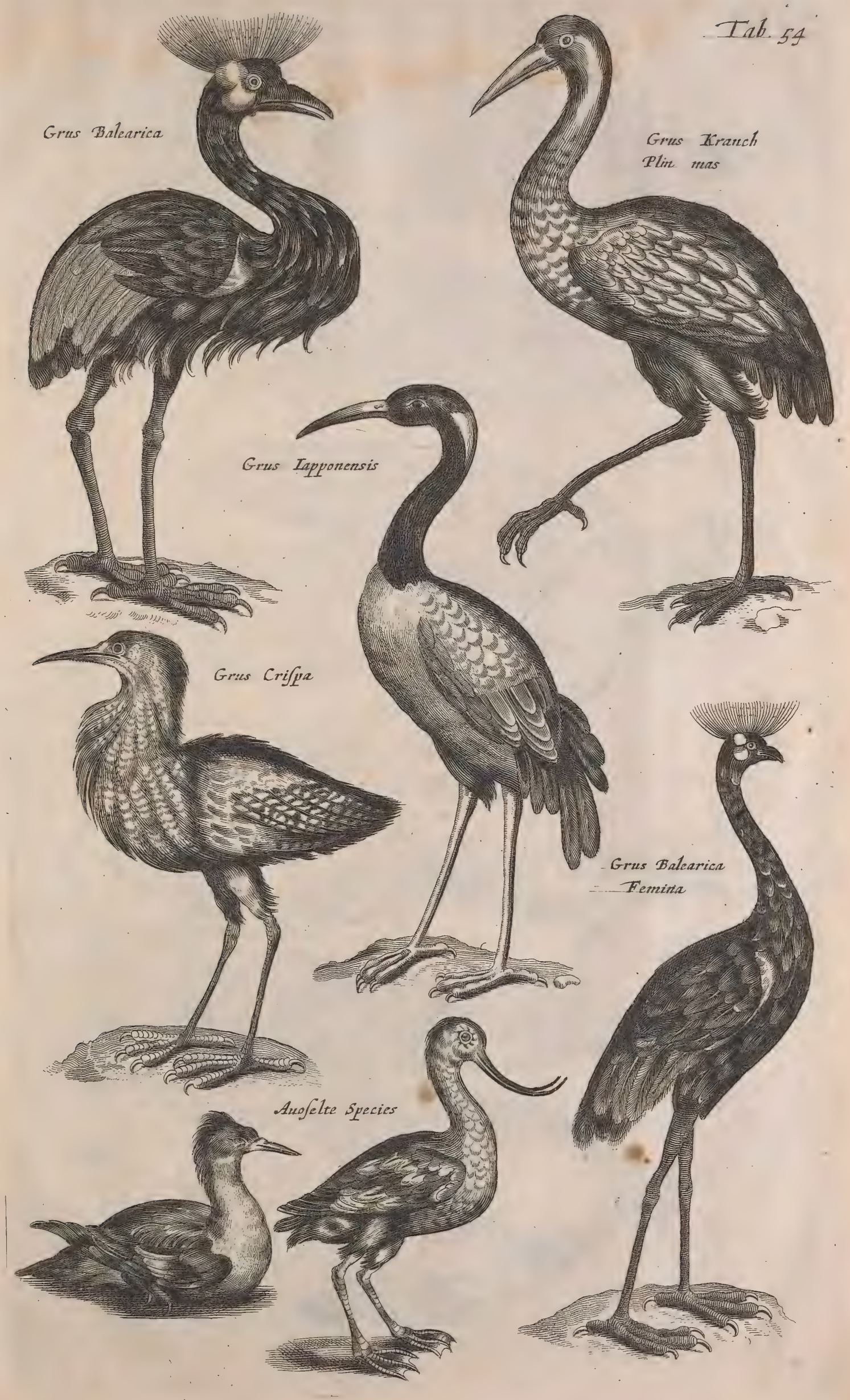





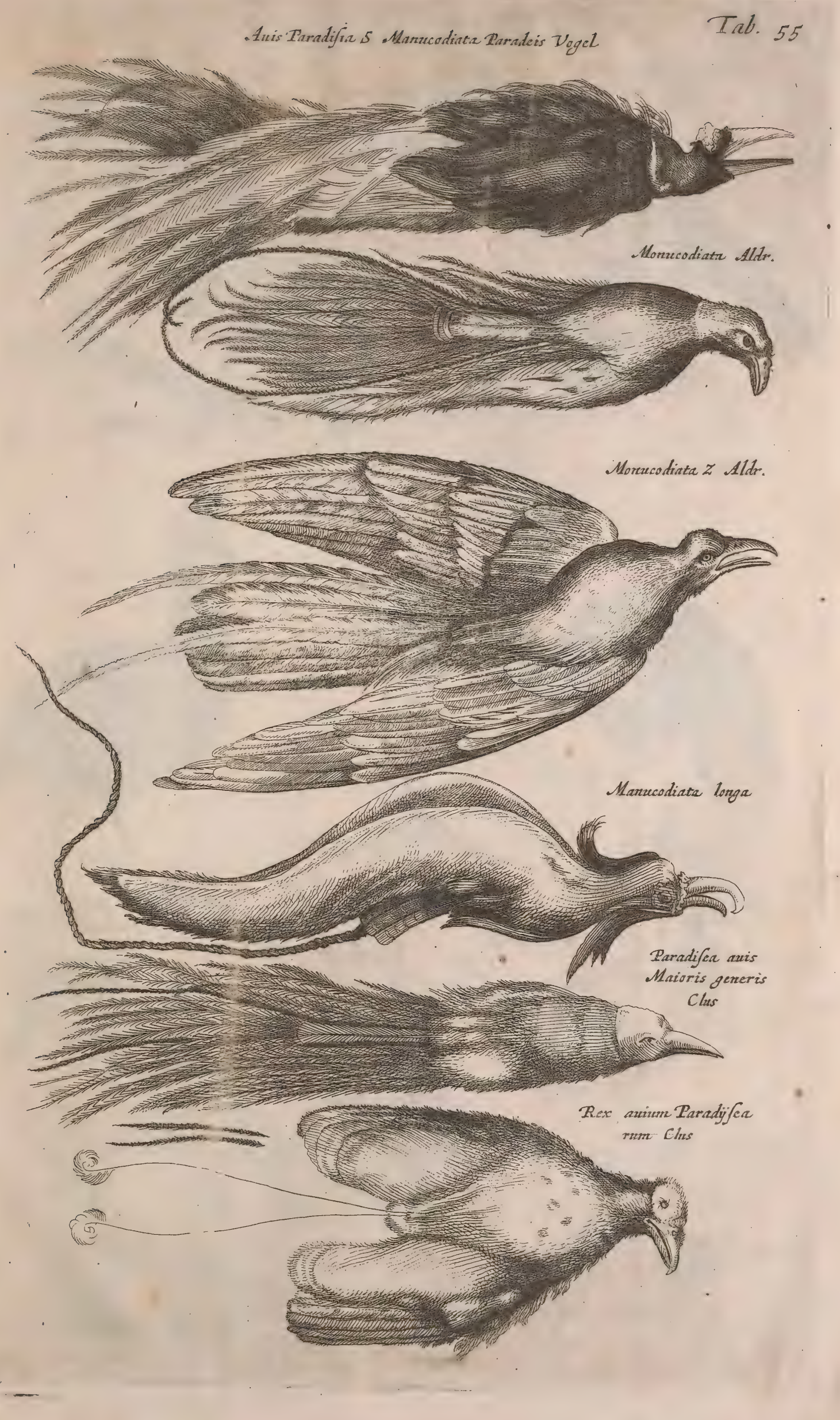



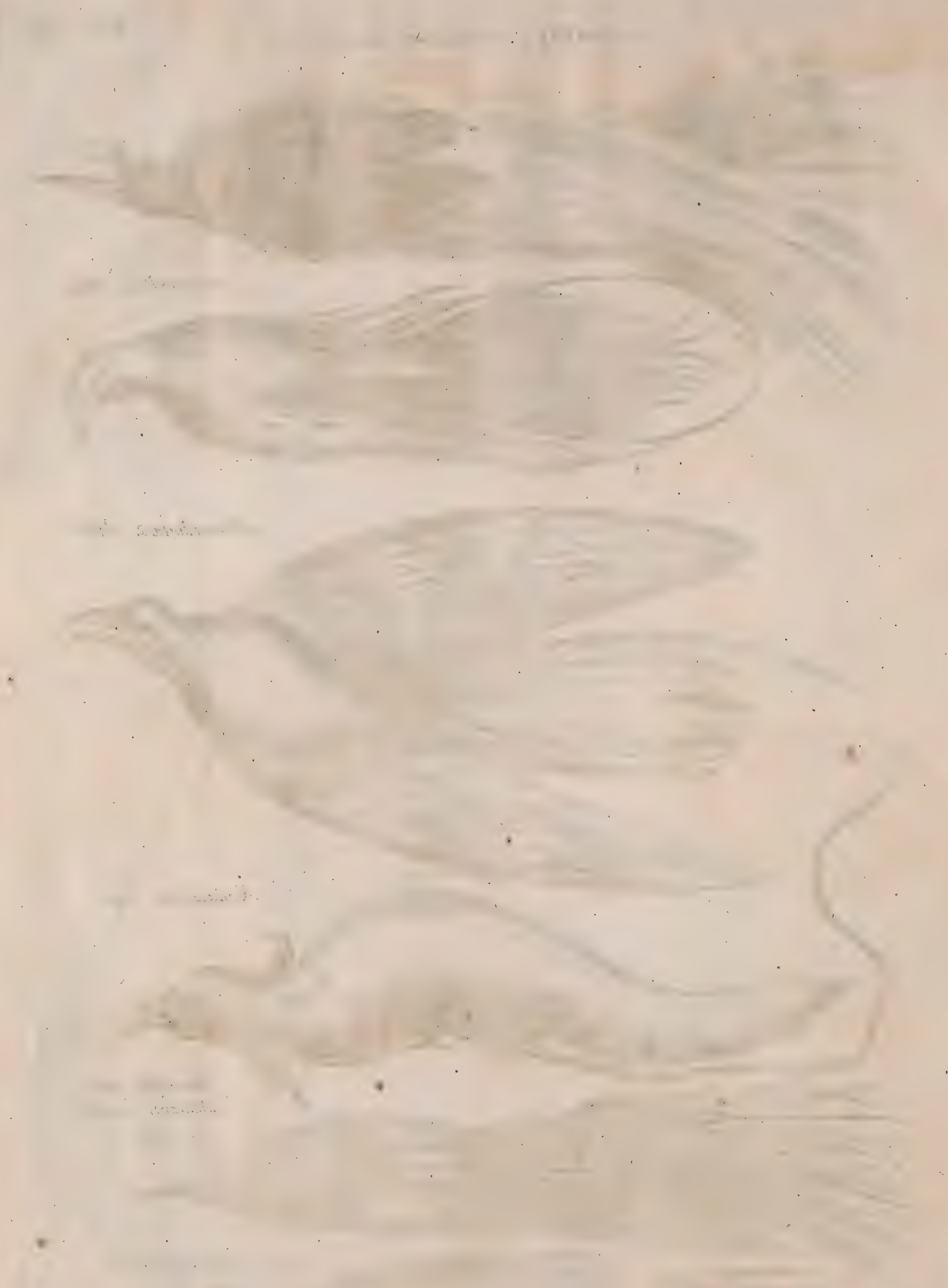

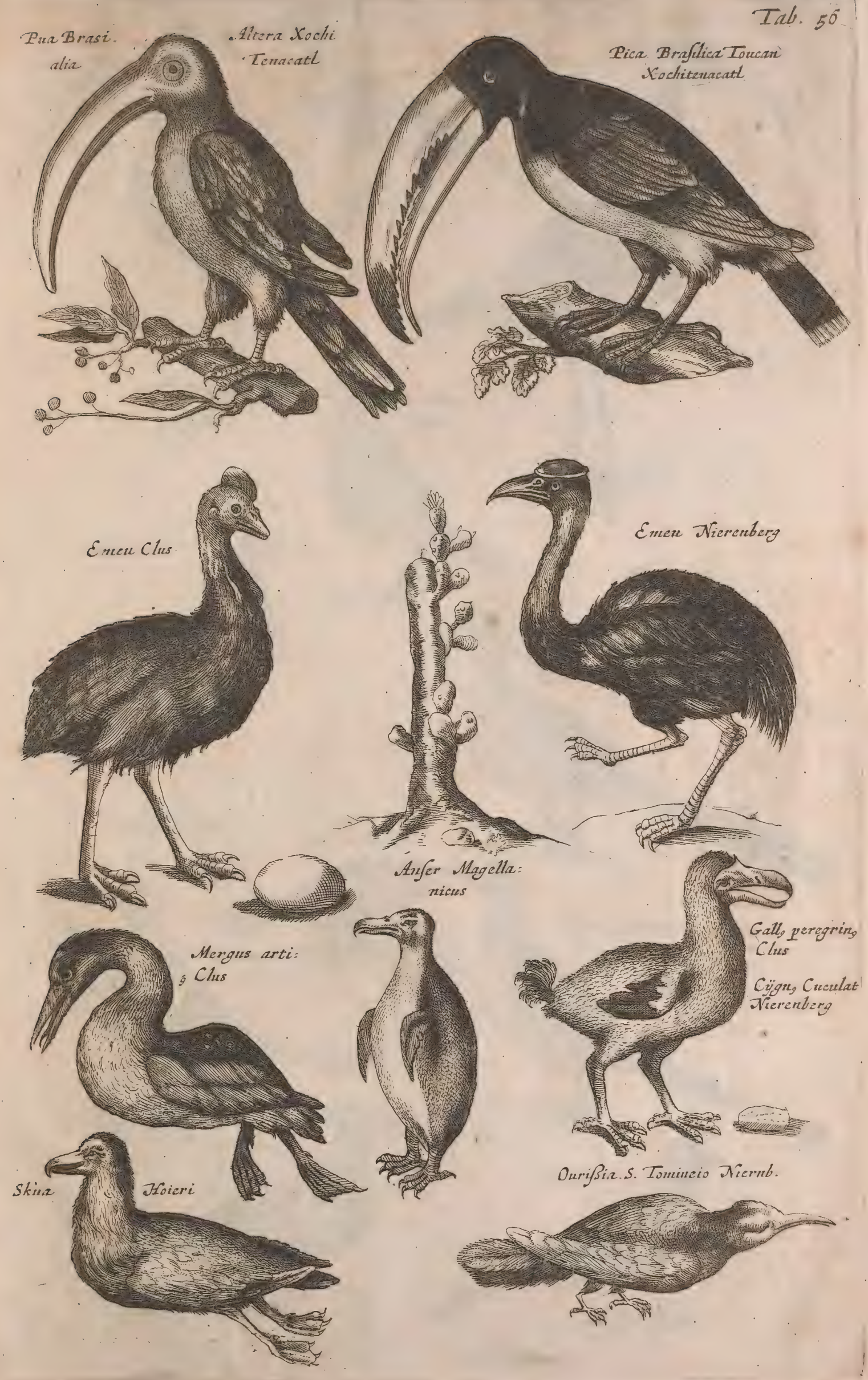

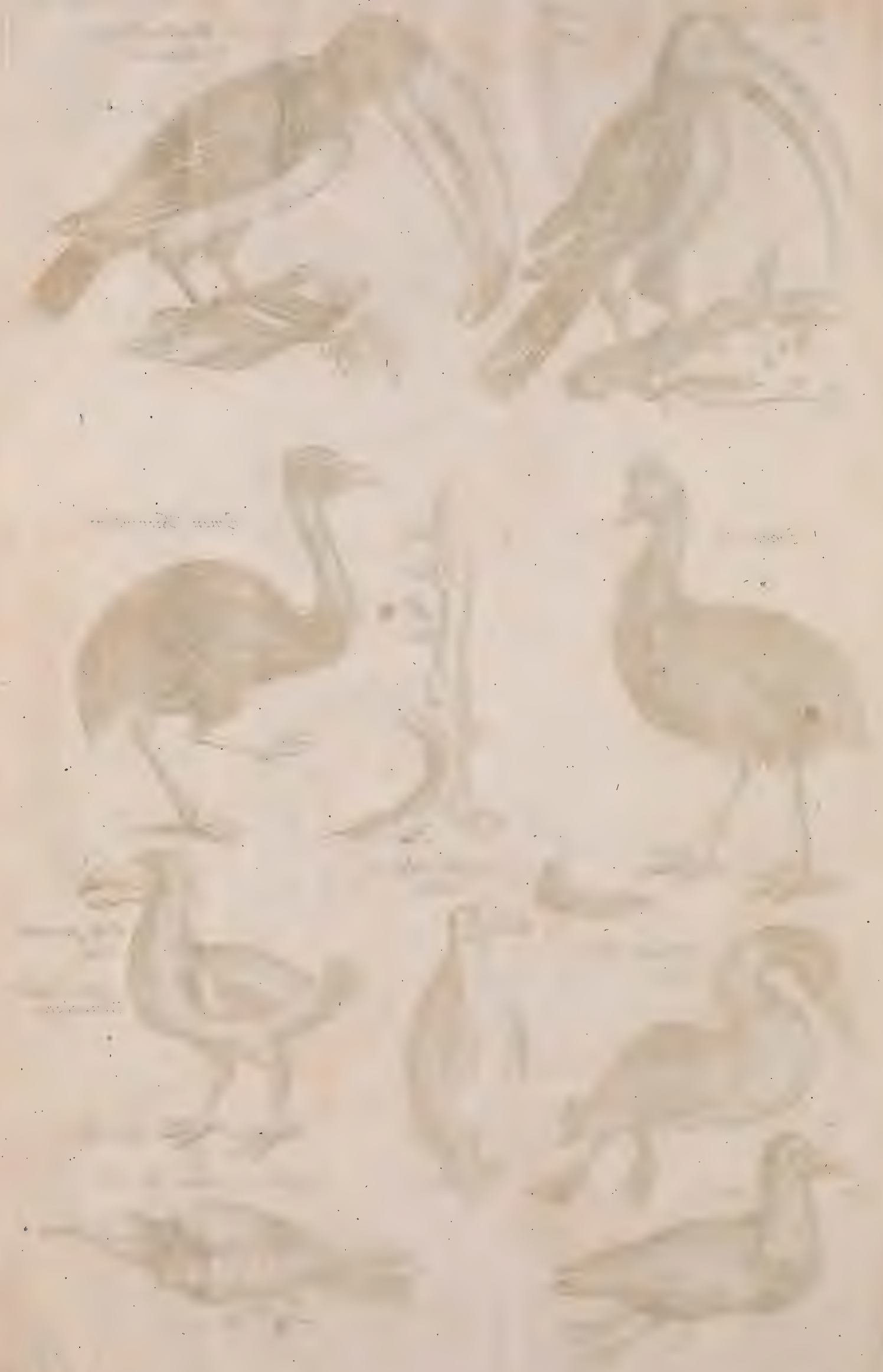


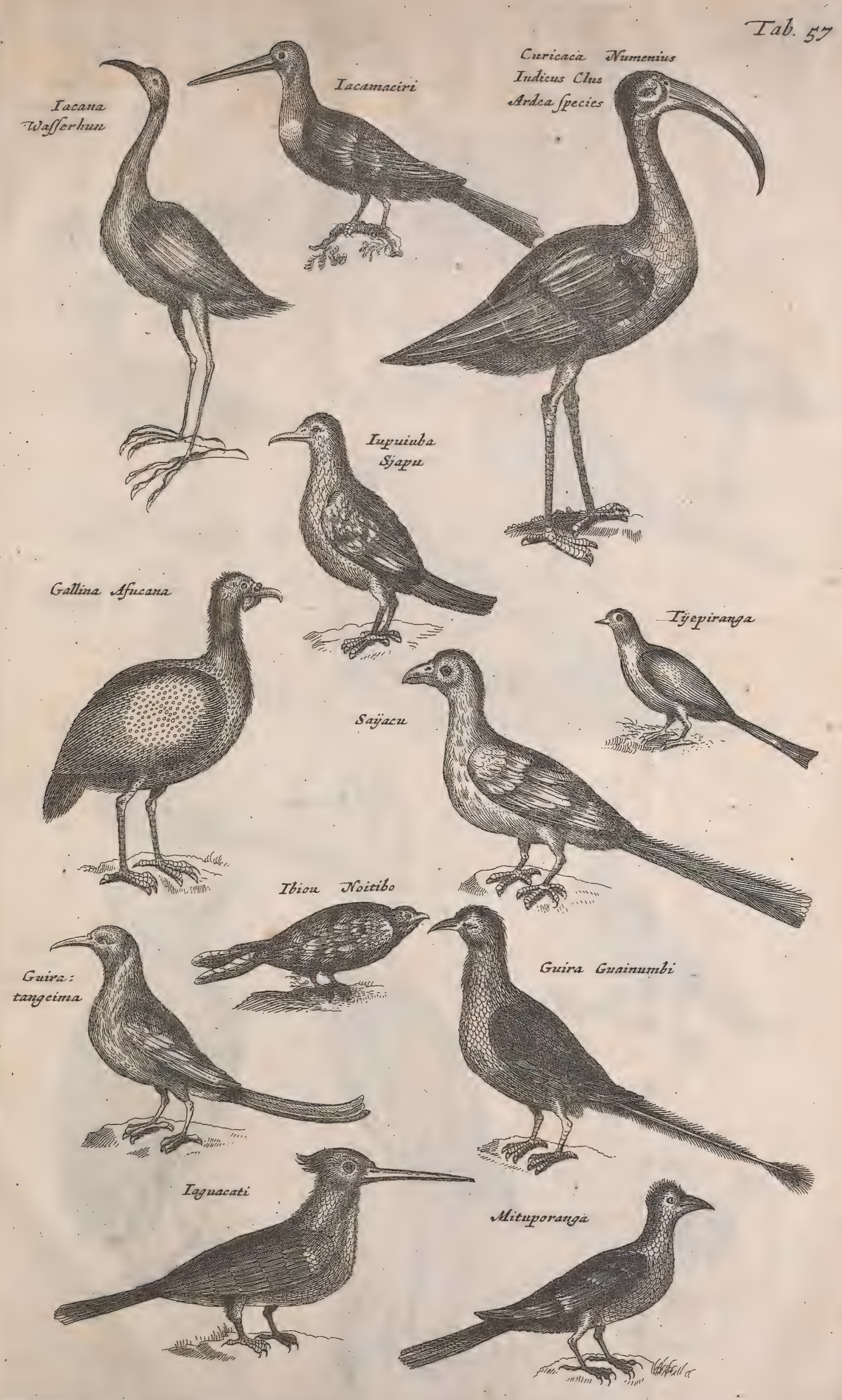


,.
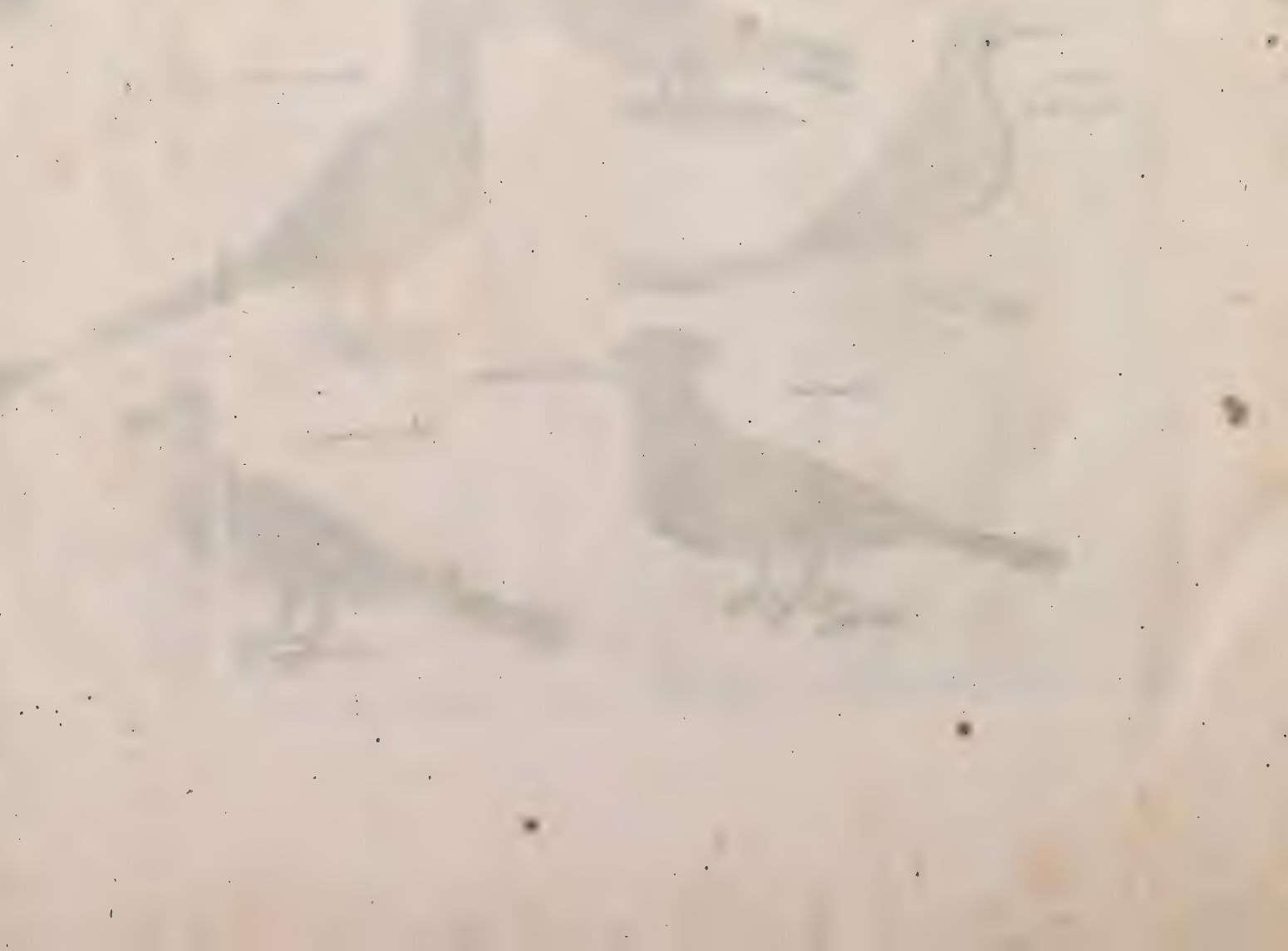


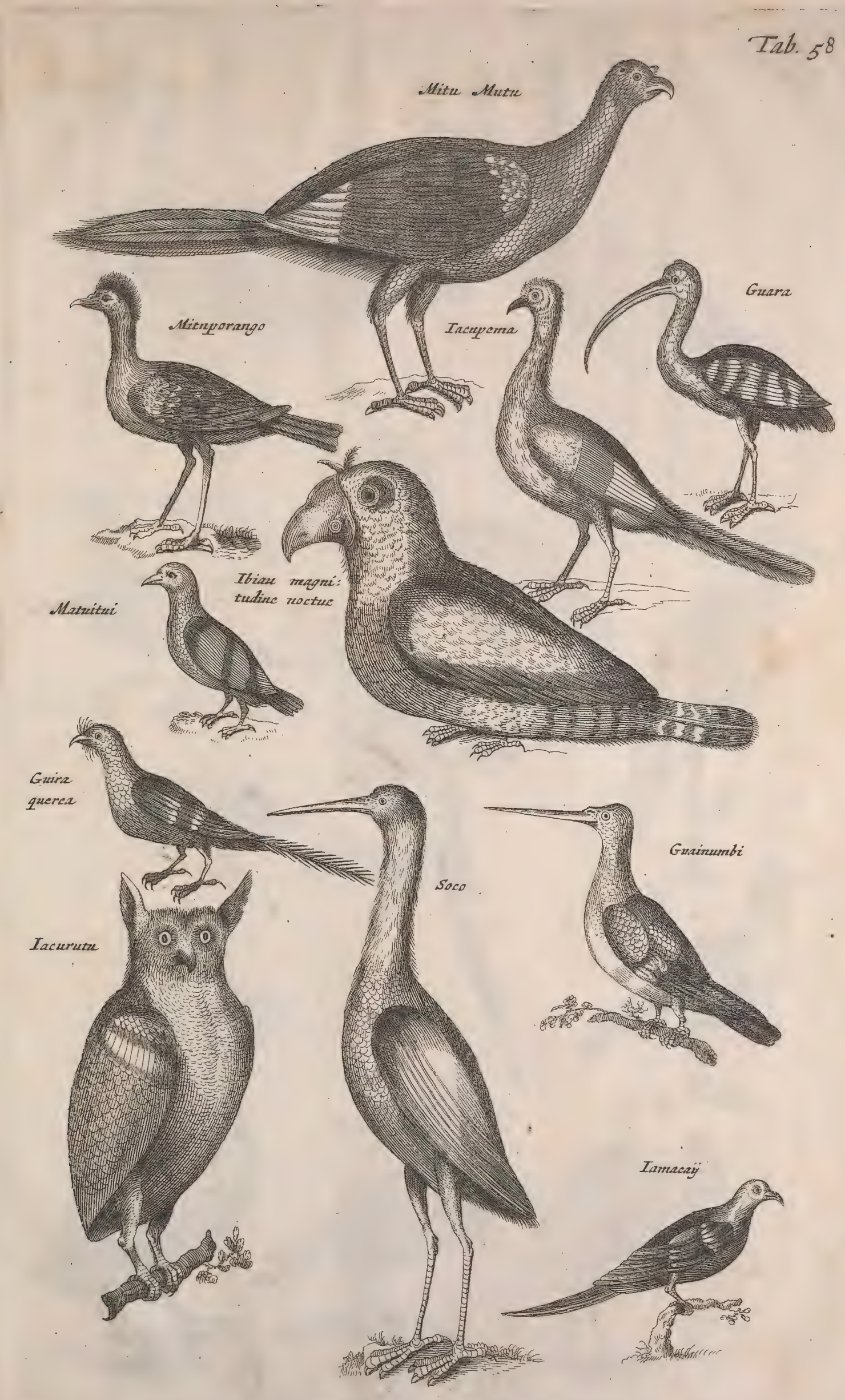





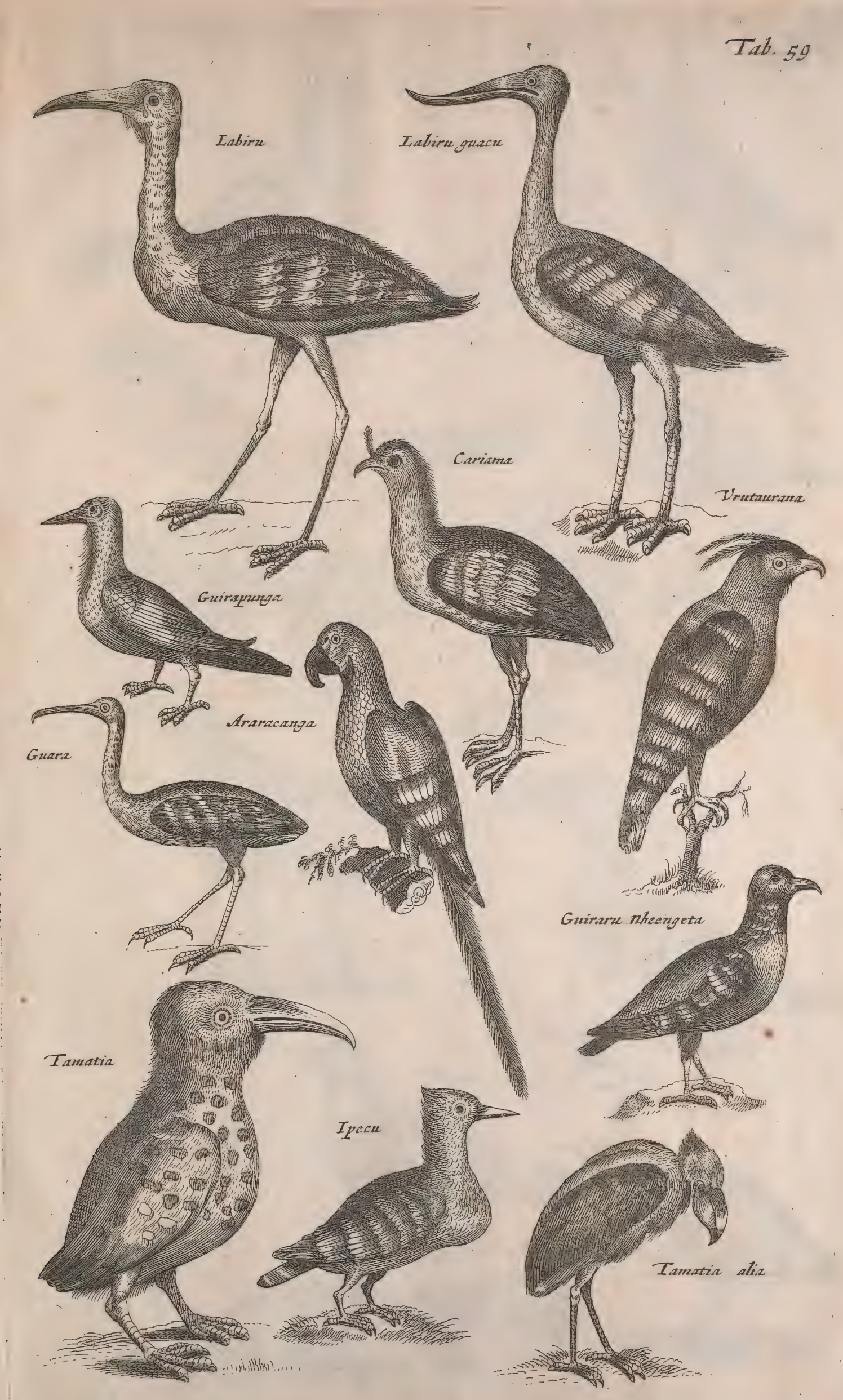




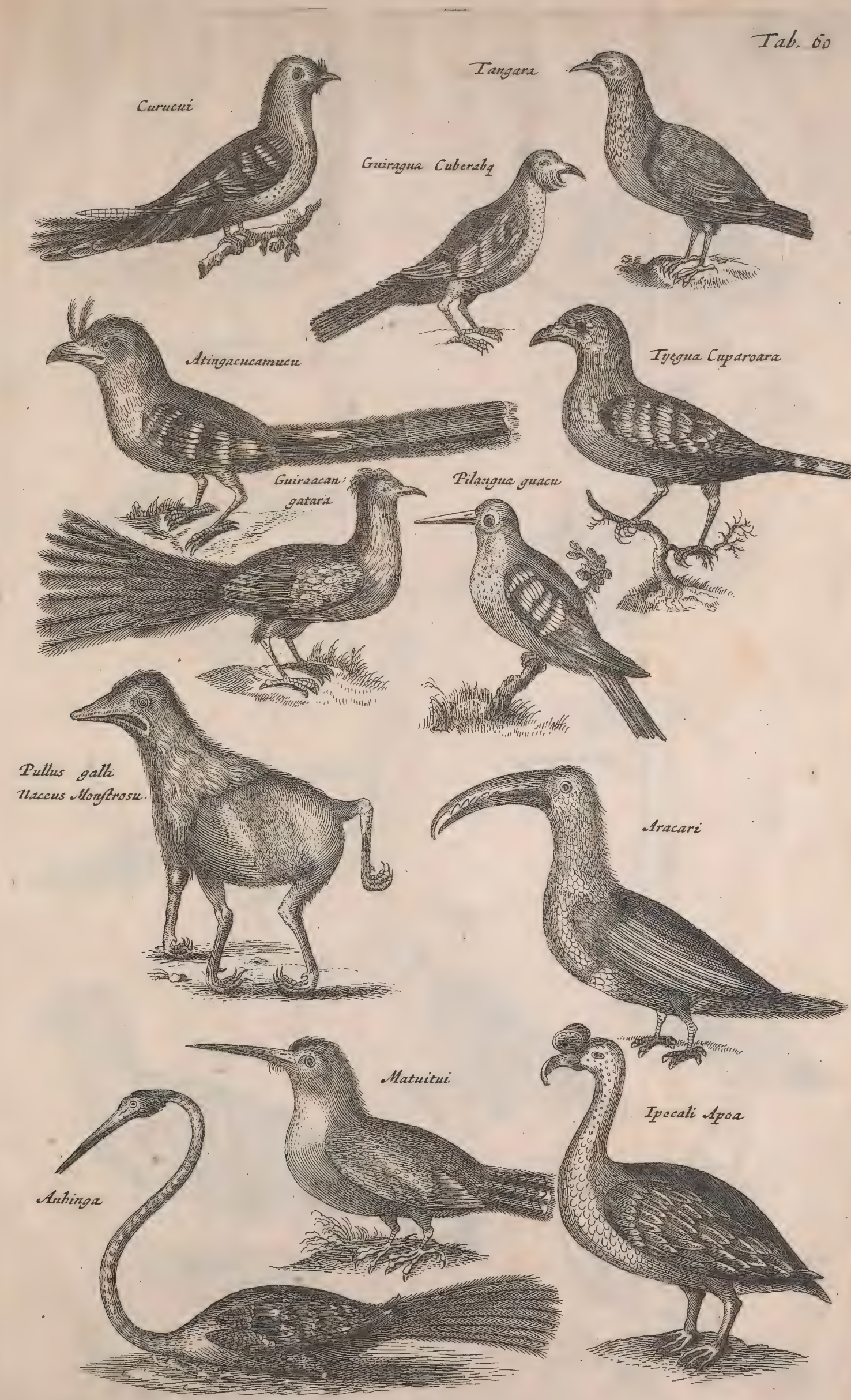



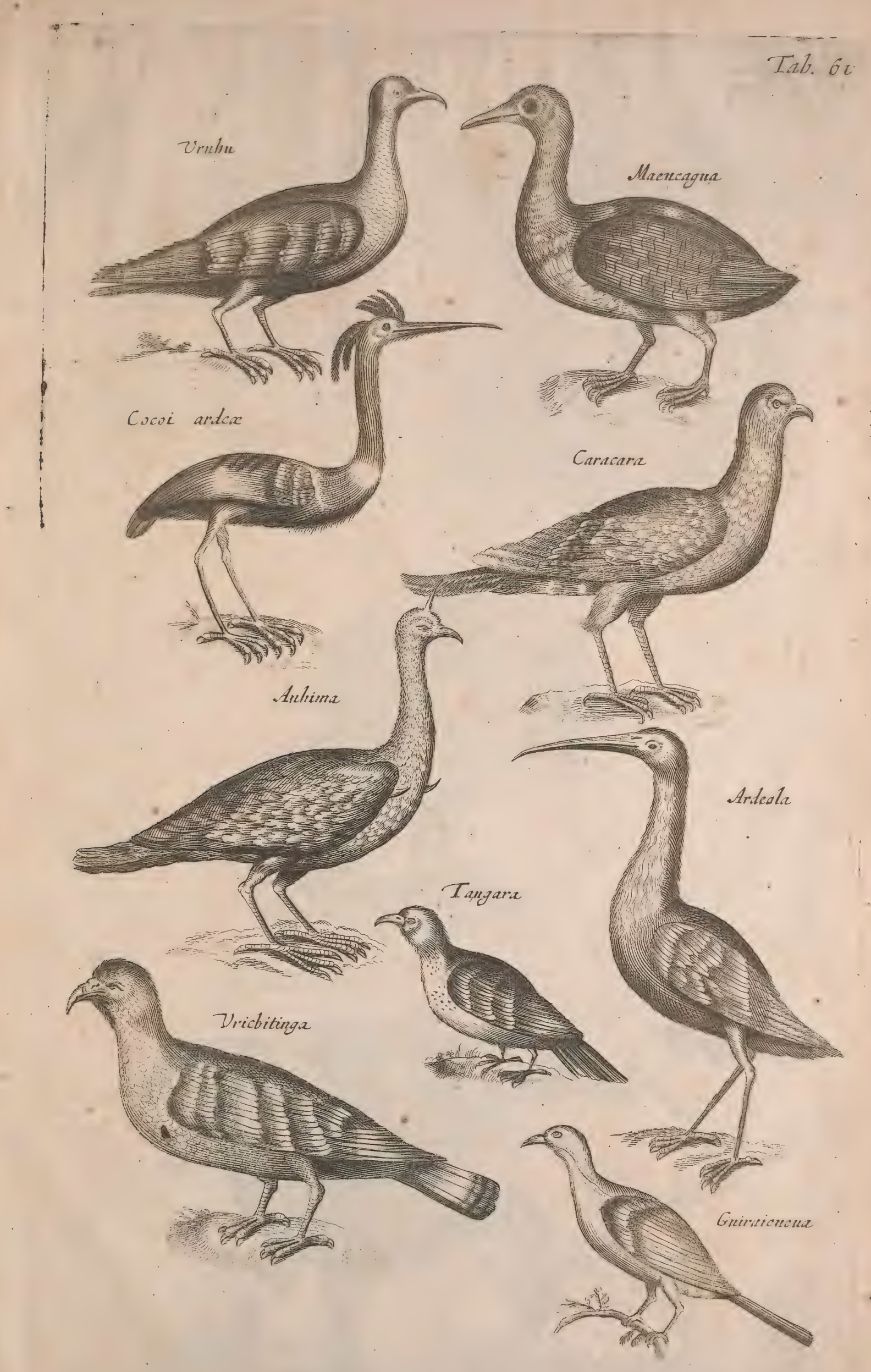




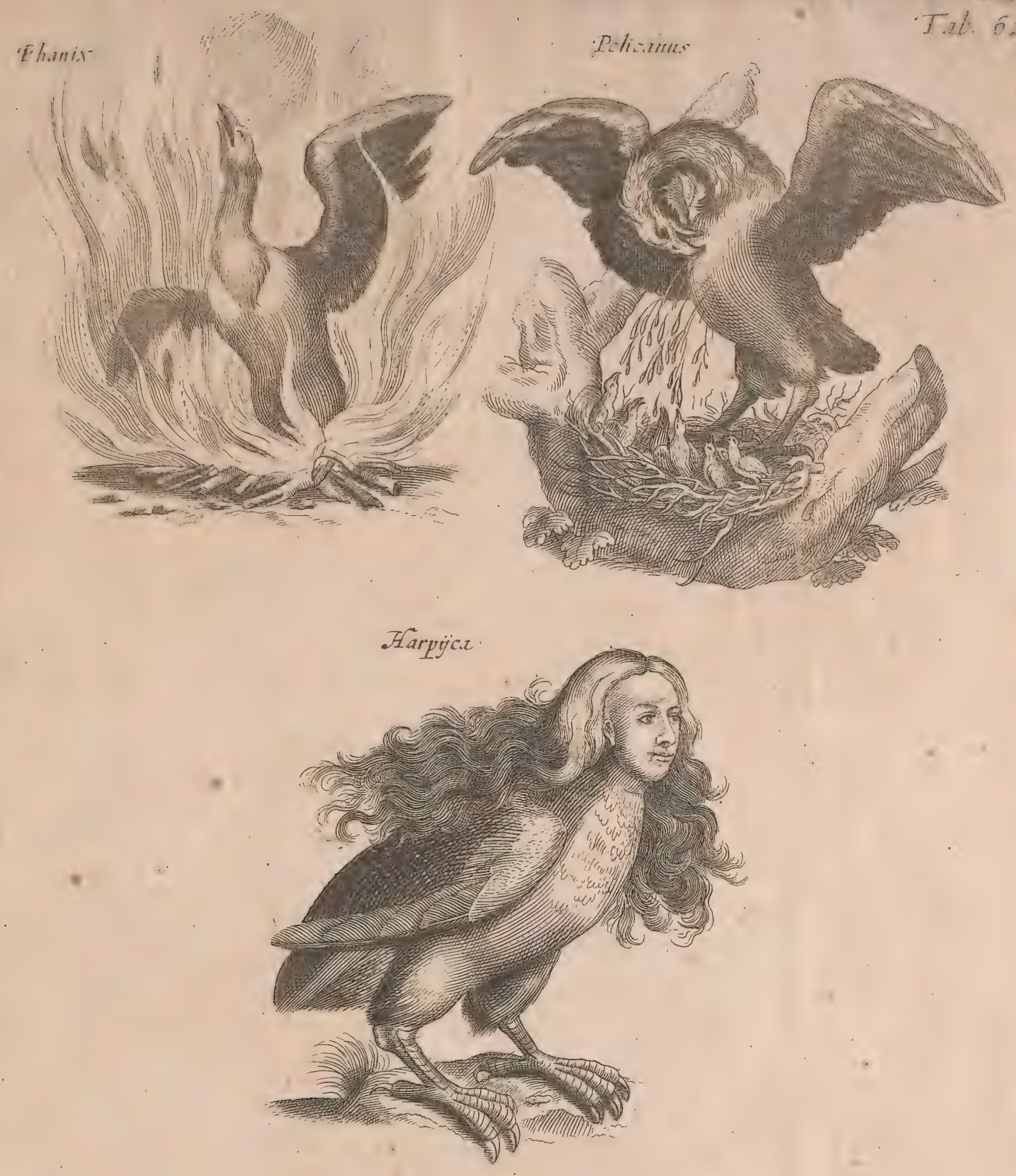

Grüphus Greitf

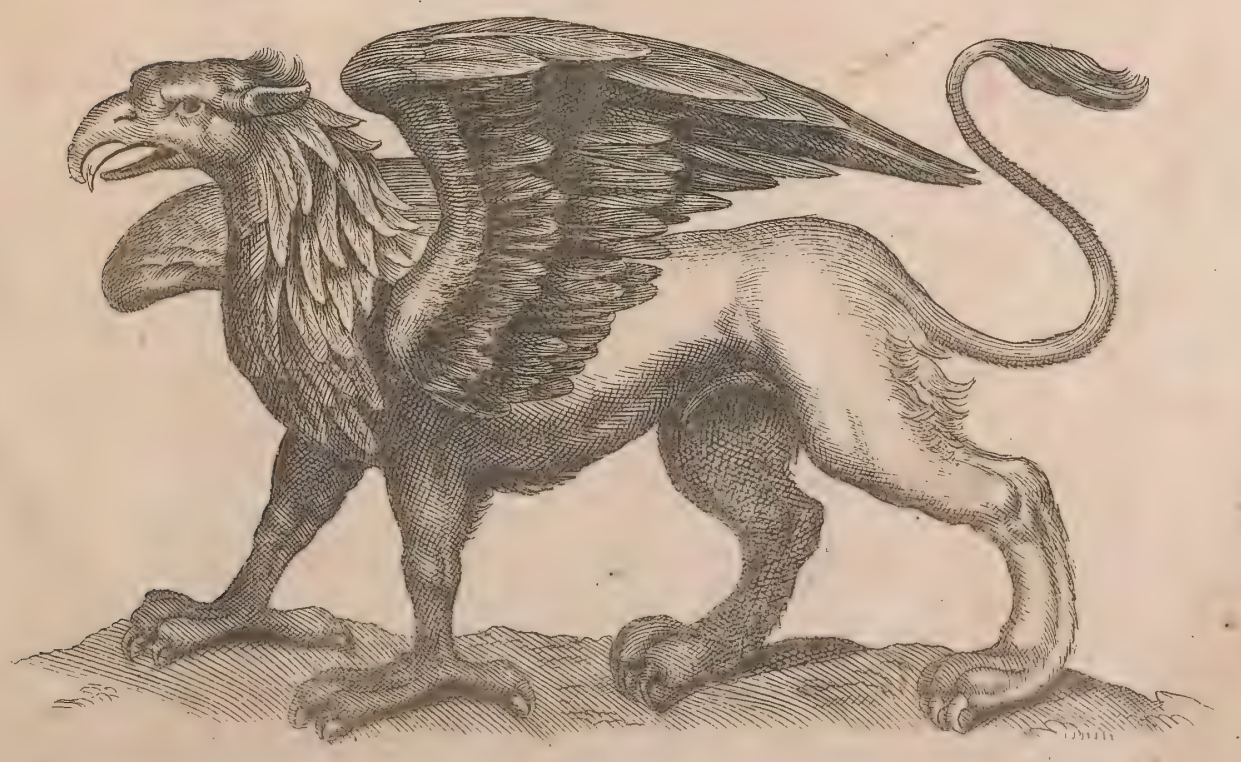




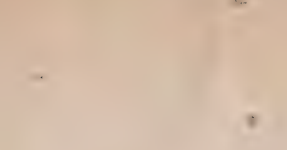

r

.
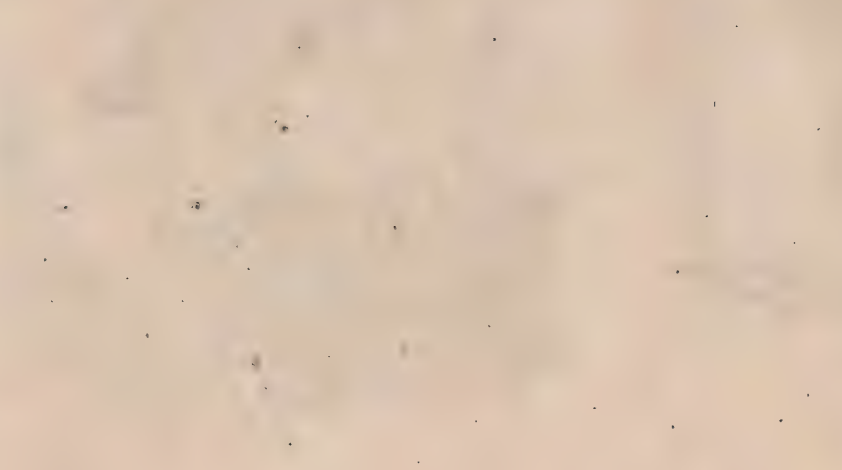

- 


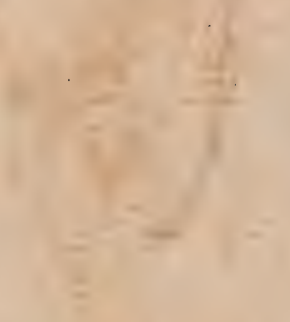

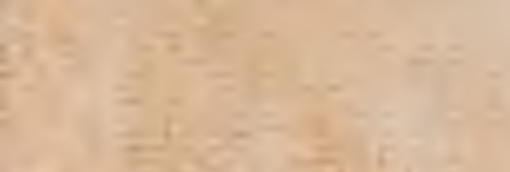

\section{$x^{2}=$}

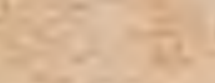

$y^{2}=$

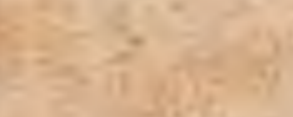

$x^{2} x^{2}=$

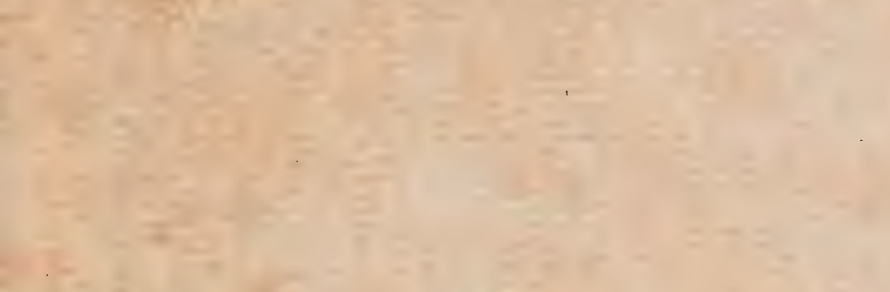

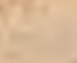

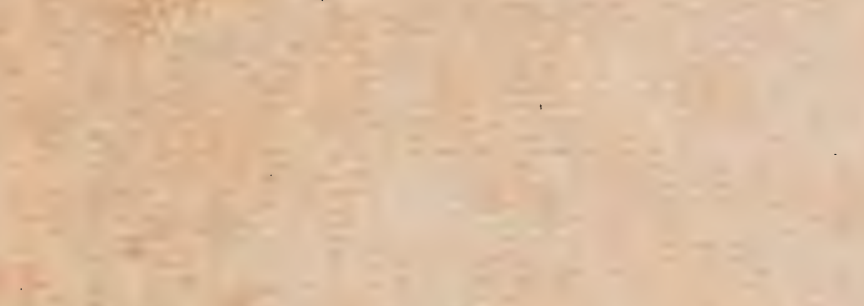

$-2$

$x^{2}-2=$

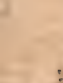

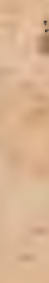

$x=1=$

$x^{2}-2$

$=$

1, no

xy

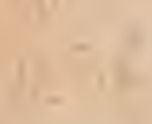

$=\frac{-}{2}$ 


\section{Paul Klincksieck}

\section{1,250}

LIBRAIRIE DES SCIENCES NATURELLS
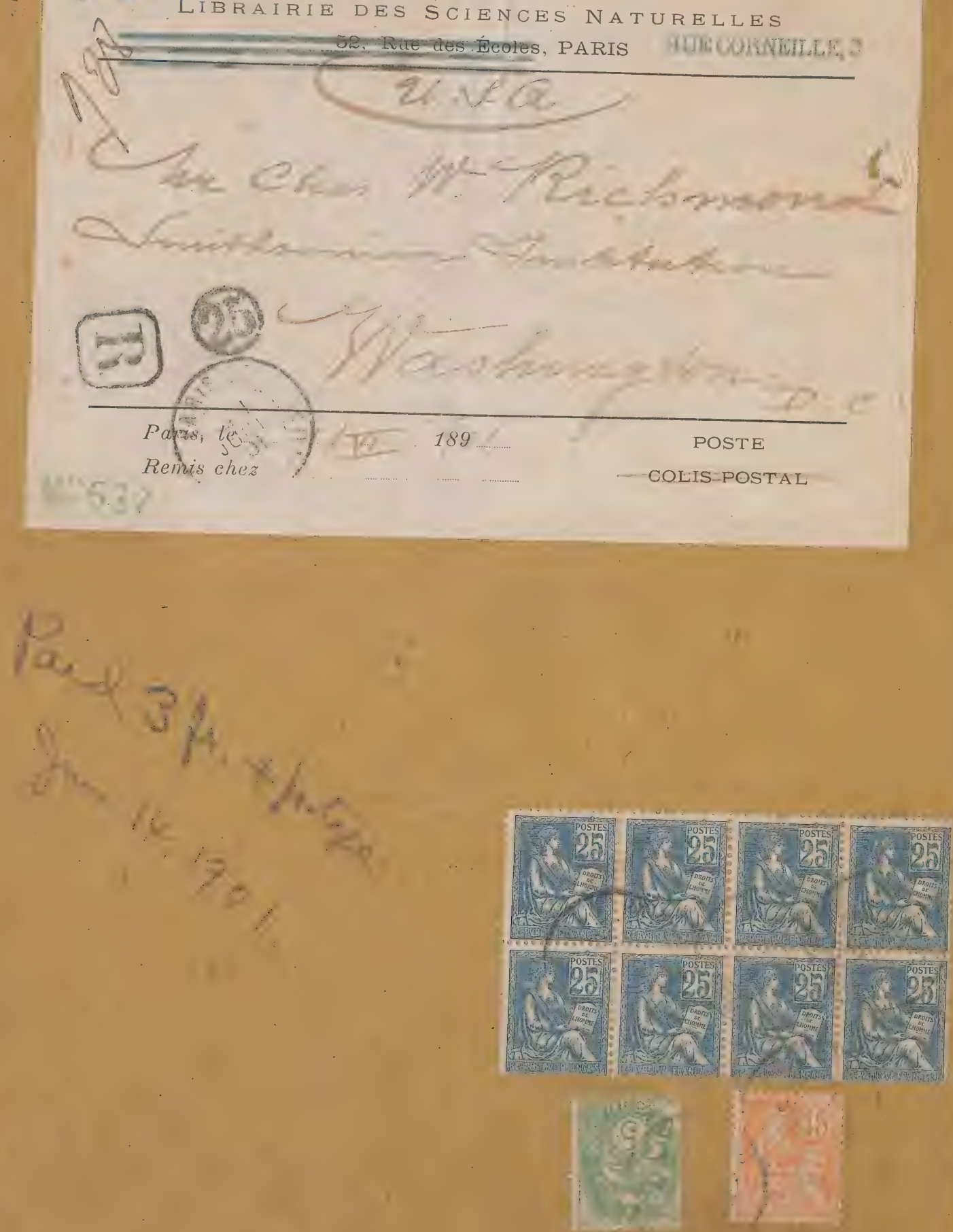


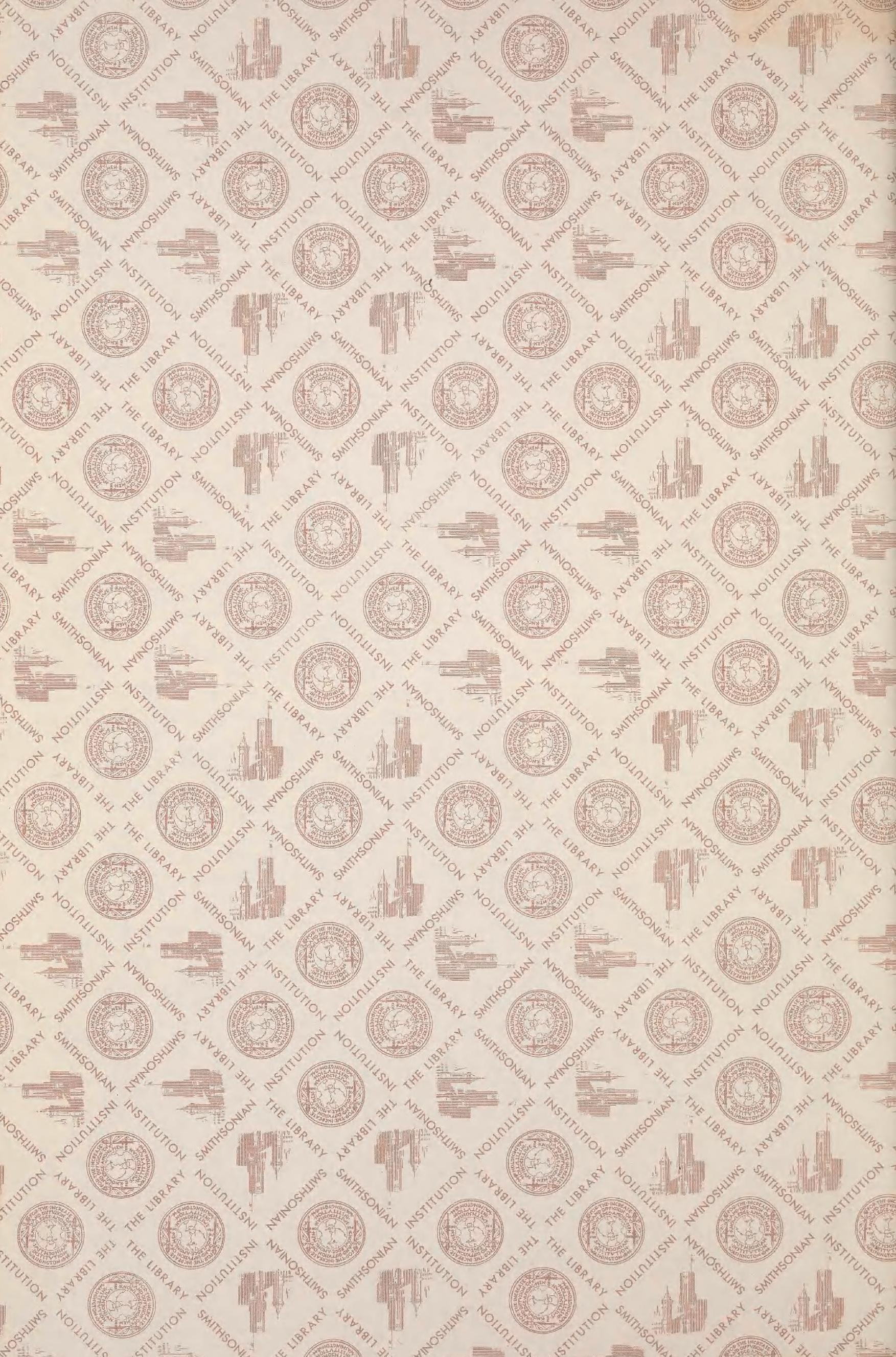

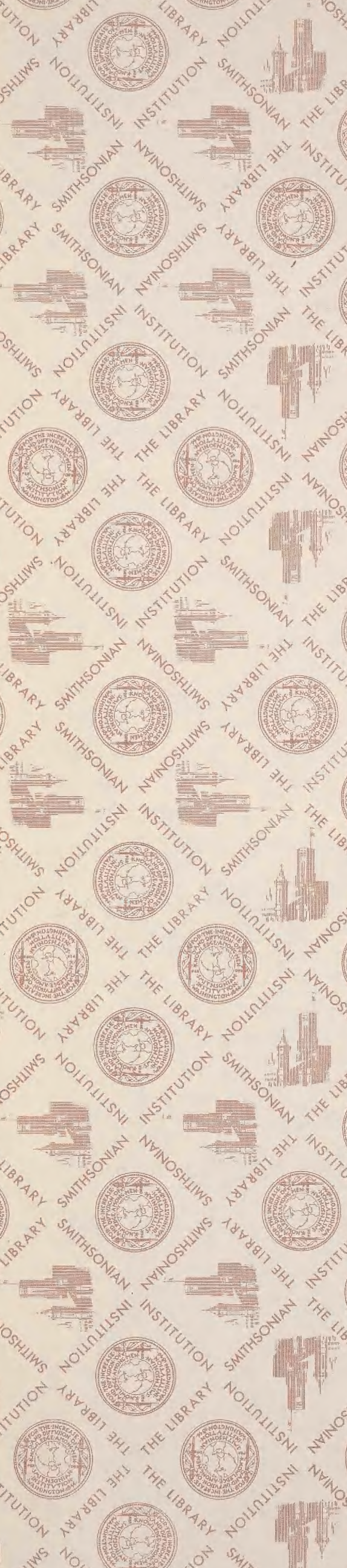


(1)

All

and (19)

2. (1) H.
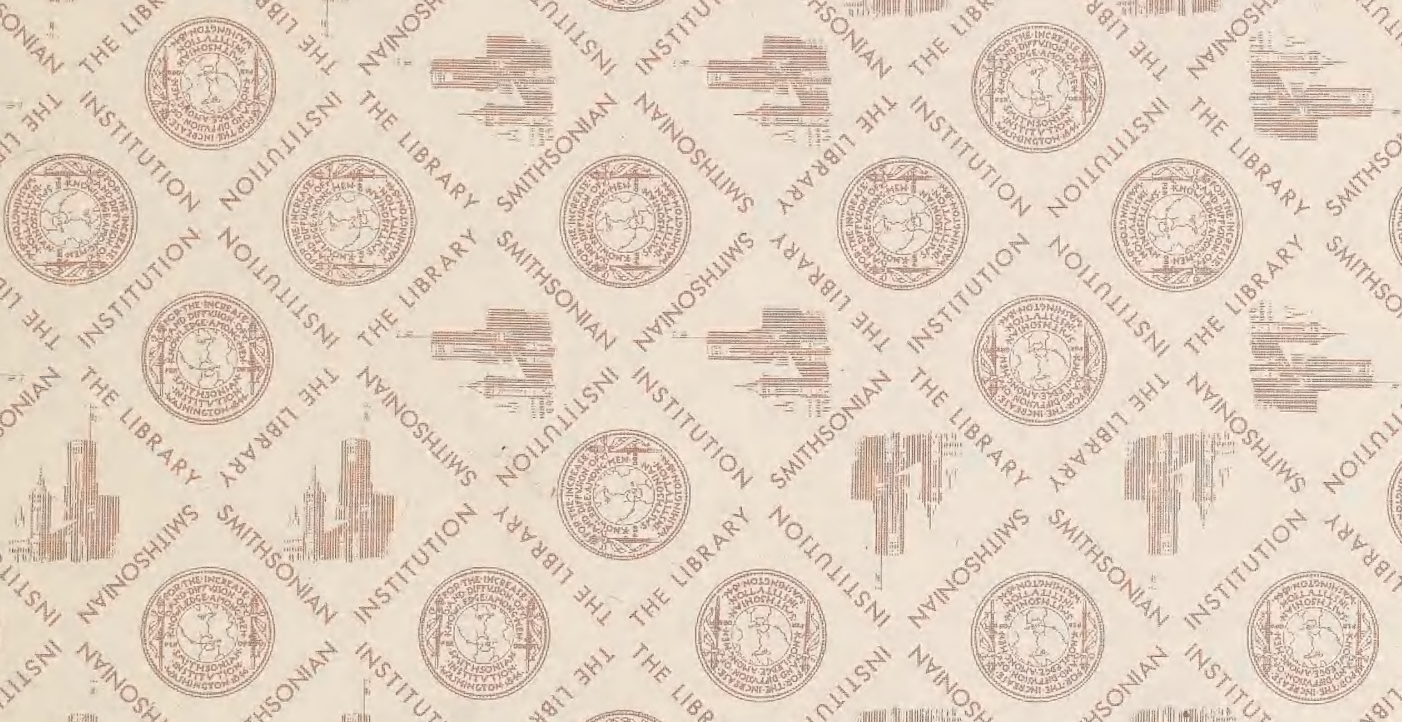

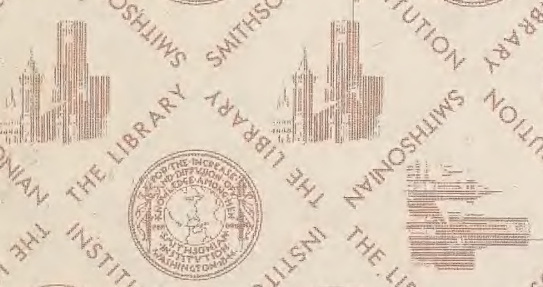

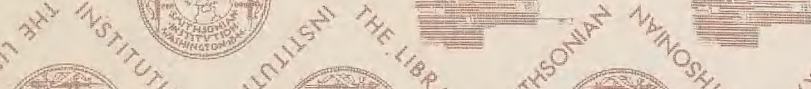

(1),

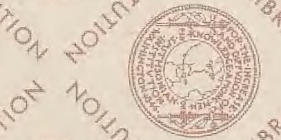

tititis

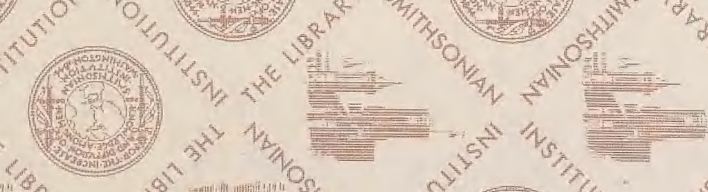

IIf

t)
(7)
(7)

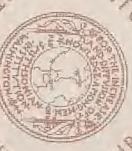

(1)

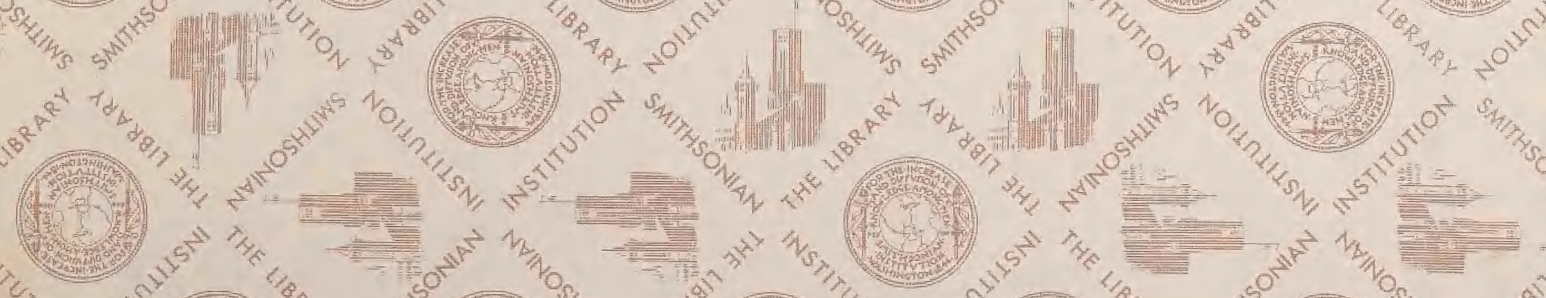

(7).
IIII

=
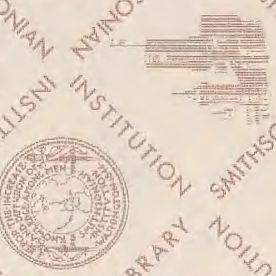

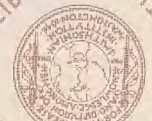
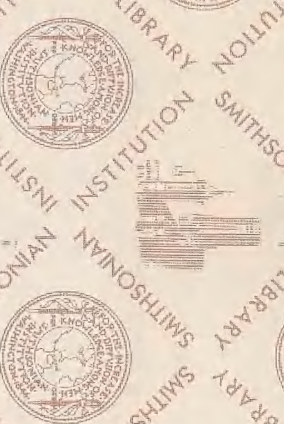

槒

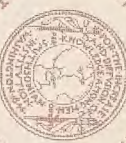

$\left(\begin{array}{c}2 \\ (x+3)\end{array}\right.$
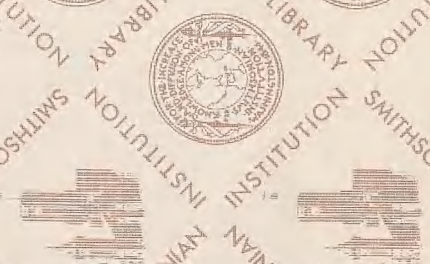

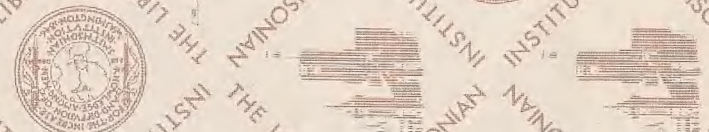

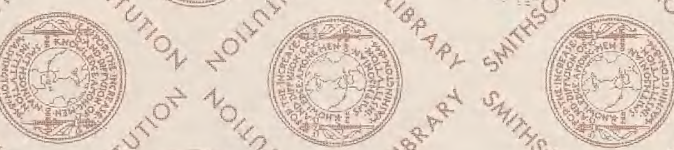

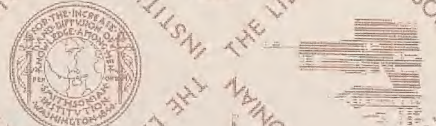
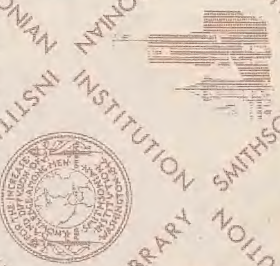

$(2,3)$
(1)

it

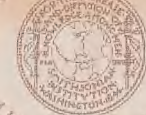


